\title{
Design Approaches for Solar Industrial Process Heat Systems
}

\section{Nontracking and Line-Focus Collector Technologies}

\author{
Charles F. Kutscher \\ Roger L. Davenport \\ Douglas A. Dougherty \\ Randy C. Gee \\ P. Michael Masterson \\ E. Kenneth May
}


Printed in the United States of America

Available from:

National Technical Information Service

U.S. Department of Commerce

5285 Port Royal Road

Springfield, VA 22161

Price:

Microfiche $\$ 3.00$

Printed Copy $\$ 14.50$

\section{NOTICE}

This report was prepared as an account of work sponsored by the United States Government. Neither the United States nor the United States Department of Energy, nor any of their employees, nor any of their contractors, subcontractors, or their employees, makes any warranty, express or implied, or assumes any legal liability or responsibility for the accuracy, completeness or usefulness of any information, apparatus, product or process disclosed, or represents that its use would not infringe privately owned rights. 


\title{
Design Approaches for Solar Industrial Process Heat Systems
}

\author{
Nontracking and Line-Focus \\ Collector Technologies
}

Charles F. Kutscher

Roger L. Davenport

Douglas A. Dougherty

Randy C. Gee

P. Michael Masterson

E. Kenneth May

August 1982

Prepared Under Task No. 1007.99

WPA No. 279-81

Solar Energy Research Institute

A Division of Midwest Research Institute

1617 Cole Boulevard

Golden, Colorado 80401

Prepared for the

U.S. Department of Energy

Contract No. EG-77-C-01-4042 


\section{ACKMODLEDGMEHTS}

The authors would like to thank everyone who took the time to review and comment on the draft of this document. Reviewers include Gerald Nix, Robert Copeland, L. M. Murphy, Larry Flowers, Shirley Stadjuhar, and Allan Lewandowski of SERI; William Marlatt and Robert Baisley of Rockwell International; Kenneth Brown of Science Applications, Inc.; Jefferson Shingleton of Mueller Associates; Walter Carey of Nestle; Ed Carnegle of California Polytechnic State Univ.; Tetsuo Noguchi of the Solar Research Laboratory, Nagoya, Japan; Danny Deffenbaugh of Southwest Research Institute; David Raplan of The Lummus Company; Michael Kast of Pacific Sun, Inc.; David Allen of Foster Wheeler; William Engel of Owens-I11inois; Nick Kaplan and Harold Wilkening of AAI Corp.; Karl Wally of Sandia National Laboratories, Livermore; Harry Gaul (formerly of SERI); and Ar1 Rabl of Princeton University.

Special thanks go to John Wright of SERI for his considerable contribution to the section on controls, to James Leach of North Carolina State University for writing the unfired boiler subroutine of SOLIPH in conjunction with a summer research project at SERI, and to Rob Farrington of SERI for his help in making the numerous SOLIPH computer runs. The authors are also very grateful to David Kearney for his extensive review of the document, in both early and final draft stages, and for supporting this undertaking at its outset while he was manager of the Solar Thermal, Ocean, and Wind Division at SERI. Finally, the authors are deeply Indebted to William Auer and Jerry Greyerbiehl of the U.S. Department of Energy, who secured the funding for this work. 
PREPACE

Since 1976, the U.S. government has funded over a dozen projects that apply solar thermal energy to industrial processes. We can draw two major conclusions from experiences gained in designing, constructing, and operating these projects: design and installation errors need to be avoided, and costs must be reduced. This design handbook was prepared with both points in mind. Designers are given a design procedure that has been formulated to help them avoid problems that have occurred in past systems. At the same time, the design tools contained in the text are intended to shorten the time required for conceptual and preliminary design, which should, in turn, reduce total design costs. (In the past, design costs have been as much as $45 \%$ of construction costs.) In addition, emphasis on cost-effective optimization of systems and components is intended to lower construction, operating, and maintenance costs.

This handbook is not without precedent. In March 1981, the Solar Energy Research Institute published a forerunner document entitled "Design Considerations for Solar Industrial Process Heat Systems." That report, which drew upon the experiences of a number of IPH system designers and Department of Energy technical advisors, contained qualitative lists of items that should be considered in the design of a solar IPH system. This document is intended to provide the quantitative information needed to complete a step-by-step design.

The contents of this handbook have been arranged to guide the user through a system design. The first part, "Objectives and Fundamentals," provides an introduction to the uses of solar thermal energy in industry. It is intended for those who do not have experience in the solar IPH field, but it could also serve as a useful review. The second part, "Conceptual Design," describes how to choose the proper application and system configuration and how to estimate the amount of energy the solar system can be expected to supply. The conceptual design should supply enough information to allow the user to make an informed decision about whether to proceed with the project, and it will also provide a firm foundation for further design work. The third part, "Preliminary Design," describes how to select and optimize system components. This section also explains how to determine the delivered energy more accurately. A chapter on installation and start-up is included, because they have caused problems in the past. Items of special interest are covered in the appendices, and a glossary is provided for those new to the solar energy field. Although SI units are used throughout, a detailed conversion table is provided in Appendix I for those who are more comfortable with English units.

The final, detailed design is left to the reader. Actual selection of hardware by brand name and model number, mechanical and electrical drawings, construction specifications, etc., are all highly specific to the system, and require the reader to draw upon his professional experience.

The reader will note that, although computer techniques are discussed in this report, the emphasis is on simplified design tools. These were generated by thousands of runs of an hour-by-hour computer program (SOLIPH) specifically 
written to model solar industrial process heat systems. These design tools are simple to use and require no computer programming knowledge. They are intended to supply values within a few percentage points of the detailed computer program and apply to both large and small installations. Considering current uncertainties about degradation of pipe insulation and collectors and the large variations in annual solar radiation at any given site, using simple design tools is a pragmatic approach. It frees the designer to concentrate on the hardware and installation problems which in the past have lowered energy collection values well below those predicted by sophisticated but idealistic computer models.

Because the field of solar thermal energy as it is applied in industry is st111 young, design questions cannot all be answered in this handbook. We hope, however, that it contains the best information currently available. The types of industrial processes and corresponding solar system configuration alternatives are manifoid. Thus, system designers will find a considerable number of opportunities to deviate from the generic design procedures contained here, and they should feel free to do so. Readers are encouraged to contact the authors with any ideas or experiences they have had that could augment or improve this handbook.

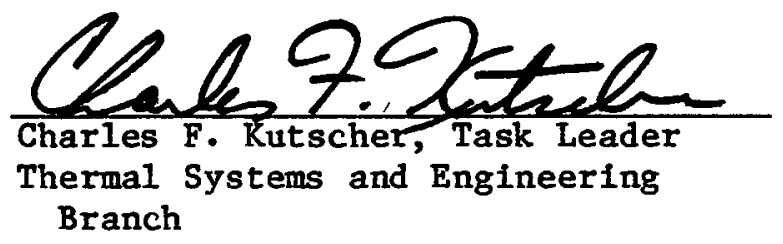

Approved for

SOLAR ENERGY RESEARCH INSTITUTE
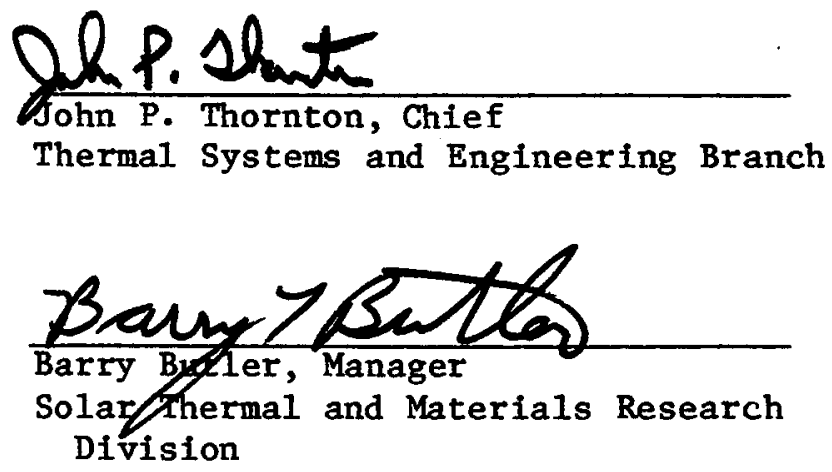


\section{ROMEITCLATURB}

A

B

bo

$c_{p}$

D

$\mathrm{D}_{\mathrm{s}}$

$\mathrm{f}_{\mathrm{s}}$

f

F

$\mathbf{F}_{\mathbf{X}}$

h

$h_{f g}$

H

I

area $\left(m^{2}\right)$

$A_{c}$ collector aperture area

$A_{g}$ ground area covered by collector array

$A_{x}$ heat exchanger surface area

factor in Eq. 7-51

incident-angle modifier coefficient

constant-pressure specific heat $\left(\mathrm{J} \mathrm{kg}^{-1} \mathrm{~K}^{-1}\right)$

diameter (m)

$D_{1} \quad$ insulation diameter

$\mathrm{D}_{\mathrm{p}} \quad$ pipe diameter

specific diameter of a pump impeller

solar fraction (portion of total load supplied by solar system)

friction factor

collector heat removal efficiency factor

$F_{R}$ based on collector inlet temperature

$\mathrm{F}_{\mathrm{m}}$ based on mean collector temperature

$F_{0}$ based on collector outlet temperature

dewinter heat exchanger factor

heat transfer film coefficient $\left(\mathrm{W} \mathrm{m}^{-2} \mathrm{~K}^{-1}\right)$

$h_{c}$ convective heat transfer coefficient

$h_{1}$ heat transfer coefficient on inside of a pipe

$h_{0}$ heat transfer coefficient on outside of a pipe

$h_{r}$ radiative heat transfer coefficient

latent heat of evaporation $\left(\mathrm{J} \mathrm{kg}^{-1}\right)$

head of a pump ( $\mathrm{Pa})$

irradiance $\left(\mathrm{W} \mathrm{m}^{-2}\right)$

$I_{a}$ irradiance available to a collector

$I_{b}$ beam irradiance

$I_{d}$ diffuse irradiance

$I_{g}$ global irradiance

$I_{h}$ global irradiance on a horizontal surface 
MOMENCLATURB (Continued)

$\overline{\mathrm{I}}_{\mathrm{b}}$ long-term average beam irradiance during daylight hours

$\bar{I}_{g}$ long-term average global irradiance during daylight hours

k

thermal conductivity $\left(\mathrm{W} \mathrm{m}^{-1} \mathrm{~K}^{-1}\right)$

$k_{a}$ thermal conductivity of air

$k_{f}$ thermal conductivity of a fluid

$k_{i}$ thermal conductivity of insulation

$k_{p} \quad$ thermal conductivity of a pipe wall

$k_{0}$ thermal conductivity on shell side of a heat exchanger

$\mathrm{K}_{\mathrm{h}} \quad$ clearness index

$\mathrm{K}_{\alpha \tau}$

incident-angle modifier (flat plate)

$\mathrm{K}_{\rho \alpha \tau}$

incident-angle modifier correction factor (evacuated tube and parabolic trough)

$\overline{\mathrm{L}}$

$L_{\text {end }}$

$\dot{m}_{\mathrm{c}}$

M

$\dot{\mathrm{M}}$

n row

N

$\mathbf{N}_{\mathbf{S}}$

NPSH

$\mathbf{P}$

$P_{\text {vap }}$

pp

q

length (m)

spillage end loss factor for parabolic troughs

collector mass flow rate per unit collector area $\left(\mathrm{kg} \mathrm{s} \mathrm{s}^{-1}\right)$

total mass $(\mathrm{kg})$

total mass flow rate $\left(\mathrm{kg} \mathrm{s} \mathrm{s}^{-1}\right)$

$\dot{\mathrm{M}}_{\mathrm{c}}$ collector mass flow rate

$\dot{M}_{\ell} \quad$ load mass flow rate

$\dot{\mathrm{M}}_{\mathrm{s}}$ mass flow rate through storage

number of rows of tubes across the diameter of the shell of a heat exchanger

rotational speed ( $\mathrm{rev} \mathrm{min}^{-1}$ )

specific speed

Net Positive Suction Head $(\mathrm{Pa})$

NPSHA NPSH available

NPSHR NPSH required

pressure ( $\mathrm{Pa}$, absolute unless otherwise noted)

vapor pressure ( $\mathrm{Pa}$, absolute)

pumping power $(W)$

energy per unit collector area $\left(\mathrm{J} \mathrm{m}^{-2}\right.$ ) (for subscripts, see Q) 


\section{MOMETCLATURB (Continued)}

$\dot{q}$
$\dot{q}_{c, \infty}$

Q

$\dot{Q}$

$\mathrm{Q}_{\mathrm{v}}$

r*

$\mathbf{R}$

S

$t$

$t_{i}$

T energy rate per unit collector area $\left(\mathrm{W} \mathrm{m}^{-2}\right)$ energy collection rate for a solar system with infinite storage
$\left(W \mathrm{~m}^{-2}\right)$

energy ( $\mathrm{J}$ )

$Q_{c} \quad$ energy collected

$Q_{d}$ energy delivered to the process from the solar system

$Q_{\ell} \quad$ energy lost

$Q_{r} \quad$ energy required by the process

$Q_{s} \quad$ energy stored

energy rate $(W)$

volumetric flow rate $\left(\mathrm{m}^{3} \mathrm{~s}^{-1}\right)$

thermal resistance per unit thickness $\left(m \mathrm{~K} \mathrm{~W}^{-1}\right.$ )

thermal resistance $\left(\mathrm{m}^{2} \mathrm{~K} \mathrm{~W}^{-1}\right)$

$\mathbf{R}_{\mathbf{f}}$ thermal resistance due to fouling

$R_{i}$ thermal resistance on inside of pipe or tube

$R_{0}$ thermal resistance on outside of pipe or tube

$R_{T}$ total thermal resistance

$R_{w}$ thermal resistance at wall of pipe or tube spacing (m)

$S_{\text {baf }}$ baffle spacing in heat exchanger

$S_{\text {min }}$ minimum tube spacing in heat exchanger

time (s)

thickness of insulation (m)

temperature $\left(\mathrm{K}\right.$ or $\left.{ }^{\circ} \mathrm{C}\right)$

$\mathrm{T}_{\mathrm{a}}$ ambient temperature

$T_{c} \quad$ collector temperature

$\mathrm{T}_{\mathrm{f}} \quad$ fluid temperature

$T_{1} \quad$ insulation temperature

$\mathrm{T}_{\ell} \quad$ load temperature

$T_{p} \quad$ plate temperature in flat-plate collector

$\mathrm{T}_{\mathrm{r}}$ effective radiative temperature of surroundings ( $\mathrm{K}$ only) 


\section{NOABRCLATURE (Continued)}

U

$\mathrm{U}_{\mathrm{L}}$

$\nabla$

W

$\mathbf{Y}$

$$
T_{s} \quad \text { storage temperature }
$$$$
\mathrm{T}_{\ell, \mathrm{r}} \text { load return temperature }\left({ }^{\circ} \mathrm{C}\right)
$$

thermal conductance $\left(W \mathrm{~m}^{-2} \mathrm{~K}^{-1}\right.$ )

overall collector heat loss coefficient $\left(W^{-2} \mathrm{~K}^{-1}\right.$ )

speed $\left(\mathrm{m} \mathrm{s}^{-1}\right)$

heat capacity flow rate $\left(\mathrm{W} \mathrm{K}^{-1}\right)$

$\mathrm{W}_{\mathrm{C}}$ collector heat capacity flow rate

$\mathrm{W}_{\mathrm{s}}$ storage loop heat capacity flow rate

parameter in Eq. 7-70

\section{Secondary Subscripts}

$\begin{array}{ll}\text { d } & \text { daytime } \\ \mathbf{f} & \text { fluid } \\ \text { m } & \text { inlet, inside } \\ \text { o } & \text { mean } \\ \text { s } & \text { outlet, outside } \\ & \text { start-up }\end{array}$

Nondimensional Numbers

$\begin{array}{ll}\text { Nu } & \text { Nusse1t. Number }\left(=h \mathrm{~K}^{-1}\right) \\ \operatorname{Pr} & \text { PrandtI Number }\left(=\mu c_{\mathrm{p}} \mathrm{K}^{-1}\right) \\ \operatorname{Re} & \text { Reynolds Number }\left(=\rho \mathrm{N} \mathrm{D}^{-1}\right)\end{array}$

Greek Symbols

$\alpha$

$\alpha_{\mathrm{s}}$

B

$\gamma$

$\Delta$

$\varepsilon$ altitude of sun $\left(0\right.$ to $\left.+90^{\circ}\right)$

absorptance for solar radiation

surface tilt ( 0 to $+90^{\circ}$; toward equator is positive)

azimuth of a surface ( 0 to $360^{\circ}$; clockwise from North)

declination ( 0 to $\pm 23.45^{\circ}$; North is positive)

heat exchanger effectiveness 
MOHFACLATURE (Concluded)

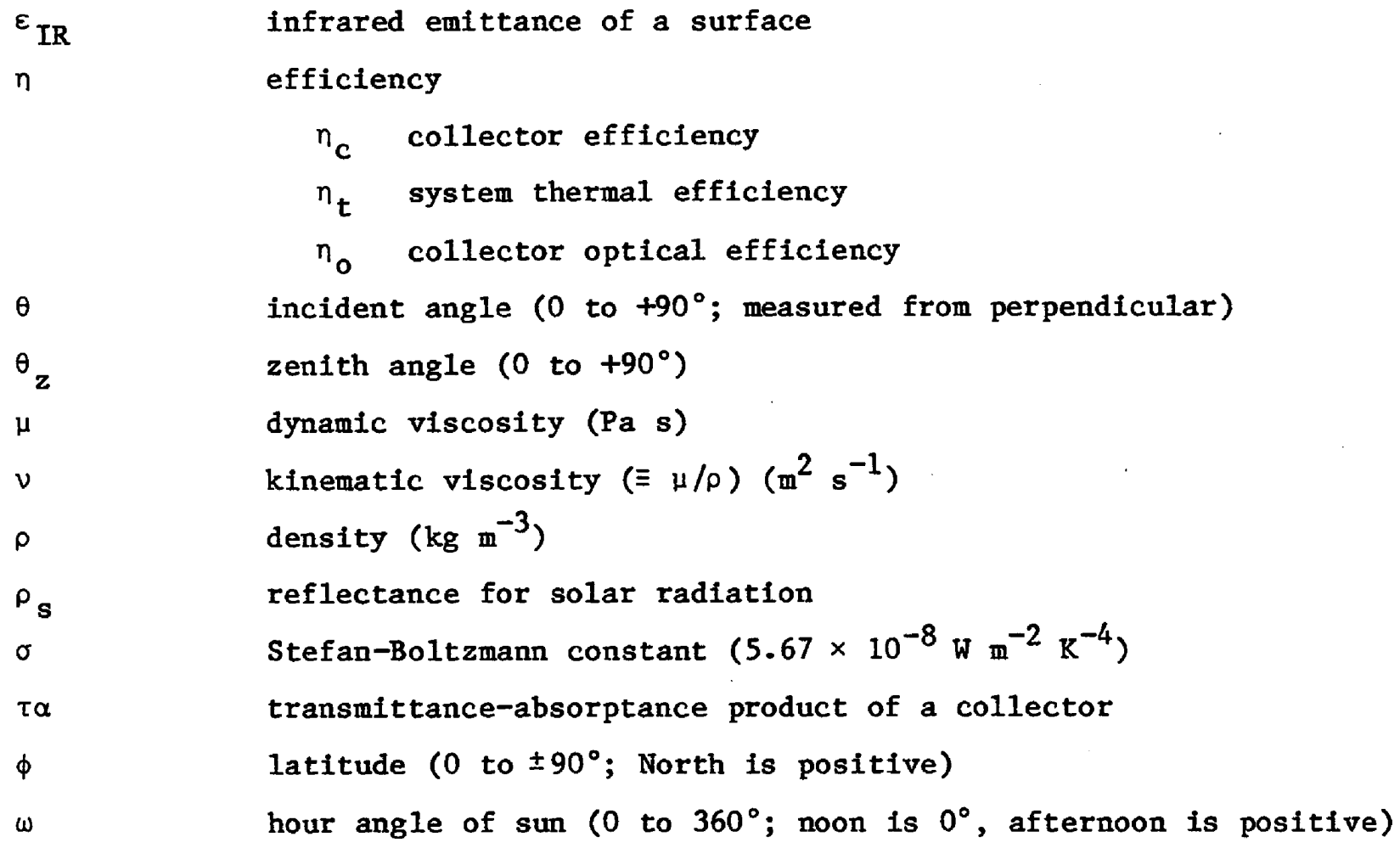




\section{LIST OF BCONOMIC TERHS}

B

$c_{c}$

$c_{i}$

$c_{j}$

$c_{1}$

$c_{m}$

${ }^{c_{T}}$

$c_{x}$

$c_{2}$

$c_{3}$

$c_{C}$

$\mathrm{C}_{\text {I }}$

$\mathrm{C}_{\mathrm{R}}$

Cs

$\mathrm{C}^{\prime} \mathrm{s}$

$\mathrm{c}_{\mathrm{T}}$

$\mathrm{C}_{\mathrm{TM}}$

CRF

d

DEP

cumulative present worth of depreciation tax credits per dollar invested

$B_{\mathrm{DB}} \quad$ with declining balance depreciation

$B_{\text {SL with straight-line depreciation }}$

${ }^{B}$ SOYD with sum-of-years-digits depreciation

collector cost per unit area $\left(\$ \mathrm{~m}^{-2}\right)$

piping insulation cost per unit length of pipe $\left(\$ \mathrm{~m}^{-1}\right)$

piping insulation jacketing cost per unit length of pipe $\left(\$ \mathrm{~m}^{-1}\right)$ cost of labor to install pipe insulation, per unit length of pipe $\left(\$ \mathrm{~m}^{-1}\right)$

annual base cost of maintenance of pipe insulation, per unit length of pipe $\left(\$ \mathrm{~m}^{-1} \mathrm{yr}^{-1}\right)$

total annual cost of pipe insulation per unit length $\left(\$ \mathrm{~m}^{-1}\right.$ $\mathrm{yr}^{-1}$ )

heat exchanger cost per unit area $\left(\$ \mathrm{~m}^{-2}\right)$

storage tank insulation cost per unit area $\left(\$ \mathrm{~m}^{-2}\right)$

storage tank insulation cost per unit volume $\left(\$ \mathrm{~m}^{-3}\right)$

total collector cost $(\$)$

total insulation cost (\$)

cost function defined by Eq. 7-10

levelized (annualized) required revenue in current dollars to purchase solar energy

levelized required revenue in constant zero-year dollars to purchase solar energy

total system cost of heat exchangers and collectors $\left(=A_{c} c_{c}\right.$ $\left.+A_{x} c_{x}\right)(\$)$

cost to minimize, defined in $\mathrm{Eq} \cdot 7-9$

capital recovery factor $\left[=\frac{R}{1-(1+R)^{-N}}\right]$

annual discount rate

present value of depreciation charges as a fraction of initial investment 


\section{LIST OF BCONOMIC TERMS (Continued)}

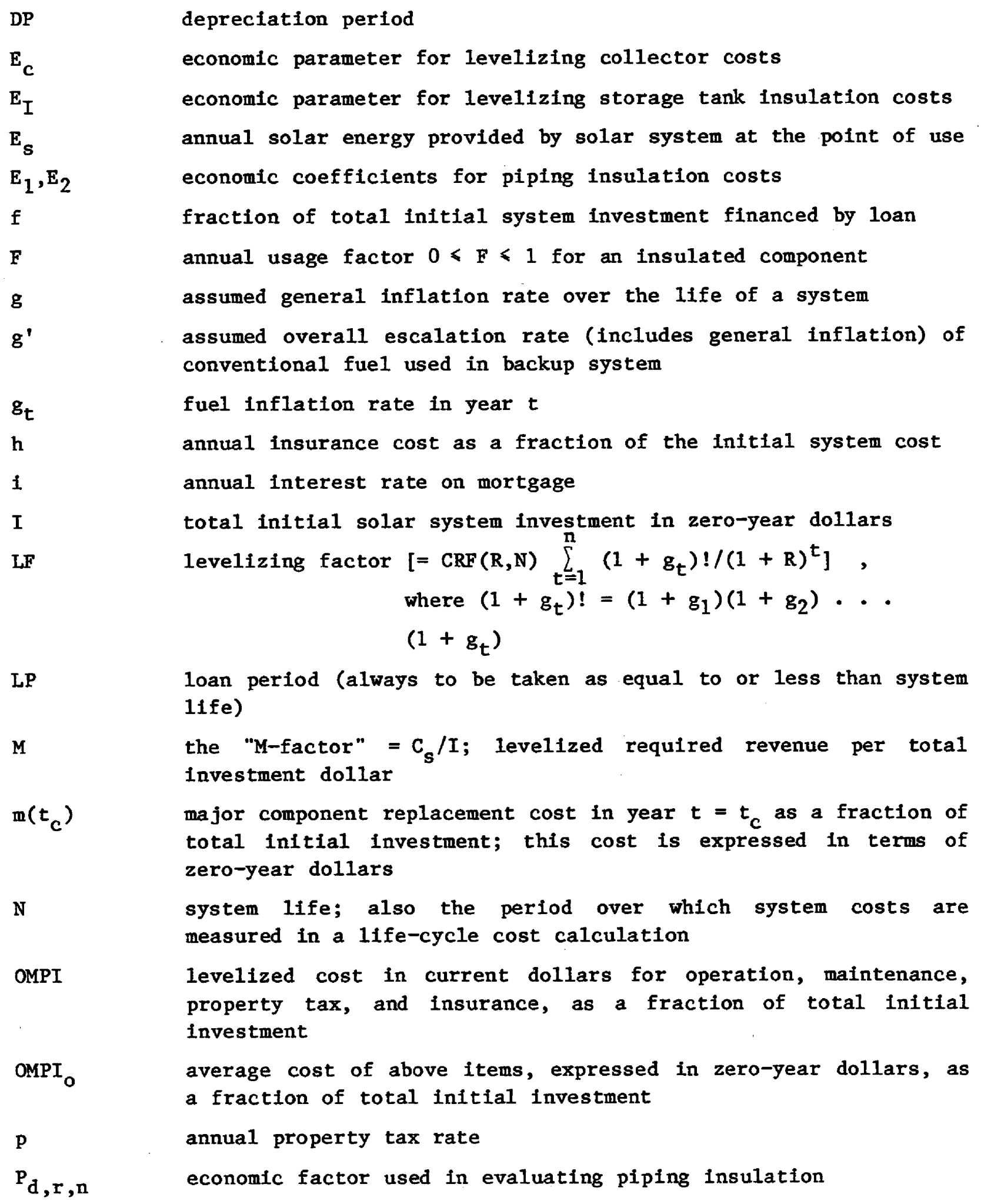




\section{LIST OF BCONOMIC TERMS (Concluded)}

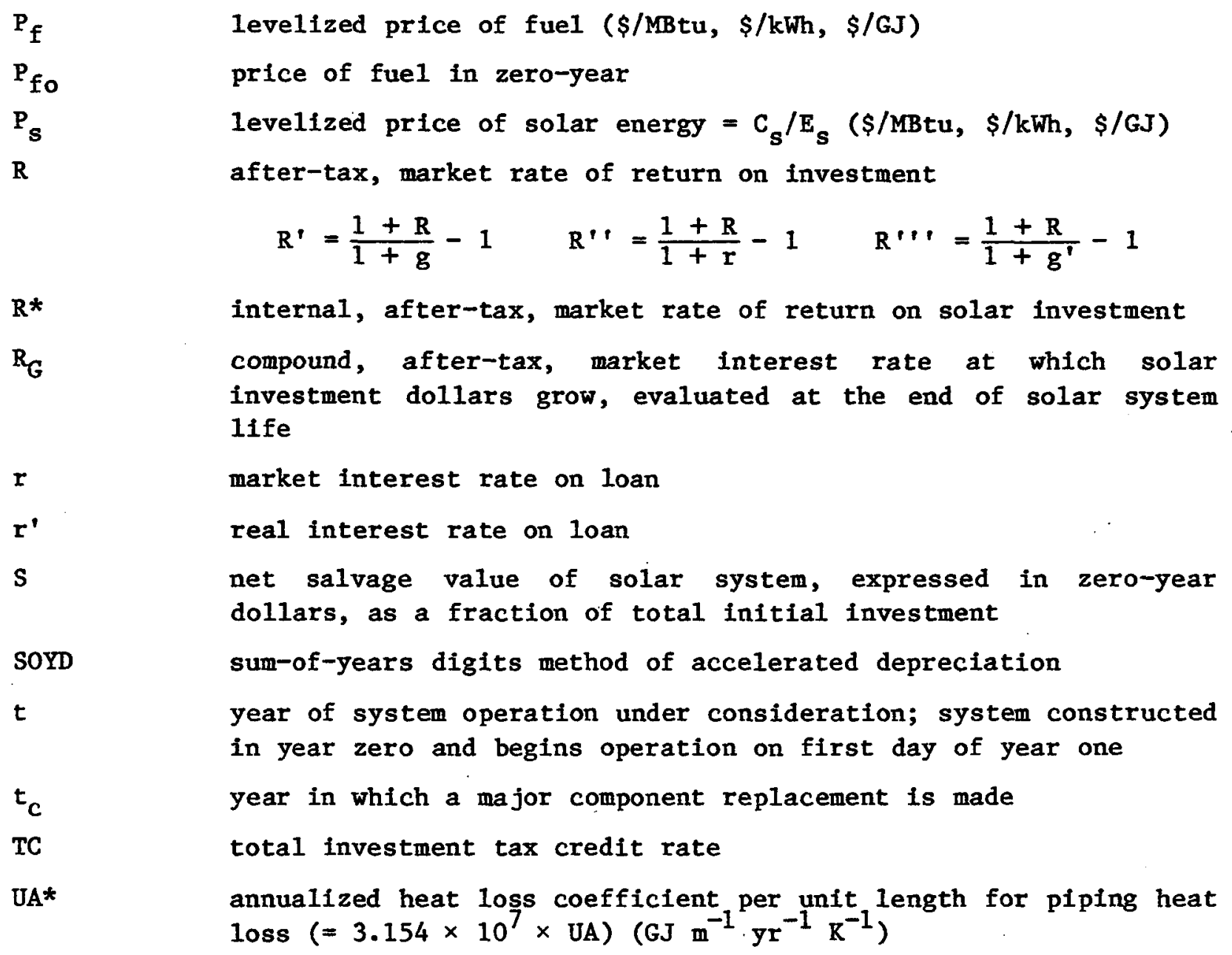

Greek Symbols

$\begin{array}{ll}\alpha & \begin{array}{l}\text { fraction of system first cost that was paid as a downpayment } \\ (=1-f)\end{array} \\ \beta & \text { investment tax credit } \\ \Delta & \text { declining balance multiplier } \\ \varepsilon & \text { solar effectiveness factor }(=\text { fuel energy saved by a solar } \\ & \text { energy system divided by the solar energy delivered) } \\ \tau & \text { marginal composite income tax rate }\left[=\tau_{s}+\left(1-\tau_{s}\right) \tau_{f}\right] \\ \tau_{f} & \text { marginal federal income tax rate } \\ \tau_{s} & \text { marginal state income tax rate }\end{array}$




\section{TABLE OF COITHETS}

PART I: Objectives and Fundamentals

1.0 Objectives and Design Methodology..........................

1.1 Introduction...................................... 1

1.2 Design Methodology .................................. 2

1.3 Additional Sources of Information.......................

2.0 Solar Energy in Industry: An Overview.......................

2.1 Introduction..................................... 7

2.2 Solar Applications in IPH............................. 12

2.2 .1 Hot Water.................................... 12

2.2 .2 Drying and Dehydration.......................... 13

2.2 .3 steam....................................... 15

2.3 Industrial Process Heat Field Tests...................... 16

2.4 References.......................................... 22

PART II: Conceptual Design

3.0 Solar IPH Suitability Analysis............................. 25

3.1 Environmental Factors................................. 25

3.2 Process Factors..................................... 28

3.3 Economic Factors................................... 32

3.4 Company Factors.................................... 33

3.5 Examples of Favorable Solar Thermal Applications............ 33

3.6 References.......................................... 34

4.0 IPH System Configuration............................... 35

4.1 Hot Air Systems..................................... 35

4.2 Hot Water Systems................................. 36

4.3 Steam Systems..................................... 38

4.3 .1 Flash steam systems........................... 40

4.3 .2 Unfired-Boiler Systems........................... 42

4.3.3 Direct Steam Generation......................... 43

4.4 Storage Configurations............................... 43

4.4 .1 Hot Water Storage.............................. 43

4.4.2 Storage for Stean Systems......................... 47

4.5 Process/Solar System Interface........................ 50

4.6 References...................................... 51 
TABLE OF COMTEMTS (Continued)

.0 Solar Collectors $\ldots \ldots \ldots \ldots \ldots \ldots \ldots \ldots \ldots \ldots \ldots \ldots \ldots \ldots \ldots \ldots \ldots \ldots \ldots \ldots$

5.1 Types of Collectors............................. 53

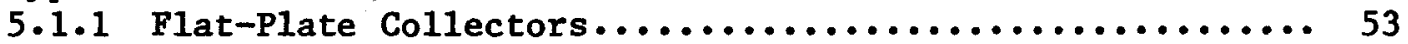

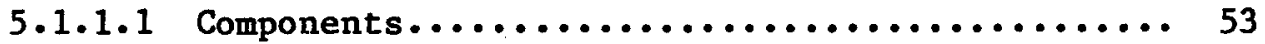

5.1 .1 .2 Improvements........................ 56

5.1 .2 Evacuated-Tube Collectors.................... 56

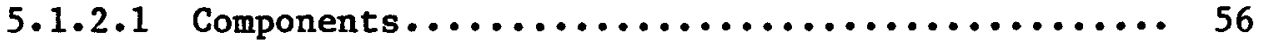

5.1 .2 .2 Improvements........................ 58

5.1 .3 Parabolic Trough Collectors..................... 59

5.1 .3 .1 Components......................... 60

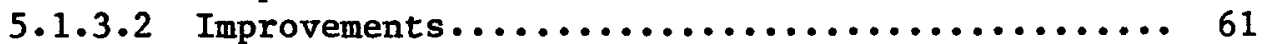

5.1 .4 0ther Types of Collectors...................... 61

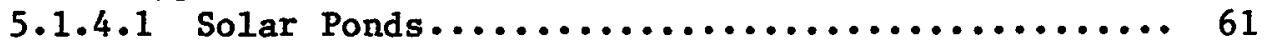

5.1 .4 .2 Compound Parabolic Concentrators........... 63

5.1.4.3 Fresnel Lens Collectors.................. 63

5.1.4.4 Multiple-Reflector Collectors............. 65

5.1.4.5 Parabolic Dish Collectors................. 65

5.1 .4 .6 Central Receivers....................6 65

5.2 Instantaneous Performance of Collectors.................. 65

5.2 .1 Analysis................................... 66

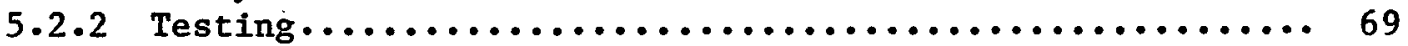

5.3 Collector Selection Procedure........................ 73

5.3.1 A Preliminary Comparison of Collector Performance...... 74

5.3.2 Other Considerations in Selecting an Appropriate

Collector............................... 79

5.4 References...................................... 80

\section{PART III: Preliminary Design}

6.0 Annual Performance of a Solar Energy System................. 83

6.1 Annual Energy Collection for Several IPH

System Configurations........................... 83

6.1 .1 Hot Air and Hot Water Systems.................. 86

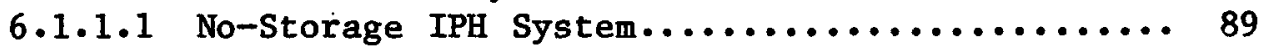

6.1.1.2 Mixed-Tank, Recirculation IPH System........ 93

6.1.1.3 Variable-Volume Storage System............ 107

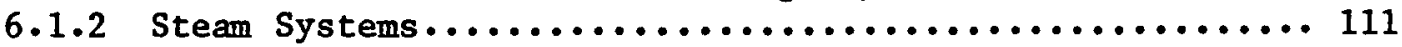

6.1 .2 .1 Unfired-Boiler Steam System.............. 111

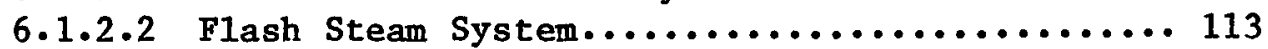

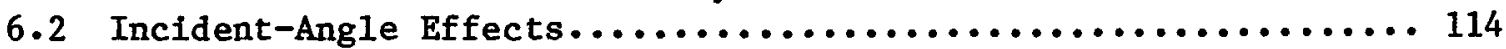

6.2 .1 Incident-Angle Modifiers...................... 115

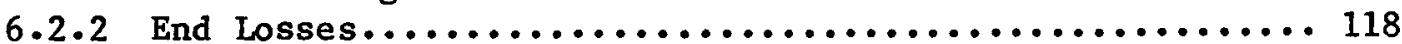

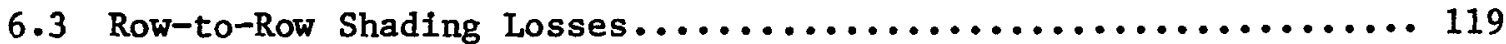

6.4 Annual Thermal Losses of Collector Field Piping and Storage.... 122

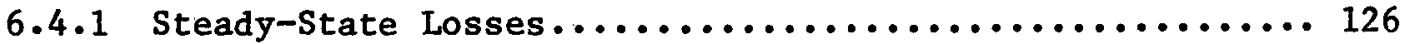

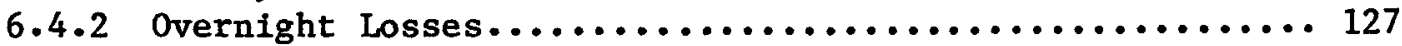

6.4 .3 Freeze-Protection Heat Losses.................... 129 


\section{TABLE OF CONrFirs (Continued)}

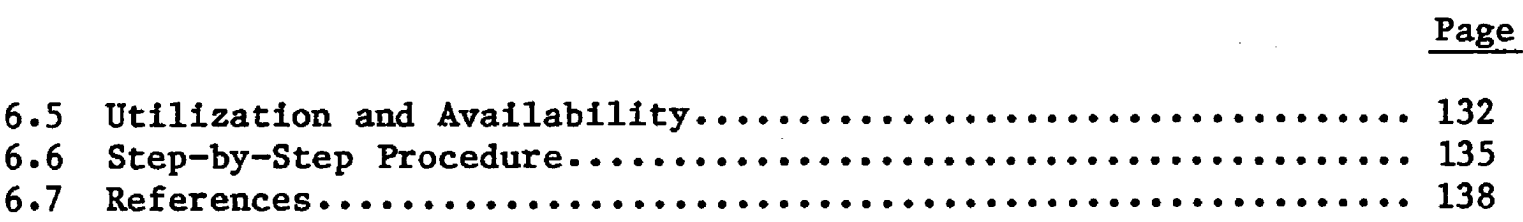

7.0 The Energy Transport System............................ 139

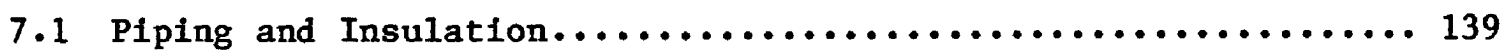

7.1.1 Collector Field Piping Configurations............... 139

7.1.2 Optimum Array Flow Rate and Collector Configuration..... 141

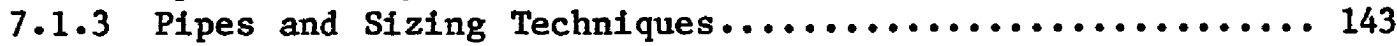

7.1 .4 Insulation and Heat Losses...................... 144

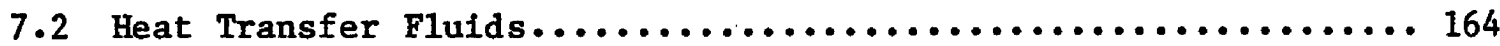

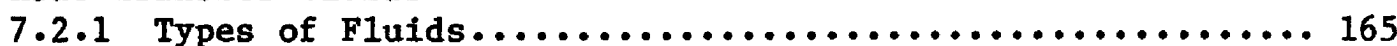

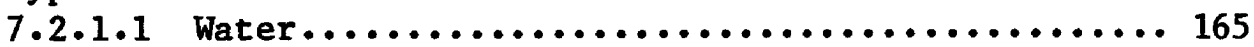

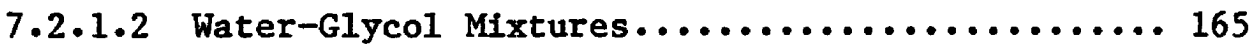

7.2.1.3 Aliphatic Hydrocarbons................. 165

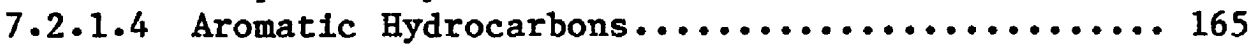

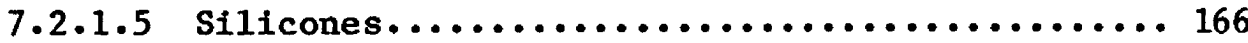

7.2.2 Temperature-Dependent Thermal Properties............ 166

7.2 .3 Other Thermal Properties....................... 170

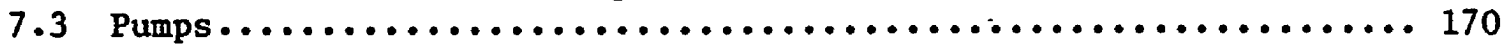

7.3.1 Sizing a Single-Speed Centrifugal Pump............. 171

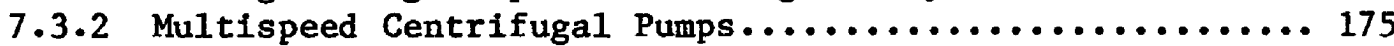

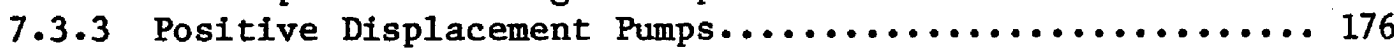

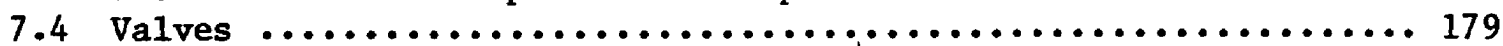

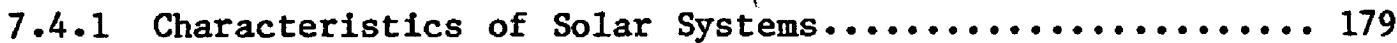

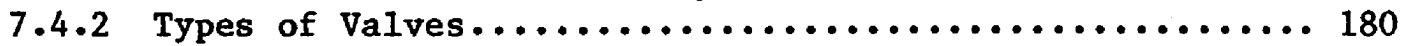

7.4.3 Guidelines for Selecting Valves................... 181

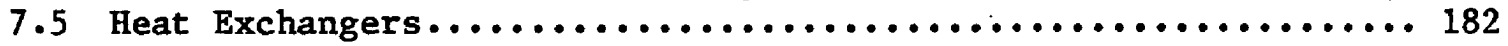

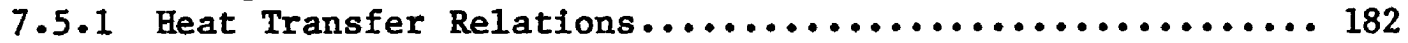

7.5 .2 Overall Heat Transfer Coefficient.................. 184

7.5.3 Heat Exchanger Factor for Solar System Performance...... 187

7.5 .4 Economical Heat Exchanger Area.................... 189

7.5.5 Practical Considerations in Selecting a Heat

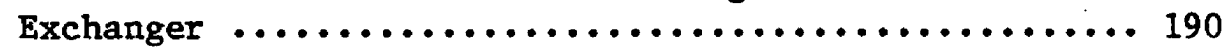

7.5 .6 Plate Heat Exchangers....................... 192

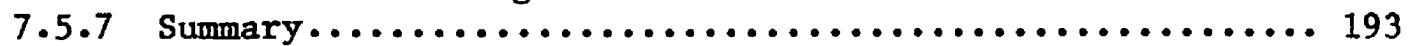

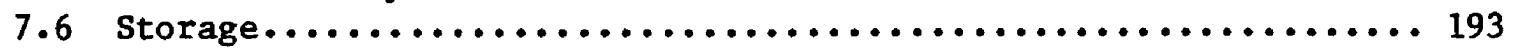

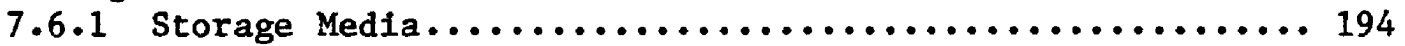

7.6.1.1 Sensible Heat Storage................... 194

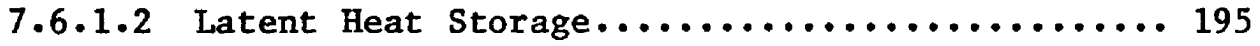

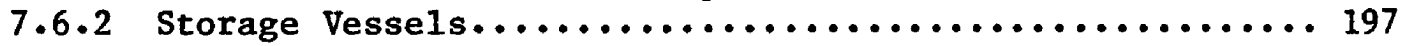

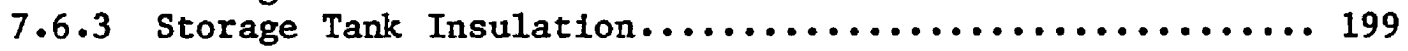

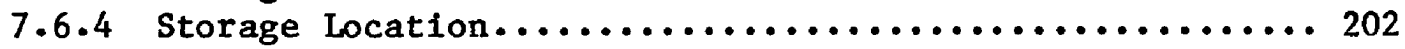

7.6 .4 .1 Interior Storage..................... 202

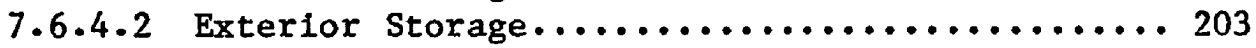

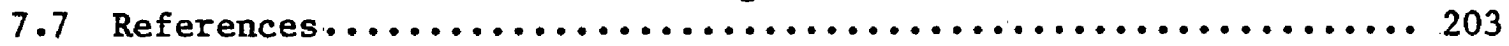

8.0 Controls and Instrumentation.......................... 207

xvil 
8.1 Fundamentals of Controls........................... 207

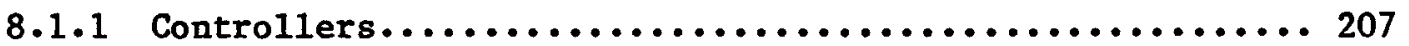

8.1 .2 Common Control Loops............................ 208

8.1.3 Measurement Dynamics............................ 209

8.1 .4 Noise..................................... 210

8.1 .5 Valves...................................... 210

8.1.6 Miscellaneous Considerations.................... 212

8.1 .7 Multivariable Control Loops..................... 212

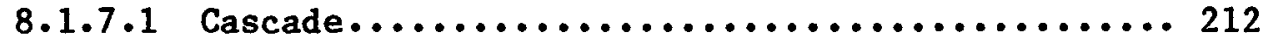

8.1 .7 .2 Feed-Forward........................ 212

8.1.7.3 Split-Range Control................... 213

8.1 .7 .4 Overrides........................... 213

8.1 .8 Computers................................ 213

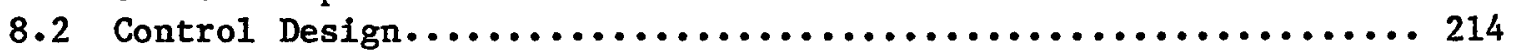

8.2.1 Normal Operating Modes........................ 214

8.2.2 Start-Up/Shutdown............................ 227

8.2 .3 Freezing/Stagnation........................... 229

8.2 .4 Emergency Conditions.......................... 229

8.2 .5 Operator Training/Display..................... 230

8.2 .6 Control System Checkout...................... 230

8.3 Instrumentation and Data Acquisition.................. 231

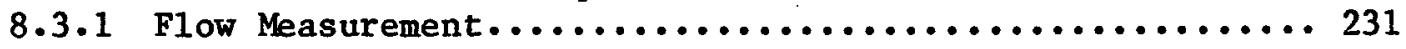

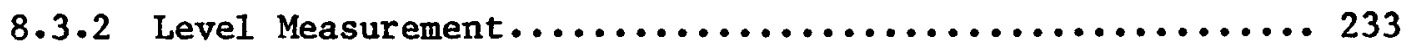

8.3.3 Pressure Measurement.......................... 233

8.3 .4 Temperature Measurement........................ 233

8.3 .5 Irradiation Measurement...................... 235

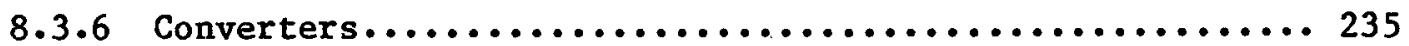

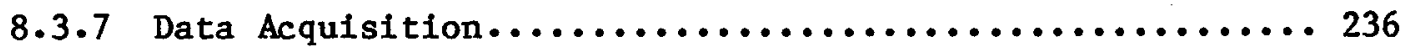

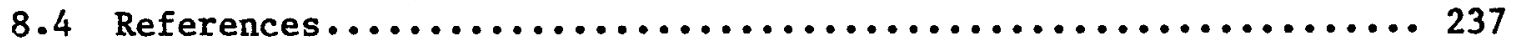

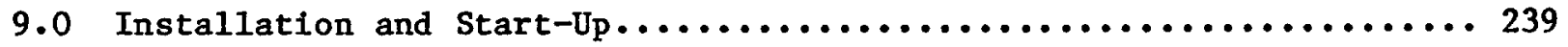

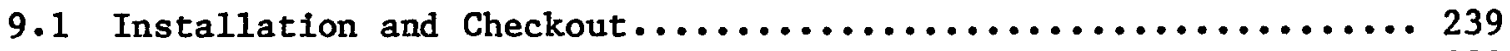

9.1 .1 Scheduling ................................ 239

9.1 .2 Installing the Collectors..................... 239

9.1.2.1 Installing. Flat-Plate Collectors........... 239

9.1.2.2 Installing Evacuated-Tube Collectors........ 240

9.1.2.3 Installing Line-Focus Collectors........... 241

9.1.2.4 Piping, Fittings, and Insulation.......... 242

9.1.3 Installing Heat Exchangers..................... 246

9.1 .4 Installing Pumps........................... 246

9.1.5 Installing Pressure Vessels and Storage Tanks........ 247

9.1.6 Installing Controls, Electrical Lines, and

Instrumentation......................... 248

9.1.7 Personnel and Environmental Safety Precautions......... 248

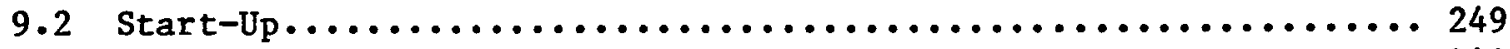

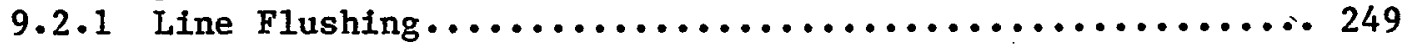

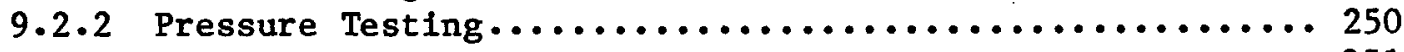

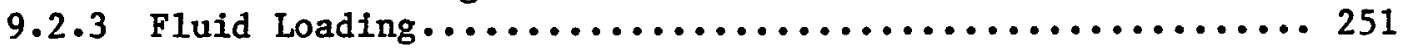

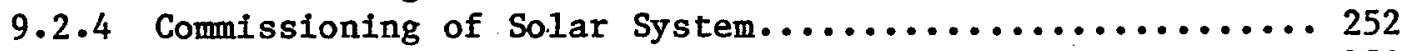

9.2 .5 Performance Testing......................... 252 


\section{TABLE OP CONTENTS (Continued)}

9.3 Summary..................................... 253

9.4 References..................................... 253

10.0 Solar System Economics............................. 257

10.1 Methods of System Cost Estimation.................... 257

10.1.1 Historical IPH System and Subsystem Costs........... 257

10.1.1.1 Historical System Costs............... 258

10.1.1.2 Historical Subsystem Costs............. 260

10.1.1.3 Estimating Construction Costs Using the Mueller Data......................261

10.1.2 Modular Cost Estimating...................... 269

10.2 Life-Cycle Cost Analysis........................... 270

10.3 Methods of Financing Solar Systems................... 281

10.3 .1 Conventional Financing........................ 281

10.3.2 Conventional Lease Arrangements................. 281

10.3.3 Solar Management Company/Limited Partnership......... 281

10.4 References..................................... 283

11.0 Safety and Environmental Issues........................ 285

11.1 Safety Concerns in IPH Systems...................... 285

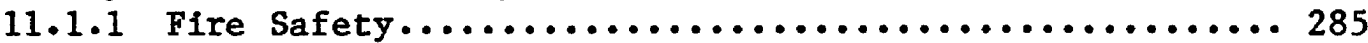

11.1 .1 .1 Materials......................... 285

11.1.1.2 Equipment and Procedures.............. 286

11.1 .2 Physical Hazards............................. 288

11.1.3 Fluid Toxicity Considerations................... 289

11.1.4 Protection from Overtemperature and Overpressure..... 289

11.1 .5 Product Contamination......................... 290

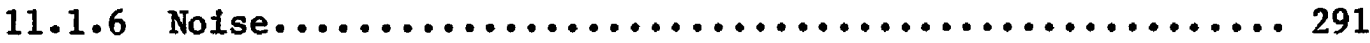

11.1.7 Applicable Regulations and Agencies................ 291

11.2 Environmental Aspects of Solar IPH Systems............... 292

11.2.1 Environmental Impacts of Solar IPH Systems.......... 292

11.2.2 National Environmental Protection Laws and

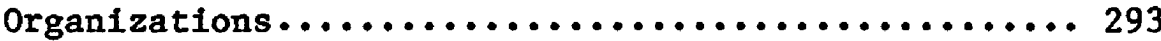

11.2.2.1 Air-Pollution Control................. 293

11.2.2.2 Water-Pollution Control................ 293

11.2 .2 .3 Waste Disposal...................... 295

11.2 .2 .4 Noise............................. 295

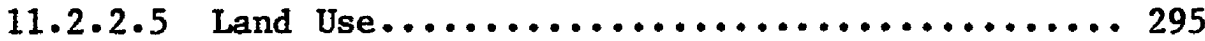

11.2.3 State Environmental Regulations.................. 295

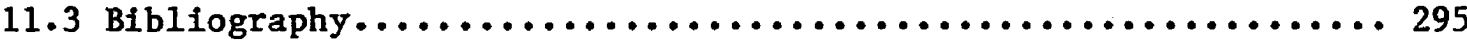

11.4 References..................................... 296

Appendix A Effects of Solar Systems on the Efficiency of Hot Water

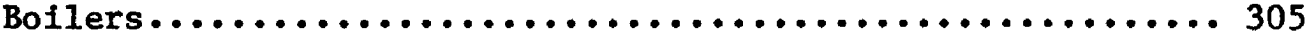

Appendix B Propertles of Heat-Transfer Flulds................... 317

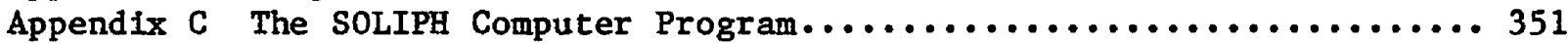

Appendix D Derivation of Annua1-Performance Emplrical Correlations...... 371 


\section{TABLE OF CONTENTS (Concluded)}

Page

Appendix E Derivation of Annual Performance Modifiers............... 383

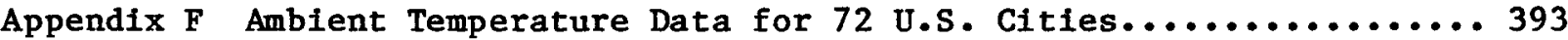

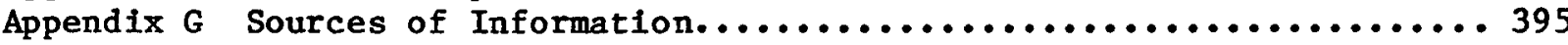

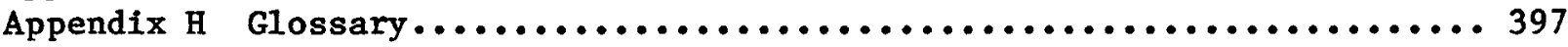

Appendix I Conversion Tables...............................4 407

Index $\ldots \ldots \ldots \ldots \ldots \ldots \ldots \ldots \ldots \ldots \ldots \ldots \ldots \ldots \ldots \ldots \ldots \ldots \ldots \ldots \ldots \ldots \ldots \ldots \ldots \ldots \ldots \ldots \ldots$ 


\section{LIST OR FIGURES}

Page

1-1 Solar IPH System Design Process......................... 3

2-1 U.S. Energy Demand by Sector.......................... 7

2-2 Solar Attractiveness Index for Parabolic Trough Collectors......... 9

2-3 Energy Use by Major Industrial Groups..................... 11

2-4 Distribution of IPH Requirements by Temperature............... 11

2-5 Operating Temperatures for Various Types of Collectors.......... 12

2-6 York Building Products Solar Hot Water System................ 13

2-7 Lamanuzzi and Pantaleo Foods Solar Air System................ 14

2-8 LaCour Lumber Kiln Solar Hot-Water-to-Air System.............. 14

2-9 Solar Steam Production Using an Unfired Boiler................. 15

2-10 Solar Steam Production Using a Flash Tank................... 16

3-1 Average Daily Global Solar Radiation on a Horizontal Surface

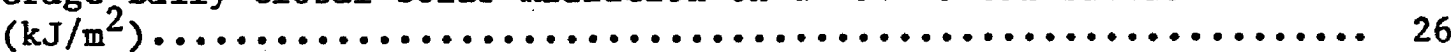

3-2 Average Daily Direct Normal Solar Radiation $\left(\mathrm{kJ} / \mathrm{m}^{2}\right) \ldots \ldots \ldots \ldots \ldots$

3-3 Normal Daily Average Temperature $\left({ }^{\circ} \mathrm{F}\right)$ in January................ 29

3-4 Normal Daily Average Temperature $\left({ }^{\circ} \mathrm{F}\right)$ in July................ 30

3-5 Mean Annual Number of Freezing Days in the United States......... 31

3-6 Real Costs of Conventional Fuels....................... 33

4-1 Direct Hot Air Solar System.......................... 35

4-2 Water-to-Air Solar System.......................... 36

4-3 A Direct Solar Hot Water System....................... 37

$4-4$ An Indirect Solar Hot Water System..................... 37

4-5 Direct Hot Water System with Drain-Out Freeze Protection......... 39

4-6 Indirect Hot Water System with Drain-Back (to Tank) Freeze Protection and Nonpressurized Tank ..................... 39 


\section{LIST OP FIGURES (Continued)}

Page

4-7 Indirect Hot Water System with Drain-Back to Holding Tank and Pressurized Storage Tank.............................. 40

4-8 Flash-Steam Solar System............................ 41

4-9 Unfired-Boiler Steam-Generating System.................... 42

4-10 Four-Pipe Storage Configuration........................ 43

4-11 Two-Pipe Storage Configuration........................ 44

4-12 Multiple-Tank Storage Configuration for Achieving Stratification.... 44

4-13 Variable-Volume Storage Configuration...................... 45

4-14 Thermocline or Mixed Tank Configuration with Unfired-Boiler Steam System...................................... 48

4-15 Variable-Volume Storage Tank Configuration for Unfired Boiler Steam System.......................................... 48

4-16 Annual Energy Delivery as a Function of Collector Area, Storage Type, and Size for an Unfired-Boiler System................ 49

5-1 Cross Section of Typical Flat-Plate Collector................. 54

5-2 Concentric Glass Evacuated-Tube Collector.................. 57

5-3 Evacuated-Tube Collector Utilizing Metal Flow Passage........... 58

5-4 Typical Parabolic Trough Collector....................... 59

5-5 System Performance Increases vs. Absorber Temperature for Various Component Improvements of Horizontal Parabolic Troughs.......... 62

5-6 A CPC Collector Module.............................. 64

5-7 Concentration With a Fresnel Lens........................ 64

5-8 Typical Instantaneous Efficiency Curves for Collectors Used in IPH Applications.................................. 68

5-9 Typical Incident-Angle Modifiers for Collectors Used in IPH Applications................................. 70

5-10 Average Global Solar Irradiance During Daylight Hours on a Horizontal Surface $\left(w / m^{2}\right) \ldots \ldots \ldots \ldots \ldots \ldots \ldots \ldots \ldots \ldots \ldots \ldots$ 


\section{LIST OF FIGURES (Continued)}

Page

5-11 Average Direct Normal Solar Irradiance During Daylight

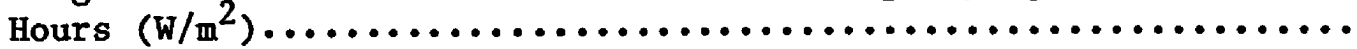

5-12 Graphiçal Determination of Yearly Average Energy Collection Rate $\left(W / \mathrm{m}^{2}\right)$ During Daylight Hours for Unshaded Flat Plates, Evacuated

Tubes, and Parabolic Troughs as a Function of Intensity Ratio.... 78

6-1 Graphical Determination of Yearly Average Energy Collection Rate $\left(\mathrm{W} / \mathrm{m}^{2}\right)$ During Daylight Hours for Unshaded Flat Plates, Evacuated Tubes, and Parabolic Troughs as a Function of Intensity Ratio.....

6-2 An Indirect Solar Hot Air or Hot Water System................ 88

6-3 Mixed-Tank Recirculation System......................... 94

6-4 Annual Recirculation System Storage-Load Modifier for Flat

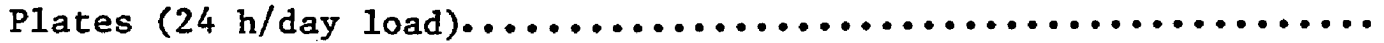

6-5 Annual Recirculation System Storage-Load Modifiers for Evacuated Tubes $(24 \mathrm{~h} /$ day $10 a d) . \ldots \ldots \ldots \ldots \ldots \ldots \ldots \ldots \ldots \ldots \ldots \ldots \ldots . \ldots \ldots$

6-6 Annual Recirculation System Storage-Load Modifiers for East-West Parabolic Troughs $(24 \mathrm{~h} /$ day load $) . \ldots \ldots \ldots \ldots \ldots \ldots \ldots \ldots$

6-7 Annual Recirculation System Storage-Load Modifiers for North-South

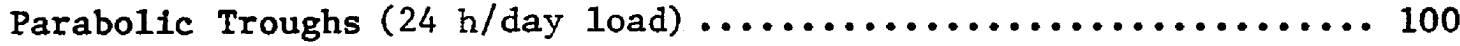

6-8 Annual Recirculation System Storage-Load Modifiers for Flat

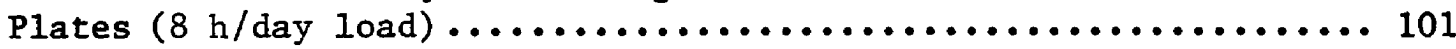

6-9 Annual Recirculation System Storage-Load Modifiers for Evacuated

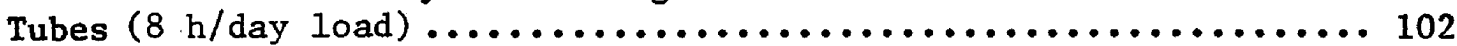

6-10 Annual Recirculation System Storage-Load Modifiers for East-West

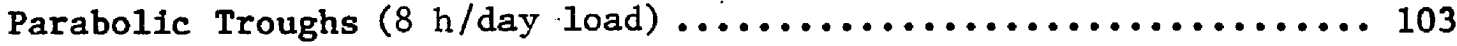

6-11 Annual Recirculation System Storage-Load Modifiers for North-South

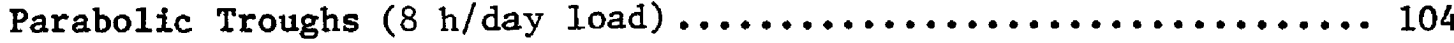

6-12 Variable-Volume Storage Configuration....................... 108

6-13 Annual Incident-Angle Modifier Correction Factors for Flat-Plate Collectors...................................... 117

6-14 Annual Optical Efficlency Incident-Angle Weighting Factors for a North-South Trough................................ 118

6-15 Row-to-Row Shading Geometries.......................... 121 


\section{LIST OF FIGURES (Continued)}

Page

6-16 Annual Row-to-Row Shading-Loss Modifier for Flat Plates and Evacuated Tubes Tilted at Latitude...................... 123

6-17 Annual Row-to-Row Shading-Loss Modifier for East-West Parabolic Troughs......................................... 124

6-18 Annual Row-to-Row Shading-Loss Modifier for North-South Parabolic Troughs......................................... 125

6-19 Hours of Freezing Temperatures per Year as a Function of Freezing Days per Year.................................... 131

6-20 Average Below-Freezing Temperatures as a Function of Average January Daytime Temperature.......................... 132

7-1 Solar System Collector Field Layouts...................... 140

7-2 Effect of Insulation Thickness on Delivered Energy Cost.......... 144

7-3 Insulated Pipe Model.............................. 145

7-4 Thermal Conductivity of Rigid Insulating Materials............. 158

7-5 Sensitivity of UA/L Values to Changes in Parameters--Outdoors....... 159

7-6 Sensitivity of UA/L Values to Changes in Parameters--Indoors....... 160

7-7 Heat Transfer Efficiency Factors for Twenty Fluids............. 169

$7-8$ Summary of Types of Pumps............................ 172

7-9 Typical Head-Flow Curves for a Centrifugal Pump............... 173

7-10 Selection Curves for a Centrifugal Pump..................... 174

7-11 Net Positive Suction Head Required by Pump.................. 175

7-12 Pumping Power Required by Different Pump Configurations......... 176

7-13 Capacity vs. NPSHR for Varlable-Speed Pumps................ 177

7-14 Head-Flow Curves for Two Centrifugal Pumps in Parallel........... 178

7-15 Example Heat Exchanger System......................... 183

7-16 Floating Tubesheet Shell-and-Tube Heat Exchanger.............. 191 
LIST OF FIGURES (Concluded)

Page

7-17 Storage Capacity per Unit Volume as a Function of Temperature

for Selected Latent-Heat Storage Materials.................. 198

8-1 Constant Flow-Rate Control........................... 215

8-2 Constant F1ow-Rate Control Using Three-Way Valve.............. 216

8-3 Outlet Temperature Control by Flow-Rate Manipulation........... 216

8-4a Turndown Ratio as a Function of Equivalent Lag and Capacitance Ratio (p) for Proportional Control...................... 218

8-4b Turndown Ratio as a Function of Equivalent Lag and Capacitance Ratio (p) for Proportional-Integral Control................ 218

8-5 Dimensionless Controller Gain as a Function of Equivalent Lag and Capacitance Ratio (p) for Proportional-Only Contro1............ 219

8-6 Dimensionless Controller Gain as a Function of Equivalent Lag and Capacitance Ratio (p) for Proportional-Integral Contro1......... 220

8-7 Dimensionless Integral Time as a Function of Equivalent Lag and Capacitance Ratio $(p)$ for Proportional-Integral Control......... 221

8-8 Solar System Response with Proportional-Only Control............ 225

8-9 Solar System Response with Proportional-Integral Control........ 226

8-10 Typical Control Loop Tracking Control...................... 228

9-1 Hose Deployment for Use With Either Rotatable or Nonrotatable Receivers....................................... 243

9-2 Examples of Insulation Techniques for Pipe Supports and Hangers.... 245

9-3 Design for Reducing Overnight Heat Losses in Drainback Systems..... 248

10-1 Economies-of-Scale Factor........................... 265

10-2 Modular Cost-Estimating Procedure Used by ECONMAT............ 271

10-3 Graphical Solution of Eq. 10-10 for Different Loan Fractions and Fuel Escalation Rates.............................. 282 


\section{HIST OP TABLES}

Page

2-1 U.S. Industrial Energy Consumption by State................ 10

2-2 Fuel Use by Industrial Sector $(1980) \ldots \ldots \ldots \ldots \ldots \ldots \ldots \ldots \ldots \ldots \ldots$

2-3 Solar Industrial Process Heat Projects in the United States........ 17

2-4 Problems Encountered in DOE-Funded Field Tests................ 20

3-1 Factors Favoring the Use of Solar IPH Systems............... 25

5-1 Typical Ranges of Liquid Collector, Performance

Characteristics................................. 75

6-1 Maximum Daily Irradiation Available for Several Collector Types..... 109

6-2 Al1-Day Average of End-Loss Factors...................... 119

7-1 Economic Fluid Velocities for Schedule 40 Steel Pipes, Obtained

Using the Perry and Chilton Method....................... 143

7-2 Typical Thicknesses of Calcium Silicate Pipe Insulation.......... 146

7-3 Average Values of Independent Variables Used in Calculation of UA/L............................................... 149

7-4 Outdoor Pipe UA/L Values (W/K-m of length) for Insulation $k=0.0288 \mathrm{~W} / \mathrm{m}-\mathrm{K}\left(0.20 \mathrm{Btu}-\mathrm{in} . / \mathrm{hr}-\mathrm{ft} \mathrm{t}^{2}{ }^{\mathrm{o}} \mathrm{F}\right) \ldots \ldots \ldots \ldots \ldots \ldots \ldots \ldots \ldots$

7-5 Outdoor Pipe UA/L Values ( $/ \mathrm{K}-\mathrm{m}$ of length) for Insulation $\mathrm{k}=0.0577 \mathrm{~W} / \mathrm{m}-\mathrm{K}\left(0.40 \mathrm{Btu}-\mathrm{in} . / \mathrm{hr}-\mathrm{ft} \mathrm{t}^{2} \mathrm{O}_{\mathrm{F}}\right) \ldots \ldots \ldots \ldots \ldots \ldots \ldots \ldots \ldots$

7-6 Outdoor Pipe UA/L Values ( $/ \mathrm{K}-\mathrm{m}$ of length) for Insulation $\mathrm{k}=0.0865 \mathrm{~W} / \mathrm{m}-\mathrm{K}\left(0.60 \mathrm{Btu}-\mathrm{in} . / \mathrm{hr}-\mathrm{ft} \mathrm{t}^{2}{ }^{\mathrm{O}} \mathrm{F}\right) \ldots \ldots \ldots \ldots \ldots \ldots \ldots \ldots \ldots \ldots \ldots \ldots$

7-7 Outdoor Pipe UA/L Value ( $W / K-m$ of length ) for Insulation $k=0.1154 \mathrm{~W} / \mathrm{m}-\mathrm{K}\left(0.80 \mathrm{Btu}-\mathrm{In} . / \mathrm{hr}-\mathrm{ft} \mathrm{t}^{2} \mathrm{O}_{\mathrm{F}}\right) \ldots \ldots \ldots \ldots \ldots \ldots \ldots \ldots \ldots \ldots$

7-8 Indoor Pipe UA/L Values (W/K-m of length) for Insulation $\mathrm{k}=0.0288 \mathrm{~W} / \mathrm{m}-\mathrm{K}\left(0.20 \mathrm{Btu}-\mathrm{in} . / \mathrm{hr}-\mathrm{ft} \mathrm{t}^{2} \mathrm{O} \mathrm{F}\right) \ldots \ldots \ldots \ldots \ldots \ldots \ldots \ldots \ldots \ldots$

7-9 Indoor Pipe UA/L Values (W/K-m of length) for Insulation $k=0.0577 \mathrm{~W} / \mathrm{m}-\mathrm{K}\left(0.40 \mathrm{Btu}-\mathrm{in} . / \mathrm{hr}-\mathrm{ft} \mathrm{t}^{2}{ }^{\circ} \mathrm{F}\right) \ldots \ldots \ldots \ldots \ldots \ldots \ldots \ldots \ldots \ldots$

7-10 Indoor Pipe $U A / L$ Values (W/K-m of length) for Insulation $k=0.0865 \mathrm{~W} / \mathrm{m}-\mathrm{K}\left(0.60 \mathrm{Btu}-\mathrm{in} . / \mathrm{hr}-\mathrm{ft}^{2}-\mathrm{O}_{\mathrm{F}}\right) \ldots \ldots \ldots \ldots \ldots \ldots \ldots \ldots \ldots$

7-11 Indoor Pipe UA/L Values (W/K-m of length) for Insulation $k=0.1154 \mathrm{~W} / \mathrm{m}-\mathrm{K}\left(0.80 \mathrm{Btu}-\mathrm{in} . / \mathrm{hr}-\mathrm{ft}^{2}-\mathrm{O}_{\mathrm{F}}\right) \ldots \ldots \ldots \ldots \ldots \ldots \ldots \ldots \ldots$ 


\section{LIST OP TABLRS (Concluded)}

Page

7-12 Typical Overall Heat Transfer Coefficient Values for Tubular

Heat Exchangers..................................... 184

7-13 Typical Fouling Resistances........................... 185

7-14 Storage Size Comparison of Different Media Based on 1 GJ Storage and $30 \mathrm{k}$ Temperature Swing............................ 196

9-1 Installation Checklist.............................. 254

10-1 Modified Solar IPH Subsystem Costs........................ 259

10-2 Conceptual Phase Cost Estimating Guide..................... 263

10-3 Design Cost Factors................................... 264

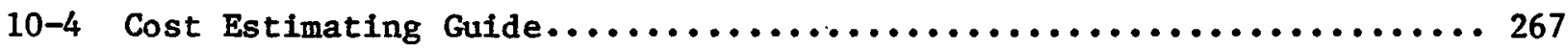

10-5 Factor Definitions for Modular Cost Estimating...............272

10-6a Recommended Values for Modular Factors...................... 272

10-6b Recommended Values for Modular Factors.................... 273

10-7 Values of Capital Recovery Factor........................ 274

10-8 Values of Levelizing Factor LF to Convert a Zero-Year Fuel Price to a Levelized Price Over $\mathbf{N}$ Years........................ 276

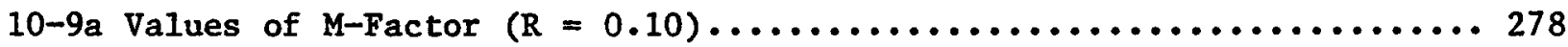

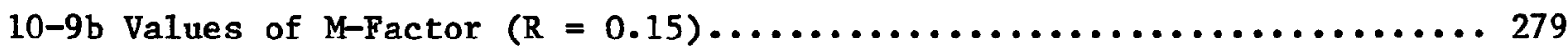

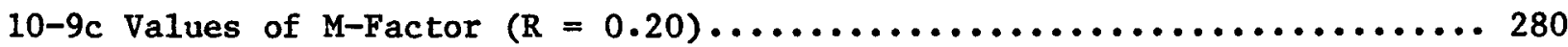

11-1 Fire-Resistance Properties of Various Insulating Materials........ 287

11-2 Safety Regulations and Agencies.......................... 291

11-3 Summary of Environmental Agencies and Regulations.............. 294

11-4 State Environmental Impact Statement Requirements.............. 297 
PART I

OBJECTIVES AND FUNDAMENTALS 
SECTION 1.0

\section{OBJECTIVES AND DESIGN METHODOLOGY}

\subsection{TITRODUCTION}

In an effort to expedite the commercialization of solar energy, the U.S. Department of Energy has funded a number of field tests. These include over 100 projects that demonstrate solar heating and cooling (SHAC) of buildings and about a dozen projects to date in which solar collectors supply industrial process heat (IPH). Results from these projects generally showed lower than predicted energy deliveries due to a variety of system design, plumbing, and hardware problems, most of which can be expected in a new technology. Various handbooks were written to help designers avold problems already encountered; later projects showed marked improvements.

Application of solar energy to industrial processes began later than the SHAC program, but similar problems have occurred in the IPH projects. Differences in types of collectors, environment, and loads created some new problems as well. There was obviously a need to make contractors for new projects aware of mistakes made in the past. A great deal had been learned from the operation of the hot air/hot water IPH projects; from those experiences, a set of guidelines was prepared to help design engineers with future solar industrial process heat systems. A questionnaire was mailed to previous contractors and DOE technical advisors, and a draft document was prepared from the results. Following a final review meeting at SERI, Design Considerations for Solar Industrial Process Heat Systems (Kutscher 1981) was published in March.

The purpose of this handbook is to provide specific design information. Choosing appropriate components such as collectors, storage, piping, insulation, pumps, valves, heat exchangers, and heat transfer fluids is covered in detail. System integration, controls, economics, start-up procedures and safety and environmental issues are also addressed, and a new, simple method for predicting energy delivery is included.

A considerable amount of time and money is often spent performing detailed computer simulations of a solar energy system. The authors believe, however, that if solar IPH applications are to become economically viable, they must be designed in ways that are typically used in the heating, ventilating, and air conditioning (HVAC) industry. Although the sensitivity of solar energy systems to variable solar input and thermal losses dictates more sophisticated "rules of thumb" than those used to size a building air conditioning system, simple graphs and tables can supply design values that are completely sufficient for system design. To save designers both extra steps and considerable expense, we have replaced the computer simulation step with some simple rules.

Design tools can be generated either from actual performance measurements taken in the field or from large numbers of computer simulations. Because actual field data are still very limited, the bulk of design tool development in this handbook has incorporated data from computer simulations. Therefore, before this handbook was written, a study was done comparing the capabilities of various solar simulation codes for IPH applications. The two most likely 
candidates were TRNSYS, developed by the University of Wisconsin, and SOLTES, developed by Sandia Laboratories (see Sec. 6.0). For a variety of reasons, each code would have required considerable modification; thus, a new in-house code specifically geared for solar IPH design tool development was created. The result, SOLIPH, is not highly user-oriented like TRNSYS or SOLTES but is very easy to modify, inexpensive to run, and well suited to the purposes of this handbook. To verify the accuracy of the design tools generated by SOLIPH, the SOLIPH program was tested against other well-respected computer programs (see Appendix C).

This handbook was designed to be used by readers with experience in basic mechanical engineering. Knowledge of computer programming is not necessary, however, and previous solar energy experlence, although advantageous, is not required. Because of its simplicity of approach, the handbook should be useful to an industrial firm contemplating solar energy and interested in having an in-house engineering staff manage conceptual and preliminary designs. It is recommended that the design engineer read the chapters in order. Results of conceptual design calculations will indicate whether the designer should proceed to the preliminary design. The iteration needed in completing a design is discussed in the next section.

Because this field is constantly changing and new information continues to come in from industry tests, this handbook is clearly not the last word in IPH design. As funding permits, efforts will be made to update the handbook when new information becomes available. Users of the handbook are encouraged to supply the authors with feedback, and we are particularly interested in how easy users find the design procedure.

\subsection{DESIGN METHODOLOGY}

As we mentioned earlier, a design process involves a considerable amount of iteration. The material in this handbook is arranged so that conceptual design is treated first, followed by more detailed aspects of the process; but it is also important to see how the different design elements interact. Figure 1-1 is intended to inject some order into the variety of items the designer must address. The figure shows the design process progressing from left to right. The same process covers both conceptual and preliminary designs. Conceptual design does not go into as much detail as preliminary design, nor does it go quite so far. All preliminary design items are denoted by an asterisk.

The overall process is subdivided into four basic design problems: Application Selection, System Specification, System Analysis, and System Optimization/Design Completion. Application Selection requires a suitability analysis. Plant location, competing alternative energy sources, conservation opportunities, and process loads are all assessed using methods described in Sec. 3.0. This analysis results in information that can be used in two major design decisions. The load schedule, load interface, and freeze protection requirements help the designer choose the system configuration. The total load, load temperature, available space, and solar radiation data aid in the selection of a collector. 


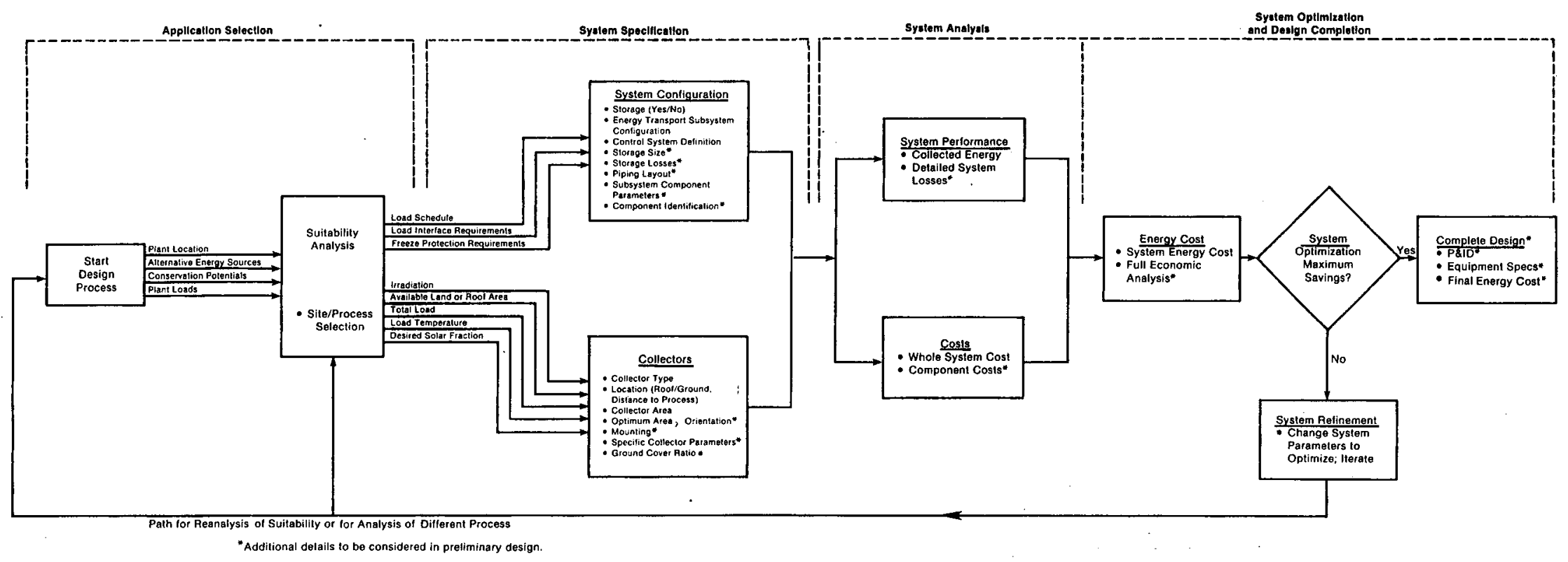

Figure 1-1. Solar IPH System Design Process 
The System Configuration segment of conceptual design includes selecting a basic configuration (e.g., open or closed loop, type of freeze protection) (Sec. 4.0); deciding whether or not to use storage (Sec. 6.0); and defining a basic control system (Sec. 8.0). Detailed design involves actually sizing storage and subsystem components (Sec. 7.0) and writing specifications for a control system (Sec. 8.0).

Selecting a collector, done along with selecting a system configuration, involves choosing a collector type, an array location, and an approximate co1lector area for conceptual design (Sec. 5.0). The optimum area, specific collector parameters, mounting details, and ground cover ratio are determined in preliminary design $(\mathrm{Sec}, 6.0)$. As we will discuss later, the system configuration and collector segments provide most of the options that require iteration (basic configuration, storage size, and collector area).

The next step, System Analysis, is to analyze system performance and overall system costs. System performance analysis involves a simple calculation of collected energy and a rough estimate of system losses (Sec. 6.0). Next, detailed system losses are determined (Sec. 6.0). The costs segment involves an estimate of total system cost (based largely on collector area), in conceptual design (Sec. 5.0); and a system cost that takes into account all the components of the actual system, in preliminary design (Sec. 10.0).

In the last segment, System Optimization/Design Completion, outputs from the system analysis provide system energy cost for the conceptual design. The results of a complete life-cycle cost analysis are avallable during preliminary design. If cost is the major criterion in sizing a system, a decision is made here. The designer reworks the System Specification segment and tries different combinations: type of collector, basic configuration, collector area, etc., in conceptual design; collector parameters, row-to-row spacing, storage, pipe and heat exchanger sizes, and collector area in preliminary design.

At the end of the conceptual design phase, it may be decided not to continue to develop a preliminary design. Before making such a negative decision, however, the designer could go all the way back to the beginning and try a different plant process with a different temperature and load profile. Moreover, a plant owner may be concerned more with fuel curtailment than economics and decide to use solar energy as a hedge against that possibility. Or, the plant owner may want to experiment with a system that has future potential. In such cases, an arbitrary solar fraction may be chosen, or collector area may be fixed by the size of a roof or by land space set aside for it. Once the iterations in conceptual design are complete and certain criteria are met, the designer moves on to the preliminary design phase. When those iterations are in turn complete, the designer then addresses items in the design completion section of Fig. 1-1. Piping and instrumentation are diagrammed, equipment spectfications are listed, and final system and energy costs are determined.

Obviously, it would be too time-consuming to go through the design process with every possible permutation of system parameters. The experienced designer, and particularly the experienced solar IPH system engineer, will be able to recognize what combinations offer the best chance of success. Suggestions are given throughout the text to help expedite the process. 


\subsection{ADDITIONAL SOURCES OP IRTORHATION}

This handbook is based on experience with the IPH field test program; thus, it covers a specific technology area. Line-focus, flat-plate, and evacuated-tube collectors are included in temperature ranges from ambient to about $290^{\circ} \mathrm{C}$ $\left(550^{\circ} \mathrm{F}\right)$. Although air collector systems are covered generally, design tools in this edition apply specifically only to liquid and steam systems. Solar ponds, point-focus collectors, and central receivers are not addressed here in great detail.

In addition, certain sources of solar thermal energy information were not enlarged upon, such as SOLMET and TMY weather data, product specifications, computer programs, etc. The reader is referred to Appendix G for additional sources of information on these subjects and on other solar thermal technologies. 


\section{S=PI㪡}




\section{SECTION 2.0}

\section{SOLAR ETERGY IN THDUSTRY: AN OVERVIEH}

\subsection{IHIRODUCTION}

The industrial sector is the largest energy user in the U.S. economy, consuming $39 \%$ of total demand (see Fig. $2-1$ ). of that $39 \%$, approximately $45 \%$ (about $18 \%$ of the overall energy usage) involves direct thermal energy use and represents a significant potential market for solar energy applications.

There are several possible advantages to using solar energy for industrial process heat (IPH) rather than for residential or commercial heating and cooling applications:

- Industrial loads are usually more constant throughout the year.

- Industrial plants usually already have crews who could attend to the maintenance of solar energy systems, thus ensuring operation of the system at peak efficiency.

- The total impact on the nation's energy use would be greater for solar IPH systems than for SHAC.

Compared with alternative industrial fuels, solar energy offers the additional advantages of being nonpolluting and independent of interruptions in supply caused by political or economic conditions. Solar energy systems can also be

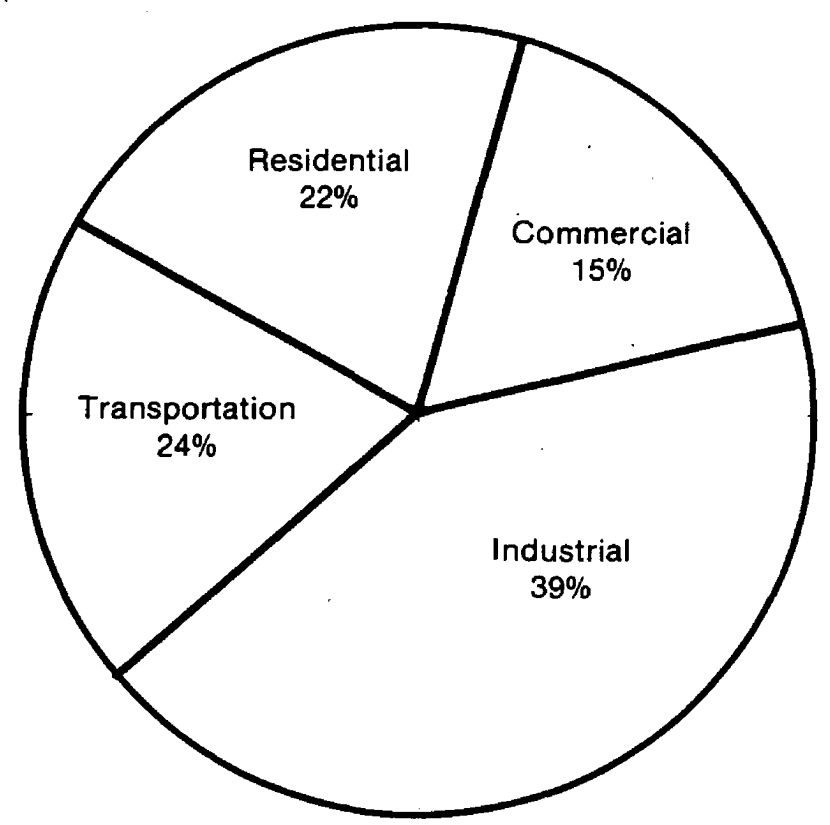

Figure 2-1. U.S. Energy Demand by Sector 
constructed in reasonably short periods of time. Of course, certain impediments to using solar energy in IPH also exist:

- Land availability: Existing roofs often are not large or strong enough to support collector arrays. Either additional supports must be built or other areas or lands must be used. (Commercial land in urban areas can be scarce.)

- Industrial effluents: An industrial environment creates greater possibilities for contamination of solar collectors than does a commercial or residential one. Concentrating collectors that require high specular reflectivity are particularly susceptible to degradation.

- Nonconstant energy source: The plant must be able to utilize a variable solar energy delivery.

- Availability of conservation alternatives: Many plants can employ simple, inexpensive energy conservation techniques which should precede any commitment to solar energy. These include using waste heat from high-temperature processes to supply low-temperature processes (such as boiler feedwater preheat).

- Economics: Industry often requires payback periods of less than 5 years. In general, solar energy systems currently are too expensive and conventional fuels are too cheap to provide such paybacks.

The suitability of solar energy in a particular application depends on a number of factors, such as climate, economics, process temperature, and available space. A market suitability study sponsored by SERI used computergenerated maps to identify regions of high solar favorability. The primary criteria were collector performance, air-quality constraints on competitive fuels, state solar tax incentives, fuel costs, and degree of coal usage. Figure 2-2 shows the resulting solar attractiveness map for parabolic trough collectors. As one might expect, the Southwest is a highly favorable region. The State of California is particularly noteworthy because of its excellent tax incentive, favorable climate, and stringent air-quality standards. Areas where coal is heavily used show up as least favorable.

Table 2-1 shows that current industrial energy consumption is highly regional; ten states account for $61 \%$ of the total. Also, whether solar energy is economical depends to a great extent on what fuel it must be measured against. Table 2-2 shows the percentages of each type of fuel (less feedstocks) used by the industrial sector in 1980. 0il and natural gas, which can be expected to become less stable in price, accounted for $67.2 \%$ of total energy use. Coal can be expected to remain fairly inexpensive (although cost and extent of use will depend greatly on pollution requirements and transportation costs). Electricity is likely to remain expensive, but it is usually used for applications other than process heat. Figure 2-3 shows that more than $80 \%$ of the total industrial process heat energy is used by six major industries. 


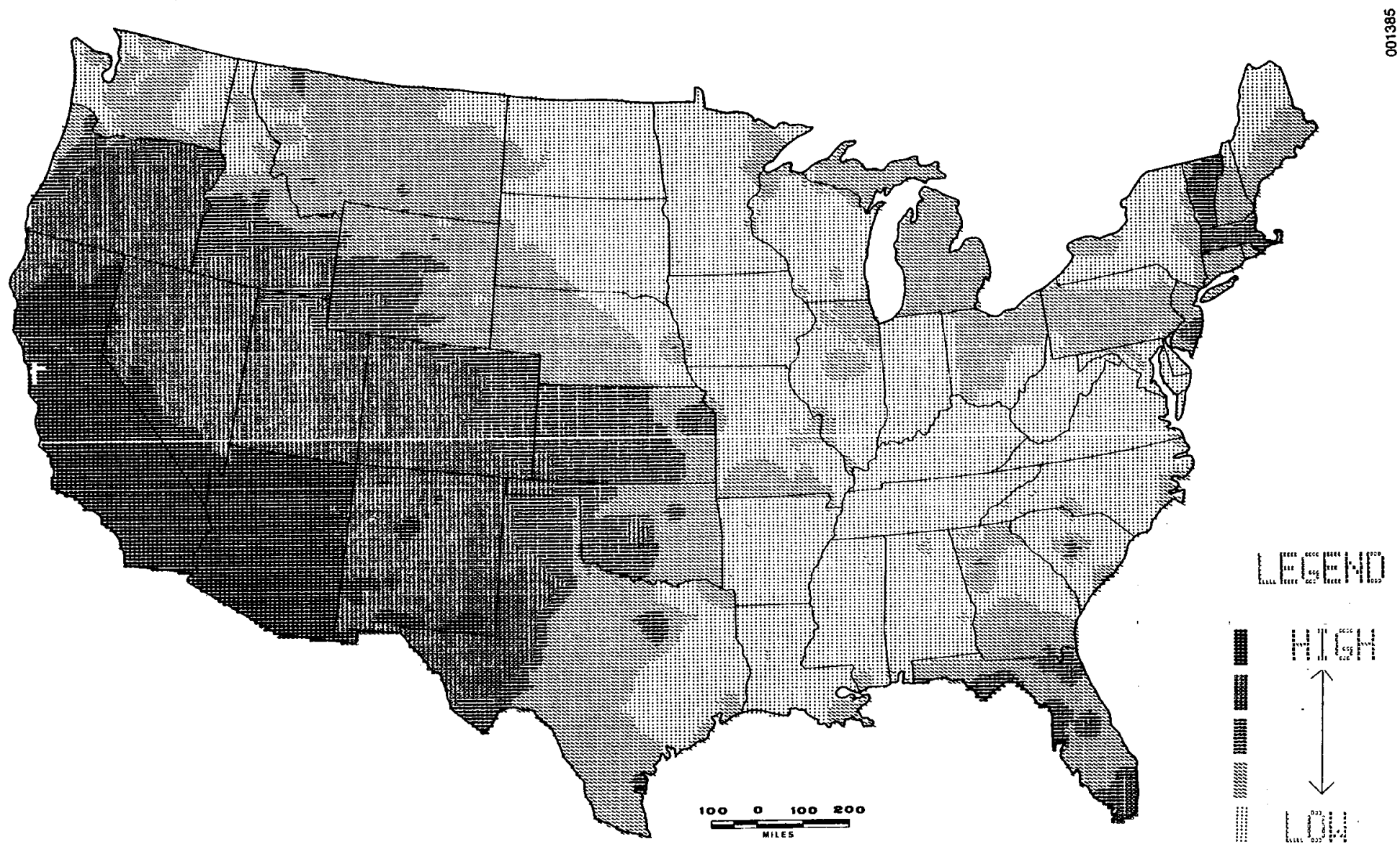

SOURCE: Turner, Weber, and DeAngelis 1981.

Figure 2-2. Solar Attractiveness Index for Parabolic Trough Collectors 
Table 2-1. 0.S. Industrial

Energy Consumption

by State (1977)

(61\% of total in 10

States)

\begin{tabular}{lr}
\hline \multicolumn{1}{c}{ State } & \% of U.S. Total \\
\hline Texas & 14.0 \\
Louisiana & 6.7 \\
Ohio & 7.2 \\
Pennsylvania & 7.0 \\
Illinois & 5.2 \\
California & 5.1 \\
Michigan & 4.8 \\
Indiana & 4.3 \\
New York & 3.6 \\
Alabama & 2.7 \\
\hline
\end{tabular}

The temperature at which energy is used is also important in assessing the solar option. At higher temperatures, solar collectors lose more of their collected heat to the environment; thus, their efficiency is reduced. But as show in Fig. 2-4, $49 \%$ of the energy consumed by industry is at temperatures below $260^{\circ} \mathrm{C}\left(500^{\circ} \mathrm{F}\right)--$ a conservative limit for collectors currently in production. The process temperature largely dictates which type of collector is most appropriate. This handbook concentrates on those that have already been used commercially: flat-plate, line-focus, and evacuated-tube collectors. Typical operating temperature ranges for these as well as for three other types of collectors being developed are shown in Fig. 2-5. All of these collectors are described in more detail in Sec. 5.0 .

Table 2-2. Fuel Use by Industrial Sector (1980)

\begin{tabular}{lr}
\hline \multicolumn{1}{c}{ Fuel } & \multicolumn{1}{c}{$\%$} \\
\hline Coal & 7.9 \\
Oil & 24.3 \\
Natural gas & 42.9 \\
Electricity & 15.8 \\
Other & 9.0 \\
\hline
\end{tabular}




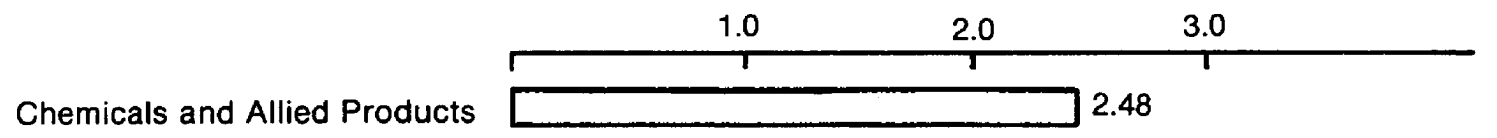

Primary Metals

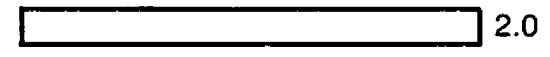

Petroleum and Coal Products

1.20

Paper and Allied Products

1.16

Stone, Clay and Glass Products

1.15

Food and Kindred Products

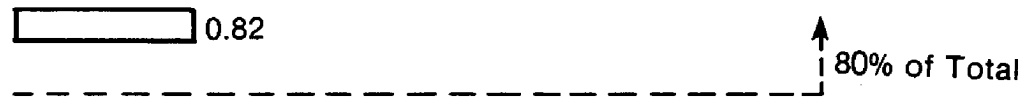

Figure 2-3. Energy Use by Major Industrial Groups

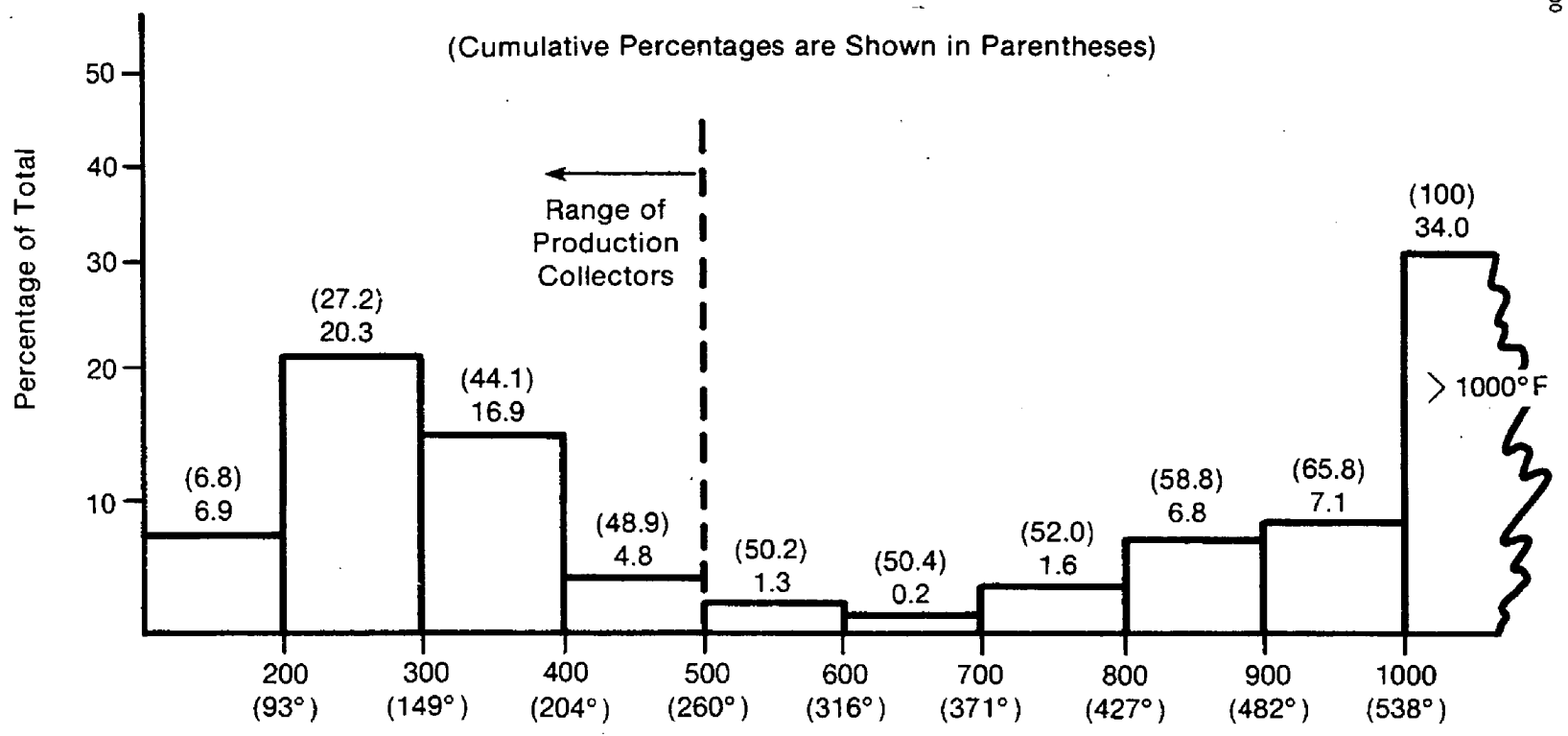

SOURCE: F. Krawiec et al., July 1981.

\section{Figure 2-4. Distribution of IPH Requirements by Temperature}




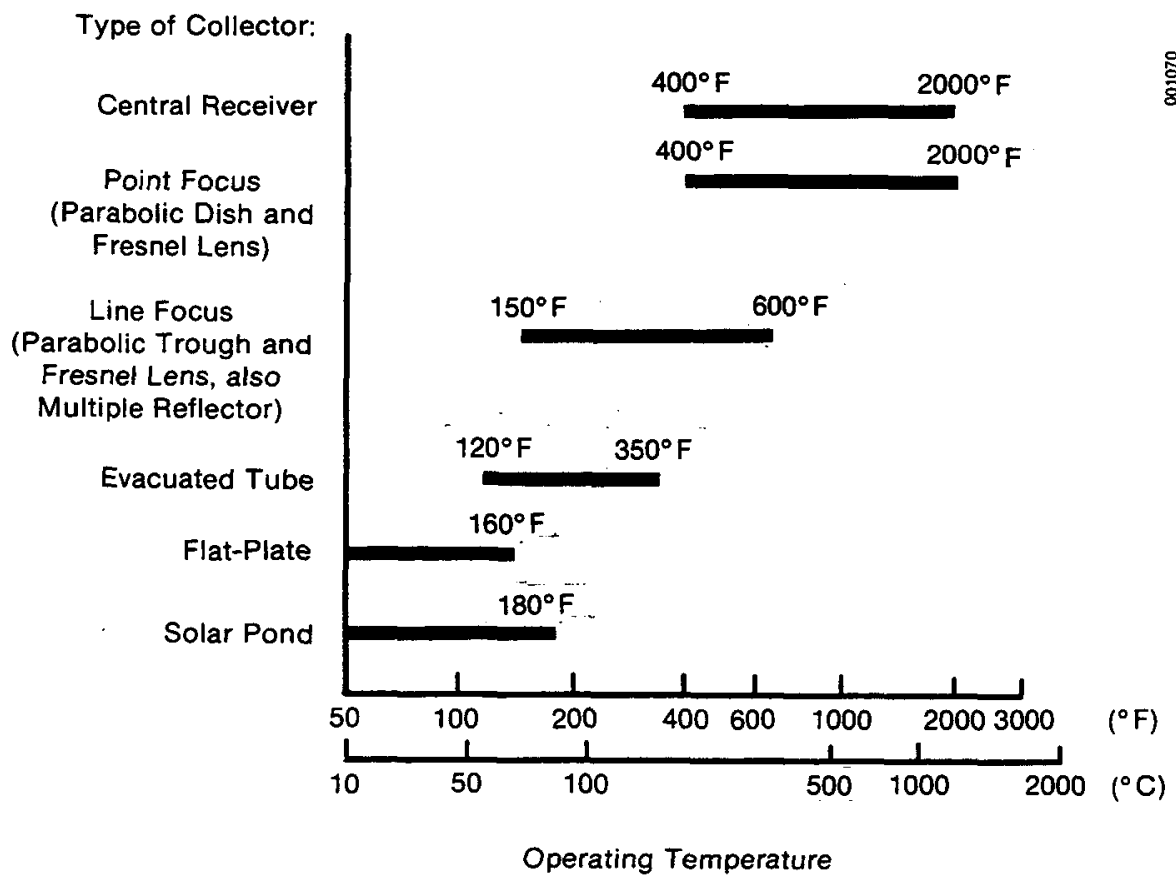

NOTE: Line-focus, evacuated-tube, and flat-plate collectors are commercially available; central receivers, point-focus collectors, and solar ponds are still being developed.

\section{Figure 2-5. Operating Temperatures for Various Types of Collectors}

\subsection{SOLAR APPLICATIONS IN IPH}

The three main areas of solar thermal application in industry are

- Process hot water

- Drying/dehydration

- Process steam.

\subsubsection{Hot Water}

Heated water is used in large amounts at temperatures between $50^{\circ}$ and $100^{\circ} \mathrm{C}$ $\left(120^{\circ}-212^{\circ} \mathrm{F}\right)$ for cooking, washing, bleaching, and anodizing and represents about $2 \%$ of the IPH demand, or 0.2 quad $\left(1\right.$ quad $\left.=10^{15} \mathrm{Btu}\right)$. Preheating boiler feedwater accounts for another 3 quads; often this could be supplied by associated higher-temperature waste heat. Water can be heated either directly in a collector loop or by means of a separate heat transfer fluid used in conjunction with a heat exchanger. The latter approach can reduce freezing and corrosion problems, but it also results in somewhat higher collector temperatures and, thus, reduced efficiency. 
An example of an IPH hot water system is shown in Fig. 2-6. This particular system supplies $454 \mathrm{~L} / \mathrm{min}(120 \mathrm{gal} / \mathrm{min})$ of hot water in the range of $55^{\circ}$ to $83^{\circ} \mathrm{C}\left(130^{\circ}\right.$ to $\left.180^{\circ} \mathrm{F}\right)$ to the York Building Products concrete blgck curing plant in Harrisburg, $\mathrm{Pa}$. The collector array consists of $829 \mathrm{~m}^{2}$ (9216 $\mathrm{ft}^{2}$ ) of multiple-reflector linear concentrators. A shell-and-tube heat exchanger is used to transfer heat from the water-and-ethylene-glycol collector loop to the process water. A unique feature of this application is that the ${ }_{3}$ large, underground, concrete curing area, or rotoclave, contains about $190 \mathrm{~m}^{3}(50,000 \mathrm{gal})$ of water and serves as built-in storage.

\subsubsection{Drying and Dehydration}

The United States uses about 1.4 quads of solar-heated air at temperatures below $177^{\circ} \mathrm{C}\left(350^{\circ} \mathrm{F}\right)$, mostly for crop drying. The two most common ways to supply solar-heated air are (1) to heat the air directly in the collectors and (2) to heat a liquid in the collectors and then use a liquid-to-air heat exchanger. An example of the first type of system is shown in Fig. 2-7.

In that particular system, $1890 \mathrm{~m}^{2}\left(21,000 \mathrm{ft}^{2}\right)$ of air collectors supply $60^{\circ} \mathrm{C}$ $\left(140^{\circ} \mathrm{F}\right)$ air to a prune- and raisin-drying tunnel at the Lamanuzzi and Pantaleo (L and P) Foods plant in Fresno, Calif. A 420-m $\mathrm{m}^{3}\left(14,000-\mathrm{ft}^{3}\right)$ rock bin is used for storage. A unique aspect of this plant is a heat recovery wheel that transfers heat from the tunnel exhaust to the collector array inlet. Although this raises the collector array's temperature, thereby lowering the array's efficiency, the heat recovered more than makes up for the loss in efficiency. The heat recovery wheel has a payback period of less than 1 year, and its success demonstrates the importance of implementing conservation a1ternatives before proceeding to solar applications.

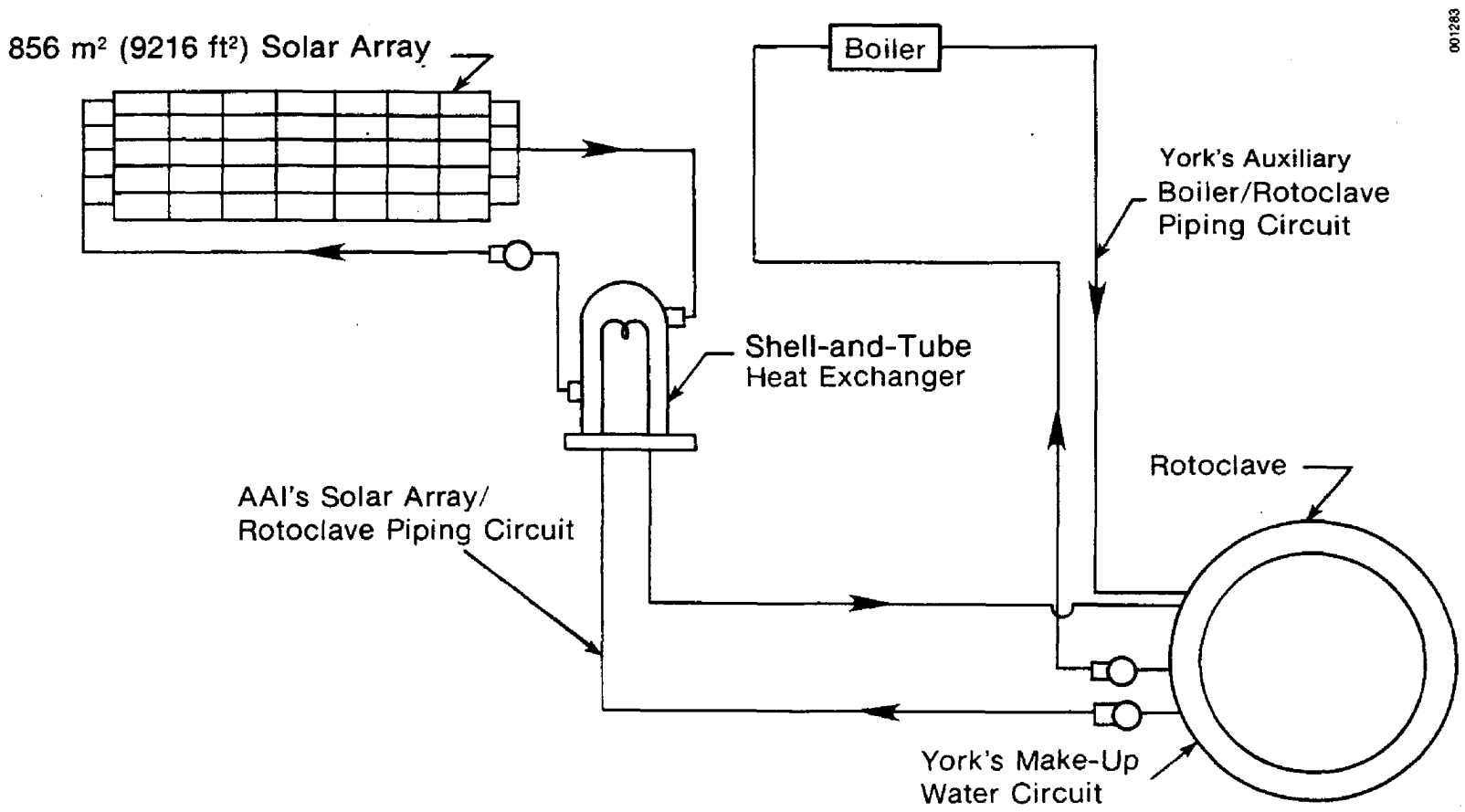

Figure 2-6. York Building Products Solar Bot Water System 


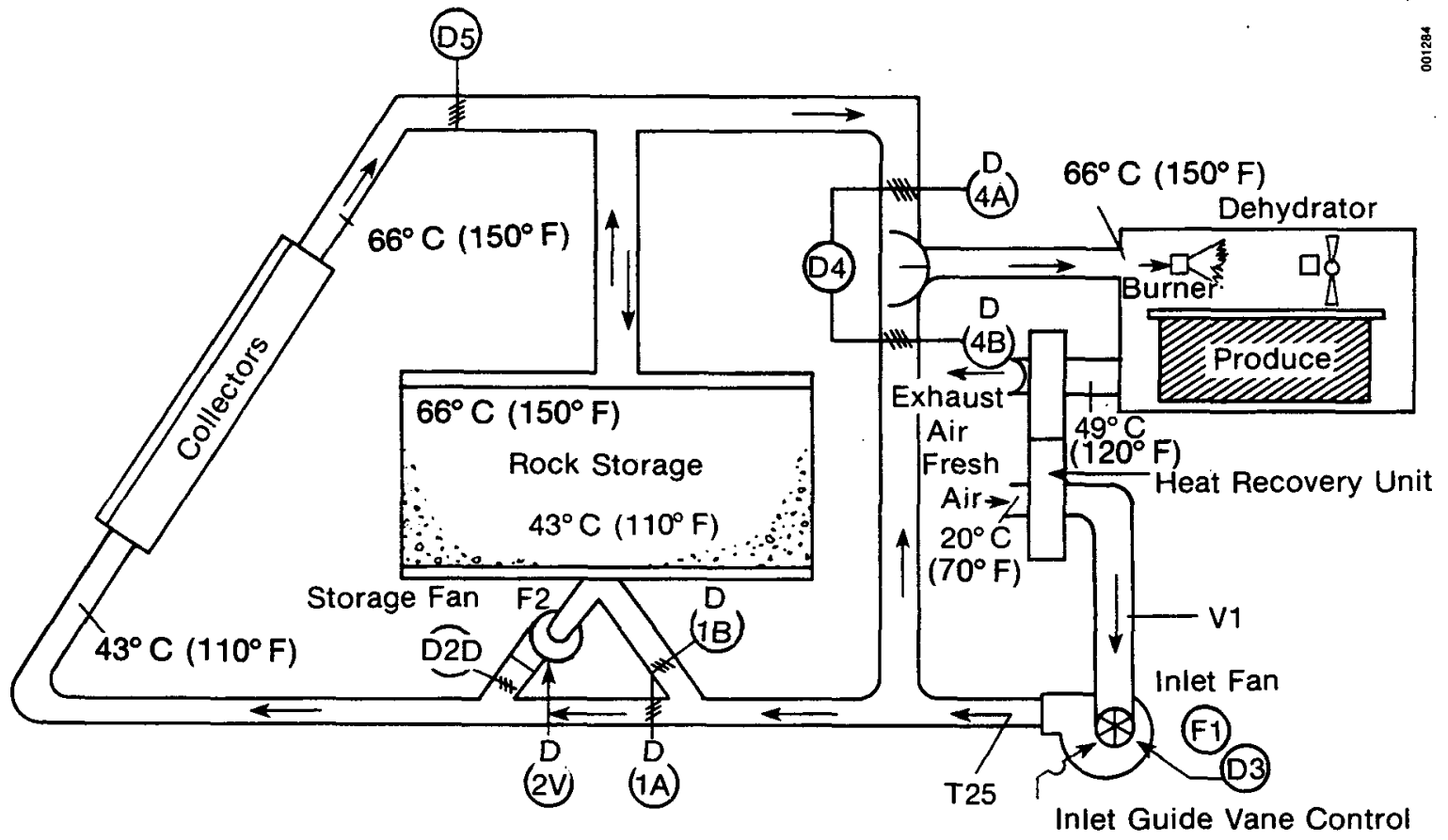

Figure 2-7. Lamanuzzi and Pantaleo Foods Solar Air Systen

An example of heating water to ultimately supply hot air is shown in Fig. 2-8, which illustrates the system in use, at the J. A. LaCour lumber-drying kiln in Canton, Miss. At this plant, $225 \mathrm{~m}^{2}\left(2500 \mathrm{ft}^{2}\right)$ of flat-plate collectors heat water to $60^{\circ} \mathrm{C}\left(140^{\circ} \mathrm{F}\right)$, which then supplies hot air to two hardwood lumber kilns via finned-tube heat exchangers. Although this system results in higher collector temperatures than does a direct-air approach, pumping power needed for the liquid loop is generally less than fan power for an air loop. To increase collected energy at the LaCour plant, $216 \mathrm{~m}^{2}\left(2400 \mathrm{ft}^{2}\right)$ of reflectors are included in the collector array.

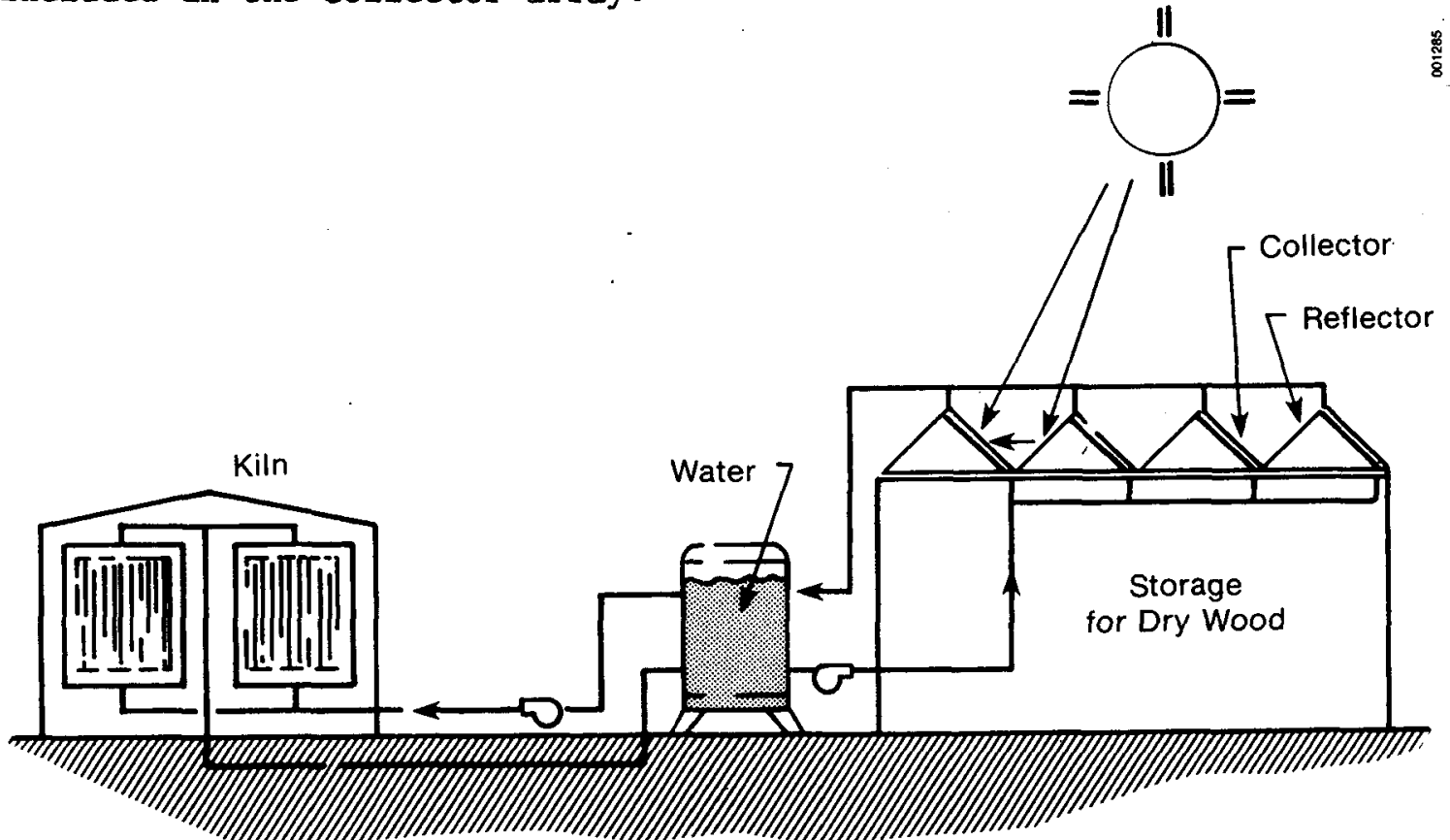

Figure 2-8. LaCour Lumber Kiln Solar Hot-Water-to-Air System 
A third way of using solar heat for drying should be mentioned. Rather than using collectors at all, drying houses can be constructed so that sunlight directly strikes the product. This method entails relatively low temperatures and long drying times and generally requires that the product be spread out over a large area. However, it can be cost-effective.

\subsubsection{Stean}

About 6 quads of energy are consumed in the United States for process steam, $80 \%$ at temperatures below $177^{\circ} \mathrm{C}\left(350^{\circ} \mathrm{F}\right)$. Steam can be supplied with solar collectors in these three ways:

- Using a high-temperature fluid in the collectors and transferring the heat to an unfired boiler

- Circulating pressurized water in the collectors and flashing it to steam in a flash tank

- Boiling water in collectors.

The first type of system is shown in Fig. 2-9. In this example, Thermingl 55 is heated to $246^{\circ} \mathrm{C}\left(475^{\circ} \mathrm{F}\right)$ in an array consisting of $900 \mathrm{~m}^{2}\left(10,000 \mathrm{ft}^{2}\right)$ of parabolic-trough collectors. The hot Therminol then boils water in an unfired boller, supplying steam at $0.96 \mathrm{MPa}$ (125 psig). The system shown was built for the Lone Star Brewery in San Antonio, Tex. The flash system shown in Fig. 2-10 was an alternative design for the brewery. In that system, water is heated directly to $247^{\circ} \mathrm{C}\left(477^{\circ} \mathrm{F}\right)$ and $4 \mathrm{MPa}(600 \mathrm{psi})$ in the collector loop and then flashed to steam. This procedure eliminates the need for an expensive

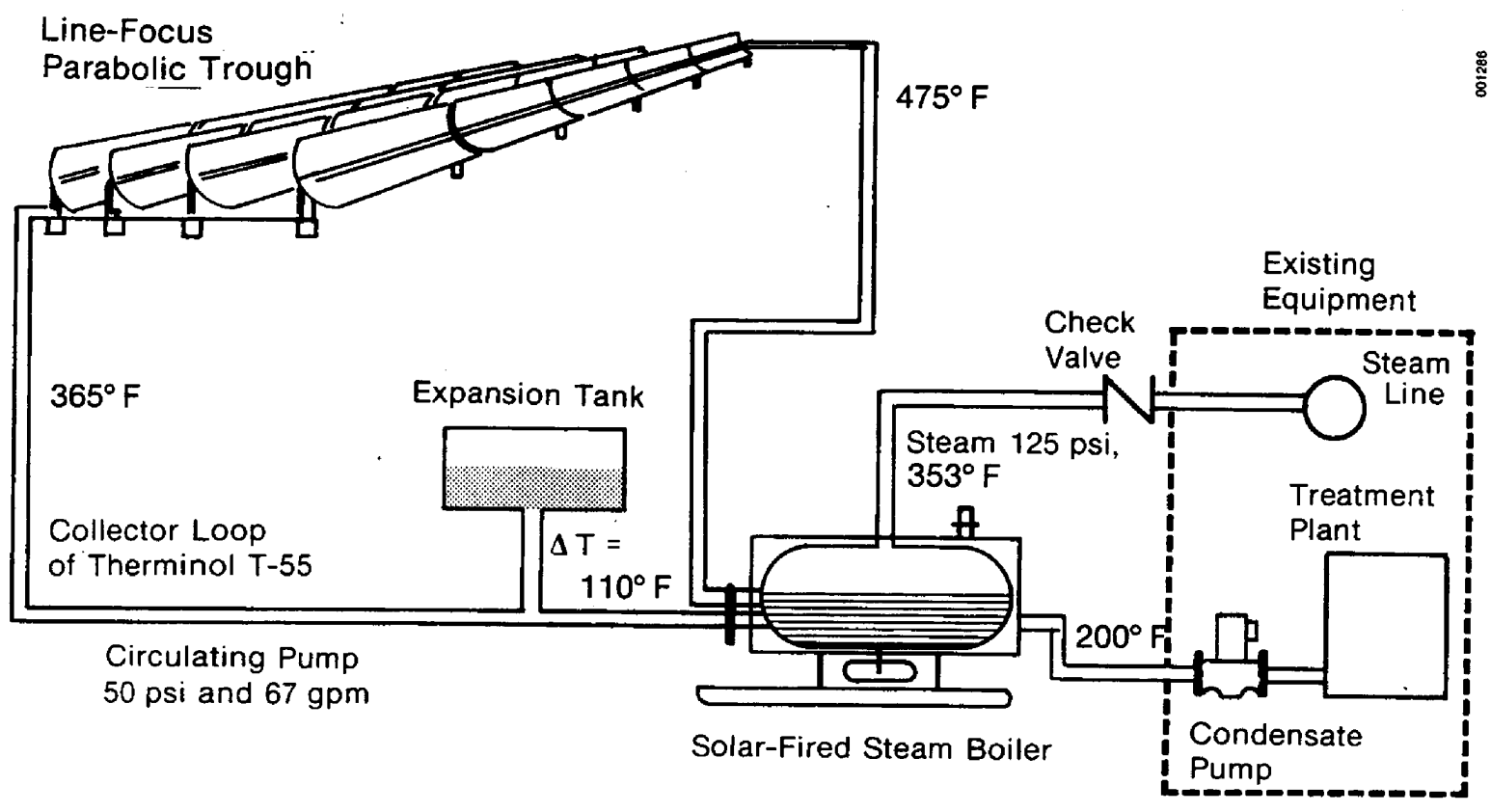

Figure 2-9. Solar Stean Production Using an Unfired Boiler 


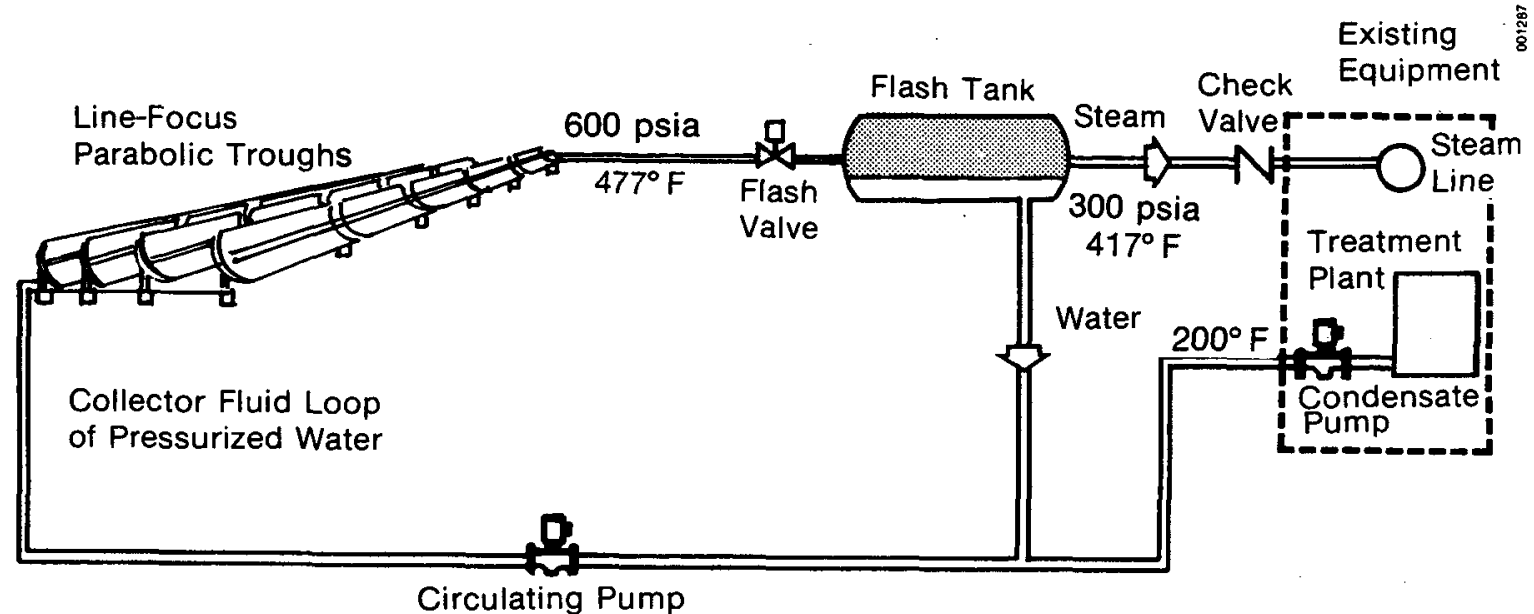

Figure 2-10. Solar Steam Production Using a Flash Tank

unfired boiler and can provide more collected energy because it eliminates the temperature difference across the heat exchanger. On the other hand, freeze protection is required, and considerable pumping power must be provided to supply the pressure difference across the flash valve. A flash system similar in principle to the one shown was built at the Ore-Ida Foods, Inc., frenchfried potato plant in Ontario, Ore. The third alternative, boiling water in the collectors, has not yet been attempted. A recent study conducted at SERI concludes that it is a promising concept, however, and merits further investigation (Murphy and May 1982) (see Sec. 4.2).

Although steam is used widely in industry to transport heat, it is probably better to combine solar energy with hot water. If hot water supplies heat to a process, solar collectors can be used without unfired boilers and without the disadvantages of flash systems. Thus, if solar energy is being considered for a new plant, some consideration should also be given to using pressurized hot water in place of steam.

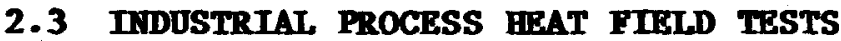

In an effort to advance the state of the art in solar industrial process heat, the U.S. Department of Energy (DOE) funded a number of field tests throughout the United States. These were funded in cycles, and each new cycle tested a different area for solar application: hot water $\left[<100^{\circ} \mathrm{C}\left(212^{\circ} \mathrm{F}\right)\right]$; hot air; low-temperature steam $\left[100^{\circ}-177^{\circ} \mathrm{C}\left(212^{\circ}-350^{\circ} \mathrm{F}\right)\right]$; and intermediate-temperature steam $\left[177^{\circ}-275^{\circ} \mathrm{C}\left(350^{\circ}-550^{\circ} \mathrm{F}\right)\right]$. In addition, two cycles were funded for large-collector-area $\left[4500 \mathrm{~m}^{2}\left(50,000 \mathrm{ft}^{2}\right)\right]$ projects both above and below $100^{\circ} \mathrm{C}\left(212^{\circ} \mathrm{F}\right)$ in order to investigate economies of scale. A list of these projects, along with privately funded efforts, is given in Table 2-3. 
Table 2-3. Solar Industrial Process Heat Projects in the United States

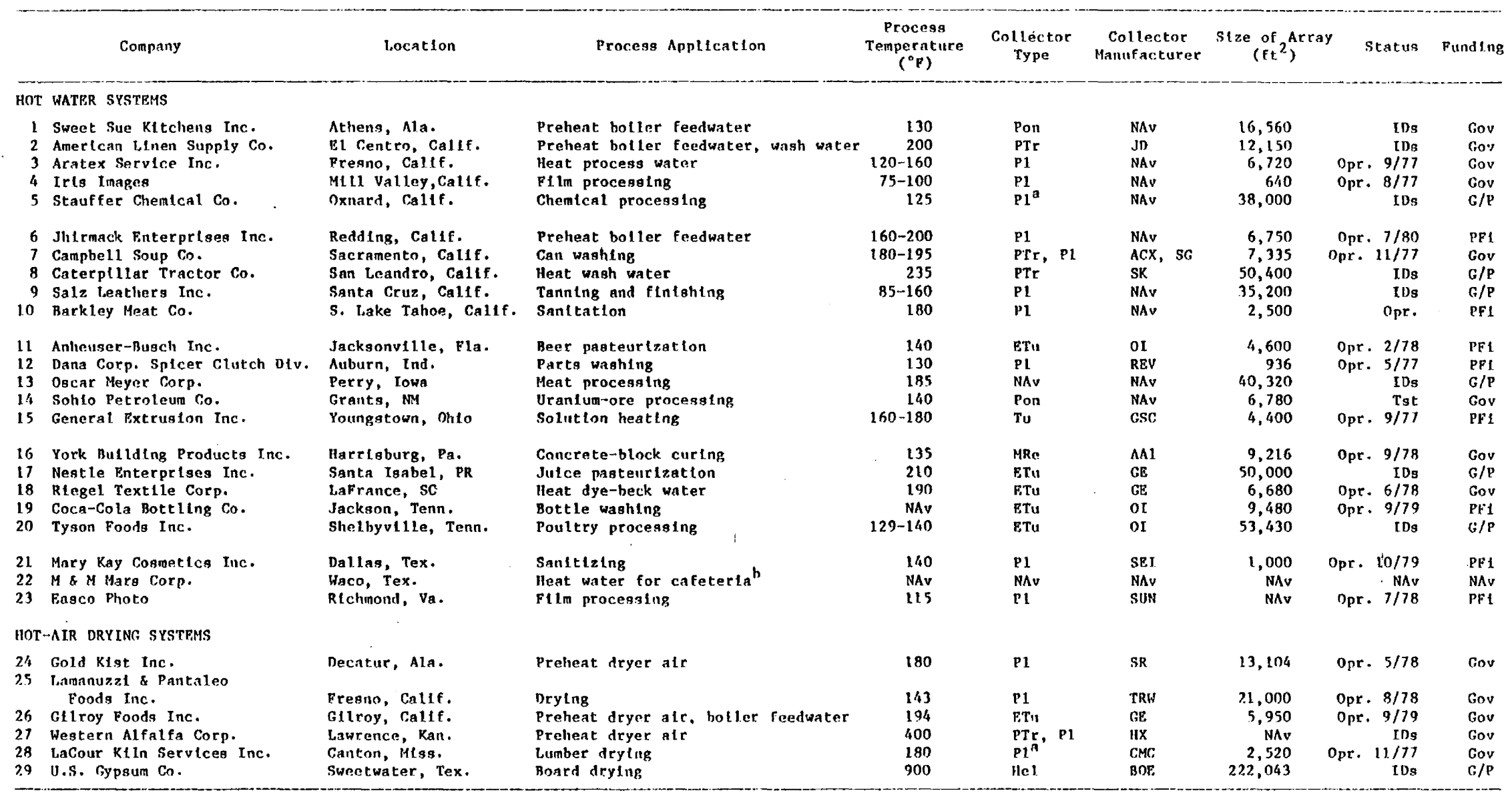

awth reflectors.

hexpansion for procesg use under way. 
Table 2-3. Solar Industrial Process Heat Projects In the United States (Concluded)

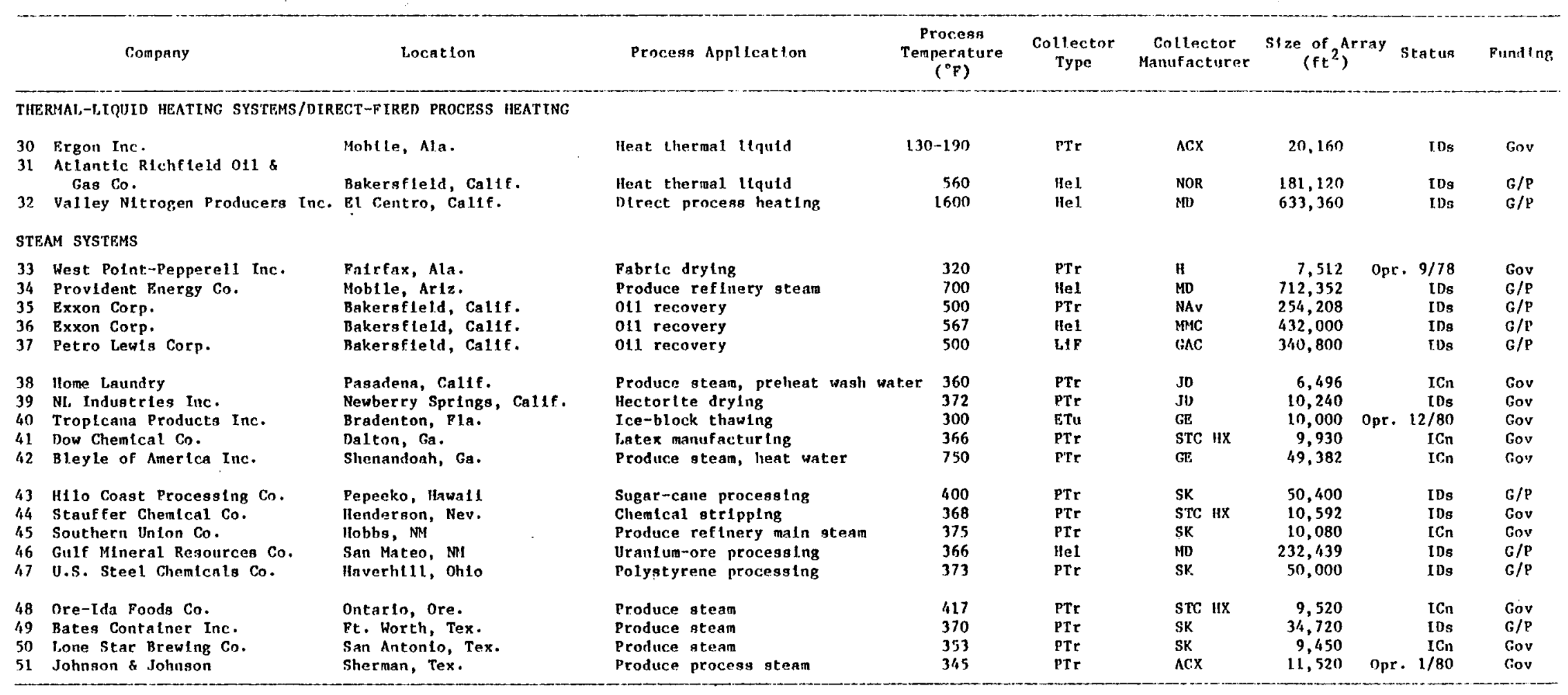

Source: Kenneth Brown. 1981 (Nov.). Power Magazine. Vo1. 125 (No. 11).

\section{legend to Table 2-3}

ETu - Evacuated tube PFi - Prtvately financed

G/P - Shared government and Pl - Flat plate

$\begin{array}{cl}\text { prtvate flnanclng } & \text { Pon - Shatlow pond } \\ \text { Gov - Government flnanced } & \text { Prr - Parabisllc trough }\end{array}$

Hel - Hellostat

tCn - In construction

IDs - In des Lgn

WA - Line focus
MRe - Multiple reflector

NAv - Not avallabl
Opr - Operat tonal

\section{MARUR ACTURERS}

$\Lambda A 1$ - MA1 Corp.

ACX - Acurex Corp.

BOR - Bnetng. Englneertng \& Construct ton Co

CMC - Chambertatn Man

GAC - General Atointe Co.

GF - Gencral plectrte Go.

(iSC - General Solar Corp.

H - lloneywell Inc.

In - Hexcel Corp.

In - Jacnbs Det. Corp. 
Much has already been learned from the existing field tests. Seven DOE projects operating for a year or longer that were the subjects of a SERI report (Kutscher and Davenport 1981) showed efficiencies ranging from $8 \%$ to $33 \%$ during their first year of operation. As corrective actions continue to be taken to solve problems, these percentages should increase considerably. As newly designed projects benefit from past experiences with these field tests, reliability and performance can be expected to increase as well.

Although seven projects represent only a limited statistical basis on which to make generalizations, some basic conclusions can be drawn that should prove useful in future projects:

- Solar collector arrays have generally shown high avallability. However, industrial processes often have not sufficiently utilized that available energy.

- The durability of collectors could prove to be a major problem in a field application of solar projects. Degradation of absorber surfaces and glazings is still relatively common.

- Problems similar to those encountered in the SHAC buildings program also occur in IPH applications. Better education in system design is needed to prevent thermal shocking of evacuated tube collectors, heat exchanger freezing due to thermosyphon heat loss, and other problems.

- Parasitic power has proved to be a major contributor to low performance in systems employing air collectors.

- Both operational and overnight piping losses can be significant in solar IPH applications.

- Data acquisition systems have generally been unreliable.

- Solar IPH is not yet cost-effective, considering the typical payback periods required by industrial owners. Some industrial managers are concerned with fuel supply curtailments, however; to a certain extent, this can offset the economic shortcomings associated with solar IPH.

- A considerable investment in maintenance has been necessary to approach predicted performance in first-generation projects.

- Environmental contaminants can seriously impede the performance of solar collectors.

- Certain adjustments in plant operation schedules, hardware, and control logic are often needed to make optimum use of a solar energy system.

- Opportunities for energy conservation are abundant in industry, and many of them provide more rapid payback periods than do solar energy systems. Just as in the SHAC buildings program, energy conservation should precede solar implementation.

- In some applications, solar energy may improve the quality of a final product in addition to saving fossil fuel.

A summary of the problems encountered in the seven projects studied is given in Table 2-4. Problems related to the data acquisition equipment in these systems are marked with asterisks. These problems caused loss of data but typically did not affect the operation of the system. For more information on 
Table 2-4. Problens Encountered in DOE-Funded Field Tests

\begin{tabular}{|c|c|c|}
\hline Project & Problems & Corrective Action \\
\hline Campbel1 Soup & $\begin{array}{l}\text { *Data logger failure } \\
\text { *Magnetic tape recorder } \\
\text { failure } \\
\text { *Nonoperative flowneters } \\
\text { Broken glass cover tubes } \\
\text { Wind damage } \\
\text { Shutdown of can line } \\
\text { while changing soup type } \\
\text { Leakage of flat-plate } \\
\text { glazings } \\
\text { Silt accumulation } \\
\text { Failure of tracker motor } \\
\text { Degradation of black } \\
\text { chrome selective surfaces }\end{array}$ & $\begin{array}{l}\text { Exhaust fan installed } \\
\text { Replaced, but interfacing } \\
\text { problems are still unsolved } \\
\text { Replaced with Rates control } \\
\text { valve, calibrated monthly } \\
\text { Removed glass tubes } \\
\text { Repaired damage } \\
\text { None } \\
\text { None } \\
\text { Installed Cyclone separator } \\
\text { (Nov. 1980) } \\
\text { Replaced (Dec. 1980) } \\
\text { Painted absorber tubes flat } \\
\text { black }\end{array}$ \\
\hline Riegel Textile & $\begin{array}{l}\text { Low flow rate through } \\
\text { collector } \\
\text { Poor insulation in collec- } \\
\text { tor headers } \\
\text { Deterioration of copper fins } \\
\text { in collectors }\end{array}$ & $\begin{array}{l}\text { Reflectors polished (April 1980) } \\
\text { None } \\
\text { Installed over-temperature } \\
\text { indicator; circuit box made } \\
\text { less accessible } \\
\text { Larger pump impeller installed; } \\
\quad \text { fittings made larger } \\
\quad \text { (April 1980) } \\
\text { Headers reinsulated (April 1980) } \\
\text { Under study }\end{array}$ \\
\hline $\begin{array}{l}\text { York Building } \\
\text { Products }\end{array}$ & $\begin{array}{l}\text { Mirror breakage (thermal) } \\
\text { Insufficient wire size for } \\
\text { motors } \\
\text { Drive motor grease too } \\
\text { thick } \\
\text { *Data logger not compatible } \\
\text { with tape drive } \\
\text { Mirror desilvering } \\
\text { *Dust problems with data } \\
\text { logger }\end{array}$ & $\begin{array}{l}\text { Painted with flat black paint } \\
\text { (completed May 1980) } \\
\text { Installed check valves in col- } \\
\text { lector loop piping; replaced } \\
\text { heat exchanger tube bundle } \\
\text { (Feb. 1979) } \\
\text { Mirrors replaced (Nov. } 1979 \text { and } \\
\text { Aug. 1980) } \\
\text { Replaced wires with heavier } \\
\text { gauge (Oct. 1978) } \\
\text { Replaced grease with low- } \\
\text { temperature grease (Dec. 1978) } \\
\text { Replaced data logger with } \\
\text { different brand (Feb. 1979) } \\
\text { New mirrors have protective } \\
\text { coating } \\
\text { Relocated to building lobby } \\
\text { (Jan. 1979) }\end{array}$ \\
\hline
\end{tabular}


Table 2-4. Problems Bncountered in DOB-Funded Field Tests (Continued)

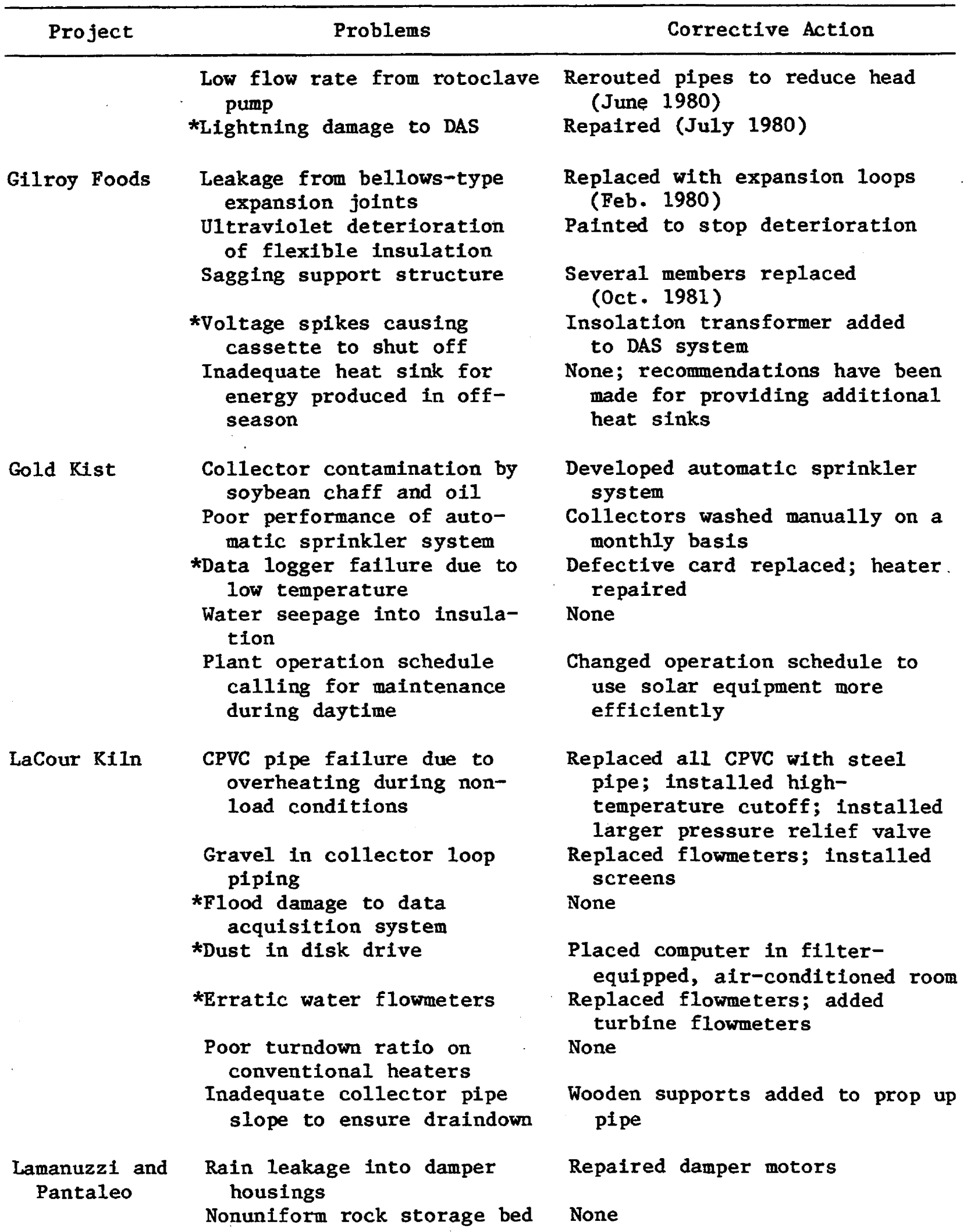


Table 2-4. Problems Encountered in DOE-Funded Field Tests (Concluded)

\begin{tabular}{lll}
\hline \multicolumn{1}{c}{ Problems } & \multicolumn{1}{c}{ Corrective Action } \\
\hline & *Timeclock failures in data & Isolated clock with capacitors \\
acquisition system & & \\
& Lexan stress failure and & Collectors reglazed (Ju1y 1980) \\
yellowing & None \\
& Vandalism & Repaired (July 1980) \\
& microprocessor-based & \\
& controller & \\
\hline
\end{tabular}

*Problems related to data acquisition equipment.

the low-temperature field tests, including total costs, the reader is referred. to Kutscher and Davenport (1981).

The future of solar energy in industrial process heat depends on a number of factors. Higher-cost fossil fuels certainly make solar energy more attractive. Interruption or curtailment of fossil-fuel supplies will have an even greater impact, and mass producing collectors could reduce solar energy costs substantially. Improvements in both the efficiency and reliability of collectors will also accelerate solar energy's implementation. It is hoped that continued research will lead to substantially lower collector and balance-ofsystem costs in the future. Cost studies have shown that tax incentives play a large part in bringing solar costs in line with what industry is willing to pay. And new financing schemes that involve leasing a collector array can increase the economic attractiveness of a solar system.

\subsection{REFERENCES}

Battelle Columbus Laboratories. 1977. Survey of the Applications of SolarThermal Energy Systems to Industrial Process Heat. Columbus, OH: 3 Vols.

Dickinson, W. C.; Brown, R. 1981 (Aug.). Economic Analysis of Solar Industrial Process Heat Systems: A Methodology to Determine Annual Required Revenue and Internal Rate of Return. UCRL-52814, Rev. 1. Livermore, CA: Lawrence Livermore Laboratory.

Fraser, M. D. 1977. Analysis of the Economic Potential of Solar Therma1 Energy to Provide Industrial Process Heat. C00/2829. 3 Vols. Warrenton, VA: InterTechnology Corporation.

Krawiec, F.; et al. 1981. Energy End-Use Requirements in Manufacturing. SERI/TR-733-790R. Golden, CO: Solar Energy Research Institute.

Kutscher, C. F.; Davenport, R. 1981 (June). Preliminary Results of the Operational Industrial Process Heat Field Tests. SERI/TR-632-385R. Golden, CO: Solar Energy Research Institute. 
Murphy, L. M; May, E. K. 1982 (Apri1). Steam Generation in Line-Focus Solar Collectors. SERI/TR-632-1311. Golden, CO: Solar Energy Research Institute.

Turner, A. K.; Weber, J. C.; DeAngelis, M. 1981. A Geographic Market Sultability Analysis for Low- and Intermediate-Temperature Solar IPH Systems. SERI/TR-733-1194. Golden, CO: Solar Energy Research Institute. 


\section{SEPI敦}


PART II

CONCEPTUAL DESIGI 
SECTION 3.0

\section{SOLAR IPH SUITABILITY ANALYSIS}

In designing a solar energy system, the objective is to minimize delivered energy costs. To meet this objective, it is important first to select the most favorable solar application. Some guidelines for selecting a favorable solar application are listed in Table 3-1 and discussed below. In the sections that follow, these factors will be quantified as part of a complete solar system design.

Table 3-1. Factors Favoring the Use of Solar IPH Systems

1. Environmental Factors

High insolation

High ambient temperatures

Low pollution levels

2. Process Factors

Low-temperature processes

Operations 7 days per week

Heat demand peak during the day and in summer

Built-in process storage

3. Economic Factors

High fuel costs

Uncertain fuel supplies

Available land or strong roof

Available capital

Federal, state, and local tax incentives

Energy-intensive operations

Conservation measures complete

New plants

4. Company Factors

Management commitment

Skilled plant maintenance

Company engineering staff

\subsection{ENVIRONIMETAL FACTORS}

The intensity of solar radiation is an obvious factor in the delivered cost of solar energy. Figure 3-1 shows average levels of global insolation on a horizonta1 plane $\left(10,000 \mathrm{~kJ} / \mathrm{m}^{2}=881 \mathrm{Btu} / \mathrm{ft}^{2}\right)$. This diagram is useful in an initial comparison of the heat output of horizontally mounted, nontracking collectors and solar ponds in various locations. Figure 3-2 shows average levels of direct-beam radiation in a plane facing the sun. The energy output of tracking collectors can be correlated to the values on this map. (More 


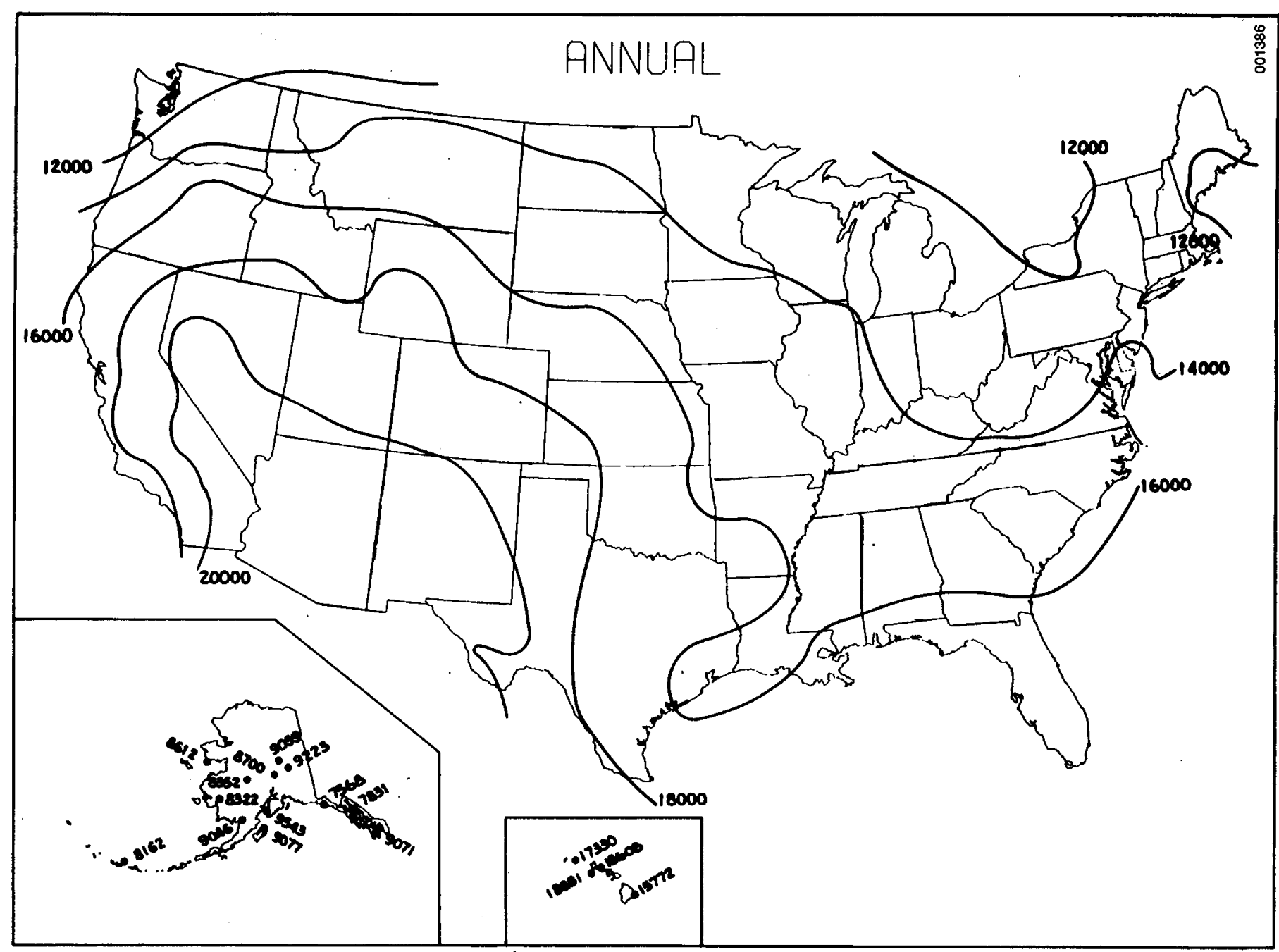

Figure 3-1. Average Daily Global Solar Radiation on a Horizontal Surface $\left(\mathrm{kJ} / \mathrm{m}^{2}\right)$ 


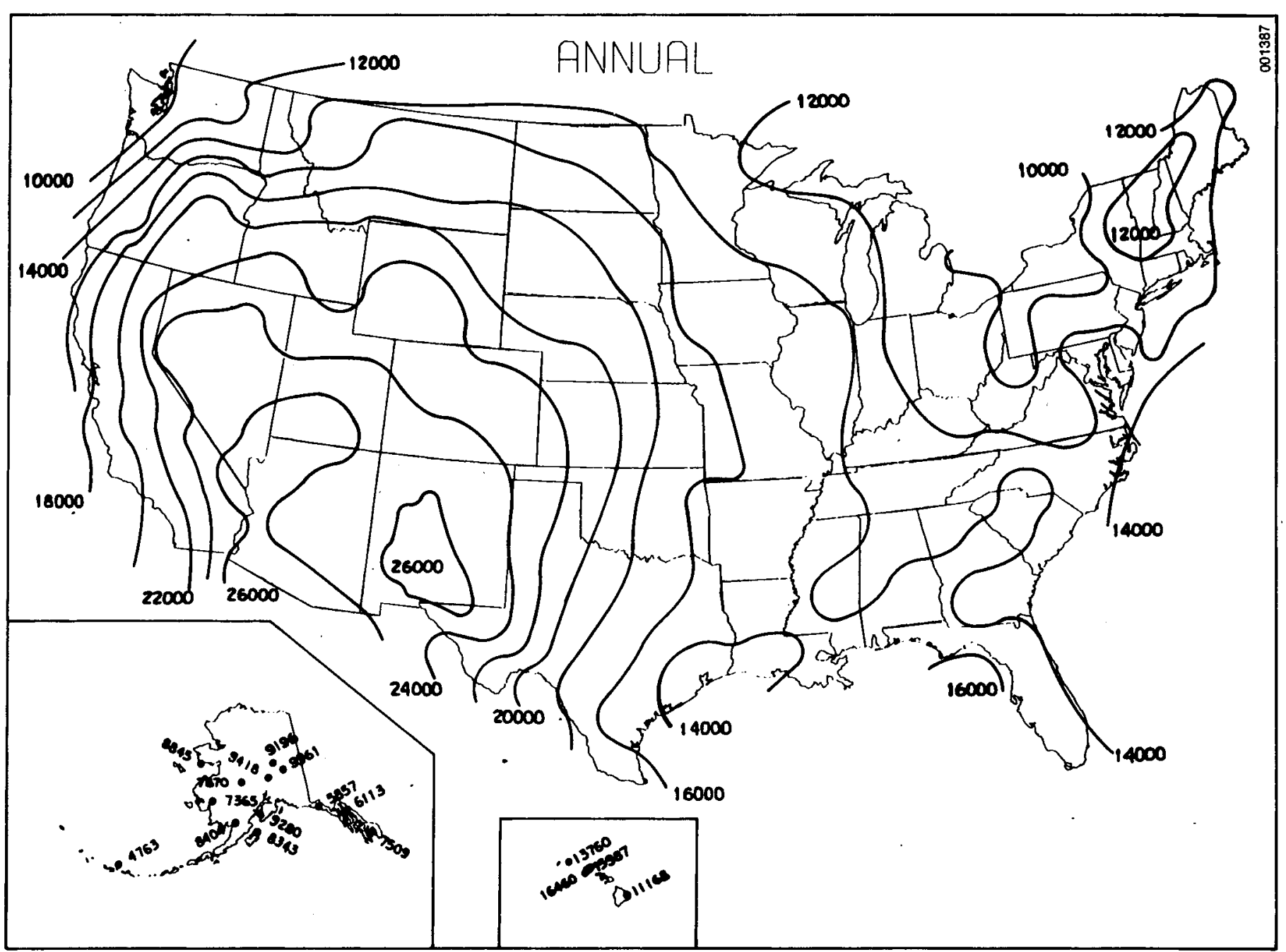

Figure 3-2. Average Dally Direct Normal Solar Radiation $\left(\mathrm{kJ} / \mathrm{m}^{2}\right)$ 
accurate methods of predicting the energy outputs of collectors are described in Sec. 6.0.) Note that collectors located in the Southwest will intercept about twice as much energy as the same collectors located in either the Northeast or the Northwest.

Ambient temperature affects the performance of a solar energy system in two ways. First, high ambient temperatures reduce the thermal losses that can be associated with solar collectors and related equipment both during operation and overnight. Second, high ambient temperatures in winter permit the use of water as a heat-transfer fluid in the collectors without the need for a freeze-protection mechanism. As will be discussed in Sec. 7.2, water is the preferred energy transport fluid if freezing problems can be overcome. Figures 3-3 and 3-4 show average ambient temperatures; and Fig. 3-5, the number of days per year that minimum temperatures reach $0^{\circ} \mathrm{C}$.

High concentrations of atmospheric pollutants can affect the life and performance of solar systems. For example, near seacoasts, chlorides can corrode aluminum surfaces. Chemicals emitted from cooling towers can form hard-toremove precipitates on collector surfaces. Smog can reduce the intensity of radiation. The effect of atmospheric pollutants on solar collectors can be so severe that a materials test program is strongly recommended. This test program would involve placing representative samples of collector materials in the vicinity of the collector field for at least six months before proceeding with construction of the entire system. Determining the effects of washing procedures should be an integral part of the exposure test, as well.

The test program need not be elaborate or expensive. Reports by Morris (1982) and DSET (1981) describe formal test programs conducted in conjunction with the DOE industrial field test program. While short-term testing does not guarantee the long-term durability of collector components, poor test results can prompt further investigations to determine the cause of the problem. As more and more solar projects come on line and operational experience increases, the need for material test programs will decline.

Pollution regulations that limit the use of conventional fuels could provide an impetus for exploring the feasibility of solar applications. This would apply only where the pollution does not affect solar system components adversely, however.

\subsection{PROCESS FACTORS}

The efficiency of a solar system decreases, and its installed cost tends to increase, as operating temperature increases. Thermal storage, which can greatly increase the contribution of solar energy to a process, is also more economical at lower temperatures. These are good reasons to adapt the industrial process to accept heat from a solar system operating as close as possible to a required process temperature. Heating washwater and preheating boiler make-up water are examples of particularly favorable solar applications. Steam is used almost universally in industry to provide indirect heating. A solar system can be designed to produce steam, if doing so would cost less than retrofitting the industrial process to accept solar heat directly (as pressurized hot water, for instance). 


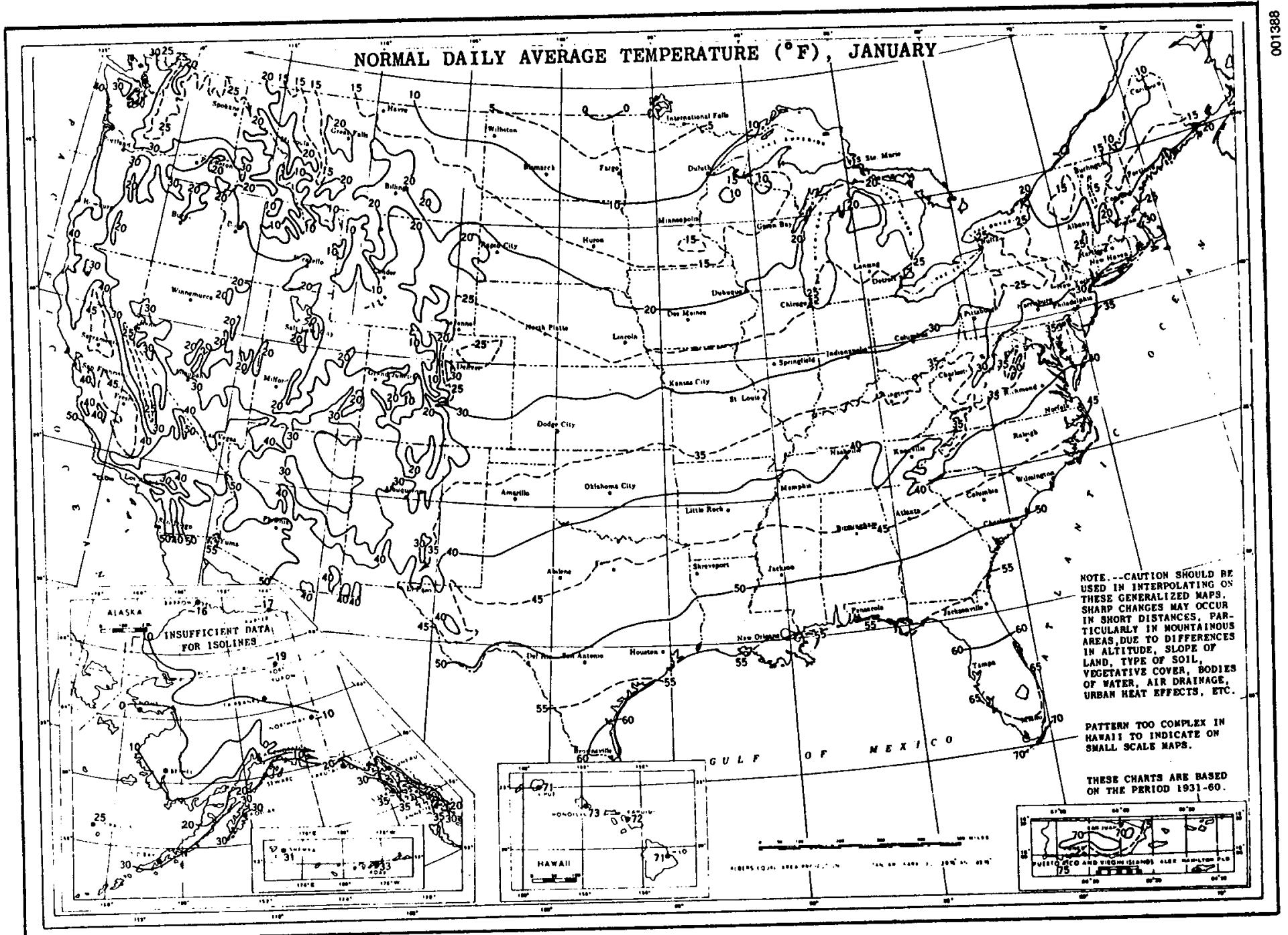

Figure 3-3. Normal Daily Average Temperatures $\left({ }^{\circ} \mathrm{F}\right)$ in January

(Average ambient temperature can be obtained by taking the mean between these temperatures and corresponding ones in Fig. 3-4.) 


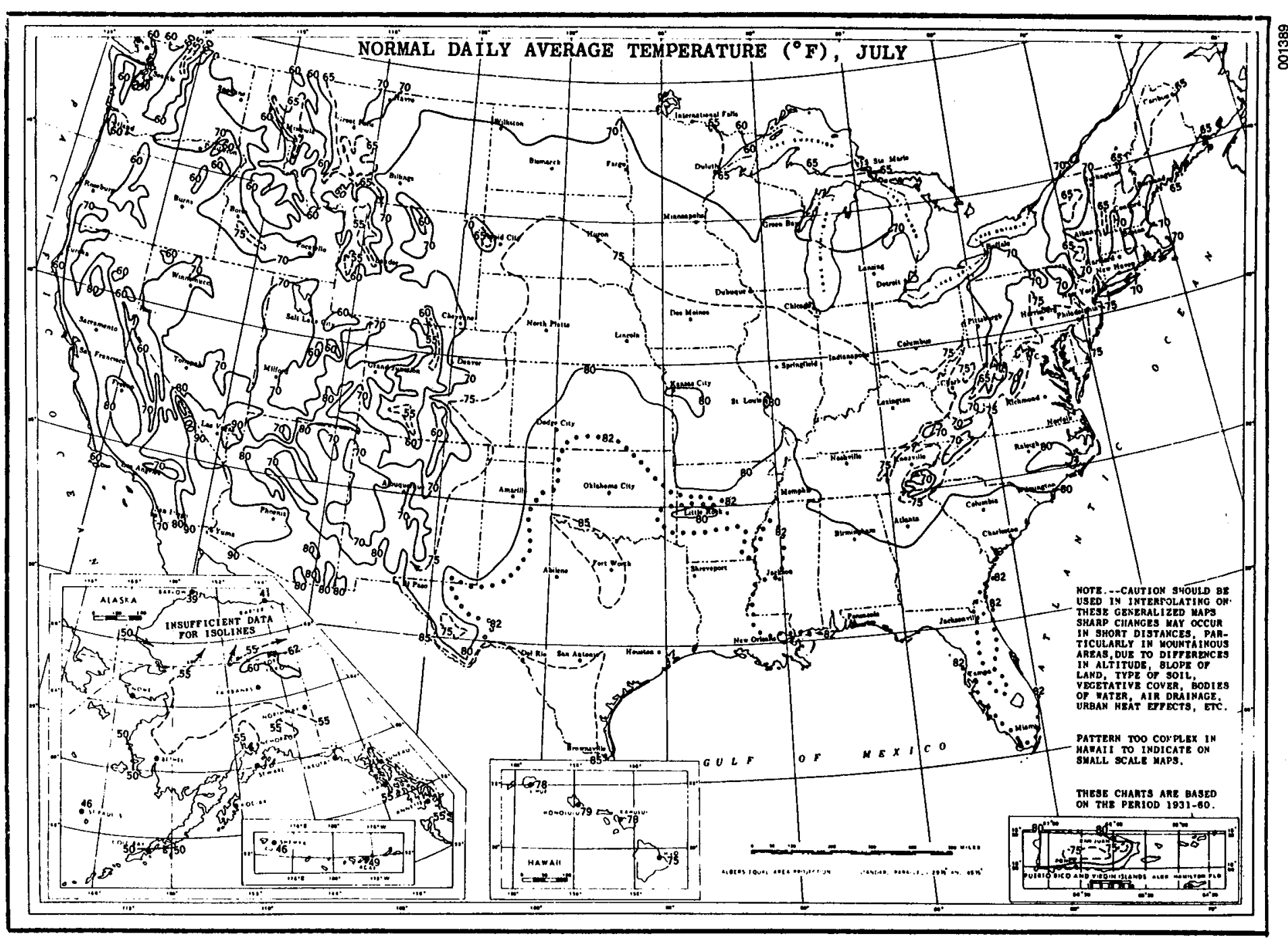

Figure 3-4. Normal Daily Average Temperatures $\left({ }^{\circ} \mathrm{F}\right)$ in July 


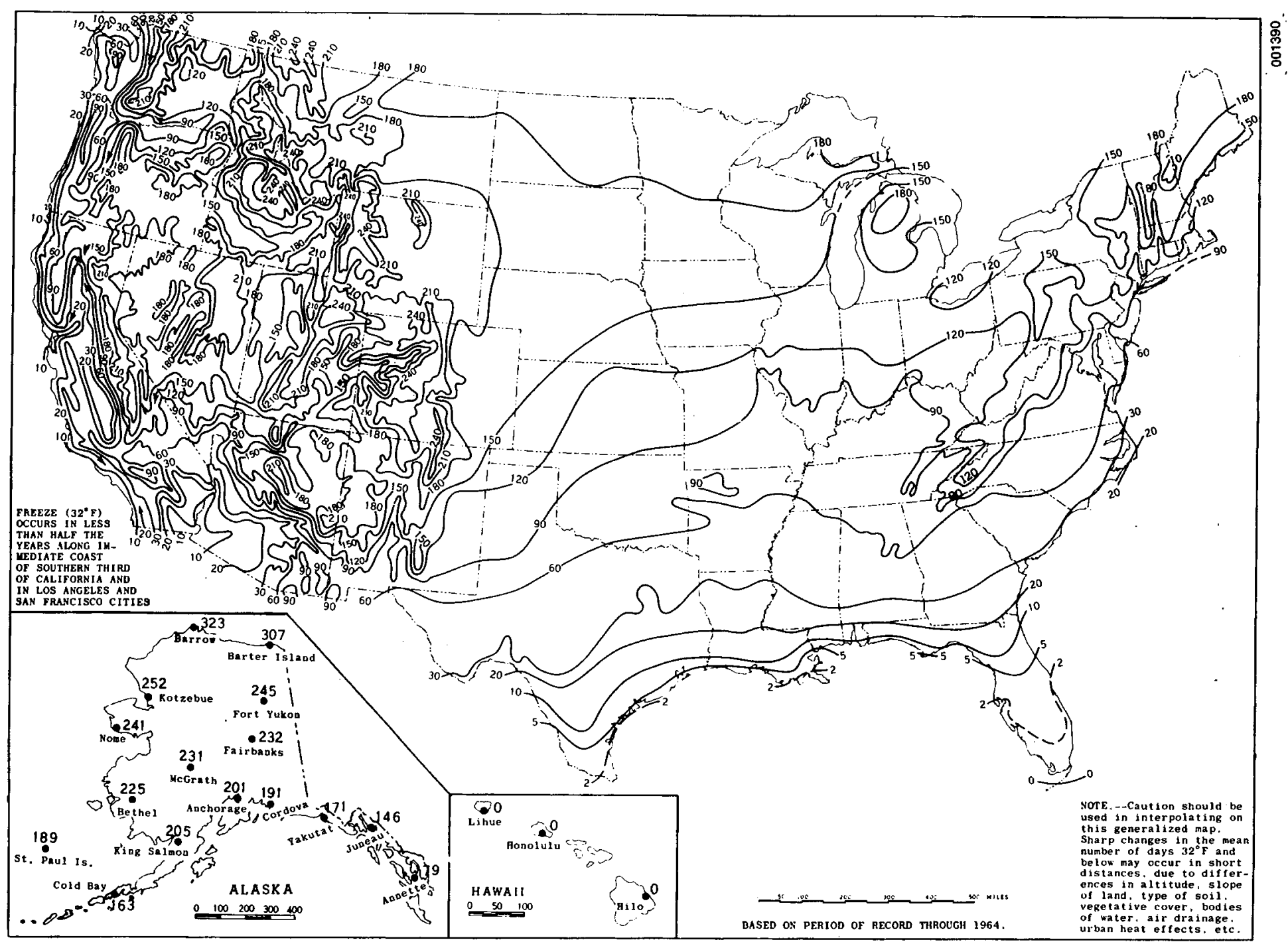

Figure 3-5. Mean Annual Number of Freezing Days in the United States 
Knowing the schedule of an industrial process is important in determining the volume of thermal storage that will be required to expand the fraction of process heat beyond that supplied directly from the solar system. (Some industrial processes provide built-in heat storage.) A seven-days-per-week schedule minimizes the need for storage capacity, as do heating requirements that peak during daylight hours and summer months. Storing solar heat as hot water at temperatures up to $121^{\circ} \mathrm{C}\left(250^{\circ} \mathrm{F}\right)$ appears to be cost-effective. At higher temperatures, a low-vapor-pressure ofl/rock system can be used, but it is more costly.

Difficulties have been encountered in fully utilizing available solar energy in some IPH projects. In selecting a process, control modifications required to maximize solar energy usage must be considered. For example, a boiler or furnace may have to be modified so that it operates at a lower firing rate. Also, it is best to make the connection between the solar system and the industrial process as flexible as possible. For example, dedicating a solar system to one of several parallel process lines would result in poor utilization if that one line were shut down. To minimize piping costs and thermal losses, a process close to the collector field site is preferable. An interface location that permits most of the piping to be run indoors minimizes heat losses and weather degradation problems.

Sufficient vacant land for siting the collectors, or a strong roof, is a major requirement. Moreover, planning a solar system for a new plant is easier than retrofitting a system to an existing plant, in terms of locating the collectors and integrating collectors with the structures and the process.

\subsection{ECONOMIC FACTORS}

The dependability of the fuel supply and the stability of the cost of solar heat are attractive features. Figure 3-6 illustrates the dramatic increases that have occurred in the costs of conventional fuels in recent years. In early 1981, distillate fuel oil cost about $\$ 1.10 / \mathrm{gal}(\$ 7.50 / \mathrm{GJ})$. Even if cost increases exceed the rate of inflation by only $3 \%$ per year, the real cost would almost double in 20 years. After deregulation, natural gas prices can be expected to climb even higher.

Solar energy systems are capital-intensive. A company must have sufficient financial resources to fund even the most favorable solar project. Federal, state, and local tax incentives, however, can defray some of these up-front costs. Currently, industrial solar system purchasers are entitled to a $25 \%$ federal tax credit. California is one state that offers an additional $25 \%$ state tax credit. Innovative financing schemes by which a holding company owns and operates the solar system and sells solar heat are becoming available and can help overcome problems encountered in obtaining capital (see Sec. 10.0). 


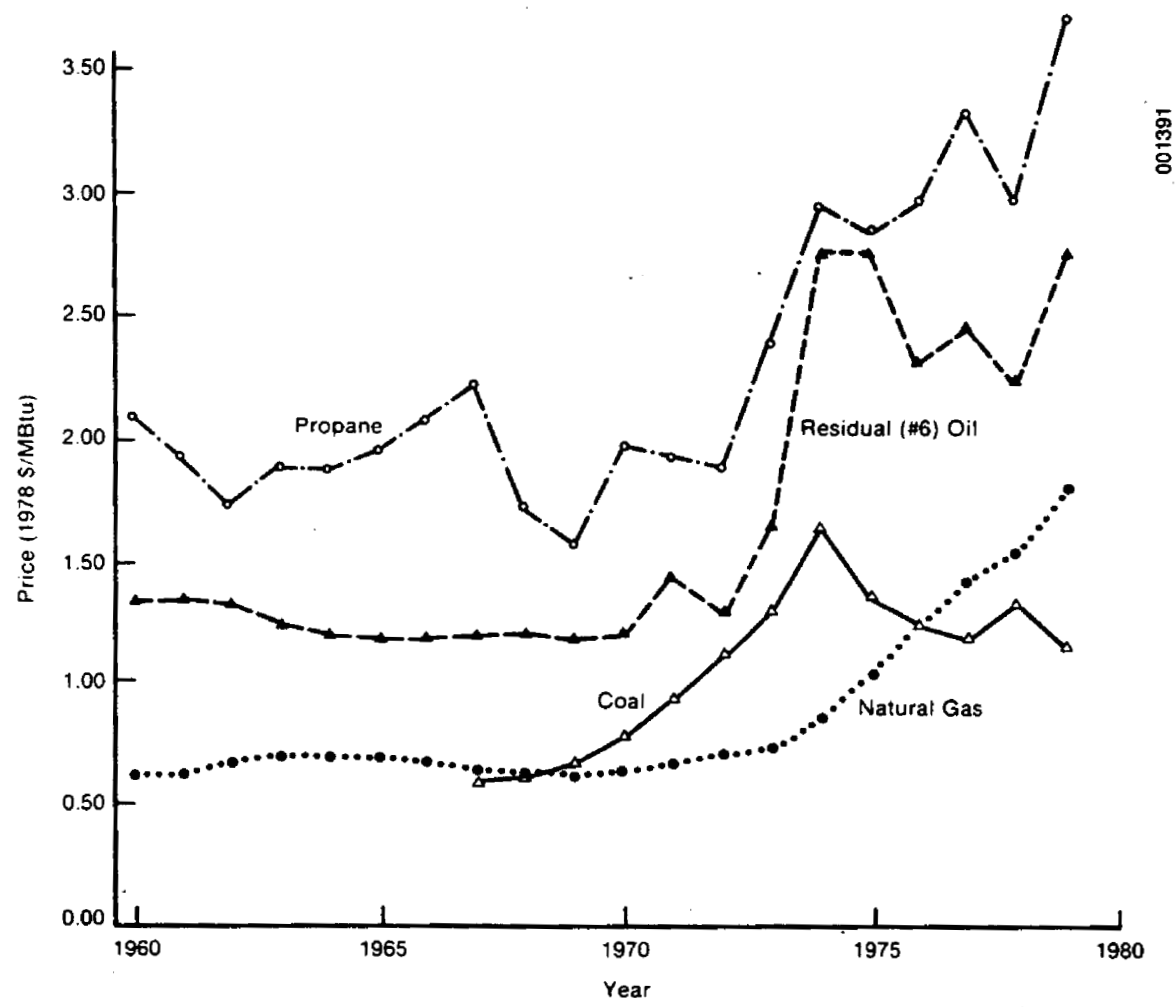

Figure 3-6. Real Costs of Conventional Puels

(Constant 1978 dollars)

Industries for which energy represents a large fraction of their processing costs are the ones most likely to consider alternative energy sources. Such energy-intensive industries are also likely to first exhaust economical energy conservation measures before converting to other fuels.

\subsection{COMPANY FACTORS}

A solar energy system can be quite complicated compared with a typical package boiler, and it will require maintenance. However, designing and managing a solar system is often within the capability of the engineering work force in residence at many medium-sized plants and certainly within the capabilities of a corporate engineering staff. On-site maintenance helps to ensure the reliability of the solar system, and in-house system design can reduce design and installation costs significantly. Material presented in this handbook will acquaint engineers with aspects of solar system design that they might not have encountered in previous work and provide them with many of the tools they will need to design, build, and operate a solar system.

\subsection{EXAMPLES OF FAVORABLE SOLAR THERHAL APPLICATIONS}

DeAngelis (1980) summarizes numerous surveys and techniques that have been used to determine which industrial markets have the greatest near-term potential for economical solar thermal applications. Industries identified include food processors; meat packers (including poultry); manufacturers of concrete blocks, bricks, and paving mixtures; wood finishing and paper plants; 
and fabric producers. However, as the Case Study Program at SERI has illustrated (Hooker et al. 1980; May et al. 1982), many suitable applications are lost after they are classified under broad industrial categories. Plants that dewater crude petroleum or produce specialty chemicals, aluminum cans, or metal castings are good prospects for solar applications. Plant engineers should therefore use all available information to evaluate their plants to determine the applicability of a solar IPH system.

\subsection{REFERENCES}

DeAngelis, M. 1980 (Dec.). Market Surveys: Potential for Solar IPH Applications." Presented at the Solar Industrial Process Heat Conference, Houston, Texas.

DSET Laboratories, Inc. 1981. Final Report: Industrial Process Heat Environmental Exposure Program. Prepared for the Solar Energy Research Institute under Subcontract XH-0-9087-1.

Hooker, D. W.; May, E. R.; West, R. E. 1980 (May). Industrial Process Heat Case Studies. SERI/TR-733-323. Golden, CO: Solar Energy Research Institute.

May, E. K.; Green, H. J.; Schlepp, D. R. 1982. Solar Industrial Process Heat Case Studies. SERI/TR-733-1024. Golden, CO: Solar Energy Research Institute.

Morris, V. L. 1982 (Jan.). Final Report on Solar Collector Materials Exposure at IPH Site Environments. Vol. II. SAND 81-7028/II. Albuquerque, NM: Sandia National Laboratories. 
SECTION 4.0

\section{IPH SYSTEH CONTIGURATION}

For the most part, the form in which the energy is to be used determines the nature and configuration of the components that will make up an IPH solar system. Since industrial process energy requirements are primarily met by hot air, hot water, and steam systems, representative configurations of these three groups are presented in this section. Each system description should be general enough to permit the system designer to identify major components and their functions easily. Simple schematics of the systems are provided to facilitate this understanding.

\subsection{HOT AIR SYSTEMS}

Industrial processes that require hot air can be configured to utilize solar energy as shown in Figs. 4-1 and 4-2. Figure 4-1 illustrates a typical direct hot-air system. Ambient air or process return air is circulated through solar collectors that in turn provide heated air to the process. The hot air can be used at the temperature supplied by the collectors or can be further heated by an auxiliary heater before it goes to the process load. This is a direct hot air system because the air provided to the process is the same as that heated by the solar collectors.

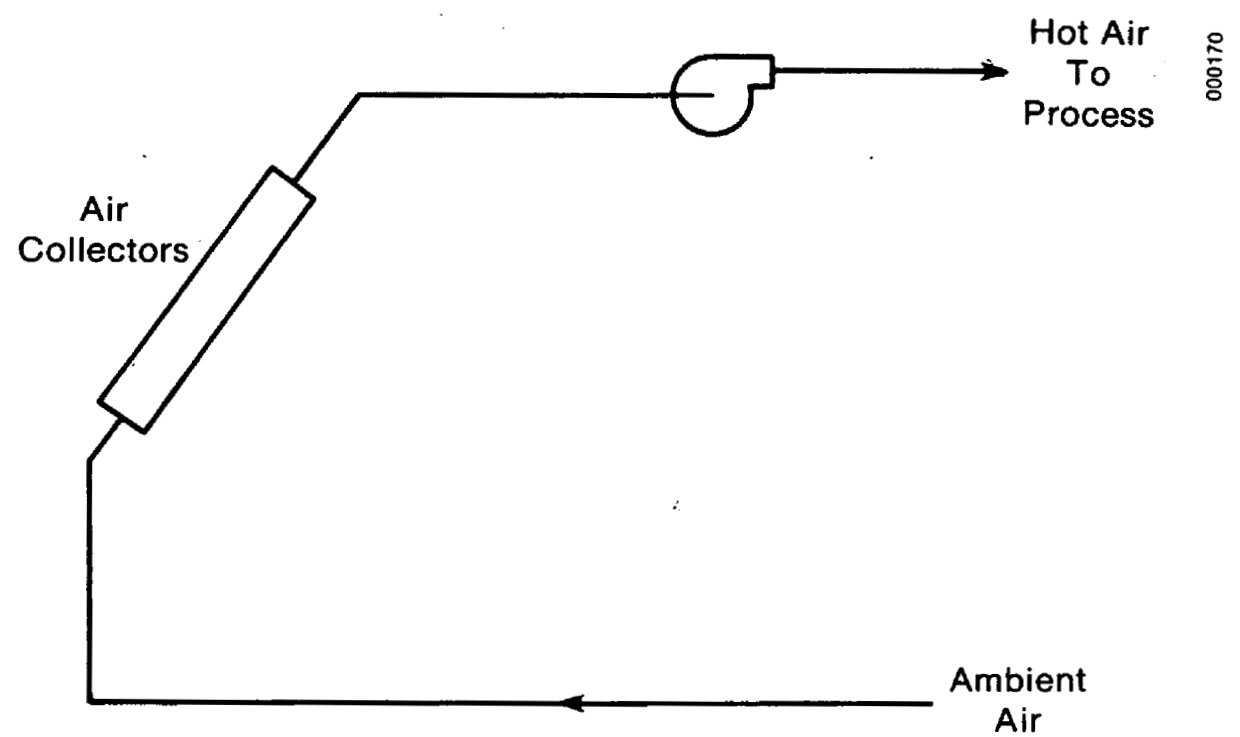

Figure 4-1. Direct Hot Air Solar System 


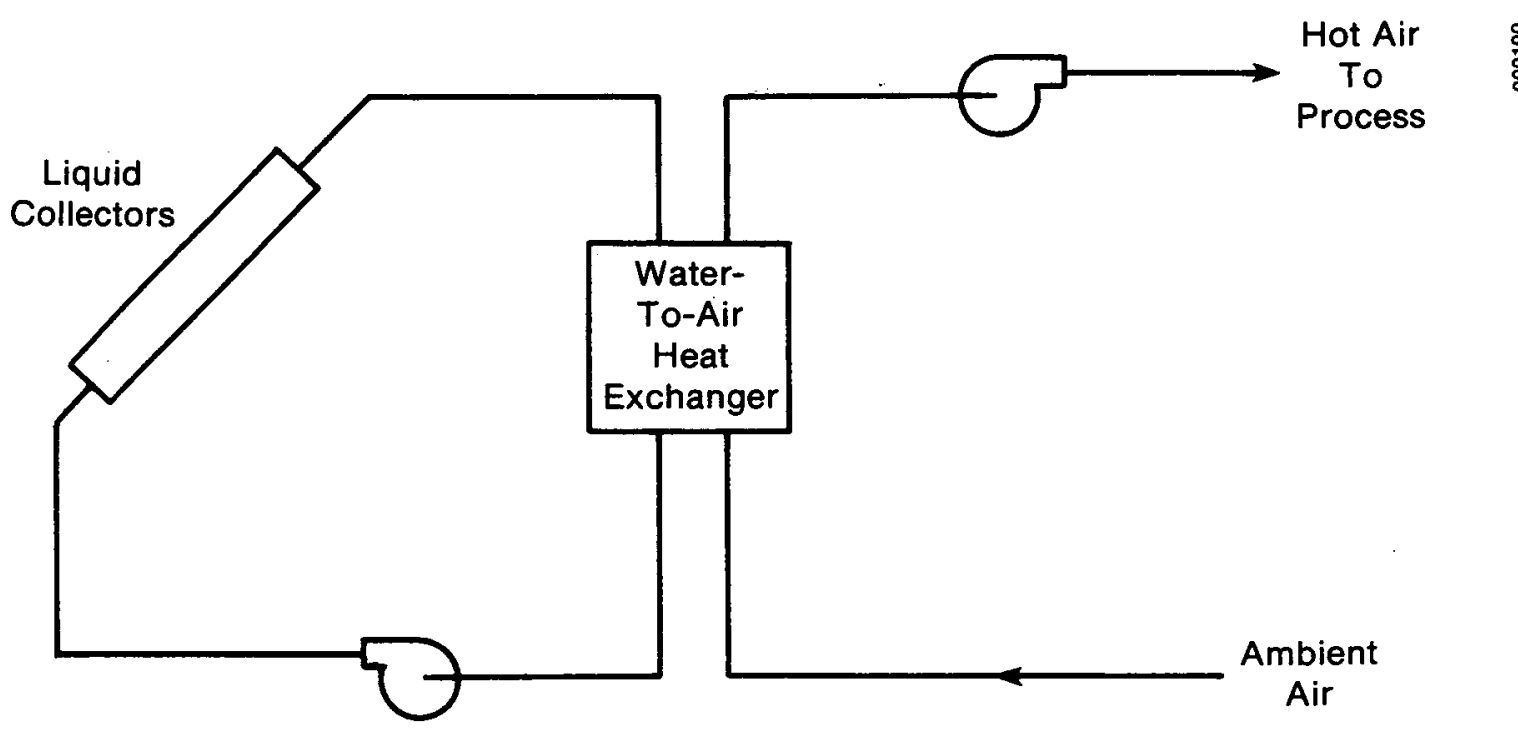

Figure 4-2. Water-To-Air Solar System

A rock-filled storage tank can be plumbed along with the solar collectors, and heated air from the collectors can be routed through the rock bin when energy is not needed by the process. Heating the rock bin when there is no load permits discharge of this stored energy later, when the process requires heat but the solar collectors are not operating. An alternative to the direct hot air system is to use liquid collectors and a liquid-to-air heat exchanger, as shown in Fig. 4-2. Thermal storage can be provided by a water-filled tank. This system reduces parasitic power requirements, but the freeze protection problem must still be addressed.

\subsection{HOT WATER SYSTEMS}

Solar systems to service industrial processes that require hot water can be configured as shown in Figs. 4-3 and 4-4. A direct hot water system is shown in the first figure, and an indirect system is shown in the second. In the direct system, process water is the working fluid in the solar collectors. The indirect system has two separate fluid loops and usually employs an antifreeze solution or a heat transfer oil in the collector loop.

When water is the heat transfer fluid, freeze protection is afforded by draining the water (either through a drain or back to the solar tank) or, in mild climates, by circulating warm water periodically during the night when the system temperature approaches freezing. Electrical heat tracing is not recommended because a power failure on a cold night could significantly damage the system. 


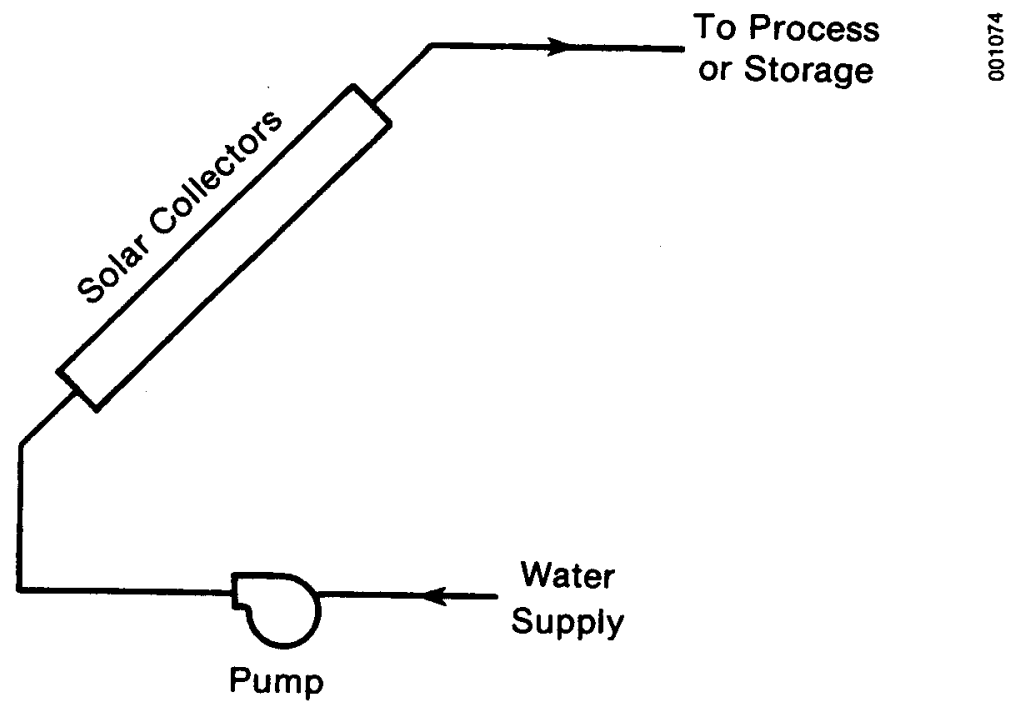

Figure 4-3. A Direct Solar Hot Water System

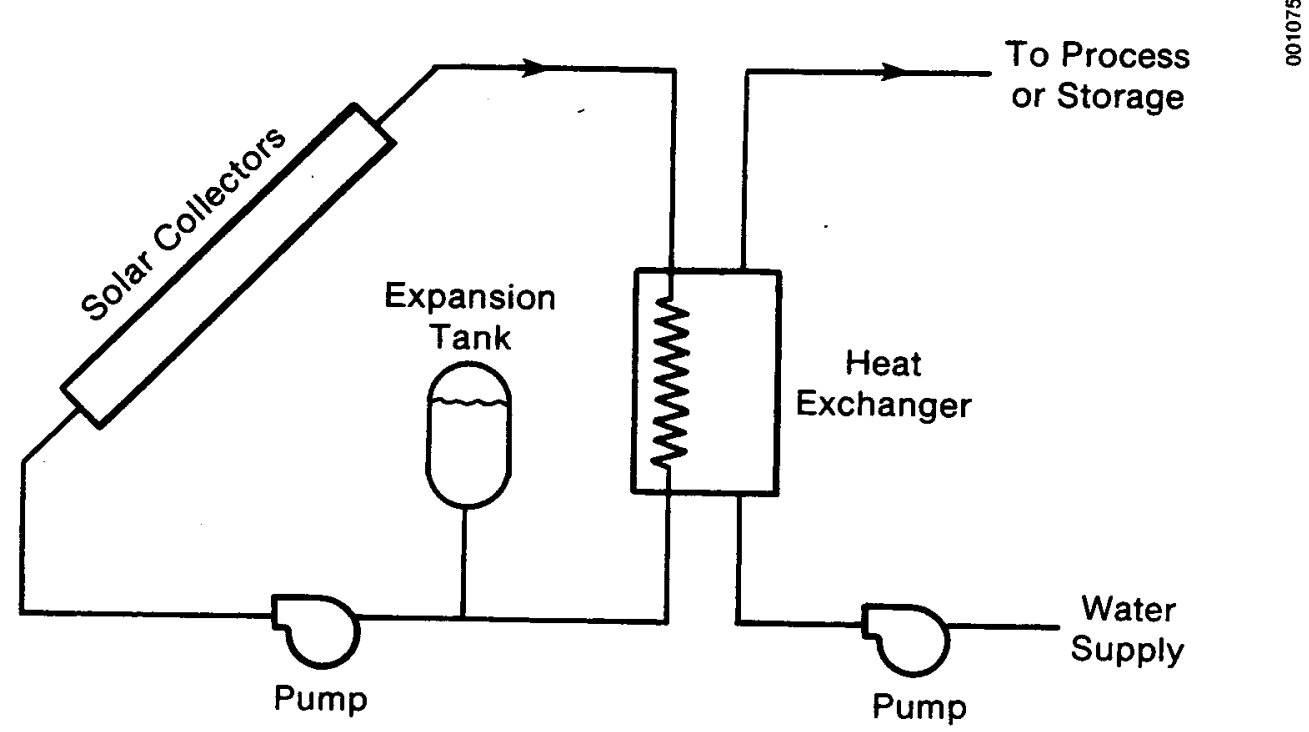

Figure 4-4. An Indirect Solar Hot Hater System 
Figures 4-5 through 4-7 show typical freeze protection configurations for domestic hot water systems using water in the collector loop. These can also be used for some IPH applications.

Figure 4-5 illustrates a direct hot water system with drain-out freeze protection. Because the collector loop operates at city water pressure, solenoid valves are needed to isolate the piping from that pressure when the system has to be drained. Figures $4-6$ and 4-7 present drain-back systems. In one case, the solar tank is unpressurized, and the collector water drains back into that tank. In the other design, a pressurized tank (at line pressure) is isolated from the solar loop, and a small holding tank is required to contain extra collector fluid. Neither system requires a solenoid valve and will drain whenever the pump stops. An excellent discussion of the advantages and disadvantages of these systems can be found in Interim Reliability and Materials Design Guidelines for Solar Domestic Hot Water Systems, published by Argonne National Laboratory (1980).

Indirect systems can diminish collector freezing problems because they employ a fluid with a lower freezing point than water. For process loads above $100^{\circ} \mathrm{C}$, indirect systems allow the collector loop to operate at lower pressures. A direct hot water system requires pressurization of the entire collector field to prevent boiling. An indirect system can employ a fluid with a lower vapor pressure in the collector loop; pressurization is not required. Corrosion problems can also be minimized with an indirect system employing a heat transfer fluid with a corrosion inhibitor. Because the indirect system requires an additional heat exchanger and a heat exchanger fluid, it is recommended only if freeze protection, corrosion, or loop pressurization concerns preclude the use of a direct hot water system. Commonly used heat transfer fluids are glycol solutions, hydrocarbon-based fluids such as Caloriam and Therminol $\mathrm{m}$, and silicones (see Sec. 7.2.).

Liquid collectors are designed to use water in direct systems; generally, liquid collectors are also used in indirect hot water systems. Theoretically, air collectors could be used in conjunction with an air-to-water heat exchanger, but the poor heat transfer and the increased power needed to transport the air make this option a poor choice. Liquid-based flat-plate collectors, evacuated-tube collectors, and parabolic troughs are all more appropriate.

A check valve is needed in the collector loop for indirect and drain-back direct systems to prevent thermosiphoning (reverse flow caused by natural convection) when the pump is not operating. An expansion tank must also be attached to the collector loop in indirect systems to allow the working fluid to expand as it is heated. Isolation valves, drains, and filters must be installed as in other piping systems.

\subsection{STEAM SYSTERS}

Steam is industry's most common heat transport medium for low-temperature (generally less than $200^{\circ} \mathrm{C}$ ), indirect process heat. Industries have gained a great deal of operating experience in using steam, and package steam boilers 


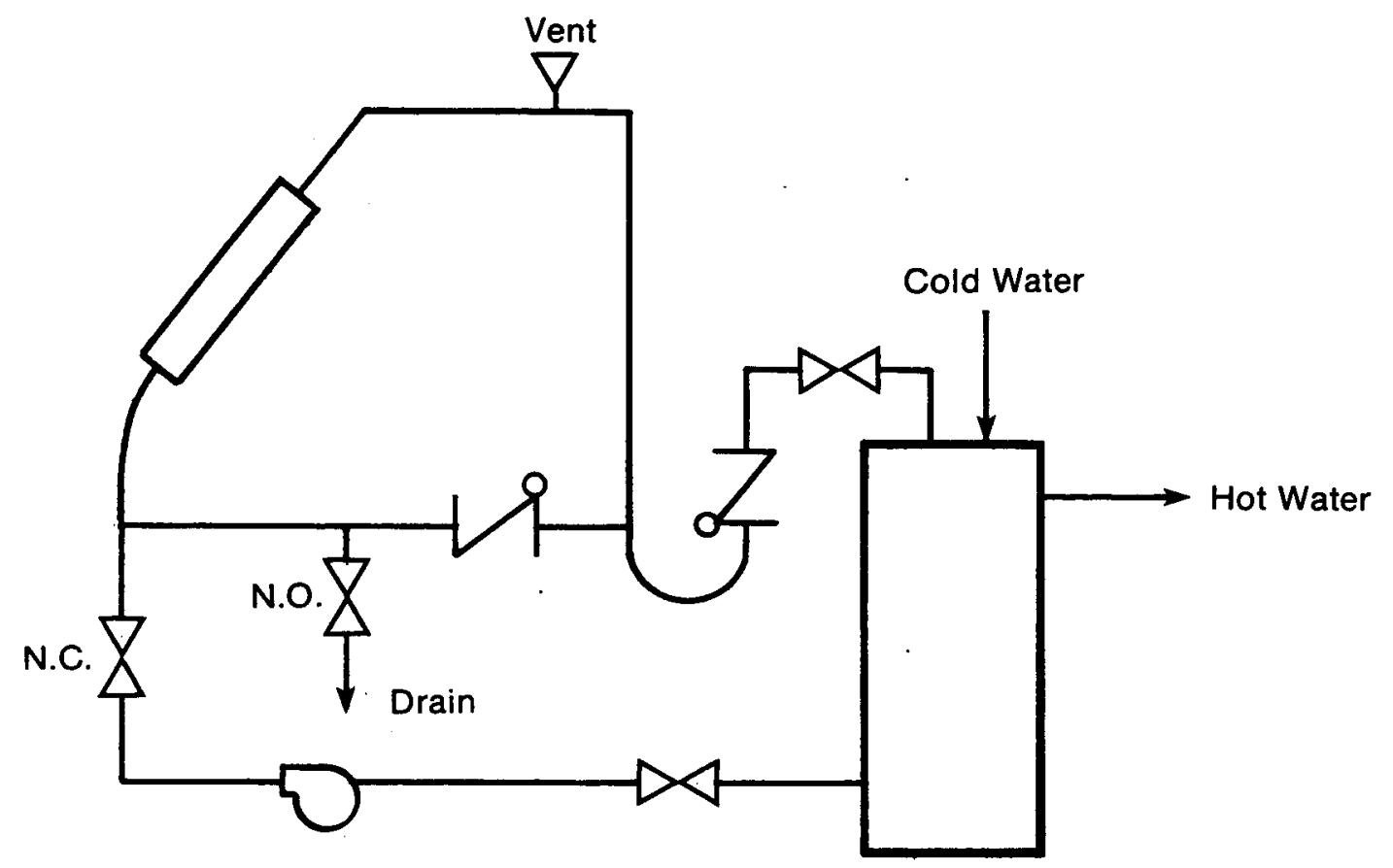

Figure 4-5. Direct Hot Water Systen With Drain-Out Freeze Protection

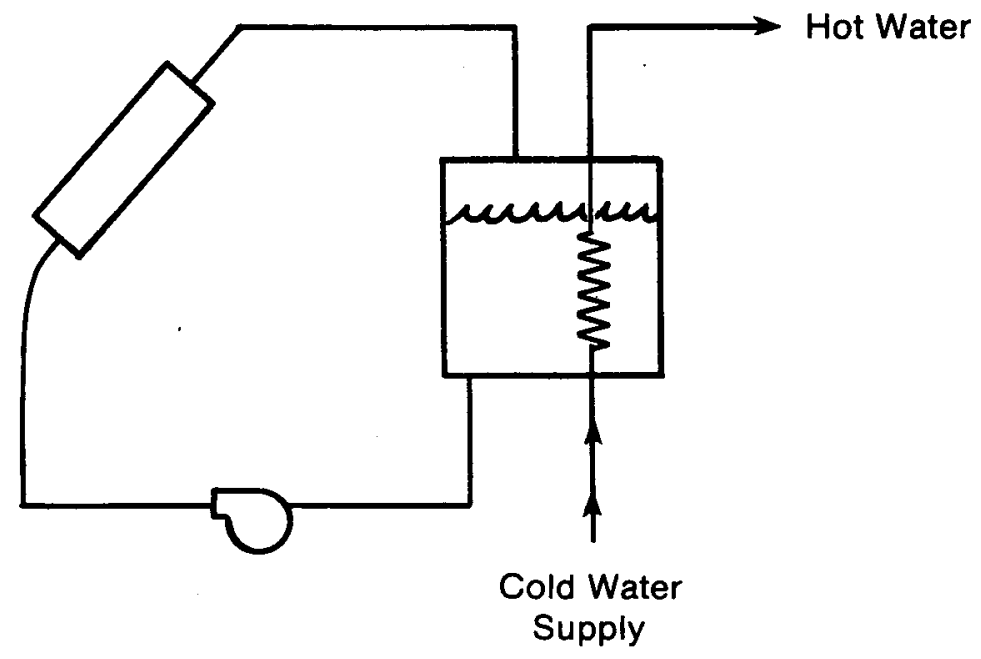

$\frac{8}{2}$

Figure 4-6. Indirect Hot Water System with Drain-Back (to Tank) Freeze Protection and Nonpressurized Tank 


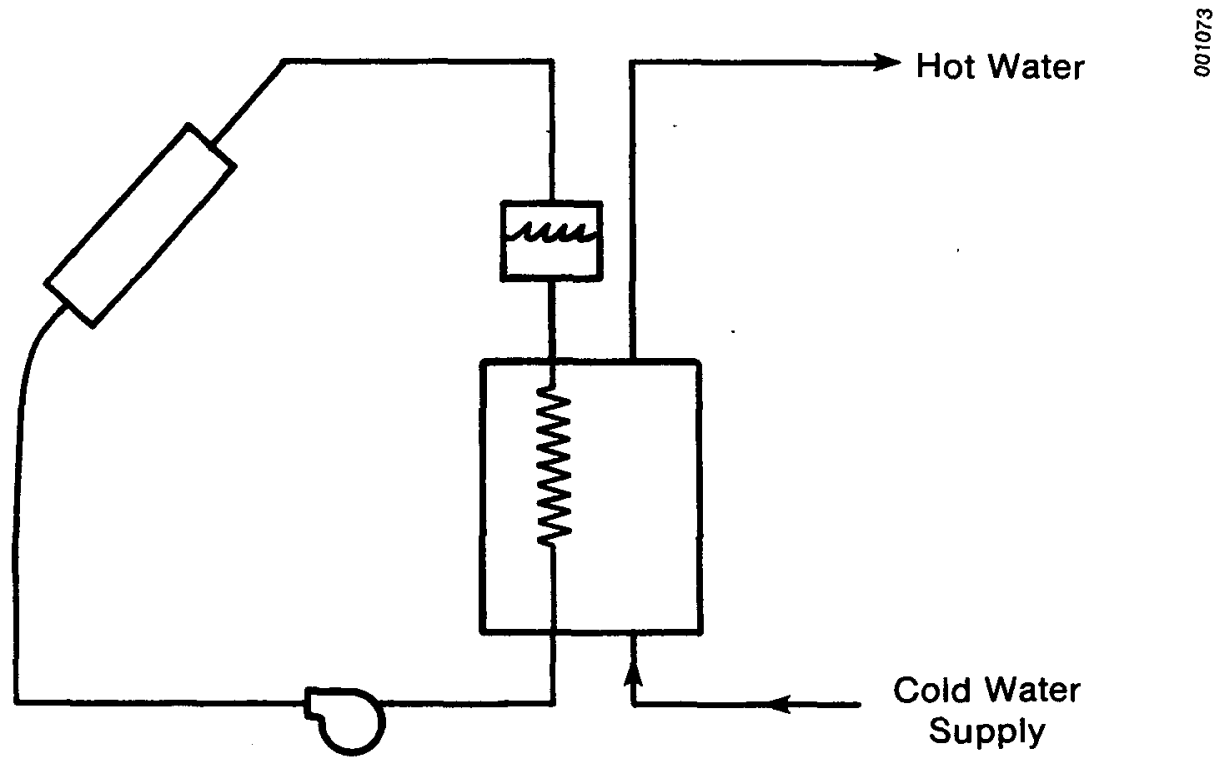

Figure 4-7. Indirect Hot Water System with Drain-Back to Bolding Tank and Pressurized Storage Tank

have proven to be extremely reliable. Generating steam by means of a solar system involves a fairly simple plant interface that feeds directly into a plant's steam distribution system without necessitating changes in existing processing practices.

Flash-steam and unfired-boiler solar energy systems utilizing line-focus concentrating collectors have already been constructed to supply industrial process steam. A third and promising option that involves generating steam directly in line-focus collector tubes is under investigation at SERI (Murphy and May 1982).

\subsubsection{Flash-Steam System}

A schematic of a flash-steam system is shown in Fig. 4-8. Water at a pressure high enough to prevent boiling is circulated through the collector field and flashed to steam across a throttling valve into a separator. This constant enthalpy process converts the sensible heat of the water into the latent heat of a two-phase mixture at the conditions prevailing in the separator. Steam qualities (the fraction of total flow that is vapor) are usually less than $10 \%$. The steam is fed into the plant utility system and the liquid is recirculated. Boiler feed water make-up is injected into the pump suction to maintain the liquid level in the separator. 
Using water as a heat transfer fluid simplifies the construction of a flashsteam system, since it is an open-loop process. However, although water is an excellent heat transport medium, freezing problems can occur. Therefore, the freeze protection mechanism must be carefully designed and controlled to ensure that a minimum amount of heat is supplied to the water to prevent freezing.

The disadvantages of the flash-steam system are associated with the steamgeneration mechanism. Collector temperatures must be considerably higher than the steam delivery temperature to obtain reasonable steam qualities downstream of the throttling valve and to limit the water recirculation rate (the ratio of collector flow rate to steam production rate or the reciprocal of steam quality). But higher temperatures reduce the collectors' efficiency. In addition, the pressure drop across the flash valve, which can be considerable, must be overcome by the circulating pump. Various control schemes have been suggested to reduce pumping power requirements by modulating the flash valve; these are described in Sec. 8.0 .

Moreover, the rapid rise in the vapor pressure of water at temperatures above about $177^{\circ} \mathrm{C}\left(350^{\circ} \mathrm{F}\right)$ limits the steam pressures that can be generated by this method to approximately $2 \mathrm{MPa}$ (305 psig) at acceptable levels of required electrical power.

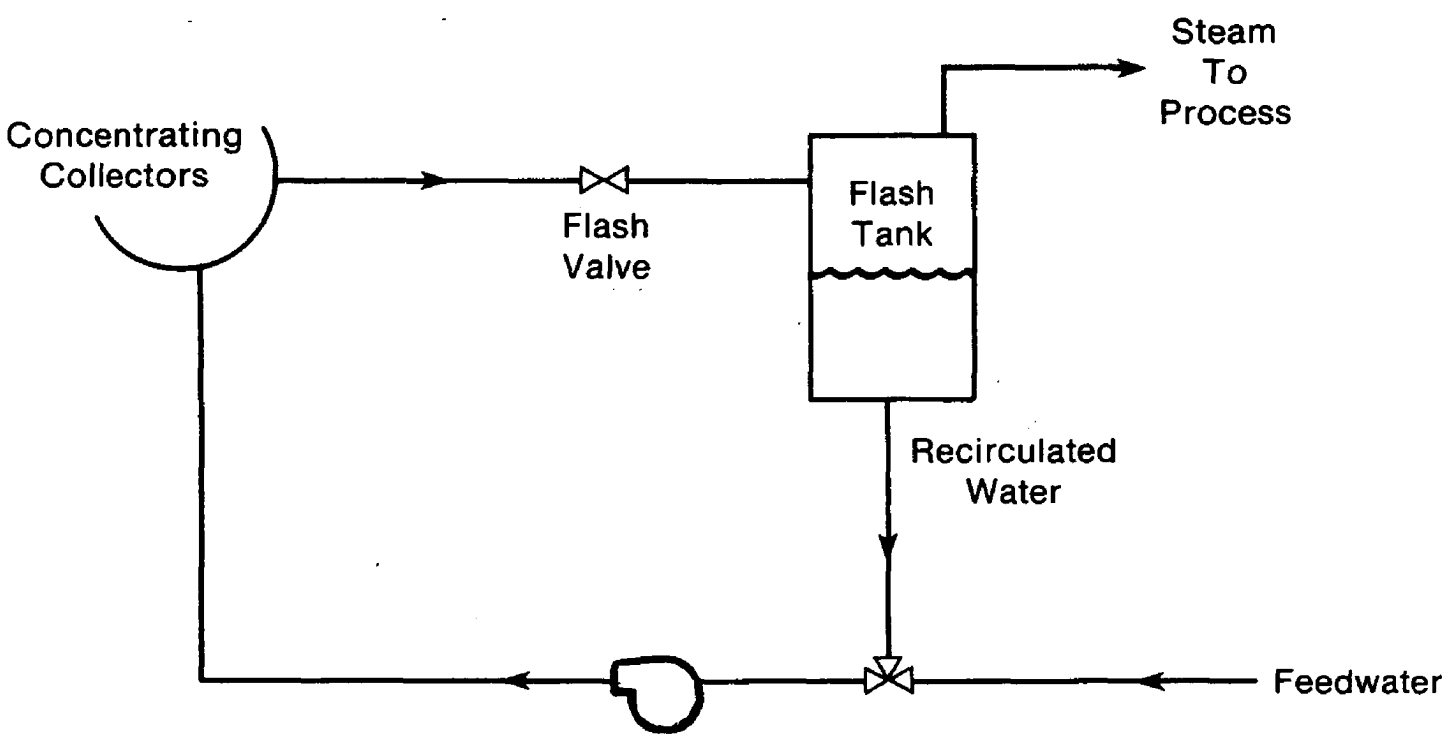

Figure 4-8. Flash-Stean Solar Systen 


\subsubsection{Unfired-Boiler System}

A schematic of an unfired-boiler steam system is presented in Fig. 4-9. A heat transfer fluid is circulated through the collector field and steam is generated in an unfired boiler. A varlation of the system shown incorporates a preheater in the water make-up line, which increases system cost but also reduces the inlet temperature to the collectors. Water could be circulated in the collector 10op, but the fluid generally selected is a low-vapor-pressure, nonfreezing hydrocarbon or silicone oil. Using such an oil overcomes the disadvantages associated with water (high vapor pressure and freezing) and accommodates energy storage, but certain characteristics of these oils cause other problems (see Sec. 7.2). Generally, precautions must be taken to prevent the oil from leaking out of the system, which could result in a fire. In addition, the oils are expensive and have poorer heat transport properties than water. They are extremely viscous when cold, and a positive displacement pump is sometimes needed to start the system after it has cooled down.

The unfired boiler itself is an expensive item requiring alloy tubes for corrosion protection, and it is an additional resistance to heat flow. As in the flash-steam system, the collectors must operate at a temperature considerably above the steam delivery temperature. Because the process steam must be maintained at a certain temperature, the solar-produced steam is delivered at a variable flow rate. The collector outlet temperature can be held constant by varying the flow rate through the collectors (see Sec. 8.2.1).

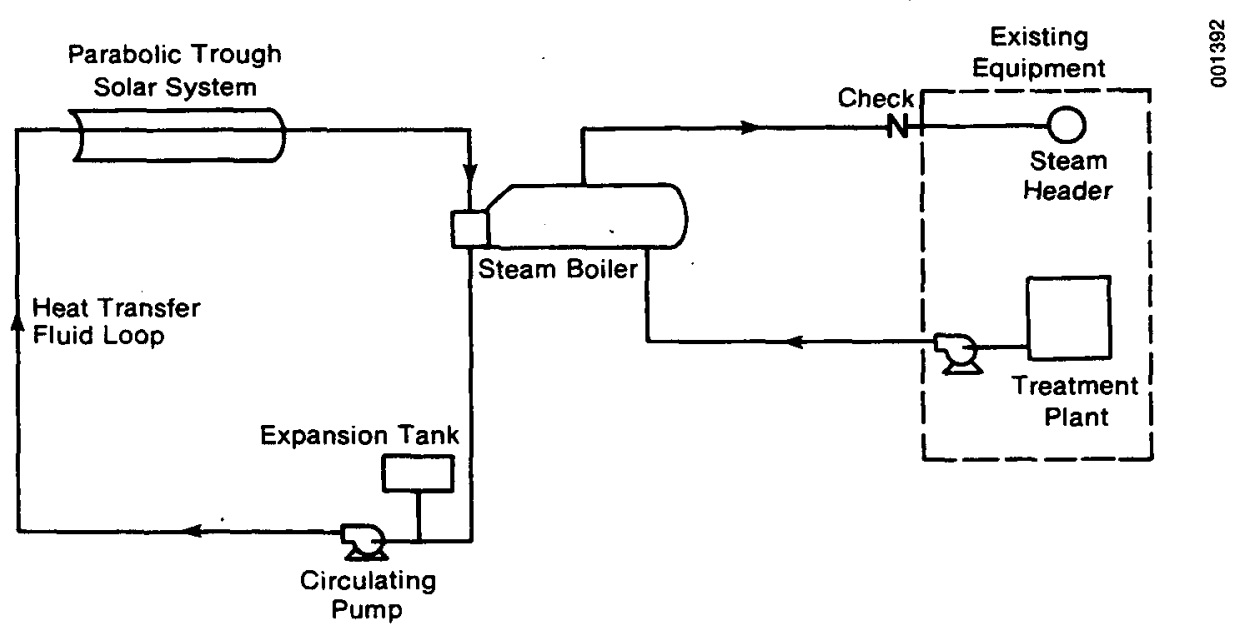

Figure 4-9. Unfired-Boiler Stean-Generating System 


\subsubsection{Direct Stean Generation}

Direct steam generation in the receiver tubes of a line-focus collector is an attractive concept because the average collector operating temperature would be near the steam delivery temperature and because the phase change reduces the required water flow rate through the circulating pump. The system schematic would be similar to that of the flash-steam system but without a flash valve. The disadvantages of the concept are associated with an incomplete understanding of the bofling mechanism and possible operating instabilities. Investigations by Murphy and May (1982) and Pederson and May (1982) validated the attractiveness of the concept. An experimental program has been proposed to test the system and to validate analytical predictions of performance.

\subsection{STORAGE CONFIGURATIONS}

When solar energy supplies only a small fraction of the process load, storage is generally not warranted unless the collectors might otherwise be idle for significant periods of time (e.g., during weekend plant shutdowns or at night). Also, if a large solar fraction is desired or a considerable load occurs at night, a storage system will be needed.

\subsubsection{Hot Water Storage}

Four possible configurations for hot water storage are shown in Figs. 4-10, 4-11, 4-12, and 4-13. Al1 four figures illustrate direct systems that incorporate process water passing through the collector array. (Freeze protection occurs by means of drain-back or recirculation). In any of them, however, a heat exchanger could be placed between the collectors and the storage tank, creating a separate collector loop containing a nonfreezing fluid.

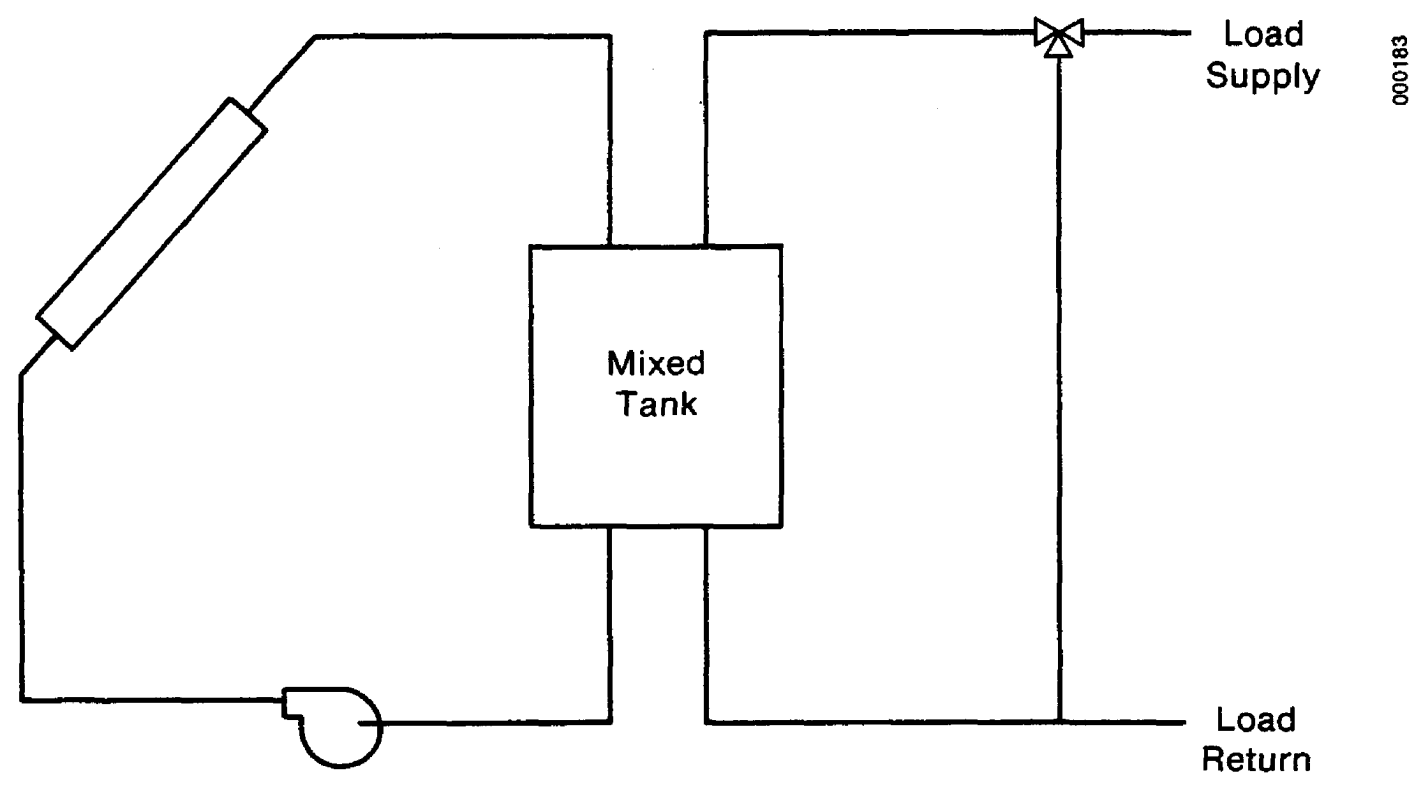

Figure 4-10. Four-Pipe Storage Configuration 


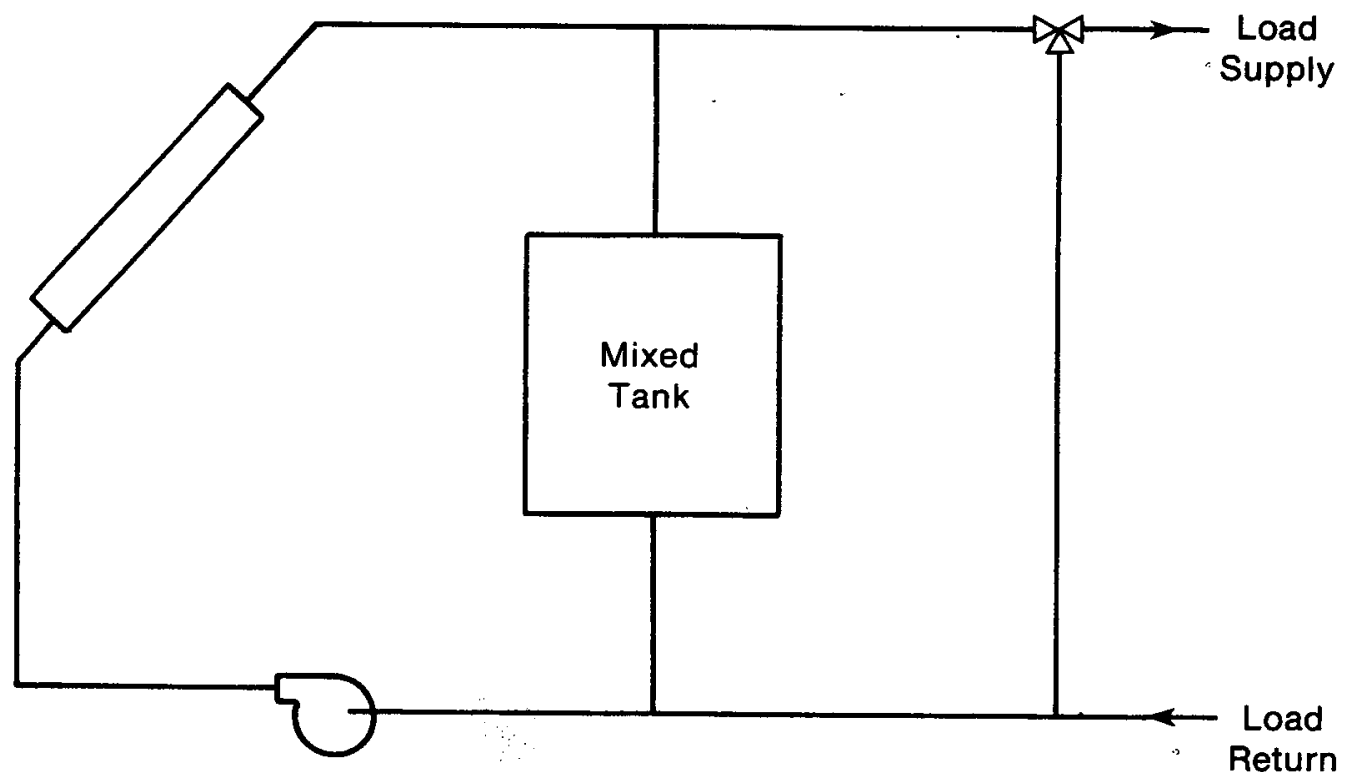

Figure 4-11. Two-Pipe Storage Configuration

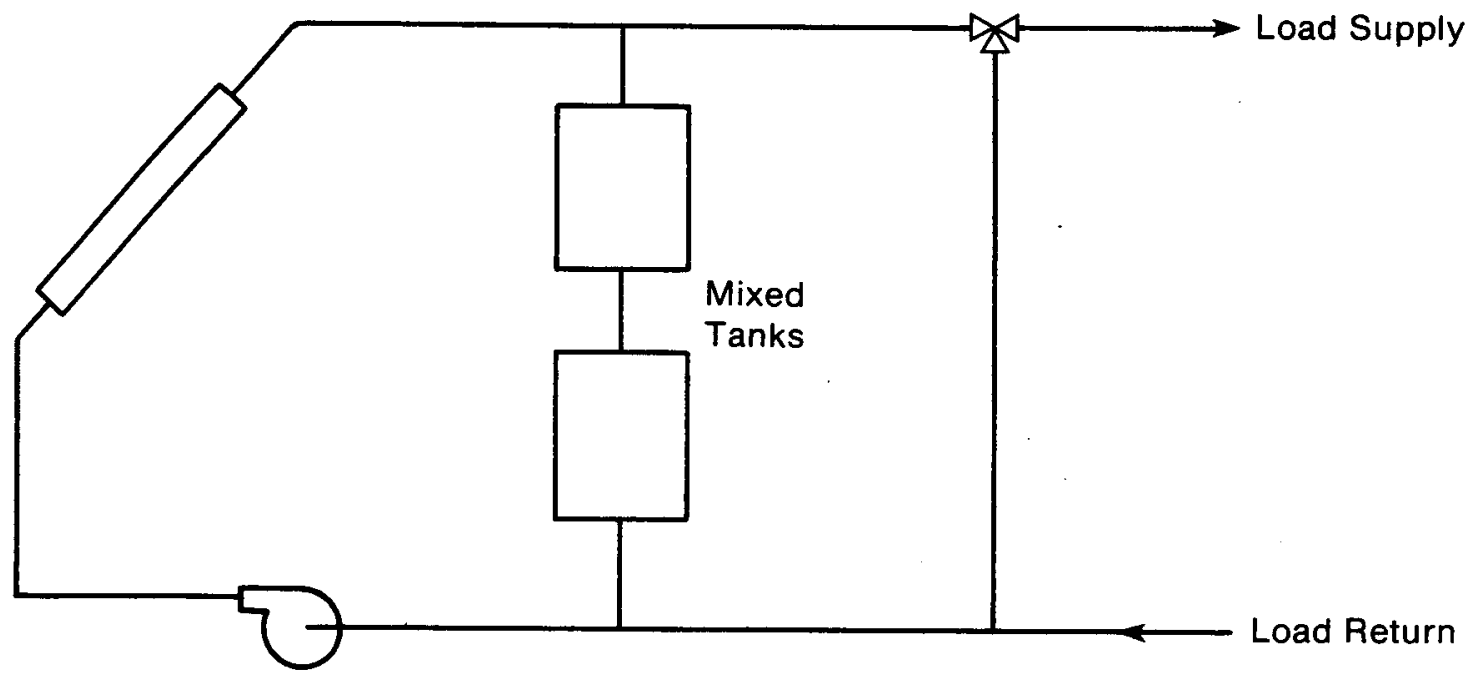




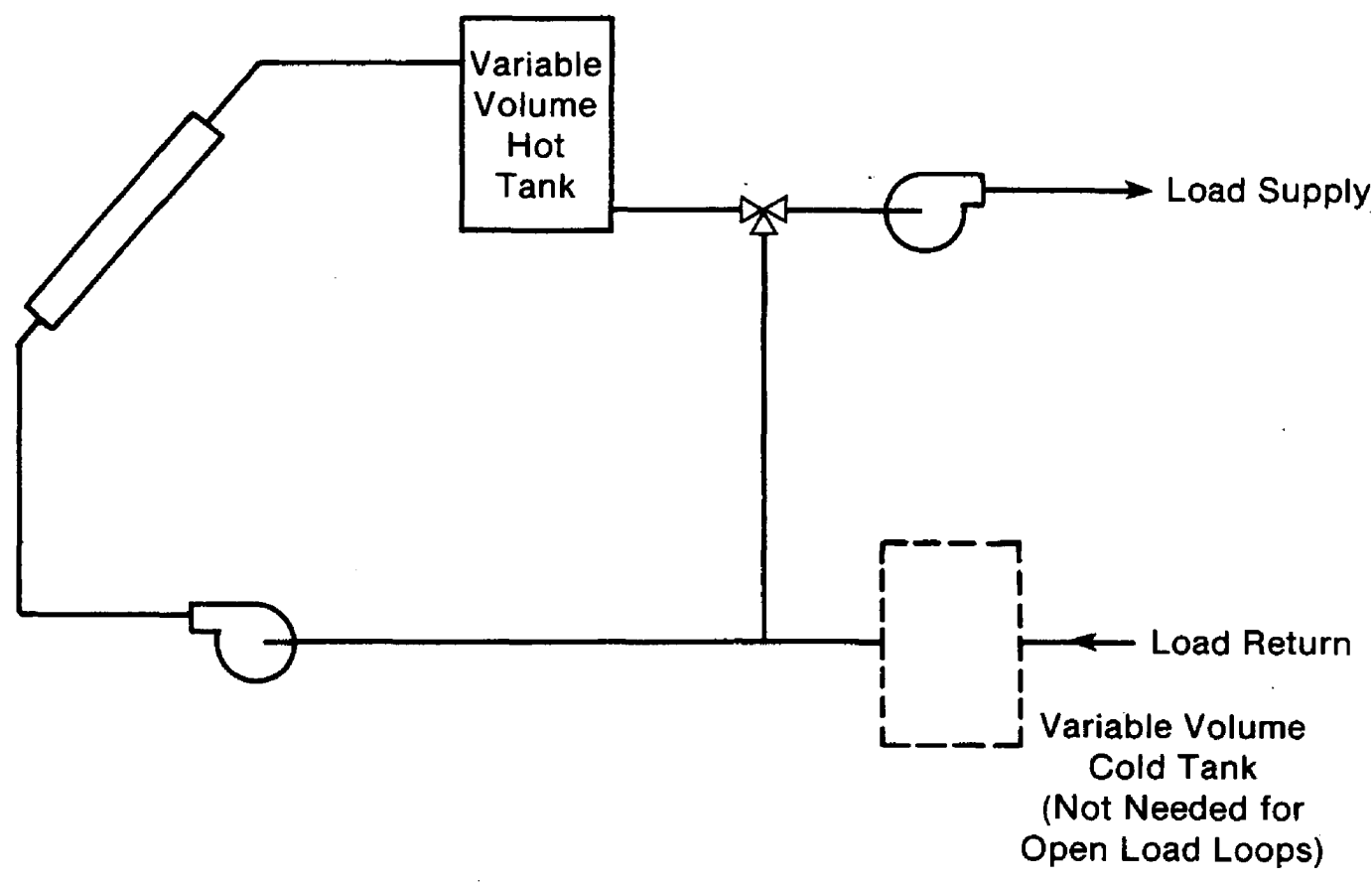

Figure 4-13. Variable-Volume Storage Configuration

Figure 4-10, a four-pipe storage system, is the most common configuration and is usually found in solar space heating/domestic hot water systems. The tank has two inlets and two outlets, one pair each for the collector loop and the load loop. The two loops operate independently of each other. The collectors can supply heat to storage whether or not the load is extracting heat from it. Conversely, heat from storage can be supplied to the load with or without available solar energy. In applications where the difference between load supply and return temperatures $(\Delta T)$ is small (e.g., space heating systems) or where the load is on only a small percentage of the time the collectors are operating (e.g., domestic hot water), a four-pipe system is appropriate. However, if the load $\Delta \mathrm{T}$ is large and the load is fairly constant during the day, the collector inlet temperature will be higher than it needs to be. This occurs because the collector inlet water comes from the mixed storage tank at a temperature close to that of the load supply. Using a thermocline storage tank would solve the problem, but such a thermocline can be difficult to achieve in water tanks because the high collector flow rate disrupts stratification.

The configuration of Fig. 4-11, a two-pipe storage system, resolves this difficulty by allowing cold load return fluid to be fed directly to the collectors. Since many IPH applications are open loop (e.g., clean-up water), this temperature will be the same as city make-up water-considerably below the load supply temperature. If the load operates during a good portion of the day, using make-up water in the collectors will increase their efficiency. At the same time, the top bypass of the tank allows the hottest water to be supplied directly to the load without mixing it with the cooler water in storage. The collector and load loop do not operate quite as independently in this arrangement as they do in the four-pipe system. Storage can be charged 
without a load, or storage can be discharged if the collector loop is not operating exactly as in the four-pipe system. However, energy cannot be directly supplied from storage at the same time the collectors deliver energy to the load unless the collector flow rate is less than the load flow rate. In some cases, this could result in higher storage temperatures than necessary. Adding an extra pump and valve would permit dual delivery to the load by lowering the collector flow rate, but this would somewhat reduce the efficiency of the collector. An increase in collector efficiency occurs only when the load is operating during periods of collection.

The performance of the two-pipe system configuration could be improved significantly if the tank could maintain a perfect thermocline. As we mentioned earlier, however, this is very difficult. A way to achieve some stratification is shown in the multiple-tank system of Fig. 4-12. Using multiple tanks (in this case, two), the collector inlet temperature can be kept below the load supply temperature during no-load conditions. Unlike the variable-volume tank system, these simple, mixed storage tanks require no level control. As more tanks are used, performance comes closer to a perfect thermocline. However, multiple tanks increase system cost and exacerbate heat-loss problems.

If the process load profile indicates that the collectors will be operating for substantial amounts of time during which there is no load (e.g., load only from 12:00 noon to 8:00 PM, or the plant is shut down on weekends), collector performance can be most effectively increased by means of the variable-volume system shown in Fig. 4-13. This is a step up in complexity from the two-pipe system that increases collector efficiency even if the load is not operating.

Essentially, variable-volume storage tanks permit a load to be rum all day as far as the collector loop is concerned. For closed-1oop load applications, two variable-volume tanks would be used-one cold and one hot. If the load is not on during the day, water is pumped from the cold tank through the collectors to the hot tank. If load is needed when the collectors are shut down, the hot water is taken out of the hot tank, and if the load loop is open, the cold tank is not needed. Make-up water can be circulated through the co1lectors during the day to charge the hot tank. In any case, the collector array is always supplied with the coldest possible water whenever it is operating, regardless of whether the load is on or off. A load-1oop bypass line permits closed-1oop flow between the collectors and the hot tank to charge the tank at temperatures above those of the load supply during long, no-load periods when the hot tank becomes full.

Which configuration to choose depends on the application. The four-pipe storage system is simple to control in any application and will perform very well at a low-load $\Delta \mathrm{T}$. A two-pipe storage system performs better, but the problem remains of how best to control the collector flow when it is necessary to supply load from the collectors and storage simultaneously. The variablevolume tank configuration has the highest performance potential, but since the total amount of water supplied to the tank should equal the required amount of load water, different collector flow rates are needed at different times of the year (a result of variations in lengths of day and in collector operating times). System performance would be less than ideal on partly cloudy days because a preset flow rate would be lower than optimum for those days. 


\subsubsection{Storage for Steam Systens}

The hot-water storage systems shown would also be appropriate for steam systems using unfired boilers, except that the collector fluid would be oil and the load supply and return would connect to the unfired boiler. 011 storage is used because of the high pressures that would be encountered with water storage. To maximize performance, a thermocline tank can be included that incorporates a mixture of oil and rocks (Fig. 4-14), or a system with two variable tanks can be used (Fig. 4-15).

In an oil system, a large $\Delta T$ can exist on the load side between the make-up water and steam supply temperatures. Because most of the energy delivered to the load is in the form of latent heat from bolling water, the make-up water flow rate in a steam system is relatively small. As a result, the temperature of the oil exiting the unfired boiler does not come very close to the make-up water temperature, and the temperature gradient that can be achieved in a thermocline tank or between two variable-volume tanks is not as great as would be expected. Moreover, the relatively flat efficiency curve of a parabolictrough collector, which would be used in a steam system, diminishes the advantage of temperature stratification.

A recent, unpublished study conducted by James Leach at SERI provided some interesting results. The study compared various storage schemes for large $\left(25-M_{t}\right)$, unfired-boiler IPH systems using projected parabolic trough efficiency curves. Leach used the SOLIPH computer program to compare configurations on the basis of annual energy delivery. Figure 4-16 presents performance data for two-tank (variable-volume) systems (which performed like a thermocline tank) compared with that of a mixed-tank system. Below solar fractions of about $40 \%$, there is no difference in performance between the systems or between them and a system with no storage. Above $40 \%$, the energy delivered by a two-tank system exceeds that of a mixed-tank system by only about 5\%. This graph was done for a daytime (6:00 AM to 6:00 PM) load. But even for a 24-hour load, the performance increase resulting from the thermocline was relatively small.

Dual-medium rock/oil is the most common method of thermocline storage in an oil system. However, it is still in the development phase (see Sec. 7.0). Using two variable-volume tanks is certainly not beyond the state of the art, but could be more expensive than the single thermocline tank. Because of the cost and uncertainties involved in achieving a storage-temperature gradient and only a minimal increase in performance, however, a simple mixed-storage tank is probably sufficient for present-day, unfired-boller applications.

In connection with the storage system study, note in Fig. 4-16 that the plot of energy delivery versus collector area is linear until, when excess energy begins to be collected, the curve deviates abruptly. This is characteristic of a steam system. Because the steam is supplied at a constant temperature, the storage tank or collector outlet must be kept to that temperature to deliver energy to the load. Preheating is not a significant fraction of the load. Increasing collector area and solar fraction results in greater water flow rate and steam production and does not appreciably affect the inlet or outlet temperatures of the collector. Thus, array efficiency stays constant 


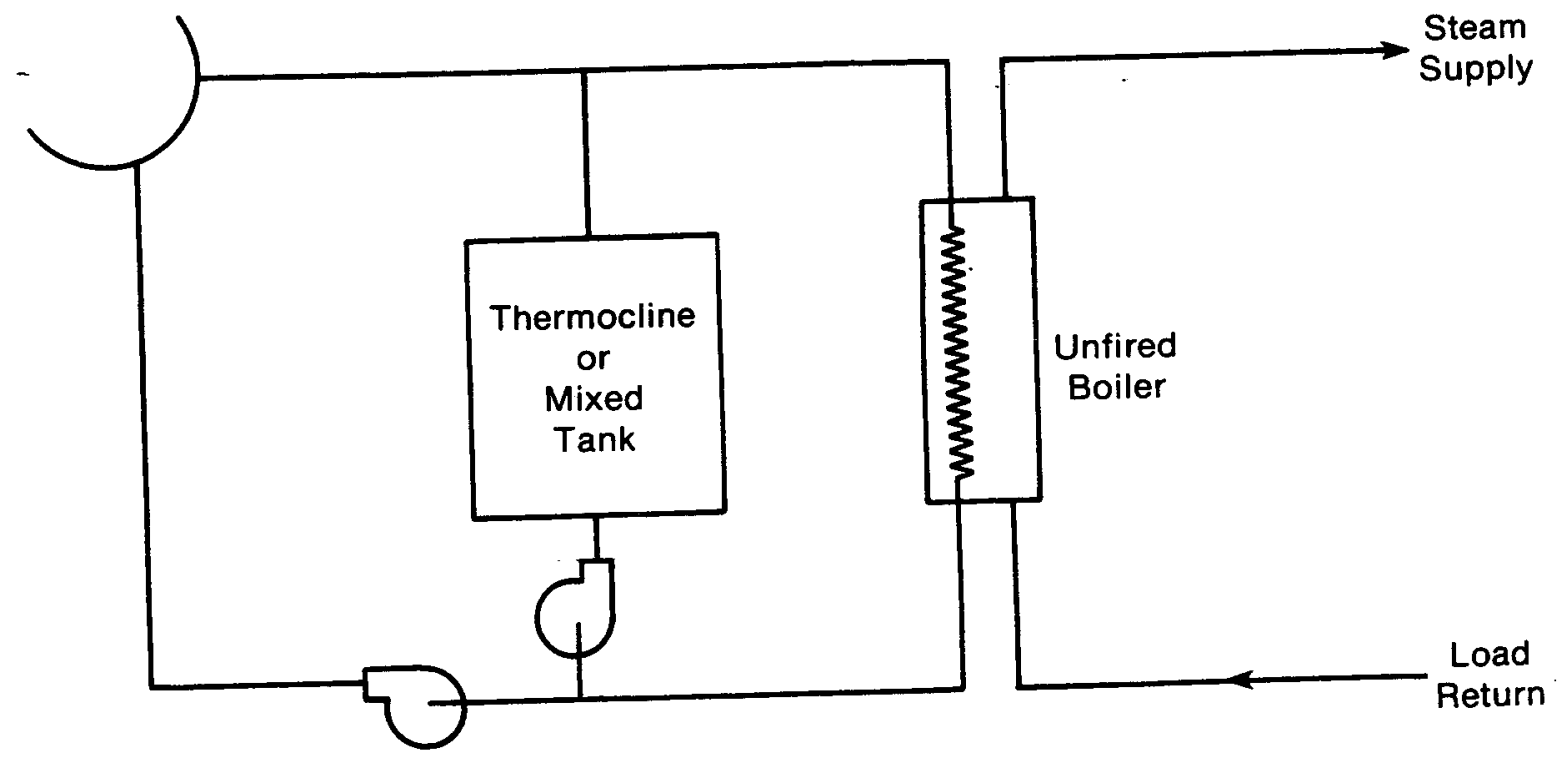

Figure 4-14. Thermocline or Mixed-Tank Configuration with Unfired-Boiler Steam Systen

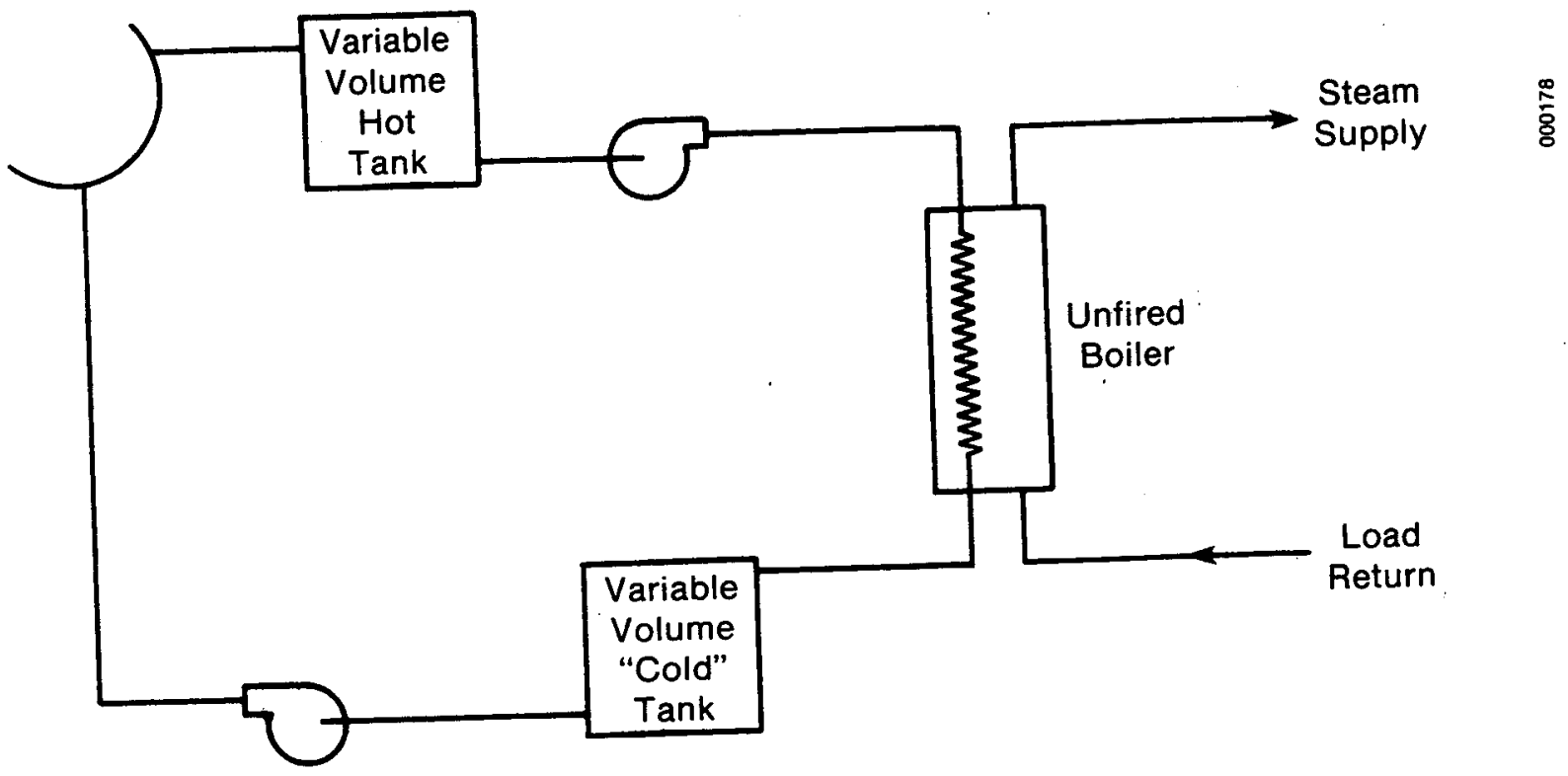

Figure 4-15. Variable-Volume Storage Tank Configuration for Unfired-Boiler Steam System 


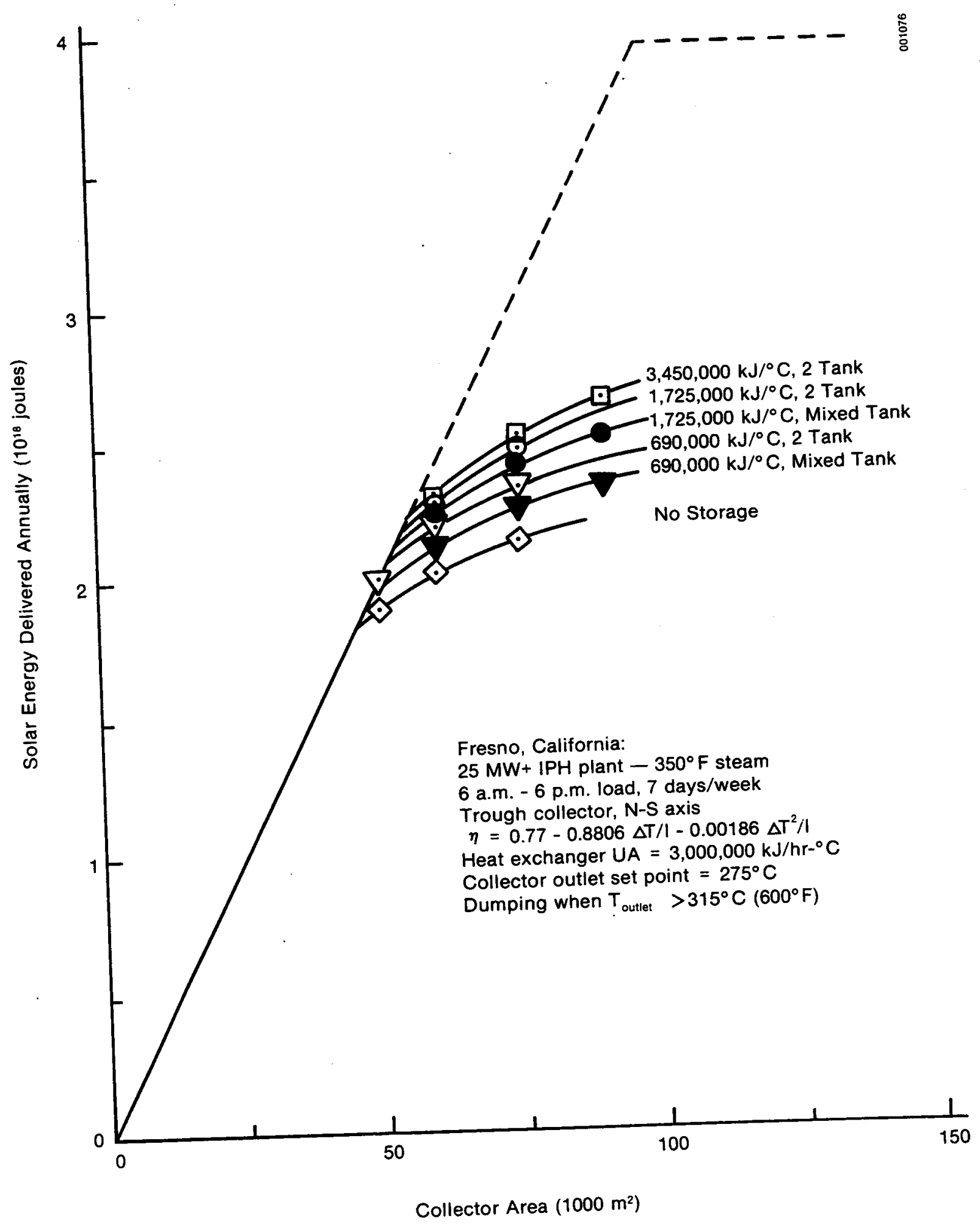

Figure 4-16. Annual Energy Delivery as a Function of Collector Area, Storage Type, and Size for an Unfired-Boiler System 
and energy delivery rises linearly as collector area increases until a point is reached at which excess energy is collected. After that point, efficiency drops as more and more energy is discarded.

In hot water systems, the most efficient way to use the collectors is to preheat all of the load water. Thus, the load flow rate is constant; as collector area increases, the solar water temperature delivered rises as well as collector outlet and storage tank temperatures. This, however, reduces the efficiency of the collector. As a result, the plot of energy delivery versus collector area diverges from a straight line at relatively low solar fractions. For a given load temperature, however, the hot water system will perform better than the steam system using the same collectors, because it can deliver energy more efficiently at lower collector outlet temperatures and it also displays lower inlet temperatures.

Flash-steam systems are ordinarily considered to be nonstorage systems, because of the cost of storing pressurized water. (It should be noted, however, that any high-temperature storage system degrades the performance and economics of a solar steam system.) Using an intermediate steam/oil/water loop for thermal storage in an open-loop steam system greatly increases system complexity and cost.

\subsection{PROCESS/SOLAR SYSTEM TMTERFACE}

A solar system may interface with the process to which it supplies heat either in series or parallel with an existing or auxiliary boiler or heater. In a series configuration, heat from the solar system is used to preheat the process working fluid, which then goes to the auxiliary heat source. If the solar system cannot heat the process fluid to the required temperature, the auxiliary heat source supplies the final boost to the load temperature. If the energy from the solar system is available at a higher temperature than that required by the load, a tempering valve mixes cool, incoming process fluid with solar-heated fluid to achieve the desired load temperature. A series configuration is used in direct systems and is preferred for indirect hot water and hot air systems because it provides a lower average collector temperature than does a parallel configuration, prompting higher collector efficiency. Series configurations cannot be used in steam systems except for preheating the feedwater, a small part of the load. In a series configuration, the backup heater must modulate to accommodate varying solar power input. Although boiler efficiency can decline in combination with low firing rates, overall fuel savings increase when the backup hot water heater is modulated over as large a range of firing rates as possible, in order to increase collector efficiency (see Appendix A).

In a parallel configuration, the solar system must produce the desired load temperature before it can deliver energy to the process. Because heat cannot be delivered to the process at a temperature lower than that of the load, the storage tank temperature remains at or above load temperature at all times; in open-loop applications, the collector inlet temperature usually is higher than it would be in a comparable series system. Parallel systems can be used in closed-1oop applications where the return temperature can vary (for example, a space heating system), because under those circumstances a series arrangement could heat storage with auxiliary heat, thereby lowering collector efficiency. 
A series configuration with storage bypass capability is possible, however. Parallel systems are also used in saturated steam production, where the solar system supplies steam directly to a plant's steam main. Because most of the heat transfer in a steam system takes place at the steam temperature, parallel systems are ideal for such applications; the penalty associated with parallel systems in lower- temperature applications is not a factor here.

In any solar system/process interface, the designer should take care to provide for complete isolation of the solar system. In this way, any solarrelated problems that might arise will not interfere with plant process operations.

\subsection{REFERENCES}

Argonne National Laboratory. 1980 (Sept.). Interim Reliability and Materials Design Guidelines for Solar Domestic Hot Water Systems. SOLAR/0907-80/70. Argonne, IL: Argonne National Laboratory.

Murphy, L. M.; May, E. K. 1982 (Apr.). Steam Generation in Line Focus Solar Collectors: A Comparative Assessment of Thermal Performance, Operating Stability, and Cost Issues. SERI/TR-632-1311. Golden, C0: Solar Energy Research Institute.

Pederson, R. J.; May, E. K. 1982 (Mar.). Flow Instability During Direct Steam Generation in a Line-Focus Solar Collector System. SERI/TR-632-1354. Golden, CO: Solar Energy Research Institute. 


\section{SEPI}




\section{SECTION 5.0}

\section{SOLAR COLLECTORS}

Basically, solar collectors are heat exchangers that transfer the radiant energy of incident solar radiation to the sensible heat of a working fluid-liquid or air: Many different types of solar collectors can supply energy to IPH systems. In this section, we describe several of these types of collectors, define the significance of a collector's instantaneous performance and how it is measured, and provide a method of selecting an appropriate collector for a particular IPH system.

\subsection{TYPES OF COLLECTORS}

A substantial number of different kinds of solar collectors have been proposed for solar industrial process heat systems, partly because of the wide range of process temperatures found in industry. However, the major types of collectors used thus far in industrial process heat field tests are flat plates, evacuated tubes, and parabolic troughs. These three kinds of collectors, their components, and potential or suggested improvements are described in the following subsections. We also describe in more general terms other types of collectors that may be utilized in IPH systems in the future.

\subsubsection{Flat-Plate Collectors}

Flat plates are the most commonly used solar collectors. They can supply hot air or hot water at temperatures up to about $90^{\circ} \mathrm{C}\left(200^{\circ} \mathrm{F}\right)$, although operating temperatures above about $70^{\circ} \mathrm{C}\left(160^{\circ} \mathrm{F}\right)$ diminish the relative efficiency of the system. The advantages of these collectors include the lack of moving parts, durability, and capability of collecting both direct and diffuse radiation.

Flat-plate collectors can be installed as a large, flat array atop a sloping roof or mounted in a sawtooth fashion on the ground. In the latter case, collector spacing must be sufficient to minimize row-to-row shading losses (see Sec. 6.3). Although it is possible to mount collectors flat on the ground, the savings in support costs would be outweighed by the losses in available irradiation at U.S. latitudes. The array should be oriented to face within $30^{\circ}$ of south to maximize incident irradiation.

\subsubsection{Components}

The flat-plate collector consists of the following basic components (shown in cross-section in Fig. 5-1):

- Absorber plate--usually copper, steel, aluminum, or plastic; surface covered with flat black paint or a selective coating to maximize absorption and minimize reradiation. 


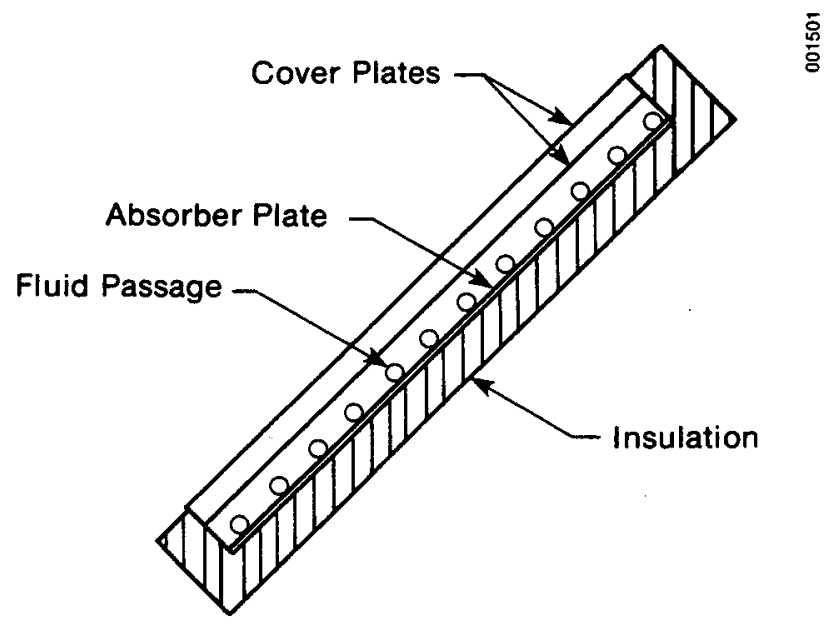

Figure 5-1. Cross Section of Typical Flat-Plate Collector

- Flow passages--liquids usually flow through tubes that are attached to, or an integral part of, the absorber plate. Air flows above or below the plate, and heat transfer surface area is maximized by means of fins, slots, or metal screening.

- Cover plate(s)--one, two, or three transparent covers, made of glass or various plastic materials, reduce convective and radiative heat losses to the outside air.

- Insulation--to reduce heat losses from the back and sides of the collector, typically fiberglass or isocyanurate.

- Enclosure--a box to hold collector components together and protect them from the weather.

In a typical liquid collector employing a metallic absorber, tubes are spaced several inches apart with the absorber surface between them acting as "fins" that absorb the heat and conduct it to the tubes. Copper, aluminum, and steel are all used for absorber plates. Copper has the highest conductivity, and although it is expensive, it is the most corrosion-resistant material. If a low thermal-conductivity material such as plastic is used for the absorber plate, the flow passages must be designed to maximize wetted surface area. Copper tubes are often welded, soldered, or clamped to copper plates or clamped to aluminum plates. The thermal conductance of the bond is critical and can vary from $5700 \mathrm{~W} / \mathrm{m}^{2} \mathrm{~K}\left(1000 \mathrm{Btu} / \mathrm{hr}-\mathrm{ft}^{2 \mathrm{O}_{\mathrm{F}}}\right)$ for a well-soldered tube to less than $30 \mathrm{~W} / \mathrm{m}^{2} \mathrm{~K}\left(5 \mathrm{Btu} / \mathrm{hr}-\mathrm{ft}^{2 \circ} \mathrm{F}\right)$ for a poorly clamped one. A better technique is to incorporate a tube pattern into the plate during manufacture. 
Tubes can be routed through the collector in parallel paths from an inlet to an outlet header, or a single tube can be routed in a serpentine fashion. The latter technique eliminates the possibility of header leaks and ensures uniform flow, it but also increases pressure drop. If a drain-down freeze protection system is used, the flow passages must be easy to drain.

Air collector absorber plates need not have high thermal conductivity because the air comes in contact with the entire surface. Flow can be above or below the plate, but the latter tends to result in less thermal loss through the glazing. An air system eliminates freezing and boiling problems, and leaks are not as troublesome as they are in a liquid system. However, fan power is significant, large ducts are required, and greater storage volume is needed.

The type of coating on the collector absorber plate determines the fraction of incident solar energy absorbed. Flat black paint is the most commonly used coating. It has an absorptance, $\alpha$, of between 0.92 and 0.96 ; that is, it absorbs between $92 \%$ and $96 \%$ of the incident short-wave solar radiation. It is also quite durable. However, a hot absorber plate will radiate long-wave energy to the cooler environment to an extent that depends on its emittance, $\varepsilon$. Flat black paint has a high $\alpha$, but its $\varepsilon$ is also high--on the order of 0.88 . So-called selective surfaces have a high short-wave $\alpha$ but a low longwave $\varepsilon$; thus, they retain heat better. Black chrome, the most popular selective surface, has an $\alpha$ of from 0.92 to 0.98 and an $\varepsilon$ of about 0.1 . Selective surfaces improve the performance of the collector but increase the cost, and their long-term durability is still questionable, especially at higher temperatures. An important characteristic of any absorptive coating is that it adheres well and does not peel or otherwise deteriorate during high-temperature stagnation (no-flow) conditions.

The most commonly used cover material is glass. A $3.2-\mathrm{mm}\left(1 / 8-\mathrm{in}_{\text {. }}\right)$ sheet of window glass $(0.12 \%$ iron content) has a transmittance to solar radiation (at normal incidence) of $85 \%(\tau=0.85)$. Water white glass $(0.01 \%$ iron) has a $\tau$ of 0.92 . Glass has the added advantage of being practically opaque to any long-wave radiation given off by the absorber plate. If 1 is is tempered, it is also highly durable. Deterioration is negligible, even over very long periods of exposure to intense ultraviolet radiation. Various plastic materials are also used for collector glazings and are cheaper and lighter than glass. Because they come in thin sheets, they of ten also have a higher transmittance. However, they often do not trap thermal radiation as well as glass and are generally not as durable. Degradation from ultraviolet radiation or high temperatures can be severe. Tedlarm, for example, should not be used as an inner glazing in a two-cover collector because of its susceptibility to thermal degradation. The number of glazings depends on the application and on a costversus-performance trade-off. A single-glazed collector with a selective coating will often outperform a double-glazed one with a nonselective coating. Generally speaking, more covers are needed as the difference between the temperature of the collector plate and the ambient temperature increases.

The collector enclosure is ordinarily made of steel, aluminum, or fiberglass and supports the absorber plate and covers. Ideally, it would expand and contract along with the components as temperatures change, although adequate clearance (around a glass cover, for example) and proper gaskets must be provided for differential expansion. The frame should be designed to cast almost 
no shadow on the absorber plate, and the aperture area should be at 1 east $85 \%$ of the gross area. Sealing compounds and gaskets should be capable of withstanding stagnation temperatures without outgassing, and they also must be capable of withstanding thermal cycling. Various types of insulation can be used in collectors to prevent heat losses from the back and sides. The insulation should not outgas under stagnation conditions, because such gases could coat the inside of the glazing and greatly reduce transmittance. More information on flat-plate collector designs and on properties of the materials used in the collectors can be found in Franta et al. (1981).

\subsubsection{Improvenents}

One recent improvement to the basic flat-plate collector involves treating the glass cover to reduce reflection; this method can increase performance by as much as $4 \%$. Coatings on the inner glass surface to reflect the long-wave radiation (which would otherwise heat the glass) have also been used, although these can reduce transmittance as well. A honeycomb between the inner cover and the absorber plate can reduce both convective and radiative heat losses, but it usually also decreases optical efficiency at off-normal incident angles. Planar reflectors placed in front of a row of flat-plate collectors can increase annual energy collection by over 25\%. However, many rows of solar collectors are usually needed for IPH applications, and the resulting shading of reflectors by adjacent rows greatly reduces the effectiveness of planar reflectors.

\subsubsection{Evacuated-Tube Collectors}

One way to reduce convective heat losses is with a vacuum between the glazing and the absorber surface. However, because a vacuum would cause a typical flat-plate collector to collapse, this technique is used in conjunction with a tubular design. Vacuums on the order of $10^{-4}$ torr eliminate both convection and conduction losses. Because evacuated-tube collectors lose less heat to the environment than flat-plate collectors do, they can operate at higher temperatures-up to about $175^{\circ} \mathrm{C}\left(350^{\circ} \mathrm{F}\right)$. Like flat plates, they can collect both direct and diffuse solar radiation and do not require tracking. However, because evacuated tubes can operate at lower insolation levels than flat plates, they can collect more energy on cloudy days. And because of the vacuum, the evacuated tube is much less susceptible to wind-induced losses than other types of collectors. Another advantage is that the selective surface is contained in a vacuum, which ensures greater stability and a longer life for the coating.

The field layout of evacuated-tube collectors is similar to that of flat plates; either roof- or ground-mounting is acceptable. Insulated leaders are usually supplied with these collectors. Because of the fragile nature of the tubes, care should be taken to protect the array from vandalism.

\subsubsection{Components}

There are various types of evacuated tube collectors on the market. One design, shown in Fig. 5-2, employs three concentric glass tubes. Fluid flows 


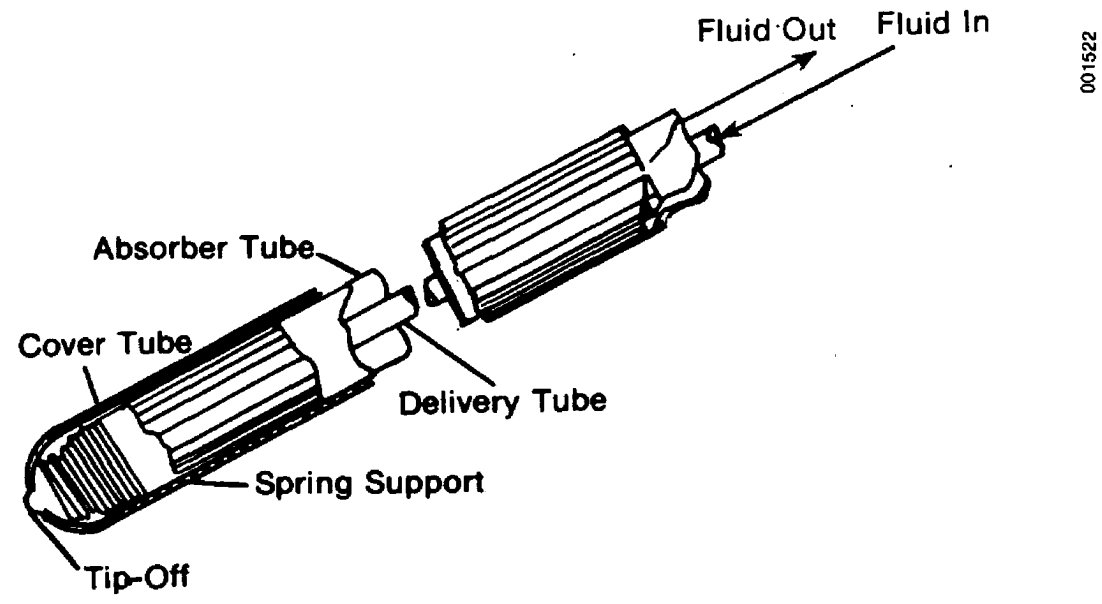

\section{Figure 5-2. Concentric Glass Evacuated-Tube Collector}

into the annular space between the inner and the second tubes and back out the inner tube. The annulus between the second and third (outer) tube is evacuated, and the outside of the second tube contains a selective coating.

Another design (Fig. 5-3) employs only two concentric glass tubes; the space between them is evacuated, and the outer surface of the inner tube contains the absorptive coating. A metal fin conforms to the inside surface of the inner tube; attached to this fin is a metal U-tube, which carries the fluid. The U-tube readily accommodates thermal expansion, and glass breakage will not result in a leak. However, cases of copper oxidation caused by stagnation temperatures have been reported. Although the fin thickness is not highly critical to the performance of the collector, it is recommended that stagnation temperatures be avoided. A V-reflector is shown in Fig. 5-3. Reflectors in other shapes (such as CPC) can be used behind evacuated tubes and provide a small amount of concentration.

The performance of evacuated-tube collectors can be substantially different from that of flat-plates at off-normal incident angles. As the sun angle gets lower, the effective gap between the tubes shrinks, thereby increasing the efficiency of panels without specular reflectors. The type of reflectors used has a large effect on off-normal performance, and although it is not evident from a solar noon efficiency curve, the effects of incident angle can give an evacuated tube an advantage in day-long performance, compared with flat plates. 


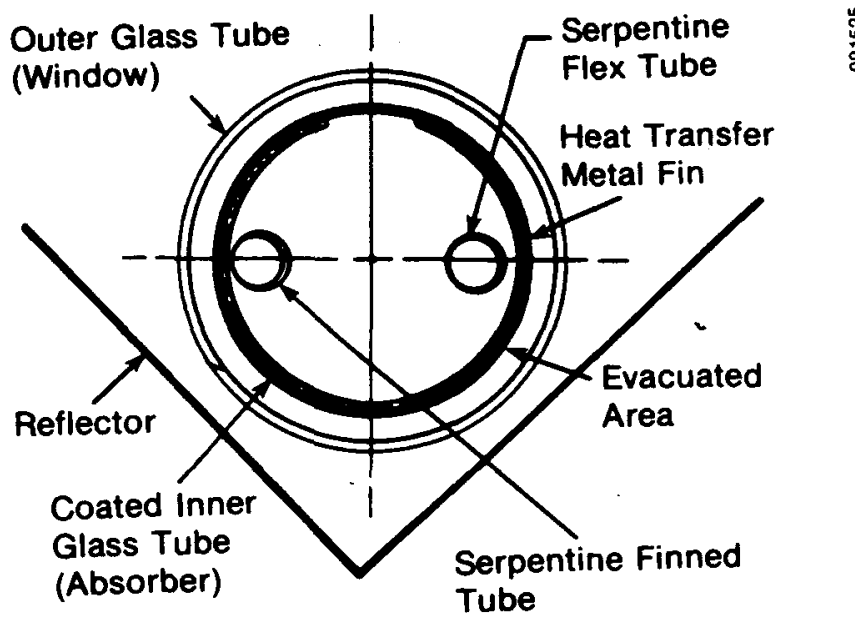

Figure 5-3. Evacuated-Tube Collector Dtilizing Metal Fiow Passage

Whereas flat-plate collectors typically are 1 imited to operating temperatures under about $70^{\circ} \mathrm{C}\left(160^{\circ} \mathrm{F}\right)$, evacuated-tube collectors can perform at temperatures over $120^{\circ} \mathrm{C}\left(250^{\circ} \mathrm{F}\right)$. Evacuated-tube collectors are more fragile, however, and glass breakage has been a problem. In some cases, "shocking" a stagnating collector array with cold water has caused the breakage; in other instances, local thermal gradients during wet stagnation have been the cause. Therefore, evacuated-tube collectors should not be filled when they are hot and should not be allowed to stagnate when they are filled. The latter consideration dictates the need for a heat rejector for nondrainable evacuatedtube collectors. Field experience has shown that borosilicate glass is more durable than soda-1ime glass in these applications.

\subsubsection{Improvements}

To improve the performance of evacuated-tube collectors, work is under way to Increase their optical efficlencies. Higher-absorptance selective coatings are being developed for application to the glass surface. Higher-reflectance materials are also being investigated for the reflectors beneath the evacuated tubes. Manufacturers are also attempting to reduce costs by making longer tubes and developing tube/header arrangements that will also lessen installation costs. 


\subsubsection{Parabolic Trough Collectors}

Parabolic troughs are the best-developed line-focus concentrating collectors and have been used in several IPH field tests. Parabolic troughs can operate at temperatures up to about $300^{\circ} \mathrm{C}\left(570^{\circ} \mathrm{F}\right)$, as the result of optical concentration effected by the parabolic-shaped concentrator. Optical concentration reduces the absorber surface area relative to the collector aperture area and thereby significantly reduces thermal losses. However, this optical concentration requires the collector to rotate to follow the apparent motion of the sun. And because only direct solar radiation is concentrated by a parabolic concentrator, the diffuse component is lost. That loss can be made up by a tracking collector, however, as it intercepts extra direct solar radiation. One noteworthy advantage of parabolic trough collectors is the low pressure drop associated with these systems as fluid passes through a single, straight absorber tube. Also, overnight thermal losses are minimal because of the small amount of fluid in the parabollc trough's receiver (see Fig. 5-4).

Parabolic troughs can be mounted on the ground or on a roof; the receiver tubes are horizontal. Because of the large point and wind loads associated with parabolic trough collectors and the necessity of a rigid support for accurate tracking, roof mounting can require expensive structural modifications. Flammable heat-transfer oils in high-temperature trough applications can also pose a fire hazard to the building. For these reasons, parabolic troughs are usually better sulted for ground mounting.

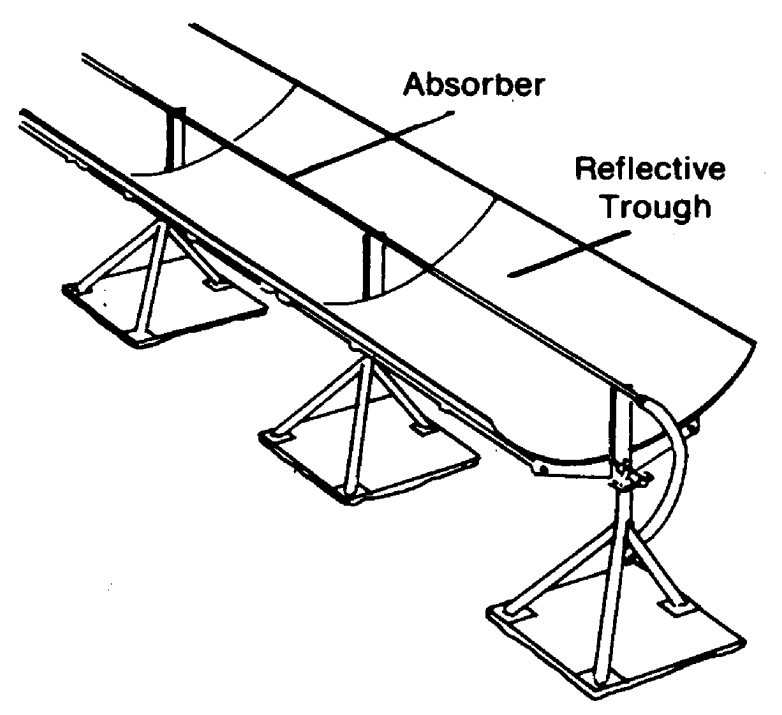

Figure 5-4. Typical Parabolic Trough Collector 


\subsubsection{Components}

The parabolic concentrator reflects direct solar radiation to an absorber tube located at the focus of the parabola. As the absorber tube is heated by solar radiation, a fluid passes within the tube and withdraws the heat. The absorber tube typically has a selective surface. To further reduce thermal losses and protect the surface, the absorber tube is usually surrounded by a cylindrical glass tube that reduces convective heat losses from the absorber tube. The receiver comprises the glass/absorber tube assembly. The parabolic concentrator is covered with a reflective material having a high specular reflectance. Three major types of reflectors have been used: polished aluminum sheets, aluminized plastics, and silvered glass. Polished aluminum has a specular reflectance of 0.75 to 0.80 when new, but it suffers from gradual reflectance loss as the aluminum weathers. Aluminized plastic films currently are the most widely used. The specular reflectance of these films is usually from 0.80 to 0.86 when new. The principal durability problem with aluminized films is the damage that results from scratching of the surface by airborne particles which, in turn, results in loss of specularity.

To maintain the flux concentration along the receiver, the collector must track the sun in one axis. A drive assembly is required for this rotation. One drive assembly is usually sufficient for several collector modules driven together in one row. A drive string is typically 24 to $36 \mathrm{~m}$ (80 to $120 \mathrm{ft}$ ) in length. The drive assembly varies among the different parabolic troughs; some manufacturers use an electric motor and gearbox combination to provide for rotation, and others use hydraulic drive systems.

Typically, several drive strings are connected in series up to about $150 \mathrm{~m}$ in length to comprise a $\Delta T$ string. To permit linear expansion of the receiver, flexible hoses are used to join the drive strings. These flexible hoses also allow for the movement of the absorber tube as the collector tracks during the day, and they are used to join the receivers to the headers at both ends of each row as well. Correct installation of flexible hoses is illustrated in Sec. 9.0, and header size and field plumbing are discussed in more detail in Sec. 7.0 .

The rotation of a parabolic trough is directed by a sun tracker. The sun tracker instructs the drive assembly when and in wich direction to rotate the collector. Typically, one sun tracker is used on each drive string. Two main types of sun trackers are utilized--shadow-band (aperture-based) trackers and flux-line trackers. Shadow-band sun trackers are mounted on the concentrator and face the sun as they are tracking. Two sensors, one on each side of a separating shadow band, detect the position of the sun. When the collector is correctly pointed, the shadow band shades both sensors equally, and both sensor output signals balance. Flux-1ine sun trackers are mounted on the receiver. Sensors are also placed on each side of the receiver to detect the concentrated flux of the receiver. The collector is correctly pointed when both sensors are illuminated equally. When installed correctly, both types of sun trackers have been shown to exhibit excellent tracking accuracies (Gee 1982).

Parabolic troughs are usually installed so that their axes of rotation are orfented either north-south or east-west. However, any orientation is suitable. The directional orientation of the troughs usually corresponds to the 
orientation of the land areas or rooftops on which the troughs are installed. The orientation has an impact on the sun's incident angle upon the tracking collector which, in turn, affects collector performance. Seasonal variations in collector output for north-south oriented troughs can be quite large. Three to four times more energy is delivered daily during average summer months than during average winter months, depending on the latitude and site weather patterns. Seasonal variations in energy delivery are much smaller for an east-west orientation, typically less than $50 \%$, and are caused primarily by seasonal variations in the amount of available insolation. See Sec. 6.0 for more on the impact of seasonal output variations on the annual performance of parabolic troughs.

\subsubsection{Improvements}

A number of improvements to parabolic troughs are under development. Three of the most promising are silvered-glass reflectors, evacuated receivers, and antireflection-coated receivers. Figure 5-5 shows the annual performance benefit that is expected from these improvements as a function of the operating temperature of the trough. The performance shown (Normalized System Performance) is the ratio of the annual performance of an improved trough to the annual performance of an unimproved one (Gee et al. 1980).

Silvered-glass reflectors perform significantly better over all operating temperatures, and they are expected to replace polished aluminum and aluminized acrylic reflectors. Evacuated-tube receivers also enhance performance significantly, especially at higher operating temperatures. Some manufacturers of parabolic troughs are now developing these receivers. Antireflection-coated receivers can also enhance annual performance considerably. Sandia National Laboratories in Albuquerque, N.M., has investigated such coatings for parabolic trough recelvers.

\subsubsection{Other Types of Collectors}

While flat plates, evacuated tubes, and parabolic troughs have been the most widely used collectors in IPH systems, several other types of collectors have also enjoyed some limited IPH field experience. With certain modifications, they could soon be sultable for IPH applications. A brief description of each follows.

\subsubsection{Solar Ponds}

Salt-gradient solar ponds and shallow solar ponds, the two basic types, are among the least expensive kinds of solar collectors.

A salt-gradient solar pond employs a salt concentration gradient to suppress natural convection. Water heated by solar radiation holds more dissolved salt than cooler water. The salty, heated water is also heavier; thus, it remains at the bottom of the solar pond. Sunlight penetrating though the top layers of the pond is absorbed at the bottom and trapped by the nonconvecting gradient layer which acts as an effective thermal insulator against conduction. In practice, a salt-gradient solar pond consists of three layers, or zones: 


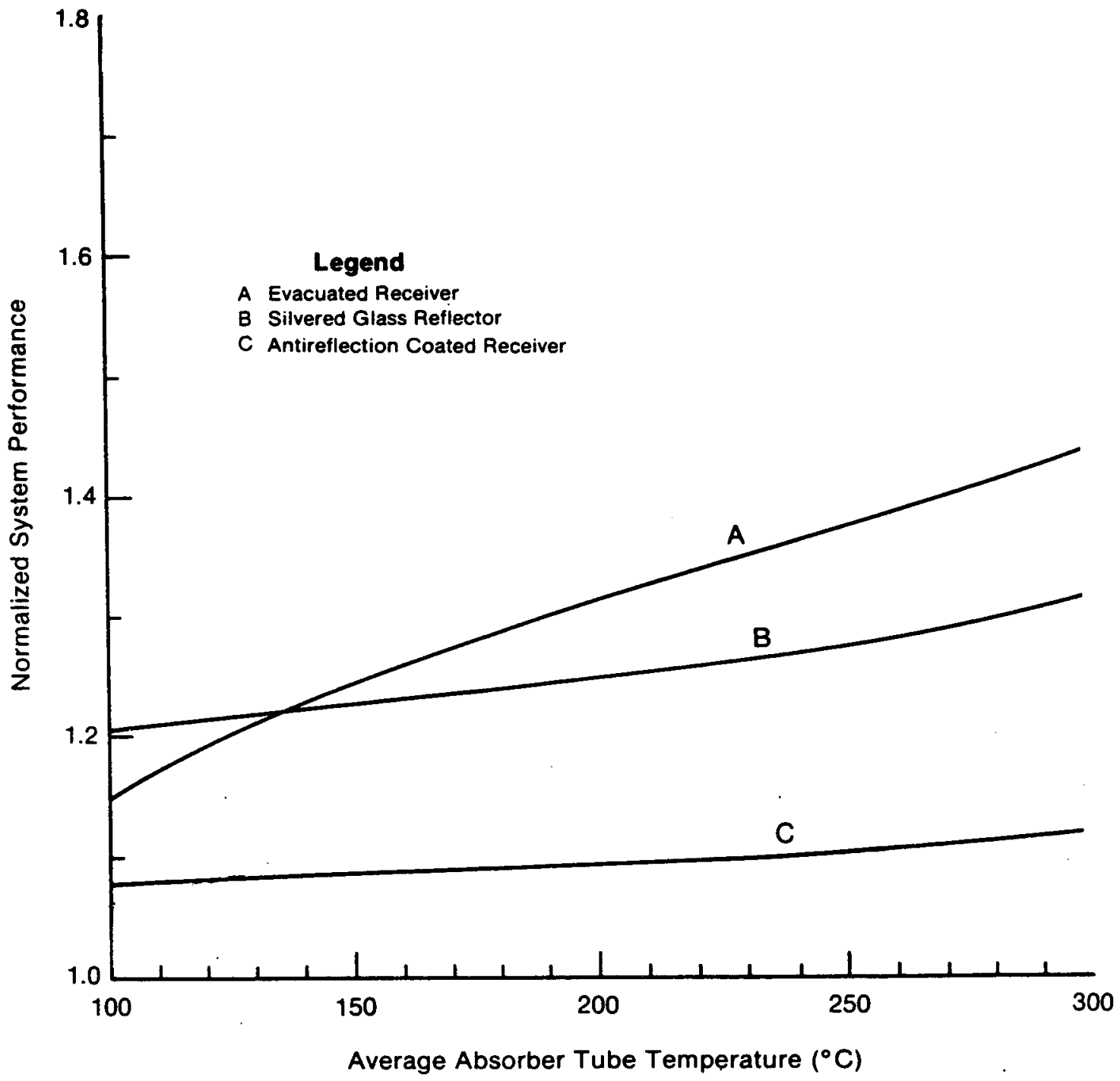

Figure 5-5. System Performance Increases vs. Absorber Temperature for Various Component Improvements of Horizontal Parabolic Troughs (Geometric concentration ratios correspond to optimum performance.) 
(1) a surface convecting zone of low-salinity water, typically 20 to 40 cm thick;

(2) a nonconvecting or salinity-gradient zone beneath the surface zone, in which salt concentration increases with depth, typically 1 to $1.5 \mathrm{~m}$ thick; and

(3) a storage zone at the bottom of the pond of uniformly high salt concentration that stores heat and is typically 1 to $3 \mathrm{~m}$ thick, depending on the system application.

A salt-gradient solar pond can provide heat at temperatures in excess of $90^{\circ} \mathrm{C}$ $\left(194^{\circ} \mathrm{F}\right)$. Such a pond provides built-in thermal storage of such volume that heat can be collected in summer and stored for use during winter. Pioneering work in this field has been done in Israel (Tabor 1981). Edesess et al. (1981) describe a simple procedure for designing salt-gradient solar ponds, and SERI has complled a selected bibliography on the subject (1981). The bibliography also contains a list of references on shallow solar ponds, and a design guide is provided by Casamajor and Parsons (1979).

Shallow solar pond collectors consist of inflatable bags of water supported by insulated footings. When insolation conditions are favorable, water is pumped from an underground storage tank into collectors. The water inside the collectors absorbs solar radiation and can attain temperatures up to $60^{\circ} \mathrm{C}$ $\left(140^{\circ} \mathrm{F}\right)$. The heated water can be used directly in an industrial process or can be drained to a storage tank for later use. At night or during unfavorable insolation conditions, the water in the collectors is drained back to the underground tank.

\subsubsection{Compound Parabolic Concentrators}

A compound parabolic concentrator (CPC) design, shown in Fig. 5-6, consists of two half-parabolic reflectors with an absorber located at the bottom of each. Some designs also utilize a cover plate above the reflectors to keep off dirt and dust. The CPC is a nonimaging concentrator and essentially "funnels" the radiation rather than focuses it. If oriented east-west, a trough with a low concentration ratio requires only seasonal adjustment and collects a considerable amount of diffuse as well as direct radiation. Unlike other concentrators, its reflective surface does not need to be highly specular; thus, it can more readily tolerate dust and degradation. Developed by Roland Winston (1974) of Argonne National Laboratory, this design offers the advantage of a wide acceptance angle at low concentration ratios. A disadvantage is the relatively large amount of reflector area it requires. A comparison of CPC performance with other types of collectors is given by Rabl (1976).

\subsubsection{Fresnel Lens Collectors}

A variety of collectors that utilize a Fresnel lens have been developed. Some track in one axis to form a line focus; others track in two axes to form a point focus. A line-focus Fresnel lens is shown in Fig. 5-7. Direct solar radiation is refracted by the Fresnel lens (consisting of many small refractive surfaces) onto an absorber tube. Although this refractive concentration 


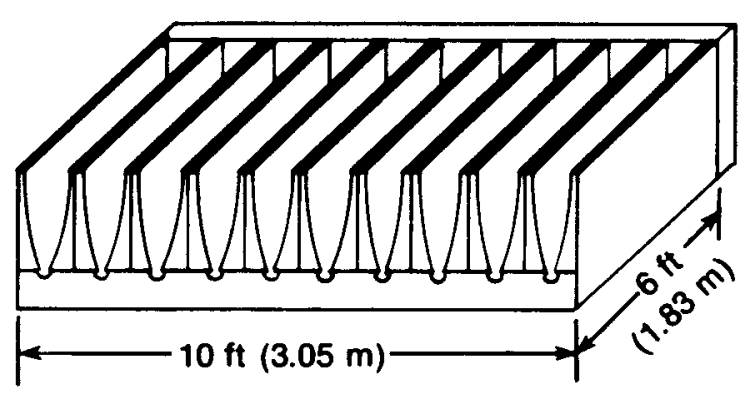

윰

Figure 5-6. A CPC Collector Module

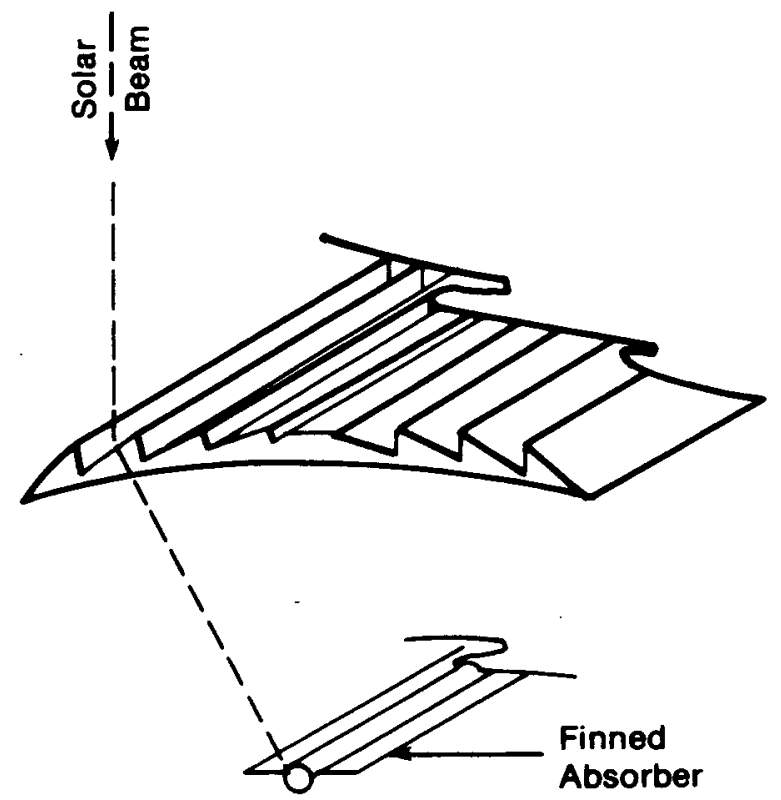

Figure 5-7. Concentration With a Fresnel Iens 
can be done with a convex lens, a Fresnel lens is utilized because it is cheaper, lighter, and absorbs less radiant energy. Line-focus Fresnel lens collectors can operate to about $290^{\circ} \mathrm{C}\left(550^{\circ} \mathrm{F}\right)$. Point-focus Fresnel lens collectors can operate at temperatures in excess of $600^{\circ} \mathrm{C}\left(1100^{\circ} \mathrm{F}\right)$.

\subsubsection{Fultiple-Reflector Collectors}

Multiple-reflector collectors are usually associated with line-focus optics. Some designs incorporate several long, narrow reflectors that rotate to the correct position to reflect sunlight to a stationary receiver. Other designs employ movable absorbers and stationary reflectors. An advantage of the movable reflector/stationary receiver designs is that the reflectors can be rotated away from the sky (stowed) when they are not collecting energy. This protects them from dirt and dust accumulation as well as from hail damage. All multiple-reflector collectors suffer somewhat in efficiency as lost sunlight falls between reflectors. Also, because of the number of reflectors, the drive mechanism tends to be more complex than that of a parabolic trough.

\subsubsection{Parabolic Dish Collectors}

The concentrators for parabolic dish collectors are shaped in paraboloids of revolution (dish-shaped). This permits a high concentration of direct solar radiation to a point at the focus of the parabola. Good thermal efficiency at high temperatures can be achieved because of the small receiver area, compared with the aperture area, of the concentrator. Temperatures of up to $1100^{\circ} \mathrm{C}$ $\left(2000^{\circ} \mathrm{F}\right)$ can be supplied. A disadvantage of these collectors is that they require two-axis tracking (azimuth and elevation) of the sun. Also, they do not use land space as efficiently as other kinds of collectors, and the field piping layouts necessary can cause relatively larger thermal losses.

\subsubsection{Central Receivers}

By mounting a recelver on a tower surrounded by a field of carefully aimed individual reflectors (hellostats), very high energy concentrations and, thus, high temperatures can be achieved. Because all of the energy is transmitted to one central receiver in the form of light, piping losses associated with distributed receivers are eliminated. Drawbacks include tower support costs, two-axis tracking requirements, highly accurate (and costly) hellostat optics, and exclusive use of direct insolation. Central receivers are still under development, and most of the development to date has been applied to electric power plants.

\subsection{INSTANTANEOUS PERFORMANCE OF COLLECTORS}

The instantaneous performance of a collector is normally expressed in terms of its efficiency. Instantaneous efficiency is important because it defines how much of the solar energy available to a collector is actually converted to useful thermal energy. However, as a measure of performance it is limited in its usefulness. For example, it cannot be used, by itself, to measure the annual performance of the collector and, therefore, should not be used as a 
means of quantitatively comparing the performance of different collectors. A method for using the instantaneous performance parameters of a collector along with site and process load characteristics to predict annual performance is described in Sec. 5.3.1. This section develops the equation that defines a collector's instantaneous efficiency and describes how collectors are tested for efficiency.

\subsubsection{Analysis}

An analysis of collector performance begins with a simple steady-state instantaneous energy balance of a solar collector:

energy collected $=$ energy absorbed - energy lost to surroundings, or

$$
\dot{q}_{c}=I_{a} n_{0}-U_{L}\left(T_{p}-T_{a}\right) \text {, }
$$

where

$$
\begin{aligned}
& \dot{\mathrm{q}}_{\mathrm{c}}=\text { energy collection rate per unit collector aperture area }\left(\mathrm{W} / \mathrm{m}^{2}\right) \\
& \mathrm{I}_{\mathrm{a}}=\text { available irradiance on collector plane }\left(\mathrm{W} / \mathrm{m}^{2}\right) \\
& \eta_{\mathrm{O}}=\text { optical efficiency of collector ( } \mathrm{\tau} \alpha \text { for a flat plate) } \\
& \mathrm{U}_{\mathrm{L}}=\text { overall collector heat loss coefficient }\left(\mathrm{W} / \mathrm{m}^{2} \mathrm{~K}^{-1}\right) \\
& \mathrm{T}_{\mathrm{p}}=\text { average absorber plate surface temperature }\left({ }^{\circ} \mathrm{C}\right) \\
& \mathrm{T}_{\mathrm{a}}=\text { outside ambient air temperature }\left({ }^{\circ} \mathrm{C}\right) .
\end{aligned}
$$

Usually, however, the average absorber surface temperature is not known. To express energy collection in terms of the more readily measured collector inlet fluid temperature, the collector heat removal efficiency factor $F_{R}$ is introduced as

$$
\mathrm{F}_{\mathrm{R}}=\frac{\text { energy collected }}{\text { energy collected if entire plate were at inlet fluid temperature }} \text {. }
$$

Assuming that $U_{L}$ is a constant, $F_{R}$ can be expressed as follows (Duffie and Beckman 1974):

$$
F_{R}=\frac{\dot{\mathrm{m}}_{\mathrm{c}^{\mathrm{c}} \mathrm{p}}}{\mathrm{U}_{\mathrm{L}}}\left[1-\exp \left(-\mathrm{F}^{\prime} \mathrm{U}_{\mathrm{L}} / \dot{\mathrm{m}}_{\mathrm{C}^{\mathrm{c}} \mathrm{p}}\right)\right]
$$

where

$$
\begin{aligned}
& \mathrm{F}^{\prime}=\frac{\text { heat transfer resistance from absorber to ambient air }}{\text { heat transfer resistance from fluid to ambient air }} \\
& \dot{\mathrm{m}}_{\mathrm{c}}=\text { collector field flow rate per unit collector area }\left(\mathrm{kg} \mathrm{s}^{-1} \mathrm{~m}^{-2}\right) \text {. }
\end{aligned}
$$


Now, the collector energy balance can be expressed as

$$
\dot{q}_{c}=F_{R}\left[I_{a} \eta_{0}-U_{L}\left(T_{f, i}-T_{a}\right)\right] \text {, }
$$

where $\mathrm{T}_{\mathrm{f}, 1}=$ inlet fluid temperature $\left({ }^{\circ} \mathrm{C}\right)$.

A collector's instantaneous efficiency is defined as

$$
n_{c}=\frac{\text { energy collected }}{\text { available irradiation }}=\frac{\dot{q}_{c}}{I_{a}} \text {, }
$$

so, we have

$$
n_{c}=F_{R}\left(n_{0}-U_{L} \frac{T_{f, i}-T_{a}}{I_{a}}\right) .
$$

All the equations above apply to all types of collectors. However, the quantity used for $I_{a}$ varies among them. For flat-plate and evacuated-tube collectors, the global irradiance on the collector plane, as measured by a pyranotreter, should be used. This includes both direct and diffuse components of solar radiation. Parabolic troughs are largely insensitive to diffuse irradiance because of their higher concentration ratios, so the available radiation is the direct irradiance incident upon the collector plane.

This first-order form of the efficiency equation is quite accurate for most types of collectors. However, for collectors that can operate at higher temperatures, such as parabolic troughs, the variation of $\mathrm{U}_{\mathrm{I}}$ with temperature can become significant, and a second-order efficiency equation is sometimes used. The correct form of such an efficiency fit (Tabor 1980) is

$$
\eta_{c}=F_{R} \eta_{0}-U_{L, 1} \frac{T_{f, i}-T_{a}}{I_{a}}-U_{L, 2} \frac{\left(T_{f, i}-T_{a}\right)^{2}}{I_{a}}
$$

To plot a parabolic trough's efficiency on the same graph as a flat plate (i.e., versus $\Delta T / I$ ), the equation 1 s often given as

$$
n=n_{c}\left(\frac{\Delta T}{I}\right)
$$

thus giving us $(\Delta T / I)^{2}$, the second-order term. This is accurate only for one value of $I$.

Figure 5-8 presents typical solar-noon instantaneous efficiency curves for collectors used in IPH applications. Two flat-plate curves are shown: one with a flat black absorber and one glazing, and the other with a black chrome selective surface and two glazings. Note that for large values of the parameter $\left(T_{f, i}-T_{a}\right) / I_{a}$ (corresponding to the collector supplying a heated fluid at a significantly higher temperature than ambient), the two-cover collector has a higher efficiency than the single-cover collector. This is because the 


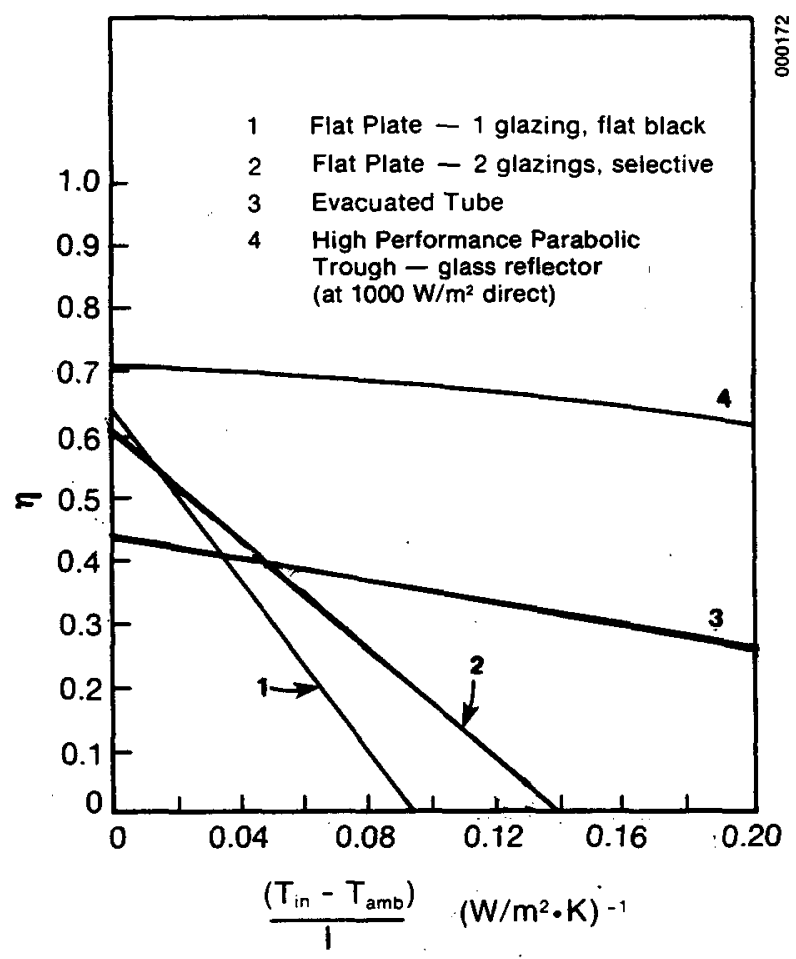

Figure 5-8. Typical Instantaneous Efficiency Curves for Collectors Used in IPH Applications

second cover and selective surface reduce heat loss, resulting in a smaller $U_{L}$ and a flatter slope of the curve. At small values of $\left(T_{f, i}-T_{a}\right) / I_{a}$, however, a single-cover collector outperforms a two-cover model, because the singlecover collector has a higher transmittance and thus a higher optical efficlency, which is, in turn, reflected in a higher intercept.

Evacuated-tube efficiency exceeds flat-plate efficiencies at higher values of $\left(T_{f, i}-T_{a}\right) / I_{a}$. This is because of the reduced heat losses from evacuated tubes compared with flat plates. Because the absorber area per unit aperture area is smaller, and convective heat transfer between the absorber and the glass envelope is eliminated, the $U_{L}$ value is significantly reduced. For this reason, evacuated-tube collectors are used for applications where higher temperatures are involved-generally between $80^{\circ} \mathrm{C}$ and $150^{\circ} \mathrm{C}$. Parabolic troughs usually exhibit even smaller heat losses because of their increased concentration and the resulting decrease in absorber area per unit aperture area. In fact, the trough's efficiency is higher than that of other types of collectors at all temperatures. Of course, trough efficiency is based only on direct radiation; the trough cannot collect the diffuse radiation available to flat plates and evacuated tubes.

Variations in optical efficiency should also be accounted for to predict collector performance closely. Optical efficiency can vary with the angle of incidence of solar radiation on the collector's aperture plane. Correction factors (incident-angle modifiers) account for this variation and are generated with standard collector performance tests. Examples of incident-angle 
modifers for flat-plate, evacuated-tube, and parabolic-trough collectors are shown in Fig. 5-9. For most flat-plate collectors, the incident-angle modifier can be plotted as a straight line against the quantity [(⿻os $\left.\theta)^{-1}-1\right]$. The equation of such a line is

$$
k_{\alpha \tau}=1-b_{0}\left[(\cos \theta)^{-1}-1\right],
$$

where

$$
\begin{aligned}
& \mathrm{b}_{\mathrm{o}}=\mathrm{a} \text { constant dependent on the collector's optical properties } \\
& \theta=\text { angle of incidence of direct solar irradiation. }
\end{aligned}
$$

\subsubsection{Testing}

The generally accepted method of testing the efficiency of a solar collector employs an open system in which the temperature rise across the collector is measured under steady-state conditions. Along with the inlet and outlet collector fluid temperatures, the fluid mass flow rate and instantaneous irradiance are measured as well. Collector efficlency is then defined as

$$
n_{c}=\frac{\text { useful energy collected }}{\text { available irradiation on collector }}=\frac{\dot{M} c_{p}\left(T_{f, e}-T_{f, i}\right)}{A_{c} I_{a}} \text {, }
$$

where

$$
\begin{aligned}
\dot{M} & =\text { mass flow rate of collector fluid } \\
c_{p} & =\text { heat capacity of fluid } \\
T_{f, e} & =\text { fluid exit temperature } \\
T_{f, I} & =\text { fluid inlet temperature } \\
A_{c} & =\text { gross collector area } \\
I_{a} & =\text { available irradiation on collector. }
\end{aligned}
$$

Based on a procedure developed by the National Bureau of Standards, the American Society of Heating, Refrigerating, and Air Conditioning Engineers (ASHRAE) adopted Standard 93-77, "Methods of Testing to Determine the Thermal Performance of Solar Collectors." It is most applicable to nontracking collectors like flat plates and evacuated tubes. Three basic tests are called for, and these determine the following:

- time constant of collector

- instantaneous collector efficiency

- incident-angle modifier of collector. 


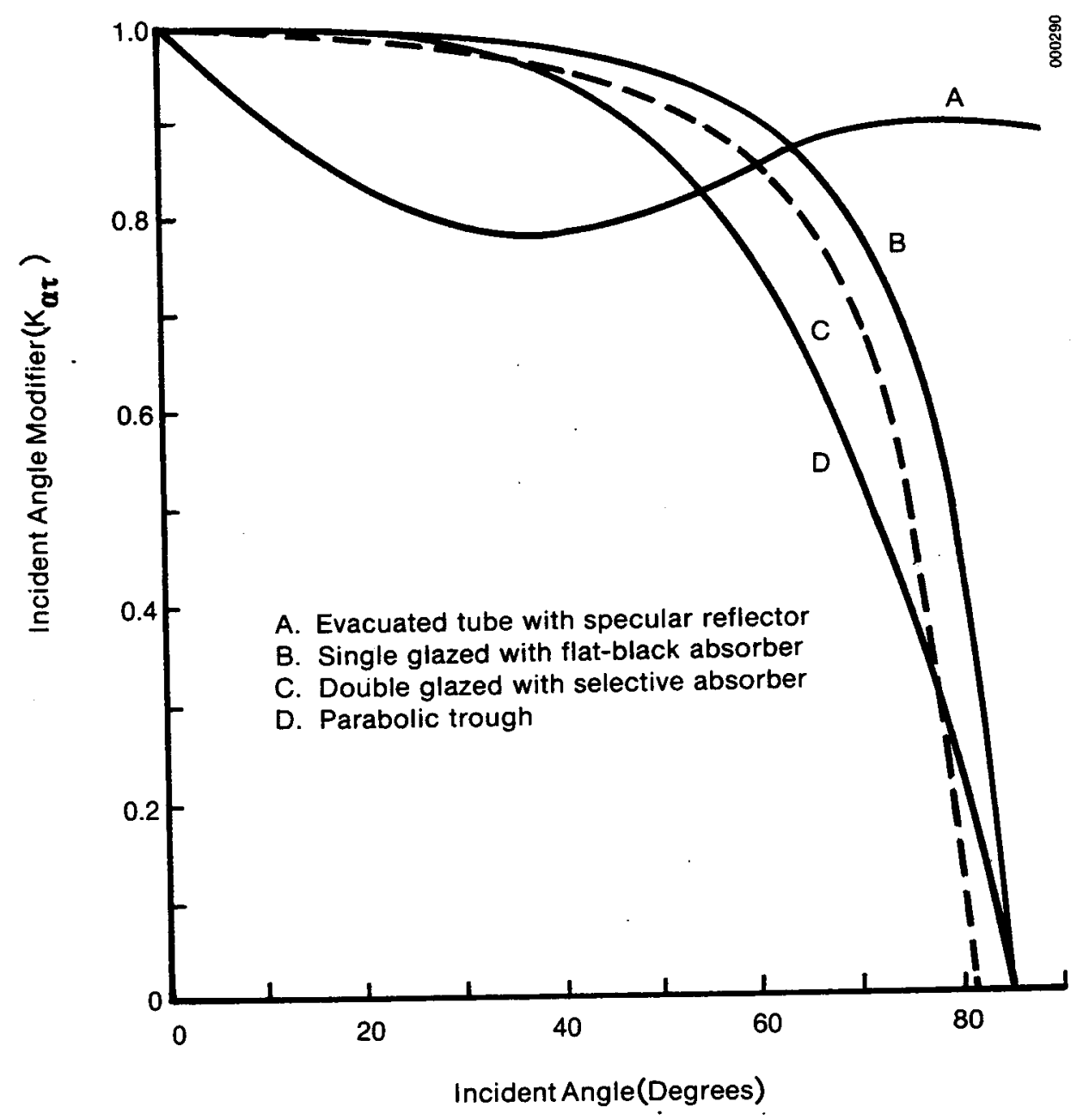

Figure 5-9. Typical Incident-Angle Modifiers for collectors Used in IPH Applications 
The collector $t$ ime constant $\tau_{c}$ is the time required for the difference between fluid inlet and outlet temperatures to drop to $36.8 \%$ of initial value after a step decrease in insolation or inlet fluid temperature. In a typical test, the incident solar flux is abruptly reduced from a steady-state value of at least $790 \mathrm{~W} / \mathrm{m}^{2} .\left(250 \mathrm{Btu} / \mathrm{h}-\mathrm{ft}^{2}\right)$ to zero. At time $t=\tau_{\mathrm{c}}$ after such a step change, with inlet collector temperature $t_{f, i}$ held constant, we have

$$
\frac{t_{f, e}\left(\tau_{c}\right)-t_{f, i}}{t_{f, e}(0)-t_{f, i}}=\frac{1}{e}=0.368
$$

The smaller the time constant, the more rapidly a collector will respond to short periods of insolation.

Over a time period $d T$, efficiency is determined to be

$$
\eta_{c}=\frac{\dot{M} c_{p}}{A_{c}} \frac{\int_{t_{1}}^{t_{2}}\left(T_{f, e}-T_{f, i}\right) d T}{\int_{T_{1} I_{a} d T}^{T_{2}}}
$$

For each data point, the efficiency is the average over a period of 5 minutes or $\tau_{c}$ (whichever is larger), during which insolation is steady and flow is maintained at $14.71 \mathrm{~b} / \mathrm{h} \mathrm{ft}^{2}\left(0.02 \mathrm{~kg} \mathrm{~s}^{-1} \mathrm{~m}^{-2}\right)$ for a liquid collector and both 1.96 and $6.0 \mathrm{cfm} / \mathrm{ft}^{2}\left(0.01\right.$ and $\left.0.03 \mathrm{~m}^{3} \mathrm{~s}^{-1} \mathrm{~m}^{-2}\right)$ for an air collector. (The efficiency of an air collector is more sensitive to flow rate than that of a 1iquid collector.) Efficiency is measured for four different values of $\left(T_{f, i}-T_{a}\right): 10 \%, 30 \%, 50 \%$, and $70 \%$ of the difference between stagnation temperáture and ambient temperature at the given conditions. For each case, four data points are taken symmetrically about solar noon. The resulting 16 points are plotted on a graph of $\eta$ versus $\left(T_{f, i}-T_{a}\right) / I_{a}$ and, for flat-plate collectors, a straight line is fitted using a least-squares analysis.

These efficiency tests should be conducted close to solar noon with the collector positioned normal to the sun's direct rays. If the collector is left in this position, its efficiency will drop during morning and late afternoon hours because of the decreasing value of $I$ and consequent increase of $\Delta T / I_{a}$. However, the efficiency curve determined above is valid only for near-normal incidence. At other angles, the optical efficiency will be less, thereby moving the whole efficiency curve downward. The incident-angle modifier quantifies this change in optical efficiency.

Two efficiency tests are performed on the collector for each of four different incident angles: $0^{\circ}$ (normal), $30^{\circ}, 45^{\circ}$, and $60^{\circ}$. In each case, the inlet temperature is controlled to within $\pm 1^{\circ} \mathrm{C}\left( \pm 1.8^{\circ} \mathrm{F}\right)$ of the ambient. Then, we have

$$
\begin{aligned}
n_{c} & =F_{R} n_{o}-F_{R} U_{L} \frac{T_{f, 1}-T_{a}}{I_{a}} \\
& =\frac{\dot{M} c_{p}\left(T_{f, e}-T_{f, i}\right)}{A_{c} I_{a}},
\end{aligned}
$$


since $t_{f, i}=t_{a}, \eta_{c}=F_{R} n_{0}$. The incident angle modified $k_{\alpha \tau}$ is defined as:

$$
K_{\alpha \tau} \equiv \frac{n_{0}}{\left(n_{0}\right)_{n}}
$$

where $\left(n_{0}\right)_{n}$ is $n_{0}$ for the normal incidence case.

Since $n_{c}=F_{R} n_{0}$ for these tests, we have $n_{0}=n_{c} / F_{R}$, and

$$
K_{\alpha \tau}=\frac{n_{c}}{F_{R}\left(n_{0}\right)_{n}}
$$

The $\eta_{c}$ values are determined for each angle, and $F_{R}\left(\eta_{0}\right)_{n}$ is the efficiency value only for the $0^{\circ}$ case. The $R_{\alpha \tau}$ values allow one to take the normal incidence efficiency curve and determine the appropriate curve for off-normal incident solar radiation.

The ASHRAE 93-77 test standard was written for nonconcentrating collectors; it does not uniformly apply to concentrating collectors. A test standard for concentrating collectors has been developed by SERI (ASTM Document No. 127) and is currently under review and ballot by an ASTM committee. However, considerable efficiency testing of parabolic troughs has been done. Sandia National Laboratories in Albuquerque has performed many efficiency tests on parabolic troughs [for example, Harrison (1980)] . Both instantaneous efficiency and incident-angle modifier tests are performed. Efficiency data are reported in the form of

$$
n_{c}=F^{\prime}\left[\eta_{o}-a_{1} \frac{T_{f}-T_{a}}{I_{a}}-a_{2}\left(\frac{T_{f}-T_{a}}{I_{a}}\right)^{2}\right],
$$

where $a_{1}$ and $a_{2}$ are constants fit to the data points, and $T_{f}$ is the average fluid temperature.

As we mentioned, this form of an efficiency fit is accurate only for one value of irradiance, $I_{a}$. To convert this form of efficiency fit to the preferred form of

$$
\eta_{c}=F_{R}\left[\eta_{o}-U_{L, 1} \frac{T_{f, 1}-T_{a}}{I_{a}}-U_{L, 2} \frac{\left(T_{f, 1}-T_{a}\right)^{2}}{I_{a}}\right],
$$

it is necessary to divide out an $I_{a}$ from the second-order term of the Sandia equation; Since collector testing is performed on clear days, an $I_{a}$ value of $1000 \mathrm{~W} / \mathrm{m}^{2}$ is recommended. We also assume for these tests that $F_{R} \approx F^{\prime}$, because in the Sandia tests, the average fluid temperature was only a few degrees hotter than the inlet fluid temperature. With these assumptions, the values of the first- and second-order $U_{L}$ terms are calculated as 


$$
\begin{aligned}
\mathrm{U}_{\mathrm{L}, 1} & =\mathrm{a}_{1} \\
\mathrm{U}_{\mathrm{L}, 2} & =\mathrm{a}_{2} / 1000 .
\end{aligned}
$$

The design procedure developed in this handbook is based on a single overall collector heat loss coefficient, $\mathrm{U}_{\mathrm{L}}$.

For a given $\Delta T=T_{f, i}-T_{a}, U_{L}$ can be calculated as

$$
\mathrm{U}_{\mathrm{L}}=\mathrm{U}_{\mathrm{L}, 1}+\mathrm{U}_{\mathrm{L}, 2} \Delta \mathrm{T}
$$

or, using Sandia's constants,

$$
\mathrm{U}_{\mathrm{L}}=\mathrm{a}_{1}+\mathrm{a}_{2} / 1000(\Delta \mathrm{T})
$$

Test results should be obtained for any collector being considered for a solar IPH system. This information can of ten be obtained from collector manufacturers. In that case, it is important that the testing was done according to the standard test procedure by a reputable collector test facility. Also, make sure that the test data pertain to the particular collector model you are Interested in. A great deal of performance test data on solar collectors have also been generated by national laboratories and test programs funded by the Department of Energy (see Harrison 1980; Mather 1980; and Sun Designs 1982).

\subsection{COLLECTOR SELECTION PROCEDURE}

The collector selection procedure is usually a two-step process. First, the appropriate type of collector is determined; then, a particular brand is chosen. The collector type is ordinarily selected during the conceptual design phase, and the particular brand is often determined in the preliminary design stage. Choosing the collector type at an early stage accelerates the rest of the system design process. The algorithm by which a collector type is selected requires a minimum number of inputs at this early stage.

In this section, we present a simple method for making a judgment on the appropriate type of collector. After various types are compared on performance and cost bases, one collector often emerges as a clear best choice. If, however, two types seem equally appropriate, it is best to defer the final selection until more information is avallable. Sections 6.0 and 10.0 explain the more detailed evaluation procedure.

Selecting the best collector for a particular IPH application involves weighing two quantities: solar system performance and solar system cost. The most meaningful measure of solar system performance is the average annual energy delivery of the system. A way of estimating it is described in Sec. 5.3.1. The second quantity, total system cost, must include direct costs such as collector hardware, piping, insulation, heat exchangers, controls, and pumps, as well as indirect costs such as installation, maintenance, and design fees. Guidelines for estimating their contributions are contained in Sec. 10.0 . 


\subsubsection{A Preliminary Comparison of collector Performance}

Since the type of collector is preferably chosen early in the design process, that decision must be based on quite 1imited data. Fortunately, the relative performance of flat-plate, evacuated-tube, and parabolic-trough collector systems is governed largely by only a few variables: site characteristics, collector characteristics, and process load temperatures. Detalled information such as system configuration, storage tank size, collector field layout, heat exchanger effectiveness, and piping network geometry are not required at this stage because, if the system is well designed, their effects on performance are small (or at least nearly equal for all three types). Thus, the dominant performance quantities are as follows:

- the average collector operating temperature

- the performance characteristics of each collector type, described simply by an optical efficiency and an overall heat-loss coefficient

- the average annual direct normal and total horizontal irradiance at the proposed IPH site.

The average collector operating temperature is not precisely known. Section 6.0 describes how to account closely for this average temperature based on the process temperatures, load profile, load flow rate, system configuration, and storage size. However, this much detall is usually not necessary at the conceptual stage. Instead, we recommended a simpler approach, as follows.

Typically, the average collector operating temperature of a hot water or hot air system is higher than the load return temperature but lower than the process load temperature. In low solar fraction systems, the average collector temperature is nearer the load return temperature. In systems with higher solar fractions, more collector area is needed, and the average collector temperature increases. For very large solar fractions, the average collector operating temperature may actually exceed that of the process load, but this situation is not likely to be economically justified. Therefore, the average collector operating temperature of a hot water or air system is likely to be bounded by the load and load return temperatures. The approach here is to consider the relative performance of the principal types of collectors at both temperatures. The differences in system performance and cost are often substantial enough that the same collector type will be the preferred choice at both temperatures. If, however, one collector type is preferred at the load return temperature and a different type is preferred at the load temperature, it is best to defer the final selection until more detailed information is available.

In steam systems, the average collector operating temperature will be somewhat above the steam saturation temperature. A reasonable approximation of the average collector operating temperature is $20^{\circ} \mathrm{C}$ above the saturation temperature of the process steam.

The performance characteristics of the different types of collectors are the next important parameters to consider. Collector optical efficiencies and heat-loss coefficients are obtained from standard collector test procedures and are readily available from manufacturers. Further, the ranges of optical 
efficiency and U-value are confined to relatively narrow bands for each collector type by their geometries and according to the materials used in them. Typical values are shown in Table 5-1.

The average annual daytime irradiance I (based on 4380 annual daylight hours or an average of 12 hours per day per year) at the proposed IPH site can be estimated from Figs. 5-10 and 5-11, yearly insolation maps for average total horizontal daytime irradiance $I_{h}$ and average daytime direct normal irradiance $\overline{\mathrm{I}}_{\mathrm{b}}$. These contour maps differ from Figs. 3-1 and 3-2 in that they denote average yearly irradiance and not average daily irradiation. The total horizontal map should be used for flat-plate and evacuated-tube collectors, and the direct normal map should be used for parabolic troughs. Of course, if better long-term irradiance data are available for the proposed site, they should be used instead. The industrial owner must supply only the average process load return temperature, the number of hours and days the process operates, and an estimate of collector field size or solar fraction.

With this information, Fig. 5-12 can help to provide annual performance estimates of the principal types of IPH collectors. The figure permits a graphical determination of $\dot{q}_{c}$, the average annual energy collection rate of an unshaded collector operating with a constant collector inlet temperature. This figure was derived from hundreds of detalled hour-by-hour computer simulations (as described in Appendix E) and essentially enables us to determine annual collector performance from instantaneous efficiency data. The ordinate of the graph is simply $\dot{q}_{c}$ divided by the product of collector optical efficiency and annual average daytime irradiance for the particular site. The ordinate can be determined once the abscissa, a simple grouping of known quantities, is defined. The abscissa here is the ratio of the collector's critical intensity to the average intensity of the sun's radiation, the intensity ratio (see Sec, 6.1). The critical intensity is that irradiance at which heat lost from the collector just balances the heat gained. A collector's critical intensity is calculated as follows:

$$
\text { critical intensity }=\frac{\mathrm{U}_{\mathrm{L}}\left(\mathrm{T}_{\text {co1lector }}-\mathrm{T}_{\text {ambient }}\right)}{n_{\mathrm{O}}} \text {. }
$$

Use Fig. 5-10 to define the annual average daytime irradiance level $\bar{I}$ for flat plates and evacuated tubes and Fig. 5-11 for parabolic troughs. After defining the abscissa, read the ordinate from the graph for the latitude of

Table 5-1. Typical Ranges of Liquid Collector Performance Characteristics

\begin{tabular}{lcc}
\hline Collector Type & $\begin{array}{c}\text { Effective Optical } \\
\text { Efficiency }\end{array}$ & $\begin{array}{c}\mathrm{U}-\mathrm{va} \text { lue } \\
\left(\mathrm{W} / \mathrm{m}^{2}-\mathrm{K}\right)\end{array}$ \\
\hline Flat-plate & & \\
single glazing & $0.65-0.8$ & $2.6-4.4$ \\
double glazing & $0.6-0.7$ & $1.9-2.8$ \\
Evacuated tube & $0.5-0.7$ & $0.5-1.0$ \\
Parabolic trough & $0.65-0.8$ & $0.25-0.75$ \\
\hline
\end{tabular}




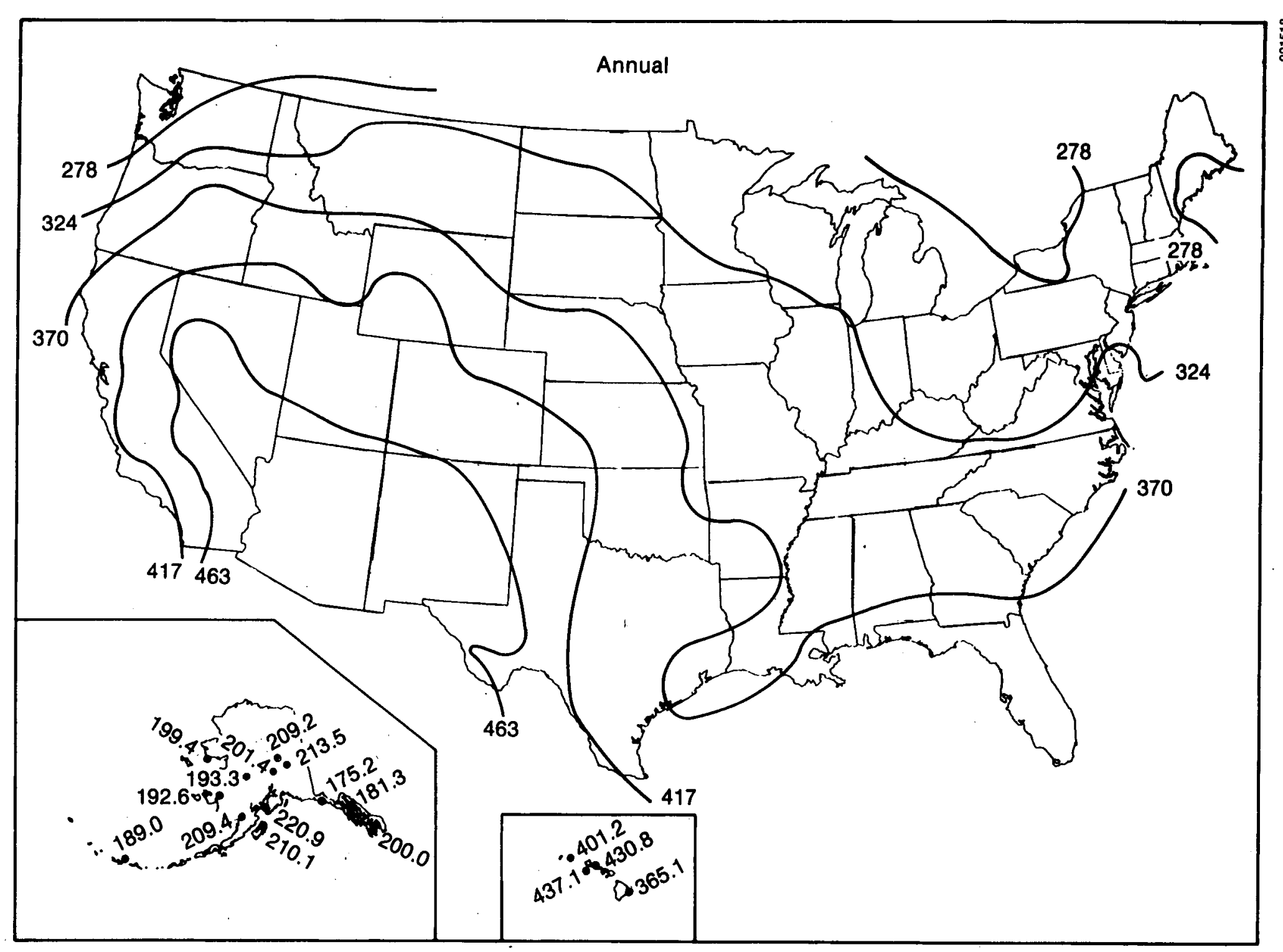

Figure 5-10. Average Global Solar Irradiance During Daylight Hours on a Horizontal Surface $\left(w / m^{2}\right)$ 


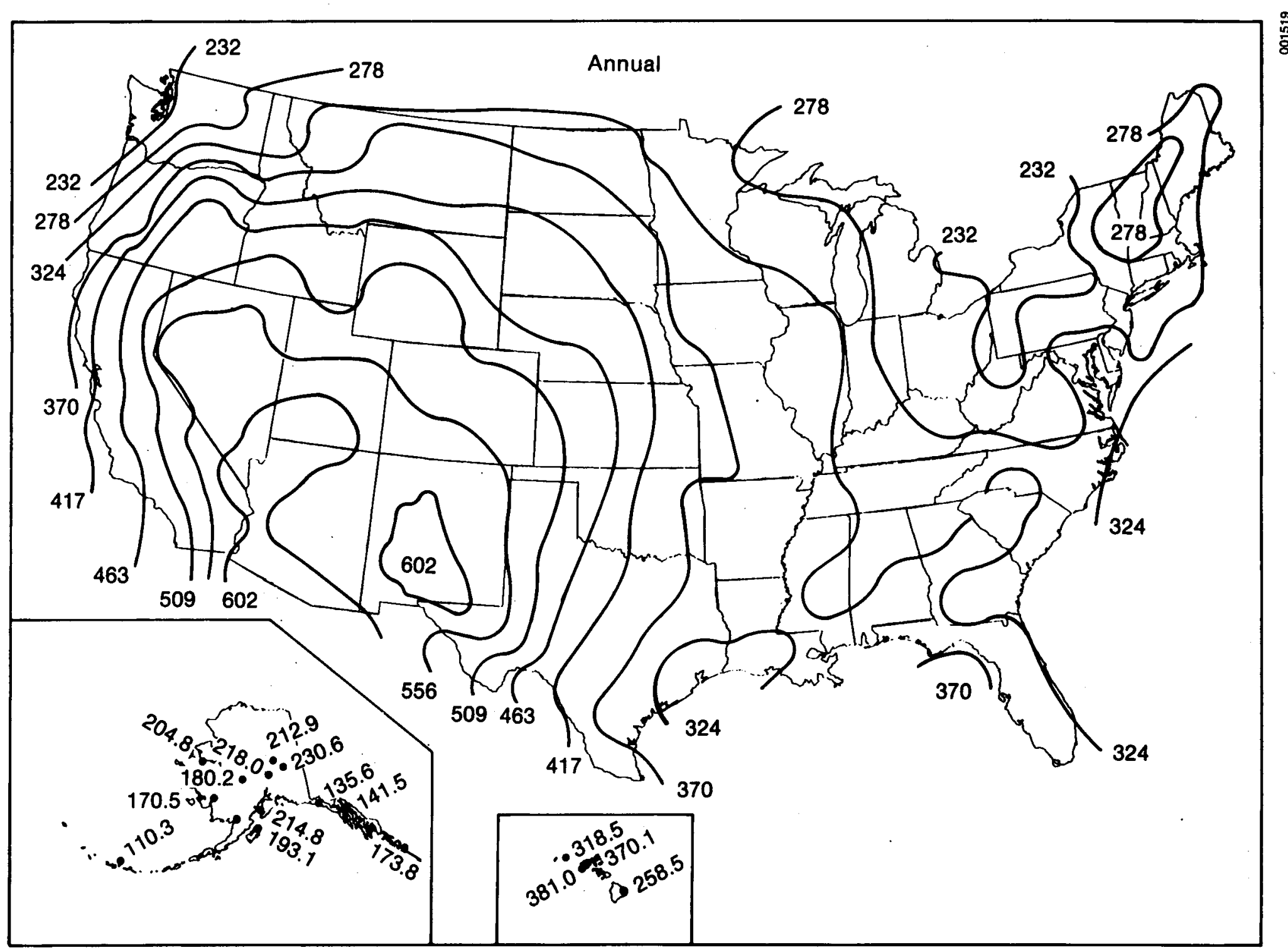

Figure 5-11. Average Direct Normal Solar Irradiance During Daylight Hours (W/m ${ }^{2}$ ) 


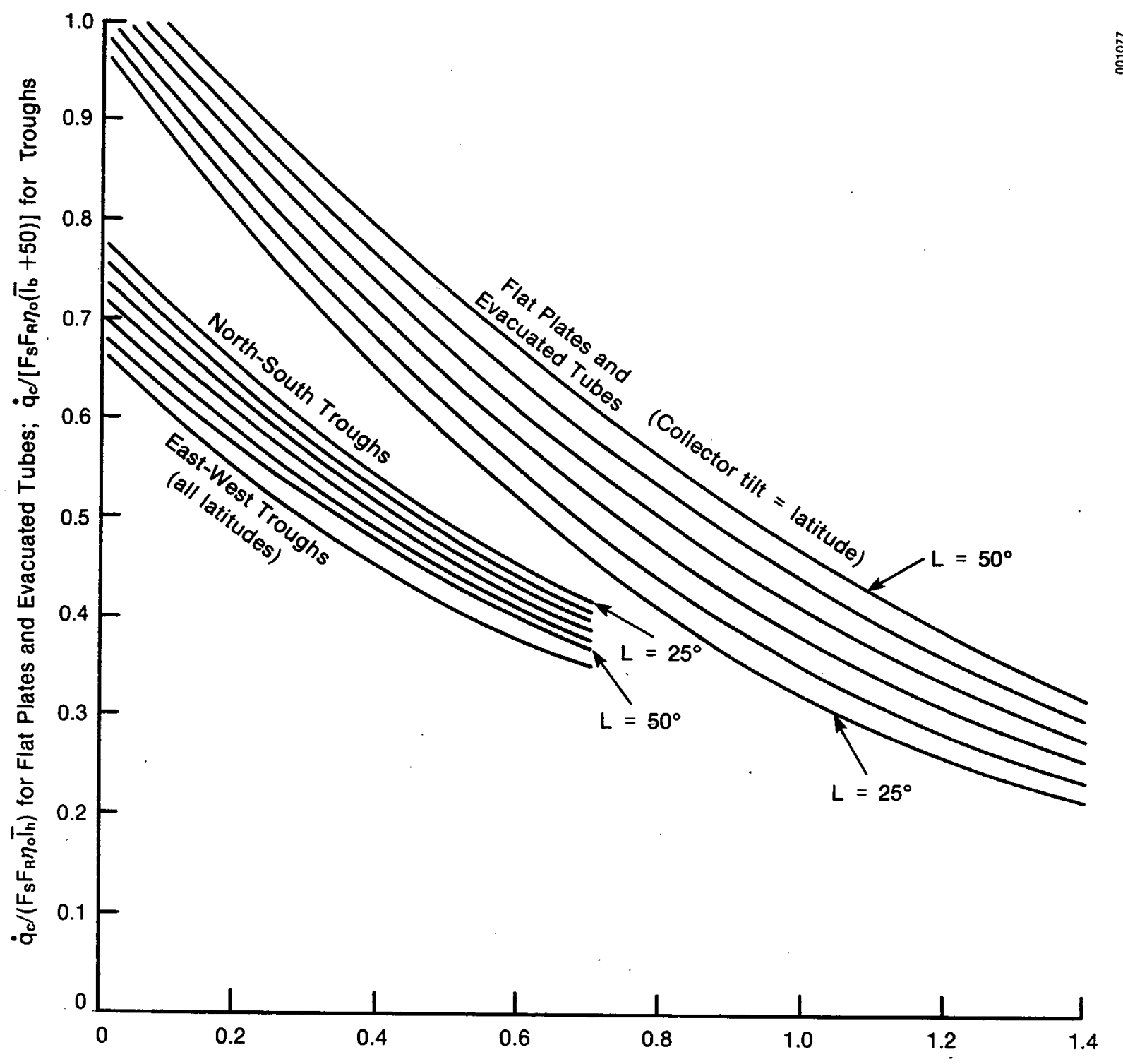

$F_{R} U_{L}\left(T_{\text {in }}-T_{B}\right) /\left(F_{R} \eta_{0} \bar{T}\right)$,

Where $T=T_{h}$ for Flat Plates and Evacuated Tubes; $\bar{T}=\bar{\zeta}_{b}$ for Troughs

Figure 5-12. Graphical Determination of Yearly Average Energy Collection Rate $\left(\mathrm{w} / \mathrm{m}^{2}\right)$ During Daylight Hours for Unshaded Flat Plates, Evacuated Tubes, and Parabolic Troughs as a Function of Intensity Ratio 
the site. The ordinate is then multiplied by the product of the collector optical efficiency and an average irradiance level to arrive at $\dot{q}_{c}$ ' the average annual energy collection rate per unit of collector area. Note that, for parabolic trough collectors, the ordinate is multiplied by the average annual direct normal irradiance plus $50 \mathrm{~W} / \mathrm{m}^{2} . *$

In referring to Fig. 5-12 for parabolic troughs, both north-south and eastwest rotational-axis orlentations are shown. If land or rooftop area considerations do not preclude north-south orientation, it is best to utilize the north-south performance curves because of the greater annual energy delivery associated with this orientation. The flat-plate and evacuated-tube performance curves are for collector panels that are oriented south and tilted from horizontal at the latitude angle. This is optimum for collector systems that operate year round as is the case for most IPH applications. (A more detailed dimension of Fig. 5-12 is contained in Sec. 6.1.)

The average annual energy collection prediction just obtained is used to normalize the total solar system cost (see Sec. 10.1.2) to provide a measure of the cost effectiveness of the particular type of collector. This measure is often called capacity cost. The lower the capacity cost is, the better the investment. This measure can, therefore, be used to judge which collector type is best suited for a particular industrial plant and process. While the procedure yields a measure in units of energy cost, note that this value is not the actual cost of energy. These values are intended only for comparing collector system options. Determining the actual cost of delivered energy requires many other factors not included in this procedure, and, therefore, a Iife-cycle economic analysis is necessary (see Sec. 10.2).

\subsubsection{Other Considerations in Selecting an Appropriate Collector}

While capacity cost (total installed system cost divided by annual collected energy) should be a major factor in deciding which collector is best for the IPH system, other factors should also be considered. Some of these are as follows:

- Determine if flat-plate glazing materials or parabolic-trough reflector materials deteriorate rapidly because of industrial contaminants at the solar IPH site by placing material samples at the site as early as possible.

- Consider the maintenance and replacement costs that each type of collector might require. Maintenance and replacement costs are not included in capacity costs, but they certainly affect the life-cycle cost of the solar system.

- Determine if the industrial plant has maintenance personnel to repair and maintain a tracking collector. Parabolic trough collectors may require maintenance and replacement of electric motors, gear reducers, bearings, and sun-tracker electronics, for example.

*This extra additive irradiance of $50 \mathrm{~W} / \mathrm{m}^{2}$ is necessary only because it permits a better empirical correlation of annual performance. 
- If a rooftop area is being considered for placement of the collectors, determine if the roof is structurally adequate for that purpose. If it is not, consider the roof modifications that each type of collector would necessitate.

\subsection{REFEREACES}

ASHRAE Standard 93-77. Collector Test Procedure of the American Society of Heating, Refrigeration, and Air Conditioning Engineers. $343 \mathrm{~W} .43 \mathrm{rd} \mathrm{St.,}$ New York, NY.

ASTM Document No. 127. "Test Method for Determining the Thermal Performance of Tracking Solar Collectors." American Society for Testing and Materials.

Casamajor, A. B.; Parsons, R. E. 1979 (Jan.). Design Guide for Shallow Solar Ponds. UCRL-52385 (Rev. 1). Livermore, CA: Lawrence Livermore Laboratory.

Duffie, J. A.; Beckman, W. A. 1974. Solar Energy Thermal Processes. New York, NY: John Wiley and Sons.

Edesess, M.; Henderson,J•; Jayadev, T. S. 1981 (Revised). A Simple Design Tool for Sizing Solar Ponds. SERI/RR-351-347R. Golden, Co: Solar Energy Research Institute.

Franta, G.; et al. 1981 (Jan.). Solar Design Workbook. SERI/SP-62-308. Golden, CO: Solar Energy Research Institute.

Gee, R. C., 1982 (May). An Experimental Performance Evaluation of Line-Focus Sun Trackers. SERITTR-632-646. Golden, CO: Solar Energy Research Institute.

Gee, R. C.; et al. 1980 (Mar.). Long-Term Average Performance Benefits of Parabolic Trough Improvements. SERI/TR-632-439. Golden, CO: Solar Energy Research Institute.

Harrison, T. D. 1980 (Nov.). Midtemperature Solar Systems Test Facility Program for Predicting Thermal Performance of Line-Focusing, Concentrating Solar Collectors. SAND80-1964. Albuquerque, NM: Sandia National Laboratories.

Lunde, P. J. 1980. Solar Thermal Engineering. New York, NY: John Wiley and Sons.

Mather, G. R., Jr. 1980 (Nov.). "ASHRAE 93-77 Instantaneous and Al1-Day Tests of the Sunpak Evacuated-Tube Collector." Journal of Solar Energy Engineering. Vol. 102.

Rab1, A. 1976. "Comparison of Solar Concentrators." Solar Energy. Vol. 18; p. 93. 
Solar Energy Research Institute. 1981 (Nov.). Solar Ponds: A Selected Bibliography. SERI/TR-752-711. Golden, Co: Solar Energy Research Institute.

Sun Designs. 1982 (July). Solar Collector Data Manual. SERI/TR-254-1515. Golden, Co: Solar Energy Research Institute.

Tabor, H. 1980. Letter to the Editor. Solar Energy. Vo1. 24; pp. 113-115.

Tabor, H. 1981. "Solar Ponds." Solar Energy. Vo1. 27 (No. 3): pp. 181-194.

Winston, R. 1974. "Solar Concentrators of a Novel Design." Solar Energy 16; p. 89. 


\section{SFP喽}


PART III

PRELIMINARY DESIGI 


\section{SECTION 6.0}

\section{ANTUAL PERFORMANCE OF A SOLAR ENERGY SYSTEM}

Because the objective of a solar IPH system is to deliver energy efficiently to a process load, we need an accurate method of calculating the performance of that solar system. Further, to size the system components and to help make the trade-offs necessary in using any solar system, we must have a performance analysis that takes into account the impact of all important parameters. Such a system performance analysis should be efficient, accurate, easy to use, and not require the use of a computer. This section presents some performance analysis design tools that were developed to meet all these requirements.

Many of these design tools were generated with the help of a detailed hour-byhour computer model, SOLIPH. Thousands of SOLIPH runs were made to formulate generalized design tools. The primary difficulty encountered in developing these tools was the number of variables that affect annual system performance. Because there are so many variables, detalled hour-by-hour computer models are often utilized during the design stages of a solar system. This can make the process very time-consuming and significantly increase system design costs. However, by grouping variables into physically meaningful groups and using regression analysis techniques, we can correlate the performance of solar systems with a great degree of accuracy and display the results graphically. The methodology used to generate these design tools was influenced greatly by the work of Ari Rabl. The simplified energy collection correlations he formulated (1981) provided valuable insight and greatly aided development of the design tools presented here. The IPH system computer model and a comparison of its results with other computer codes is contained in Appendix C. Our design tool methodology is presented in more detail in Appendix D, along with the accuracy (rms error) of each design tool. The reader is cautioned that the energy prediction design tools were developed for the continental United States only, and use in other areas can result in less accuracy than that indicated in the Appendix.

Each subsection in this section addresses one aspect of IPH system performance and presents design tools for predicting its impact on the annual performance of the entire IPH system. The annual energy collection design tool introduced in Sec. 6.1 is the fundamental correlation upon which the performance analysis is based. It is applied to a variety of IPH system configurations for hot air, hot water, and steam systems. Section 6.2 describes how to account for incident-angle modifier effects and end losses (for a parabolic trough) on an annual basis. In Sec. 6.3, annual correction factors for row-to-row shading losses are presented. Section 6.4 provides a method of calculating annual losses from field piping, including steady-state losses, overnight losses, and freeze protection losses. Section 6.5 presents annual correction factors that account for downtime and utilization of the solar system. Section 6.6 summarizes the design tool information step-by-step.

\subsection{ANNUAL ENERGY COLLECTION FOR SEVERAL IPH SYSTEM CONFIGURATIONS}

The first step in determining how much energy is delivered from the solar system to the process load is to calculate how much energy is produced by the collector field. Energy collection depends on the type of collector, its 
fluid specific heats, heat exchanger effectiveness, storage tank size, process load supply temperature, process load energy requirement, and the hours the process operates. Because there are so many varfables, detailed hour-by-hour computer models are often employed to make IPH system trade-off decisions and to size various components. Fortunately, some of these variables can be accounted for in closed-form analysis. Other key variables have been appropriately grouped and correlated empirically with the annual performance results of SOLIPH. The resulting basic annual energy correlation is presented here, and its application to specific IPH system configurations is treated in subsections that follow.

As shown in Sec. 5.0, the instantaneous energy collection of a collector can be described in the form

$$
\dot{q}_{c}=F_{R}\left[I_{a} \eta_{0}-U_{L}\left(T_{c, i}-T_{a}\right)\right] .
$$

The heat transfer efficiency factor $F_{R}$ accounts for the temperature rise across the collector and the resultant decrease in energy collection due to this elevation in collector operating temperature. This factor, as shown in Sec. 5.2, is calculated as

$$
\mathrm{F}_{R}=\frac{\dot{\mathrm{M}}_{c} c_{p}}{\mathrm{~A}_{c} \mathrm{U}_{\mathrm{L}}}\left[1-\exp \left(-\mathrm{F}^{\prime} \mathrm{U}_{\mathrm{L}^{A_{c}}} / \dot{\mathrm{M}}_{\mathrm{c}} \mathrm{c}_{\mathrm{p}}\right)\right] .
$$

Equation 6-1 is useful when the collector inlet temperature is known. In direct hot water and air systems (see Figs. 4-1 and 4-3), the collector inlet temperature is the load return temperature. However, in indirect systems that incorporate a heat exchanger between the collector loop and the load (see Figs. 4-2 and 4-4), the collector inlet temperature is higher than the load return temperature because of the finite heat transfer area of the heat exchanger. The collector inlet temperature is also not specifically known for steam systems. As we show later in this section, simple modifiers can be developed that account for the effects of intermediate heat exchangers, unfired boilers, and steam flash tanks. We define this system-dependent modifier to be $F_{S}$. With 1t, energy collection can be written as

$$
\dot{q}_{c}=F_{S} F_{R}\left[I_{a} \eta_{0}-U_{L}\left(T_{i n}-T_{a}\right)\right] \text {. }
$$

Here, $T_{\text {in }}$ is a known temperature which is also dependent on system configuration. In hot air and hot water systems, $\mathrm{T}_{1 \mathrm{n}}$ is the load return temperature; in steam systems, $T_{i n}$ is the saturated steam temperature. Although Eq. 6-3 is useful in defining instantaneous performance, it does not quantify the most important quantity--long-term average performance of a collector. We need only three primary quantities to quantify long-term collector performance (see Appendix D): primarily the intensity ratio, the geographic latitude, and the product of collector optical efficiency and the average intensity of the sun's irradiation during daylight hours at the solar site.

The intensity ratio is the critical intensity of the collector divided by the average intensity of the sun's irradiance during daylight hours and is denoted as $\bar{I}$. The critical intensity of a collector is that irradiance at which heat loss just balances heat gain. A collector's critical intensity (based on 4380 annual daylight hours, or an average of 12 hours per day per year) is calculated as 


$$
\text { critical intensity }=\frac{\left.F_{R_{L}} U_{i n}-T_{a}\right)}{F_{R^{n}}} \text {. }
$$

Al1 the quantities necessary to define the intensity ratio are readily available and, therefore, provide a simple method for calculating energy collection. Simple empirical correlations for energy collection based on the intensity ratio are shown graphically in Fig. 6-1 (which is Fig. 5-12 with the addition of polynomials for use with hand calculators). Evacuated-tube and flat-plate collectors are assumed to be oriented south and tilted at the latitude angle. Parabolic troughs are assumed to be mounted horizontally.

To use the figure, first define the intensity ratio, which is the variable grouping

$$
\left[F_{R^{U}} U_{L}\left(T_{\text {in }}-T_{a}\right) /\left(F_{R_{0}} \bar{I}\right)\right] \text {. }
$$

Both $F_{R} U_{L}$ and $F_{R^{n}}$ are collector properties. The collector optical efficiency term $F_{R^{n}}$ is often lowered to account for the long-term optical degradation of the collector from dirt and dust. The amount by which $F_{R^{n}}$ should be reduced is highly site dependent and should be based on observed degradation of material samples placed at the site (see Sec. 3.1). $\bar{I}$ is the long-term average irradiance during daylight hours for the site being considered. $\bar{I}$ is to be taken as $\overline{\mathrm{I}}_{\mathrm{b}}$ for parabolic troughs (see Fig. 5-11). For flat-plate and evacuated-tube collectors, use $\bar{I}_{h}$ (see Fig. 5-10). $T_{a}$ is the average annual daytime temperature for the site (see Appendix F). The correct temperature to use for $T_{\text {in }}$ depends on the configuration of the system. Use the load return temperature of the process for hot air and hot water systems, and use the saturated steam temperature for steam systems. This is explained more fully in the subsections that follow.

With the $x$-axis defined, the quantity $\left[\dot{q}_{c} / F, F_{R} \bar{I}\right]$ can be read directly from the graph along the $y$-axis for the latilude of the site. Multiplying this ordinate value by the product of $F_{S}, F_{R}$, the collector optical efficiency, and the appropriate annual average daytime irradiation results in the quantity $q_{c}$, which is the annual average energy collection rate, per unit of collector area, for the unshaded collector for a constant value of $T_{\text {in }}$. Note that, for parabolic troughs, an additional $50 \mathrm{w} / \mathrm{m}^{2}$ is added to the annual average irradiance used on the $y$-axts, which allows a better empirical fit than one based on the annual average irradiance alone.*

Note that the parabolic trough performance curves extend to intensity ratios of 0.7, while for flat plates and evacuated tubes they extend to 1.4. This is consistent with the operating temperature range in use for each type of collector. This covers temperatures up to about $90^{\circ} \mathrm{C}$ for flat plates and up to about $300^{\circ} \mathrm{C}$ for parabolic troughs. Because a flat-plate collector loses more heat at $90^{\circ} \mathrm{C}$ than a parabolic trough does at $300^{\circ} \mathrm{C}$, the curves extend to higher intensity ratios for flat plates.

*If a second-order efficiency equation is provided by the collector supplier, use the $\mathrm{U}_{\mathrm{L}}$ value at the load temperature. As noted in Sec. 5.2, $\mathrm{U}_{\mathrm{L}}$ should be evaluated as $\mathrm{U}_{\mathrm{L}}=\mathrm{U}_{\mathrm{L}, 1}+\mathrm{U}_{\mathrm{L}, 2}\left(\mathrm{~T}_{1}-\mathrm{T}_{\mathrm{a}}\right)$. 
Another characteristic of these curves is that those for flat plates are well above those for parabolic troughs at low intensity ratios. This is so because flat-plate and evacuated-tube curves are based on average daytime total horizontal irradiance, but parabolic-trough curves are based on average daytime direct normal irradiance. For many sites, direct normal irradiance values can be significantly higher than the total horizontal irradiance values. Only one curve is shown for east-west rotational axis troughs. In that particular orientation, performance is essentially independent of site latitude, because the incident angle of incoming irradiance is the same for all latitudes. Note that the north-south orientation outperforms (on an annual basis) the eastwest orientation, but they approach each other at high latitudes. Shading losses tend to further diminish this performance difference, as shown in Sec. 6.3.

The annual performance of a parabolic trough with a rotational axis oriented between north-south and east-west limits is typically between that of a northsouth trough and an east-west trough. At some sites, performance may be slightly enhanced with a small off-north-south orientation because of weather patterns marked by very cloudy mornings or afternoons. However, this asymmetry is usually slight on an annual basis, and the annual performance of a parabolic trough oriented between north-south and east-west can be approximated (Harrigan 1981) by:

$$
\dot{q}_{c}, \theta_{\text {axis }}=\frac{\dot{q}_{c, e-w}+\dot{q}_{c, n-s}}{2}+\frac{\dot{q}_{c, n-s}-\dot{q}_{c, e-w}}{2} \cos \left(2 \theta_{\text {axis }}\right) \text {, }
$$

where

$$
\begin{aligned}
& \dot{q}_{c}, \theta \text { axis }=\text { annual energy collection rate of trough with rotational axis } \\
& \dot{q}_{c, e-w}=\underset{\text { annual energy collection rate of east-west rotational axis }}{\text { trough (from Fig. 6-1) }} \\
& \dot{q}_{\mathrm{c}, \mathrm{n}-\mathrm{s}}=\underset{\text { annual energy collection rate of north-south rotational axis }}{\text { trough }} \\
& \theta_{\text {axis }}=\text { direction of trough rotational axis measured from south } \\
& \text { (north-south }=0^{\circ} \text {, east-west }=90^{\circ} \text { ). }
\end{aligned}
$$

Note that the polynomial expressions for the annual collector performance curves are provided at the bottom of Fig. 6-1. These polynomials are given for those wishing to use a hand-held calculator rather than the graphical representations.

\subsubsection{Hot Fater and Bot Air Systems}

An indirect hot water or hot air system is shown in Fig. 6-2. The term "indirect" is used to denote that a heat exchanger is used between the collector loop and the load. As noted in Sec. 6.1, this heat exchanger affects system performance because the temperature of the fluid entering the collector system is higher than the process return temperature. The heat exchanger factor $F_{x}$ 


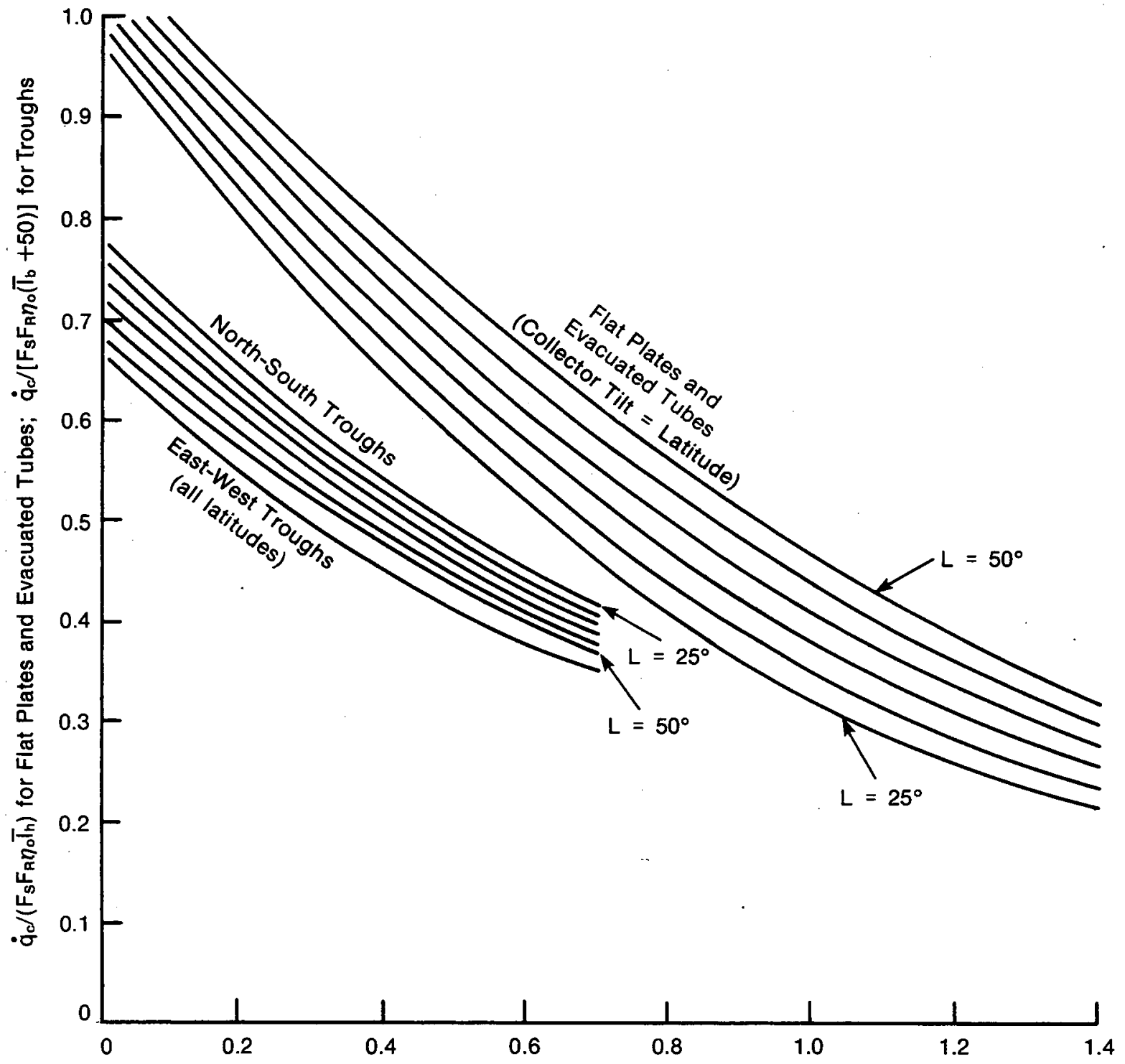

$\mathrm{F}_{\mathrm{R}} \mathrm{U}_{\mathrm{L}}\left(\mathrm{T}_{\text {in }}-\mathrm{T}_{\mathrm{Q}}\right) /\left(\mathrm{F}_{\mathrm{R}} \eta_{\mathrm{O}} \overline{\mathrm{I}}\right)$,

Where $T=T_{h}$ for Flat Plates and Evacuated Tubes; $T=\bar{l}_{b}$ for Troughs

Flat Plates and Evacuated Tubes:

$$
\dot{\mathrm{q}}_{\mathrm{c}} /\left(\mathrm{F}_{\mathrm{S}} \mathrm{F}_{\mathrm{R}} \eta_{\mathrm{o}} \bar{T}_{\mathrm{h}}\right)=0.8813-1.095 \cdot \mathrm{X}+0.3905 \cdot \mathrm{X}^{2}+0.003655 \cdot \mathrm{L}+0.006785 \cdot \mathrm{L} \cdot \mathrm{X}-0.004602 \cdot \mathrm{L} \cdot \mathrm{X}^{2}
$$

East-West Parabolic Troughs:

$$
\dot{q}_{c}\left\langle F_{S} F_{A} \eta_{0}\left(T_{b}+50\right)\right]=0.6688-0.6745 \cdot x+0.3166 \cdot x^{2}
$$

North-South Parabolic Troughs:

$\dot{q}_{c} /\left[F_{S} F_{A} \eta_{0}\left(T_{0}+50\right]=0.8810-0.8117 \cdot X+0.3130 \cdot X^{2}-0.003919 \cdot L+0.003864 \cdot L \cdot X-0.001484 \cdot L \cdot X^{2}\right.$

$$
\text { Where } \begin{aligned}
L & =\text { latitude in degrees } \\
X & =F_{R} U_{L}\left(T_{\text {in }}-T_{D}\right) /\left(F_{,}, \bar{J}\right) \\
\text { Use } T & =T_{n} \text { for Flat Plates and Evacuated Tubes } \\
T & =T_{b} \text { for Troughs }
\end{aligned}
$$

Figure 6-1. Graphical Determination of Yearly Average Energy Collection Rate $\left(w / m^{2}\right)$ During Daylight Hours for Unshaded Flat Plates, Evacuated Tubes, and Parabolic Troughs as a Function of Intensity Ratio 
can be used to account for this effect (dewinter 1975). The heat exchanger factor* is defined as

$$
F_{X}=\left[1+\frac{F_{R}^{U_{L} A_{c}}}{\dot{M}_{c} c_{p}^{\prime}}\left(\frac{1}{\varepsilon}-1\right)\right]^{-1} .
$$

where $\varepsilon$ is heat exchanger effectiveness. Therefore, for hot air and hot water systems, the system-dependent modifier $F_{S}$ is equal to $F_{X^{*}}$ Also, for hot air and hot water systems, the process return temperature is used for $T_{\text {in }}$ in referring to Fig. 6-1. If a heat exchanger is not part of the system (i.e., it is a direct system), set $F_{s}$ equal to unity.

Figure 6-2 shows a collector flow loop and a secondary loop. If no storage is provided, the secondary loop fluid must be delivered to the process load. If storage is added, the secondary loop fluid can either be delivered to the process load or stored for later use. Whether to choose a storage or a nostorage system depends to a great extent on the hours that energy is needed by the process, and such process heat requirements are governed by the production schedule of the industrial plant. Typically, industrial plants operate on either a single-shift, two-shift, or three-shift schedule, so that process loads of 8,16 , or 24 hours per day are common. A no-storage system and two systems with storage are described in the subsections that follow.

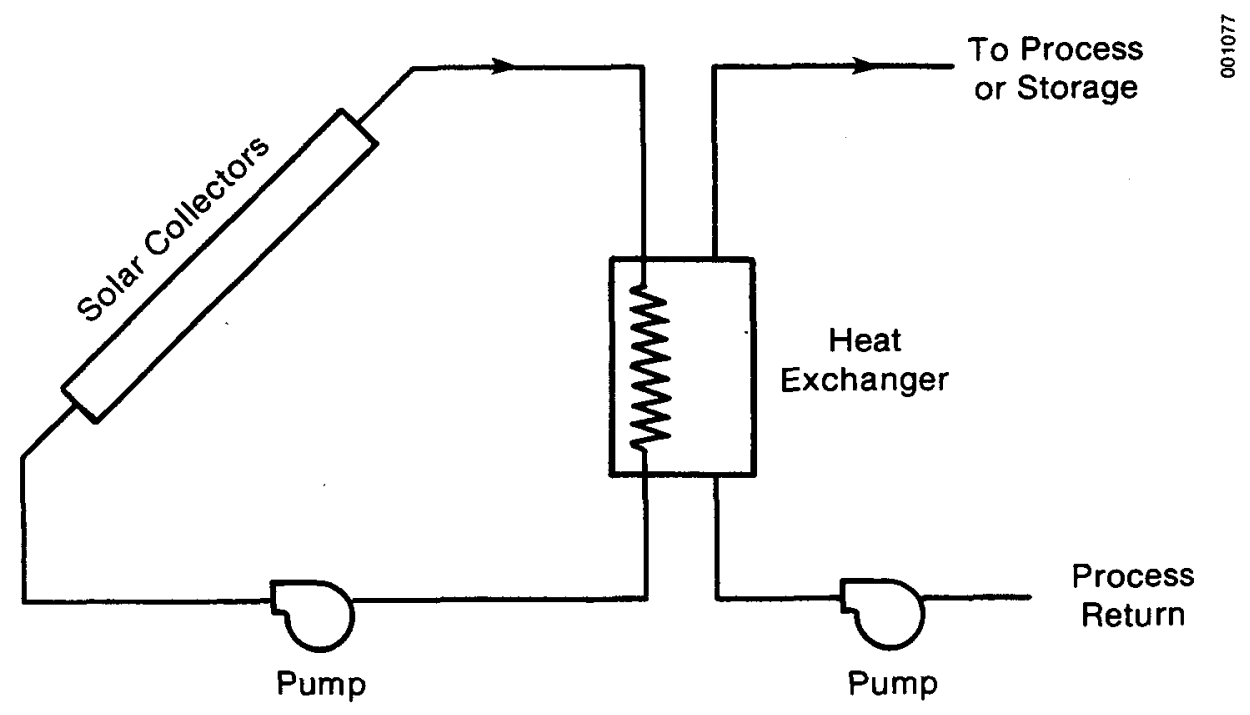

Figure 6-2. An Indirect Solar Hot Water or Hot Air System

*Equation 6-5 assumes that the collector loop flow capacity rate is less than or equal to the load loop flow capacity rate. A more general form is given in Sec. 7.5 . 


\subsubsection{No-Storage IPH System}

An IPH system without storage would be configured as shown in Fig. 6-2. Whenever solar energy is collected, both pumps are turned on, and all the return water (or air) is heated as it passes through the heat exchanger. The collector system should be slzed so that, under the best conditions for solar collection, the heated fluid does not exceed the required process temperature. Thus, when the collectors are producing less than their peak energy output, the heated process flufd leaves the heat exchanger at less than the required process temperature. The additional energy needed to bring the preheated fluid to that temperature must be supplied by a back-up boller* which is placed in series with the solar heat exchanger.

A no-storage solar system should be considered for industrial plants with process loads that occur during all or nearly all daylight hours. If the plant operates only a single shift ( 8 hours) per day, the no-storage system is not a good choice because there will be too many daylight hours when no process load exists. During such no-load perlods, collectable energy is lost, which can significantly reduce the annual performance of the collector system.

The no-storage system is also a poor choice if the industrial plant shuts down on weekends. Without storage, collectable energy is lost two days of every week. This significantly reduces the cost effectiveness of the solar system. But a no-storage system. is a good choice for industrial plants having daytime, 7-day-per-week loads. Many two- and three-shift industrial operations fall into this category.

To size the collector area for a no-storage system, we follow the guideline that under the best conditions for solar collection, the solar collector field should not produce more energy than the process can use. This is consistent with the belief that no collected energy should ever be dumped. Actually, a small amount of dumping is economically justified [Gordon and Rabl (forthcoming)]. But the economic advantages of a slightly oversized system over a nodump system are slight. For purposes of preliminary solar system design, the no-dump philosophy is entirely adequate.

To find the maximum collector area needed for a no-storage system, we simply equate the rate at which the process load requires energy to the rate at which the collector field can deliver energy under the best solar collection conditions:

$$
\begin{aligned}
\dot{Q}_{\text {load }} & =\dot{Q}_{c, \text { max }} \\
& =A_{c, \text { max }} \dot{q}_{c, \text { max }} \\
& =A_{c, \text { max }} F_{x}\left[F_{R} \eta_{o} I_{\max }-F_{R} U_{L}\left(T_{\text {in }}-T_{a, \text { max }}\right)\right],
\end{aligned}
$$

*The impact of operating a boller at variable heating rates is discussed in Appendix A. 
where

$$
\begin{aligned}
I_{\max } & =\text { peak irradiance available to collector } \\
\mathrm{T}_{\mathrm{a}, \max } & =\text { highest expected ambient temperature. }
\end{aligned}
$$

It is suggested that $I_{\max }$ be set to $1000 \mathrm{~W} / \mathrm{m}^{2}$ for parabolic troughs and to $1100 \mathrm{~W} / \mathrm{m}^{2}$ for flat-plate and evacuated-tube collectors. These values may be slightly too high for some locations and slightly too low for others, but on the average they represent good design values. The design value of high ambient temperature may be estimated for the site from ASHRAE $99 \%$ guidelines (ASHRAE 1981). Alternatively, a value of $40^{\circ} \mathrm{C}$ may be used since it represents a typical maximum temperature for much of the United States.

Values for $F_{R_{0}}{ }_{0}$ and $F_{R} U_{L}$ are taken directly from the performance data of the collector. $T_{i n}$ is the process return temperature, and $F_{X}$ is the heat exchanger factor (see Eq. 6-5), which is a function of the effectiveness of the heat exchanger. Again, if no heat exchanger is present, use $F_{x}=1$.

After determining all the appropriate values, we solve for the maximum collector area for a no-storage system as follows:

$$
A_{c, \max }=\dot{Q}_{\text {load }} /\left\{F_{x}\left[F_{R} \eta_{0} I_{\max }-F_{R} U_{L}\left(T_{\text {in }}-T_{a, \max }\right)\right]\right\} .
$$

This collector area represents the maximum; smaller collector fields can also be used with a correspondingly smaller amount of fossil fuel energy displacement. If, for example, available land is limited, a collector area smaller than $A_{c, \max }$ may be necessary.

The annual performance of the solar system can be predicted using Fig. 6-1. Use the process return temperature for $T_{\text {in }}$ and the calculated value of $F_{x}$ for $F_{s}$. Assuming that the no-storage system configuration has been selected because a process load exists during all daylight hours, the total annual energy collected is calculated as

$$
Q_{c}=\dot{q}_{c} A_{c} N_{\text {daylight }},
$$

where

$$
\begin{aligned}
Q_{c}= & \text { total annual average energy collection } \\
\dot{q}_{c}= & \text { annual average energy collection rate per unit of collector } \\
& \text { area during daylight hours (from Fig. 6-1) } \\
A_{c}= & \text { collector area }\left(\leqslant A_{c} \text {, max }\right) \\
N_{\text {daylight }}= & \text { number of daylight hours in year }(=4380) .
\end{aligned}
$$

The total annual process load is as follows:

$$
\mathrm{Q}_{\text {load }}=\dot{Q}_{\text {load }} \mathrm{N}_{\text {load }} \text {, }
$$


where

$$
\begin{aligned}
& \dot{Q}_{\text {load }}=\text { average process load energy rate }\left\{=\left[\dot{\mathrm{m}}_{\text {load }} \mathrm{c}_{\mathrm{p}}\left(\mathrm{T}_{\ell}-\mathrm{T}_{\ell, \mathrm{r}}\right)\right]\right\} \\
& \mathrm{N}_{\text {load }}=\text { number of hours load operates during the year. }
\end{aligned}
$$

Now, the solar fraction (fraction of total process load that is displaced by solar energy system) can be calculated as:

$$
\mathbf{f}=\frac{\mathrm{Q}_{c}}{\mathrm{Q}_{\text {load }}}
$$

An example illustrates this procedure. A chemical manufacturing plant near Columbus, Ohio, is considering adding a solar system to provide some of its process heat. Chemical reaction vessels are heated 24 hours per day, 7 days per week with $120^{\circ} \mathrm{C}$ hot water. After heating the reaction vessels, the water is returned at $90^{\circ} \mathrm{C}$ for reheat. The chemical plant uses $38,000 \mathrm{~kg} / \mathrm{h}$ $(84,000 \mathrm{lb} / \mathrm{h})$ of hot water for this chemical process. The $24 \mathrm{~h} /$ day load ensures that a process load exists during all daytime hours; hence, a nostorage system is a good choice.

The roof area of the plant is too cluttered with ventilation equipment to accommodate solar collectors. However, the plant has 2.5 acres of vacant land adjacent to it. First, we must calculate how much of the 2.5 acres of land may be used for the solar system, assuming a ground cover ratio (collector aperture width divided by row-to-row spacing) of 0.4 . Then, we calculate the solar fraction that the collectors can meet.

Assume that evacuated-tube collectors will be used that have the following performance characteristics (as tested with a water flow rate through the co1lectors of $\left.0.02 \mathrm{~kg} \mathrm{~s}^{-1} \mathrm{~m}^{-2}\right)$ :

$$
\begin{aligned}
& \mathrm{F}_{\mathrm{R}^{n_{O}}}=0.6 \\
& \mathrm{~F}_{\mathrm{R}_{\mathrm{L}}}=0.8 \mathrm{~W} / \mathrm{m}^{2}{ }^{\circ} \mathrm{C} .
\end{aligned}
$$

The collector loop will use a heat transfer fluid other than water because of both freeze protection concerns and the load temperature requirement of $120^{\circ} \mathrm{C}$. Because the process load loop uses water, a heat exchanger between the two loops is necessary. Assume that the heat exchanger factor $F_{x}$ has a value of 0.95. The process load use rate, Qload, is calculated as

$$
\begin{aligned}
\dot{Q}_{\text {load }} & =\dot{\operatorname{m}}_{\text {load }} \mathrm{C}_{\mathrm{p}}\left(\mathrm{T}_{\ell}-\mathrm{T}_{\ell, \mathrm{r}}\right) \\
& =\left(38,000 \frac{\mathrm{kg}}{\mathrm{h}}\right)\left(4186 \frac{\mathrm{J}}{\mathrm{kg}^{\circ} \mathrm{C}}\right)\left(120^{\circ} \mathrm{C}-90^{\circ} \mathrm{C}\right) \\
& =4.77 \times 10^{9} \frac{\mathrm{J}}{\mathrm{h}}
\end{aligned}
$$

Based on this load use rate, the maximum collector area for the no-storage system is calculated (see Eq. 6-7) as 


$$
\begin{aligned}
& A_{c, \max }=\dot{Q}_{\text {load }} /\left\{F_{x}\left[F_{R} n_{0} I_{\max }-F_{R} U_{L}\left(T_{\text {in }}-T_{a, \max }\right)\right]\right\} \\
& =\frac{\left(4.77 \times 10^{9} \frac{\mathrm{J}}{\mathrm{h}}\right)\left(\frac{\mathrm{h}}{3600 \mathrm{~s}}\right)}{0.95\left[0.6\left(1100 \mathrm{~W} / \mathrm{m}^{2}\right)-0.8\left(90^{\circ} \mathrm{C}-40^{\circ} \mathrm{C}\right)\right]} \\
& =2250 \mathrm{~m}^{2} \text {. }
\end{aligned}
$$

Using this collector area and a ground cover ratio of 0.4 , land requirements are

$$
A_{g}=A_{c} / G C R=2250 \mathrm{~m}^{2} / 0.4=5625 \mathrm{~m}^{2},
$$

or about 1.4 acres of land area.

Because the assumed collector $F_{R} U_{L}$ and $F_{R} n_{0}$ values correspond only to the tested flow capacity rate, it is necessary to adjust their values for the actual flow capacity of this application. Using a collector loop flow rate equal to half the load flow rate (see Sec. 7.5.4), adjustment of $F_{R}$ for different flow capacities, as shown by Lunde (1981), can be calculated as

$$
\begin{aligned}
& \frac{\left(F_{R}\right)_{\text {new }}}{\left(F_{R}\right)_{\text {old }}}=\left[1+\frac{\left(F_{R} U_{L}\right)_{o l d}}{2\left(\dot{m} C_{p}\right)_{\text {new }}}-\frac{\left(F_{R} U_{L}\right)_{o l d}}{2\left(m \dot{C}_{p}\right)_{\text {old }}}\right]^{-1} \\
& =\left[1+\frac{\left(0.8 \frac{\mathrm{W}}{\mathrm{m}^{20} \mathrm{C}}\right)\left(3600 \frac{\mathrm{s}}{\mathrm{h}}\right)}{2\left(19,000 \frac{\mathrm{kg}}{\mathrm{h}}\right)\left(4186 \frac{\mathrm{J}}{\mathrm{kg}^{\circ} \mathrm{C}}\right) / 2250 \mathrm{~m}^{2}}\right. \\
& \left.-\frac{0.8 \frac{\mathrm{W}}{\mathrm{m}^{20} \mathrm{C}}}{2\left(0.02 \frac{\mathrm{kg}}{\mathrm{s}-\mathrm{m}^{2}}\right)\left(4186 \frac{\mathrm{J}}{\mathrm{kg}^{\circ} \mathrm{C}}\right)}\right]^{-1} \\
& =0.965 \text {. }
\end{aligned}
$$

Therefore, the $F_{R} U_{L}$ and $F_{R} n_{0}$ values assumed are $3.5 \%$ too high. This correction is small enough that it is not necessary to recalculate a new value of $A_{c, \max }$. After all, $A_{c, \max }$ is an approximate value. However, the $F_{R}$ correction should be included in the annual performance calculations. To do so, use corrected $F_{R^{n}}$ and $F_{R_{L}} U_{L}$ values of

$$
\begin{aligned}
& F_{R^{n_{O}}}=(0.985) 0.6=0.579 \\
& F_{R^{U_{L}}}=(0.985) 0.8=0.772 .
\end{aligned}
$$


With these values,* Fig. 6-1 can help to provide an annual energy collection prediction. Because the collector is an evacuated tube, the correct $\bar{I}$ value to use is average daytime total horizontal irradiance. The annual average total horizontal irradiance during daylight hours at Columbus is about $350 \mathrm{~W} / \mathrm{m}^{2}$. (as read from Fig. 5-10). The annual average ambient temperature is $13^{\circ} \mathrm{C}$ (from Appendix E). The value of the intensity ratio ( $\mathrm{x}$-axis of $\mathrm{Fig} \cdot 6-1$ ) is, therefore,

$$
\frac{F_{R^{U}} U_{L}\left(T_{i n}-T_{a}\right)}{F_{R^{n}} \bar{I}}=\frac{\left(0.772 \frac{W}{\mathrm{~m}^{20} \mathrm{C}}\right)\left(90^{\circ} \mathrm{C}-13^{\circ} \mathrm{C}\right)}{(0.579)\left(350 \mathrm{~W} / \mathrm{m}^{2}\right)}=0.293
$$

For the $40^{\circ}$ latitude of Columbus this provides a y-axis value of 0.81 . Now, $q_{c}$ can be calculated as

$$
\begin{aligned}
\dot{q}_{C} & =0.81\left(F_{X} F_{R_{0}} \bar{I}\right) \\
& =0.81(0.95)(0.579)\left(350 \mathrm{~W} / \mathrm{m}^{2}\right) \\
& =156 \mathrm{~W} / \mathrm{m}^{2} .
\end{aligned}
$$

The total annual energy collected can be calculated (from Eq. 6-9) as

$$
\begin{aligned}
Q_{c} & =\left(156 \mathrm{~W} / \mathrm{m}^{2}\right)\left(2250 \mathrm{~m}^{2}\right)(4380 \mathrm{~h}) \\
& =1.537 \times 10^{9} \mathrm{Wh}\left(5.53 \times 10^{12} \mathrm{~J}\right) .
\end{aligned}
$$

The total annual process load is

$$
\begin{aligned}
Q_{\text {load }} & =\left(4.77 \times 10^{9} \mathrm{~J} / \mathrm{h}\right)(24 \mathrm{~h} / \text { day })(365 \mathrm{day} / \text { year }) \\
& =4.18 \times 10^{13} \mathrm{~J} .
\end{aligned}
$$

The solar fraction is then given as

$$
f=\frac{Q_{c}}{Q_{\text {load }}}=\frac{5.53 \times 10^{12} \mathrm{~J}}{4.18 \times 10^{13} \mathrm{~J}}=0.132 \text {. }
$$

\subsubsection{Mixed-Tank, Recirculation IFH System}

A mixed-tank, recirculation (four-pipe storage) system such as that illustrated in Fig. 6-3 is historically the most common configuration for a system with storage. This configuration has been used in several IPH systems and in almost all solar domestic hot water systems. As noted in Sec. 4.4, this configuration is best suited for applications where the load is not continuous, or where the temperature difference between load supply and load return is

*As we describe later, incident-angle modifier effects can be included with a modification of the $F_{R^{n}}$ term. 


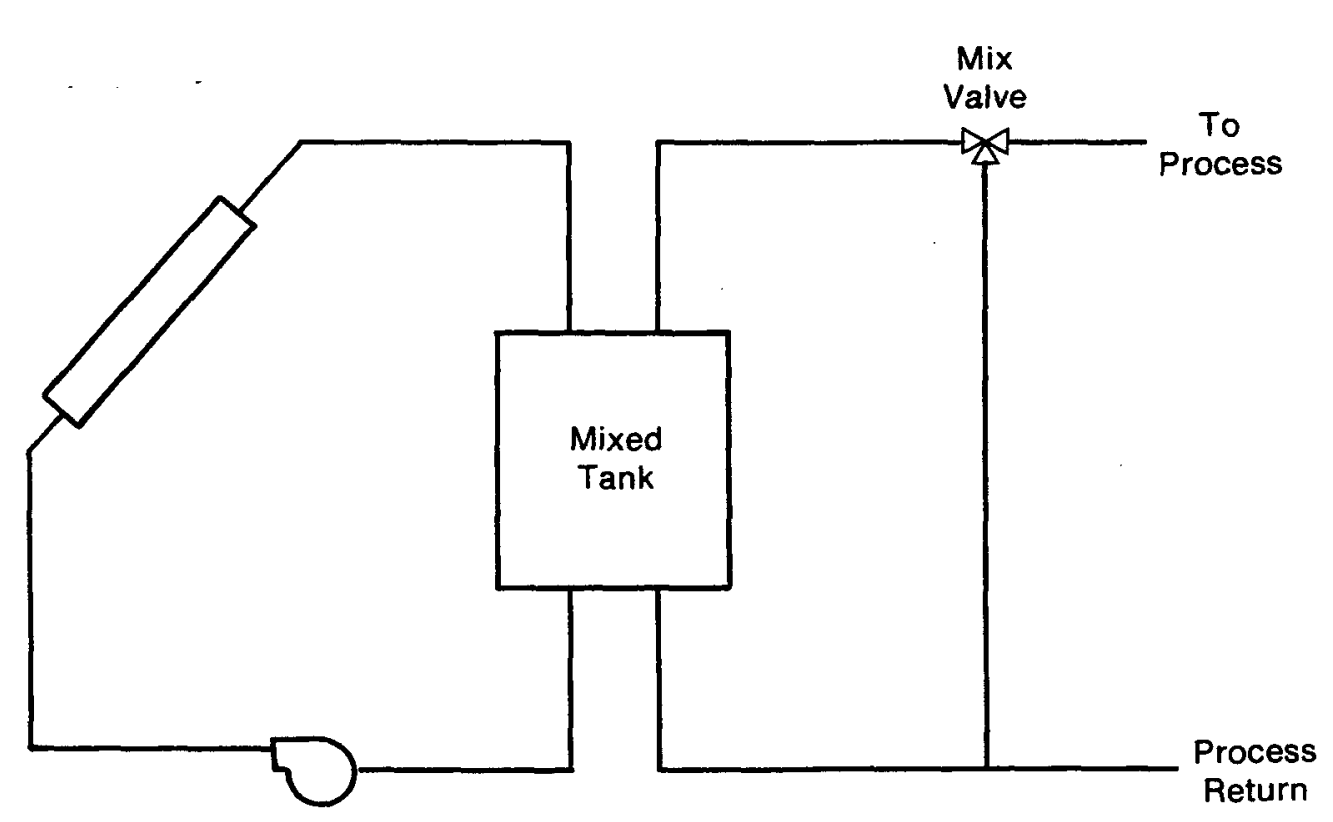

Figure 6-3. Mixed-Tank Recirculation System

sma11.* The storage tank has two inlets and two outlets, one pair for each of the flow loops. The storage tank is assumed to be completely mixed at one average temperature. This is slightly conservative from a performance viewpoint, because a small amount of thermal stratification usually occurs within the tank.

A mix valve is shown in Fig. 6-3. This valve is needed so that the temperature of the fluid provided to the process will not exceed the required process temperature. The valve mixes some of the process return fluid with the hot fluid from the storage tank to maintain a temperature at or below the process temperature. When the storage tank is below the required process temperature, the mix valve is fully open, and no fluid bypasses the storage tank.

The mixed-tank recirculation system shown in Fig. 6-3 has a heat exchanger between the collector loop and the storage tank/load loop. This heat exchanger is usually used in conjunction with a nonfreezing fluid in the collector loop. In that case, the heat exchanger factor should be calculated as shown in Eq. 6-5. When the same fluid is used throughout the system and no heat exchanger is present, set $F_{x}=1$.

The heat exchanger factor allows us to use the inlet temperature on the cold side of the heat exchanger as the value on which to base performance. In the

*An alternate mixed-tank, recirculation (two-pipe storage) system configuration that allows bypass of storage is described in Sec. 4.4 . 
no-storage system configuration, the cold side inlet is simply the process load return temperature. In the mixed-tank recirculation system, the cold side of the heat exchanger is fed by the storage tank. However, the storage tank temperature is not constant, because it heats up and cools down during the day as energy is added or removed from the tank. Therefore, another performance modifier is introduced that relates the storage tank temperature to a known temperature--the process load return temperature. Because this modifier accounts for the effects of the storage tank* and is also a strong function of the process load profile, it is known as the load-storage modifier. Appendix $E$ derives the functional relationships important to it. For a specified collector type and load profile, three variable groupings define the loadstorage modifier:

$$
\frac{A_{c} \dot{q}_{c, \infty}}{\dot{Q}_{\text {load }}}, \frac{\left(M c_{p}\right)_{\text {stor }}}{A_{c} F_{x} F_{R} U_{L}}, \frac{\left(\dot{M}_{p}\right)_{1 o a d}}{A_{c} F_{x} F_{R} U_{L}} \text {. }
$$

The first term is the ratio of the average energy collection rate of the collector field (assuming infinite storage size) divided by the average process load demand rate. The second term accounts for the size of the storage tank relative to the sensitivity of the collectors to increased temperature. The third accounts for the heat withdrawal rate from storage as defined by the load flow capacitance. Figures 6-4 to 6-11 graphically represent the loadstorage modifiers for single-shift $(8 \mathrm{~h} / \mathrm{day})$ and three-shift $(24 \mathrm{~h} /$ day) load profiles. Seven-day-per-week operation is assumed. A separate figure is given for flat plates, evacuated tubes, north-south parabolic troughs, and east-west parabolic troughs.

A separate figure is needed for each of the two trough orientations because of their different seasonal outputs (due to incident-angle effects) and their subsequent impact on annual performance. The north-south orientation shows a greater drop in performance than that of the east-west orientation as the ratio of collection rate to load rate increases (moving to the right along the $x$-axis). This is the result of the large variation in energy collection that occur seasonally with north-south oriented troughs. As we increase collector area, excess energy can be collected during the summer with the north-south orientation. This drives the average storage temperature up; the result is a higher inlet temperature to the collectors and a loss in collection efficlency. East-west-oriented troughs vary less in seasonal output and, therefore, their performance drops less significantly as collector area is increased.

The impact of the energy collection rate normalized to the load demand rate (along the $x$-axis) is the most important quantity. As the ratio of energy collection rate to energy demand rate increases, the performance penalty also increases. This performance degradation occurs because the collectors are providing a larger fraction of the process load, which drives storage tank temperatures up and causes the collectors to operate at higher temperatures. Smaller storage capacity, larger collector $U_{\mathrm{L}}$ values, and smaller load flow

*The load-storage modifier also accounts for the impact of the mixing valve and load flow rate. 
rates also result in larger performance losses and storage-load modifiers farther below unity.

Three storage sizes are shown, as defined by the values of [(Mcp) sor' $^{\prime}$ $\left.\left(A_{c} F_{x} F_{R} U_{i}\right)\right]$. They span the range of storage capacity typically considered for solar systems. Note that storage capacity is considerably less important to annual performance for the single-shift load profile than the three-shift load profile. Storage size is more important for a 24-hours-per-day load because storage can considerably extend the number of hours that part of the load can be met with stored solar heat. For example, stored heat may permit energy to be withdrawn from the tank late into the evening. In the single-shift load, no load exists in the late afternoon or evening; thus, stored energy can be withdrawn only during cloudy, daytime periods.

The curves shown on Figs. 6-4 to 6-11 extend over the range of storage capacitance, load flow rates, and ratios of collection rate to load demand rate for which SOLIPH computer results were generated. These ranges are in part defined by the range in process load temperatures that was considered: up to $90^{\circ} \mathrm{C}$ for flat plates, up to $150^{\circ} \mathrm{C}$ for evacuated tubes, and up to $300^{\circ} \mathrm{C}$ for parabolic troughs. Extrapolation beyond these limits is not recommended.

The annual performance of a mixed-tank, recirculation system can now be predicted by first using Fig. 6-1 to determine the annual energy collection rate of the collector. Use the process load return temperature for $T_{i n}$ and use the calculated value of $F_{x}$ for $F_{S}$ if a heat exchanger is present. Now, use the result to compute the load-storage modifier for a given storage size, collector area, load flow rate, load demand, and collector $U_{L}$ value. Because the load-storage modifiers are defined by three quantities, interpolation may be necessary for two of the quantities when reading from Figs, 6-4 to 6-11.

The total annual energy collected by a mixed-tank, recirculation system is calculated as

$$
Q_{c}=\dot{q}_{c, \infty} A_{c} F_{\ell-s} N_{d a y 1 i g h t},
$$

where

$$
\begin{aligned}
\mathrm{Q}_{c}= & \text { total annual average energy collection } \\
\dot{\mathrm{q}}_{\mathrm{c}, \infty}= & \text { annual average energy collection rate during daylight hours } \\
\quad \text { (from Fig. 6-1) } & \mathrm{A}_{\mathrm{c}}=\text { collector area } \\
\mathrm{F}_{\ell-s}= & \text { annual load-storage modifier (from Figs } \cdot 6-2 \text { to } 6-9) \\
\mathrm{N}_{\text {daylight }}= & \text { number of daylight hours in year }(=4380) .
\end{aligned}
$$

The total annual process load is

$$
\mathrm{Q}_{\text {load }}=\dot{\mathrm{Q}}_{\text {load }} \mathrm{N}_{\text {load }} \text {, }
$$




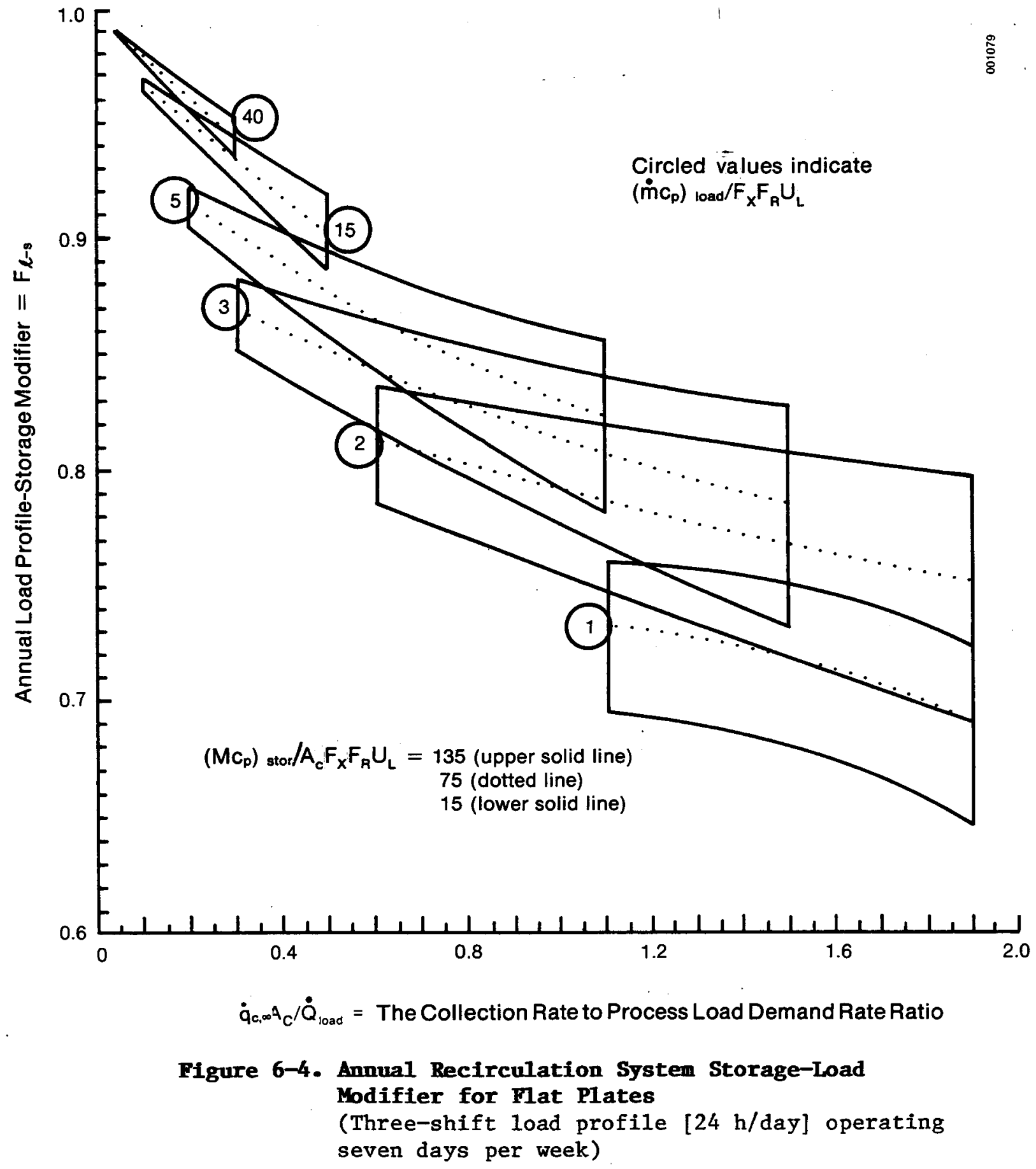




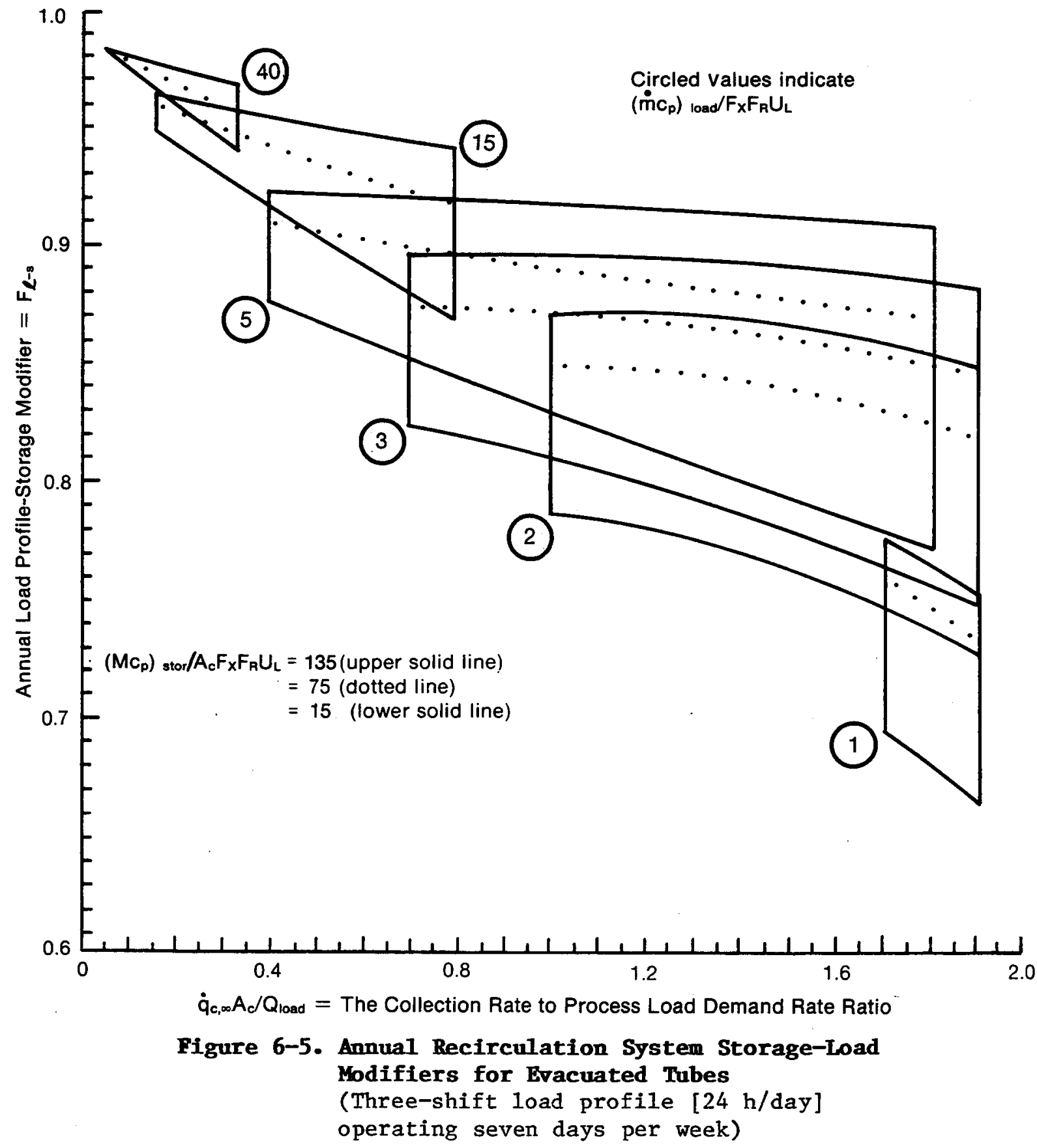




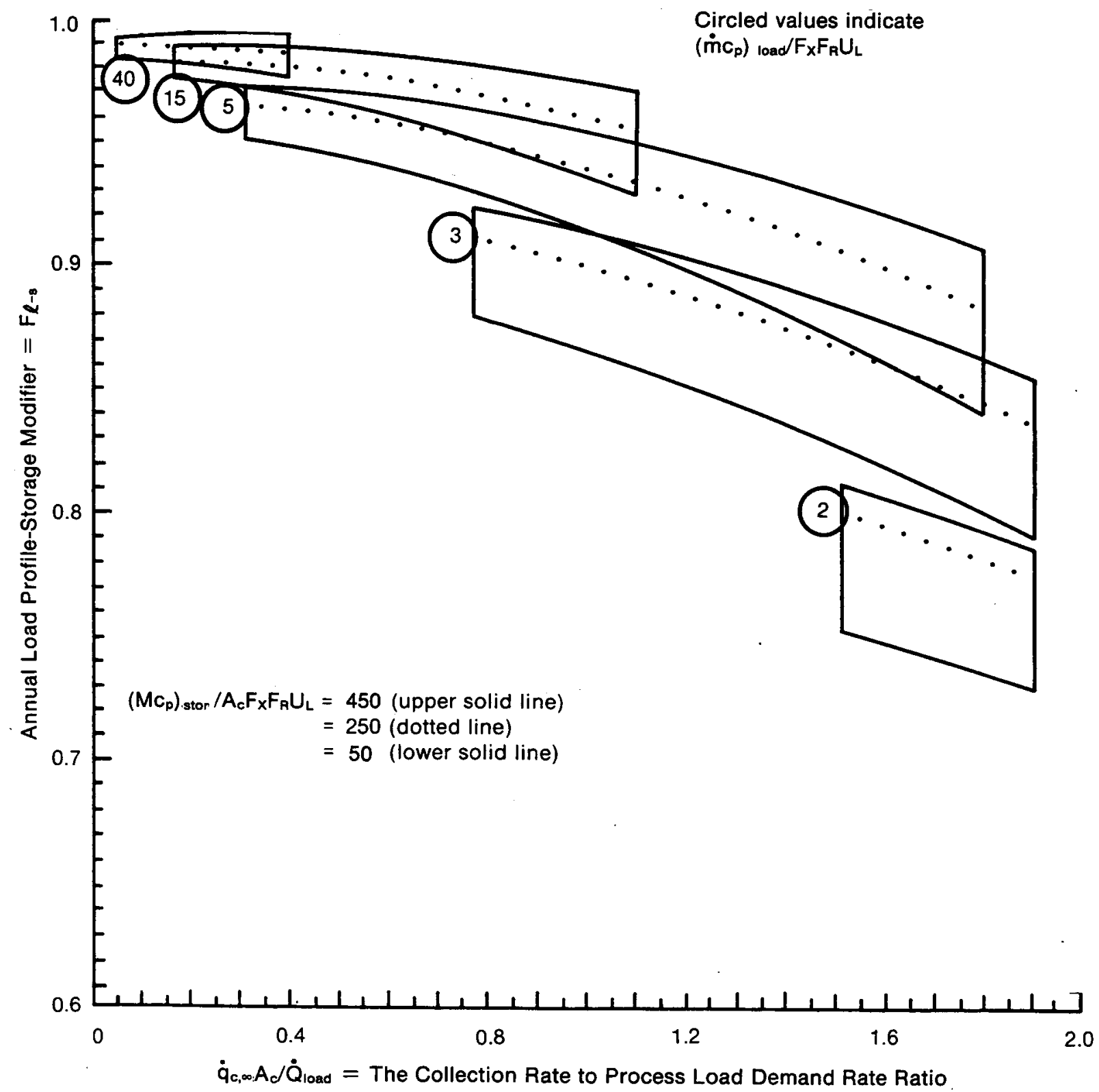

Figure 6-6. Annual Recirculation System Storage-Load Modifiers for East-West Parabolic Troughs (Three-shift load profile [24 h/day] operating seven days per week) 


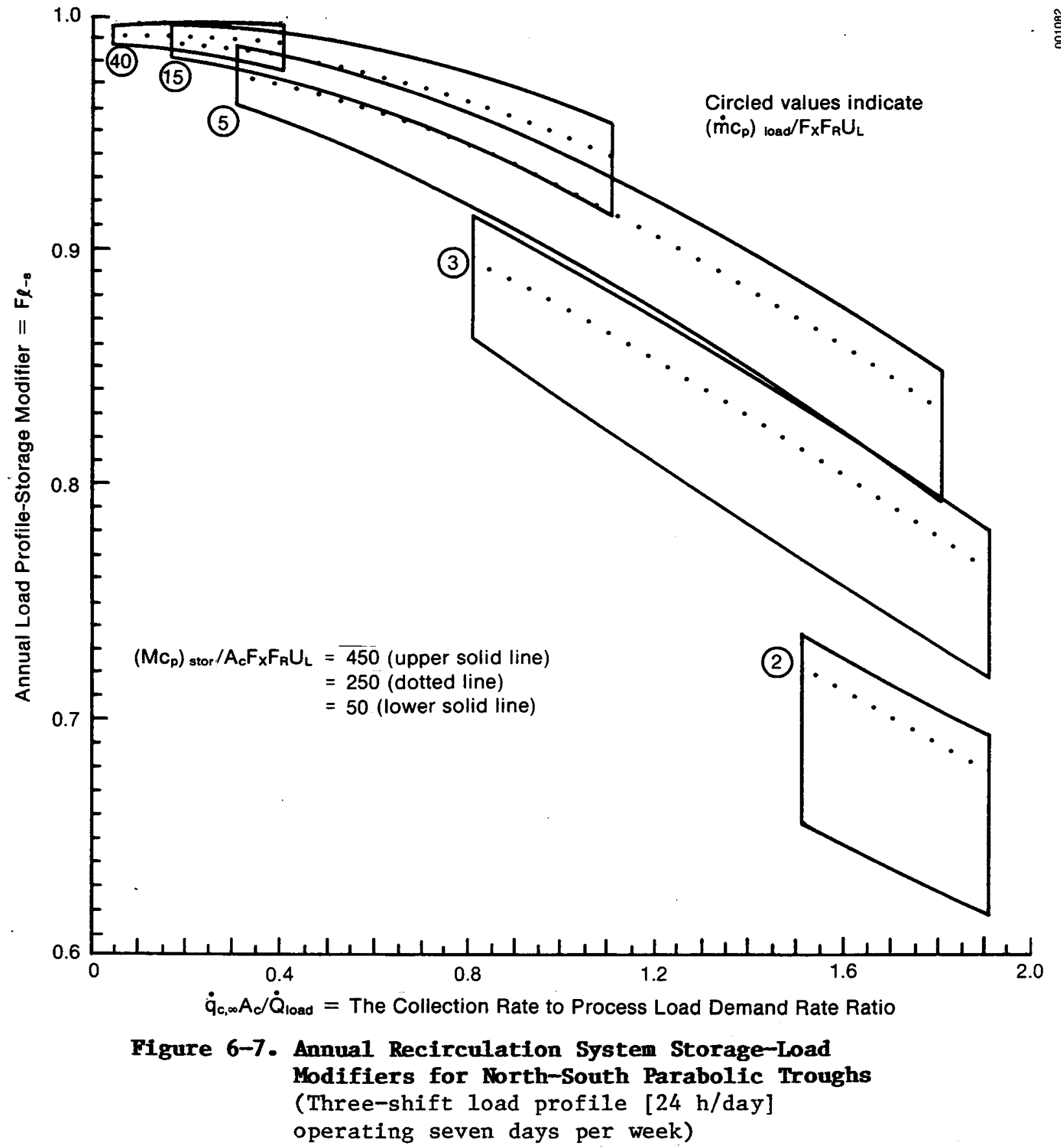




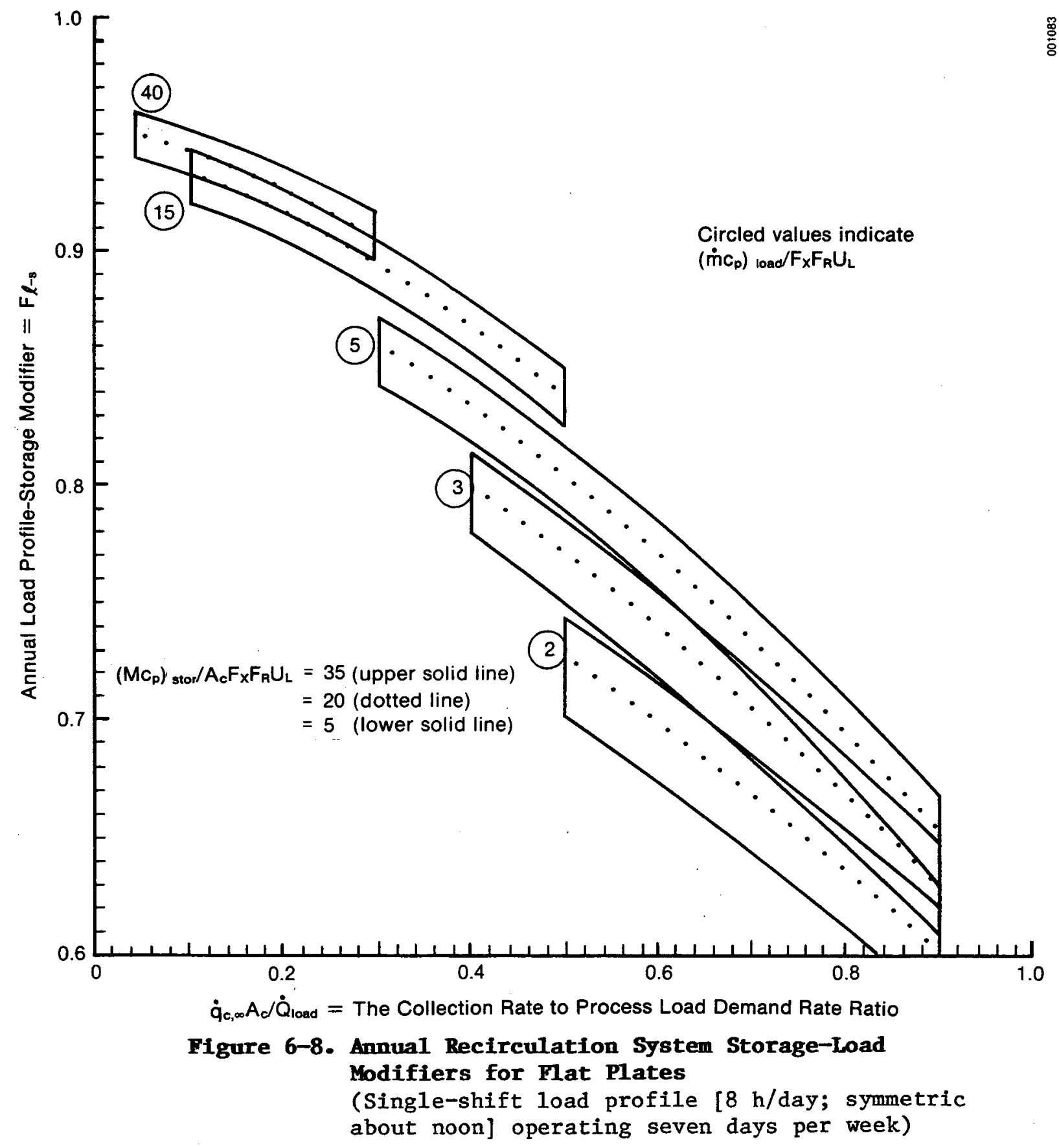




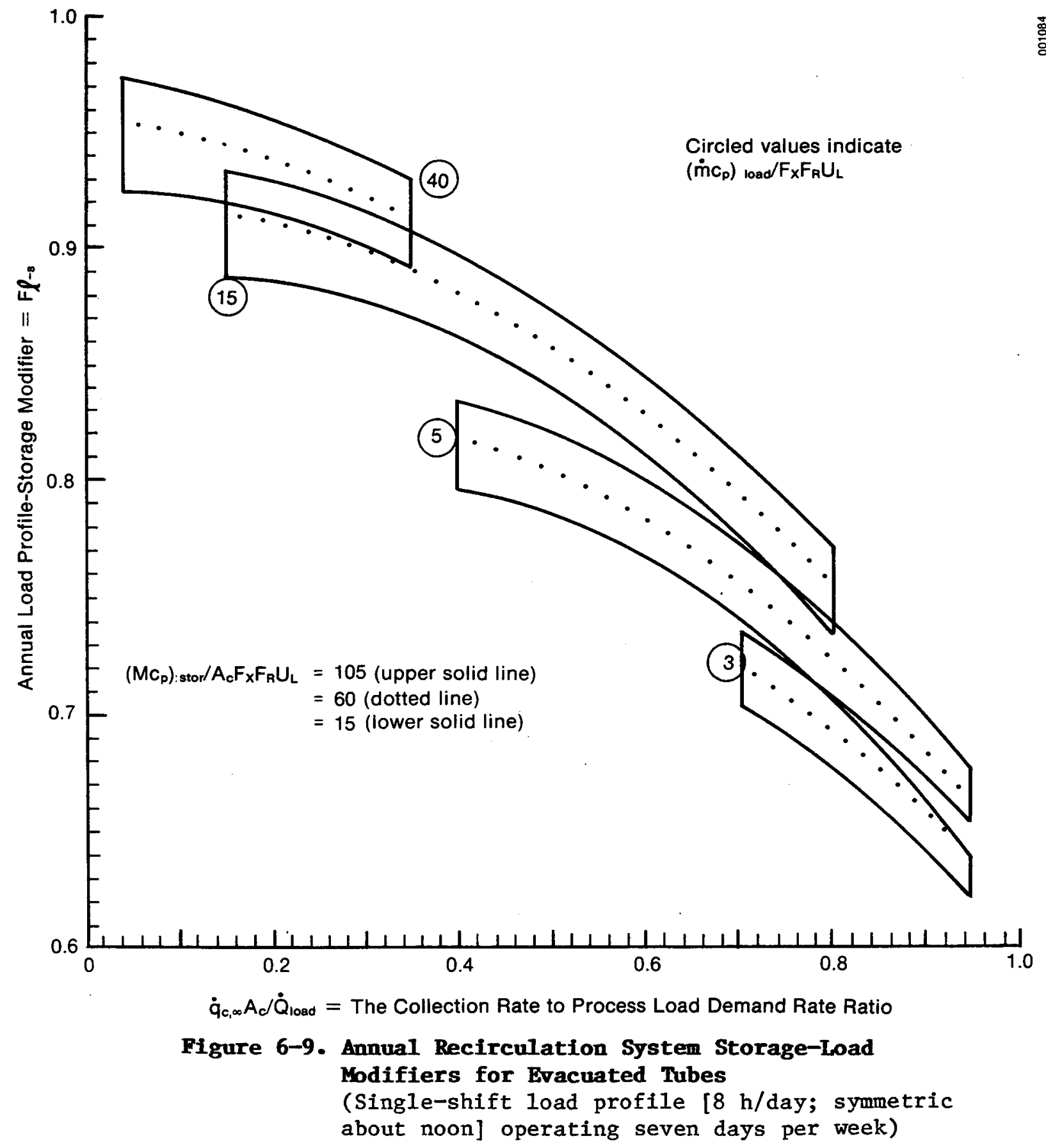




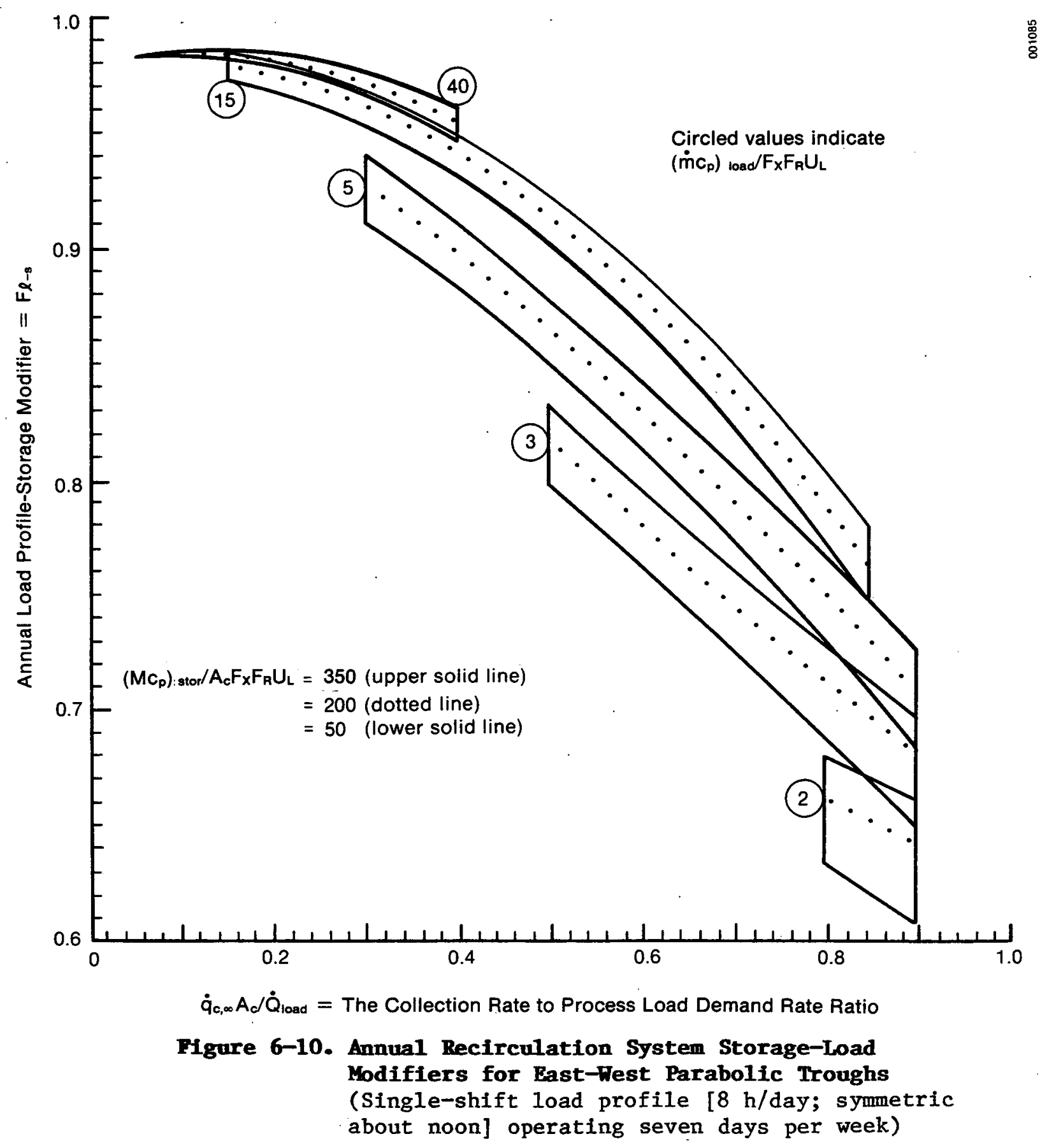




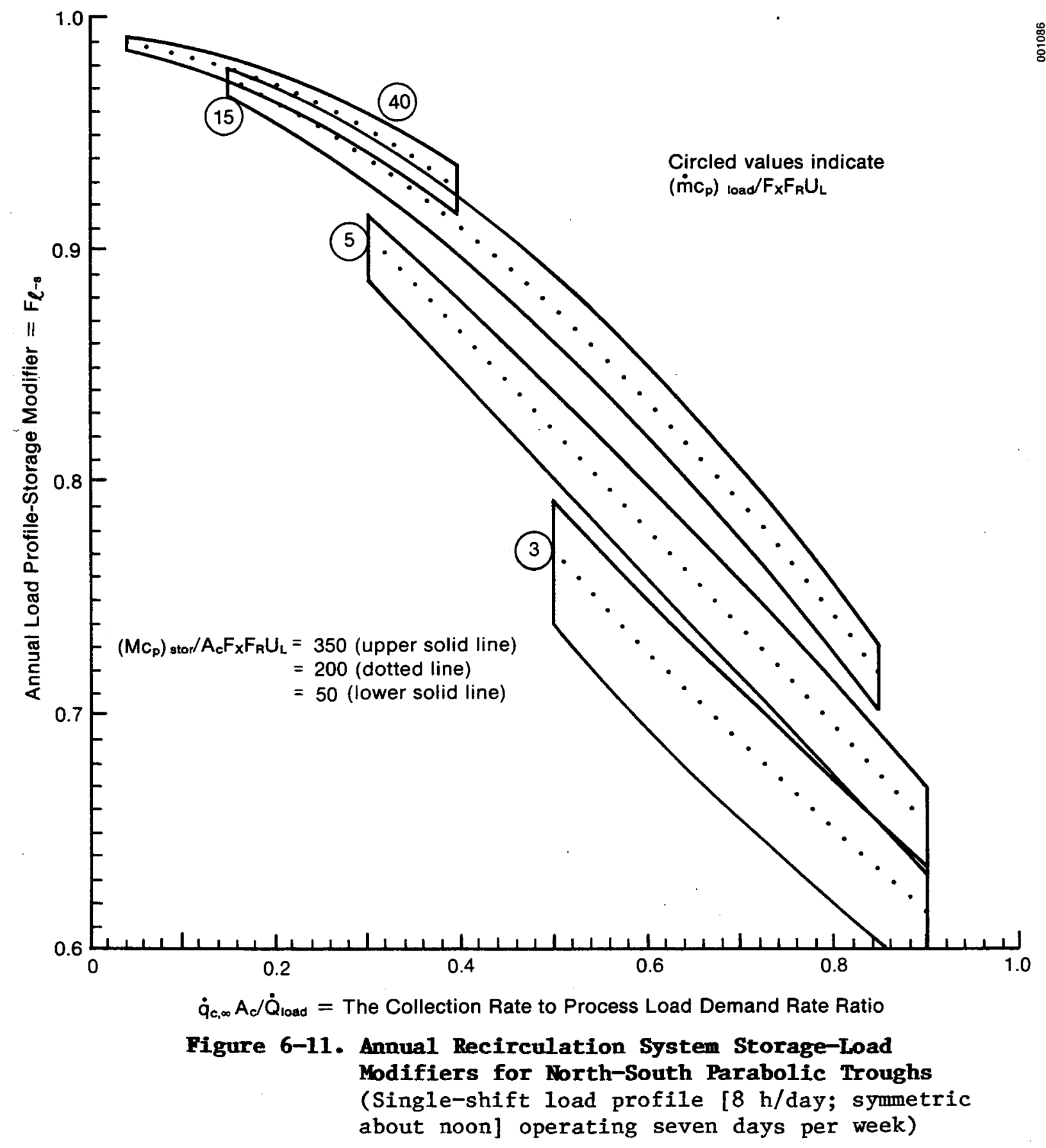


where

$$
\begin{aligned}
& \dot{Q}_{1 \text { oad }}=\text { average process load energy demand }\left[=\dot{M}_{\text {load }_{p}}\left(T_{\ell}-T_{\ell, r}\right)\right] \\
& \mathrm{N}_{1 \text { load }}=\text { number of hours load operates during the year, }
\end{aligned}
$$

Now, the solar fraction can be calculated as

$$
f=\frac{Q_{c}}{Q_{\text {load }}} \text {. }
$$

The following example 1llustrates the procedure. A solar industrial process heat system is to be installed at a medium-sized fluid milk-processing plant located in Fort Worth, Texas.* A major use of low-temperature process heat is to generate hot water for clean-up. A minimum water temperature of $43^{\circ} \mathrm{C}$ $\left(110^{\circ} \mathrm{F}\right)$ is required to dissolve milk fats. The dairy uses $16,000 \mathrm{~kg} / \mathrm{h}$ $(35,000 \mathrm{Ib} / \mathrm{h})$ of such water from $8 \mathrm{AM}$ to $4 \mathrm{PM}$ seven days per week. The hot water is produced in a steam-to-water exchanger and is piped throughout the plant to the various wash stations. Inlet water temperature is $20^{\circ} \mathrm{C}\left(68^{\circ} \mathrm{F}\right)$. The contaminated nature and low temperature of the wash water effluent make heat recovery impractical. The dairy has $800 \mathrm{~m}^{2}$ ( $8650 \mathrm{ft}^{2}$ ) of usable roof space, but much of that is over warehousing; only minimal increases in roof loads are permissible. However, the dairy owns three acres of vacant land, within $46 \mathrm{~m}$ (150 ft) of the process building, that are available for a solar energy system.

For a thorough analysis, we should compare flat-plate, evacuated-tube, and parabolic-trough collectors. For purposes of demonstrating the procedure, however, we will examine only flat plates, because of the very low temperature requirement in this application. The total annual load is as follows:

$$
\begin{aligned}
Q_{\text {Ioad }}= & \left(\dot{\mathrm{m}}_{\ell} \Delta \mathrm{t}\right) \mathrm{c}_{\mathrm{p}} \Delta \mathrm{T} \\
= & 16,000 \mathrm{~kg} / \mathrm{h} \times 56 \mathrm{~h} / \text { week } \times 52 \text { weeks } / \mathrm{yr} \times 4186 \mathrm{~J} / \mathrm{kgK} \\
& \times\left(43^{\circ} \mathrm{C}-20^{\circ} \mathrm{C}\right) \\
= & 4.84 \times 10^{12} \mathrm{~J} / \mathrm{yr} .
\end{aligned}
$$

Let us start by determining how much energy the roof area could provide. A good, single-glazed, selective-surface flat plate would have the following values (from Table 5-1):

$$
\begin{gathered}
\mathrm{F}_{\mathrm{R}_{0}}=0.65-0.8 \rightarrow \text { use } 0.72 \\
\mathrm{~F}_{\mathrm{R}_{\mathrm{L}}}=2.6-4.4 \rightarrow \text { use } 3.1 \mathrm{~W} / \mathrm{m}^{2{ }^{\circ} \mathrm{C}}
\end{gathered}
$$

In Fort Worth, Tex., the annual average total horizontal irradiance during daylight hours is about $400 \mathrm{~W} / \mathrm{m}^{2}$ (from Fig. 5-10). The $\Delta \mathrm{T}$ needed for $\mathrm{Fig}$. $6-1$ is the difference between load return and ambient. The load return is $20^{\circ} \mathrm{C}$ and the average daytime ambient in Fort Worth is $21^{\circ} \mathrm{C}$. Thus, $\Delta \mathrm{T} \approx 0$. The

*This example is based upon a case study from a SERI report by Hooker et al. (1980). 
value of $F_{x}$ will be set to one because no heat exchanger is expected to be needed. (The load return water will be circulated directly through the collectors.) So, the value on the $\mathrm{x}$-axis of Fig. 6-1 is

$$
\frac{F_{R} U_{L} \Delta T}{F_{x} F_{R} \eta_{0} I}=\frac{3.1 \times 0}{1.0 \times 0.72 \times 400}=0 \text {. }
$$

With latitude $=32.5^{\circ}$ and $X=0$, Fig. 6-1 yields a value along the $y$-axis of 1.0 .

Solving for $\dot{q}_{c, \infty}$, we obtain

$$
\frac{\dot{q}_{c, \infty}}{F_{S} F_{R} n_{o} \bar{I}}=1.0
$$

$$
\dot{q}_{c, \infty}=1.0(1.0 \times 0.72 \times 400)=288 \mathrm{~W} / \mathrm{m}^{2} \text {. }
$$

Now, use Fig. 6-8 to determine the load-storage modifier. Looking at Fig. 6-8, we see that for this load profile, minimal storage is needed. We will use a value of $20 \mathrm{~h}$ as our baseline for $\left[\left(\dot{M}_{c}\right)\right.$ stor/ $\left.\left(A F_{F} V_{U}\right)\right]$. Since we have an $800 \mathrm{~m}^{2}$ roof, we will start with a collector areac of $400 \mathrm{~m}^{2}$ (ground cover ratio of 0.5 ).

The value of $\frac{\left(\dot{M} c_{p}\right)_{1 o a d}}{A_{c} F_{S} F_{R} U_{L}}$ is then

$$
\frac{\left(16,000 \frac{\mathrm{kg}}{\mathrm{h}}\right)\left(4186 \frac{\mathrm{J}}{\mathrm{kg}^{\circ} \mathrm{C}}\right)\left(\frac{\mathrm{h}}{3600 \mathrm{~s}}\right)}{\left(400 \mathrm{~m}^{2}\right) 1\left(3.1 \frac{\mathrm{W}}{\mathrm{m}^{20} \mathrm{C}}\right)}=15.0
$$

The process load use rate, $\dot{Q}_{1 \text { oad }}$, is calculated as

$$
\dot{\mathrm{Q}}_{\text {load }}=\frac{\left(4.84 \times 10^{12} \frac{\mathrm{J}}{\mathrm{yr}}\right)\left(\frac{\mathrm{h}}{3600 \mathrm{~s}}\right)}{\left(365 \frac{\mathrm{days}}{\mathrm{yr}}\right)\left(8 \frac{\mathrm{h}}{\text { day }}\right)}=4.60 \times 10^{5} \mathrm{~W} .
$$

We can now calculate the $y$-axis value to be used with Fig. 6-8:

$$
\frac{\dot{q}_{c, \infty} A_{c}}{\dot{Q}_{1 \text { load }}}=\frac{\left(288 \mathrm{~W} / \mathrm{m}^{2}\right)\left(400 \mathrm{~m}^{2}\right)}{460 \times 10^{5} \mathrm{~W}}=0.25
$$

From Fig. 6-8, the load-storage modifier is 0.934 .

Now, the annual energy collected by $400 \mathrm{~m}^{2}$ of flat-plate collectors is given by 


$$
\begin{aligned}
Q_{c} & =\dot{q}_{c, \infty} A_{c} F_{1-s^{N}}{ }_{\text {daylight }} \\
& =\left(288 \mathrm{~W} / \mathrm{m}^{2}\right)\left(400 \mathrm{~m}^{2}\right)(0.934)(4380 \mathrm{~h}) \\
& =4.713 \times 10^{8} \mathrm{~W} / \mathrm{h}\left(17.0 \times 10^{11} \mathrm{~J} / \mathrm{yr}\right) .
\end{aligned}
$$

The solar fraction is

$$
f=\frac{Q_{c}}{Q_{\text {load }}}=\frac{17.0 \times 10^{11} \mathrm{~J} / \mathrm{yr}}{4.84 \times 10^{12} \mathrm{~J} / \mathrm{yr}}=0.35 .
$$

To increase the solar fraction substantially above 0.35 , it would be necessary to mount collectors on the land adjacent to the plant. Selecting the optimum collector area for a mixed-tank recirculation system requires a trade-off of the increased energy collection that occurs as collector area is added against the increased costs of the system. Typically, several collector areas will be selected, and the life-cycle costs of these optlons will be compared.

The collector area with the most favorable life-cycle economics is usually selected. Sometimes, however, other considerations dictate a different choice. For example, the land or roof area avallable for mounting the collectors may constrain maximum collector area. Or, if an industrial plant must operate at a certain minimum capacity to be profitable, sufficient collector area may be installed so that, in the event of an interruption of fossil-fuel supply, the solar system can maintain the thermal needs of that minimum capacity.

\subsubsection{Variable-Volume Storage System}

A variable-volume storage system is shown in Fig. 6-12. In this configuration there is no recirculation of fluid between the storage tank and the collector field. Heating the collector loop fluid is accomplished with a single pass through the collector field. The hot water is stored in a tank that can be completely drained and used by the industrial process. When solar energy is being collected, hot water is added to the tank. When a process load exists and hot water is available in the tank, the hot water is pumped from the tank to the process load. If the industrial process is an open loop (1.e., the hot water is consumed and not returned for reheat), the cold tank is not needed. Make-up water is then supplied from the water main during the day. If the industrial process is a closed loop, the return water must be stored in an additional tank (see Fig. 6-12).

An advantage of the variable-volume storage system is that the collector array is always supplied with the coldest possible fluid, whenever it is operating, regardless of whether the load is on or off. In this respect, it is similar to a no-storage system. However, because this configuration has storage, it is an efficient system configuration for all load profiles, daytime or nighttime shifts.

Our approach to the design and performance analysis of a variable-volume system follows the basic precept that thermal energy delivered by the collector system should never be dumped. This no-dump requirement is equivalent to 


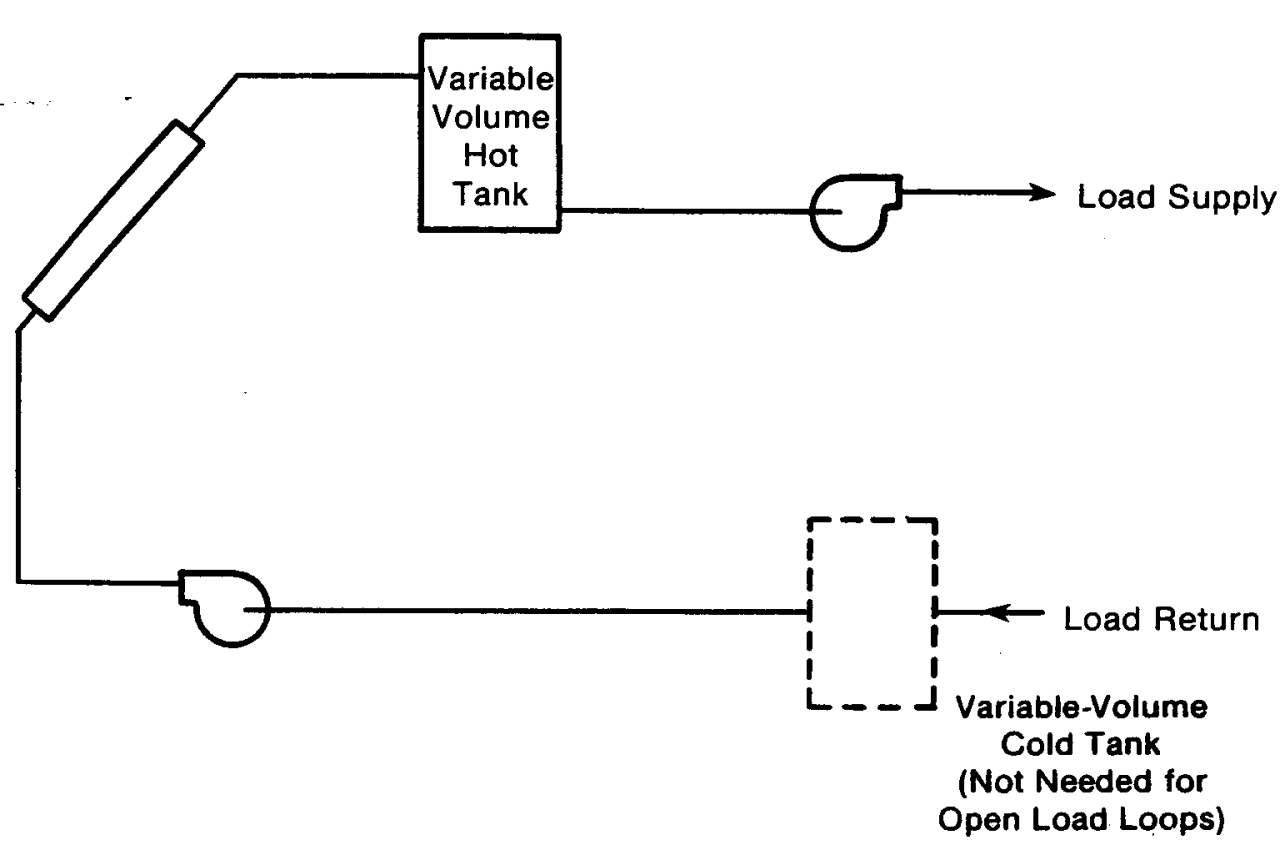

Figure 6-12. Variable-Volume Storage Configuration

sizing the system so that the peak daily energy collection of the solar system does not exceed the daily process load. Further, the volume of water heated during the day by the collectors and delivered to the storage tank should not exceed the volume of water the process needs for one day of operation. The maximum daily energy collection of the solar system can be estimated as

$$
Q_{\text {daily,max }}=A_{c} q_{a, \max } n_{c, d a i l y},
$$

where

$$
\begin{aligned}
A_{c}= & \text { collector area }\left(\mathrm{m}^{2}\right) \\
\mathrm{q}_{\mathrm{a}, \max }= & \text { maximum daily total irradiation available to collectors per } \\
& \text { unit of collector area } \\
\eta_{c, d a i l y}= & \text { day-long efficiency of collector. }
\end{aligned}
$$

The day-long efficiency of the collector can be estimated as

$$
n_{c, \text { daily }}=F_{R} n_{0}-\frac{F_{R} U_{L}\left(T_{\text {in }}-T_{a, \max }\right)}{I_{a, \text { daily }}} \text {, }
$$

where $I_{a}$ daily is the average irradiance $\left(\mathrm{W} / \mathrm{m}^{2}\right)$ avallable to the collector on a clear day. A value of $650 \mathrm{~W} / \mathrm{m}^{2}$ for $I_{\text {a,daily }}$ is a good average for clear-day irradiance and can be used as an approximation. Values of $F_{R} n_{0}$ and $F_{R} U_{L}$ can 
be taken directly from the collector performance data sheets. $T_{\text {in }}$ should be set to the process load return temperature. The maximum ambient temperature can be taken as $40^{\circ} \mathrm{C}$. Values of $q_{2}$ max are provided in Table 6-1 for the various collector types at latitudes of $24^{\circ}$ to $56^{\circ}$. These values have been derived from clear-day design tables provided in the ASBRAE Handbook of Fundamentals. The maximum dally energy collection obtained from $\overline{\text { Eqs. } 6-15 \text { and 6-16 }}$ is approximate but sufficient for system design. The constraint that the maximum energy collected in one day is less than or equal to the daily process load demand can be expressed as

$$
Q_{\text {daily,max }}<Q_{\text {load,day }} \cdot
$$

Substituting from Eq. 6-15, the maximum collector area that can be utilized and still satisfy this condition is calculated as

$$
A_{c, \max }=\frac{Q_{1 o a d, d a y}}{q_{a, \max } n_{c, \text { daily }}}
$$

The constraint that the maximum volume of water provided to storage in one day must be less than or equal to the volume of water used by the process every day can be used to determine the maximum pump mass flow rate.

$$
\dot{\mathrm{M}}_{\text {pump }}=\mathrm{M}_{\text {process }} / \mathrm{t}_{\mathrm{c}, \max } \text {, }
$$

where

\begin{tabular}{|c|c|c|c|c|c|c|}
\hline $\begin{array}{r}\begin{array}{r}\text { Latitude } \\
\text { (degrees) }\end{array} \\
24\end{array}$ & \multicolumn{2}{|c|}{$\begin{array}{c}\text { Flat-Plate } \\
\text { and Evacuated- } \\
\text { Tube Collectors }\end{array}$} & \multicolumn{2}{|c|}{$\begin{array}{c}\text { East-West } \\
\text { Parabolic } \\
\text { Trough Collectors }\end{array}$} & \multicolumn{2}{|c|}{$\begin{array}{c}\text { North-South } \\
\text { Parabolic } \\
\text { Trough Collectors }\end{array}$} \\
\hline $\begin{array}{l}24 \\
32 \\
40 \\
48 \\
56\end{array}$ & $\begin{array}{l}26.47 \\
25.37 \\
25.26 \\
25.03 \\
24.60\end{array}$ & $\begin{array}{l}(2331) \\
(2234) \\
(2225) \\
(2204) \\
(2166)\end{array}$ & $\begin{array}{l}24.47 \\
24.73 \\
25.11 \\
26.34 \\
27.33\end{array}$ & $\begin{array}{l}(2155) \\
(2178) \\
(2211) \\
(2319) \\
(2407)\end{array}$ & $\begin{array}{l}32.64 \\
33.61 \\
34.66 \\
35.74 \\
36.70\end{array}$ & $\begin{array}{l}(2874) \\
(2960) \\
(3052) \\
(3147) \\
(3232)\end{array}$ \\
\hline
\end{tabular}

$$
\begin{aligned}
M_{\text {process }} & =\text { daily process water usage }(\mathrm{kg}) \\
t_{c, \max } & =\text { maximum operating time of pump (collectors) in one day } .
\end{aligned}
$$

Table 6-1. Maximum Daily Irradiation Available for Several Collector Types ${ }^{a}$ 
The maximum operating time for a parabolic trough can be estimated from the number of daylight hours during the longest summer day. The number of hours between sunrise and sunset on the summer solstice is given (in hours) by

$$
\mathrm{t}_{\text {day, } \max }=\frac{2}{15}\left[\cos ^{-1}\left(-\tan \mathrm{L} \tan 23.5^{\circ}\right)\right],
$$

where $\mathrm{L}=$ local latitude of site, in degrees.

Realistically, two hours may be subtracted from this length of time because the solar irradiance will not be sufficient to maintain collector operation in the earliest morning hour or latest afternoon hour. Thus, the maximum operating time of a parabolic trough, for a single day, can be approximated (in hours) by

$$
t_{c, \max }=t_{\text {day,max }}-2
$$

With a flat-plate or evacuated-tube collector, no energy can be collected on a summer day until the sun is sufficiently high in the sky that sunlight falls on the front of the tilted collector. With a collector tilted at the local latitude angle, a maximum of twelve hours of sunlight is available for solar collection (Liu and Jordan 1977):

$$
t_{c, \max }=12 \text { for flat plates. }
$$

The flow rate determined from Eq. 6-18 will ensure that the volume of water heated by the solar system can always be used by the process; hence, no energy will have to be dumped. This is also consistent with a design philosophy that minimizes the operating temperature of the collector and, hence, maximizes collector efficiency, within the constraints of a single-speed pump and a nodump requirement.

Having determined the pump flow rate, we can now determine the correct value of $F_{R}$ (see Eq. 6-2) for any given collector area up to $A_{c \text { max }}$ the maximum collector area for which no dumping occurs. Adding collector area up to $A_{c, m a x}$ for a constant system flow rate results in a lower value of $F_{R}$ because the average collector operating temperature increases. Conversely, decreasing the collector area lowers the average collector operating temperature, and $F_{R}$ approaches one. Now, the annual performance of the variable-volume storage system can be predicted using only Fig. 6-1. Use the process load return temperature for $\mathrm{T}_{\mathrm{in}}$. As with the other systems, if a heat exchanger is used the heat exchanger factor $F_{X}$ should be calculated and used as $F_{S^{*}}$. The value of $F_{R}$ should be calculated based on the calculated system flow rate and the collector area being considered. The total annual energy collected is then calculated as

$$
Q_{c}=\dot{q}_{c} A_{c} N_{\text {daylight }},
$$

where

$Q_{c}=$ total annual average energy collection

$\dot{q}_{c}=$ annual average energy collection rate during daglight hours (from Fig. 6-1) 


$$
\begin{aligned}
\mathrm{A}_{\mathrm{C}} & =\text { collector area }\left(\leqslant \mathrm{A}_{\mathrm{c}, \max }\right) \\
\mathrm{N}_{\text {daylight }} & =\text { number of daylight hours in a year }(=4380) .
\end{aligned}
$$

The total annual process load is

$$
\mathrm{Q}_{\text {load }}=\dot{\mathrm{Q}}_{\text {1oad }} \mathrm{N}_{1 \mathrm{oad}} \text {, }
$$

where

$$
\begin{aligned}
& \dot{\mathrm{Q}}_{\text {load }}=\text { average process load energy rate }\left[=\dot{\mathrm{mc}}_{\mathrm{p}}\left(\mathrm{T}_{\ell}-\mathrm{T}_{\ell, \mathrm{r}}\right)\right] \\
& \mathrm{N}_{\text {load }}=\text { number of hours load operates during the year. }
\end{aligned}
$$

The solar fraction can then be calculated as

$$
\mathrm{f}=\frac{\mathrm{Q}_{\mathrm{c}}}{\mathrm{Q}_{\text {load }}} \text {. }
$$

\subsubsection{Stean Systens}

The largest share of the total industrial process heat requirement is current1y met by steam. An alternative to generating steam with a packaged steam boiler is a steam-generating solar system. In either case, the steam is delivered to the point of use in a saturated state. This saturated steam is used typically to heat a vessel to drive a chemical reaction, or it may be employed for evaporation, crystallization, etc. The steam is condensed during the process; after treatment, the hot water is returned to the boiler or solar system for revaporization. Generating steam with a solar system requires a significantly different system configuration than that for air or water process heating. Two system approaches to generating steam are considered here: flash steam systems and unfired-boiler systems. The operating temperatures needed for steam generation ordinarily preclude using water as a heat storage fluid, because an expensive high-pressure storage tank would be required. Instead, an oil is usually the heat-storage medium. Such fluids are quite expensive. Therefore, because storage for steam systems is so expensive, it is not likely to be used widely in the near future and is not discussed here. Information on the performance of steam systems using thermocline storage can be found in Harrigan (1981).

\subsubsection{Unfired-Boiler Steam Systems}

In an unfired-boiler steam system (see Fig. 4-4), an organic heat transfer fluid is pumped through the collector field and then to an unfired boiler. The hot fluid within the tubes of the boiler vaporizes the water next to the tubes; this saturated steam is fed to the existing steam header, which delivers energy to the industrial process. As the steam is generated, additional condensate is supplied to the boiler. The hot condensate is assumed to be saturated. Steam generation is a latent-heat process; therefore, no temperature change occurs on the water side of the boiler. Because heat is being transferred from the collector loop fluid to the water, the fluid in the collector loop must always exceed the steam saturation temperature. Therefore, 
the temperature of the fluid at the inlet to the collector fluid must exceed the steam saturation temperature. To account for the temperature elevation of the collector loop inlet above the steam temperature, a performance modifier is introduced-the unfired boiler factor, $F_{B}$. It is calculated as follows:

where

$$
F_{B}=\left[1+\frac{F_{R} U_{L}}{\dot{m}_{c} c_{p}\left(e^{U_{b} A_{b} / \dot{M}_{c} c_{p}}-1\right)}\right]^{-1},
$$

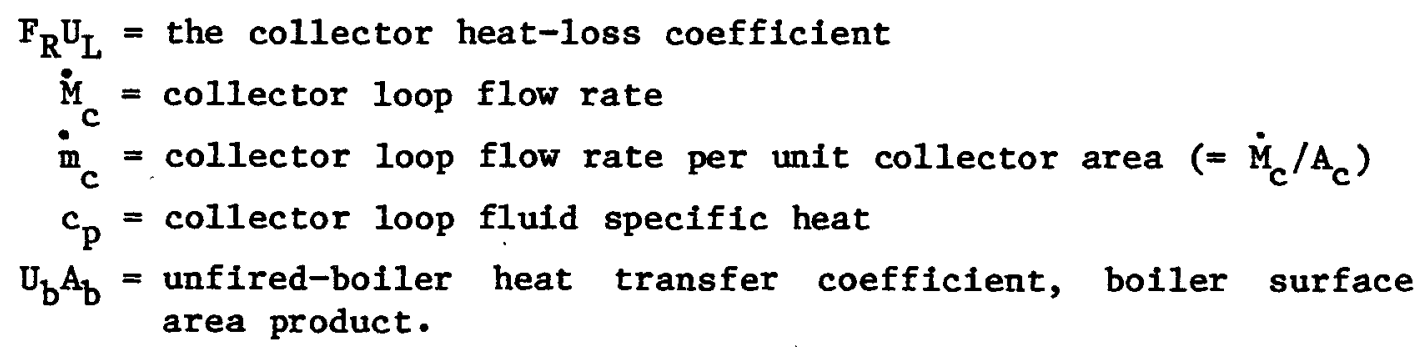

The unfired-boiler modifier is shown to be a function of the unfired-boiler UA value, the collector loop flow rate, and the collector $U_{L}$ value. The derivation of this modifier is given in Appendix E. It assumes that the collector loop flow rate is constant. A constant collector loop flow rate is usually used for steam systems, although variable flow rate systems that maintain a constant collector outlet temperature are sometimes employed. However, the greater complexity of a variable flow rate system is usually unwarranted. More details on variable flow control systems are given in Sec. 8.0.

The unfired-boiler modifier allows energy collection for an unfired-boiler steam system to be written as

$$
\dot{q}_{c}=F_{B} F_{R}\left[n_{0} I_{a}-U_{L}\left(T_{i n}-T_{a}\right)\right] \text {. }
$$

To size the maximum collector area for an unfired-boiler system without storage, follow the guideline that no collected energy should be dumped, the same as for the no-storage hot air and hot water systems. The rate at which the process load requires energy is equated to the rate at which the collector field can deliver energy under the best solar collection conditions:

$$
\begin{aligned}
\dot{Q}_{\text {load }} & =\dot{Q}_{C, \max }=A_{C} \dot{q}_{C, \max } \\
& =A_{C} F_{B} F_{R}\left[\eta_{0} I_{\max }-U_{L}\left(T_{i n}-T_{a, \max }\right)\right] .
\end{aligned}
$$

As suggested in Sec. 6.1 .1 .1 , a value of $1000 \mathrm{~W} / \mathrm{m}^{2}$ can be used for parabolic troughs and $1100 \mathrm{~W} / \mathrm{m}^{2}$ for flat-plate and evacuated-tube collectors. Also, a maximum ambient temperature $\left(T_{a}\right.$,max $)$ of $40^{\circ} \mathrm{C}$ is recommended. Values of $F_{R^{n}}$ and $\mathrm{F}_{\mathrm{R}} \mathrm{U}_{\mathrm{L}}$ are taken directly from the performance data of the collector. $\mathrm{T}_{\text {in }}$ should be set to the steam saturation temperature. After all the appropriate values are determined, the maximum collector area for the no-storage system is then solved as

$$
A_{c, \max }=\dot{Q}_{\text {load }} /\left\{F_{B}\left[F_{R} I_{\max } n_{o}-F_{R} U_{L}\left(T_{\text {in }}-T_{a, \max }\right)\right]\right\} \text {. }
$$


This collector area is the maximum amount that can be used within the no-dump constraint. Smallex collector fields can also be used with a resulting smaller amount of solar system energy collection. Now, the annual performance of the solar system can be predicted using Fig. 6-1. Use the unfired boiler factor $F_{B}$ for $F_{S}$ and the steam saturation temperature for $T_{\text {in }}$. The total annual energy collected is then calculated as

$$
Q_{c}=\dot{q}_{c} A_{c} N_{\text {daylight }},
$$

where

$$
\begin{aligned}
\dot{q}_{c}= & \text { annual average energy collection rate during daylight hours } \\
& \text { per unit collector area (from Fig. } 6-1) \\
A_{c}= & \text { collector area }\left(\leqslant A_{c, \text { max }}\right) \\
N_{\text {daylight }}= & \text { number of daylight hours in year }(=4380) .
\end{aligned}
$$

The total annual process load is

$$
\mathrm{Q}_{\text {load }}=\dot{\mathrm{Q}}_{\text {load }} \mathrm{N}_{\text {load }},
$$

where

$$
\begin{aligned}
& \dot{Q}_{\text {load }}=\text { average process load energy rate }\left[=\dot{\operatorname{mload}}_{\mathrm{p}}\left(\mathrm{T}_{\ell}-\mathrm{T}_{\ell}, \mathrm{r}\right)\right] \\
& \mathrm{N}_{\text {load }}=\text { number of hours that process load operates during year. }
\end{aligned}
$$

Now, the solar fraction can be calculated as

$$
f=\frac{Q_{c}}{Q_{\text {load }}} \text {. }
$$

\subsubsection{Flash Steam Systems}

In a flash steam solar system (see Fig. 4-3), pressurized water is circulated through the collector field and flashed to low-quality steam across a throttling valve into a flash, or separator, tank. Flashing is a constant enthalpy process that converts the sensible heat of the water into a two-phase mixture of saturated water and saturated steam at conditions prevailing in the flash tank. The steam quality (fraction of total mass flow that is flashed to vapor) usually is less than $10 \%$. Steam separated in the flash tank is fed into the plant steam distribution system to be used by the industrial process. The saturated liquid is recirculated through the collector field. To maintain the necessary liquid level in the flash tank, boiler feedwater is injected into the pump suction.

To prevent boiling within the collectors or the collector field piping, the water must be pressurized. Pressure is maintained by the recirculation pump which, in the simplest control mode, operates at constant flow. The pump is sized so that water exiting the collector fleld is under sufficient pressure to prevent boiling. The collector field outlet temperature must be considerably above the steam delivery temperature to obtain reasonable steam qualities 
downstream of the throttling valve. Higher steam qualities allow the water to be recirculated through the collector field fewer times. Therefore, the average collector operating temperature is usually significantly above the steam saturation temperature. A performance modifier accounts for this temperature elevation-the =flash system factor $F_{F}$. It is calculated as follows:

where

$$
\mathrm{F}_{F}=\left[\overline{1}-\frac{\mathrm{F}_{R} \mathrm{U}_{\mathrm{L}} / \dot{\mathrm{m}}_{\mathrm{c}}}{\Delta \mathrm{h}_{\mathrm{fg}}+\mathrm{c}_{\mathrm{p}}\left(\mathrm{T}_{\mathrm{s}}-\mathrm{T}_{\mathrm{f}}\right)}\left(\mathrm{T}_{\mathrm{s}}-\mathrm{T}_{\mathrm{f}}\right)\right]^{-1}
$$

$$
\begin{aligned}
\dot{m}_{c} & =\text { collector loop flow rate per unit collector area } \\
\Delta \mathrm{h}_{\mathrm{fg}} & =\text { heat of vaporization of steam at its saturation temperature } \\
\mathrm{c}_{\mathrm{p}} & =\text { specific heat of saturated water } \\
\mathrm{T}_{\mathrm{s}} & =\text { steam saturation temperature } \\
\mathrm{T}_{\mathrm{f}} & =\text { feedwater temperature. }
\end{aligned}
$$

The derivation of this modifier is given in Appendix E. It allows energy collection for a flash system to be written as

$$
\dot{\mathrm{q}}_{\mathrm{c}}=\mathrm{F}_{\mathrm{F}} \mathrm{F}_{\mathrm{R}}\left[\mathrm{n}_{\mathrm{O}} \mathrm{I}_{\mathrm{a}}-\mathrm{U}_{\mathrm{L}}\left(\mathrm{T}_{\mathrm{in}}-\mathrm{T}_{\mathrm{a}}\right)\right] .
$$

This is identical to the unfired boiler (Eq. 6-26) except that $F_{F}$ is substituted for $F_{B}$. Therefore, Eqs. 6-27 to 6-31 can be used for the flash system sizing and performance analysis, using $\mathrm{F}_{\mathrm{F}}$.

\subsection{INCIDENT-ANGLE EFFECTS}

The incident angle of solar radiation on a solar collector is defined as the angle between the normal-to-the-collector aperture and the direction of the sun. In describing off-normal irradiance, only the direct or beam component of irradiation is considered. Diffuse irradiance does not affect incidentangle corrections because it is nondirectional by definition.

The incident angle of solar radiation has an impact on energy collection in several ways. First, the intensity of the beam irradiance component available to the collector decreases at off-normal incidence according to the cosine of the incident angle. This effect has been incorporated into the performance curves of Fig. 6-1, because the hour-by-hour computer model from which the figure was generated computed the incident angle for each hour and provided for this correction.

Second, off-normal irradiation typically reduces the optical efficiency of a collector below that for normally incident irradiation. The effect is described by an incident-angle modifier that shows how the optical efficiency 
of a collector changes with incident angle, relative to its optical efficiency at normal incidence. The impact of a collector's incident-angle modifier upon the annual performance of a collector is described in Sec. 6.2.1.

The third effect applies to parabolic-trough collectors but not to flat-plate or evacuated-tube collectors. This incident-angle effect, end loss, refers to energy lost from the end of a parabolic trough when the incident radiation is not normal. Some of the radiation reflected at the end of a parabolic concentrator will spill off the end of the row and not be intercepted by the receiver. This loss is accounted for in Sec. 6.2.2.

\subsubsection{Incident-Angle Modifiers}

The optical efficiency of most collectors decreases as the incident angle of incoming irradiation increases. This is shown in Fig. 5-9, which provides typical incident-angle modifiers of various collectors. In some cases, however, a collector's optical efficiency can increase with off-normal irradiation. Evacuated-tube collectors without specular reflectors can have incident-angle modiflers that increase with that angle because, as the sun angle gets lower, the effective gap between tubes shrinks and intercepted irradiation increases. Flat-plate collectors decrease in optical efficiency at offnorma1 incidence because, as incident angles increase, the transmittance of glazing materials and the absorptance of the absorber coatings decrease. Parabolic troughs exhibit a reduction in optical efficiency at off-normal incidence because of glazing and absorber properties as well as because of the increase in path length of the reflected radiation at off-normal incidence. That increased path length permits a wider spread in the reflected beam and causes the amount of radiation intercepted by the receiver to drop.

For each of the three types of collectors, a typical incident-angle modifier has been assumed in the curves of Fig. 6-1. For energy-collection predictions for collectors with other than these assumed incident-angle modifiers, correction factors are used. Correction factors for flat plates, evacuated tubes, and parabolic troughs are given below.

As noted in Sec. 5.2, the incident-angle modifier for a flat-plate collector can be correlated by an equation of the form:

$$
k_{\alpha \tau}=1-b_{0}\left[(\cos \theta)^{-1}-1\right],
$$

where $b_{0}$ is the incident-angle modifier coefficient.

Figure 6-1 assumes $a b_{o}$ value of 0.11 , which is typical of single-glazed flatplate collectors with black painted absorbers. However, $b_{0}$ values down to about 0.06 have been found, and $b_{0}$ values up to about 0.17 are typical of double-glazed flat-plate collectors. We need a way to account for these differences to provide an accurate collector performance analysis. Figure 6-13 provides a simple graphical correction factor for the performance impact of incident-angle modifiers of flat-plate collectors. The $x$-axis is simply the incident-angle modifier coefficient $b_{0}$ for the given flat plate. Along the y-axis, the graph provides a value of the annual incident-angle modifier. This annual modifier yields a correction term to the optical efficiency of a 
collector that closely accounts for the performance impact of the incidentangle modiffer on an annual basis. Note that because $a b_{0}$ value of 0.11 was assumed for Fig. 6-1, the annual modifier for $a b_{0}$ value of 0.11 is one; $1 . e$. , no correction is necessary. For $b_{0}$ values other than 0.11 we must correct the optical efficiency term $\eta_{0}$ in Fig. $6-1$, on both the $x$-axis and $y$-axis.

The incident-angle modifiers of evacuated-tube collectors usually cannot be expressed in the form of Eq. 6-34; therefore, Fig. 6-13 does not apply. Instead, a simple equation helps us to arrive at an annual modifier that closely accounts for incident-angle effects. The evacuated-tube annual modifier correction can be calculated as

$$
\mathrm{K}_{\mathrm{p} \tau \alpha}=0.24 \mathrm{~K}_{7.5}+0.23 \mathrm{~K}_{22.5}+0.22 \mathrm{~K}_{37.5}+0.20 \mathrm{~K}_{52.5}+0.15 \mathrm{~K}_{67.5} \cdot
$$

The $\mathrm{K}$ values are the incident-angle modifiers at the particular incident angle denoted by the subscript. Essentially, Eq. 6-35 breaks up a collector's incident-angle modifier curve into $15^{\circ}$ intervals and applies a weighting factor to each interval. These empirical weighting factors are defined largely by the fraction of collectable energy that occurs within each incident-angle span.

Equation 6-35 allows the performance impact of the incident-angle modifier of an evacuated tube to be evaluated quickly even if it is highly irregular, as it is for some evacuated tube collectors. Because the same curves on Fig. 6-1 are used for both flat plates and evacuated tubes, the baseline evacuated-tube incident-angle modifier was assumed to be also given by Eq-6-34. Therefore, the correction factor calculated with $\mathrm{Eq} \cdot 6-35$ is relative to the same baseline incident-angle modifier as the flat-plate collectors. As before, the modifier calculated with Eq. $6-35$ is applied to the optical efficiency in using Fig. 6-1.

Parabolic-trough incident-angle modifiers, like those of evacuated-tube collectors, are not well correlated by an equation like Eq. 6-34. Typically, parabolic-trough incident-angle modifiers decrease more rapidly with incident angle than do those of flat-plate collectors (Gaul and Rabl 1980). To account for these differences, an annual modifier correction (similar to that for an evacuated tube) is provided. The annual incident-angle modifier correction for an east-west parabolic trough is calculated as:

$$
\mathrm{K}_{\mathrm{p} \tau \alpha}=0.33 \mathrm{~K}_{7.5}+0.30 \mathrm{~K}_{22.5}+0.22 \mathrm{~K}_{37.5}+0.14 \mathrm{~K}_{52.5}+0.03 \mathrm{~K}_{67.5}
$$

As before, the $K$ values are taken from the incident-angle modifier curve for the collector at the incident angles denoted by the subscript. Because little energy is available for collection at high incident angles, the weighting factor for them is small. Most of the energy available to a parabolic trough occurs at small incident angles; thus, the weighting is greater there.

A general equation with constant weighting factors (of the simple form of Eq. 6-36) is not accurate for north-south parabolic troughs because of the impact that latitude has on the average incident angles of north-south troughs. The weighting factors are a function of the latitude of the site, as shown in Fig. 6-14. The weighting is larger at low incldent angles for low latitudes 


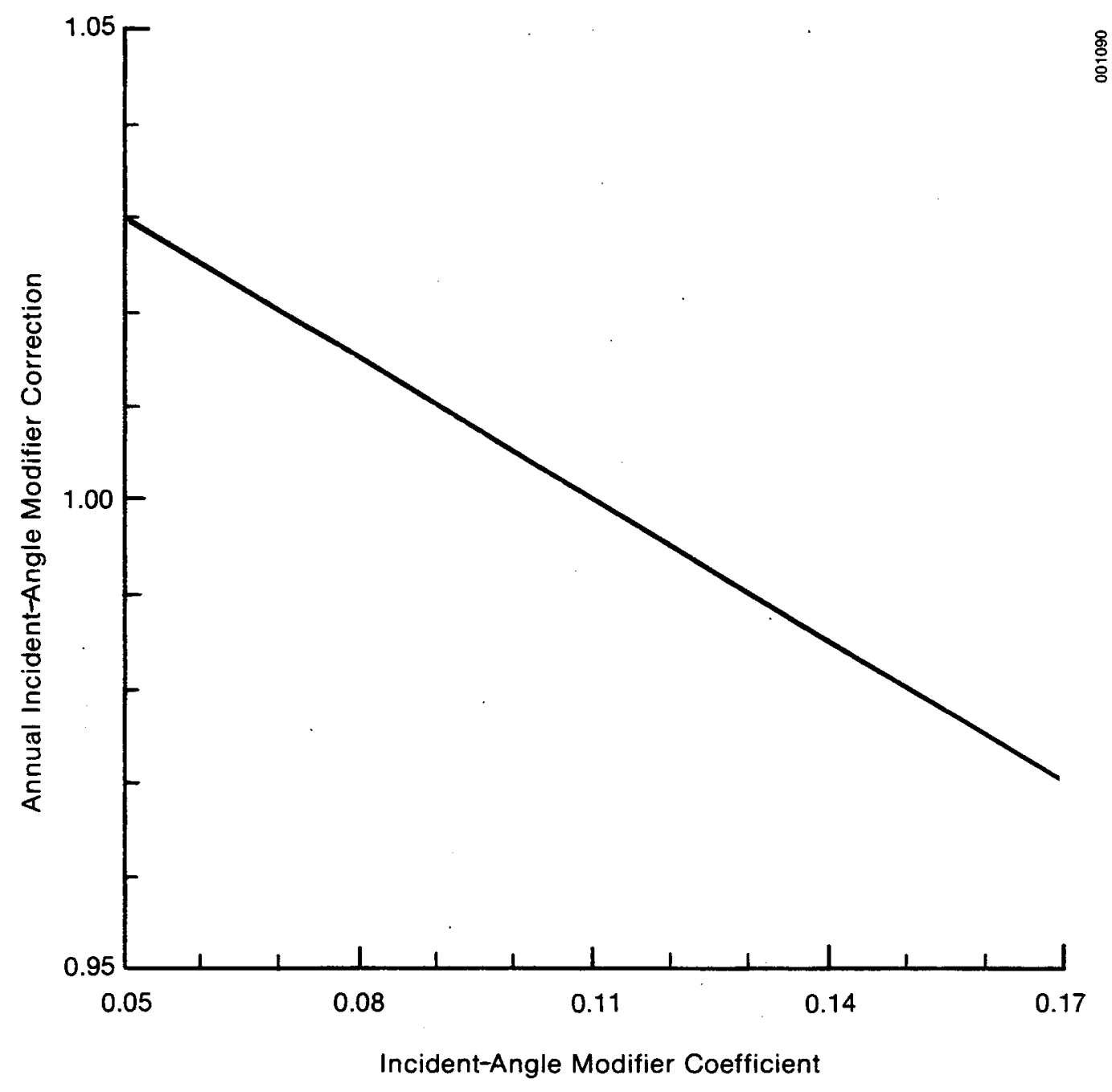

Figure 6-13. Annual Incident-Angle Modifier Correction Factor for Flat-Plate collectors 


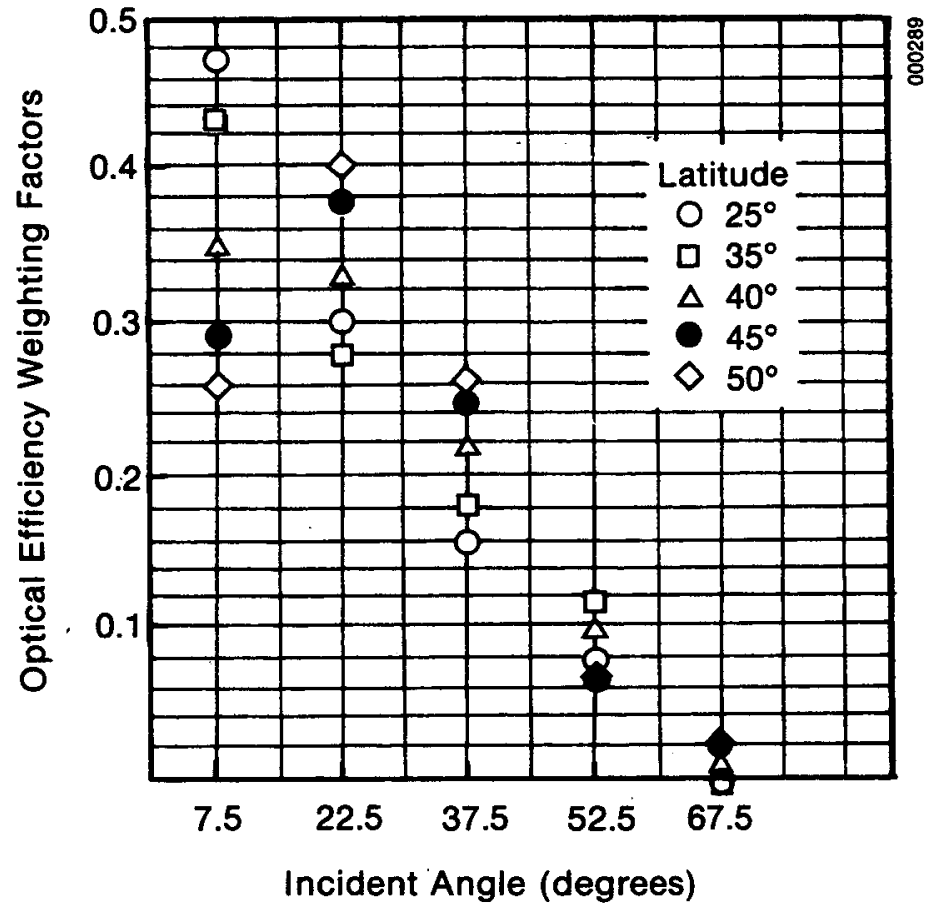

\section{Figure 6-14. Annual Optical Efficiency Incident-Angle Weighting Factors for a North-South Trough}

because, at low latitudes, the bulk of the energy striking a north-south parabolic trough occurs at low incident angles. At high latitudes, north-south troughs often operate when incident angles are high; therefore, the weighting is smaller at low incident angles.

\subsubsection{End Losses}

Radiation spillover, or end loss, from parabolic troughs of finite length can be calculated (Gaul and Rabl 1980) as:

$$
L_{\text {end }}=1-\frac{f}{\ell}\left[1+w^{2} /\left(48 f^{2}\right)\right] \tan \theta,
$$

where

$$
\begin{aligned}
\mathrm{L}_{\text {end }} & =\text { end loss factor }(1-\text { fraction lost }) \\
\mathrm{f} & =\text { trough focal length } \\
\ell & =\text { trough length } \\
\mathrm{w} & =\text { trough aperture width } \\
\theta & =\text { incidence angle. }
\end{aligned}
$$


This equation assumes that the receiver has the same length as the concentrator. The end-loss factor is shown to decrease as parabolic trough lengths increase and incident angles decrease.

Gaul and Rabl (1980) evaluated the a11-day average of the end-loss factor for a typical parabolic trough on a seasonal basis. Their results are shown in Table 6-2. An additional column of data has been added for the annual endloss factor, based on the average of the summer, autumn, winter, and spring end-1oss factors. For typical parabolic trough drive strings with $\mathrm{l} / \mathrm{f}$ ratios exceeding 25, the annual end-loss factor is above $0.96 . *$ Therefore, less than $4 \%$ of the collectable energy is lost because of end spillage. The annual endloss factor should be estimated from Table 6-2 for the particular collector drive string to be configured for the IPH collector system. This end-loss factor should then be used to modify the energy predictions computed from Fig. 6-1.

\subsection{RON-TO-RON SHADING EFFECTS}

Typical IPH collector flelds are arranged with multiple rows of collectors. These collector rows are set quite close together to minimize land area requirements and collector field piping. However, this close proximity causes row-to-row shading losses. These shading losses are not accounted for in the curves of Fig. 6-1. The graphs in this subsection quantify these row-to-row shading losses on an annual basis. The analysis of row-to-row shading loss is greatly simplified if end effects are ignored and each row is assumed to be much longer than it is wide, a good approximation for typical IPH collector rows. With this assumption in mind, consider parallel rows of collectors

Table 6-2. Al1-Day Average of End-Loss Factors ( $\mathrm{L}_{\text {end }}$ )

\begin{tabular}{|c|c|c|c|c|c|c|c|c|}
\hline \multirow{2}{*}{$\frac{\ell}{f}$} & \multicolumn{4}{|c|}{ East-West Axis } & \multicolumn{4}{|c|}{ North-South Axis } \\
\hline & Summer & Equinox & Winter & Year & Summer & Equinox & Winter & Year \\
\hline 6.44 & $\begin{array}{l}0.861^{a} \\
0.880\end{array}$ & $\begin{array}{l}0.872 \\
0.896\end{array}$ & $\begin{array}{l}0.911 \\
0.930\end{array}$ & $\begin{array}{l}0.879 \\
0.901\end{array}$ & $\begin{array}{l}0.947 \\
0.967\end{array}$ & $\begin{array}{l}0.899 \\
0.887\end{array}$ & $\begin{array}{l}0.760 \\
0.736\end{array}$ & $\begin{array}{l}0.876 \\
0.869\end{array}$ \\
\hline 12.90 & $\begin{array}{l}0.928 \\
0.937\end{array}$ & $\begin{array}{l}0.934 \\
0.944\end{array}$ & $\begin{array}{l}0.952 \\
0.960\end{array}$ & $\begin{array}{l}0.937 \\
0.946\end{array}$ & $\begin{array}{l}0.978 \\
0.978\end{array}$ & $\begin{array}{l}0.944 \\
0.938\end{array}$ & $\begin{array}{l}0.873 \\
0.861\end{array}$ & $\begin{array}{l}0.935 \\
0.929\end{array}$ \\
\hline 25.70 & $\begin{array}{l}0.961 \\
0.965\end{array}$ & $\begin{array}{l}0.965 \\
0.969\end{array}$ & $\begin{array}{l}0.972 \\
0.975\end{array}$ & $\begin{array}{l}0.966 \\
0.970\end{array}$ & $\begin{array}{l}0.984 \\
0.984\end{array}$ & $\begin{array}{l}0.967 \\
0.963\end{array}$ & $\begin{array}{l}0.930 \\
0.924\end{array}$ & $\begin{array}{l}0.962 \\
0.959\end{array}$ \\
\hline
\end{tabular}

$a_{\text {Top number }}$ represents cutoff time one hour before sunset; bottom number represents cutoff time two hours before sunset.

Source: Gaul and Rab1 1980.

*This assumes that the losses that occur between adjacent modules on a drive string are negligible. 
(either tracking or nontracking) as shown in Fig. 6-15a. The row-to-row spacing is designated as $R$ and the aperture width of the collector is $W$. We define the ground cover ratio (GCR) to be the ratio of $W$ to $R$ :

$$
\mathrm{GCR}=\frac{\mathrm{W}}{\mathrm{R}} \text {. }
$$

First, let us consider the beam component of radiation. Either the beam component is shaded from one row to another, as shown in Fig. 6-15b, or the beam component is not shaded from row to row, as shown in Fig. 6-15c. Note that when shading does occur, no beam irradiance reaches the ground; that is, a11 the beam irradiance that would normally reach the ground has been intercepted by the collectors. Hence, the radiation incident on the collector array is

$$
A_{g} I_{b} \cos \theta_{h} \text {, }
$$

where

$$
\begin{aligned}
& A_{g}=\text { ground area } \\
& I_{b}=\text { beam irradiance (direct norma1) } \\
& { }^{\theta_{h}}=\text { incident angle of direct irradiance on the horizontal sur- } \\
& \text { face. }
\end{aligned}
$$

Whenever no shading occurs, the radiation incident upon the collector is

$$
A_{c} I_{b} \cos \theta
$$

where

$$
\begin{aligned}
A_{C}= & \text { collector area } \\
\theta= & \begin{array}{l}
\text { incident angle of beam irradiance on the aperture of the } \\
\text { collector. }
\end{array}
\end{aligned}
$$

Therefore, as given by Rabl (1981), the beam irradiance avallable per unit of collector aperture area is

$$
I_{a}=I_{b} \cdot \operatorname{Min}\left\{\cos \theta, \frac{\cos \theta_{h}}{G C R}\right\} \text {. }
$$

Therefore, the direct irradiation available to a collector, including shading effects, is a function of incident angles (which are defined by the collector type and the site latitude) and the ground cover ratio. The collector tilt angle is assumed to be equal to the site latitude.

Now, consider the diffuse component of radiation for flat-plate and evacuatedtube collectors. A fraction of the diffuse component of radiation that would normally fall upon a collector is blocked by the row immediately in front of it. To the extent that diffuse radiation is isotropic (as is typically assumed), the fraction of the diffuse radiation incident on a horizontal surface that is available to a tilted collector can be calculated as the view 


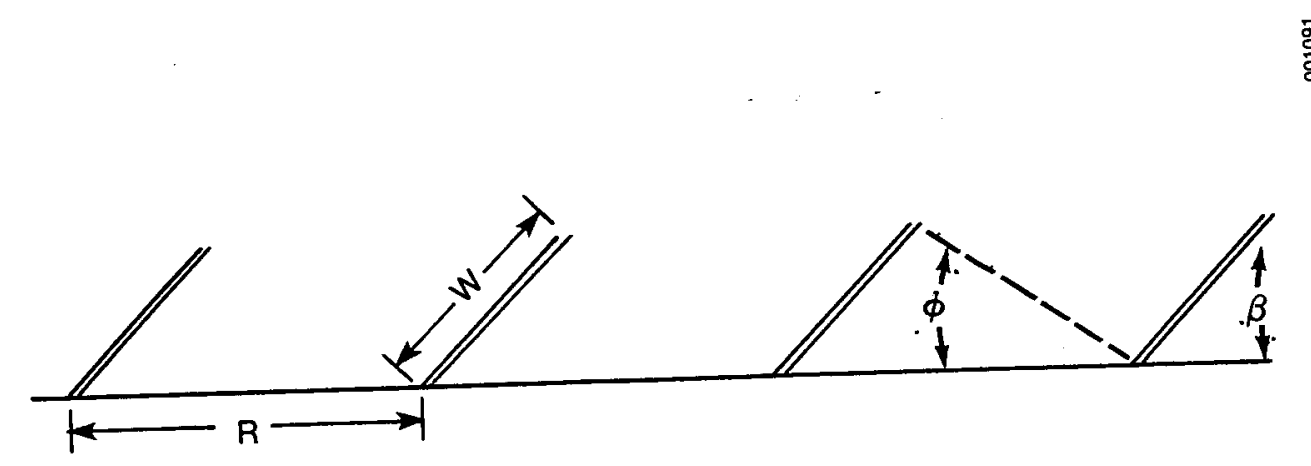

(a)

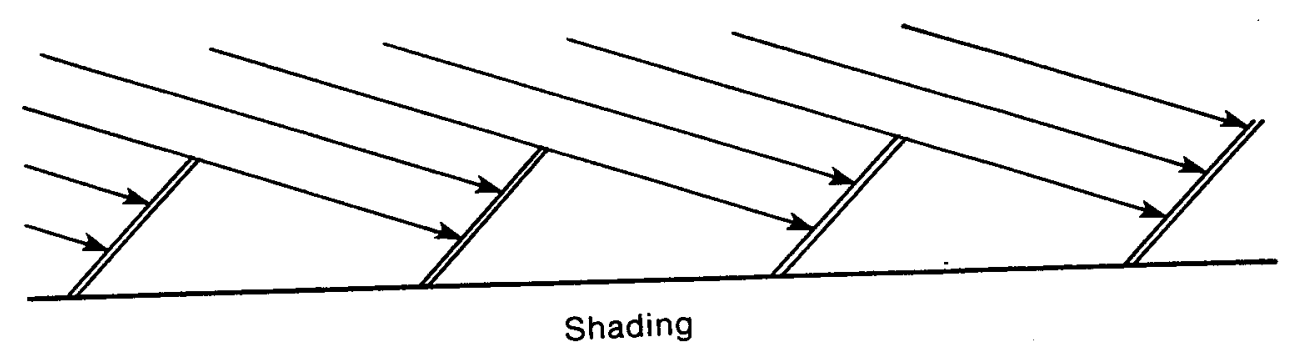

(b)

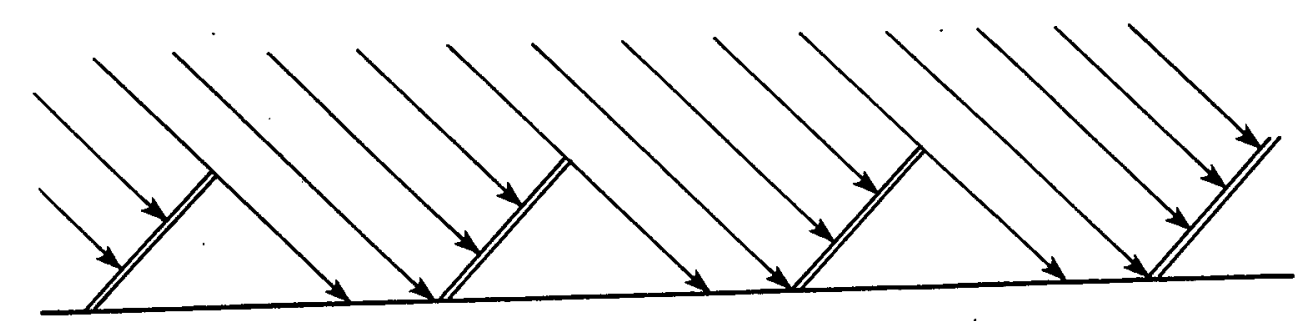

(c)

No Shading

Figure 6-15. Row-to-Row Shading Geometries 
factor of the sky as seen by the collector. This view factor can be calculated using a crossed-string method (Jones and Burkhart 1981) as

$$
F_{d}=0.5\{1+[\sin (\phi+\beta) / \sin \phi]-[\sin \beta / \sin \phi]\},
$$

where the angles $\phi$ and $\beta$ are shown on Fig. 6-15a.

The ground cover ratio can be defined in terms of the angles $\phi$ and $\beta$ as

$$
\operatorname{GCR}=(\cos \beta+\sin \beta / \tan \phi)^{-1} \text {. }
$$

Therefore, the fraction of diffuse radiation avallable to a flat-plate or evacuated-tube collector is a function of the collector tilt angle and the ground cover ratio. The collector tilt angle is assumed to be equal to the site latitude.

Because the direct and diffuse radiation losses due to row-to-row shading are principally dependent only on collector type, site latitude, and ground cover ratio, they can be expressed in graphical form as shown in Figs. 6-16 to 6-18. These figures show annual row-to-row shading correction factors as a function of latitude for parabolic troughs, flat-plate collectors, and evacuated-tube collectors. As explained above, these correction factors account for the loss of beam irradiation and, for flat-plate and evacuated-tube collectors, the loss of diffuse irradiation due to the reduction in view factor from the collector to the sky.

The shading factor obtained from Figs. 6-16 to 6-18 applies only to the rows being shaded--that is, all rows but the first. To account for the unshaded row, use the following equation to compute an average field shading factor:

$$
F_{\text {shad,field }}=\frac{1+(N-1) F_{\text {shad }}}{N}
$$

where

$$
\begin{aligned}
\mathrm{F}_{\text {shad }} & =\text { shading factor as determined from Figs. 6-16 to 6-18 } \\
\mathrm{N} & =\text { number of rows in field. }
\end{aligned}
$$

Row-to-row shading losses increase for all types of collectors as site latitude increases, because the sun is, on the average, lower in the sky at high latitudes, resulting in more shading. Collector rows can, therefore, be spaced much closer together at low latitudes than at high ones. The impact of row-to-row shading losses is especially significant for north-south rotational-axis parabolic troughs. Therefore, north-south parabolic troughs should be spaced significantly farther apart than east-west troughs.

\subsection{ANRUAL THERMAL LOSSES OF COLIECTOR FIELD PIPING AND STORAGE}

Thermal losses from the collector field piping and storage tank (if any) can reduce the energy delivery of a solar system significantly. Section 7.0 describes how to arrange collector field piping and how to determine how much insulation should be added around the piping and the storage tank. Here, we 


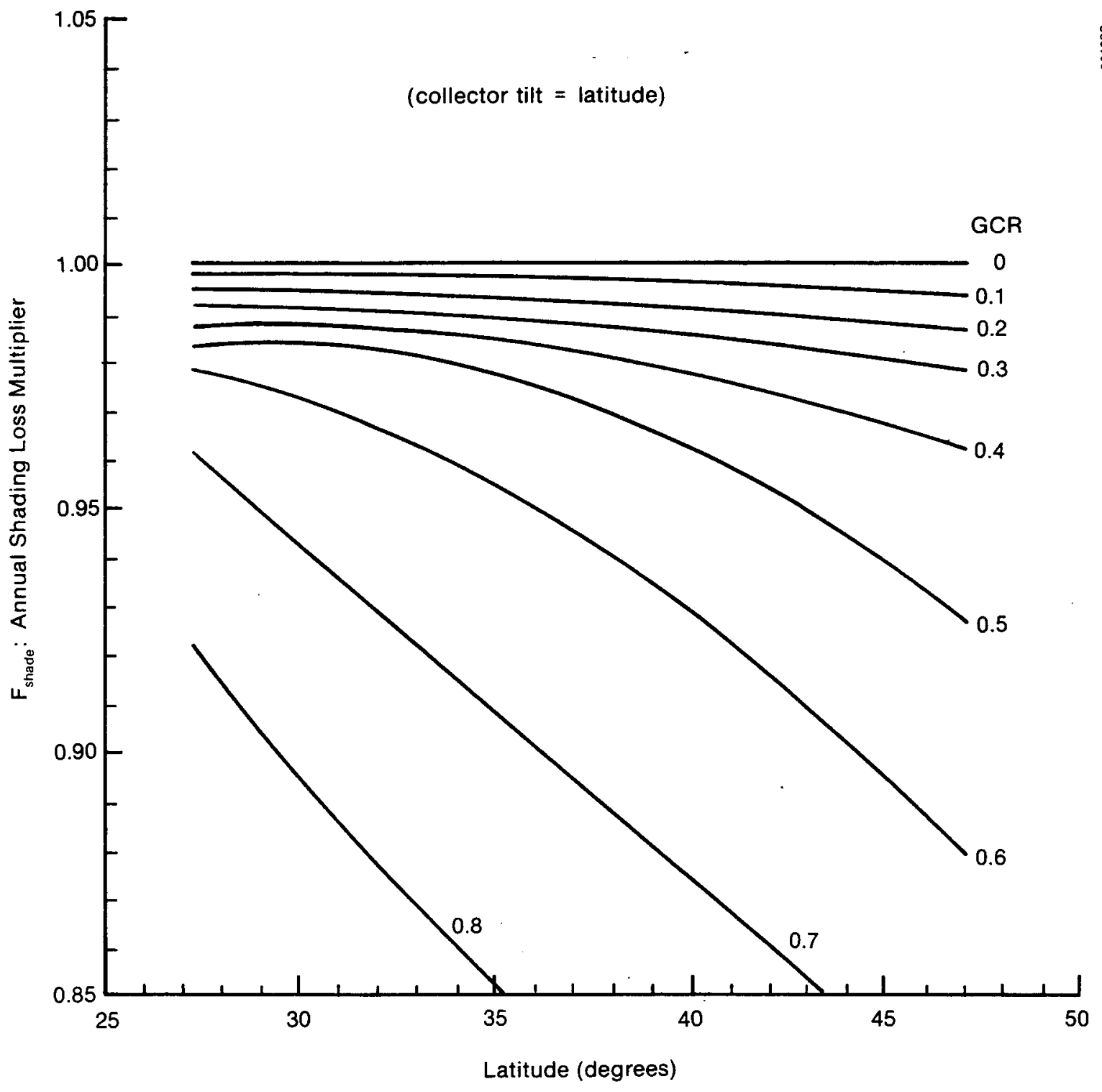

Figure 6-16. Annual Row-to-Row Shading-Loss Modifiers for Flat Plates and Evacuated Tubes Tilted at Latitude 


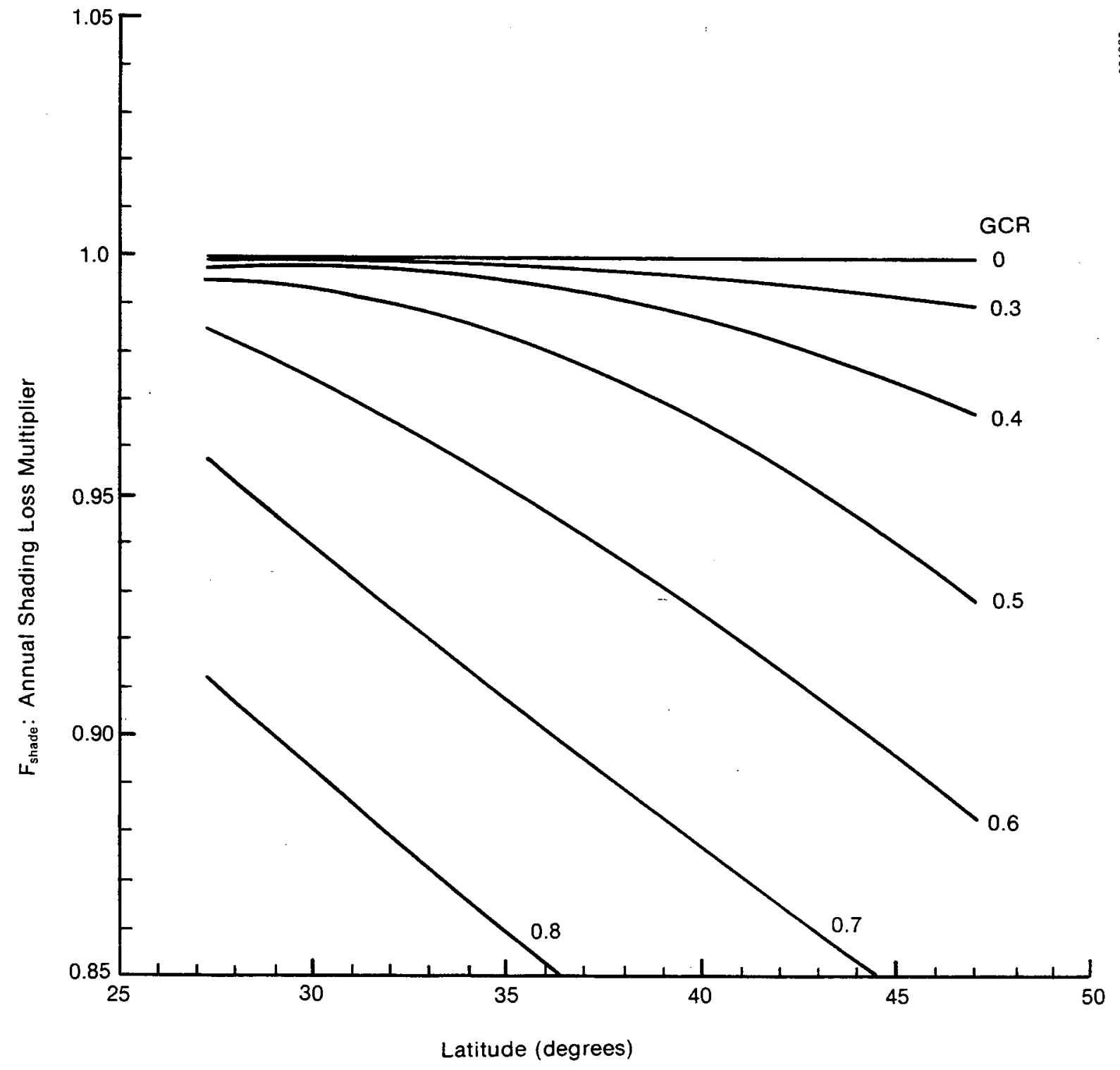

Figure 6-17. Annual Row-to-Row Shading-Loss Modifier for East-West Parabolic Troughs 


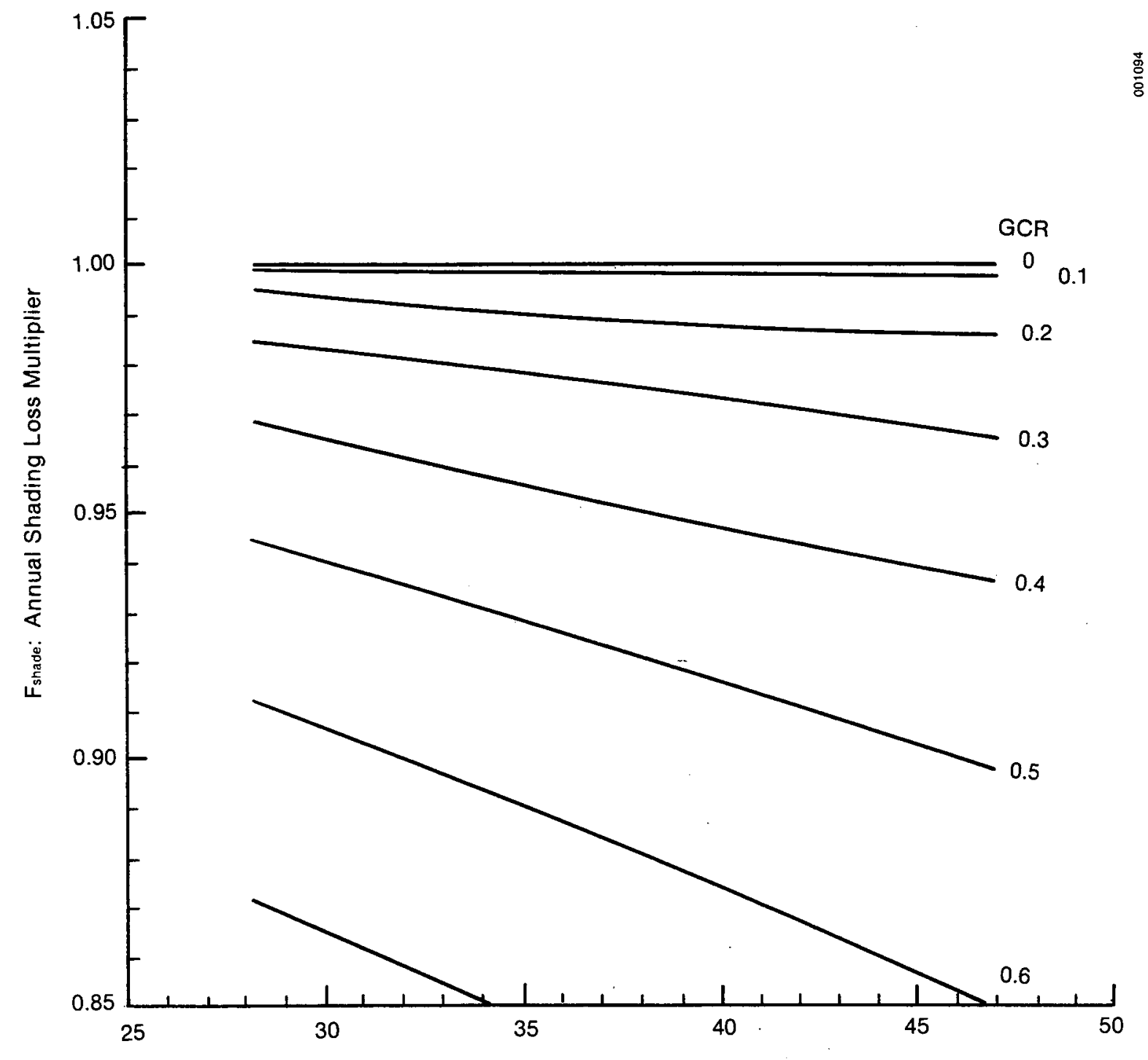

Figure 6-18. Annual Row-to-Row Shading-Loss Modifier for North-South Parabolic Troughs 
describe how to account for the annual thermal losses from these components, so that annual energy delivery can be predicted for the solar system. Three different thermal losses are considered: steady-state losses, overnight losses, and recirculation losses.

\subsubsection{Steady-State Iosses}

Steady-state losses are thermal losses that occur during operation of the solar system. By a simple adjustment of the collector parameters $\eta_{0}$ and $U_{L}$, it is possible to account for most of the thermal losses from piping and storage on an annual basis. The derivation of the corrected $n_{0}$ and $U_{L}$ values follows the analysis of Beckman (1978) and is included in Appendix $E$, which shows that by replacing the collector parameters $n_{0}$ and $U_{L}$ with modified values $n_{0}$ ' and $\mathrm{U}_{\mathrm{L}}$ ', we can account for the steady-state losses. These modified values are defined as

$$
\frac{n_{0}^{\prime}}{n_{0}}=e^{-U_{0} A_{0} / \dot{M}_{c} c_{p}}
$$

and

$\frac{F_{R} U_{L}^{\prime}}{F_{R} U_{L}}=e^{-U_{o} A_{o} / \dot{M}_{c} c_{p}}\left[e^{-U_{i} A_{i} / \dot{M}_{c} c_{p}}+\frac{\dot{M}_{c} c_{p}}{A_{c} F_{R} U_{L}}\left(e^{U_{0} A_{o} / \dot{M}_{c} c_{p}}-e^{-U_{i} A_{i} / \dot{M}_{c} c_{p}}\right)\right]$

where

$$
\begin{aligned}
\dot{\mathrm{M}}_{c} c_{p}= & \text { collector loop flow capacitance } \\
\mathrm{U}_{0} \mathrm{~A}_{0}= & \begin{array}{l}
\text { overall heat loss coefficient of piping and other components } \\
\text { located on outlet (hot) side of collector field }
\end{array} \\
\mathrm{U}_{i} \mathrm{~A}_{i}= & \text { overall heat loss coefficient of piping and other components } \\
& \text { located on inlet (cold) side of field } \\
A_{c}= & \text { collector area. }
\end{aligned}
$$

The modified $\eta_{0}$ and $U_{L}$ values defined by Eqs. 6-43 and 6-44 can be used directly with Fig. 6-1 to determine the annual energy delivery of the collector system. To determine the steady-state thermal losses from the field piping, storage tank, and other components, it is neccesary to group the components in either $U_{0} A_{0}$ or $U_{i} A_{i}$. Components included in $U_{0} A_{0}$ will have a greater impact on energy delivery because they operate at a higher average temperature.

UA values for insulated pipes can be obtained from Sec. 7.1.3, in which a method of determining the most economic pipe insulation thickness is given. (For purposes of conceptual design, the designer should estimate the insulation thickness based on past experience; detailed design requires iteration between insulation thickness and the resulting cost of delivered solar 
energy.) Note that pipe UA values in Sec. 7.1 .3 are values per unit length of pipe; thus, they should be multiplied by the pipe lengths involved to obtain overall UA values.

Estimates -of UA values for pumps, valves, fittings, and pipe anchors, for example, are not as straightforward as they are for pipes. We can use the equations in Sec. 7.1.3 to estimate $U$ values for these components, however. The $U$ value can then be multiplied by the estimated total hot surface area of these components to arrive at an overall UA value. In practice, care must be taken to achieve low $U$ values for such components as exposed valve stems, pipe supports, and anchors, as they will act as fins to conduct heat away to the environment. (It is worthwhile to isolate pipe supports and anchors from the pipes thermally with a noncompressible insulation.)

Piping, valves, fittings, pipe anchors, and the like, located on the inlet side of the collector, should be added to the inlet overall heat loss coefficient $U_{1} A_{1}$, and those on the outlet piping should be added to $U_{0} A_{0}$. Pump UA values should account for the overall heat loss from the pump's surface as well as the heat required for cooling the pump seal, which could possibly cause significant thermal losses. Seal configurations that reduce sealcooling requirements are recommended. The collector loop pump is located on the inlet side of the collector field; thus, it should be grouped into $U_{1} A_{1}$.

If storage is used in the system, the appropriate UA value can be calculated based on its size and the amount of insulation that surrounds it. When it is multiplied by the storage tank surface area, this $U$ value provides an estimate of the storage tank UA value, which should be added to the outlet side overall heat-loss coefficient. This is a conservative analysis of a mixed-tank recirculation system, because the storage tank temperature will be lower than that of the collector outlet fluid. For a variable-volume system, however, the storage tank is filled directly from the collectors; hence, the fluid exiting the collectors is the same average temperature as the storage. (In the detailed design and construction phase, efforts should be made to minimize heat leaks from storage tanks assoclated with pipe penetrations and support structures.) When $\mathrm{UA}$ values for all components have been determined, then UA values for components at like temperatures are summed to provide $\mathrm{U}_{1} \mathrm{~A}_{1}$ and $\mathrm{U}_{\mathrm{O}} \mathrm{A}_{\mathrm{O}}$

\subsubsection{Overnight Losses}

When a solar system is shut down at the end of a day, the piping, components, and fluid inventory are often still hot but can lose heat during the night. These nightly thermal losses have been termed nonoperating, overnight, or cool down losses, and they represent energy collected but never dellvered to the process load. Overnight losses can be estimated by calculating the total heat capacitance of the components and the fraction of heat lost overnight. The most significant components in terms of overnight losses are the storage tank, the collectors, the field piping and insulation, and the heat transfer fluid they contain.

The total heat capacitance of flat-plate collectors should include contributions from the absorber plate, the fluid it contains, and any interconnecting piping between collectors. For evacuated tubes, the heat capacitance of the 
absorber surface, the fluid within each tube, the headers that connect adjacent tubes, and the fluid within the headers should be summed. For parabolic troughs, the heat-capacitance contributions are from the absorber tube, the fluid in the absorber, flexhoses, and the fluid they contain.

The piping that runs to and from the collector field usually does not cool down to ambient overnight. If an insulated fluid-filled pipe has negligible internal resistance, it will exhibit a uniform temperature as it cools, given by

$$
T=T_{a}+\left(T_{i}-T_{a}\right) e^{-\Delta t / \tau},
$$

where

$$
\begin{aligned}
\mathrm{T}_{\mathrm{a}} & =\text { ambient temperature } \\
\mathrm{T}_{\mathrm{i}} & =\text { initial temperature of pipe } \\
\Delta t & =\text { length of time pipe has cooled } \\
\tau & =\text { time constant of pipe given by } \mathrm{Mc}_{\mathrm{p}} / \mathrm{UA} .
\end{aligned}
$$

The total amount of heat lost is

$$
Q_{1 \text { ost }}=\left[1-e^{-\Delta t / \tau}\right] M c_{p}\left(T_{i}-T_{a}\right)
$$

For an example, consider a water-filled $12.7-\mathrm{cm}(5-\mathrm{in}$.$) , schedule 40$ pipe covered with $7.6 \mathrm{~cm}$ ( $3 \mathrm{in}$ ) of insulation having a thermal conductivity of $0.156 \mathrm{~kJ} / \mathrm{h} /{ }^{\circ} \mathrm{C}$ per meter of length $\left(0.214 \mathrm{Btu} / \mathrm{h} /{ }^{\circ} \mathrm{F}\right.$ per foot). The total heat capacity $\mathrm{Mc}$ of such a pipe is about $64 \mathrm{~kJ} / \mathrm{k}$ per meter of length $(10.2 \mathrm{Btu} / \mathrm{F}$ per foot). The time constant $\tau$ is, then, about 48 hours. In a 16-hour cooldown period (system shut-down to start-up the next morning), the total amount of heat lost is

$$
\begin{aligned}
Q_{\text {lost }} & =\left[1-e^{-16 / 48}\right] \mathrm{Mc}_{p}\left(T_{i}-T_{a}\right) \\
& =0.28 \operatorname{Mc}_{p}\left(T_{i}-T_{a}\right)
\end{aligned}
$$

Thus, the pipe in the example theoretically loses only about $28 \%$ of its heat overnight. Smaller pipes, or pipes with less insulation, exhibit higher heat losses. In practice, valve stems, pipe supports and anchors, etc., provide conduction paths that significantly increase heat loss. Until such additional heat losses can be quantified experimentally (tests are being done at Sandia National Laboratories in Albuquerque), it is recommended that half the energy left in the piping and associated components be counted as lost overnight.

Storage tank insulation should keep thermal losses to a small fraction of the solar energy delivered to storage, as noted in Sec.7.6. Because of the large thermal mass of typical storage tanks, the temperature of the storage fluid will not decrease substantially overnight. Hence, storage loss overnight can 
be based on a constant heat loss rate. This heat loss rate can be calculated as

$$
\dot{Q}_{\text {stor,o }}=\mathrm{U}_{\text {stor }} \mathrm{A}_{\text {stor }}\left(\mathrm{T}_{\text {stor }}-\mathrm{T}_{\mathrm{a}}\right) \text {, }
$$

where

$$
\begin{aligned}
\mathrm{U}_{\text {stor }} & =\text { storage tank heat-loss coefficient } \\
\mathrm{A}_{\text {stor }} & =\text { storage tank surface area } \\
\mathrm{T}_{\text {stor }} & =\text { storage temperature } \\
\mathrm{T}_{\mathrm{a}} & =\text { ambient temperature. }
\end{aligned}
$$

The storage tank temperature is reasonably assumed to be the same as the process load return temperature, because energy typically is withdrawn from storage until the tank approaches the process return temperature. Also, the initial temperature $T_{i}$ of the field piping and collectors is assumed to be the same as the process return temperature, because when the collectors shut down at the end of the day, they usually are not producing much energy, and the average temperature of the piping is close to the load return temperature. Therefore, the total annual overnight losses of a collector system can be estimated as

$$
\begin{aligned}
\text { Qovernight }= & \frac{\sum\left(M c_{p}\right)_{\text {pipe }}\left(T_{\ell, r}-T_{a}\right) N_{\text {oper }}}{2}+\sum\left(M c_{p}\right)_{c o l 1}\left(T_{\ell, r}-T_{a}\right) N_{\text {oper }} \\
& +U_{\text {stor }} A_{\text {stor }}\left(T_{\ell, r}-T_{a}\right) 16 N_{d}
\end{aligned}
$$

The factor $\mathrm{N}_{\text {oper }}$ is the number of days of operation per year, which determines the number of days of cooldown losses. A value of 300 days is a conservative assumption. The factor 16 in the final term of Eq. 6-49 is the average number of nonoperational hours per day that the storage tank loses heat, and the factor $\mathrm{N}_{\mathrm{d}}$ is the number of days per year that the storage tank does so. A value of 365 can be used because the storage tank will lose heat even if the collectors did not operate every day. The value of $\mathrm{T}_{\mathrm{a}}$, the average nighttime ambient temperature, may be determined from the tables in Appendix $F$ for many U.S. cities. That appendix contains average daytime temperatures, but by simply subtracting $6^{\circ} \mathrm{C}$ from the daytime values, average nighttime temperatures are closely approximated.

\subsubsection{Freeze-Protection Heat Losses}

In addition to the energy lost as pipes, components, and fluids cool down overnight, heat losses will occur in the freeze-protection system if warm water is circulated through the collectors in freezing weather. Such circulation freeze-protection systems are usually appropriate only in mild climates.

A typical freeze-protection strategy is to circulate warm water (usually from storage) with the collector loop pump when sensors located in the collector 
plumbing indicate that near-freezing temperatures are being reached. The flow is halted after the low-temperature signals stop, and the system is allowed to cool down with no flow unt11 the low-temperature alarm is activated again. The average heat loss rate from this freeze protection system when it is in operation-is expressed by

where

$$
\dot{Q}_{L}=\frac{\left(U A_{1}+U_{L} A_{c}+U A_{o}\right)\left(T_{r}-T_{s e t}\right)}{\ln \left(T_{r}-T_{a}\right)-\ln \left(T_{s e t}-T_{a}\right)} \text {, }
$$

$$
\begin{aligned}
\dot{\mathrm{Q}}_{\mathrm{L}} & =\text { heat loss rate }(\mathrm{W}) \\
\mathrm{T}_{\mathrm{a}} & =\text { ambient temperature when freeze protection is used }\left({ }^{\circ} \mathrm{C}\right) \\
\mathrm{T}_{\mathrm{r}} & =\text { recirculation fluid temperature }\left({ }^{\circ} \mathrm{C}\right) \\
\mathrm{UA}_{1}, \mathrm{UA}_{\mathrm{o}} & =\mathrm{UA} \text { values of pipes going to and from the collectors }(\mathrm{W} / \mathrm{K}) \\
\mathrm{U}_{\mathrm{L}} & =\text { heat loss coefficient of collectors }\left(\mathrm{W} / \mathrm{m}^{2}-\mathrm{K}\right) \\
\mathrm{A}_{\mathrm{C}} & =\text { collector area }\left(\mathrm{m}^{2}\right) \\
\mathrm{T}_{\text {set }} & =\text { temperature set-point for recirculation }\left({ }^{\circ} \mathrm{C}\right) .
\end{aligned}
$$

In most systems, $\mathrm{U}_{\mathrm{L}} \mathrm{A}_{c}$ is much greater than $\mathrm{UA}_{1}+\mathrm{UA}_{0}$, and the losses from the collectors dominate the solution.

To use Eq - 6-50 to estimate the annual energy lost by such a freeze-protection system, it is necessary to know how many hours per year the system will be operated. Fig. 3-4 shows the incidence of freezing days in the United States on an annual basis. To estimate the number of hours of freezing weather per year, data from the SOLMET sites were analyzed to find a correlation between the number of days of freezing weather and the number of hours of freezing weather per year when the collectors are not operating. The results of that analysis are plotted in Fig. 6-19, both as the least-squares curve fit to the data and the actual data points, so that the range of error can be seen. Using the two figures together, we can estimate the total number of hours of freezing weather that will occur at a given location in the United States.

The average ambient temperature when freeze protection is needed, $T_{a}$, can be determined from Fig. 6-20 as a function of the average January daytime temperature for the particular site. Average January daytime temperatures are given in Appendix E for 72 U.S. cities. The correlation shown in Fig. 6-20 was based on data from all 26 SOLMET sites. $T_{a}$ is defined as the average ambient temperature for all times when ambient temperature is both below freezing $\left(0^{\circ} \mathrm{C}\right)$ and the collectors are not operating because of insufficient irradiation. This restricts temperature averaging to times when recirculation is necessary for freeze protection. 


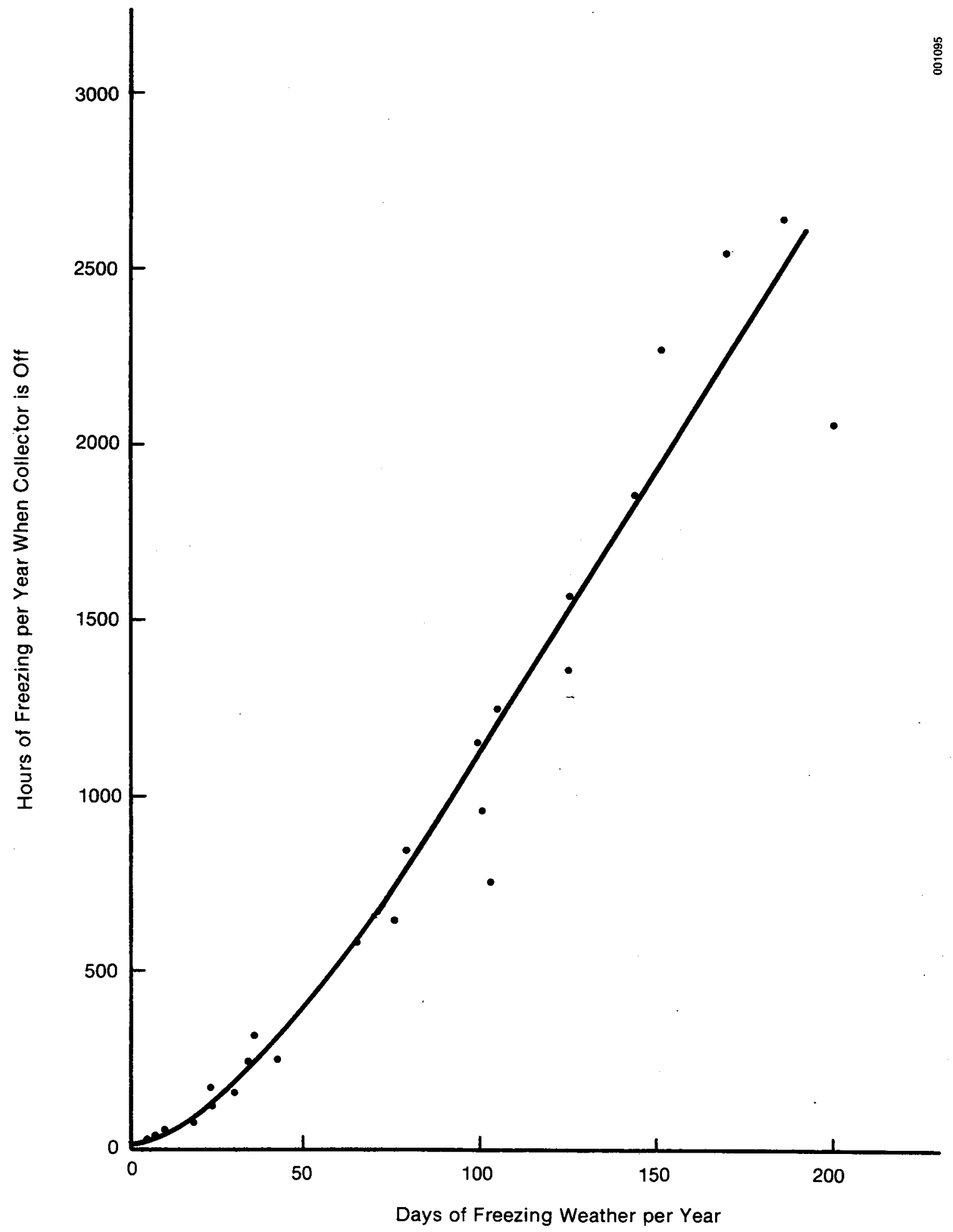

Figure 6-19. Hours of Freezing Temperatures per Year as a Function of Freezing Days per Year 


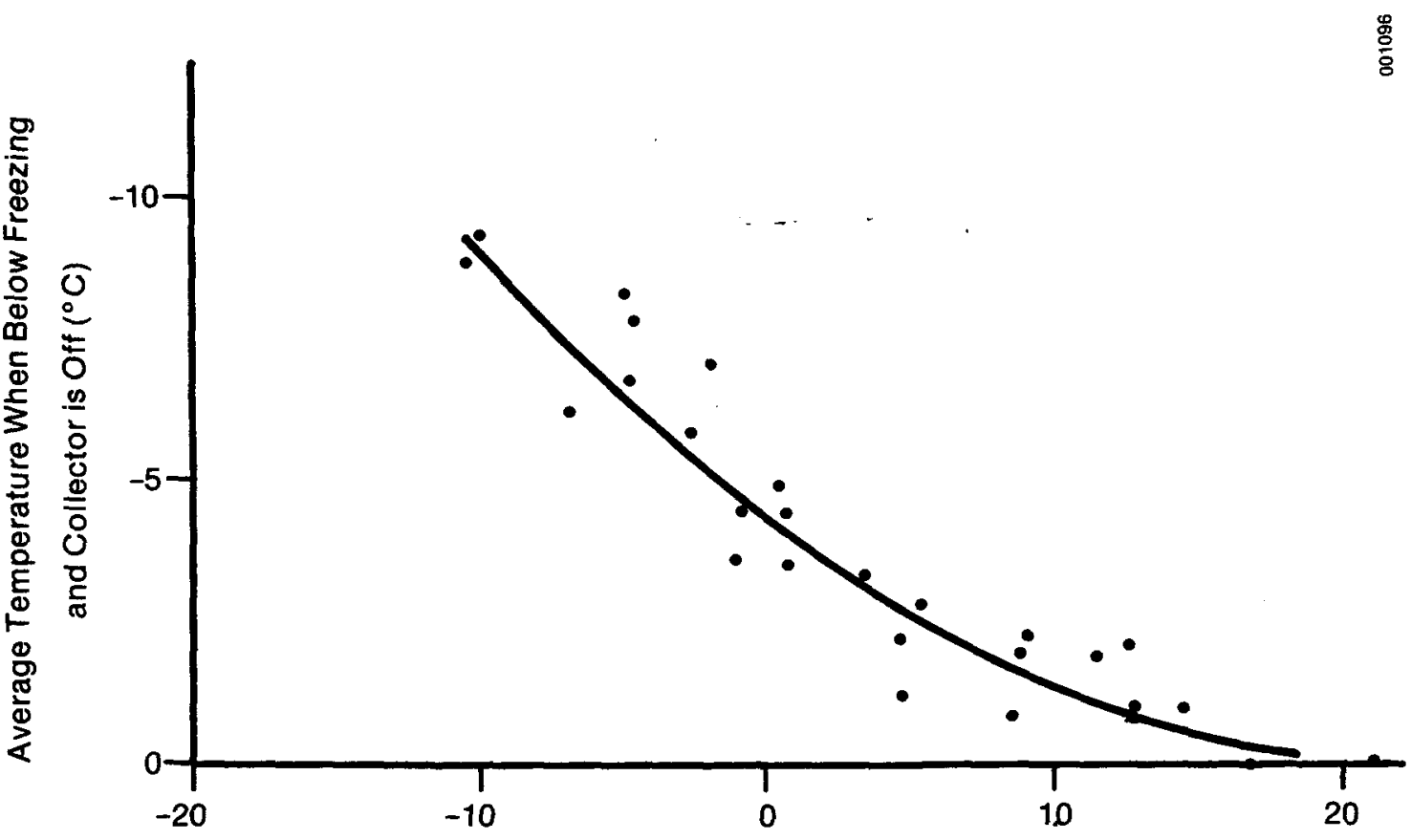

Average January Daytime Temperature $\left({ }^{\circ} \mathrm{C}\right)$

Figure 6-20. Average Below-Freezing Temperatures as a Function of Average Jamuary Daytime Temperature

\subsection{UTILIZATION AND AVAII_ABILITY}

After we have taken into account climatic conditions, collector performance, amount of storage, and the load profile using the energy collection design tools presented here, we must consider how the process will utilize the solar system and how reliable the solar system itself will be.

The overall economics of a solar system depends not only on how much energy the system can collect in a year, but also on how much of that energy will be used by the industrial process and on how much time the system will be able to collect that energy. It is of no use to have either a solar system that collects energy that the process cannot use or one that can never collect and deliver energy because of malfunctions. The two indices that quantify these effects, then, are utilization and availability. Strictly defined, these indices should be based on energy quantities. Thus, energy collected but not delivered to the industrial process because that process is unavallable should be accounted for in the utilization term. Energy lost because of solar system downtime should be accounted for in the availability term. Because these energy quantities are very difficult (if not impossible) to determine during the solar system design process, an approximation based on time estimates is recommended. Solar system utilization and availability are defined in terms of time fractions as follows: 


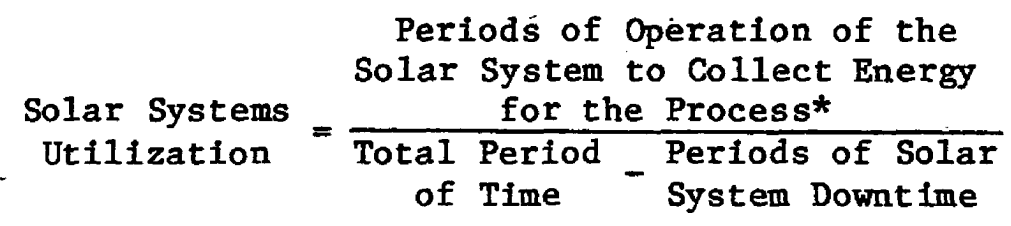

and

Solar System Availability

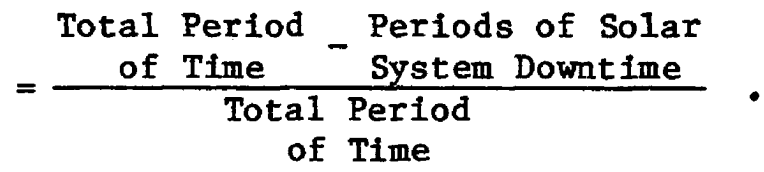

Availability is based on the total period of time, so that all periods of solar system downtime are included, even if the industrial plant happens to be down at the same time. If only a portion of the collector field is down, this should be reported as a reduction in availability. (For example, if half the fleld is down during a 10-hour collection day, downtime would be 5 hours.) Utilization is based on the amount of time the solar system is available, so that it measures system usage by the industrial plant without a penalty for system downtime. The two indices are multiplied together to obtain the overall system capacity factor, the factor by which the yearly collected energy must be multiplied to determine the annual usable energy collection, including system and plant operation effects. Ideally, an industrial process would use solar energy all year (high utilization), and the solar system would be reliable enough to supply its portion of the load whenever it was called upon to do so (high availability), so that the system operation factor would be nearly equal to one.

Because we lack long-term experience with solar IPH systems, solar system availability is difficult to predict with confidence. It is encouraging, however, that even in the first-round DOE field tests, which were among the first large IPH projects built, the availabilities of all but one project were greater than $85 \%$, and two of the seven were greater than $97 \%$ (Kutscher and Davenport 1981). These were all nontracking collector fields, however. Preliminary data from new systems employing parabolic troughs indicate significantly lower availabilities. A characteristic of solar systems that leads to high availability is that collector field maintenance can be conducted at night or on cloudy or rainy days without affecting system performance. It is also possible to perform maintenance tasks during the day on some sections of a collector field while continuing to operate others.

Utilization is also difficult to approximate, but may have a sizable impact on the actual amount of useful energy a solar system collects. The energy collection design tool presented in this handbook assumes that the collectors will operate every day that weather permits. However, if plant operation scheduling causes the collectors to be idle for significant periods when they could be operating, the actual solar energy collected will be less than that predicted by the design tool. For industrial processes that are seasonal or

*That is, the total period of time less solar system downtimes and periods of time the collectors were idled when they could have been used to collect energy • 
shut down for considerable lengths of time, the utilization factor can be quite significant.

For systems with storage, calculating utilization is difficult and, at best, approximate. Engineering judgment is required to estimate the contribution of various effects on utilization, and no clear-cut rules apply. If periods of no load are very long in comparison to the amount of storage avallable (e.g., seasonal shutdowns or extended plant holidays), storage will be of little value. The solar system can continue to be operated for a short time, but only the amount of energy that can be stored in the fully-charged storage system will be useful, and any extra energy collected after storage is charged wi11 be wasted. However, for no-load periods of the same order as the time it takes to charge storage, we must determine what the effect will be on the energy collected. Occasional no-load periods of just a few hours have little effect and can be ignored.

For solar systems with no storage, utilization is relatively easy to estimate if we know the annual plant operation schedule. In such a case, we need only total the periods of time that the system would be idle because of plant maintenance, seasonal shutdowns, holidays, etc., and subtract this tota1, along with the estimated downtimes of the solar system (allowing for any overlap), from the total period of time for which the analysis is performed, to obtain the numerator of Eq. 6-51.

A further difficulty in estimating utilization is associated with the effect of seasonal variations. Although the definition of utilization given in Eq. 6-51 does not mention when the operation of the solar system takes place, it does matter; a shutdown in winter will have a smaller effect on energy collection then one in summer.

It is important to keep in mind that calculating the system utilization is merely a crude attempt to quantify the effect of process scheduling on the amount of energy that will be collected and delivered by a solar system, and is a refinement to the general annual energy collection design tool. As such, its usefulness is determined largely by the insight and judgment of the designer. Careful consideration of how the solar system will be operated can bring about useful corrections. In any case, the result will be an energy collection estimate more conservative than the estimate obtained with the energy collection design tool.

Some examples will illustrate how utilization and availability factors might be calculated for actual systems.

Example 1: A food processing firm is considering using solar energy for a fruit-drying operation. Because the fruit is available only seasonally, the system will be operated for only seven months of the year, from May through November. During that time, processing occurs seven days per week. No storage will be provided. Since five months are available for maintenance, the system availability should be high, estimated at $98 \%$. The utilization is approximately

$$
\begin{aligned}
\text { Utilization } & =\frac{31+30+31+31+30+31+30}{365} \times 100 \\
& =60 \% .
\end{aligned}
$$


The system capacity factor is $(0.98)(0.60) \times 100=59 \%$.

Example 2: An ofl and gas company is contemplating using solar energy in remote location to heat crude oil before pumping it. The process would be in use dafly, and storage would be provided for some additional operation at night. Because of the nature of the crude oil, clogging of the main solar heat exchanger is expected to lead to downtimes of the solar system of one day per month. The area is one of frequent hailstorms, and 10 days of operation per year are expected to be lost because of the storms. The process is shut down completely for two weeks every year for major maintenance and parts replacement.

$$
\begin{aligned}
\text { Availability } & =\frac{365 \text { days }-12 \text { days of downtime }}{365 \text { days }} \\
& =97 \% . \\
\text { Utilization } & =\frac{365 \text { days }-12 \text { days of downtime }-14 \text { days of process down time }}{365 \text { days }-12 \text { days of downtime }} \\
& =96 \% .
\end{aligned}
$$

Thus, the overall system capacity factor is $(0.97)(0.96) \times 100=93 \%$. Note that the incidence of hailstorms does not affect availability; only shutdowns caused by mechanical problems with the solar system are included. Weather effects are considered only in the calculation of the energy available for collection.

\subsection{STEP-BY-STEP PROCEDURE}

To summarize the calculation of the annual energy collection of an IPH solar system, a step-by-step procedure is provided here. Note that the inputs required of the industrial owner or system designer are largely readily available items of information, and the outputs of this procedure are quantities of significance to the industrial owner.

Step 1 - Obtain necessary information

- Define collector and obtain its $F_{R} U_{L}$ and $F_{R} \eta_{0}$ values and $K_{\alpha \tau}$ data.

- Define process load with its load schedule and $T_{\ell, r}, T_{\ell}$, and $\dot{m}_{1 o a d}$ for hot water and $T_{s}$ and $T_{f}$ for steam systems.

- Define latitute and average ambient temperature (see Appendix F) of proposed site and obtain long-term irradiance data from Figs. 5-10 and 5-11.

- Define land availability at proposed IPH site.

- Define system-dependent heat exchange factor $F_{S}$. Use $F_{X}$ for hot air and hot water systems. Use $F_{F}$ for steam flash systems and $F_{B}$ for unfiredboiler steam systems. 
- Correct the value of $\mathrm{F}_{\mathrm{R}} \mathrm{U}_{\mathrm{L}}$ to account for steady-state pipe losses by Eq. 6-44.

Step 2-Calculate long-term average optical efficiency

- Define dirt and dust optical losses based on material coupon degradation.

- Calculate or look up incident-angle modifier annual correction (Figs. 6-13 and 6-14 and Eqs. 6-35 and 6-36).

- Multiply normal incidence optical efficiency by both modifiers to arrive at long-term average optical efficiency.

- Correct the optical efficiency to account for steady-state pipe losses by $\mathrm{Eq} \cdot 6-43$.

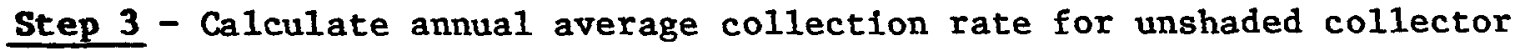

- If a variable-volume storage system is selected, calculate the maximum collector area $A_{c, \max }$ based on the maximum daily process load requirement.

- If a no-storage hot air, hot water, or steam system is selected, calculate the maximum collector area $A_{c}$, max based on the maximum instantaneous process load use rate.

- Determine the collector heat transfer efficiency factor $F_{R}$ for the given flow rate and for the specified collector area ( $A_{c, m a x}$ or less). If a mixed tank recirculation system is selected, use the collector flow rate recommended by the collector manufacturer.

- Determine value of variable grouping $\left[\frac{F_{R_{U}}\left(T_{i n}-T_{a}\right)}{F_{R} \bar{I}_{0}}\right]$ and locate on
abscissa of Fig. $6-1$.

(Use the load return temperature $T_{l, r}$ for $T_{1 n}$ with hot air and hot water systems. Use steam temperature $T_{S}$, for $T_{i n}$ for both unfired-boiler and flash steam systems. Use $\bar{I}=I_{h}$ (Fig. 5-10) for flat-plate and evacuated-tube collectors. Use $\overline{\mathrm{I}} \stackrel{\mathrm{h}}{=} \overline{\mathrm{I}}_{\mathrm{b}}$ (Fig. 5-11) for parabolic trough collectors.)

- Locate value of $\dot{q}_{c} / F_{S} F_{R} \eta_{o} \bar{I}$ on ordinate of Fig. 6-1 consistent with value of abscissa and site latitude.

- Multiply ordinate by $F_{S} F_{R} n_{0} \bar{I}$ to determine $\dot{q}_{C}$. [Note that $\bar{I}=\bar{I}_{h}$ for flat plates and evacuated tubes, but that $\bar{I}=\bar{I}_{b}+50\left(\mathrm{~W} / \mathrm{m}^{2}\right)$ for troughs.]

- If the system chosen is a recirculation system, select the collector area and storage tank sizes. On the load-storage modifier figure appropriate for the collector type and.process load schedule (see Figs. 6-4 to 6-11), determine $\mathrm{F}_{\ell-s}$. Correct $\dot{q}_{c}$ for storage and load effects by multiplying by $\mathrm{F}_{\ell-s^{*}}$

Step 4 - Calculate annual shading loss factor and end-loss factor for parabolic troughs 
- Determine proposed ground cover ratio (GCR = collector length/row-to-row spacing).

- Calculate required collector field size as $A_{g}=A_{c} / G C R$.

- Determine whether enough collector field area is available. If not, increase GCR or reduce $A_{c}$.

- Locate annual shading-1oss factor ( $F_{\text {shade }}$ ) on Figs. 6-16 to 6-18 for specified GCR and latitude of site.

- Correct $\dot{q}_{c}$ for shading losses by multiplying by $F_{\text {shade,field (see }}$ $\mathrm{Eq} \cdot$ 6-42).

- For parabolic troughs, determine end-loss factor for specified row length (see Table 6-2).

- Correct $\dot{q}_{c}$ for end losses by multiplying by $\dot{L}_{\text {end }}$.

Step 5 - Calculate annual energy collection

- Multiply the energy collection rate per unit of collector area $\dot{q}_{c}$ by the collector area to determine $\dot{Q}_{c}$, the average annual energy collection rate of the collector field.

- Since $\dot{Q}_{c}$ is an average collection rate based on all daytime hours, multiply $Q_{c}$ by 4380 (the number of daylight hours in a year) to obtain annual energy collection in watt-hours.

Step 6 - Calculate collector overnight and freeze-protection losses from field piping and storage

- Calculate total collector field piping thermal capacitance and total collector area thermal capacitance. Calculate UA value for storage. Use these values to determine overnight thermal losses using Eq. 6-49.

- If a warm-water circulation freeze-protection system is used to protect the collector system from freezing, use Figs. 6-19 and 6-20 to determine the annual number of freezing hours and average ambient temperature when freeze-protection is needed. (Data from a local weather station or from the U.S. Climatic Atlas are preferred if available for the site in question.)

- Calculate UA values for piping and collector field and use this information to evaluate $\mathrm{Eq} \cdot 6-50$ for the annual freeze protection thermal loss.

Step 7 - Estimate utilization and avallability of solar system

- Estimate solar system utilization based on plant operation schedule and any expected plant shutdowns (see Eq. 6-51).

- Estimate solar system availability based on expected solar system downtime and likelihood of doing maintenance work during the evening or night (see Eq. 6-52). 
Step 8 - Calculate annual energy delivery and solar fraction

- Subtract annual overnight losses and freeze-protection losses (from Step 6) from the annual energy collection determined in Step 5 .

- Multiply this value by both solar system availability and utilization to obtain solar system annual energy delivery.

- To obtain that fraction of the process load met by solar energy (neglecting parasitics), divide the annual energy delivered by the annual process load.

\subsection{REFEREICES}

ASHRAE Handbook, 1981 Fundamentals. New York, NY: American Society of HeatIng, Refrigerating, and Air Conditioning Engineers, Inc.

Beckman, W. 1978. "Duct and P1pe Losses in Solar Energy Systems." Solar Energy. Vol. 21 (No. 6); p. 531 .

deWinter, F. 1975. "Heat Exchanger Penalties in Double-Loop Solar Water Heating Systems." Solar Energy. Vol. 17; p. 335.

Gaul, H.; Rabl, A. 1980 (Feb.). "Incidence-Angle Modifier and Average Optical Efficiency of Parabolic Trough Collectors." Journal of Solar Energy Engineering. Vo1. 102 .

Gordon, J.; Rabl, A. (Forthcoming in Solar Energy.) "Design, Analysis, and Optimization of Solar Industrial Process Heat Plants Without Storage."

Harrigan, R. 1981 (July). Handbook for the Conceptual Design of Parabolic Trough Solar Energy Systems - Process Heat Applications. SAND-81-0763. Golden, CO: Solar Energy Research Institute.

Hooker, D.; May, E. K.; West, R. 1980 (May). Industrial Process Heat Case Studies. SERI/TR-733-323. Golden, CO: Solar Energy Research Institute.

Jones, R. Jr.; Burkhart, J. 1981. "Shading Effects of Collector Rows Tilted Toward the Equator." Solar Energy. Vo1. 26; p. 563.

Jordan, R.; Liu, B. 1977. Applications of Solar Energy for Heating and Cooling of Buildings. ASHRAE GRP170.

Kutscher, C.; Davenport, R. 1981 (June). Preliminary Operational Results of the Low-Temperature Solar Industrial Process Heat Field Test. SERI/TR-632385R. Golden, C0: Solar Energy Research Institute.

Lunde, P. 1980. Solar Thermal Engineering Space Heating and Hot Water Systems. New York, NY: John Wiley and Sons.

Rabl, A. 1981 (Jan.). Yearly Average Performance of the Principal Solar Collector Types. SERI/TR-631-716. Golden, C0: Solar Energy Research Institute. 


\section{SECTION 7.0}

\section{THE ENERGY TRANSPORT SYSTEM}

This section presents the design requirements of the energy transport system-the piping, pumps, valves, heat exchangers, and storage components that convey the energy absorbed by the solar collectors to the proper place in the process stream. Because the energy transport system can be a source of significant system inefficiency, it is important to avoid design errors in this area.

In Sec. 7.1 we discuss piping and insulation and review collector field layouts and pipe sizing, including a method of optimizing pipe insulation thickness. Heat transfer fluids that can be used if water is impractical are discussed in Sec. 7.2. Effects of fluid properties on heat transfer and pumping power are reviewed, and the heat transfer efficiency factor (HTEF), an effective ratio of heat transfer ability to pumping power requirements, is explained. In Sec. 7.3, we review the kinds of pumps available for solar IPH systems and discuss how to select the proper pump. The many types of valves needed in an IPH system are covered in Sec. 7.4, and sizing various types of heat exchangers is discussed in Sec. 7.5. Section 7.6 summarizes characteristics and methods of thermal storage.

\subsection{PIPING AND INSULATION}

\subsubsection{Collector Field Piping Configurations}

Three basic types of collector field layouts are employed in solar IPH systems. These layouts--direct return, reverse return, and center feed--are shown schematically in Fig. 7-1. In each case, the hot outlet piping is shorter than the supply piping, to minimize thermal losses. There are advantages and disadvantages to each of these configurations.

The direct-return piping configuration (shown in Fig. 7-1a) is the simplest, and probably most extensively used, of the three. Its main disadvantage is that there is a much greater pressure differential across the collector row nearest the field inlet than across the last collector row, so that balancing valves must be used to maintain equal flows through each row. These valves are responsible for most of the pressure drop in the beginning of the array; thus, their contribution to the total head loss in the system is significant. The result is a higher parasitic energy requirement for the direct-return system than for the reverse-return system, in which the fluid enters the collector array at the opposite end. Of course, larger headers can also be used to balance array flow, since the imbalance is caused by pressure drop and pressure recovery along the headers. Using larger headers will also result in lower parasitic power requirements, but these could be offset by increases in initial costs and energy losses.

The reverse-return design (Fig. 7-1b) has an inherently better balanced flow; balancing valves may still be required, but they add much less head loss to 


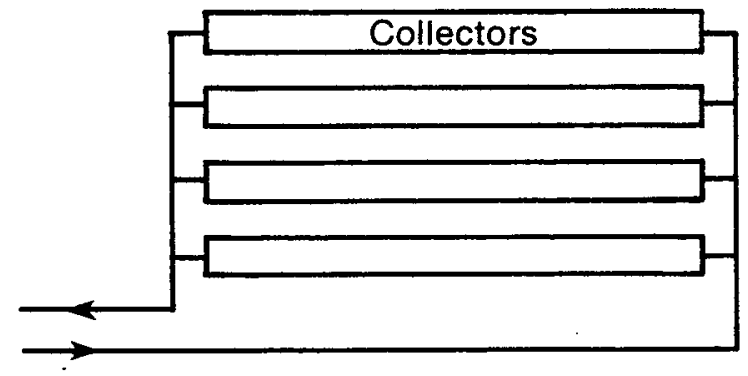

a. Direct Return

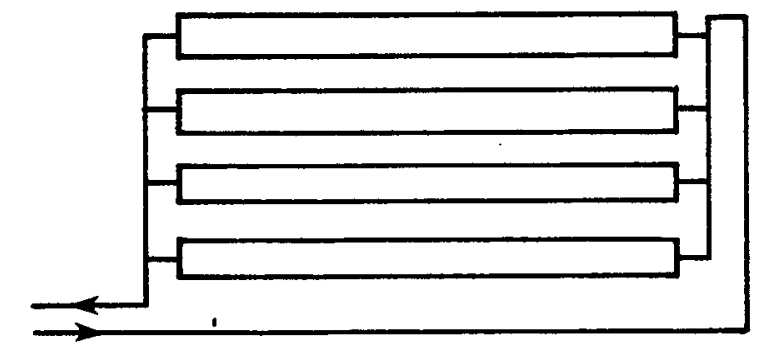

b. Reverse Return

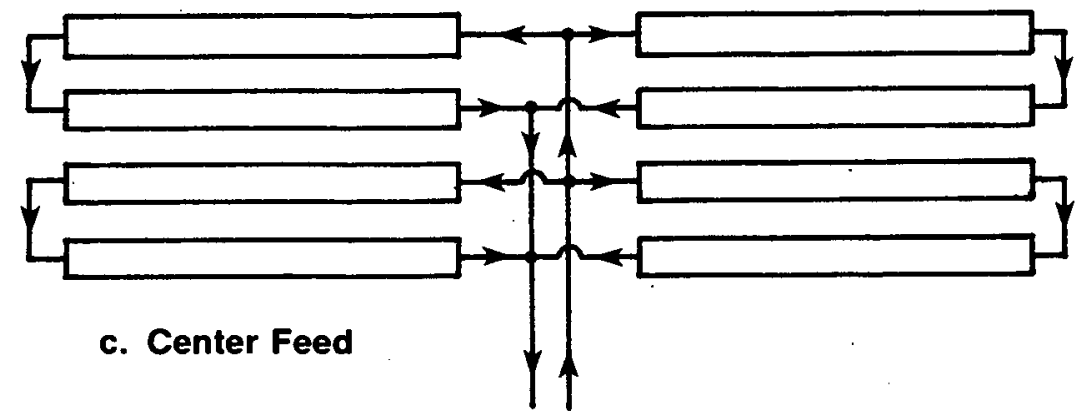

Figure 7-1. Solar Collector Field Layouts 
the system than they would in a direct-return configuration. (Alternatively, header pipes can be stepped down in size on the inlet side and stepped up on the outlet side to maintain constant velocity in the headers, thereby providing uniform flow.) The extra length of supply piping is a disadvantage in the reverse-return array because of additional heat loss, although this depends greatly on the supply fluid temperature.- If supply fluid temperatures are near ambient, additional heat loss is negligible. Adding length to the pipes, however, results in higher piping, insulation, and fluid inventory costs.

The center-feed configuration is gaining favor with some IPH system designers. As with the direct-return design, balancing valves contribute a significant portion of the head loss; but the design minimizes the amount of piping needed by eliminating a pipe that runs the length of the collector row. Also, direct access to each collector row is possible without having to bury any pipes.

\subsubsection{Optimum Array F1od Rate and Collector Configuration}

Along with the array configuration, we must also determine the optimum array flow rate and the number of collectors to be connected in series and in paral1el. Determining the optimum collector flow rate involves a trade-off between collector and heat exchanger performance and parasitic energy requirements. Consider the effect of changing the collector mass flow rate $M_{c}$. If we ignore changes in collector efficiency as a function of $\Delta \mathrm{T}_{c}$ (the temperature rise through the collectors), the mass flow rate is inversely proportional to $\Delta T^{\circ}$ Thus, halving the flow rate doubles $\Delta T_{c}$. Whether that is desirable depends ${ }^{\circ}$ whether the inlet temperature to the collectors drops (increasing $\eta_{c}$ ) or the outlet temperature rises (decreasing $\eta_{c}$ ).

As $\dot{M}_{c}$ is reduced, the effectiveness of the heat exchanger drops slightly because of a reduction in the heat transfer coefficient of the collector fluid. Since the heat transferred through the heat exchanger is $\dot{M}_{c} c_{p} \Delta T$, if $\dot{M}_{c}$ is halved, the $\Delta T$ across the heat exchanger will be slightly less than doubled. If the heat exchanger has a high effectiveness, the temperature of the exiting collector fluid will already be close to the cold inlet temperature on the other side of the heat exchanger; thus, the change in $\dot{M}_{c}$ has little effect on the collector inlet temperature. Therefore, decreasing $\dot{M}_{c}$ increases the collector outlet temperature and reduces efficiency.

With this effect in mind, we want a collector flow rate large enough to keep array outlet temperatures low (providing good efficiency) but not so large that greater array efficiency is offset by greater parasitic energy requirements. We also want a heat exchanger large enough to provide a minimum collector inlet temperature. The optimum mass flow rate will be somewhat higher in a parallel-configured array (with lower $\Delta T_{\text {}}$ ) than in a series array because of the lower parasitics associated with paralfel flow.

Along with choosing an optimum overall flow rate, we must make certain tradeoffs between the collectors in parallel and those in series. For $n$ collectors in parallel, the head losses for a given total flow rate are

$$
\mathrm{H}_{\mathrm{p}}=\frac{1}{\mathrm{n}^{2}}\left(\mathrm{f} \frac{\mathrm{L}}{2 \mathrm{gD}}\right) \mathrm{v}^{2} \text {. }
$$

For collectors in series with the same total flow rate, 


$$
\mathrm{H}_{\mathrm{s}}=\mathrm{n}\left(\mathrm{f} \frac{\mathrm{L}}{2 \mathrm{gD}}\right) \mathrm{v}^{2}
$$

Thus, $\mathrm{H}_{\mathrm{s}} / \mathrm{H}_{\mathrm{p}}=\mathrm{n}^{3}$, so the head loss in a series system is $\mathrm{n}^{3}$ times the head loss in a system plumbed in parallel. To minimize parasitics, therefore, we should probably have more collectors configured in parallel than in series. On the other hand, collector performance decreases as the flow rate is decreased, because $F_{R}$ changes with flow rate. Lunde (1980) gives the following expression for $F_{R}^{R}$ :

$$
F_{R}=\frac{\dot{\mathrm{M}}_{c} c_{p}}{U_{L} A_{c}}\left\{1-\exp \left[-\frac{U_{L} A_{c}}{M_{c} c_{p}} \div\left(\frac{1}{\eta_{F}}+\frac{U_{L} A_{c}}{U_{f} A_{f}}\right)\right],\right.
$$

where

$\dot{\mathrm{M}}_{\mathrm{c}}=$ mass flow rate through the collector

$c_{p}=$ specific heat of collector fluid

$\mathrm{U}_{\mathrm{L}}^{\mathrm{p}}=$ collector heat loss coefficient

$A_{c}=$ collector aperture area

$n_{\mathrm{F}}=$ fin efficiency of absorber plate

$\mathrm{U}_{\mathrm{f}}=$ heat transfer coefficient from absorber to collector fluid

$A_{f}=$ area of heat transfer to collector fluid.

For small changes in flow rate, the following approximate formula holds:

$$
\frac{F_{R}}{\left(F_{R}\right)_{o l d}}=\frac{1}{1+\frac{\left(F_{R} A_{c} U_{L}\right)_{o l d}}{2 c_{p}}\left(\frac{1}{\dot{M}_{c}}-\frac{1}{\left(\dot{M}_{c}\right)_{o l d}}\right)} \text {. }
$$

This leads to lower collector efficiency in parallel collectors compared with series collectors at the same total flow rate.

Thus far, we have mentioned only collector pressure drops and have ignored interconnecting piping. A parallel array requires more of such interconnecting piping, which adds to cost and parasitics, especially in a trough array where the collectors must be spaced far apart enough to minimize row-to-row shading. Also, the troughs themselves are marked by fairly low pressure drops. These factors suggest that an optimum trough field will have more collectors in series than an optimum field of flat-plate or evacuated-tube co1lectors. On the other hand, collectors with high individual pressure drops, such as some evacuated-tube designs and flat plates with serpentine flow, are more likely to function optimally with parallel plumbing.

Note also that measures must be taken in parallel configurations to ensure reasonably uniform flow through each collector. This can be done by balancing valves, which add to pressure drops and pumping costs, or by increasing the size of the header pipes, which adds to pipe costs. Again, this problem is a function of collector pressure loss characteristics: collectors with higher $\Delta \mathrm{P}$ have more uniform flow. So, the optimum plumbing configuration is the result of a cost trade-off. Adding more series collectors decreases field 
piping $\Delta P$ (and both piping and life-cycle pumping costs) but rapidly increases collector $\Delta P$. Any final arrangement will be a series/parallel combination, but the actual configuration will be a function of the particular collector pressure drop and, to a lesser extent, electricity costs for pumping and local installed piping costs.

\subsubsection{Pipes and Sizing Techniques}

Plping material must be capable of withstanding stagnation temperatures for a long period of time, which rules out PVC and CPVC pipe in most cases. Although certain plastics are appropriate for low-temperature applications, Schedule 40 steel pipe is a common, readily available choice. In small sizes, copper pipe can be used well with copper flat-plate collectors because it eliminates the galvanic corrosion problem associated with multiple metals. Note that dielectric insulation should be used at the junctions of any dissimilar metals to prevent such galvanic corrosion.

Many pipe sizing techniques are available. One technique often used is the method found in the Chemical Engineers' Handbook (Perry and Chilton 1973). The Perry and Chilton method uses pipe cost correlations, physical property data, and flow rates to estimate optimum pipe diameter. Table 7-1 summarizes typical results of economic fluid velocities for turbulent flow in Schedule 40 steel pipes that were obtained using this method.

Another complex sizing method is that employed in the ETRANS computer program (Barnhart 1981). ETRANS optimizes piping in a solar field by searching for the combination of pipe diameter and insulation thickness with the lowest life-cycle cost. This technique uses cost estimates for piping, insulation, valves, fittings, labor, heat loss, and pumping power, and incorporates features of previous work by Powel1 (1974), Caputo (1975), Williams (1978), and Iannucci (1980).

A number of pipe sizing analyses for solar thermal systems [e.g., Alexander and Kutscher (1978) and Thornton (forthcoming)] indicate that economically optimum pipe velocities, based on pumping power versus installed cost and heat losses, are usually greater than good design practice allows. So, considerations such as erosion-corrosion (HUD 1977) limit that maximum velocity and thereby determine pipe size. In the collector array, header pipe sizes may be larger to provide for more uniform flow.

Table 7-1. Economic Fluid Velocities for Schedule 40 Steel PIpes, Obtained Using the Perry and Chilton Method

\begin{tabular}{lcccc}
\hline Density, $\mathrm{kg} / \mathrm{m}^{3}\left(1 \mathrm{~b} / \mathrm{ft}^{3}\right)$ & $1600(100)$ & $1000(62.4)$ & $800(50)$ & $15(1.0)$ \\
Viscosity, centipoise & 1.0 & 1.0 & 1.0 & 0.02 \\
Economic velocity, m/s (ft/s) & $2(6.5)$ & $2.3(7.4)$ & $2.4(7.9)$ & $9.5(31)$ \\
\hline
\end{tabular}




\subsubsection{Insulation and Heat Losses}

Collecting thermal energy with a solar system involves considerable expense; therefore, as much of that energy as possible should be retained by insulating the system piping. This does not mean, however, that a builder should purchase the thickest possible pipe insulation, because there is a point where the additional cost of thicker insulation is higher than the value of the energy saved over the lifetime of the system. Optimum insulation is achieved with an appropriate insulating material at a thickness that provides the low-. est total life-cycle costs in materials, installation, maintenance, and lost energy •

The effect of insulation thickness on the cost of energy delivered by a solar system is illustrated in Fig. 7-2. Increasing the amount of insulation on a hot pipe surface decreases the amount of energy lost from that surface, and it reduces accordingly the amount of energy that would otherwise have to be made up by additional collector area or by an auxiliary source. The effect is inversely logarithmic, however, so each additional increment of insulation saves less energy than the one before. To this decreasing cost of lost energy, we must add the increasing cost of the insulation itself. The total cost exhibits a minimum value at some optimal insulation thickness. (Adding insulation to smal1-diameter tubes can increase heat loss up to a point by increasing the area available for heat loss. This is not the case for the pipe sizes we are addressing here, however.)

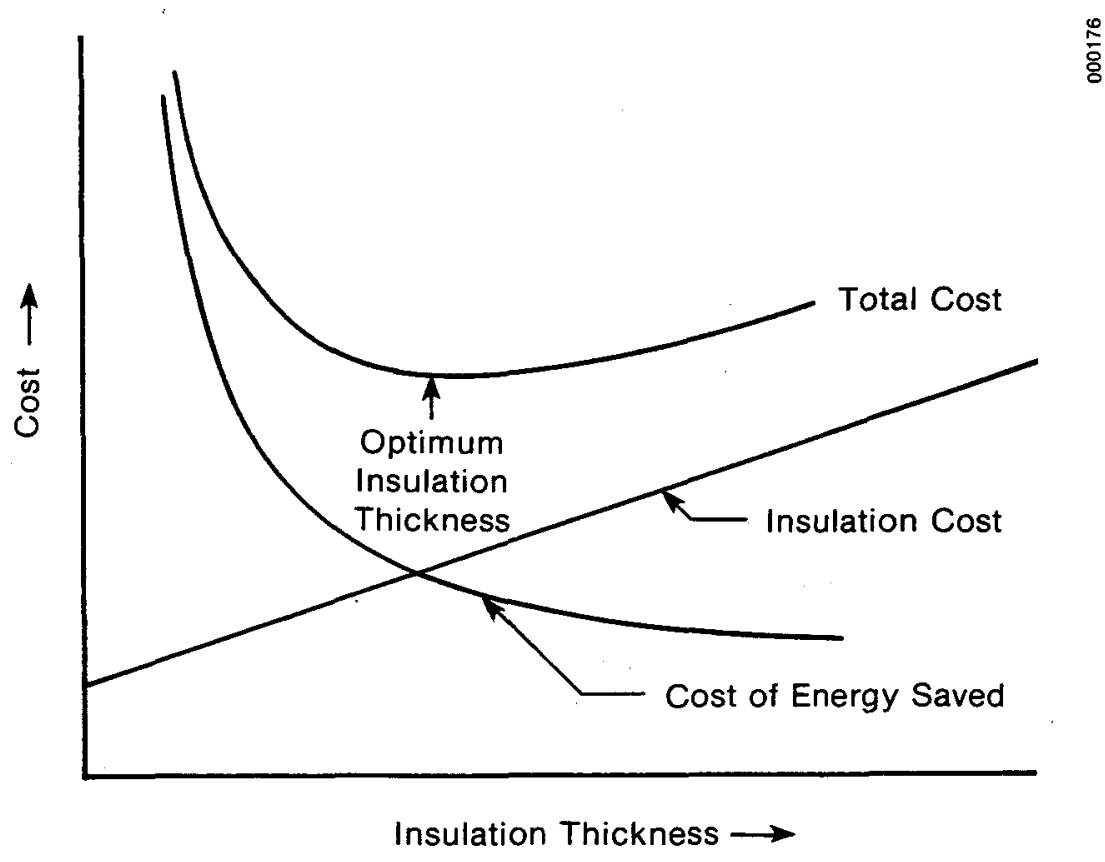

Figure 7-2. Effect of Insulation Thickness on Delivered Energy Cost 
As a rough guide, Table 7-2 gives typical thicknesses of pipe insulation at different temperatures (Perry and Chilton 1973). Another rough rule of thumb is that optimal insulation thickness is approximately the maximum thickness of a single layer of insulation that can be installed without introducing problems associated with thermal expansion of the pipe or vessel (Allen 1981). Additional insulation requirements, including flammability, durability, and permeability to water, should be satisfied before a least-cost optimization is conducted. The optimization process described here does not deal directly with such requirements, but information on flammability and other properties of insulating materials is given in Table 11-1.

The following model is based on both thermal and economic parameters and permits a solar system designer to select an insulating material and thickness with the lowest total life-cycle cost for a particular application. The method follows and extends the work of Jones and Lior (1979), who developed the method for solar space-heating systems. Whereas Jones and Lior considered a maximum nominal pipe diameter of $127 \mathrm{~mm}$ (5 in.) and a maximum insulation thickness of $152 \mathrm{~mm}$ ( $6 \mathrm{in.})$, the present work addresses pipe diameters up to $610 \mathrm{~mm}$ (24 in.) at insulation thicknesses up to $254 \mathrm{~mm}$ (10 in.).

The heat transfer model is based on an insulated pipe like that shown schematically in Fig. 7-3. A heat transfer fluid flows axially through the pipe and loses heat through the pipe wall, insulation, and finally to the surrounding air via convection and radiation. The equation governing the total radial heat loss per unit length of pipe between the fluid and surrounding air is

$$
\frac{\overline{\mathrm{Q}}_{1}}{\overline{\mathrm{L}}_{\mathrm{i}}}=\left(\mathrm{T}_{\mathrm{f}}-\mathrm{T}_{\mathrm{a}}\right) /\left(\mathrm{L} \sum_{\mathrm{i}=1}^{4} \mathrm{R}_{\mathrm{i}}\right) \text {, }
$$

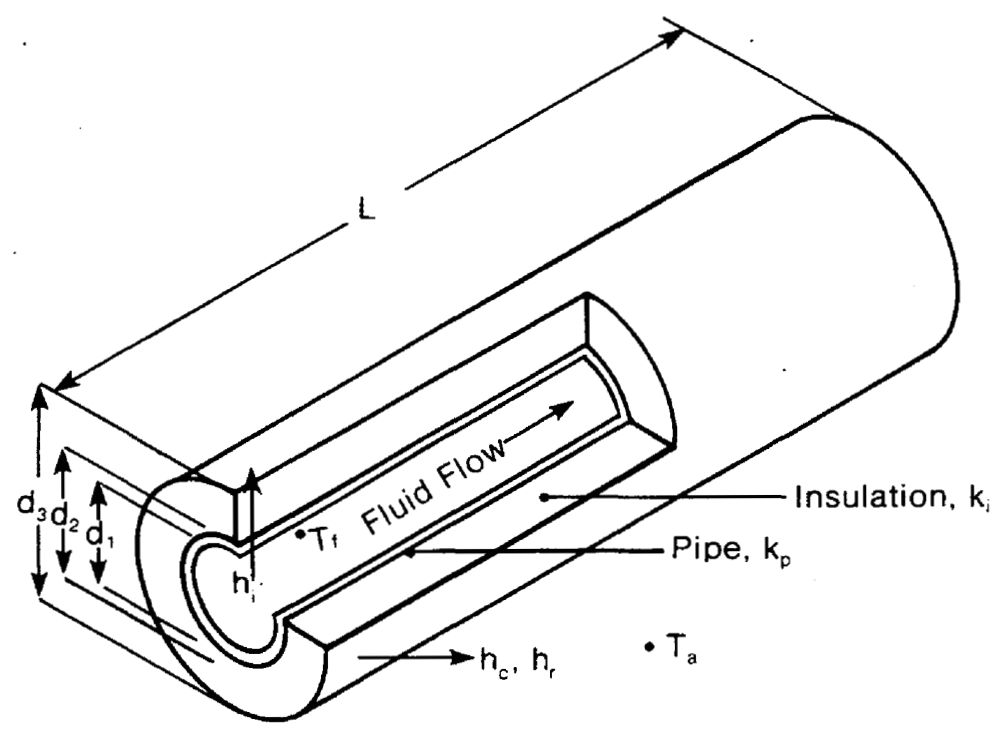


Table 7-2. Typical Thicknesses of Calcium Silicate Pipe Insulation (inches)

\begin{tabular}{cccccc}
\hline $\begin{array}{c}\text { Nominal } \\
\text { Pipe Size } \\
\text { (in.) }\end{array}$ & $100-199$ & $200-299$ & $300-399$ & $400-499$ & $500-599$ \\
\cline { 2 - 6 } 1.5 and less & 1 & 1.5 & 2 & $2.5^{\mathrm{a}}$ & $2.5^{\mathrm{a}}$ \\
2 & 1 & 1.5 & 2 & $2.5^{\mathrm{a}}$ & $3^{\mathrm{a}}$ \\
2.5 & 1 & 2 & 2.5 & $3^{\mathrm{a}}$ & $3^{\mathrm{a}}$ \\
3 & 1.5 & 2 & 2.5 & $3^{\mathrm{a}}$ & $3.5^{\mathrm{a}}$ \\
3.5 & 1.5 & 2 & 2.5 & $3^{\mathrm{a}}$ & $3.5^{\mathrm{a}}$ \\
4 & 1.5 & 2 & 2.5 & $3^{\mathrm{a}}$ & $3.5^{\mathrm{a}}$ \\
4.5 & 1.5 & 2 & 2.5 & $3^{\mathrm{a}}$ & $3.5^{\mathrm{a}}$ \\
5 & 1.5 & 2 & 2.5 & $3^{\mathrm{a}}$ & $3.5^{\mathrm{a}}$ \\
6 & 1.5 & 2 & 3 & $3.5^{\mathrm{a}}$ & $4^{\mathrm{a}}$ \\
7 & 1.5 & 2 & 3 & $3.5^{\mathrm{a}}$ & $4^{\mathrm{a}}$ \\
8 & 1.5 & 2 & 3 & $3.5^{\mathrm{a}}$ & $4^{\mathrm{a}}$ \\
9 & 1.5 & 2.5 & 3 & $3.5^{\mathrm{a}}$ & $4^{\mathrm{a}}$ \\
10 & 1.5 & 2.5 & 3 & $3.5^{\mathrm{a}}$ & $4^{\mathrm{a}}$ \\
11 & 1.5 & 2.5 & 3 & $3.5^{\mathrm{a}}$ & $4^{\mathrm{a}}$ \\
12 & 1.5 & 2.5 & 3.5 & $4^{\mathrm{a}}$ & $4.5^{\mathrm{a}}$ \\
\hline and up & 2 & 2.5 & 3.5 & $4^{\mathrm{a}}$ & $4.5^{\mathrm{a}}$ \\
\hline
\end{tabular}

Source: Perry and Chilton 1973.

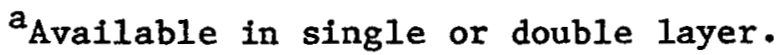

where

$\mathrm{T}_{\mathrm{f}}=$ fluid temperature $(\mathrm{K})$

$\mathrm{T}_{\mathrm{a}}=$ air temperature $(\mathrm{K})$

$\mathrm{L}=$ pipe length (m)

$R_{1}=$ thermal resistances $(\mathrm{mK} / \mathrm{W})$

$U=$ overall heat transfer coefficient $\left(W / m^{2}-K\right)$

$A=$ heat transfer area $\left(\mathrm{m}^{2}\right)$

$\Delta \mathrm{T}=\mathrm{T}_{\mathrm{f}}-\mathrm{T}_{\mathrm{a}}(\mathrm{K})$. 
Inserting the appropriate expressions for the thermal resistance, we have

$$
\frac{\dot{Q}}{L}=\frac{\pi\left(T_{f}-T_{a}\right)}{-\frac{1}{D_{p, i} h_{i}}+\frac{\ln \left(D_{p, o} / D_{p, i}\right)}{2 k_{p}}+\frac{\ln \left(D_{i} / D_{p, o}\right)}{2 k_{i}}+\frac{1}{D_{i}\left(h_{c}+h_{r}\right)}},
$$

where

$$
\begin{aligned}
& \mathrm{D}_{\mathrm{p}, \mathrm{i}}=\text { pipe inside diameter (m) } \\
& \mathrm{D}_{\mathrm{p}, \mathrm{O}}=\text { pipe outside diameter = insulation inner diameter (m) } \\
& D_{i}=\text { insulation outside diameter (m) } \\
& h_{i}=\text { heat transfer coefficient inside pipe }\left(W / m^{2}-K\right) \\
& h_{c}=\text { convective heat transfer coefficient between insulation and sur- } \\
& h_{r}=\text { radiative heat transfer coefficient between insulation and sur- } \\
& k_{p}=\text { pipe thermal conductivity }(W / m-K) \\
& k_{1}=\text { insulation thermal conductivity }(\mathrm{W} / \mathrm{m}-\mathrm{K}) \text {. }
\end{aligned}
$$

Combining Eqs. $7-1$ and $7-2$, and using the relation $\dot{Q}=U A \Delta T$, we obtain

$$
\frac{\mathrm{UA}}{\mathrm{L}}=\frac{\pi}{\frac{1}{\mathrm{D}_{\mathrm{p}, i^{h_{i}}}}+\frac{\ln \left(\mathrm{D}_{\mathrm{p}, \mathrm{o}} / \mathrm{D}_{\mathrm{p}, i}\right)}{2 \mathrm{k}_{\mathrm{p}}}+\frac{\ln \left(\mathrm{D}_{1} / \mathrm{D}_{\mathrm{p}, \mathrm{o}}\right)}{2 \mathrm{k}_{1}}+\frac{1}{\mathrm{D}_{\mathrm{i}}\left(\mathrm{h}_{\mathrm{c}}+\mathrm{h}_{\mathrm{r}}\right)}} \text {. }
$$

Physically, UA/L represents the rate of heat loss per unit temperature difference between the fluid and ambient per unit length of pipe. The three heat transfer coefficients, $h_{1}, h_{c}$, and $h_{r}$, can be determined as follows. The inside film coefficient $h_{i}$ can be obtained from

$$
h_{1}=N u_{i} k_{f} / d_{p, i},
$$

where

$$
\begin{aligned}
& \mathrm{Nu}_{i}=\underset{\text { the fluid] }}{0.023 \operatorname{Re}_{f}^{0.8}} \operatorname{Pr}_{\mathrm{f}}^{0.3} \text { [see Dittus and Boelter (1930) for cooling of } \\
& \mathrm{k}_{\mathrm{f}}=\text { fluld thermal conductivity }(\mathrm{W} / \mathrm{m}-\mathrm{K}) \\
& R e_{f}=\text { fluid Reynolds number } \\
& \operatorname{Pr}_{f}=\text { fluid Prandtl number. }
\end{aligned}
$$


For outdoor piping, where forced convection dominates because of the wind, the convective heat-loss coefficient can be calculated (Kreith 1973) from

$$
h_{c}=\left(k_{a} / D_{1}\right)\left(0.4 \operatorname{Re}_{a}^{0.5}+0.6 \operatorname{Re}_{a}^{0.67}\right) \operatorname{Pr}_{a}^{0.4}\left(\mu_{a} / \mu_{a s}\right)^{0.25}, \quad(7-5 a)
$$

where

$$
\begin{aligned}
k_{a} & =\text { air thermal conductivity }(\mathrm{W} / \mathrm{m}-\mathrm{K}) \\
\operatorname{Re}_{\mathrm{a}} & =\text { air Reynolds number based on the outside diameter of the } \\
& \text { insulation } \\
\operatorname{Pr}_{\mathrm{a}} & =\text { air Prandt1 number } \\
\mu_{a} & =\text { air dynamic viscosity at ambient temperature }\left(\mathrm{kg} \mathrm{s}-1 \mathrm{~m}^{-1}\right) \\
\mu_{a s} & =\text { air dynamic viscosity at insulation film temperature }\left(\mathrm{kg} \mathrm{s}^{-1} \mathrm{~m}^{-1}\right)
\end{aligned}
$$

For indoor piping, where free convection dominates, the convective heat transfer coefficient is*

$$
h_{c}=1.32\left[\left(T_{i, 0}-T_{a}\right) / D_{1}\right]^{0.25},
$$

where $T_{1,0}=$ insulation outside surface temperature $(K)$.

The radiative heat transfer coefficient is

$$
h_{r}=\sigma \varepsilon\left(T_{i, o}^{2}+T_{r}^{2}\right)\left(T_{i, o}+T_{r}\right) \text {, }
$$

where

$$
\begin{aligned}
\sigma & =\text { Stefan-Boltzmann constant }\left(5.67 \times 10^{-8} \mathrm{~W} / \mathrm{m}^{2}-\mathrm{K}^{4}\right) \\
\varepsilon & =\text { insulation surface emissivity } \\
\mathrm{T}_{\mathrm{r}} & =\text { effective radiative temperature of surroundings }(\mathrm{K}) .
\end{aligned}
$$

It is important to note that the outside surface temperature $T_{i, 0}$ is not known a priori and must be calculated iteratively. For that reason, the expression for UA/L was evaluated for all combinations of the 18 Schedule 40 pipe sizes and 20 insulation thicknesses using nominal values of the independent variables listed in Table 7-3. Tables 7-4 through 7-11 present the resulting UA/L values for indoor and outdoor piping and four values of insulation conductivity. The conductivities investigated span the range of those for the most common types of pipe insulation. For example, fiberglass insulation has a conductivity that varies between approximately $0.032 \mathrm{~W} / \mathrm{m}-\mathrm{K} \quad(0.22 \mathrm{Btu}-\mathrm{in} . /$ $\left.\mathrm{ft}^{2}-\mathrm{h}-\mathrm{F}\right)$ at $0^{\circ} \mathrm{C}\left(32^{\circ} \mathrm{F}\right)$ and $0.089 \mathrm{~W} / \mathrm{m}-\mathrm{K}\left(0.62 \mathrm{Btu}-\mathrm{in} . / \mathrm{ft} \mathrm{t}^{2} \mathrm{~h}-\mathrm{F}\right)$ at $260^{\circ} \mathrm{C}$ $\left(500^{\circ} \mathrm{F}\right)$, and the conductivity of calcium silicate varies between $0.053 \mathrm{~W} / \mathrm{m}-\mathrm{K}$ $\left(0.37 \mathrm{Btu}-\mathrm{in} . / \mathrm{ft}^{2}-\mathrm{h}-\mathrm{F}\right)$ at $35^{\circ} \mathrm{C}\left(95^{\circ} \mathrm{F}\right)$ to $0.125 \mathrm{~W} / \mathrm{m}-\mathrm{K}\left(0.87 \mathrm{Btu}-\mathrm{in} . / \mathrm{ft}{ }^{2}-\mathrm{h}-\mathrm{F}\right)$ at

\footnotetext{
*For English units (Btu/hr•ft ${ }^{2}{ }^{\circ} \mathrm{F}$ ) the coefficient 1.32 becomes 0.27 with temperatures in degrees $F$ and $D_{i}$ in feet (Lauer 1953).
} 
Table 7-3. Average Values of Independent Variables Used in Calculation of UA/L

\begin{tabular}{ll}
\hline Fluid & Water \\
Fluid temperature & $200^{\circ} \mathrm{C}$ \\
Fluid velocity & $2 \mathrm{~m} / \mathrm{s}$ \\
Pipe conductivity & $43.3 \mathrm{~W} / \mathrm{m}-\mathrm{K}$ \\
& $\left(25 \mathrm{Btu} / \mathrm{ft}-\mathrm{h}-{ }^{\circ} \mathrm{F}\right)$ \\
Insulation surface emissivity & 0.5 \\
Wind velocity & $5 \mathrm{~m} / \mathrm{s},{ }^{\mathrm{a} \quad} 0 \mathrm{~m} / \mathrm{s}$ \\
Ambient temperature & $10^{\circ} \mathrm{C},{ }^{\mathrm{b}} 25^{\circ} \mathrm{C}^{\mathrm{b}}$ \\
\hline
\end{tabular}

aOutdoor pipes.
bIndoor pipes.

$540^{\circ} \mathrm{C}\left(1000^{\circ} \mathrm{F}\right)$. Figure $7-4$ shows variations in thermal conductivity with temperature of common rigid insulating materials. This information is usually available from insulation manufacturers.

In evaluating heat loss through insulation, the average insulation conductivity should be used. Since the conductivity of many insulating materials is approximately linear with temperature, as shown in Fig. 7-4, the average conductivity is simply the average of the values at inside and outside insulation surface temperatures. To find the heat-loss coefficient per unit length of pipe, average conductivity is estimated and interpolated with the appropriate table (Tables 7-4 through 7-11).

Sensitivity studies examined the effect of changes in the independent variables in Table 7-3 on UA/L; the results are shown in Fig. 7-5 for outdoor pipes and in Fig. 7-6 for indoor pipes. The value of $(U A / L) /(U A / L)$, where (UA/L)。 is the value of $\mathrm{UA} / \mathrm{L}$ for the nominal inputs in Table 7-3, is graphed as $a$ function of $\left(x-x_{0}\right) / x_{0}$, where $x$ represents one of the varied parameters and $x_{0}$ is the nominal value of that parameter (also from Table 7-3). As indicated by the values of $\left(x-x_{0}\right) / x$, the fluid temperature was varied between $100^{\circ}$ and $300^{\circ} \mathrm{C}$, the fluid velocity was varied between 0.2 and $4.0 \mathrm{~m} / \mathrm{s}$, and the insulation outside surface emissivity was varied between 0.1 and 0.9 . The ambient temperature was varied between $-30^{\circ}$ and $40^{\circ} \mathrm{C}\left[\left(\mathrm{x}-\mathrm{x}_{0}\right) / \mathrm{x}_{0}=-4\right.$ to +3$]$ for outdoor pipes and $0^{\circ}$ and $40^{\circ} \mathrm{C}$ for indoor pipes. The wind velocity was varied between $I$ and $20 \mathrm{~m} / \mathrm{s}\left[\left(\mathrm{X}-\mathrm{X}_{0}\right) / \mathrm{X}_{0}=-0.8\right.$ to +3$]$ for outdoor pipes only. The pipe thermal conductivity was not varied, because only Schedule 40 commercial steel pipe was used to develop the UA/L values; however, since metal pipe will provide much less resistance to heat flow than any insulation, we can assume that different pipe materials and thicknesses (schedules) will have a minuscule effect on the value of $U A / L$ as long as alternative pipe is compared with Schedule 40 pipe of comparable actual diameter.

Figures 7-5 and 7-6 show that the effects of parameter changes on $\mathrm{UA} / \mathrm{L}$ are limited to a few percentage points and are greater for indoor pipes than outdoor ones. These effects are greatest for large pipes with thin insulation, and for this combination [part (c) of each figure], the deviation in UA/L is 


\section{Table 7-4. Outdoor PIpe UA/L Values ( $\mathrm{H} / \mathrm{K}-\mathrm{m}$ of length) for Insulation $\mathrm{k}=0.0288 \mathrm{~W} / \mathrm{m}-\mathrm{K}$ $\left(0.20 \mathrm{Btu}-\mathrm{In} / \mathrm{hr}-\mathrm{ft}^{2-\mathrm{o}_{\mathrm{F}}}\right)$}

\begin{tabular}{|c|c|c|c|c|c|c|c|c|c|c|c|c|c|c|c|c|c|c|c|c|}
\hline \multirow{2}{*}{$\begin{array}{l}\text { Nom. } \\
\text { P1pe } \\
\text { D1 am*, } \\
\text { mm } \\
\text { (In.) }\end{array}$} & \multicolumn{20}{|c|}{ Insulation Thickness, mm (1n.) } \\
\hline & $\begin{array}{c}13 \\
(0.5)\end{array}$ & $\begin{array}{c}25 \\
(1.0)\end{array}$ & $\begin{array}{c}38 \\
(1.5)\end{array}$ & $\begin{array}{c}51 \\
(2.0)\end{array}$ & $\begin{array}{c}64 \\
(2.5)\end{array}$ & $\begin{array}{c}76 \\
(3.0)\end{array}$ & $\begin{array}{c}89 \\
(3.5)\end{array}$ & $\begin{array}{c}102 \\
(4.0)\end{array}$ & $\begin{array}{c}114 \\
(4.5)\end{array}$ & $\begin{array}{c}127 \\
(5.0)\end{array}$ & $\begin{array}{c}140 \\
(5.5)\end{array}$ & $\begin{array}{c}152 \\
(6.0)\end{array}$ & $\begin{array}{c}165 \\
(6.5)\end{array}$ & $\begin{array}{c}178 \\
(7.0)\end{array}$ & $\begin{array}{c}191 \\
(7.5)\end{array}$ & $\begin{array}{c}203 \\
(8.0)\end{array}$ & $\begin{array}{c}216 \\
(8.5)\end{array}$ & $\begin{array}{c}229 \\
(9.0)\end{array}$ & $\begin{array}{c}241 \\
(9.5)\end{array}$ & $\begin{array}{c}254 \\
(10.0)\end{array}$ \\
\hline $\begin{array}{r}25 \\
(1.0)\end{array}$ & 0.317 & 0.195 & 0.152 & 0.129 & 0.115 & 0.105 & 0.098 & 0.092 & 0.088 & 0.084 & 0.081 & 0.078 & 0.076 & 0.074 & 0.072 & 0.070 & 0.069 & 0.067 & 0.066 & 0.065 \\
\hline $\begin{array}{r}32 \\
(1.25)\end{array}$ & 0.381 & 0.228 & 0.175 & 0.147 & 0.130 & 0.118 & 0.110 & 0.103 & 0.097 & 0.093 & 0.089 & 0.086 & 0.083 & 0.081 & 0.079 & 0.077 & 0.075 & 0.073 & 0.072 & 0.071 \\
\hline $\begin{array}{r}38 \\
(1.5)\end{array}$ & 0.424 & 0.251 & 0.191 & 0.160 & 0.140 & 0.127 & 0.117 & 0.110 & 0.104 & 0.099 & 0.095 & 0.091 & 0.088 & 0.085 & 0.083 & 0.081 & 0.079 & 0.077 & 0.076 & 0.074 \\
\hline $\begin{array}{r}51 \\
(2.0)\end{array}$ & 0.510 & 0.295 & 0.221 & 0.183 & 0.160 & 0.144 & 0.132 & 0.123 & 0.116 & 0.110 & 0.105 & 0.101 & 0.097 & 0.094 & 0.091 & 0.089 & .086 & 0.084 & 0.082 & 0.081 \\
\hline & 0.600 & 0.341 & 0.253 & 0.207 & 0.179 & 0.160 & 0.147 & 0.136 & 0.128 & 0.121 & 0.115 & 0.110 & 0.106 & 0.102 & 0.099 & 0.096 & 0.094 & 0.091 & 0.089 & 0.087 \\
\hline $\begin{array}{r}76 \\
(3.0) \\
\end{array}$ & 0.712 & 0.398 & 0.292 & 0.237 & 0.204 & 0.181 & 0.165 & 0.152 & 0.142 & 0.134 & 0.127 & 0.122 & 0.117 & 0.113 & 0.109 & 0.105 & 0.102 & 0.100 & 0.097 & 0.095 \\
\hline $\begin{array}{r}89 \\
(3.5)\end{array}$ & 0.801 & 0.444 & 0.322 & 0.261 & 0.223 & 0.197 & 0.179 & 0.165 & 0.154 & 0.144 & 0.137 & 0.131 & 0.125 & 0.120 & 0.116 & 0.113 & 0.109 & 0.106 & 0.104 & 0.101 \\
\hline $\begin{array}{l}102 \\
(4.0)\end{array}$ & 0.890 & 0.489 & 0.353 & 0.284 & 0.242 & 0.213 & 0.193 & 0.177 & 0.165 & 0.155 & 0.146 & 0.139 & 0.133 & 0.128 & 0.123 & 0.119 & 0.116 & 0.113 & 0.110 & 0.107 \\
\hline $\begin{array}{r}127 \\
(5.0)\end{array}$ & 1.079 & 0.586 & 0.418 & 0.333 & 0.282 & 0.247 & 0.222 & 0.203 & 0.188 & 0.176 & 0.166 & 0.157 & 0.150 & 0.144 & 0.138 & 0.134 & 0.129 & 0.125 & 0.122 & 0.119 \\
\hline $\begin{array}{r}152 \\
(6.0)\end{array}$ & 1.268 & 0.681 & 0.483 & 0.382 & 0.321 & 0.280 & 0.251 & 0.228 & 0.211 & 0.197 & 0.185 & 0.175 & 0.167 & 0.159 & 0.153 & 0.147 & 0.142 & 0.138 & 0.134 & .130 \\
\hline $\begin{array}{c}203 \\
(8.0)\end{array}$ & 1.622 & 0.861 & 0.604 & 0.474 & 0.395 & 0.342 & 0.304 & 0.276 & 0.253 & 0.235 & 0.220 & 0.208 & 0.197 & 0.188 & 0.180 & 0.173 & 0.166 & 0.161 & 0.156 & 0.151 \\
\hline $\begin{array}{r}254 \\
(10.0)\end{array}$ & 1.998 & 1.052 & 0.732 & 0.570 & 0.473 & 0.407 & 0.360 & 0.325 & 0.297 & 0.275 & 0.257 & 0.241 & 0.228 & 0.217 & 0.207 & 0.199 & 0.191 & 0.184 & 0.178 & 0.172 \\
\hline $\begin{array}{r}305 \\
12.0)\end{array}$ & 2.350 & 231 & 352 & 361 & 546 & 468 & 413 & 371 & 339 & 312 & 0.291 & 0.273 & .257 & .244 & 0.233 & 0.223 & 0.214 & 0.206 & 0.198 & 0.192 \\
\hline $\begin{array}{r}356 \\
(14.0)\end{array}$ & 2.571 & 1.343 & 0.927 & 0.717 & 0.591 & 0.506 & 0.446 & 0.400 & 0.364 & 0.336 & 0.312 & 0.292 & 0.276 & 0.261 & 0.249 & 0.237 & 0.228 & 0.219 & 0.211 & 0.204 \\
\hline $\begin{array}{r}406 \\
(16.0)\end{array}$ & 2.922 & 1.521 & 1.047 & 0.808 & 0.663 & 0.567 & 0.498 & 0.446 & 0.405 & 0.372 & 0.346 & 0.323 & 0.304 & 0.288 & 0.274 & 0.261 & 0.250 & 0.240 & 0.231 & 0.223 \\
\hline $\begin{array}{r}457 \\
(18.0)\end{array}$ & 3.273 & 1.700 & 1.166 & 0.898 & 0.736 & 0.628 & 0.550 & 0.491 & 0.446 & 0.409 & 0.379 & 0.354 & 0.333 & 0.314 & 0.299 & 0.285 & 0.272 & 0.261 & 0.251 & 0.242 \\
\hline $\begin{array}{r}508 \\
20.0)\end{array}$ & 3.624 & 1.878 & 1.286 & 0.988 & 0.808 & 0.688 & 0.602 & 0.537 & 0.486 & 0.446 & 0.413 & 0.385 & 0.361 & 0.341 & 0.323 & 0.308 & 0.294 & 0.282 & 0.271 & .261 \\
\hline $\begin{array}{r}610 \\
24.0)\end{array}$ & 4.325 & 2.235 & 1.525 & 1.168 & 0.953 & 0.809 & 706 & 628 & 567 & 0.519 & 0.479 & 0.446 & 0.418 & 0.394 & 0.373 & 0.354 & 0.338 & 0.323 & 0.310 & $0.299^{\circ}$ \\
\hline
\end{tabular}




\section{Table 7-5. Outdoor Pipe UA/L Values ( $/ \mathrm{K}-\mathrm{m}$ of length) for Insulation $\mathrm{k}=0.0577 \mathrm{~W} / \mathrm{m}-\mathrm{K}$}

(0.40 Btu-in./hr-ft $\left.{ }^{2}-{ }^{\mathrm{F}}\right)$

\begin{tabular}{|c|c|c|c|c|c|c|c|c|c|c|c|c|c|c|c|c|c|c|c|c|}
\hline \multirow{2}{*}{$\begin{array}{l}\text { Nom. } \\
\text { P1pe } \\
\text { Dlam., } \\
\text { mm } \\
\text { (In.) }\end{array}$} & \multicolumn{20}{|c|}{ Insulation Thickness, mn ( $\left.1 n_{0}\right)$} \\
\hline & $\begin{array}{c}13 \\
(0.5)\end{array}$ & $\begin{array}{c}25 \\
(1.0)\end{array}$ & $\begin{array}{c}38 \\
(1.5)\end{array}$ & $\begin{array}{c}51 \\
(2.0)\end{array}$ & $\begin{array}{c}64 \\
(2.5)\end{array}$ & $\begin{array}{c}76 \\
(3.0)\end{array}$ & $\begin{array}{c}89 \\
(3.5)\end{array}$ & $\begin{array}{c}102 \\
(4.0)\end{array}$ & $\begin{array}{c}114 \\
(4.5)\end{array}$ & $\begin{array}{c}127 \\
(5.0)\end{array}$ & $\begin{array}{c}140 \\
(5.5)\end{array}$ & $\begin{array}{c}152 \\
(6.0)\end{array}$ & $\begin{array}{c}165 \\
(6.5)\end{array}$ & $\begin{array}{c}178 \\
(7.0)\end{array}$ & $\begin{array}{c}191 \\
(7.5)\end{array}$ & $\begin{array}{c}203 \\
(8.0)\end{array}$ & $\begin{array}{c}216 \\
(8.5)\end{array}$ & $\begin{array}{c}229 \\
(9.0)\end{array}$ & $\begin{array}{c}241 \\
(9.5)\end{array}$ & $\begin{array}{c}254 \\
(10.0)\end{array}$ \\
\hline $\begin{array}{r}25 \\
(1.0)\end{array}$ & 0.629 & 0.388 & 0.303 & 0.258 & 0.230 & 0.211 & 0.196 & 0.185 & 0.176 & 0.168 & 0.162 & 0.156 & 0.152 & 0.147 & 0.144 & 0.140 & 0.137 & 0.135 & 0.132 & 0.130 \\
\hline & 0.753 & 0.454 & 0.349 & 0.294 & 0.260 & 0.236 & 0.219 & 0.205 & 0.194 & 0.186 & 0.178 & 0.172 & 0.166 & 0.161 & 0.157 & 0.153 & 0.150 & 0.146 & 0.144 & 0.141 \\
\hline $\begin{array}{r}38 \\
(1.5)\end{array}$ & 0.839 & 0.499 & 0.380 & 0.318 & 0.280 & 0.254 & 0.234 & 0.219 & 0.207 & 0.197 & 0.189 & 0.182 & 0.176 & 0.170 & 0.166 & 0.161 & 0.158 & 0.154 & 0.151 & 0.148 \\
\hline $\begin{array}{r}51 \\
(2.0)\end{array}$ & 1.008 & 0.587 & 0.441 & 0.365 & 0.319 & 0.287 & 0.263 & 0.245 & 0.231 & 0.219 & 0.209 & 0.201 & 0.194 & 0.187 & 0.182 & 0.177 & 0.172 & 0.168 & 0.165 & 0.161 \\
\hline $\begin{array}{r}64 \\
(2.5)\end{array}$ & 1.185 & 0.678 & 0.503 & 0.413 & 0.358 & 0.320 & 0.293 & 0.272 & 0.255 & 0.241 & 0.230 & 0.220 & 0.212 & 0.204 & 0.198 & 0.192 & 0.187 & 0.183 & 0.178 & 0.175 \\
\hline $\begin{array}{r}76 \\
(3.0)\end{array}$ & 1.405 & 0.792 & 0.581 & 0.473 & 0.406 & 0.361 & 0.329 & 0.304 & 0.284 & 0.268 & 0.254 & 0.243 & 0.233 & 0.225 & 0.217 & 0.211 & 0.205 & 0.199 & 0.195 & 0.190 \\
\hline $\begin{array}{r}89 \\
(3.5)\end{array}$ & 1.580 & 0.882 & 0.642 & 0.519 & 0.445 & 0.394 & 0.357 & 0.329 & 0.307 & 0.289 & 0.274 & 0.261 & 0.250 & 0.241 & 0.232 & 0.225 & 0.218 & 0.212 & 0.207 & 0.202 \\
\hline $\begin{array}{r}102 \\
(4.0)\end{array}$ & 1.755 & 0.972 & 0.703 & 0.566 & 0.482 & 0.426 & 0.385 & 0.354 & 0.329 & 0.309 & 0.292 & 0.278 & 0.266 & 0.256 & 0.247 & 0.239 & 0.231 & 0.225 & 0.219 & 0.214 \\
\hline $\begin{array}{r}127 \\
(5.0) \\
\end{array}$ & 2.126 & 1.162 & 0.832 & 0.664 & 0.562 & 0.493 & 0.443 & $\begin{array}{c}0.405 \\
.\end{array}$ & 0.375 & 0.351 & 0.331 & 0.315 & 0.300 & 0.288 & 0.277 & 0.267 & 0.258 & 0.251 & 0.244 & 0.237 \\
\hline $\begin{array}{r}152 \\
(6.0)\end{array}$ & 2.494 & 1.352 & 0.960 & 0.761 & 0.641 & 0.559 & 0.500 & 0.456 & 0.421 & $0.393^{\circ}$ & 0.369 & 0.350 & 0.333 & 0.318 & 0.306 & 0.295 & 0.285 & 0.276 & 0.268 & $0.260^{\circ}$ \\
\hline $\begin{array}{r}203 \\
(8.0)\end{array}$ & 3.186 & 1.707 & 1.200 & 0.943 & 0.787 & 0.682 & 0.607 & 0.550 & 0.505 & 0.469 & 0.440 & 0.415 & 0.393 & 0.375 & 0.359 & 0.345 & 0.332 & 0.321 & 0.311 & 0.302 \\
\hline $\begin{array}{r}254 \\
(10.0)\end{array}$ & 3.919 & 2.083 & 1.454 & 1.135 & 0.942 & 0.812 & 0.719 & 0.649 & 0.593 & 0.549 & 0.513 & 0.482 & 0.456 & 0.434 & 0.414 & 0.397 & 0.381 & 0.368 & 0.355 & 0.344 \\
\hline $\begin{array}{r}305 \\
(12.0)\end{array}$ & 4.605 & 2.437 & 1.692 & 1.315 & 1.087 & 0.934 & 0.824 & 0.741 & 0.676 & 0.624 & 0.581 & 0.545 & 0.514 & 0.488 & 0.465 & 0.445 & 0.427 & 0.411 & .396 & 0.383 \\
\hline $\begin{array}{r}356 \\
(14.0)\end{array}$ & 5.033 & 2.657 & 1.841 & 1.427 & 1.177 & 1.009 & 0.889 & 0.798 & 0.727 & 0.670 & 0.623 & 0.584 & 0.550 & 0.521 & 0.496 & 0.474 & 0.455 & 0.437 & 0.422 & 0.408 \\
\hline $\begin{array}{r}406 \\
(16.0)\end{array}$ & 5.716 & 3.009 & 2.078 & 1.606 & 1.321 & 1.130 & 0.993 & 0.889 & 0.808 & 0.743 & 0.690 & 0.645 & 0.607 & 0.575 & 0.546 & 0.522 & 0.499 & 0.480 & 0.462 & 0.446 \\
\hline $\begin{array}{r}457 \\
(18.0)\end{array}$ & 6.397 & 3.360 & 2.315 & 1.785 & 1.465 & 1.250 & 1.096 & .980 & 0.889 & 0.817 & 0.757 & .707 & 0.664 & 0.628 & 0.596 & 0.568 & 0.544 & 0.522 & 0.502 & 0.484 \\
\hline $\begin{array}{l}508 \\
(20.0)\end{array}$ & 7.076 & 3.711 & 2.552 & 1.964 & 1.609 & 1.371 & 1.200 & 1.071 & 0.970 & 0.890 & 0.824 & 0.768 & 0.721 & 0.681 & 0.646 & 0.615 & 0.588 & 0.563 & 0.541 & 0.522 \\
\hline $\begin{array}{r}610 \\
(24.0)\end{array}$ & 8.431 & 4.412 & 3.025 & 2.321 & 1.896 & 1.611 & 1.406 & 1.252 & 1.132 & 1.035 & 0.956 & 0.890 & 0.834 & 0.786 & 0.744 & 0.707 & 0.675 & 0.646 & 0.620 & 0.597 \\
\hline
\end{tabular}


Table 7-6. Outdoor PIpe UA/L Values ( $\mathrm{W} / \mathrm{K}-\mathrm{m}$ of length) for Insulation $\mathrm{k}=0.0865 \mathrm{~W} / \mathrm{m}-\mathrm{K}$ (0.60 Btu-in./hr-ft $\left.{ }^{2}{ }^{\circ} \mathrm{F}\right)$

\begin{tabular}{|c|c|c|c|c|c|c|c|c|c|c|c|c|c|c|c|c|c|c|c|c|}
\hline \multirow{2}{*}{$\begin{array}{l}\text { Nom. } \\
\text { P1pe } \\
\text { D1am., } \\
\text { mm } \\
\left(1 \text { In. }_{0}\right)\end{array}$} & \multicolumn{20}{|c|}{ Insulation Thickness, [mm (1n.)] } \\
\hline & $\begin{array}{c}13 \\
(0.5)\end{array}$ & $\begin{array}{c}25 \\
(1.0)\end{array}$ & $\begin{array}{c}38 \\
(1.5)\end{array}$ & $\begin{array}{c}51 \\
(2.0)\end{array}$ & $\begin{array}{c}64 \\
(2.5)\end{array}$ & $\begin{array}{c}76 \\
(3.0)\end{array}$ & $\begin{array}{c}89 \\
(3.5)\end{array}$ & $\begin{array}{c}102 \\
(4.0)\end{array}$ & $\begin{array}{c}114 \\
(4.5)\end{array}$ & $\begin{array}{c}127 \\
(5.0)\end{array}$ & $\begin{array}{c}140 \\
(5.5)\end{array}$ & $\begin{array}{c}152 \\
(6.0)\end{array}$ & $\begin{array}{c}165 \\
(6.5)\end{array}$ & $\begin{array}{c}178 \\
(7.0)\end{array}$ & $\begin{array}{c}191 \\
(7.5)\end{array}$ & $\begin{array}{c}203 \\
(8.0)\end{array}$ & $\begin{array}{c}216 \\
(8.5)\end{array}$ & $\begin{array}{c}229 \\
(9.0)\end{array}$ & $\begin{array}{c}241 \\
(9.5)\end{array}$ & $\begin{array}{c}254 \\
-(10.0)\end{array}$ \\
\hline $\begin{array}{r}25 \\
(1.0)\end{array}$ & 0.935 & 0.580 & 0.453 & 0.387 & 0.345 & 0.315 & 0.294 & 0.277 & 0.263 & 0.252 & 0.242 & 0.234 & 0.227 & 0.221 & 0.215 & 0.211 & 0.206 & 0.202 & .198 & .195 \\
\hline $\begin{array}{r}32 \\
(1.25)\end{array}$ & 1.119 & 0.678 & 0.522 & $0 . \dot{4} 40$ & 0.389 & 0.354 & 0.328 & 0.308 & 0.291 & 0.278 & 0.267 & 0.257 & 0.249 & 0.242 & 0.235 & 0.230 & 0.224 & 0.220 & 0.215 & 0.211 \\
\hline $\begin{array}{r}38 \\
(1.5) \\
\end{array}$ & 1.246 & 0.744 & 0.568 & 0.476 & 0.419 & 0.380 & 0.351 & 0.328 & 0.310 & 0.295 & 0.283 & 0.273 & 0.263 & 0.255 & 0.248 & 0.242 & 0.236 & 0.231 & .226 & 0.222 \\
\hline $\begin{array}{r}51 \\
(2.0)\end{array}$ & 1.495 & 875 & 0.658 & 0.546 & .477 & 0.429 & 0.394 & 0.367 & 0.346 & 0.328 & 0.314 & 0.301 & 0.290 & 0.281 & 0.273 & .265 & 0.259 & 0.252 & .247 & .242 \\
\hline $\begin{array}{r}64 \\
(2.5)\end{array}$ & 1.756 & 1.011 & 0.752 & 0.618 & 0.536 & 0.480 & 0.438 & 0.407 & 0.382 & 0.361 & 0.344 & 0.330 & 0.317 & 0.306 & 0.297 & 0.288 & 0.281 & 0.274 & 0.267 & 0.262 \\
\hline $\begin{array}{r}76 \\
(3.0)\end{array}$ & 2.080 & 1.180 & 0.867 & 0.707 & 0.608 & 0.541 & 0.492 & 0.455 & 0.425 & 0.401 & 0.381 & 0.364 & 0.350 & 0.337 & 0.326 & 0.316 & 0.307 & 0.299 & 0.292 & 0.285 \\
\hline $\begin{array}{r}89 \\
(3.5)\end{array}$ & 2.338 & 1.314 & 0.959 & 0.777 & 0.665 & 0.589 & 0.534 & 0.492 & 0.459 & 0.432 & 0.410 & 0.391 & 0.375 & 0.360 & 0.348 & 0.337 & 0.327 & 0.318 & .310 & .303 \\
\hline $\begin{array}{r}102 \\
(4.0)\end{array}$ & 2.595 & .447 & 1.049 & 0.846 & 0.722 & 0.637 & 0.576 & 0.529 & 0.493 & 0.463 & 0.438 & 0.417 & 0.399 & 0.383 & 370 & . 358 & 0.347 & . 337 & .328 & 320 \\
\hline $\begin{array}{r}127 \\
(5.0) \\
\end{array}$ & 3.140 & 1.730 & 1.242 & 0.992 & 0.840 & 0.738 & 0.663 & $\begin{array}{c}0.607 \\
:\end{array}$ & 0.562 & 0.526 & 0.496 & 0.471 & 0.450 & 0.431 & 0.415 & 0.400 & 0.387 & 0.376 & 0.365 & 0.356 \\
\hline $\begin{array}{r}152 \\
(6.0)\end{array}$ & 3.681 & 2.011 & 1.432 & 1.137 & 0.958 & 0.837 & 0.749 & 0.683 & 0.630 & 0.588 & 0.553 & 0.524 & 0.499 & 0.477 & 0.458 & 0.441 & 0.426 & 0.413 & 0.401 & .390 \\
\hline $\begin{array}{r}203 \\
(8.0)\end{array}$ & 4.695 & 2.538 & 1.789 & 408 & 1.177 & 1.021 & 0.908 & .823 & 0.756 & 0.703 & 0.658 & 0.621 & 0.589 & 0.562 & .538 & 0.517 & 0.498 & 0.481 & .466 & .452 \\
\hline $\begin{array}{r}254 \\
(10.0)\end{array}$ & 5.766 & 3.095 & 2.167 & 1.694 & 1.407 & 1.214 & 1.075 & 0.971 & 0.888 & 0.822 & 0.768 & 0.722 & 0.683 & 0.649 & 0.620 & 0.594 & 0.571 & 0.551 & 0.533 & 0.516 \\
\hline $\begin{array}{r}305 \\
(12.0)\end{array}$ & 6.769 & 3.617 & 2.521 & 1.962 & 1.623 & 1.396 & 1.232 & 1.108 & 1.011 & 0.933 & 0.869 & 0.816 & 0.770 & 0.731 & 0.696 & 0.666 & 0.639 & 0.616 & 0.594 & .575 \\
\hline $\begin{array}{r}356 \\
(14.0)\end{array}$ & 7.393 & 3.943 & 2.741 & 2.129 & 1.758 & 1.508 & 329 & 1.194 & 1.088 & 1.003 & 0.932 & 0.874 & 0.824 & .781 & 0.744 & 0.711 & 0.682 & 0.655 & .632 & .611 \\
\hline $\begin{array}{r}406 \\
(16.0)\end{array}$ & 8.388 & 4.463 & 3.094 & 2.396 & 1.973 & 1.689 & 1.484 & 1.330 & 1.209 & 1.113 & 1.033 & 0.966 & 0.910 & 0.861 & 0.819 & 0.781 & 0.748 & 0.719 & 0.692 & 0.668 \\
\hline $\begin{array}{r}457 \\
(18.0)\end{array}$ & 9.378 & 4.982 & 3.446 & 2.662 & 2.187 & 1.868 & 1.639 & 1.466 & 1.331 & 1.222 & 1.133 & 1.058 & 0.995 & 0.940 & 0.893 & 0.851 & 0.814 & 0.781 & 0.752 & 0.725 \\
\hline $\begin{array}{r}508 \\
(20.0)\end{array}$ & 10.367 & 5.500 & 3.797 & 2.928 & 2.402 & 2.048 & 1.793 & 1.602 & 1.452 & 1.331 & 1.233 & 1.150 & 1.080 & 1.020 & 0.967 & 0.921 & 0.880 & 0.844 & .811 & .782 \\
\hline $\begin{array}{r}610 \\
(24.0)\end{array}$ & 12.333 & 6.534 & 4.498 & 3.459 & 2.829 & 2.405 & 2.101 & 1.872 & 1.693 & 1.549 & 1.431 & 1.333 & 1.249 & 1.177 & 1.114 & 1.059 & 1.011 & 0.968 & 0.929 & 0.894 \\
\hline
\end{tabular}


Table 7-7. Outdoor Pipe UA/L Value (W/K-m of length) for Insulation $k=0.1154 \mathrm{~W} / \mathrm{m}-\mathrm{K}$ $\left(0.80 \mathrm{Btu}-\mathbf{i n} . / \mathrm{hr}-\mathrm{ft}^{2}-{ }^{\mathrm{O}} \mathrm{F}\right)$

\begin{tabular}{|c|c|c|c|c|c|c|c|c|c|c|c|c|c|c|c|c|c|c|c|c|}
\hline \multirow{2}{*}{$\begin{array}{l}\text { Nom. } \\
\text { Pfpe } \\
\text { Diam., } \\
\text { mm } \\
(1 \text { ln. })\end{array}$} & \multicolumn{20}{|c|}{ Insulation ThIckness, mom (1n.) } \\
\hline & $\begin{array}{c}13 \\
(0.5)\end{array}$ & $\begin{array}{c}25 \\
(1.0)\end{array}$ & $\begin{array}{c}38 \\
(1.5)\end{array}$ & $\begin{array}{c}51 \\
(2.0)\end{array}$ & $\begin{array}{c}64 \\
(2.5)\end{array}$ & $\begin{array}{c}76 \\
(3.0)\end{array}$ & $\begin{array}{c}89 \\
(3.5)\end{array}$ & $\begin{array}{c}102 \\
(4.0)\end{array}$ & $\begin{array}{c}114 \\
(4.5)\end{array}$ & $\begin{array}{c}127 \\
(5.0)\end{array}$ & $\begin{array}{c}140 \\
(5.5)\end{array}$ & $\begin{array}{c}152 \\
(6.0)\end{array}$ & $\begin{array}{c}165 \\
(6.5)\end{array}$ & $\begin{array}{c}178 \\
(7.0)\end{array}$ & $\begin{array}{c}191 \\
(7.5)\end{array}$ & $\begin{array}{c}203 \\
(8.0)\end{array}$ & $\begin{array}{c}216 \\
(8.5)\end{array}$ & $\begin{array}{c}229 \\
(9.0)\end{array}$ & $\begin{array}{c}241 \\
(9.5)\end{array}$ & $\begin{array}{c}254 \\
(10.0)\end{array}$ \\
\hline $\begin{array}{r}25 \\
(1.0)\end{array}$ & 1.236 & 0.770 & 0.603 & 0.514 & 0.459 & 0.420 & 0.391 & 0.369 & 0.351 & 0.336 & 0.323 & 0.312 & 0.303 & 0.294 & .287 & 0.281 & 0.275 & 0.269 & .264 & .260 \\
\hline $\begin{array}{r}32 \\
(1.25)\end{array}$ & 1.477 & 0.899 & 0.693 & 0.585 & 0.518 & 0.471 & 0.436 & 0.410 & 0.388 & 0.370 & 0.356 & 0.343 & 0.332 & 0.322 & 0.313 & 0.306 & 0.299 & 0.293 & 0.287 & 0.282 \\
\hline $\begin{array}{r}38 \\
(1.5)\end{array}$ & 1.644 & 0.988 & 0.755 & 0.633 & 0.558 & 0.505 & 0.467 & 0.437 & 0.413 & 0.394 & 0.377 & 0.363 & 0.351 & 0.340 & 0.331 & 0.322 & 0.315 & 0.308 & 0.302 & 0.296 \\
\hline $\begin{array}{r}51 \\
(2.0)\end{array}$ & 1.972 & 1.160 & 0.875 & 0.726 & 0.634 & 0.571 & 0.525 & 0.489 & 0.461 & 0.437 & 0.418 & 0.401 & 0.387 & 0.374 & 0.363 & 0.353 & 0.344 & 0.336 & 0.329 & .322 \\
\hline $\begin{array}{r}64 \\
(2.5)\end{array}$ & 2.313 & 1.340 & 0.998 & 0.822 & 0.713 & 0.638 & 0.584 & 0.542 & 0.508 & 0.481 & 0.459 & 0.439 & 0.423 & 0.408 & 0.395 & 0.384 & 0.374 & 0.365 & 0.356 & 0.349 \\
\hline $\begin{array}{r}76 \\
(3.0)\end{array}$ & 2.738 & 1.563 & 1.151 & 0.939 & 0.809 & 0.720 & 0.655 & 0.606 & 0.566 & 0.534 & 0.508 & 0.485 & 0.466 & 0.449 & 0.434 & 0.421 & 0.409 & 0.398 & 0.389 & 0.380 \\
\hline $\begin{array}{r}89 \\
(3.5)\end{array}$ & 3.076 & 1.740 & 1.272 & 1.032 & 0.885 & 0.784 & 0.711 & 0.656 & 0.612 & 0.576 & 0.546 & 0.521 & 0.499 & 0.480 & 0.464 & 0.449 & 0.436 & 0.424 & 0.413 & 0.404 \\
\hline $\begin{array}{r}102 \\
(4.0)\end{array}$ & 3.412 & 1.916 & 1.393 & 1.124 & 0.960 & 0.848 & 0.767 & 0.705 & 0.656 & 0.616 & 0.583 & 0.555 & 0.532 & 0.511 & 0.493 & 0.476 & 0.462 & 0.449 & .437 & .427 \\
\hline $\begin{array}{r}127 \\
(5.0) \\
\end{array}$ & 4.124 & 2.289 & 1.647 & 1.318 & 1.117 & 0.981 & 0.882 & 0.807 & 0.748 & $\begin{array}{l}0.701 \\
1\end{array}$ & 0.661 & 0.628 & 0.599 & 0.574 & 0.552 & 0.533 & 0.516 & 0.501 & 0.487 & 0.474 \\
\hline $\begin{array}{r}152 \\
(6.0)\end{array}$ & 4.831 & 2.660 & 1.899 & 1.510 & 1.273 & 1.112 & 0.996 & 0.908 & 0.839 & 0.783 & 0.737 & 0.698 & 0.664 & 0.636 & 0.610 & 0.588 & 0.568 & 0.550 & 0.534 & 0.520 \\
\hline $\begin{array}{r}203 \\
(8.0)\end{array}$ & 6.152 & 3.354 & 2.372 & 1.869 & 1.563 & 1.357 & 1.208 & 1.095 & 1.007 & 0.935 & 0.876 & 0.827 & 0.785 & 0.748 & 0.716 & 0.688 & 0.663 & 0.641 & 0.621 & 0.602 \\
\hline $\begin{array}{r}254 \\
(10.0) \\
\end{array}$ & 7.545 & 4.087 & 2.870 & 2.248 & 1.869 & 1.614 & 1.430 & 1.291 & 1.182 & 1.094 & 1.022 & 0.961 & 0.909 & 0.865 & 0.826 & 0.792 & 0.761 & 0.734 & 0.709 & 0.687 \\
\hline $\begin{array}{r}305 \\
(12.0)\end{array}$ & 8.847 & 4.774 & 3.338 & 2.603 & 2.156 & 1.855 & 1.638 & 1.474 & 1.345 & 1.242 & 1.157 & 1.086 & 1.025 & 0.973 & 0.927 & 0.887 & 0.852 & 0.820 & .791 & .765 \\
\hline $\begin{array}{r}356 \\
(14.0)\end{array}$ & 9.657 & 5.203 & 3.629 & 2.824 & 2.334 & 2.004 & 1.767 & 1.587 & 1.447 & 1.334 & 1.241 & 1.163 & 1.097 & 1.040 & 0.990 & 0.946 & 0.908 & 0.873 & 0.842 & 0.814 \\
\hline $\begin{array}{r}406 \\
(16.0) \\
\end{array}$ & 10.946 & 5.886 & 4.095 & 3.177 & 2.619 & 2.243 & 1.973 & 1.768 & 1.609 & 1.480 & 1.375 & 1.286 & 1.211 & 1.146 & 1.090 & 1.040 & 0.996 & 0.957 & 0.922 & 0.890 \\
\hline $\begin{array}{r}457 \\
(18.0)\end{array}$ & 12.228 & 6.567 & 4.559 & 3.530 & 2.903 & 2.481 & 2.178 & 1.949 & 1.770 & 1.626 & 1.508 & .409 & 1.324 & 1.252 & .189 & 1.134 & 1.084 & 1.041 & .001 & .966 \\
\hline $\begin{array}{r}508 \\
(20.0)\end{array}$ & 13.506 & 7.247 & 5.022 & 3.881 & 3.187 & 2.719 & 2.383 & 2.129 & 1.931 & 1.771 & 1.640 & 1.530 & 1.437 & 1.357 & 1.287 & 1.226 & 1.172 & 1.124 & 1.080 & 1.041 \\
\hline $\begin{array}{r}610 \\
(24.0)\end{array}$ & 16.045 & 8.602 & 5.947 & 4.583 & 3.753 & 3.194 & 2.791 & 2.488 & 2.251 & 2.060 & 1.904 & 1.773 & 1.662 & 1.566 & 1.483 & 1.410 & 1.346 & 1.288 & 1.237 & 1.190 \\
\hline
\end{tabular}


Table 7-8. Indoor Pipe UA/L Values (W/K-m of length) for Insulation $k=0.0288 \mathrm{~W} / \mathrm{m}-\mathrm{K}$ $\left(0.20 \mathrm{Btu}-\mathrm{in} . / \mathrm{hr}-\mathrm{ft}^{2}-{ }^{\mathrm{o}} \mathrm{F}\right)$

\begin{tabular}{|c|c|c|c|c|c|c|c|c|c|c|c|c|c|c|c|c|c|c|c|c|}
\hline \multirow{2}{*}{$\begin{array}{l}\text { Nom. } \\
\text { P1pe } \\
\text { Diam., } \\
\text { mm } \\
\text { (in.) }\end{array}$} & \multicolumn{20}{|c|}{ Insulation Th1ckness, mm (1n.) } \\
\hline & $\begin{array}{c}13 \\
(0.5)\end{array}$ & $\begin{array}{c}25 \\
(1.0)\end{array}$ & $\begin{array}{c}38 \\
(1.5)\end{array}$ & $\begin{array}{c}51 \\
(2.0)\end{array}$ & $\begin{array}{c}64 \\
(2.5)\end{array}$ & $\begin{array}{c}76 \\
(3.0)\end{array}$ & $\begin{array}{c}89 \\
(3.5)\end{array}$ & $\begin{array}{c}102 \\
(4.0)\end{array}$ & $\begin{array}{c}114 \\
(4.5)\end{array}$ & $\begin{array}{c}127 \\
(5.0)\end{array}$ & $\begin{array}{c}140 \\
(5.5)\end{array}$ & $\begin{array}{c}152 \\
(6.0)\end{array}$ & $\begin{array}{c}165 \\
(6.5)\end{array}$ & $\begin{array}{c}178 \\
(7.0)\end{array}$ & $\begin{array}{c}191 \\
(7.5)\end{array}$ & $\begin{array}{c}203 \\
(8.0)\end{array}$ & $\begin{array}{c}216 \\
(8.5)\end{array}$ & $\begin{array}{c}229 \\
(9.0)\end{array}$ & $\begin{array}{c}241 \\
(9.5)\end{array}$ & $\begin{array}{c}254 \\
(10.0)\end{array}$ \\
\hline $\begin{array}{r}25 \\
(1.0)\end{array}$ & 0.271 & 0.179 & 0.144 & 0.124 & 0.111 & 0.103 & 0.096 & 0.091 & 0.086 & 0.083 & 0.080 & 0.077 & 0.075 & 0.073 & 0.071 & 0.070 & 0.068 & 0.067 & 0.066 & 0.065 \\
\hline $\begin{array}{r}32 \\
(1.25)\end{array}$ & 0.322 & 0.209 & 0.165 & 0.141 & 0.126 & 0.115 & 0.107 & 0.101 & 0.095 & 0.091 & 0.088 & 0.085 & 0.082 & 0.080 & 0.078 & 0.076 & 0.074 & 0.073 & 0.071 & 0.070 \\
\hline $\begin{array}{r}38 \\
(1.5)\end{array}$ & 0.358 & 0.229 & 0.179 & 0.152 & 0.135 & 0.123 & 0.114 & 0.107 & 0.102 & 0.097 & 0.093 & 0.090 & 0.087 & 0.084 & 0.082 & 0.080 & 0.078 & 0.076 & 0.075 & 0.073 \\
\hline $\begin{array}{r}51 \\
(2.0)\end{array}$ & 0.427 & 0.268 & 0.207 & 0.174 & 0.153 & 0.139 & 0.128 & 0.120 & 0.113 & 0.108 & 0.103 & 0.099 & 0.096 & 0.093 & 0.090 & 0.088 & 0.085 & 0.083 & 0.082 & 0.080 \\
\hline $\begin{array}{r}64 \\
(2.5)\end{array}$ & 0.499 & 0.308 & 0.236 & 0.197 & 0.172 & 0.155 & 0.142 & 0.133 & 0.125 & 0.118 & 0.113 & 0.108 & 0.104 & 0.101 & 0.098 & 0.095 & 0.093 & 0.090 & 0.088 & 0.087 \\
\hline $\begin{array}{r}76 \\
(3.0)\end{array}$ & 0.588 & 0.359 & 0.271 & 0.224 & 0.195 & 0.175 & 0.160 & 0.148 & 0.139 & 0.131 & 0.125 & 0.120 & 0.115 & 0.111 & 0.107 & 0.104 & 0.101 & 0.099 & 0.096 & 0.094 \\
\hline $\begin{array}{r}89 \\
(3.5)\end{array}$ & 0.660 & 0.399 & 0.299 & 0.246 & 0.213 & 0.190 & 0.173 & 0.160 & 0.150 & 0.141 & 0.134 & 0.128 & 0.123 & 0.119 & 0.115 & 0.111 & 0.108 & 0.105 & 0.102 & 0.100 \\
\hline $\begin{array}{c}102 \\
(4.0)\end{array}$ & 0.730 & 0.438 & 0.327 & 0.268 & 0.231 & 0.205 & 0.186 & 0.172 & 0.161 & 0.151 & 0.143 & 0.137 & 0.131 & 0.126 & 0.122 & 0.118 & 0.114 & 0.111 & 0.108 & 0.106 \\
\hline $\begin{array}{r}127 \\
(5.0) \\
\end{array}$ & 0.880 & 0.522 & 0.386 & 0.314 & 0.268 & 0.237 & 0.214 & 0.197 & 0.183 & 0.172 & 0.162 & 0.154 & 0.148 & 0.142 & 0.136 & 0.132 & 0.128 & 0.124 & 0.120 & 0.117 \\
\hline $\begin{array}{r}152 \\
(6.0)\end{array}$ & 1.029 & 0.606 & 0.444 & 0.359 & 0.305 & 0.269 & 0.242 & 0.221 & 0.205 & 0.192 & 0.181 & 0.171 & 0.164 & 0.157 & 0.151 & 0.145 & 0.140 & 0.136 & 0.132 & 0.129 \\
\hline $\begin{array}{r}203 \\
(8.0)\end{array}$ & 1.308 & 0.762 & 0.554 & 0.443 & 0.374 & 0.327 & 0.293 & 0.266 & 0.246 & 0.229 & 0.215 & 0.203 & 0.193 & 0.184 & 0.177 & 0.170 & 0.164 & 0.158 & 0.153 & 0.149 \\
\hline $\begin{array}{r}254 \\
(10.0)\end{array}$ & 1.602 & 0.927 & 0.669 & 0.532 & 0.447 & 0.389 & 0.346 & 0.314 & 0.288 & 0.267 & 0.250 & 0.236 & 0.223 & 0.213 & 0.203 & 0.195 & 0.188 & 0.181 & 0.175 & 0.170 \\
\hline $\begin{array}{r}305 \\
(12.0)\end{array}$ & 1.878 & 1.081 & 0.777 & 0.615 & 0.515 & 0.446 & 0.396 & 0.358 & 0.328 & 0.303 & 0.283 & 0.266 & 0.252 & 0.239 & 0.228 & 0.219 & 0.210 & 0.202 & 0.195 & 0.189 \\
\hline $\begin{array}{r}356 \\
(14.0)\end{array}$ & 2.049 & 1.178 & 0.844 & 0.667 & 0.557 & 0.482 & 0.427 & 0.385 & 0.352 & 0.326 & 0.304 & 0.285 & 0.269 & 0.256 & 0.244 & 0.233 & 0.224 & 0.215 & 0.208 & 0.201 \\
\hline $\begin{array}{r}406 \\
(16.0)\end{array}$ & 2.323 & 1.332 & 0.952 & 0.750 & 0.625 & 0.539 & 0.476 & 0.429 & 0.391 & 0.361 & 0.336 & 0.315 & 0.297 & 0.282 & 0.268 & 0.256 & 0.246 & 0.236 & 0.228 & 0.220 \\
\hline $\begin{array}{r}457 \\
(18.0)\end{array}$ & 2.595 & 1.485 & 1.059 & 0.833 & 0.692 & 0.596 & 0.526 & 0.472 & 0.430 & 0.396 & 0.368 & 0.345 & 0.325 & 0.307 & 0.292 & 0.279 & 0.267 & 0.257 & 0.247 & 0.239 \\
\hline $\begin{array}{r}508 \\
(20.0)\end{array}$ & 2.867 & 1.638 & 1.167 & 0.916 & 0.759 & 0.653 & 0.575 & 0.516 & 0.469 & 0.432 & 0.401 & 0.375 & 0.352 & 0.333 & 0.316 & 0.302 & 0.289 & 0.277 & 0.267 & 0.257 \\
\hline $\begin{array}{r}610 \\
(24.0)\end{array}$ & 3.409 & 1.944 & 1.381 & 1.081 & 0.894 & 0.766 & 0.673 & 0.602 & 0.547 & 0.502 & 0.465 & 0.434 & 0.407 & 0.384 & 0.364 & 0.347 & 0.331 & 0.317 & 0.305 & 0.294 \\
\hline
\end{tabular}


Table 7-9. Indoor Pipe UA/L Values ( $\mathrm{W} / \mathrm{K}-\mathrm{m}$ of length) for Insulation $\mathrm{k}=0.0577 \mathrm{~W} / \mathrm{m}-\mathrm{K}$ (0.40 Btu-in./hr-ft $\left.{ }^{2}{ }^{\circ} \mathrm{F}\right)$

\begin{tabular}{|c|c|c|c|c|c|c|c|c|c|c|c|c|c|c|c|c|c|c|c|c|}
\hline \multirow{2}{*}{$\begin{array}{l}\text { Nom. } \\
\text { P1pe } \\
\text { D1am., } \\
\text { mm } \\
\left(1 n_{\bullet}\right)\end{array}$} & \multicolumn{20}{|c|}{ Insulation Thickness, mm (In.) } \\
\hline & $\begin{array}{c}13 \\
(0.5)\end{array}$ & $\begin{array}{c}25 \\
(1.0)\end{array}$ & $\begin{array}{c}38 \\
(1.5)\end{array}$ & $\begin{array}{c}51 \\
(2.0)\end{array}$ & $\begin{array}{c}64 \\
(2.5)\end{array}$ & $\begin{array}{c}76 \\
(3.0)\end{array}$ & $\begin{array}{c}89 \\
(3.5)\end{array}$ & $\begin{array}{c}102 \\
(4.0)\end{array}$ & $\begin{array}{c}114 \\
(4.5)\end{array}$ & $\begin{array}{c}127 \\
(5.0)\end{array}$ & $\begin{array}{c}140 \\
(5.5)\end{array}$ & $\begin{array}{c}152 \\
(6.0)\end{array}$ & $\begin{array}{c}165 \\
(6.5)\end{array}$ & $\begin{array}{c}178 \\
(7.0)\end{array}$ & $\begin{array}{c}191 \\
(7.5)\end{array}$ & $\begin{array}{c}203 \\
(8.0)\end{array}$ & $\begin{array}{c}216 \\
(8.5)\end{array}$ & $\begin{array}{c}229 \\
(9.0)\end{array}$ & $\begin{array}{c}241 \\
(9.5)\end{array}$ & $\begin{array}{c}254 \\
(10.0)\end{array}$ \\
\hline $\begin{array}{r}25 \\
(1.0)\end{array}$ & 0.482 & 0.336 & 0.274 & 0.240 & 0.217 & 0.200 & 0.188 & 0.178 & 0.170 & 0.163 & 0.157 & 0.153 & 0.148 & 0.144 & 0.141 & 0.138 & 0.135 & 0.133 & 0.130 & .128 \\
\hline $\begin{array}{r}32 \\
(1.25)\end{array}$ & 0.571 & 0.389 & 0.314 & 0.271 & 0.244 & 0.224 & 0.209 & 0.197 & 0.188 & 0.180 & 0.173 & 0.167 & 0.162 & 0.158 & 0.154 & 0.150 & 0.147 & 0.144 & 0.141 & 0.139 \\
\hline $\begin{array}{r}38 \\
(1.5)\end{array}$ & 0.631 & 0.426 & 0.341 & 0.293 & 0.262 & 0.240 & 0.22 .3 & 0.210 & 0.200 & 0.191 & 0.183 & 0.177 & 0.171 & 0.166 & 0.162 & 0.158 & 0.155 & 0.151 & 0.148 & 0.146 \\
\hline $\begin{array}{r}51 \\
(2.0)\end{array}$ & 0.750 & 0.496 & 0.392 & 0.334 & 0.297 & 0.270 & 0.250 & 0.235 & 0.222 & .212 & 0.203 & 0.195 & 0.189 & 0.183 & 0.178 & 0.173 & 0.169 & 0.165 & 0.162 & 0.159 \\
\hline $\begin{array}{r}64 \\
(2.5)\end{array}$ & 0.873 & 0.570 & 0.446 & 0.377 & 0.332 & 0.301 & 0.278 & 0.259 & 0.245 & 0.232 & 0.222 & 0.213 & 0.206 & 0.199 & 0.193 & 0.188 & 0.183 & 0.179 & 0.175 & 0.172 \\
\hline $\begin{array}{r}76 \\
(3.0)\end{array}$ & 1.025 & 0.661 & 0.512 & 0.429 & 0.376 & 0.339 & 0.311 & 0.289 & 0.272 & 0.258 & 0.246 & 0.235 & 0.227 & 0.219 & 0.212 & 0.206 & 0.200 & 0.195 & 0.191 & 0.187 \\
\hline $\begin{array}{r}89 \\
(3.5)\end{array}$ & 1.146 & 0.733 & 564 & 0.470 & 410 & 368 & 0.337 & 0.313 & 0.293 & 0.277 & 264 & 252 & 0.242 & 34 & 226 & .219 & .213 & 0.208 & .203 & .198 \\
\hline & 1.266 & 0.804 & 0.615 & 0.511 & 0.444 & 0.397 & 0.362 & 0.336 & 0.314 & 0.296 & 0.282 & 0.269 & 0.258 & 0.249 & 0.240 & 0.233 & 0.226 & 0.220 & 0.214 & 0.209 \\
\hline $\begin{array}{r}127 \\
(5.0)\end{array}$ & 1.520 & 0.955 & 0.724 & 0.596 & 0.515 & 0.458 & 0.416 & 0.383 & .0 .357 & 0.336 & 0.318 & 0.303 & 0.290 & 0.279 & 0.269 & 0.260 & 0.252 & 0.245 & 0.238 & 0.232 \\
\hline $\begin{array}{r}152 \\
(6.0)\end{array}$ & 1.772 & 1.105 & 0.832 & 0.681 & 0.585 & .518 & 0.469 & 0.430 & 0.400 & 0.375 & 0.354 & 0.337 & 0.322 & 0.308 & 0.297 & 0.286 & 0.277 & 0.269 & 0.261 & .254 \\
\hline $\begin{array}{r}203 \\
(8.0)\end{array}$ & 2.241 & 1.384 & 1.033 & 0.839 & 0.715 & .629 & 0.566 & 0.517 & 0.478 & 0.447 & 0.420 & 0.398 & 0.379 & 0.362 & 0.347 & .335 & 0.323 & 0.313 & 0.303 & .295 \\
\hline $\begin{array}{r}254 \\
(10.0)\end{array}$ & 2.735 & 1.679 & 1.245 & 1.005 & 0.852 & 0.746 & 0.668 & 0.608 & 0.560 & 0.521 & 0.489 & 0.462 & 0.438 & 0.418 & 0.400 & 0.384 & 0.370 & 0.357 & 0.346 & 0.336 \\
\hline $\begin{array}{r}305 \\
(12.0)\end{array}$ & 3.196 & 1.955 & 1.443 & 1.160 & 0.981 & 0.856 & 0.764 & 0.693 & 0.637 & 0.591 & 0.553 & 0.521 & 0.493 & 0.469 & 0.449 & 0.430 & 0.414 & 0.399 & 0.386 & .373 \\
\hline $\begin{array}{r}356 \\
(14.0)\end{array}$ & 3.483 & 2.127 & 1.566 & 1.257 & 1.060 & .924 & 0.823 & 0.745 & 0.684 & 0.634 & 0.593 & 0.557 & 0.527 & 0.501 & 0.479 & 0.458 & 0.441 & 0.424 & 0.410 & .397 \\
\hline $\begin{array}{r}406 \\
(16.0)\end{array}$ & 3.939 & 2.401 & 1.764 & 1.412 & 1.188 & 1.032 & 0.917 & 0.829 & 0.759 & 0.703 & 0.656 & 0.616 & 0.582 & 0.552 & 0.526 & 0.503 & 0.483 & 0.465 & 0.449 & 0.434 \\
\hline $\begin{array}{r}457 \\
18.0)\end{array}$ & 4.394 & 2.673 & 1.960 & 566 & 315 & 40 & 1.012 & 13 & 0.835 & 0.771 & 18 & 0.674 & 0.635 & 0.602 & 0.574 & 548 & .525 & .505 & 0.487 & 0.470 \\
\hline $\begin{array}{l}508 \\
20.0)\end{array}$ & 4.846 & 2.945 & 2.156 & 1.719 & 1.441 & 1.248 & 1.105 & 0.996 & 0.909 & 0.839 & 0.781 & 0.731 & 0.689 & 0.653 & 0.621 & 0.593 & 0.567 & 0.545 & 0.525 & 0.507 \\
\hline $\begin{array}{r}610 \\
24.0)\end{array}$ & 5.746 & 3.488 & 2.547 & 2.026 & 1.693 & 1.463 & 1.293 & 1.162 & 1.059 & 0.974 & 0.905 & 0.846 & 0.796 & 0.752 & 0.714 & 0.681 & 0.651 & 0.624 & 0.600 & 0.578 \\
\hline
\end{tabular}


Table 7-10. Indoor PIpe UA/L Values (W/K-m of length) for Insulation $k=0.0865 \mathrm{~W} / \mathrm{m}-\mathrm{K}$ (0.60 Btu-1n./hr-ft $\left.{ }^{2}{ }^{-} \mathrm{F}\right)$

\begin{tabular}{|c|c|c|c|c|c|c|c|c|c|c|c|c|c|c|c|c|c|c|c|c|}
\hline \multirow{2}{*}{$\begin{array}{l}\text { Nom. } \\
\text { Plpe } \\
\text { D1am., } \\
\text { mm } \\
\text { (1n.) }\end{array}$} & \multicolumn{20}{|c|}{ Insulation Thickness, mm (1n.) } \\
\hline & $\begin{array}{c}13 \\
(0.5)\end{array}$ & $\begin{array}{c}25 \\
(1.0)\end{array}$ & $\begin{array}{c}38 \\
(1.5)\end{array}$ & $\begin{array}{c}51 \\
(2.0)\end{array}$ & $\begin{array}{c}64 \\
(2.5)\end{array}$ & $\begin{array}{c}76 \\
(3.0)\end{array}$ & $\begin{array}{c}89 \\
(3.5)\end{array}$ & $\begin{array}{c}102 \\
(4.0)\end{array}$ & $\begin{array}{c}114 \\
(4.5)\end{array}$ & $\begin{array}{c}127 \\
(5.0)\end{array}$ & $\begin{array}{c}140 \\
(5.5)\end{array}$ & $\begin{array}{c}152 \\
(6.0)\end{array}$ & $\begin{array}{c}165 \\
(6.5)\end{array}$ & $\begin{array}{c}178 \\
(7.0)\end{array}$ & $\begin{array}{c}191 \\
(7.5)\end{array}$ & $\begin{array}{c}203 \\
(8.0)\end{array}$ & $\begin{array}{c}216 \\
(8.5)\end{array}$ & $\begin{array}{c}229 \\
(9.0)\end{array}$ & $\begin{array}{c}241 \\
(9.5)\end{array}$ & $\begin{array}{c}254 \\
(10.0)\end{array}$ \\
\hline $\begin{array}{r}25 \\
(1.0)\end{array}$ & 0.657 & 0.475 & 0.395 & 0.348 & 0.317 & 0.294 & 0.276 & 0.262 & 0.251 & 0.241 & 0.233 & 0.226 & 0.220 & 0.215 & 0.210 & 0.205 & 0.201 & 0.197 & 0.194 & 0.191 \\
\hline $\begin{array}{r}32 \\
(1.25)^{2}\end{array}$ & 0.774 & 0.549 & 0.451 & 0.394 & 0.356 & 0.328 & 0.307 & 0.291 & 0.277 & 0.266 & 0.256 & 0.248 & 0.241 & 0.234 & 0.228 & 0.223 & 0.219 & 0.214 & 0.210 & 0.207 \\
\hline $\begin{array}{r}38 \\
(1.5)\end{array}$ & 0.854 & 0.600 & 0.489 & 0.424 & 0.382 & 0.351 & 0.328 & 0.309 & 0.294 & 0.282 & 0.271 & 0.262 & 0.254 & 0.247 & 0.241 & 0.235 & 0.230 & 0.225 & 0.221 & 0.217 \\
\hline $\begin{array}{r}51 \\
(2.0)\end{array}$ & 1.011 & 0.698 & 0.562 & 0.483 & 0.432 & 0.395 & 0.367 & 0.345 & 0.327 & 0.312 & 0.300 & 0.289 & 0.280 & 0.271 & 0.264 & 0.257 & 0.251 & 0.246 & 0.241 & 0.236 \\
\hline $\begin{array}{r}64 \\
(2.5)\end{array}$ & 1.173 & 0.799 & 0.637 & 0.544 & 0.483 & 0.440 & 0.407 & 0.381 & 0.360 & 0.343 & 0.328 & 0.316 & 0.305 & 0.295 & 0.287 & 0.279 & 0.272 & 0.266 & 0.260 & 0.255 \\
\hline $\begin{array}{r}76 \\
(3.0)\end{array}$ & 1.374 & 0.924 & 0.729 & 0.618 & 0.545 & 0.494 & 0.455 & 0.425 & 0.400 & 0.380 & 0.363 & 0.348 & 0.335 & 0.324 & 0.314 & 0.305 & 0.297 & 0.290 & 0.284 & 0.278 \\
\hline $\begin{array}{r}89 \\
(3.5)\end{array}$ & 1.533 & 1.023 & 0.802 & 0.677 & 0.595 & 0.536 & 0.493 & 0.459 & 0.431 & 0.408 & 0.389 & 0.373 & 0.359 & 0.346 & 0.335 & 0.325 & 0.317 & 0.309 & 0.301 & 0.295 \\
\hline $\begin{array}{r}102 \\
(4.0)\end{array}$ & 1.691 & 1.121 & 0.875 & 0.734 & 0.643 & 0.578 & 0.530 & 0.492 & 0.462 & 0.436 & 0.415 & 0.397 & 0.382 & 0.368 & 0.356 & 0.345 & 0.335 & 0.326 & 0.319 & 0.311 \\
\hline $\begin{array}{r}127 \\
(5.0) \\
\end{array}$ & 2.024 & 1.328 & 1.027 & 0.856 & 0.745 & 0.666 & 0.607 & 0.561 & 0.525 & $\begin{array}{l}0.495 \\
\vdots\end{array}$ & 0.469 & 0.448 & 0.429 & 0.412 & 0.398 & 0.385 & 0.374 & 0.363 & 0.354 & 0.345 \\
\hline $\begin{array}{r}152 \\
(6.0)\end{array}$ & 2.354 & 1.533 & 1.178 & 0.976 & 0.845 & 0.752 & 0.683 & 0.630 & 0.587 & 0.551 & 0.522 & 0.496 & 0.475 & 0.456 & 0.439 & 0.424 & 0.411 & 0.399 & 0.388 & 0.378 \\
\hline $\begin{array}{r}203 \\
(8.0)\end{array}$ & 2.967 & 1.916 & 1.458 & 1.199 & 1.031 & 0.912 & 0.824 & 0.755 & 0.701 & 0.656 & 0.618 & 0.586 & 0.559 & 0.535 & 0.514 & 0.495 & 0.478 & 0.463 & 0.449 & 0.437 \\
\hline $\begin{array}{r}254 \\
(10.0)\end{array}$ & 3.612 & 2.318 & 1.754 & 1.434 & 1.226 & 1.080 & 0.971 & 0.887 & 0.820 & 0.764 & 0.718 & 0.679 & 0.646 & 0.616 & 0.591 & 0.568 & 0.548 & 0.529 & 0.513 & 0.498 \\
\hline $\begin{array}{r}305 \\
(12.0)\end{array}$ & 4.213 & 2.694 & 2.031 & 1.653 & 1.409 & 1.237 & 1.109 & 1.010 & 0.930 & 0.866 & 0.812 & 0.766 & 0.726 & 0.692 & 0.662 & 0.635 & 0.612 & 0.590 & 0.571 & 0.553 \\
\hline $\begin{array}{r}356 \\
(14.0)\end{array}$ & 4.586 & 2.928 & 2.203 & 1.790 & 1.522 & 1.334 & 1.194 & 1.086 & 0.999 & 0.928 & 0.869 & 0.819 & 0.776 & 0.739 & 0.706 & 0.677 & 0.651 & 0.628 & 0.607 & 0.588 \\
\hline $\begin{array}{r}406 \\
(16.0)\end{array}$ & 5.180 & 3.301 & 2.477 & 2.008 & 1.703 & 1.489 & 1.330 & 1.207 & 1.108 & 1.028 & 0.961 & 0.904 & 0.856 & 0.813 & 0.776 & 0.743 & 0.714 & 0.688 & 0.664 & 0.642 \\
\hline $\begin{array}{r}457 \\
(18.0)\end{array}$ & 5.770 & 3.672 & 2.750 & 2.225 & 1.884 & 1.644 & 1.466 & 1.327 & 1.217 & 1.127 & 1.052 & 0.989 & 0.934 & 0.887 & 0.845 & 0.809 & 0.776 & 0.747 & 0.720 & 0.696 \\
\hline $\begin{array}{r}508 \\
(20.0)\end{array}$ & 6.357 & 4.042 & 3.022 & 2.441 & 2.064 & 1.798 & 1.601 & 1.448 & 1.326 & 1.226 & 1.143 & 1.073 & 1.013 & 0.960 & 0.914 & 0.874 & 0.838 & 0.805 & 0.776 & 0.750 \\
\hline $\begin{array}{r}610 \\
(24.0)\end{array}$ & 7.524 & 4.778 & 3.565 & 2.872 & 2.422 & 2.105 & 1.870 & 1.687 & 1.542 & 1.423 & 1.324 & 1.240 & 1.168 & 1.106 & 1.051 & 1.003 & 0.960 & 0.922 & 0.887 & 0.855 \\
\hline
\end{tabular}




\section{Table 7-11. Indoor PIpe UA/L Values ( $\mathrm{W} / \mathrm{K}-\mathrm{m}$ of length) for Insulation $\mathrm{k}=0.1154 \mathrm{~W} / \mathrm{m}-\mathrm{K}$}

(0.80 Btu-in./hr-ft $\left.{ }^{2}-{ }^{0} \mathrm{~F}\right)$

\begin{tabular}{|c|c|c|c|c|c|c|c|c|c|c|c|c|c|c|c|c|c|c|c|c|}
\hline \multirow{2}{*}{$\begin{array}{l}\text { Nom. } \\
\text { P1pe } \\
\text { D1am., } \\
\text { mm } \\
\text { (1n.) }\end{array}$} & \multicolumn{20}{|c|}{ Insulation Th1ckness, mm (1n.) } \\
\hline & $\begin{array}{c}13 \\
(0.5)\end{array}$ & $\begin{array}{c}25 \\
(1.0)\end{array}$ & $\begin{array}{c}38 \\
(1.5)\end{array}$ & $\begin{array}{c}51 \\
(2.0)\end{array}$ & $\begin{array}{c}64 \\
(2.5)\end{array}$ & $\begin{array}{c}76 \\
(3.0)\end{array}$ & $\begin{array}{c}89 \\
(3.5)\end{array}$ & $\begin{array}{c}102 \\
(4.0)\end{array}$ & $\begin{array}{c}114 \\
(4.5)\end{array}$ & $\begin{array}{c}127 \\
(5.0)\end{array}$ & $\begin{array}{c}140 \\
(5.5)\end{array}$ & $\begin{array}{c}152 \\
(6.0)\end{array}$ & $\begin{array}{c}165 \\
(6.5)\end{array}$ & $\begin{array}{c}178 \\
(7.0)\end{array}$ & $\begin{array}{c}191 \\
(7.5)\end{array}$ & $\begin{array}{c}203 \\
(8.0)\end{array}$ & $\begin{array}{c}216 \\
(8.5)\end{array}$ & $\begin{array}{c}229 \\
(9.0)\end{array}$ & $\begin{array}{c}241 \\
(9.5)\end{array}$ & $\begin{array}{c}254 \\
(10.0)\end{array}$ \\
\hline $\begin{array}{r}25 \\
(1.0)\end{array}$ & 0.805 & 0.602 & 0.507 & 0.451 & 0.412 & 0.384 & 0.362 & 0.345 & 0.330 & 0.318 & .308 & 0.298 & 0.290 & 0.283 & 0.277 & .271 & .266 & 0.261 & .257 & .253 \\
\hline & 0.945 & 0.694 & 0.578 & 0.509 & 0.462 & 0.428 & 0.402 & 0.381 & 0.364 & 0.350 & .337 & 0.327 & 0.318 & 0.309 & 0.302 & 0.295 & 0.289 & 0.284 & 0.279 & 0.274 \\
\hline $\begin{array}{r}38 \\
(1.5)\end{array}$ & 1.041 & 0.756 & 0.625 & 0.548 & 0.496 & 0.458 & 0.429 & 0.406 & 0.387 & 0.371 & 0.357 & 0.356 & 0.335 & 0.326 & 0.318 & 0.311 & 0.304 & 0.298 & 0.293 & 0.287 \\
\hline $\begin{array}{r}51 \\
(2.0)\end{array}$ & 1.229 & 0.878 & 0.718 & 0.623 & 0.560 & 0.514 & .480 & 0.452 & 0.429 & 0.411 & .395 & 0.381 & 0.369 & 0.358 & 0.348 & .340 & .332 & 0.325 & .319 & .313 \\
\hline $\begin{array}{r}64 \\
(2.5)\end{array}$ & 1.423 & 1.003 & 0.812 & 0.700 & 0.626 & 0.572 & 0.531 & 0.499 & 0.472 & 0.450 & 0.432 & 0.416 & 0.402 & 0.389 & 0.379 & 0.369 & 0.360 & 0.352 & 0.344 & 0.338 \\
\hline $\begin{array}{r}76 \\
(3.0) \\
\end{array}$ & 1.663 & 1.158 & 0.928 & 0.794 & 0.706 & .642 & .593 & 0.555 & 0.524 & .498 & .476 & 0.458 & 0.441 & 0.427 & 0.414 & .403 & .393 & 0.383 & .375 & .367 \\
\hline $\begin{array}{r}89 \\
(3.5)\end{array}$ & 1.853 & 280 & 1 & 69 & 68 & 6 & 42 & 9 & 64 & 5 & 1 & 30 & 0.472 & 0.456 & 2 & 29 & 418 & 0.408 & .398 & 39 \\
\hline $\begin{array}{c}102 \\
(4.0)\end{array}$ & 2.041 & 1.401 & 1.111 & 0.942 & 0.830 & 0.750 & .690 & 0.642 & 0.604 & 0.572 & .545 & 0.522 & 0.502 & 0.484 & 0.469 & .455 & .442 & 0.431 & 0.421 & .411 \\
\hline $\begin{array}{r}127 \\
(5.0) \\
\end{array}$ & 2.438 & 1.656 & 1.302 & 1.096 & 0.960 & 0.863 & 0.790 & 0.732 & 0.686 & 0.647 & 0.615 & 0.588 & 0.564 & 0.543 & 0.524 & 0.508 & 0.493 & 0.479 & 0.467 & 0.456 \\
\hline $\begin{array}{r}152 \\
(6.0)\end{array}$ & 2.829 & 1.909 & 1.491 & 1.248 & 1.088 & 0.973 & 887 & 820 & 0.766 & .721 & 684 & .651 & 0.624 & 0.599 & 0.578 & .559 & .541 & 0.526 & .512 & .499 \\
\hline $\begin{array}{r}203 \\
(8.0)\end{array}$ & 3.558 & 2.379 & 1.843 & 1.531 & 1.325 & 179 & 069 & 983 & 0.914 & 0.857 & 0.809 & 0.768 & 0.733 & 0.702 & 0.675 & 0.651 & 0.630 & 0.610 & .593 & .577 \\
\hline $\begin{array}{r}254 \\
(10.0) \\
\end{array}$ & 4.322 & 2.874 & 2.212 & 1.827 & 1.574 & 1.393 & 1.258 & 1.152 & 1.068 & 0.998 & 0.939 & 0.890 & 0.847 & 0.809 & 0.776 & 0.747 & .721 & 0.697 & 0.676 & .656 \\
\hline $\begin{array}{r}305 \\
(12.0)\end{array}$ & 5.034 & 3.335 & 2.557 & 2.105 & 1.806 & 594 & 435 & 1.310 & 11 & 1.129 & 060 & 002 & 952 & 908 & 0.869 & .835 & .805 & 0.777 & .752 & .729 \\
\hline $\begin{array}{r}356 \\
(14.0)\end{array}$ & 5.475 & 3.622 & 2.772 & 2.277 & 1.951 & 1.718 & .544 & 1.409 & 1.300 & 1.210 & 1.135 & 1.072 & 1.017 & 0.969 & 0.927 & .890 & .856 & 0.826 & 0.799 & .775 \\
\hline $\begin{array}{r}406 \\
(16.0) \\
\end{array}$ & 6.177 & 4.079 & 3.114 & 2.552 & 2.181 & 1.917 & 1.719 & 1.565 & 1.441 & 1.339 & 1.254 & 1.182 & 1.120 & 1.066 & 1.018 & 0.976 & 0.938 & 0.904 & 0.874 & .846 \\
\hline $\begin{array}{r}457 \\
8.0)\end{array}$ & 6.875 & 533 & 3.455 & 2.825 & 2.410 & 14 & 93 & 20 & 82 & 68 & 373 & 292 & 23 & 62 & 109 & 62 & 20 & 982 & 948 & 917 \\
\hline $\begin{array}{c}508 \\
20.0)\end{array}$ & 7.569 & 986 & 3.794 & 3.098 & 2.638 & 2.311 & 2.066 & 1.875 & 1.722 & 1.596 & 1.491 & 1.401 & 1.324 & 1.258 & 1.199 & 1.147 & 1.100 & 1.059 & 1.021 & .987 \\
\hline $\begin{array}{r}610 \\
24.0)\end{array}$ & 8.945 & 5.886 & .470 & 3.641 & 3.093 & 2.703 & 2.411 & 2.183 & 2.000 & 1.850 & .725 & 1.619 & 1.527 & .447 & 1.378 & .316 & .260 & 1.211 & .166 & .125 \\
\hline
\end{tabular}




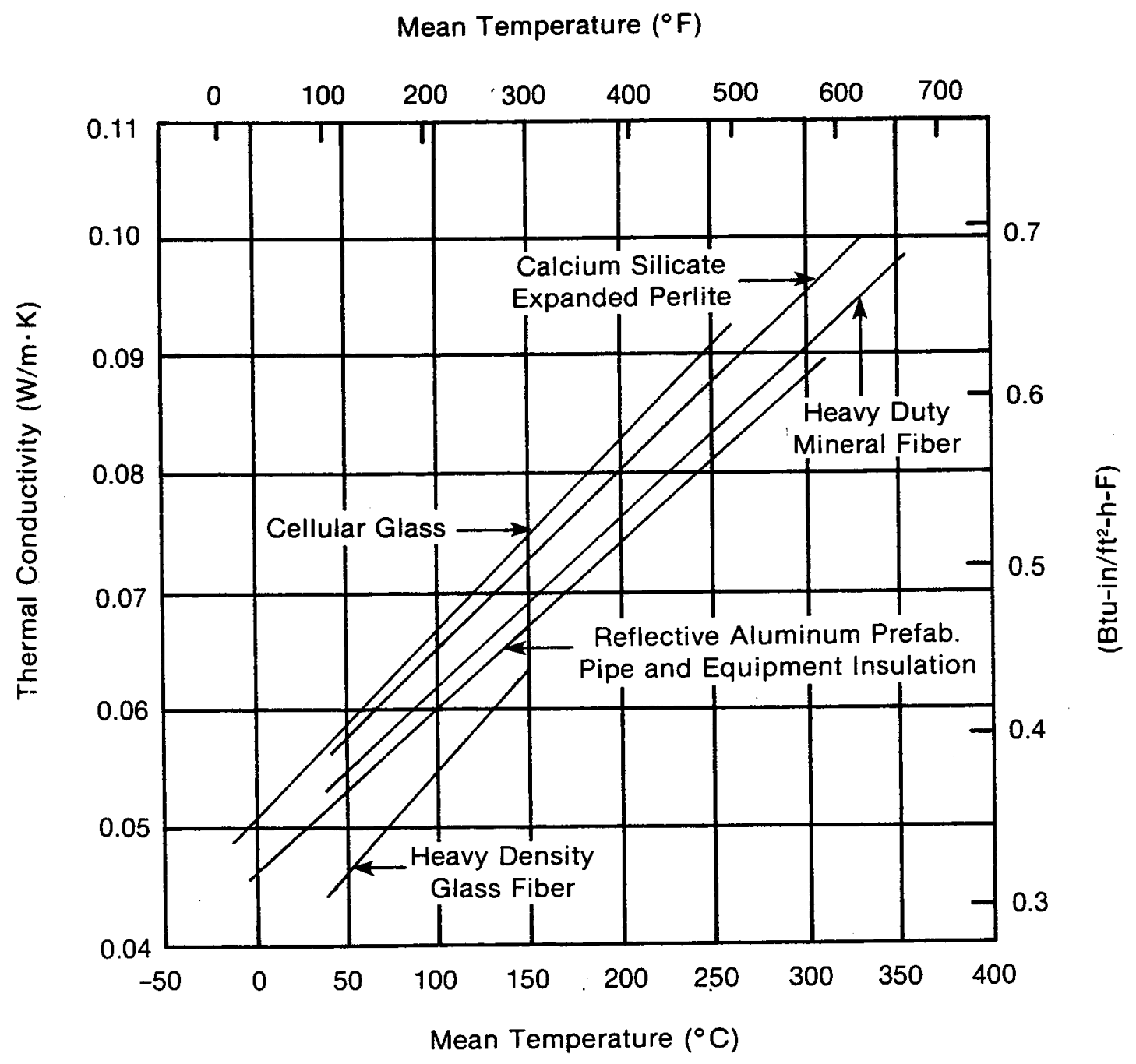

Figure 7-4. Thermal Conductivity of Rigid Insulating Materials 


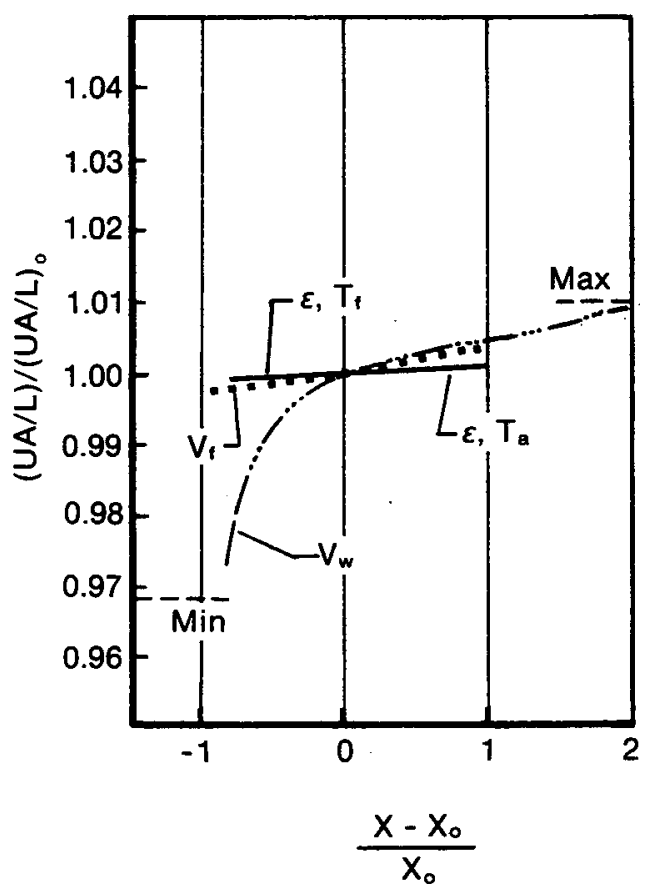

(a) 25-mm (1-in.) pipe, 13-mm (0.5-in.) insulation

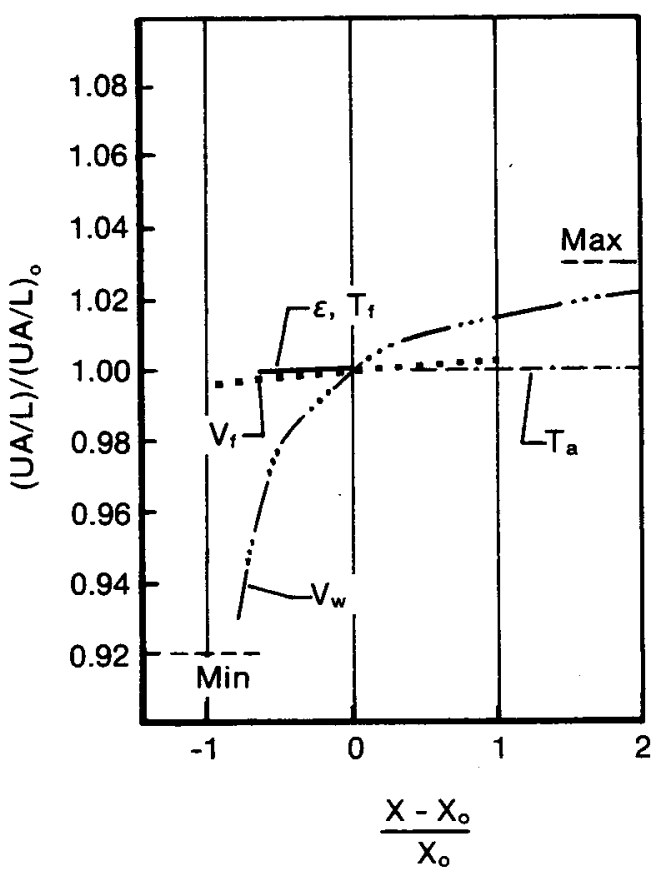

(c) 610-mm (24-in.) pipe, 13-mm (0.5-in.) insulation

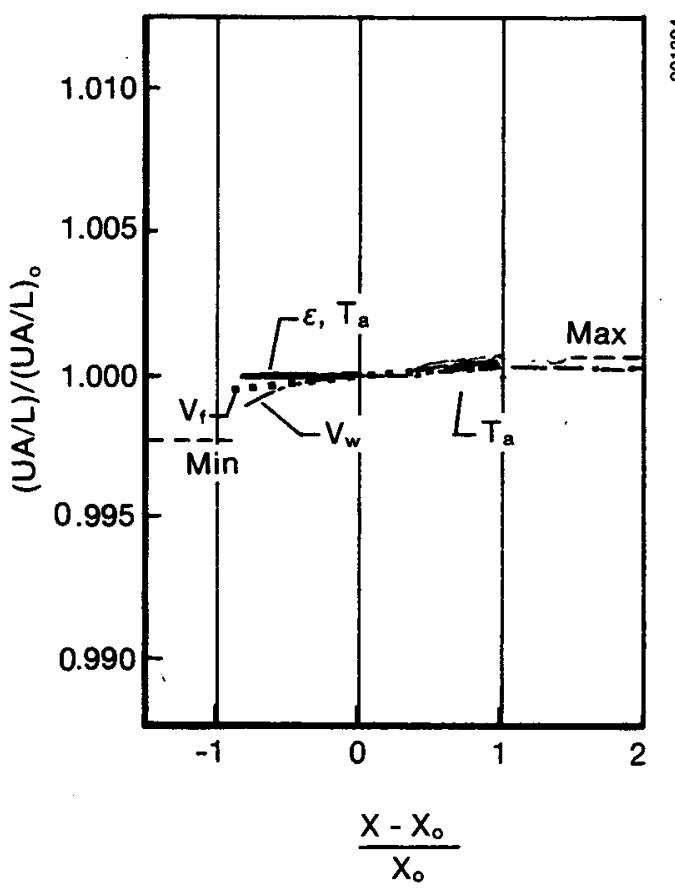

(b) 25-mm (1-in.) pipe, 254-mm (10-in.) insulation

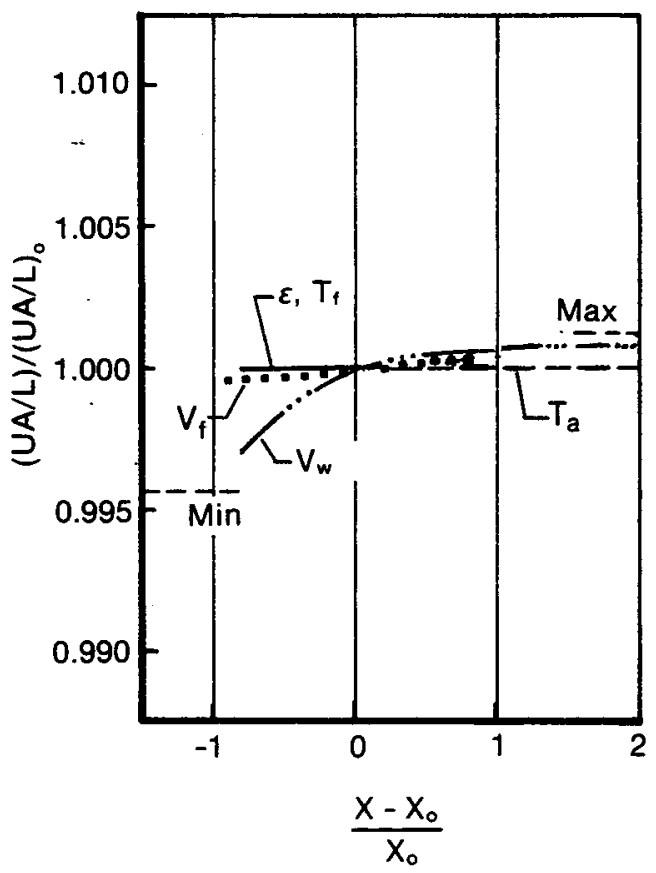

(d) $610-\mathrm{mm}$ (24-in.) pipe, 254-mm $(10-$ in.) insulation

Figure 7-5. Sensitivity of UA/L Values to Change in Parameters-Outdoors 


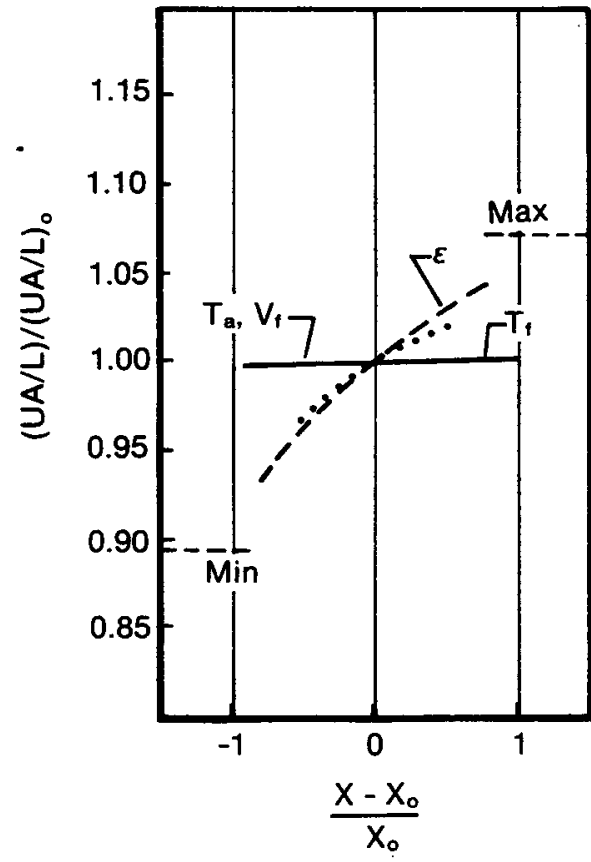

(a) 25-mm (1-in.) pipe, 13-mm (0.5-in.) insulation

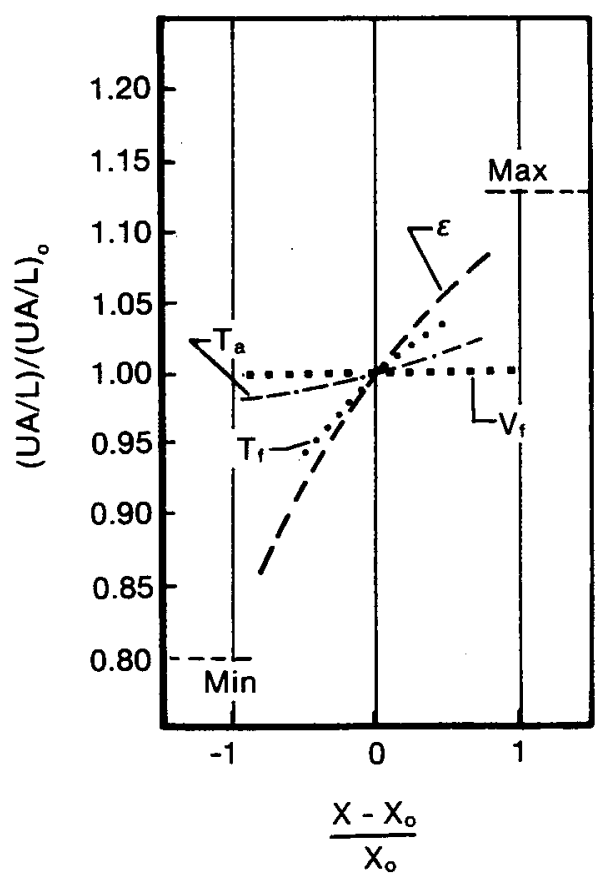

(c) 610-mm (24-in.) pipe, 13-mm $(0.5$-in.) insulation

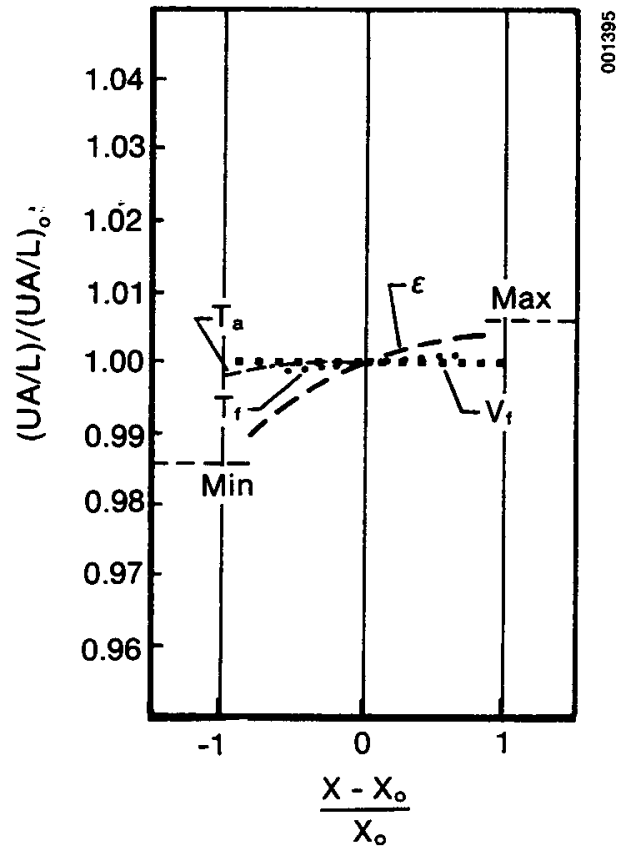

(b) $25-\mathrm{mm}$ (1-in.) pipe, 254-mm $(10-$ in.) insulation

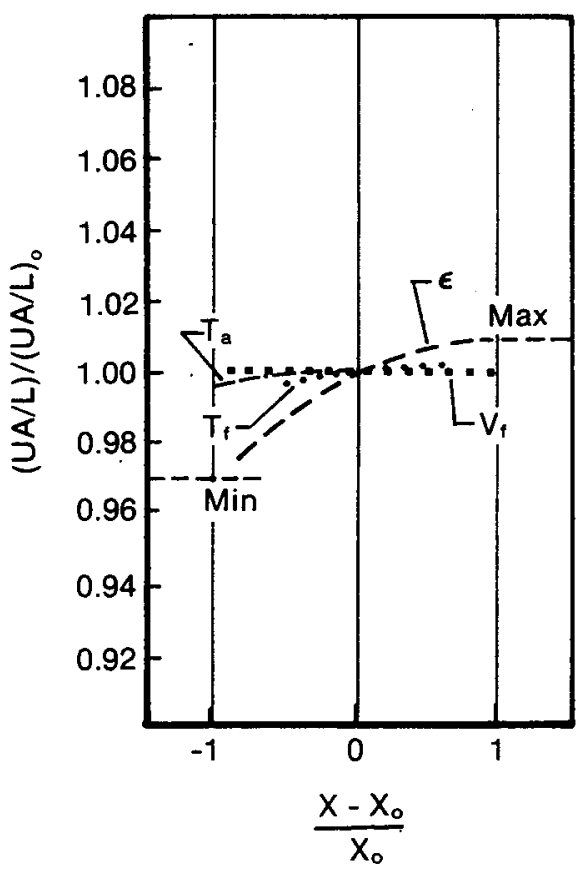

(d) 610-mm (24-in.) pipe, 254-mm (10-in.) insulation

Figure 7-6. Sensitivity of JA/L Values to Changes in Parameters--Indoors 
as much as $+13 \%$ to $-21 \%$ indoors when all parameters are at their maximum and minimum values, respectively. If we use smaller pipes or thicker insulation, however, the thermal resistance of the insulation becomes increasingly important and possible deviations in UA/L are less significant.

In the economic model, three cost sources are considered: the cost of Insulation material and labor, of maintenance, and of the solar energy provided by the system. Following Jones and Lior (1979), the equation that expresses the total present-value average cost per unit length of piping insulation is

$$
C_{T}=\left[E_{1(1)} / \mathrm{n}\right]\left(C_{i}+C_{j}+C_{1}\right)+\left[E_{2(1)} / \mathrm{n}\right] C_{m}+0.0315 \mathrm{FC}_{s} \mathrm{UA}\left(\mathrm{T}_{f}-\mathrm{T}_{\mathrm{a}}\right),
$$

where

$$
\begin{aligned}
{\left[\mathrm{E}_{1(1)} / \mathrm{n}\right]\left(\mathrm{C}_{i}+\mathrm{C}_{j}+\mathrm{C}_{1}\right) } & =\text { cost of insulation material and labor } \\
{\left[\mathrm{E}_{2(1)} / \mathrm{n}\right] \mathrm{C}_{\mathrm{m}} } & =\text { maintenance costs } \\
\mathrm{FC}_{s} \mathrm{UA}\left(\mathrm{T}_{f}-\mathrm{T}_{\mathrm{a}}\right) & =\text { cost of solar energy provided by the system, }
\end{aligned}
$$

and where

$$
\begin{aligned}
& \mathrm{E}_{1(1)}, \mathrm{E}_{2(1)}=\begin{array}{l}
\text { economic coefficients for converting cash flows to present } \\
\text { values, }
\end{array} \\
& \mathrm{n}=\text { period of economic analysis (usually, the life of the sys- } \\
& \text { tem, in years) } \\
& C_{i}=\text { base cost of the insulation material, including the cost of } \\
& c_{j}=\text { base cost of insulation jacketing }(\$ / m) \\
& c_{1}=\text { base cost of insulation labor }(\$ / m) \\
& \mathrm{C}_{\mathrm{m}}=\text { base cost of maintenance during the first year }(\$ / \mathrm{m}) \\
& F=\text { annual usage factor }(0 \leqslant F \leqslant 1) \text { of the insulated component }
\end{aligned}
$$


Dividing $E q \cdot 7-7$ by $C_{s} F\left(T_{f}-T_{a}\right)$, we obtain

$$
C_{T M}=C_{T} / C_{s} F\left(T_{f}-T_{a}\right)=C_{R}+U A^{*},
$$

where

$$
\underline{\mathrm{UA}}=0.0315 \times \mathrm{UA}(\mathrm{GJ} / \mathrm{m}-\mathrm{yr}-\mathrm{K}),
$$

and

$$
C_{R}=\left[E_{1(1)}\left(C_{1}+C_{j}+C_{1}\right)+E_{2(1)} C_{m}\right] / C_{s} F\left(T_{f}-T_{a}\right) .
$$

The E-terms used to convert cash flows to present values (Barley and Wynn 1978) are defined as follows:

$$
\begin{aligned}
E_{1}= & \alpha-\beta-\sigma[(1+g) /(1+d)]^{n}+[(1-t) p+h] P(d, g, n) \\
& +(1-\alpha)\{(1-t)[P(d, 0, m) / P(i, 0, m)] \\
& +[P(d, i, m) / P(0, i, m)] t\}-B \\
E_{2}= & \left(1-t_{1}\right) P\left(d, r_{m}, n\right)
\end{aligned}
$$

where

$$
\begin{aligned}
\alpha= & \text { down-payment fraction of first cost } \\
\beta= & \text { investment tax credit fraction, if applicable } \\
\sigma= & \text { fractional salvage value at end of equipment life } \\
g= & \text { annual general inflation rate (percent } \div 100) \\
\mathrm{d}= & \text { annual discount rate, designated either as that for inflation, } \\
& \text { for an opportunity cost of money, or for a required return on } \\
& \text { investment (percent } \div 100) \\
t= & \text { annual incremental income-tax rate (applicable only in busi- } \\
& \text { ness, where capital expenses are income-tax deductible; other- } \\
& \text { wise, } t=0) \text { (percent } \div 100) \\
t_{1}= & \text { same as } t, \text { but applicable only if maintenance, operating, and/ } \\
& \text { or fuel expenses are tax-deductible; otherwise, } t=0 \text { (percent } \\
& \div \quad 100) \\
\mathrm{p}= & \text { actual annual property tax rate (per cent/100) } \\
\mathrm{h}= & \text { annual insurance cost as a fraction of the first cost }
\end{aligned}
$$


and

$$
\begin{gathered}
P(d, r, n)=\left[(1+d)^{n}-(1+r)^{n}\right] /(1+d)^{n}(d-r) \text { for } d \neq r, \quad(7-13) \\
P(d, r, n)=n /(1+r) \text { for } d=r,
\end{gathered}
$$

where

$n=$ period of economic analysis, usually the life of the system (years)

$i=$ annual interest rate on loan or mortgage (per cent/100)

$m=$ period of loan or mortgage (years)

$B=$ cumulative present worth of depreciation tax credits per dollar invested.

With straight-1ine depreciation:

$$
B_{S L}=t(1-\sigma) P(d, 0, k) / k
$$

With declining balance:

$$
\mathrm{B}_{\mathrm{DB}}=t \delta \mathrm{P}(\mathrm{d}-\delta / \mathrm{k}, \mathrm{k}) / \mathrm{k}
$$

With sum of years digits:

$$
\mathrm{B}_{\mathrm{SOYD}}=2 t(1-\sigma)\{\mathrm{P}(\mathrm{d}, 0, \mathrm{k})+[\mathrm{k}-1-\mathrm{P}(\mathrm{d}, 0, \mathrm{k})-1] / \mathrm{d}\} / \mathrm{k}(\mathrm{k}+1)(\bar{j}-17)
$$

where

$$
\begin{aligned}
\mathrm{k} & =\text { depreciation lifetime } \\
\delta & =\text { declining balance multiplier } \\
\mathbf{r}_{\mathrm{m}} & =\text { annual fractional rate of increase in maintenance expense }
\end{aligned}
$$

The optimal insulation thickness for a particular pipe size is determined as follows :

- Obtain insulation material and jacketing costs for each insulation thickness, starting with the smallest thickness available for the particular pipe size of interest; from economic and system design information and labor costs that apply to the project, calculate $C_{R}$ for each thickness, using Eq. 7-10.

- From the applicable table, find the value of UA/L that corresponds to the particular pipe size under consideration for the proper value of $k$ and for the range of insulation thicknesses being investigated. 
- Find $\mathrm{UA}^{*}$ from $\mathrm{Eq} \cdot 7-9$.

- Obtain $\mathrm{C}_{\mathrm{TM}}$ from $\mathrm{Eq} \cdot 7-8$ by adding the values of $\mathrm{UA}^{*}$ and $\mathrm{C}_{\mathrm{R}}$ that correspond to the same pipe-size and insulation-thickness combination.

- The optimal insulation thickness is the value that gives us the smallest value of " $\mathrm{C}_{\mathrm{TM}}$. For this optimal insulation thickness, the total annual cost per unit length of piping is

$$
C_{T}=C_{T M} C_{s} F\left(T_{f}-T_{a}\right)(\$ / m-y r),
$$

and the total annual heat loss per unit length of insulated pipe is

$$
\mathrm{Q}_{1}=\left(\mathrm{UA}^{*}\right) \mathrm{F}\left(\mathrm{T}_{\mathrm{f}}-\mathrm{T}_{\mathrm{a}}\right)(\mathrm{GJ} / \mathrm{m}-\mathrm{yr})
$$

The procedure can be repeated for different insulation materials with different $k$ values to determine the economic optimal insulation material for a particular pipe size. The system variables $F, C_{s}, T_{f}$, and $T_{a}$ can be determined by methods described elsewhere in this handbook.

\subsection{HRAT TRANSFER FLUIDS}

Water is a popular heat transfer fluid because it is nontoxic, nonflammable, inexpensive, and has excellent heat transfer characteristics. It does, however, attain high vapor pressures at elevated temperatures: $1 \mathrm{MPa}$ at $180^{\circ} \mathrm{C}$ $\left(135 \mathrm{psia}\right.$ at $\left.350^{\circ} \mathrm{F}\right)$ to $7 \mathrm{MPa}$ at $285^{\circ} \mathrm{C}\left(1050 \mathrm{psia}\right.$ at $\left.550^{\circ} \mathrm{F}\right)$. Because highpressure design adds to overall system costs, water is not economical for high-temperature systems. However, the extra cost of high-pressure design may be offset by the savings realized from using smaller pipes and heat exchangers and from avoiding the costs of other heat transfer fluids and extensive fire protection systems. But because water freezes at a relatively high temperature, it may be an impractical if not unfeasible heat transfer fluid.

If water cannot be used as the working fluid, the designer faces the troublesome task of determining which of over 50 other fluids can best serve the needs of the IPH system. Alternative fluids include water-glycol mixtures, silicone compounds, fluorocarbons, inorganic salt mixtures, and petroleumbased and synthetic hydrocarbons. Comparing them is not easy, because different manufacturers present their data in different ways. And in the majority of cases, complete property information over the total operating range of a fluid is simply not available. The designer must also compare the fluids' flammability, toxicity, corrosiveness, and thermal stability, as well as cost. Detailed tables of information on many heat transfer fluids appropriate for solar applications are presented in Appendix B.

In the following section, we summarize some general characteristics of different types of fluids, particularly as they relate to a solar IPH system. Glycols, silicone fluids, and hydrocarbons are discussed in some detail. Inorganic salts, because of their high melting points, are best suited to very high-temperature systems and thus have little relevance as IPH collector fluids. Fluorocarbons are used in some two-phase domestic hot water systems but have not been suggested for larger IPH systems. 


\subsubsection{Types of Fluids}

\subsubsection{Water}

We have already noted several characteristics that make water a valuable working fluid (it is nontoxic, nonflammable, inexpensive, has good thermal properties, etc.). But we should expand here on some of its disadvantages:

- Water has a low boiling point. This is a problem not only in concentrating collectors, where the temperature routinely surpasses $100^{\circ} \mathrm{C}$, but also in flat-plate collectors, if they are allowed to stagnate while filled with water and exposed to sufficient sunlight.

- Water has a freezing point higher than the lowest temperature that occurs in most parts of the United States. Thus, freeze-protection methods are required for most water systems.

- Water will corrode most metals, unless it is treated. Water treatment technology is advanced enough, however, that this problem is not as severe as the others.

\subsubsection{Water-Glycol Mixtures}

Aqueous solutions of ethylene and propylene glycol are the most commonly used nonfreezing fluids in solar systems. In proper concentrations, these mixtures freeze only at temperatures below $-45^{\circ} \mathrm{C}\left(-50^{\circ} \mathrm{F}\right)$; thus, they can provide adequate freeze protection in most parts of the United States. These mixtures still boil at relatively low temperatures [about $110^{\circ} \mathrm{C}\left(230^{\circ} \mathrm{F}\right)$ ], however, so they are usually restricted to process temperatures less than $100^{\circ} \mathrm{C}$. Another reason for this temperature limit is that glycols decompose into organic acids if they are exposed to air and elevated temperatures; thus, glycols increase corrosion problems. Glycol manufacturers often add inhibitors to their products to reduce the rate of decomposition and provide corrosion protection for various metals. Since different manufacturers use different inhibitors, a solar system designer should ascertain whether the inhibitors in a candidate glycol heat-transfer fluid will provide adequate protection.

\subsubsection{Aliphatic Hydrocarbons}

Aliphatic hydrocarbons consist of open-chain structures and include olefins and paraffinic oils. They can be natural petroleum fractions or synthetic oils, and they can be used at higher temperatures than water (but become fairly viscous at lower temperatures). They exhibit low toxicities and are thermally stable at high temperatures if there is no air in the system and stagnation is avoided. Excluding air generally requires that expansion tanks be pressurized with nitrogen.

\subsubsection{Aromatic Hydrocarbons}

By definition, aromatic hydrocarbons contain at least one benzene ring. Biphenyls, terphenyls, and naphthenic oils are examples of these cyclic 
molecules. Aromatic hydrocarbons have lower viscosities than aliphatic hydrocarbons and slightly higher maximum operating temperatures, but they also have relatively low flash points. Aromatic compounds dissolve roofing tar and asphalt shingles; thus, they may not be suitable for roof-mounted systems. They also degrade elastomeric materials, so gaskets and hoses must be chosen carefully:

\subsubsection{Silicones}

Silicone fluids on the market today (all polydimethylsiloxanes) have the highest permissible operating temperatures of any of the heat transfer fluids discussed in this handbook. They are also nontoxic, have high flash points, and will not harm roofing materials--all attractive qualities for solar systems. On the other hand, their relatively high viscosities and low specific heats require high flow rates (thus, a great deal of pumping power) for adequate heat transfer. Silicone fluids are incompatible with neoprene or butyl rubber, and because they have very low surface tensions, they leak through joints tight enough to contain other fluids. Silicones are also the most expensive heat transfer fluids marketed, costing three to ten times as much as alternative fluids.

\subsubsection{Temperature-Dependent Thermal Properties}

Certain thermal properties of fluids determine a fluid's ability to transfer heat as well as the pumping power required to pump it through a given circuit. These properties include density ( $\rho)$, thermal conductivity $(k)$, specific heat $\left(c_{p}\right)$, and kinematic viscosity $(\nu)$ [dynamic viscosity $(\mu)$ can also be used: $\mu \underline{=} \rho \nu]$. Although vapor pressure does not enter into the heat transfer or pumping calculations, it is important, too, because it reveals the atmospheric boiling point of a fluid as well as the absolute pressure that must be maintained to prevent the fluid from boiling. All of these properties vary with temperature. Appendix B summarizes these properties for many fluids appropriate for solar IPH systems.

The most important trade-off to make in selecting a heat transfer fluid for a solar application is between heat transfer properties and pumping power requirements. In this section, we present an index to use in making this trade-off, the heat transfer efficiency factor (Fried 1973). To begin with, we consider the effect of a fluid's thermal properties on its heat transfer characteristics. Heat transfer to or from a fluid flowing through a circular pipe or tube can be determined from the Dittus-Boelter equation (Dittus and Boelter 1930),

$$
\mathrm{Nu}=0.023 \mathrm{Re}^{0.8} \mathrm{Pr}^{\mathrm{n}} \text {, }
$$

where

$$
\begin{aligned}
& \mathrm{Nu}=\text { Nusselt number }(\mathrm{hD} / \mathrm{k}) \\
& \mathrm{Re}=\text { Reynolds number }(\rho \mathrm{VD} / \mu) \\
& \operatorname{Pr}=\operatorname{Prandt} 1 \text { number }\left(\mu c_{\mathrm{p}} / \mathrm{k}\right)
\end{aligned}
$$




$$
\begin{aligned}
& n=0.4 \text { for heating the fluid, } 0.3 \text { for cooling the fluid } \\
& D=\text { hydraulic diameter of pipe } \\
& V=\text { fluid flow velocity. }
\end{aligned}
$$

The heat transfer coefficient $h$ is obtained from the definition of the Nusselt number:

$$
\mathrm{h}=\mathrm{Nu} \cdot \mathrm{k} / \mathrm{D}
$$

Substituting the thermal property expressions into the dimensionless numbers gives us, in the heating case,

$$
\mathrm{h}=0.023\left(\frac{\rho \mathrm{VD}}{\mu}\right)^{0.8}\left(\frac{\mu \mathrm{c}_{\mathrm{p}}}{\mathrm{k}}\right)^{0.4} \frac{\mathrm{k}}{\mathrm{D}},
$$

or

$$
h=0.023 \frac{\rho^{0.8} c_{p} 0.4 k^{0.6}}{\mu^{0.4}} \cdot \frac{v^{0.8}}{D^{0.2}}
$$

Thus, for a given flow velocity and pipe diameter, we see that high density, specific heat, thermal conductivity, and low viscosity enhance heat transfer.

Now, we must consider the effect of fluid properties on pumping power (pp). From the first law of thermodynamics for fluid flowing in a tube (see Shames 1962), we have

$$
\mathrm{pp}=\dot{\mathrm{m}}_{\ell}
$$

where pp is the pumping power required to move fluid at a mass flow rate $\dot{m}$ through a path with a head loss $h_{\ell}$. Head loss is determined from

$$
\mathrm{h}_{\ell}=\mathrm{f} \frac{\mathrm{L}}{\mathrm{D}} \frac{\mathrm{V}^{2}}{2}
$$

where $f$ is the friction factor. If $A$ is the pipe cross-sectional area $\left(\pi D^{2} / 4\right)$, then

$$
\dot{\mathrm{m}}=\rho \mathrm{AV}=\frac{\pi}{4} \rho \mathrm{D}^{2} \mathrm{~V}
$$

Substituting the expressions for $h_{\ell}$ and $\dot{m}$ into the equation for pp and dividing through by $L$ (the pipe length) yields

$$
\frac{\mathrm{pP}}{\mathrm{L}}=\frac{\pi}{8} \mathrm{f \rho DV} \mathrm{V}^{3} .
$$

For long, smooth pipes with Re between 5,000 and 200,000 (McAdams 1954), we have

$$
f=0.184 \operatorname{Re}^{-0.2} \text {. }
$$


With $\operatorname{Re}=\rho V D / \mu$, substituting f from Eq. 7-28 into Eq. 7-27 gives us

$$
\frac{\mathrm{pP}}{\mathrm{L}}=0.023 \pi \mu^{0.2} \rho^{0.8} \mathrm{D}^{0.8} \mathrm{~V}^{2.8}
$$

Thus, for a given flow velocity and pipe diameter, fluids with low density and viscosity minimize pumping power requirements.

Comparing $h$ in Eq. 7-23 with pp/L in Eq. 7-29, we find that $c$ and $k$ should be high and $\mu$ should be low for high heat transfer and low pumping power, but it is unclear whether high or low density is desired. However, by solving the $\mathrm{pp} / \mathrm{L}$ equation for $\mathrm{V}$ and then substituting for $\mathrm{V}$ in the $\mathrm{h}$ equation, we obtain

$$
h=\frac{(0.023)^{5 / 7}}{(\pi)^{2 / 7}} \cdot \frac{\rho^{4 / 7} c_{p} 0.4 k^{0.6}}{\mu^{16 / 35}} \cdot \frac{(p p / L)^{2 / 7}}{D^{3 / 7}} .
$$

The first term is simply a numerical constant, $C$. The second term, following the work of Fried (1973), is the heat transfer efficiency factor HTEF:

$$
\text { HTEF }=\frac{\rho^{4 / 7} c_{p}^{0.4} k^{0.6}}{\mu^{16 / 35}}
$$

Combining Eqs. $7-30$ and $7-31$ yields

$$
\mathrm{HTEF}=\frac{\mathrm{h} \cdot \mathrm{D}^{3 / 7}}{\mathrm{C}(\mathrm{pp} / \mathrm{L})^{2 / 7}}
$$

Equation 7-32 shows that, for a particular pipe diameter, fluids with high values of HTEF will have relatively low pumping power requirements or, alternatively, a high heat transfer coefficient per unit pumping power. Note that HTEF is independent of mass flow rate but is a function only of temperaturedependent fluid properties. Therefore, it varies with temperature.*

Water is the most thermally efficient fluid available in its temperature range. If freeze protection is needed and process temperatures are not high, ethylene glycol-water solutions are the next most efficient. Several of the Dowtherm fluids ( $A, E$, and $J$ ) also have relatively high efficiencies. In the mid-range efficiency band, the Syltherm 800 silicone fluid, the "Sun-Temp" $\left.{ }^{(}\right)$ fluid, and Dowtherm $\otimes$ appear best at various temperatures. There are only slight differences among the remaining petroleum fluids. Figure 7-7 shows heat transfer efficiency factors for a number of fluids.

*Fried (1973) originally defined HTEF as $\left(\rho^{4 / 7} c^{1 / 3} k^{2 / 3}\right) /\left(\mu^{16 / 35}\right)$, where the difference in the exponents of $c_{p}$ and $k$ results from using $n=1 / 3$ as the Prandt1 number exponent when calculating the Nusselt number. Fried's development of HTEF considered cooling a fluid by means of a heat exchanger rather than heating by means of a solar collector. Fried also included the numerical constant in HTEF in the text of his paper, though. his graphical results did not contain it. 


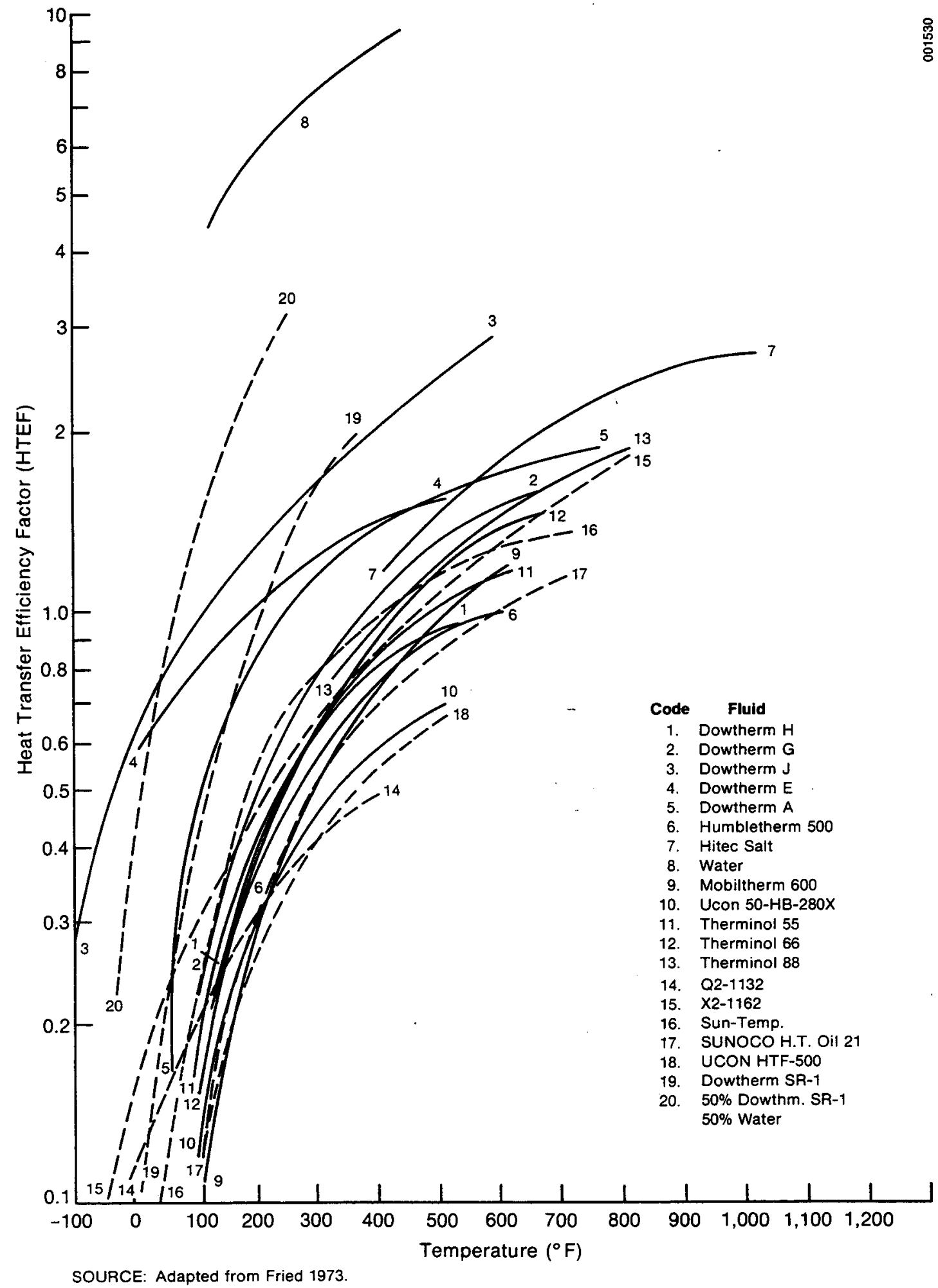

Figure 7-7. Heat Transfer Efficiency Factors for Twenty Fluids 


\subsubsection{Other Thermal Properties}

A heat transfer fluid should not be selected on the basis of the HTEF alone. The solar system designer may find that more efficient fluids are also more toxic, flammable, or corrosive, or more prone to thermal degradation. Fluid manufacturers usually specify recommended operating temperature ranges for their fluids. The range is usually viscosity-1imited at low temperatures (because the fluid becomes too difficult to pump) and degradation-limited at high temperatures. The high limit usually refers to bulk fluid temperature; a somewhat higher maximum film temperature may also be specified. Operating ranges are given for many fluids in Appendix B (see Table B-3).

The flammability of a fluid is usually defined by the flash point, the fire point, and the autoignition temperature. The flash point is the lowest temperature at which an air-vapor mixture will burn when it is exposed to a spark or flame; but if the ignition source is eliminated, the mixture will not keep burning. The fire point is the lowest temperature at which an air-vapor mixture will burn when it is exposed to a spark or flame and will continue to burn after the source is removed. The autoignition temperature (AIT) is the temperature at which the vapor will burn spontaneously when it is exposed to air; and here, no separate ignition source is needed. The fire point of a fluid is slightly higher than the flash point, and the AIT may be several hundred degrees higher. These values are also presented in Appendix $B$ (see Table B-6). Fluids are often operated at temperatures above their fire points; therefore, system operators should be aware of the possible dangers and should know what actions to take if a fluid leak develops.

Toxicity levels were established by the National Academy of Sciences Committee on Hazardous Materials and are given in Appendix B (see Table B-8). Propylene glycol is nontoxic and often used in food-processing systems, sometimes as a food additive; silicone fluids are also nontoxic. However, ethylene glycol is considered toxic. And adding corrosive inhibitors and $\mathrm{pH}$ buffers can render a pure, nontoxic fluid toxic. High temperatures (for example, like those occurring in stagnation) can cause oxidation, which also increases a fluid's toxicity.

\subsection{PUIPS}

Temperatures, pressures, and the kind of heat transfer fluid used in an IPH system as well as pump materials, drivers, couplings, and seals all affect the choice of an appropriate pump. Although using relatively small pipes throughout the solar field may minimize piping costs, this could result in high head losses which could, in turn, necessitate a bigger, more expensive pump. Thus, both capital and operating pump costs should be an integral part of the piping design process. Because pump technology is so well known and developed, detailed pump selection criteria are not presented in this handbook; rather, some basic information regarding types of pumps and preliminary sizing techniques is given. The solar IPH system designer is urged to evaluate this information with each project, and then to consult pump suppliers or manufacturers for assistance in the final selection of a pump. 
Pumps fall into two broad categories: centrifugal pumps and positive displacement pumps. Figure 7-8 summarizes the various subcategories of each type. The basic difference between the two is that, at a constant pump speed, a positive displacement pump maintains a constant capacity (i.e., it always delivers the same volume of fluid per unit time), but the capacity of a centrifugal pump depends on the head that it must work against. In both cases, the brake horsepower required of the driver and pump efficiency vary with the head. A typical pump curve for a centrifugal pump showing efficiency and head-versus-flow-rate characteristics at various speeds is displayed in Fig. 7-9. Similar pump curves for a positive displacement pump would be nearly vertical and would show the flow rate increasing nearly linearly with the pump speed. Efficiencies of positive displacement pumps tend to increase with speed because slippage losses have less effect at higher speeds. Both types of pumps have been used in solar IPH systems.

Before choosing a pump for a particular application, certain preliminary information is needed:

- The tentative system piping layout should be designed and the system head-flow curves calculated for all conditions, including cold start-up.

- The required pump capacity $Q$ should be determined. This capacity is a function of the energy collected by the collector field, field inlet and preferred outlet temperatures, and fluid specific heat and density.

- The system head loss to be made up by the pump $H$ must be calculated, using system head-flow curves. Since the head loss depends on the pipe sizes used in the system layout, piping and pumping sizing are iterative procedures.

- The net positive suction head available (NPSHA) to the pump must be determined. This parameter represents the amount of energy in the fluid at the pump datum. NPSHA is the absolute pressure at the pump inlet plus the velocity head, minus the vapor pressure of the fluid at the inlet temperature.

With this information, pump size can be estimated.

\subsubsection{Sizing a Single-Speed Centrifugal Pump}

To size a centrifugal pump, first calculate the specific speed $N_{S}$ :

$$
\mathrm{N}_{\mathrm{S}}=\mathrm{N} \sqrt{\mathrm{Q}} / \mathrm{H}^{3 / 4},
$$

where

$$
\begin{aligned}
\mathrm{N}= & \text { an initial estimate of the pump speed in rpm, chosen from the } \\
& \text { approximate full-1oad speeds of induction motors: } 3500,1750, \\
& 1160,875, \text { and } 700 \mathrm{rpm} \text { for } 60-\mathrm{Hz} \text { motors, or } 2900,1450,975,730, \\
& \text { and } 585 \mathrm{rpm} \text { for } 50-\mathrm{Hz} \text { motors } \\
\mathrm{Q}= & \text { flow rate, in } \mathrm{gpm} \\
\mathrm{H}= & \text { head, in feet. }
\end{aligned}
$$




\section{Centrifugal}

Horizontal

General Service

Chemical (ANSI)

High Temp. (API)

Multistage

Slurry

Self-Priming

Mixed Flow

Propeller

Sealed Rotor

\section{Vertical}

General Service

Turbine Type

Volute Type

Sump Type

Chemical Type In-line

High Speed in-Line

Can Type (Low NPSH)

Mixed Flow

Propeller

\begin{tabular}{|c|c|}
\hline & $\begin{array}{l}\text { Positive } \\
\text { splacement }\end{array}$ \\
\hline & Rotary \\
\hline & $\begin{array}{l}\text { Gear } \\
\text { Screw } \\
\text { Progressing Cavity } \\
\text { Lobe } \\
\text { Vane }\end{array}$ \\
\hline & Reciprocating \\
\hline & $\begin{array}{l}\text { Direct Acting Type } \\
\text { Power Frame Type } \\
\text { Plunger or Piston } \\
\text { Horizontal or Vertical }\end{array}$ \\
\hline & Controller Volume \\
\hline & $\begin{array}{l}\text { Plunger Type } \\
\text { Diaphragm Type } \\
\text { Number of Feeds } \\
\text { Types of Stroke } \\
\text { Adjustment }\end{array}$ \\
\hline
\end{tabular}

Figure 7-8. Summary of Types of Pumps 


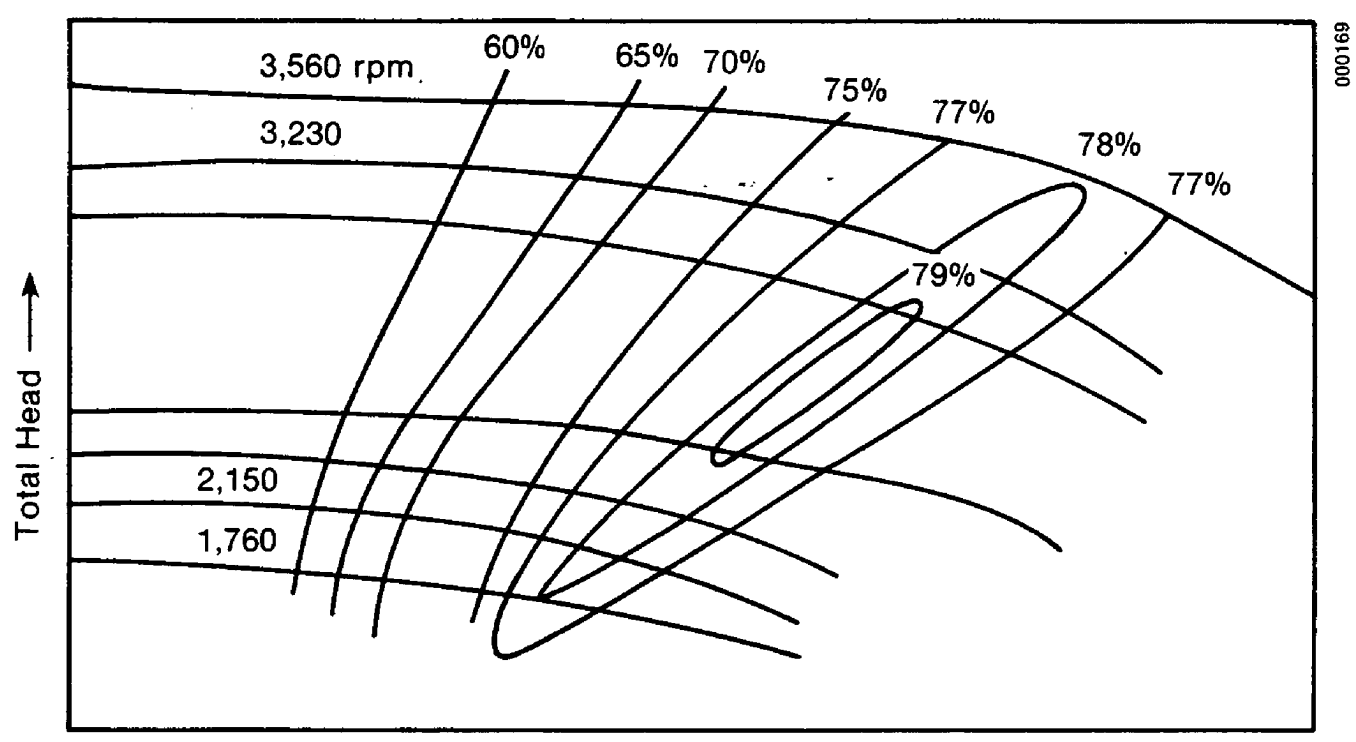

Flow rate $\longrightarrow$

SOURCE: Johnson 1981

Figure 7-9. Typical Bead-Flow Curves for a Centrifugal Pump

$\mathrm{N}_{\mathrm{S}}$ ranges from 7,000 to 10,000 in a typical impeller design. Values between 10,000 and 13,000 indicate special impeller designs that might be unstable when operated at less than $50 \%$ of the capacity for maximum pump efficiency (Lobanoff 1979).

Next, use Fig. 7-10 to find the point of maximum efficiency for the value obtained for $\mathrm{N}_{\mathrm{s}}$. Then, read the corresponding value of specific diameter $\mathrm{D}_{\mathbf{s}}$ from the vertical axis of the figure. $D_{s}$ is defined by

$$
D_{S}=D \cdot H^{1 / 4} / \sqrt{Q} \text {, }
$$

which can be solved for $D$, the required impeller diameter (in inches).

Figure 7-11 enables the designer to estimate the net positive suction head required (NPSHR) by a pump sized for $N=3550$ or $1760 \mathrm{rpm}$; NPSHR is a characteristic of pump design and is the net positive suction head necessary to avoid cavitation in the pump. To use Fig. 7-11, find the range of NPSHR corresponding to $7000 \leqslant \mathrm{~N}_{S} \leqslant 10,000$ at design capacity Q. For a viable pump selection, NPSHA should exceed NPSHR by at least 2 or $3 \mathrm{ft}$ to provide a margin of safety. If the value of NPSHR is lower than the value of NPSHA, or unreasonably high, the designer should select a different pump speed or consider double-suction pumps and develop another preliminary pump design.

At this point, pump manufacturers' catalogs can be scrutinized for pumps closely matching the required values of $\mathrm{N}_{S}, D, Q, H$, and NPSHR that are also suitable for the fluids and temperature that will be encountered in the system. When a candidate pump is selected, its performance curve should be compared with the system head-flow curve to ensure that it is appropriate for all 


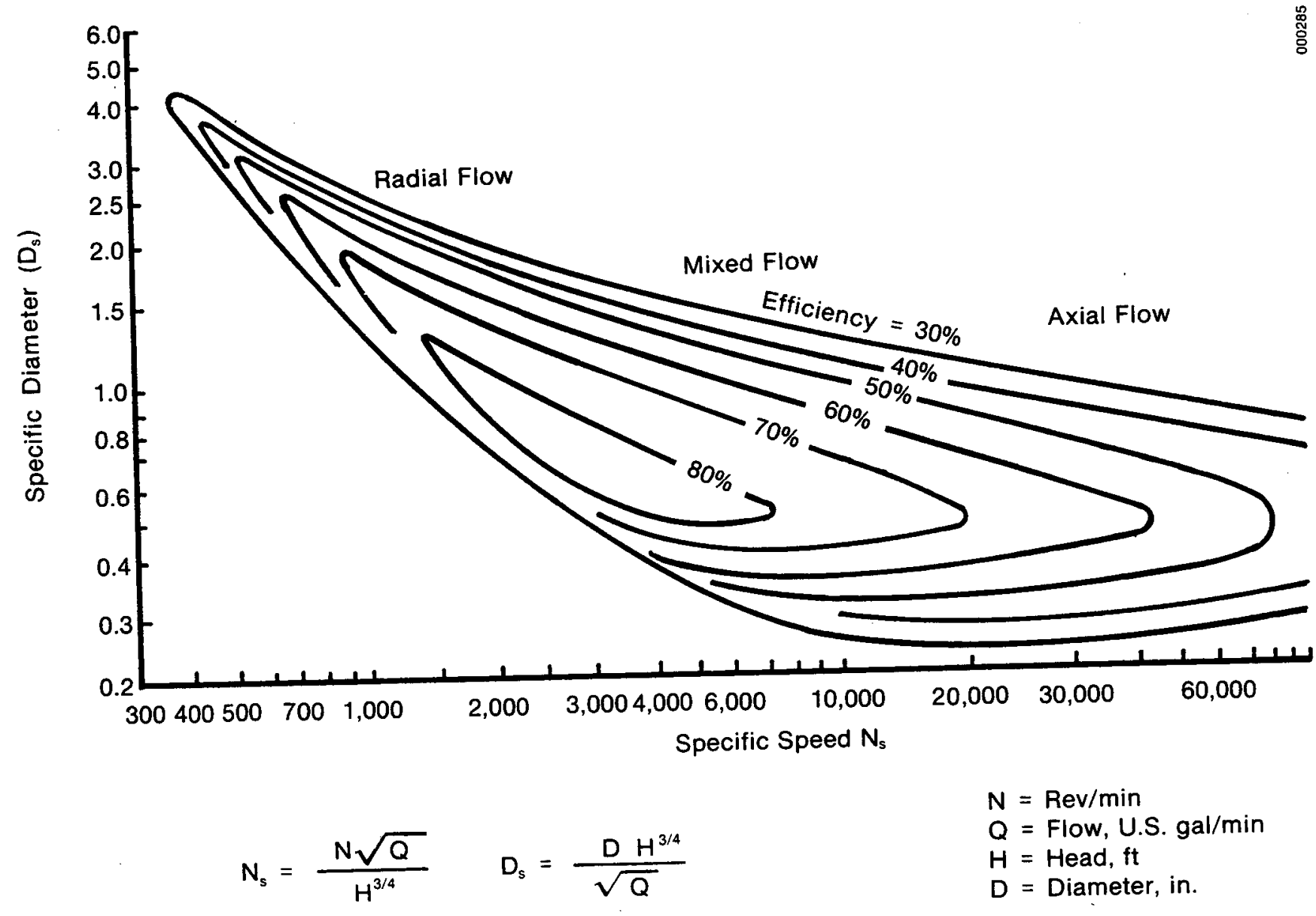

Figure 7-10. Selection Curves for a Centrifugal Pump 
Based on suction specific speed

$N_{s s}=\frac{N \sqrt{Q}}{H_{s} s^{3 / 4}} \quad N=$ rpm $Q=$ Flow, gpm $\quad H_{s}=N P S H$ required, $f t$

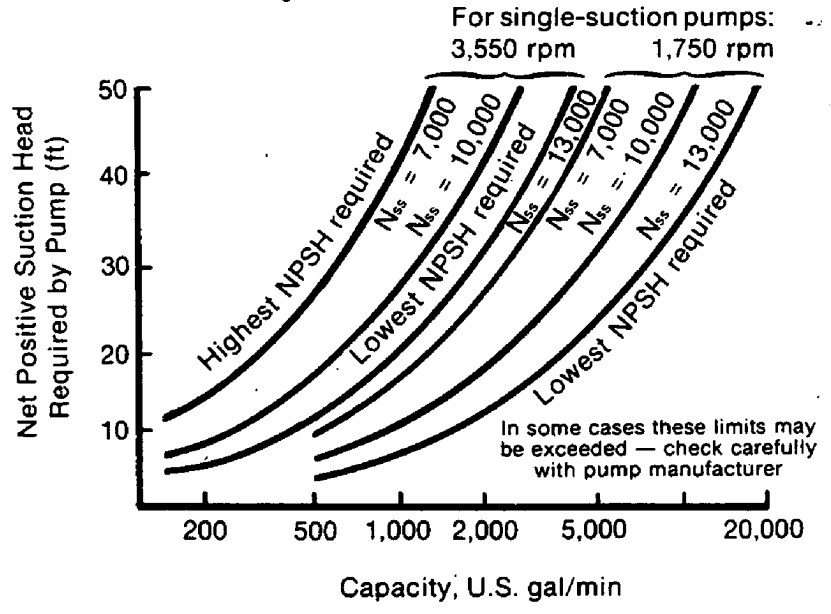

SOURCE: Neerken 1978

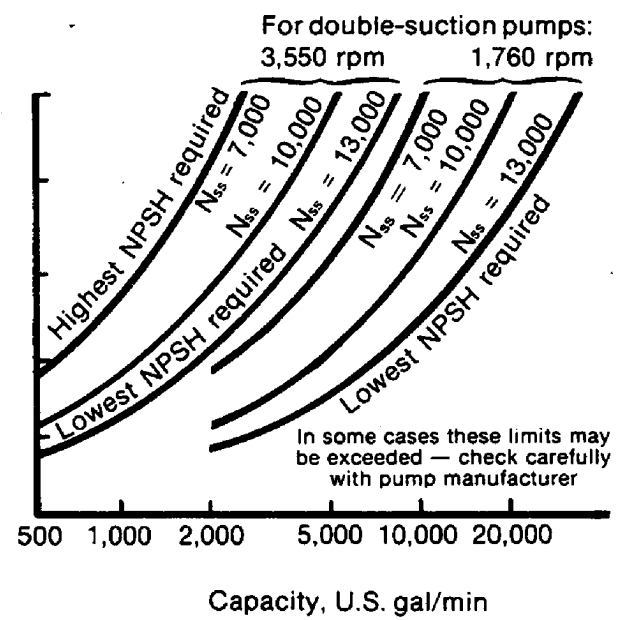

Capacity, U.S. gal/min

Figure 7-11. Net Positive Suction Head Required by Pump

conditions of operation. It is critical that the normal operation point (the intersection of the pump head-flow curve and the system normal operation curve) is near the "knee" of the pump curve, so that errors in estimating system head loss will cause little change in the flow rate. It is also important to make sure that the pump generates sufficient head and flow for all modes of system operation, especially cold start-up. Finally, a pump driver (usually electric) must be selected with adequate torque and power to drive the pump under all circumstances.

\subsubsection{Multispeed Centrifugal Pumps}

A designer may want to vary the flow rate from the collector pump for several reasons. For example, varying solar radiation requires a variable flow rate, if we want a constant collector array outlet temperature. For freeze protection by means of circulation, a lower flow rate might be desirable. Changes in fluid viscosity and density caused by temperature variations during system operation can lead to undesirable, uncontrolled flow-rate changes during the day. Typically, the flow from a single-speed pump is controlled by throttling down its outlet, although this procedure can lead to higher parasitic losses. An alternative is to use a variable-speed driver (Johnson 1981, Morton 1980).

Multispeed or variable-speed pumps, as their names imply, are driven at different speeds in response to changing $\mathrm{H}-\mathrm{Q}$ requirements. The effect of varying the speed of a typical pump may be seen in Fig. 7-9. And an interesting study 
by Morton (1980) compared the operating costs of a single-speed, a two-speed, and a variable-speed pump and electric driver in a $4650 \mathrm{~m}^{2}\left(50,000 \mathrm{ft}^{2}\right)$ collector field. The field produced $315^{\circ} \mathrm{C}\left(600^{\circ} \mathrm{F}\right)$ heat transfer oil at flow rates between $11.4 \mathrm{~m}^{3} / \mathrm{h}(50 \mathrm{gpm})$ and $68.1 \mathrm{~m}^{3} / \mathrm{h}(300 \mathrm{gpm})$. The resulting pump motor power requirements are shown in Fig. 7-12. Morton determined that the additional amortized capital cost of the variable-speed driver would be more than offset by the savings in required electrical energy, and so he chose the variable-speed pump for his application. Figure 7-13 relates capacity to NPSHR for variable-speed pumps for which water is the fluid. Methods for controlling flow rate to maintain a constant outlet temperature are discussed in Sec. 8.2 .1 .

Two or more single-speed pumps in parallel also represent a viable configuration for solar IPH systems. A large pump in parallel with a smaller pump is analogous to a single pump with three speeds; each pump can be operated alone or the two can be operated together. Such flexibility can significantly reduce parasitic power. When they are working together, both pumps operate against the same head but contribute only a portion of the total flow rate. An example $H-Q$ curve for parallel centrifugal pumps is shown in Fig. 7-14. However, the size difference between pumps mist not be so great that the smaller one cannot operate under the head produced by the larger.

\subsubsection{Positive Displacement Pumps}

As we noted in Fig. 7-8, positive displacement pumps come in three types: rotary, reciprocating, and controller volume. of these, the rotary types are probably best suited to IPH applications, because they are readily available

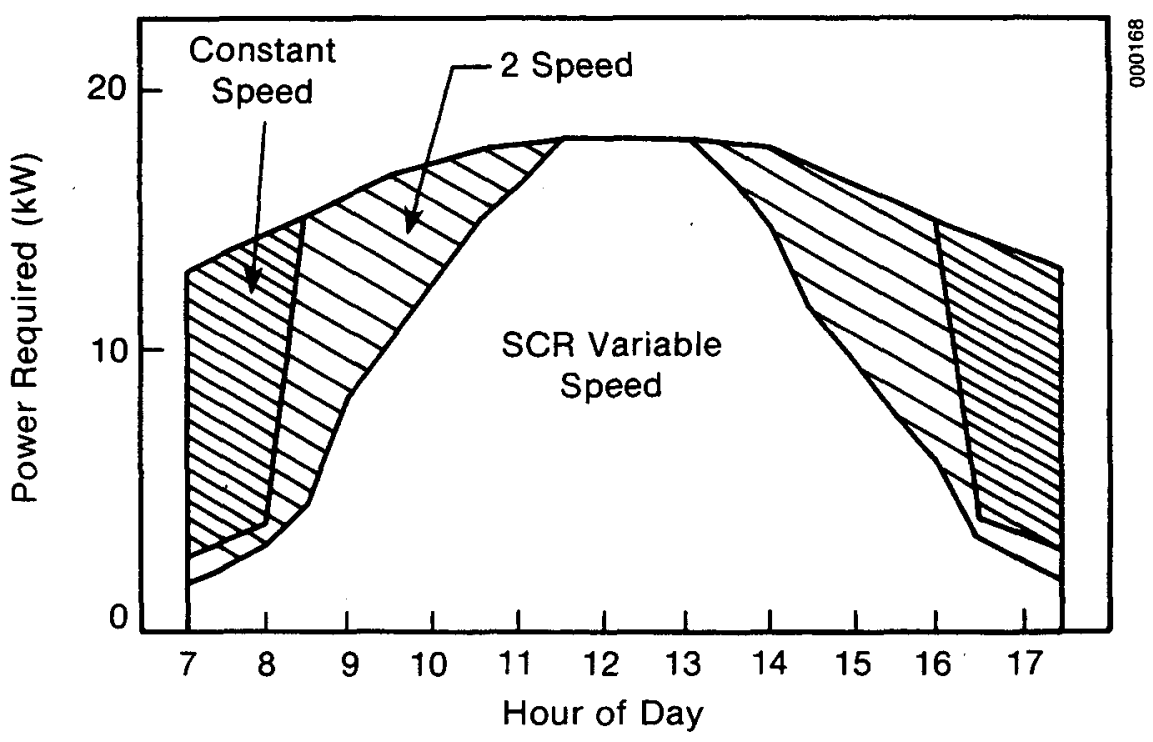

SOURCE: Morton 1980.

Figure 7-12. Pumping Power Required by Different Pump Configurations 


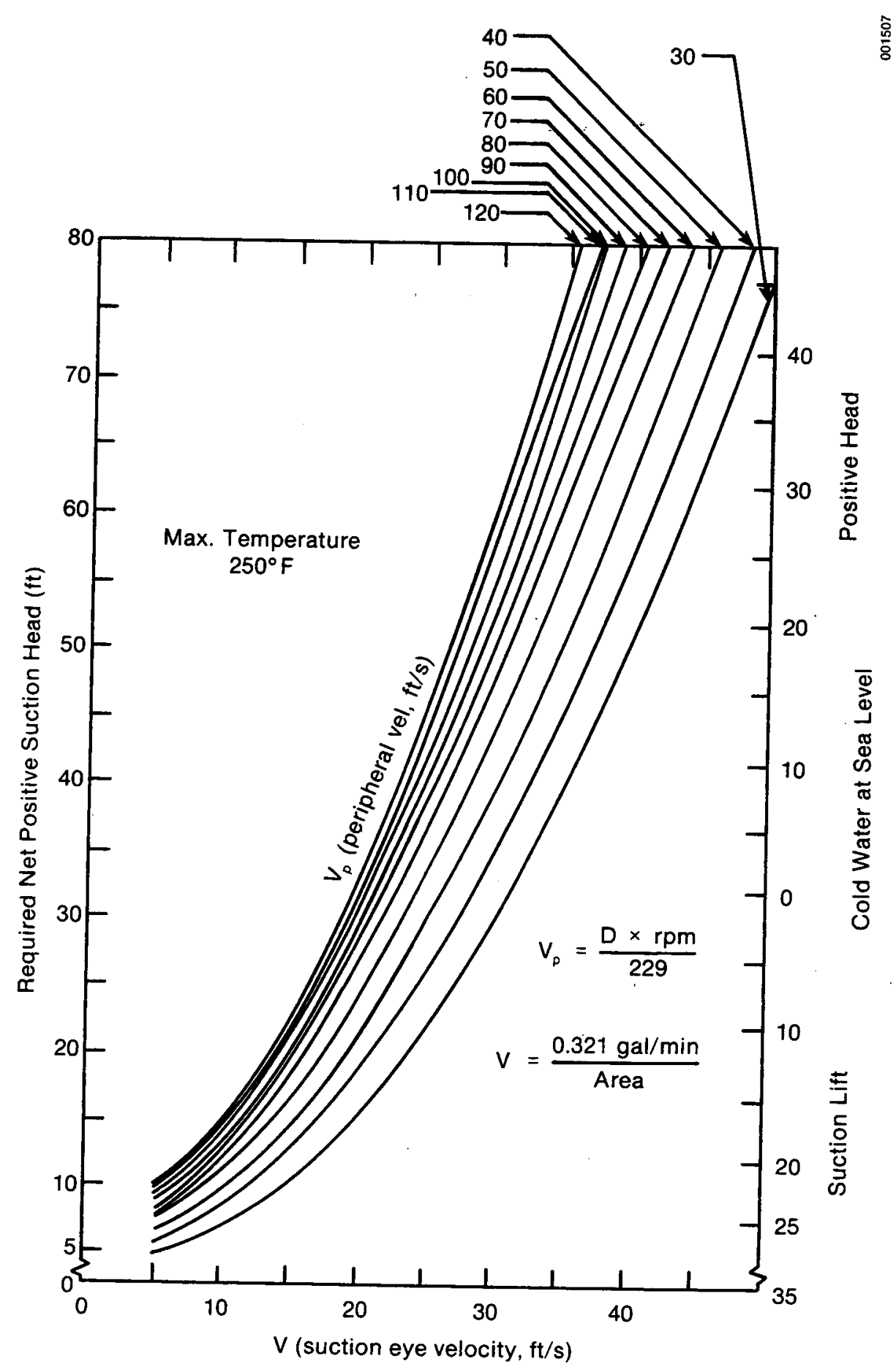

SOURCE: Lobanoff 1979.

Figure 7-13. Capacity vs. NPSHR for Variable-Speed Pumps 


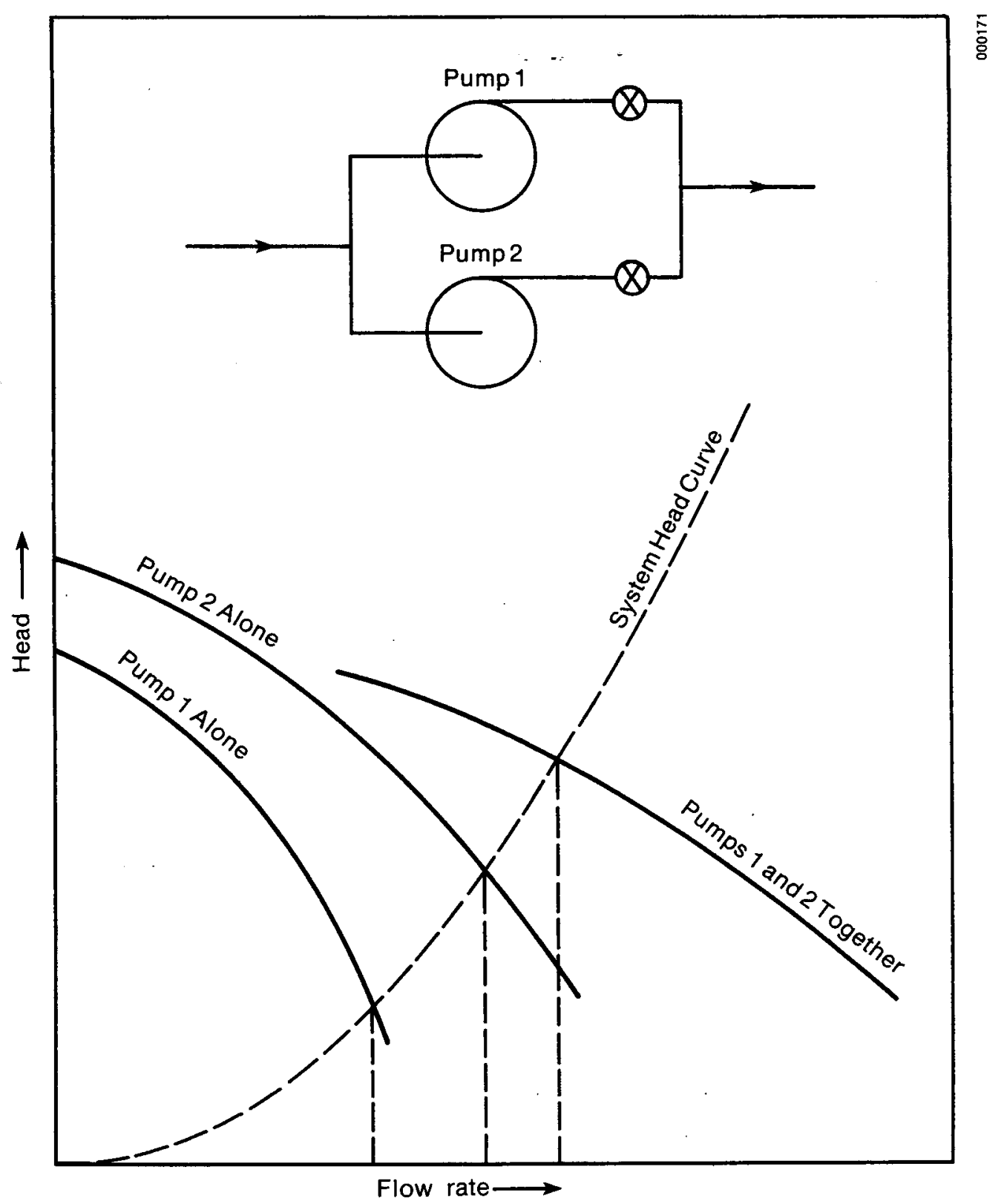

Figure 7-14. Head-Flow Curves for Two Centrifugal Pumps in Parallel 
in appropriate sizes, provide a smooth flow, and are relatively efficient. However, reciprocating or controller volume pumps may also be suitable for certain applications; for example, a diaphragm pump might be most appropriate for a fluid that tends to leak.

Several characteristics of positive displacement pumps make them attractive for solar IPH applications. They are often self-priming, reducing the suction head requirement in system design. The flow rate of a positive displacement pump is nearly proportional to its speed and insensitive to the head against which it must pump; thus, precise flow rate control and cold start-up, even with a viscous fluid, are not difficult. These pumps can be used in hightemperature applications, and have generally higher efficiencies than centrifugal pumps. They are also relatively inexpensive in small sizes compared with centrifugal pumps [less than about $6 \mathrm{~L} / \mathrm{s}$ (100 gpm)] and when used for highhead applications (Perry and Chilton 1973).

But other characteristics of positive displacement pumps may be less beneficial. Because of the close clearances needed for efficient pump operation, the fluid must be clean and nonabrasive. Many pumps require a fluid with good lubricating properties, since the fluid must lubricate internal bearings. Thus, pumps for water or other fluids with few lubricating qualities may have to be specially designed to ensure long life. The insensitivity of these pumps to the head against which they operate can cause a rapid, large pressure buildup at the pump outlet if flow is blocked. Pressure relief, valves are usually added to the pump casing to vent fluid from the outlet back to the suction side of the pump. However, if an overpressure condition is allowed to persist for any length of time, provision must be made for removing the excess heat or the pump will overheat. A system design employing a positive displacement pump must include protection for components and sensors against such overpressure conditions.

Selecting a positive displacement pump involves first determining the system head curves, the design flow rate and head loss, and NPSHA, the same as for a centrifugal pump system. Next, the manufacturers' literature must be scanned to find a pump that matches these requirements. As with a centrifugal pump, care must be taken to ensure that the pump will operate under all conditions and that the pump driver is adequate, especially in the case of a variablespeed system.

\subsection{VALVES}

\subsubsection{Characteristies of Solar Systems}

Valves regulate and isolate flow in a mechanical system. The number and kinds of valves for a solar system should be selected carefully because valves add to system cost and are sources of pressure drop and heat loss during operation and overnight cool-down. Some characteristics of solar systems, such as overnight shutdown, that provide daily intervals for maintenance, make fewer valves necessary in the system than for a conventional process plant. 
Solar systems that operate at low temperatures allow for great flexibility in the choice of valves. In addition, solar systems, particularly closed systems, usually do not operate at high pressures. Sealing pressures are low, and absolute shutoff is generally not necessary. Isolation valves would most often be closed only when the solar system is down and some amount of leakage would then be acceptable.

\subsubsection{Types of Valves}

With the proper seat elastomers, butterfly valves are operational at temperatures up to $135^{\circ} \mathrm{C}\left(275^{\circ} \mathrm{F}\right)$. Butterfly valves combine many attributes that are favorable to solar system applications: they are inexpensive, have low thermal mass, present 1ittle resistance to fluid flows, and are quick-acting, opening and closing over a one-quarter turn. These valves are a good choice for isolation or crude throttling in a low-temperature solar system. They are available in large diameters but generally not in sizes of less than 2 in. and should not be used when absolute shutoff is required.

With teflon seats, ball valves are suitable for service at temperatures up to $200^{\circ} \mathrm{C}\left(400^{\circ} \mathrm{F}\right)$. These valves are more expensive than butterfly valves, but they are also lightweight, compact, and quick-acting over a one-quarter turn. In addition, the straight-through flow characteristic of these valves minimizes pressure drop. They provide positive flow shutoff and can be used for flow throttling. In solar systems, they are a good choice for vent, drain, and flow-balancing valves. Ball valves come in sizes ranging from $1 / 4$ in. to over 12 in., with screwed or flanged fittings or connections suitable for soldering. Ball valves equipped with pressure taps simplify flow-balancing procedures.

In high-temperature solar systems, steel valves (or metal alloy, as required) must be used: gate valves for isolation and globe valves for throttling. Gate and globe valves are considerably more massive than butterfly or ball valves, and their stems provide a considerable surface for heat loss. Gate valves should be used only in the fully open or fully closed position. In the partially open position, the gate is subject to rapid wear and positive sealing is not possible. When it is fully open, however, a gate valve causes minimal pressure drop. Globe valves are always associated with a considerable pressure drop. Flow through the valve is almost proportional to the number of screw turns that the valve is open.

It is generally preferable to weld steel valves in place in a solar system, particularly when it is operating under high pressure or contains synthetic heat transfer oils. Compared with flanges and screwed fittings, welds are less massive, are leak free, have lower friction losses, and are more easily insulated. The disadvantage of welding, in addition to a generally higher initial cost, is the lack of flexibility that results in the piping system.

For example, a line cannot be broken for cleaning. Care must be taken not to gall the seat of welded-in-place valves because they are so difficult to replace.

Control valves are usually globe-type, although butterfly control valves with plastic or all-steel construction are available. Three-way control valves 
should be avoided, because field experience indicates that leaks into the shutoff line soon develop. Check valves are needed in nondraining solar collector loops to prevent thermosiphon heat loss, which could result in the heat exchanger freezing. They should be selected to minimize pressure drop, which usually requires the use of a swing check. A flow-through valve with a check that swings clear of the flow is preferred. Fluid velocities should be high enough to keep the check fully open at all times. Partial opening or fluttering will increase pressure drop and wear, and lead to less efficient sealing.

\subsubsection{Guidelines for Selecting Valves}

Solar system designs have been quite conservative in the past, employing a great number of isolation and throttling valves. This trend has also increased the chances for leakage and large thermal losses. Too few data are available to make definite rules about the placement and type of valves suitable for solar IPH systems; but the following guidelines, based on minimizing the number of valves, should be considered by the system designer.

Isolation valves should be placed around pumps, and butterfly valves should be used for temperatures of less than $135^{\circ} \mathrm{C}\left(275^{\circ} \mathrm{F}\right)$, if possible. A clear-away swing check valve should be located on the pump discharge between the isolation valves, and storage tanks and other vessels should be isolated with valves.

Ball valves should be used for vents and drains as well as to isolate instruments such as pressure and flow indicators. Ball valves are unsuitable only for the highest pressure steam flash systems and for systems using oil heat transfer fluids. If piping is sloped correctly with as few slope changes as possible, a minimum number of vent and drain valves can be located to serve large lengths of line.

Most of the valves in an industrial solar system are used for flow balancing and isolating individual rows of collectors. The block-in capability of each collector string invariably dictates placement of safety valves in each string, but this further increases thermal losses and makes fluid leaks more likely. Unless isolation capability is required for proper maintenance, however, omitting these valves should be seriously considered; they should not be necessary in an industrial solar system. While small leaks can be tolerated, large fluid leaks will shut down the entire collector field. But an ability to operate a portion of a collector field while the rest is shut down gains little energy, because maintenance can be performed at the end of each day. A good compromise for large collector fields is to provide isolation valves for various sections of the field. Eliminating isolation valves on each row allows the use of fewer safety valves, and these can be located in the header piping.

Flow equalization between individual collector strings is a major concern in solar system design. Flow equalization can be accomplished using reversereturn, multiple-diameter piping configurations, but this increases piping costs, thermal losses, and pumping power requirements. An alternative is to use balancing valves to achieve sufficient pressure loss across each collector string to eliminate the effect of pressure drops along the header piping. These balancing valves can be located at either the inlet or outlet of the 
collector. An outlet location can be more convenient for making adjustments, because this is where the temperature reading will be taken. In any case, however, balancing flows with valves is a time-consuming process. Valve settings change easily over time, as the valves wear or through accidental interference. An alternative to using conventional valves for flow balancing is to use automatic variable-orifice valves. These valves are designed to control the flow rate to within $5 \%$ over the desired range of operating pressure drop.

Another alternative is to use fixed-orifice plates instead of valves to induce the needed pressure differential in combination with appropriate pipe sizing. Orifice plates are cheaper, more reliable, and result in less thermal loss than valves. Although perfect flow balancing using orifice plates requires an extremely detailed pressure analysis of the piping system, this is not necessary because a small degree of liquid maldistribution has little effect on system performance. In an oil system operating close to the temperature limit of the oil, or a flash-steam system operating near the pressure limitation of the collectors, maintaining flow equality could be more crucial. If collector outlet temperatures indicate serious maldistribution of flow, it is possible to change the orifice plate to a different diameter, although the effect of this procedure on pump performance and overall flow rate must be considered.

Control valves are required in an IPH solar system in which control of the collector outlet temperature is desired. Butterfly control valves are, again, particularly suitable here and have been advocated for more demanding process applications (Baumann 1979). Since few control valves are likely to be employed in the solar site, and they could be widely scattered and remote from the system control station, electrical activators should be considered. Pneumatic systems with a compressor and large lengths of piping are not as economical for the small number of valves involved, and pneumatic leaks are bothersome.

\subsection{HEAT EXCHANGERS}

Often, process fluid should not pass directly through the collector field; thus, many solar applications require heat exchangers. A closed-loop solar system allows the use of nonfreezing collector fluids that are less corrosive and less prone to scaling than the process fluid. Possible contamination of the process fluid is another factor to take into account in selecting a closed-1oop system. However, incorporating a heat exchanger in a solar system introduces cost penalties associated with that exchanger and with auxiliary piping; and the performance of the solar system is reduced by virtue of the increased operating temperature of the collector system working fluid. Another penalty is the result of the greater pumping power needed because of the increase in system pressure drop and the need for an additional pump. Thus, the objective in designing an exchanger for a solar IPH application is to size the exchanger so that performance and pumping power penalties and heat exchanger costs are minimized.

\subsubsection{Heat Transfer Relations}

For the system illustrated in Fig. 7-15, the heat transferred across the heat exchanger $Q$ in watts $(B t u / h)$ is 


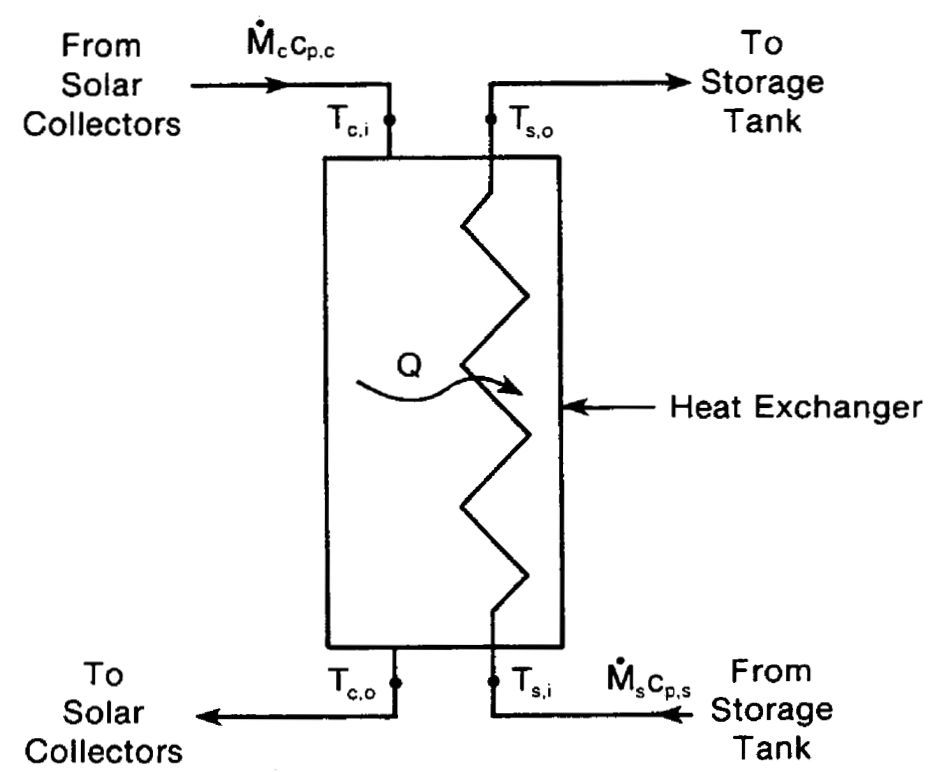

Figure 7-15. Example Heat Exchanger System

$$
\dot{Q}=\dot{M}_{c} c_{p, c}\left(T_{c, i}-T_{c, o}\right)=\dot{M}_{s} c_{p, s}\left(T_{s, o}-T_{s, i}\right),
$$

where $\dot{M}_{c}$ and $\dot{M}_{s}$ are flow rates $(\mathrm{kg} / \mathrm{s}, 1 \mathrm{~b} / \mathrm{h})$ and $c_{p, c}$ and $c_{p, s}$ are specific heats $\left(\mathrm{J} / \mathrm{kg} \mathrm{K}, \mathrm{Btu} / 1 \mathrm{~b}^{\circ} \mathrm{F}\right.$ ) of the collector and storage fluids, respectively. It is convenient to define the capacity rate $W\left(W / K, B t u / h^{\circ} F\right)$ for each fluid as

$$
\begin{aligned}
& \mathrm{w}_{\mathrm{c}}=\dot{\mathrm{M}}_{\mathrm{c}} c_{\mathrm{p}, \mathrm{c}}, \\
& \mathrm{w}_{\mathrm{s}}=\dot{\mathrm{M}}_{\mathrm{s}} c_{\mathrm{p}, \mathrm{s}} .
\end{aligned}
$$

In a heat exchanger of infinite area, the heat transferred would be at a maximum and would be

$$
\dot{Q}_{\max }=W_{\min }\left(T_{c, i}-T_{s, i}\right),
$$

where $\mathrm{W}_{\min }$ is the smaller of $\mathrm{W}_{\mathrm{c}}$ and $\mathrm{w}_{\mathrm{s}}$.

Heat exchanger effectiveness $\varepsilon$ is defined as

$$
\varepsilon=\dot{Q} / \dot{Q}_{\max },
$$

and, thus,

and

$$
\varepsilon=\frac{T_{c, i}-T_{c, o}}{T_{c, i}-T_{s, i}} \text { when } W_{c}<W_{S} \text {, }
$$




$$
\varepsilon=\frac{T_{S, 0}-T_{S, i}}{T_{c, i}-T_{S, i}} \text { when } W_{c}>W_{S}
$$

\subsubsection{Overall Heat Transfer Coefficient}

The heat transferred between fluids within a counterflow heat exchanger with constant fluid specific heats is given as

$$
\dot{\mathrm{Q}}=\mathrm{UA \Delta} \Delta \mathrm{T}_{\mathrm{LM}} \text {, }
$$

where $\mathrm{W}$ is the overall heat transfer coefficient between the fluids $\left(\mathrm{W} / \mathrm{m}^{2} \mathrm{~K}\right.$,

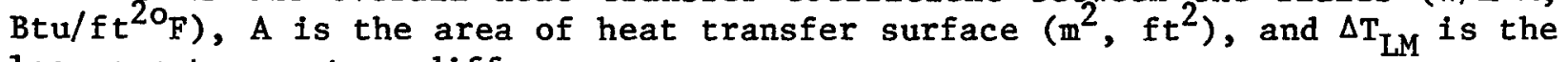
log mean temperature difference:

$$
\Delta T_{L M}=\frac{\left(T_{c, i}-T_{s, o}\right)-\left(T_{c, 0}-T_{S, i}\right)}{\ln \left(\frac{T_{c, i}-T_{s, 0}}{T_{c, o}-T_{s, i}}\right)} .
$$

Typical values for overall heat transfer coefficients for some of the fluids likely to be encountered in a solar system are shown in Table 7-12. If greater accuracy is required to size the heat exchanger, the following simplified procedure can be employed. (More detailed procedures that take into account the physical characteristics of the heat exchanger are employed by heat exchanger suppliers, but are not required for the initial stage of design.)

The overall heat transfer coefficient is generally based upon the exterior tube surface and can be defined as

$$
\mathrm{U}_{\mathrm{o}}=1 / \mathrm{R}_{\mathrm{T}}
$$

where $R_{T}$ is the total resistance to heat transfer. The resistances to heat transfer are in series, so that

$$
\begin{aligned}
R_{T} & =R_{i}+R_{f, i}+R_{w}+R_{f, o}+R_{o} \\
& =\frac{D_{o}}{h_{i} D_{i}}+\frac{R_{f, i} D_{o}}{D_{i}}+\frac{D_{o}}{2 k_{t}} \ln \frac{D_{o}}{D_{i}}+R_{f, o}+\frac{1}{h_{o}},
\end{aligned}
$$

Table 7-12. Typical Overall Heat Transfer Coefficient Values for Tubular Heat Exchangers

\begin{tabular}{lcc}
\hline $\begin{array}{c}\text { Tube-Side } \\
\text { Fluid }\end{array}$ & $\begin{array}{c}\text { Shell-Side } \\
\text { Fluid }\end{array}$ & $\begin{array}{c}\text { Overall Heat Transfer } \\
\text { Coefficient }\left[\mathrm{W} / \mathrm{m}^{2} \mathrm{~K}\left(\mathrm{Btu} / \mathrm{h}-\mathrm{ft} \mathrm{t}^{2}-{ }^{\circ} \mathrm{F}\right)\right]\end{array}$ \\
\hline Water & Water & $1140-1420(200-250)$ \\
Water & Demineralized water & $1700-2840(300-500)$ \\
Feed water & Steam & $2270-5680(400-1000)$ \\
Heat transfer fluid & Boiling water & $570-850(100-150)$ \\
Water & Air & $114-142(20-25)$ \\
\hline
\end{tabular}


where $D_{0}$ and $D_{i}$ are the outside and inside tube diameters (m,ft), respectively; $k_{t}$ is the thermal conductivity of the tube material (W/m-K, $\mathrm{Btu} / \mathrm{h}-\mathrm{ft} \mathrm{O}_{2 \mathrm{~F}}$; $\mathrm{h}_{\mathrm{o}}$ and $\mathrm{h}_{i}$ are the outside and inside film coefficients (W/m $\mathrm{m}^{2} \mathrm{~K}$, $\mathrm{Btu} / \mathrm{h}-\mathrm{ft} \mathrm{t}^{2 \mathrm{o}} \mathrm{F}$ ), respectively; and $R_{f, \rho}$ and $R_{f, i}$ are the outside and inside fouling resistances $\left(\mathrm{m}^{2} \mathrm{~K} / \mathrm{W}, \mathrm{h}^{\circ} \mathrm{Fft}^{2} / \mathrm{Bt} \dot{\mathrm{u}}\right)$, respectively. The fouling resistances account for the reduced heat transfer efficiency caused by scaling. Typicai values for fouling resistances are listed in Table 7-13. In general, fouling in the solar collector side of the exchanger should be minimal, and the collector working fluid should be selected to minimize scaling. Scaling on the process side could be much greater, depending on the characteristics of the process fluid.

The thermal conductivity of the tube material is readily obtainable. Typical materials are steel $\left(142 \mathrm{~W} / \mathrm{m}-\mathrm{K}, 25 \mathrm{Btu} / \mathrm{h}-\mathrm{ft}^{\circ} \mathrm{F}\right)$ and brass $(340 \mathrm{~W} / \mathrm{m}-\mathrm{K}$, $\left.60 \mathrm{Btu} / \mathrm{h}-\mathrm{ft} \mathrm{O}^{\circ} \mathrm{F}\right)$. The remaining unknowns in Eq. 7-45 are the film coefficients.

The inside heat transfer coefficient can be calculated using the DittusBoelter (1930) equation:

$$
\mathrm{Nu}_{i}=0.023 \operatorname{Re}_{i}^{0.8} \operatorname{Pr}_{i}{ }^{\mathrm{n}},
$$

where

$$
\begin{aligned}
\mathrm{Nu}_{i} & =\text { Nusselt number }\left(\mathrm{h}_{i} D_{i} / k_{i}\right) \\
\operatorname{Re}_{i} & =\text { Reynolds number }\left(\rho_{i} D_{i} V_{i} / \mu_{i}\right) \\
\operatorname{Pr}_{i} & =\text { Prandt } 1 \text { number }\left(c_{p, i} \mu_{i} / k_{i}\right) \\
n & =0.4 \text { for heating the fluid, } 0.3 \text { for cooling the fluid. }
\end{aligned}
$$

The dimensionless numbers are calculated using fluid properties evaluated at the mean operating temperature:

$$
\begin{aligned}
& \rho_{i}=\text { is the density of the fluid inside the tubes }\left(\mathrm{kg} / \mathrm{m}^{3}, 1 \mathrm{~b} / \mathrm{ft}^{3}\right) \\
& v_{i}=\text { the fluid velocity }(\mathrm{m} / \mathrm{s}, \mathrm{ft} / \mathrm{s}), \text { and } \\
& \mu_{i}=\text { the viscosity }(\mathrm{kg} / \mathrm{m}-\mathrm{s} 1 \mathrm{~b} / \mathrm{ft}-\mathrm{h}) .
\end{aligned}
$$

Table 7-13. Typical Fouling Resistances

\begin{tabular}{lc}
\hline Type of Fluid & $\begin{array}{l}\text { Fouling Resistance } \\
\times 0^{-5} \mathrm{C} \mathrm{m} / \mathrm{W}\left({ }^{\circ} \mathrm{F} \mathrm{ft} / \mathrm{htu}\right)\end{array}$ \\
\hline Distilled water & $8.8(0.0005)$ \\
Treated boiler feed water & $17.6(0.001)$ \\
City water below $52^{\circ} \mathrm{C}$ & $17.6(0.001)$ \\
City water above $52^{\circ} \mathrm{C}$ & $35.2(0.002)$ \\
Heat transfer media & $17.6(0.001)$ \\
Refrigerant 1iquids & $17.6(0.001)$ \\
Industrial air & $35.2(0.002)$ \\
\hline
\end{tabular}


The Dittus-Boelter equation assumes turbulent flow within the tubes ( $\operatorname{Re}>$ 10,000). Establishing turbulent flow conditions should be a requirement for a solar heat exchanger design, because heat transfer under laminar or transition flow is much less efficient. In industrial solar systems, the use of forced convective heat transfer equipment is assumed. Natural convective heat transfer is inefficient; placing exchanger coils within a heat storage tank would cause maintenance problems. The procedure described by Cole et al. (1980) can be used to determine the she11-side heat transfer coefficient. A similar Nusselt number relation is used to correlate the film coefficient,

$$
h_{0}=0.33 \frac{k_{0}}{D_{0}} \operatorname{Pr}^{0.33} \operatorname{Re}_{0}^{0.6} \text {, }
$$

where

$$
\begin{aligned}
\operatorname{Re}_{0} & =\frac{\dot{\mathrm{m}}_{\mathrm{o}} \mathrm{D}_{\mathrm{o}}}{\mu_{\mathrm{o}} \mathrm{A}_{\mathrm{min}}\left(\mathrm{n}_{\mathrm{row}}+\mathrm{I}\right)} \\
\operatorname{Pr}_{\mathrm{o}} & =\frac{\mathrm{c}_{\mathrm{po}} \mu_{\mathrm{o}}}{\mu_{\mathrm{o}}} \\
\mathrm{A}_{\text {min }} & =\mathrm{S}_{\text {baf }} S_{\text {min }},
\end{aligned}
$$

and

$$
\begin{aligned}
& \dot{\mathrm{m}}_{\mathrm{O}}=\text { the shell-side mass flow rate }(\mathrm{kg} / \mathrm{s}, 1 \mathrm{~b} / \mathrm{h}) \\
& \mathrm{n}_{\text {row }}=\text { the number of tube rows across the diameter of the shell } \\
& \mathrm{s}_{\text {baf }}=\text { the baffle spacing }(\mathrm{m}, \mathrm{ft}) \text { in the longitudinal direction along the } \\
& \quad \text { exchanger } \\
& \mathrm{s}_{\text {min }}=\text { the minimum spacing between tubes }(\mathrm{m}, \mathrm{ft}) \\
& \mathrm{A}_{\min }=\text { the minimum cross-sectional area between the tubes. }
\end{aligned}
$$

After calculating the fluid film coefficients, the overall heat transfer coefficient can be calculated using Eqs. 7-44 and 7-45. The effectiveness of a counterflow heat exchanger is related to the overall heat transfer coefficient by

$$
\varepsilon=\frac{1-\exp (-B)}{1-\frac{W_{\min }}{W_{\max }} \exp (-B)} \text {, }
$$

where

$$
\begin{aligned}
\mathrm{B} & =\mathrm{U}_{\mathrm{O}} \mathrm{A}_{X}\left(\frac{1}{\mathrm{~W}_{\min }}-\frac{1}{\mathrm{~W}_{\max }}\right) \\
& =\mathrm{NTU}\left(1-\frac{\mathrm{W}_{\min }}{\mathrm{W}_{\max }}\right) .
\end{aligned}
$$

The number of heat transfer units, NTU $=U_{0} A_{x} / W_{\min }$, is a dimensionless measure of the adequacy of heat exchanger area. For proper heat exchange, NTU will 
generally be in the range of 1 to 10 (Lunde 1980). Equation 7-48 can be solved for $\varepsilon$ when a heat exchange area must be found for a particular effectiveness.

$$
\left.\operatorname{NTU}=\frac{U_{0} A_{x}}{W_{\min }}=\frac{\ln \left(\frac{1-\varepsilon W_{\min } / W_{\max }}{1-\varepsilon}\right)}{\left(1-W_{\min } / W_{\max }\right.}\right)
$$

When the flow capacity rates on both sides of the exchanger are equal, Eq. 7-48 becomes

$$
\varepsilon=\frac{\mathrm{NTU}}{1+\mathrm{NTU}}
$$

\subsubsection{Heat Exchanger Factor for Solar System Performance}

The following analysis applies to the collector system illustrated in Fig. 4-4. It describes a factor that can account analytically for the presence of the heat exchanger between the collectors and storage. The basic collector performance equation can be written as

$$
\frac{\dot{Q}}{A_{C}}=F_{R} \tau \alpha I-F_{R} U_{L}\left(T_{1}-T_{a}\right)
$$

where

$$
\begin{aligned}
& A_{C}=\text { collector aperture area }\left(\mathrm{m}^{2}, \mathrm{ft}^{2}\right) \\
& \mathrm{F}_{\mathrm{R}}=\text { heat transfer factor based on collector inlet temperature } \\
& \tau \alpha=\text { collector optical efficiency } \\
& \mathrm{U}_{\mathrm{L}}=\text { overall heat transfer coefficient for heat loss from the collec- } \\
& \quad \text { tor }\left(\mathrm{W} / \mathrm{m}^{2} \mathrm{~K}, \text { Btu } / \mathrm{h}-\mathrm{ft} \mathrm{t}^{\left.2 \mathrm{O}_{\mathrm{F}}\right)}\right.
\end{aligned}
$$

Rearranging Eq. 7-35 and assuming that line losses in the collector loop are negligible (i.e., $T_{i}=T_{c, o}$ and $T_{o}=T_{c, i}$ ), then

$$
\mathrm{T}_{1}=\mathrm{T}_{\mathrm{o}}-\frac{\dot{\mathrm{Q}}}{\mathrm{W}_{\mathrm{c}}} .
$$

Substituting this equation into $\mathrm{Eq} \cdot 7-51$ yields

$$
\frac{\dot{Q}}{A_{c}}=\frac{F_{R} \tau \alpha I-F_{R} U_{L}\left(T_{o}-T_{a}\right)}{1-\frac{F_{R} U_{L} A_{c}}{W_{c}}} .
$$


Using Eqs. 7-40 and 7-41 and assuming a well-mixed storage tank, $T_{S, i}=T_{s}$, a general expression for the heat transferred can be derived:

$$
\frac{\dot{Q}}{A_{C}}=\frac{F_{R}^{\tau \alpha I}-F_{R} U_{L}\left(T_{s}-T_{a}\right)}{1+\frac{F_{R}^{U_{L} A_{C}}}{W_{C}}\left(\frac{W_{C}}{\varepsilon W_{\text {min }}}-1\right)} .
$$

The expression

$$
F_{X}=\frac{1}{1+\frac{F_{R} U_{L} A_{C}}{W_{C}}\left(\frac{W_{C}}{\varepsilon W_{\text {min }}}-1\right)}
$$

is known as the deWinter heat exchanger factor (deWinter 1975). Thus, $F_{x}$ represents the penalty imposed on an open-loop system, where $T_{s}$ would equal $T_{i}$, by the incorporation of the heat exchanger to form the double-1oop configuration shown in Fig. 4-6.

The performance of flat-plate collectors is generally categorized in terms of the collector inlet temperature. Parabolic trough performance is often correlated in terms of the collector outlet temperature or the average of the inlet and outlet temperatures. The heat exchanger factor $F_{x, 0}$ for a collector performance equation in terms of the outlet temperature $T_{0}$, is

$$
\mathrm{F}_{\mathrm{X}, 0}=\frac{1}{1+\frac{\mathrm{F}_{\mathrm{o}} \mathrm{U}_{\mathrm{L}} \mathrm{A}_{\mathrm{c}}}{\varepsilon \mathrm{W}_{\min }}},
$$

where $F_{0}$ is the heat transfer factor based upon the collector outlet temperature. The heat exchanger factor $\mathrm{F}_{x, m}$, in terms of the average collector operating temperature $T_{m}$, is

$$
F_{x, m}=\frac{1}{\left(1+\frac{F_{m} U_{L} A_{c}}{W_{\min }}\right)\left(\frac{1}{\varepsilon}-\frac{W_{\text {min }}}{2 W_{c}}\right)} .
$$

The performance curve of a parabolic trough collector is generally presented as a quadratic function of $\Delta T / I$, unlike flat-plate collectors whose performance curves are linearized. Consequently, for a parabolic trough collector, an appropriate operating temperature (whether inlet, average, or outlet) must be selected. Given this temperature, the term $F_{R} U_{L}, F_{o} U_{L}$, or $F_{m} U_{L}$ can be determined by evaluating the slope of the performance curve at this point. Selecting the appropriate operating temperature involves a judgment based on the nature of the solar heating process, the storage temperature, and the variations likely in collector temperatures. In any case, given that the performance curve of a line-focus collector is fairly flat over a wide temperature range, the operating temperature selection is not critical. An overestimate of temperature is conservative, leading to an increased value of $\mathrm{FU}_{\mathrm{L}}$ and a larger heat exchanger. 


\subsubsection{Economical Heat Exchanger Area}

The foregoing analysis indicates that a heat exchanger reduces the performance of the solar system by a constant factor $F_{x^{*}}$. Thus, to meet a given load, the collector area must be increased in inverse proportion to $F_{X}$. For economical heat exchanger sizing, the heat exchanger factor typically has a value of about 0.95. Such information can be used for preliminary heat exchanger sizing by solving Eq. 7-55, 7-56, or 7-57 for $\varepsilon$. The heat exchanger area can then be calculated using Eq. 7-49.

The optimum heat exchanger area represents a trade-off between the cost of the heat exchanger and the cost of the solar collectors. The total system cost $C_{T}$ can be represented by

$$
\mathrm{C}_{\mathrm{T}}=\mathrm{A}_{\mathrm{c}} \mathrm{C}_{\mathrm{c}}+\mathrm{A}_{\mathrm{x}} \mathrm{C}_{\mathrm{x}} \text {, }
$$

where $C_{c}$ and $C_{x}$ are the costs of the collectors and heat exchanger per unit area, respectively, and $A_{c}$ and $A_{x}$ are their respective areas. The energy delivered by the system is

$$
\dot{Q}=A_{c} F_{X}\left[F \tau \alpha I-F_{L}\left(T_{s}-T_{a}\right)\right],
$$

where $F$ is $F_{R}, F_{0}$, or $F_{m}$. The minimum cost of delivered energy with respect to exchanger surface area is

$$
\frac{\mathrm{d}}{\mathrm{dA}_{\mathrm{X}}}\left(\frac{C_{\mathrm{T}}}{\mathrm{Q}}\right)=0
$$

For equal flow capacity rates $\left(W_{c}=W_{s}\right)$, and assuming that the overall heat transfer coefficient $U_{0}$ does not vary with $A_{x}$, the optimum (minimum cost) ratio $A_{x} / A_{c}$ is

$$
\frac{A_{x}}{A_{C}}=\left(\frac{F_{U_{L} C_{C}}}{U_{O} C_{x}}\right)^{1 / 2} .
$$

According to Horel and deWinter (Cole et al. 1979), the optimum heat exchanger invariably has a storage capacity rate $W_{s}$ higher than its collector capacity rate $W_{c}$. They found that the ratio $W_{c} / W_{s}$ for the optimum exchanger is 0.5 to 0.6 , and that Eq. 7-61 can still be used to find the optimum heat exchanger area because that value varies from the value determined in the optimum (unmatched capacity rate) case by about $1 \%$. The optimum storage capacity rate is generally greater than the collector capacity rate because of the effect of the individual flows on collector operating temperature. Increasing the storage flow rate has a greater effect on reducing collector inlet temperature (and thus the temperature of the entire collector field) than an equivalent increase in the collector flow rate. Increasing the storage flow rate would result in less of an increase in electric power consumption than an equal increase in collector flow, because the pressure drop through the collector loop is usually larger. 


\subsubsection{Practical Considerations in Selecting a Heat Bxchanger}

In previous sections, heat exchanger sizing has been discussed in terms of perfect countercurrent flow. Such conditions are attainable only in doublepipe exchangers that are generally economical only in small sizes. Shell-andtube heat exchangers accommodate large heat exchanger areas in a compact volume. A diagram of a floating tubesheet she11-and-tube heat exchanger is shown in Fig. 7-16. Since steel shell-and-tubes are the most economical type of heat exchanger, they are the most likely kind to be incorporated into a solar IPH system. This section presents some of the practical aspects of selecting a heat exchanger. Operating experience with heat exchanger systems in industrial solar systems is limited. Consequently, only some general points about heat exchangers are incorporated here and tend toward a rather conservative exchanger design.

A major variable in a shell-and-tube heat exchanger is the number of shellside and tube-side passes; i.e., the number of times the fluid changes direction from one end of the exchanger to the other. Because some means must be built into the exchanger to compensate for thermal expansion, flows into and out of the tube side are generally at the same end of the exchanger. Thus, normally, the number of tube-side passes is even. By appropriate baffling it is easy to produce two, four, or more tube passes. However, the greater the number of passes, the greater the deviation from countercurrent flow, the greater the path length, and hence, the greater the pressure drop of the tubeside fluid.

A single shell pass is the most common shell-side configuration because of the difficulty of adequately sealing a multi-shell pass exchanger. The effect of multiple shell-side passes can be achieved by connecting identical single-pass exchangers in series. Because multiple-pass heat exchangers are not associated with perfect countercurrent flow, correction factors must be applied to the log mean temperature differential. Such correction factors are available from graphs (Kreith 1973, Perry and Chilton 1973).

The unique characteristics of a solar system must be considered in determining the number of exchanger passes. In general, compared with conventional thermal processes, a solar system involves larger flows and smaller temperature differentials. Because solar collector performance depends more on operating temperature than conventional heating equipment does, a closer similarity between the hot side (collector) and cold side (process) temperatures is desirable. This demands maximum heat exchanger efficiency and a minimum number of heat exchanger passes. Other considerations working in this direction are pumping power and thermal losses (both operational and overnight). Thus, as a general rule, unless a large mismatch of flows precludes it, a two-tube, single-shell pass exchanger is probably the most appropriate configuration for a solar system.

The designation of tube-side and shell-side fluids is another, largely practical, decision that must be made. It is more difficult to clean the shell side of an exchanger than the tube side, so a dirty, scaling, or corrosive fluid is generally placed on the tube side. A great difference in operating pressure would place the high-pressure fluid in the tubes. Placing the hottest fluid in the tubes reduces insulation requirements on the exterior shell. Turbulence is more easily achieved on the shell side; thus, the fluid with poorer 


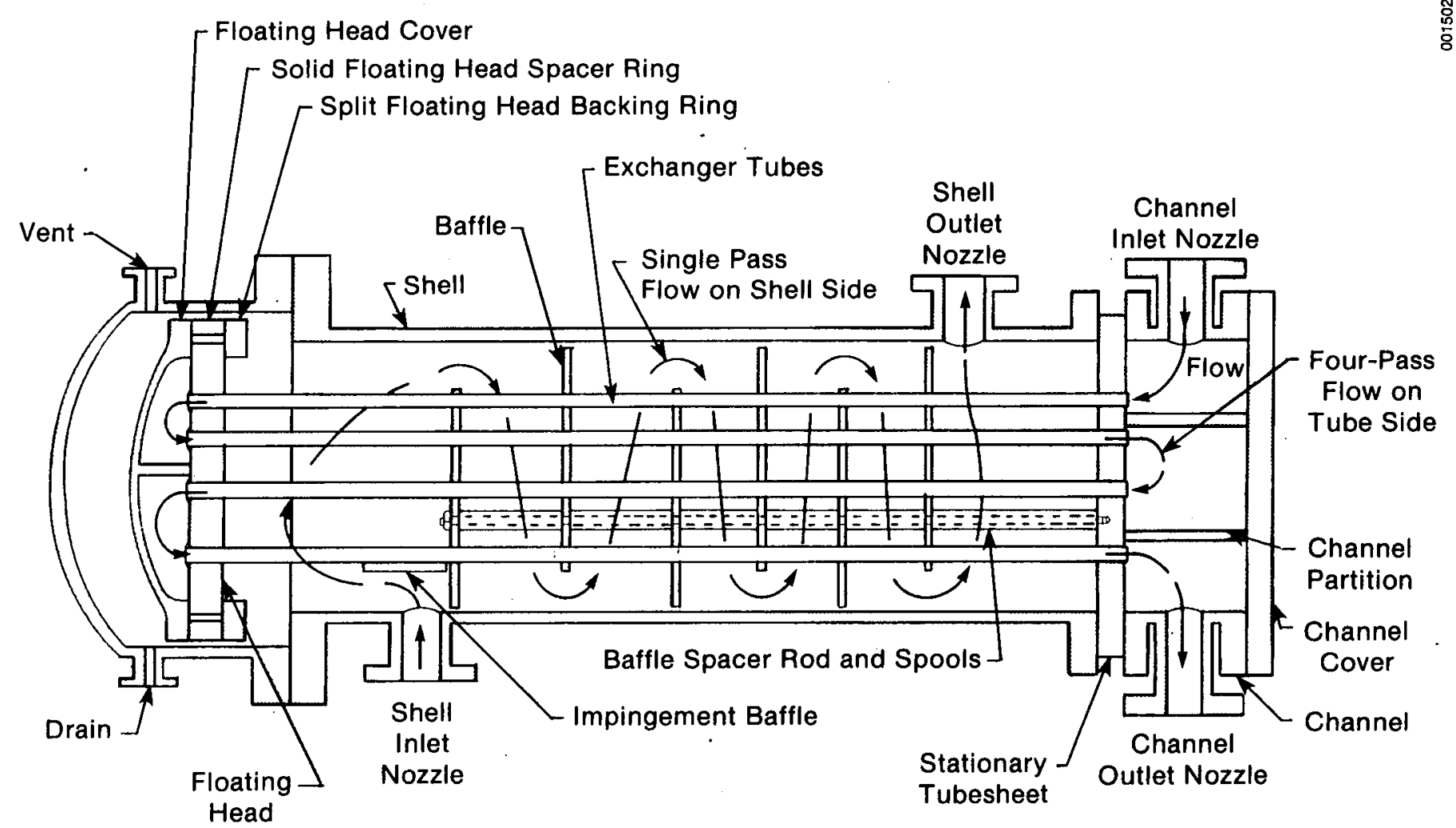

Figure 7-16. Floating Tubesheet She11-and-Tube Heat Exchanger 
heat transfer characteristics would be placed in the shell. She11-side pressure drop for a given flow is also generally lower. These characteristics of exchanger fluids are not entirely consistent in the choice of flow path, so engineering judgment must be used. Moreover, the cleaning and maintenance factor will often place the collector fluid in the exchanger shell.

Finally, with the help of the exchanger manufacturer, the type of exchanger must be specified. A major factor in this decision is the degree of differential thermal expansion and cycling. Fixed-tube sheet exchangers are usually less expensive, but the severe strains placed on the exchanger seals by the diurnal solar cycle must be fully considered. Hairpin exchangers readily accommodate thermal expansion but are difficult to clean and are often unsuitable for dirty or scaling fluids. They are, however, applicable in unfired steam generators with a heat transfer fluid in the tubes. Generally, 90:10 copper-nickel tubes are specified for such service.

For most solar energy systems, floating-head exchangers appear to be preferable. The tubes are easily cleaned without requiring removal of the tube bundle, and they are designed to accommodate thermal expansion. Although the operating pressure of a solar system is generally low, because of the high level of thermal cycling it is probably wise to specify a heat exchanger rating beyond that dictated by operating pressure alone.

Liquid-to-air exchangers invariably pass the air on the shell side. Since the air-side heat transfer coefficients are the major resistors to heat flow, extended surface-finned tubes are generally employed. Passing the air transverse to the tubes in a direction parallel to the fins results in little increase in shell-side pressure drop, but the air-side heat transfer coefficient typically increases two to three times.

\subsubsection{Plate Heat Exchangers}

Plate heat exchangers are ideally suited for certain solar applications and should also be considered. However, plate heat exchangers are not normally suitable for pressures exceeding $2.2 \mathrm{MPa}(300 \mathrm{psig})$, temperatures over $200^{\circ} \mathrm{C}$ $\left(400^{\circ} \mathrm{F}\right)$, or for heat exchange involving a phase change (Raju and Chand 1980). The plate exchanger becomes economically attractive when an expensive construction material is required or if a double-walled shell-and-tube heat exchanger (for leak protection) is the alternative. This is often the case in food industries (which usually offer excellent potential for solar energy applications) when any possibility of product contamination must be eliminated. As long as the integrity of the plates is maintained, the sealing mechanism of the plate exchanger precludes cross-contamination of exchanger liquids. The plate exchanger cost is comparable to or cheaper than equivalent shell-and-tube exchangers constructed of stainless steel. It does not have to be insulated, it can be supported on a less expensive foundation, and it requires less energy for pumping than a shell-and-tube exchanger. Plate exchangers generate highly turbulent conditions that result in high heattransfer rates, and approach temperatures may be as $10 \mathrm{w}$ as $1^{\circ} \mathrm{C}$. In addition, plate exchangers have lower thermal mass and hold-up volumes than shel1-andtube heat exchangers. These are important considerations in solar system design. 


\subsubsection{Summary}

The following generalizations can be made about heat exchangers:

- Forced-convection heat exchange should be used for industrial solar systems.

- Fluid velocities in the heat exchanger should be adequate to maintain turbulent flow ( $\operatorname{Re}>10,000)$.

- For proper heat exchange, the number of heat transfer units (NTU = $\mathrm{UA} / \mathrm{W}_{\min }$ ) will generally range from 1 to 10.

- The economical heat transfer area is obtained from the expression

$$
\frac{A_{x}}{A_{C}}=\left(\frac{F_{L} C_{C}}{U_{0} C_{x}}\right)^{1 / 2} .
$$

This generally results in a value of about 0.95 for the dewinter heatexchanger factor.

- The flow capacity ratio for the optimum heat exchange, $w_{c} / W_{s}$, generally ranges from 0.5 to 0.6 .

- The most appropriate shel1-and-tube heat exchanger configuration is probably two tube passes and a single shell pass.

- If scaling, corrosion, or dirt buildup preclude the use of a hairpin exchanger, either a fixed or floating tube sheet (depending on the amount of thermal expansion) exchanger is probably the most appropriate alternative.

- Consider a plate heat exchanger if the alternative is a double-walled she11-and-tube heat exchanger or if plain steel is unsuitable as a construction material.

\subsection{STORAGE}

In conventional IPH applications, fuel consumption (oil, gas, electricity) is adjusted to match the load. The supply of solar energy, however, cannot be regulated. To reduce the mismatch between solar supply and process demand, storage systems are often deemed appropriate. The cost-effectiveness of storage depends on the particular application, however. For systems in which solar energy supplies only a small fraction of the load, storage would ordinarily not be warranted unless the collectors might not be used for significant periods of time (e.g., if the plant is shut down on weekends). Storage can be worthwhile, however, if the collector array is large enough to supply more energy than the load requires during times of peak insolation.

There are many ways in which energy can be stored; these include mechanical, electrochemica1, chemical, and thermal means. We are concerned here only with thermal energy storage (TES) because the energy delivered by the collectors to the load is thermal in solar IPH systems. 
Thermal energy storage is most commonly sensible heat or latent heat. In a sensible heat application, the thermal energy to be stored raises the temperature of the storage material. When the energy is later extracted, the storage temperature drops. Latent heat storage uses the heat of fusion of a storage material as it undergoes a phase change (melting when heat is added, freezing when heat is extracted) to store energy, usually at a nearly constant temperature. Both types of thermal energy storage can be used on either an annual or short-term basis. Because of the cost of annual storage systems,* we address only short-term storage here. (Solar ponds, which act both as collectors and long-term sensible storage, can be cost-effective but thus far have not been used in industrial applications and so are not addressed here.) Short-term storage allows the solar energy collected during the day to be used at night, and also allows energy to be collected on days when the plant is shut down, such as on weekends and holidays.

\subsubsection{Storage Media}

\subsubsection{Sensible Heat Storage}

The vast majority of existing solar IPH systems use sensible heat storage. Liquid systems typically use water or oil storage; steam systems employ water, oil, or a mixture of oil and rock; air systems usually use a rock bed.

When liquid collectors are used, it is easiest to store sensible heat in a liquid medium since this permits straightforward heat exchange. The same characteristics that make water an excellent heat transfer fluid also make it an ideal fluid for low-temperature storage. It has a high volumetric heat capacity, is easy to pump, is cheap, and is readily available. At higher storage temperatures, materials other than water must be considered if high pressures and the associated high cost of storage tanks are to be avoided. Using other low vapor pressure fluids is an alternative; however, they can also be expensive. Another alternative is to use solid storage. Ordinarily, the high-temperature heat transfer fluid is brought into direct contact with the solid medium. Because of its low cost, rock is a common choice for a solid storage medium.

When a storage tank is filled with a mixture of rocks and a heat transfer fluid, a great deal of stratification is possible because of the large surface area of the solid, the corresponding rapid heat transfer, and low thermal conductivity. This setup distributes high-temperature fluid to the load from the top of the tank and low temperatures to the collectors from the bottom.

The stratification associated with a solid storage device is well utilized at lower temperatures as well, specifically in air collector heating systems using rock storage. Air collectors generally have lower $F_{R}$ values than liquid flat-plate collectors $(\sim 0.7$ versus $\sim 0.9)$, because of the lower heat-transfer coefficients associated with air. Rock-bed stratification provides low inlet collector temperatures which compensate for the low $F_{R}$ values and result in

*That is, storage systems with capacities comparable to energy collected on an annual basis. 
efficiencies similar to those of liquid collectors. It is important that the rocks used not vary much in size, however, and that they be loaded carefully, otherwise nonuniform flow will be the result. Cole et al. (1980) describe the design of rock storage bins for air heating systems in detail.

\subsubsection{Latent Heat Storage}

Utilizing the latent heat capacity of storage materials permits us to have smaller storage volumes. And the relatively constant temperature of storage can maximize collector efficiency and minimize storage heat losses. An ideal phase-change material (PCM) should have the following characteristics:

- appropriate phase-change temperature

- high latent heat

- Iow cost

- ready availability

- nontoxicity and nonflammability

- uniform phase-change characteristics (no subcooling or separation).

Two basic material types have been used for short-term phase change storage-organic compounds and salt hydrates. A good example of an organic compound is paraffin. Like other organics, it suffers certain limitations--flammability, low thermal conductivity, and volumetric change during phase change (causing separation from container walls). The latter two problems make it difficult to get heat into and out of the material. As a result of such limitations in organic compounds, most of the work in phase-change materials has centered on salt hydrates. Maria Telkes, who has done much of the pioneering work in this field, has concentrated on one salt hydrate in particular because of its low cost--sodium sulfate decahydrate, or Glauber's salt. The chemical reaction involved in the phase change of Glauber's salt $\left(\mathrm{Na}_{2} \mathrm{SO}_{4} \cdot 10 \mathrm{H}_{2} \mathrm{O}\right)$ is

$$
\mathrm{Na}_{2} \mathrm{SO}_{4} \cdot 10 \mathrm{H}_{2} \mathrm{O}+251 \mathrm{KJ} / \mathrm{kg}\left(108 \mathrm{Btu} / 1 \mathrm{~b}_{\mathrm{m}}\right) \underset{\text { Cooling }}{\stackrel{\text { Heating }}{\rightleftarrows}} \mathrm{Na}_{2} \mathrm{SO}_{4}+10 \mathrm{H}_{2} \mathrm{O} \text {. }
$$

When the solid hydrate is heated, $\mathrm{Na}_{2} \mathrm{SO}_{4}$ dissolves in the water of hydration; the result is a liquid. When it cools, the hydrate is reformed and $251,000 \mathrm{~J}$ of heat are released for each kilogram that solidifies. To illustrate the volumetric storage capacity of Glauber's salt, consider $100 \mathrm{~kg}$ (220 1b) undergoing a $30 \mathrm{~K}\left(54^{\circ} \mathrm{F}\right)$ temperature swing that includes the phase change at $32^{\circ} \mathrm{C}$ $\left(89^{\circ} \mathrm{F}\right):$

$$
\begin{aligned}
& Q=Q_{\text {sensible }}+Q_{\text {latent }} \\
& Q=M c_{p} \Delta T+M h_{f g}
\end{aligned}
$$

where

$$
h_{f g}=\text { latent heat of fusion, } 251 \mathrm{~kJ} / \mathrm{kg}\left(108 \mathrm{Btu} / 1 \mathrm{~b}_{\mathrm{m}}\right)
$$




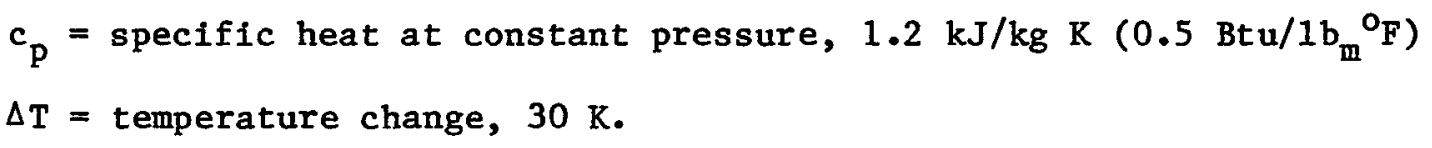

Substituting numerical values, we have

$$
\begin{aligned}
& Q=100 \mathrm{~kg}(1.2 \mathrm{~kJ} / \mathrm{kg}-\mathrm{K}) 30 \mathrm{~K}+100 \mathrm{~kg}(251 \mathrm{~kJ} / \mathrm{kg}) \\
& Q=3,600 \mathrm{~kJ}+25,100 \mathrm{~kJ} \\
& Q=28,700 \mathrm{~kJ} .
\end{aligned}
$$

Note that the latent heat term is a constant independent of temperature. The smaller the temperature swing, the less the contribution from sensible heat. In this example of a $30 \mathrm{~K}$ change, $87 \%$ of the heat stored is latent and $13 \%$ is sensible.

In Table 7-14 one can readily see the advantage in both mass and volume inherent in using Glauber's salt rather than rocks or water. The comparison is based on each material sized for a heat storage capacity of one gigajoule over a $30 \mathrm{~K}\left(54^{\circ} \mathrm{F}\right)$ temperature swing (typical for a solar space heating system). Only $3200 \mathrm{~kg}$ of Glauber's salt is needed, compared with $8000 \mathrm{~kg}$ of water and $38,100 \mathrm{~kg}$ of rock.

Unfortunately, the commercialization of Glauber's salt storage has faced a number of obstacles, arising from the phase-change behavior of this salt. Glauber's salt is considered an incongruent material because, upon melting, two distinct phases result: a saturated solution of $\mathrm{Na}_{2} \mathrm{SO}_{4}$ in water and an excess amount of insoluble $\mathrm{Na}_{2} \mathrm{SO}_{4}$ which precipitates out. Once the precipitate settles to the bottom, it no longer participates in the reaction, which causes a decrease in overall heat capacity with each melting/freezing cycle. Various approaches have been used to address this problem, such as using thickeners like paper, pulp, and thixotropic agents (similar to those used in thickening paints), active mixing, and thin containers.

\section{Table 7-14. Storage Size Comparison of Different Media Based on $1 \mathrm{GJ}$. Storage and $30 \mathrm{~K}$ Temperature Swing}

\begin{tabular}{lcc}
\hline Medium & $\begin{array}{c}\text { Weight } \\
(\mathrm{kg})\end{array}$ & $\begin{array}{c}\text { Volume } \\
\left(\mathrm{m}^{3}\right)\end{array}$ \\
\hline Rocks & 38,100 & 20.3 \\
Water & 8,000 & 8.0 \\
Glauber's salt & 3,200 & 2.1 \\
\hline
\end{tabular}


Another problem with Glauber's salt is its tendency to supercool below the normal freezing point. To solve this problem, nucleating agents (such as borax) have been added. A cold rod can also be inserted in the salt hydrate to serve as an initiating nucleation site.

Although storage devices containing Glauber's salt have been marketed, the problems discussed above have not yet been completely solved. As a result, some manufacturers have looked into other salt hydrates--calcium chloride hexahydrate, for example. Considered a semicongruent material, it does not exhibit the same degree of separation as Glauber's salt, and according to one manufacturer, it only supercools for the first several cycles [to $11^{\circ} \mathrm{C}\left(20^{\circ} \mathrm{F}\right)$ below its freezing point]. Unfortunately, it is expensive [over $\$ 2 / \mathrm{kg}$ $(\$ 1 / 1 \mathrm{~b})]$ in package form and has a low melting point $\left[27^{\circ} \mathrm{C}\left(81^{\circ} \mathrm{F}\right)\right]$, which makes it unsuitable for all but the lowest-temperature storage applications.

For higher temperature applications, other materials must be considered. Carbonates can be useful at temperatures as high as $700^{\circ} \mathrm{C}$, and they have good anticorrosion characteristics. Below $500^{\circ} \mathrm{C}$, nitrates are good candidates that are also relatively noncorrosive and inexpensive. Figure 7-17 shows the storage capacities of various candidate phase-change materials, and the temperatures at which the phase change occurs. Work in phase-change storage continues. Problems with containment, heat addition/extraction, and in some cases, corrosion still need to be resolved.

\subsubsection{Storage Vessels}

Whatever fluid is used, the storage capacity is a function of specific heat of the fluid, its mass, and the temperature range over which it can be used. The following section focuses on sensible heat storage units, but some parts of the discussion can also apply to latent heat systems. We must keep in mind that phase-change storage units store a large amount of heat at a particular temperature. The heat stored in a sensible storage tank is expressed by

$$
Q=M c_{p} \Delta T
$$

Thus, for a given fluid and minimum operating temperature, the storage capacity can be increased by increasing the amount of fluid or raising the maximum storage temperature. Often, however, the temperature is limited by the heat transfer fluid.

To enhance any stratification that might occur, storage tanks are usually plumbed so that solar return and load supply lines are connected near the top of the tank where the temperatures are the hottest. Load return and solar supply lines are connected near the tank bottom, allowing the coolest fluid to be pumped to the collectors, which in turn maximizes efficiency. In actual practice collector flow rates are often high enough to disrupt stratification. Some stratification may occur in direct systems as well, if loads are drawn from storage when there is no collection, and if the flow rates are small.

The design of a stratified tank usually requires that the height of the tank be at least twice its diameter, that diffusers be used, and that the tank volume is passed only once each day. Various devices such as baffles, perforated headers, and floating membranes have been studied to help maintain a vertical 


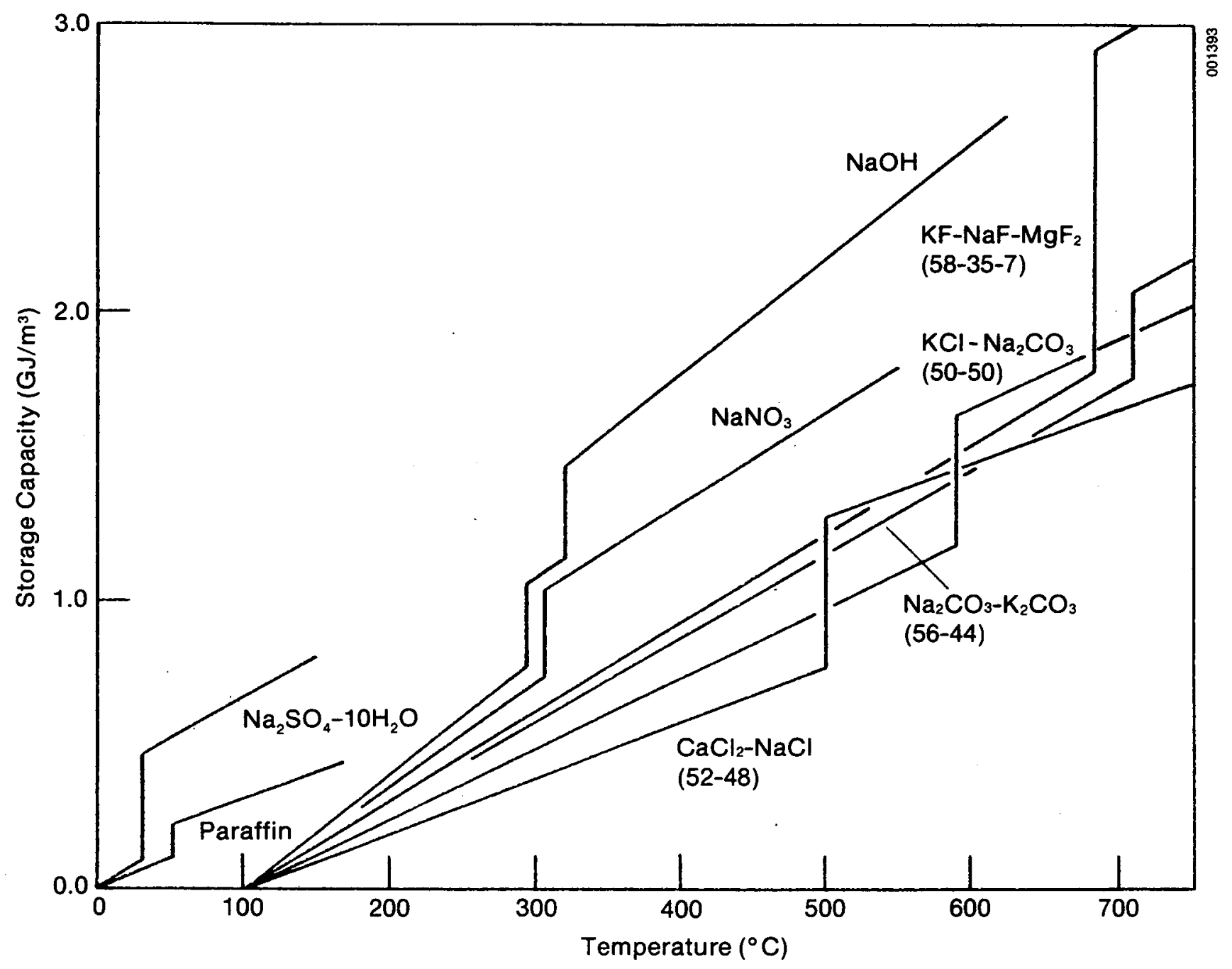

Figure 7-17. Storage Capacity per Unit Volume as a Function of Temperature for Selected Latent-Heat Storage Materials. (The molar composition of mixtures is shown in parentheses.) 
temperature gradient; however, these add to system cost. Multiple tanks are also sometimes used with each tank operated at a different temperature to achieve a measure of stratification; but, as we might expect, several small tanks cost more than one large tank and also provide greater area for heat 1oss. For instance, in a solar water heating study, higher heat losses were identified. as the major factor causing single-tank domestic hot water tank systems to outperform two-tank systems (Farrington, Murphy, and Noreen 1980).

Typically, several different materials are used to construct storage tanks; of these, steel is the most commonly used. It is also the only material used in pressure applications. Steel tanks are readily available and, when they are not the pressurized type, are inexpensive. Steel tanks are subject to corrosion, however, and have less resistance to underground loads than concrete tanks. Fiberglass tanks have good corrosion resistance and are 1ightweight. Resins typically limit the maximum operating temperature to between $65^{\circ} \mathrm{C}$ $\left(150^{\circ} \mathrm{F}\right)$ and $95^{\circ} \mathrm{C}\left(200^{\circ} \mathrm{F}\right)$, however. Fiberglass tanks are usually more expensive and are less readily available than steel tanks. Concrete tanks can be formed in any shape or size, are corrosion resistant, and resist underground loads well. However, they are heavy and often require a liner to prevent leakage. Wood tanks, properly lined, can be cost-effective in applications that require unpressurized storage. Their durability must be considered, however. Liners are used to prevent leakage and, in steel tanks, corrosion. Butyl rubber, EPDM, PVC, and polyethylene are common materials. Polyethylene has less puncture resistance than the others; and PVC is 1imited to a maximum temperature of about $70^{\circ} \mathrm{C}\left(160^{\circ} \mathrm{F}\right)$.

The optimum size of storage is a function of collector area, load profile, and solar fraction. Experience in the solar heating of buildings and hot water showed that the optimum size was about 200 to $300 \mathrm{~kJ} / \mathrm{m}^{2}$ of collector area/K (10 to $15 \mathrm{Btu} / \mathrm{ft}^{2}-\mathrm{O}_{\mathrm{F}}$ ) which translates to about 60 to 90 liters of water per square meter of collector area ( 1.2 to $\left.1.8 \mathrm{gal} / \mathrm{ft}^{2}\right)$. Because IPH applications can have such different load profiles, however, optimum storage size can be significantly different from these figures; it can be determined using the procedure given in Sec. 6.0 .

\subsubsection{Storage Tank Insulation}

Storage heat loss can cause a significant drop in system performance. There are various standards for tank insulation; for example, the SMACNA standard for solar heating systems specifies that insulation must be of sufficient thickness to keep heat loss less than $2 \%$ in $12 \mathrm{~h}$. This means $2 \%$ of storage capacity, defined as $M c{ }_{p} \Delta T_{\text {useful }}$, where $\Delta \mathrm{T}_{\text {useful }}$ is the temperature range over which storage is operated. The maximum temperature to determine a $\Delta T$ can be somewhat arbitrary, yet it affects the result greatly. In general, the U value for storage required to meet such a standard can be written as:

$$
\mathrm{U}=\frac{\mathrm{f}}{\mathrm{t}} \frac{\mathrm{Mc} \mathrm{p}_{\mathrm{p}}\left(\mathrm{T}_{\max }-\mathrm{T}_{\min }\right)}{\mathrm{A}\left(\mathrm{T}_{\mathrm{avg}}-\mathrm{T}_{\mathrm{amb}}\right)},
$$


where

$$
\begin{aligned}
f & =\begin{array}{l}
\text { fraction of stored heat loss specified by the standard (0.02 for } \\
\text { SMACNA) }
\end{array} \\
\mathrm{t} & =\text { specified time period }(12 \mathrm{~h} \text { for SMACNA) } \\
\mathrm{M} & =\text { storage mass } \\
\mathrm{c}_{\mathrm{p}} & =\text { specific heat of storage medium } \\
\mathrm{T}_{\max }, \mathrm{T}_{\min } & =\text { maximum and minimum operating temperatures of storage } \\
\mathrm{T}_{\mathrm{avg}} & =\text { average storage temperature } \\
\mathrm{T}_{\mathrm{amb}} & =\text { ambient temperature. }
\end{aligned}
$$

An alternative to the SMACNA standard is to calculate the most economic insulation thickness for a storage vessel, based on a comparison of the cost of collecting an additional amount of energy versus the cost of insulating the storage tank to save an additional amount of energy (Cole et al. 1980). If the cost of collecting additional energy is higher than the cost of saving it, the system needs insulation; but if the cost of collecting energy is less than the cost of saving it, the system has too much insulation. The economic thickness is the thickness that makes the cost of saving additional energy equal to the cost of collecting it. In many cases, the resulting insulation thickness will be close to that required by the SMACNA standard.

The incremental cost of collected energy is calculated by adding a smal1 amount of collector area and determining the increment of additional energy collected over a year $\Delta Q_{c}$ and the additional cost associated with the additional collector area $\Delta \mathrm{C}_{c}$. Using an economic factor $\mathrm{E}_{c}$ to convert initial costs to an annual equivalent cost, the ratio $E_{c} \Delta C_{c} / \Delta Q_{c}$ is the incremental cost of collecting energy, in $\$ / J(\$ / B t u)$. This quantity is compared with the cost of saving energy to determine the optimum insulation thickness. If we assume the same economic basis for calculating the cost of saving energy, the economic factor can be ignored and the costs can be compared on an initial cost basis.

Next, the energy lost and the cost of insulation are calculated as a function of the insulation thickness. For a cylindrical tank surface, the following procedure is used. The insulation is assumed to have three parts: an inside surface thermal resistance $R_{i}\left(i n m^{2} \mathrm{~K} / W\right)$, a layer of insulation with thickness $s_{2}\left(\right.$ in $m$ ) to be determined, and an outside surface thermal resistance $R_{0}$ (in $\left.\mathrm{m}^{2} \mathrm{~K} / \mathrm{W}\right)$. The annual heat loss from such a surface is

$$
Q_{\ell}=\frac{\pi L t\left(\bar{T}-\bar{T}_{a}\right)}{\frac{R_{i}}{D}+\frac{r^{*} \ln \left(1+\frac{2 s}{D}\right)}{2}+\frac{R_{0}}{D\left(1+\frac{2 s}{D}\right)}},
$$


where

$L=$ height (length) of storage tank (m)

$\overline{\mathrm{T}}$. = ayerage temperature $\left({ }^{\circ} \mathrm{C}\right)$ of the storage during the time it is hot (a good estimate is the average of the peak storage temperature and the minimum temperature during operation)

$\overline{\mathrm{T}}_{\mathrm{a}}=$ average ambient temperature $\left({ }^{\circ} \mathrm{C}\right)$, also averaged during the time the storage tank is used (the temperature at the tank location, either indoors or outdoors)

$D=$ diameter of the tank (m)

$R_{i}=$ inside surface thermal resistance $\left(m^{2} \mathrm{~K} / \mathrm{W}\right)$, calculated similariy to $R$ in $\mathrm{Eq} \cdot 7-1$

$\mathrm{r}^{*}=$ thermal resistance of the insulating material per unit thickness (mK/W), adjusted for parallel heat loss (without parallel heat loss, it is the inverse of the thermal conductivity of the material)

$R_{0}=$ outside surface thermal resistance $\left(m^{2} K / W\right)$, also calculated like $R$ in Eq. 7-1.

Differentiating with respect to the insulation thickness, we have

$$
\frac{\mathrm{dQ}_{\ell}}{\mathrm{ds}}=\frac{\pi \operatorname{Lt}\left(\overline{\mathrm{T}}-\overline{\mathrm{T}}_{\mathrm{a}}\right)\left[\frac{\mathrm{r}^{*}}{\mathrm{D}\left(1+\frac{2 s}{\mathrm{D}}\right)}-\frac{2 \mathrm{R}_{0}}{\mathrm{D}^{2}\left(1+\frac{2 s}{\mathrm{D}}\right)^{2}}\right]}{\left[\frac{\mathrm{R}_{i}}{\mathrm{D}}+\frac{\mathrm{r}^{*} \ell \mathrm{n}\left(1+\frac{2 s}{\mathrm{D}}\right)}{2}+\frac{\mathrm{R}_{\mathrm{o}}}{\mathrm{D}\left(1+\frac{2 \mathrm{~s}}{\mathrm{D}}\right)}\right]^{2}} .
$$

We assume that the cost of the insulation consists of a fixed cost $C_{1}$, a cost proportional to the outside surface area $C_{2}$, and a cost proportional to the insulation volume $\mathrm{C}_{3}$, as follows:

$$
C_{I}=C_{1}+\pi(D+2 s) L C_{2}+\frac{\pi}{4}\left[(D+2 s)^{2}-D^{2}\right] L C_{3}
$$

The derivative of the insulation cost with respect to insulation thickness is

$$
\frac{\mathrm{dC}_{\mathrm{I}}}{\mathrm{ds}}=\pi \mathrm{L}\left[2 \mathrm{C}_{2}+\mathrm{DC}_{3}(1+\overline{\mathrm{2s}})\right]
$$

Combining Eqs. 7-63 and 7-65 yields the incremental cost of saving energy: 


$$
\begin{aligned}
E_{I} \frac{d C_{I}}{d Q_{l}} & =\frac{E_{I} d C_{I} / d s}{d Q_{l} / d s} \\
& =\frac{E_{I}\left[C_{2}+\frac{D C_{3}}{2}\left(1+\frac{2 s}{D}\right)\right]\left[R_{i}\left(1+\frac{2 s}{D}\right)+\frac{r^{*} D}{2}\left(1+\frac{2 s}{D}\right) \ln \left(H \frac{2 s}{D}\right)+R_{0}\right]^{2}}{\left[\frac{r^{*} D}{2}\left(1+\frac{2 s}{D}\right)-R_{0}\right] t\left(\bar{T}-\bar{T}_{a}\right)} .
\end{aligned}
$$

Finally, the two incremental costs are set equal to one another. Since the incremental cost of saving energy $E_{T} \mathrm{dC}_{T} / \mathrm{dQ}_{\ell}$ must equal the incremental cost of collecting energy $E_{c} \Delta C_{c} / \Delta Q_{c}$ at the optimum insulation thickness, then, assuming equal economic factors $\left(E_{I}=E_{c}\right)$, we obtain

$$
\left(C_{2}+\frac{C_{3} D y}{2}\right)\left(R_{1} y+\frac{r^{*} D y \ell_{n} y}{2}+R_{0}\right)^{2}-\left(\frac{r^{*} D y}{2}-R_{0}\right) t\left(\bar{T}-\bar{T}_{a}\right) \frac{\Delta C_{c}}{\Delta Q_{c}}=0,(7-67)
$$

where $y=1+2 s / D$.

We can solve for $y$ in terms of $C_{2}, C_{3}, D, R_{i}, R_{0}$, and $r *$ using Eq. 7-67 either by trial and error or by more sophisticated methods such as the Newton-Raphson method. Once $y$ is obtained, the optimum thickness of insulation is simply

$$
\mathrm{s}_{\text {opt }}=\frac{\mathrm{D}}{2}(\mathrm{y}-1) \text {. }
$$

If the surface to be insulated is flat, such as the top or bottom of a tank, or the radius of curvature is large compared with the insulation thickness, a similar analysis yields a closed-form solution for the optimum insulation thickness

$$
\text { sopt }_{\text {op }}\left[\frac{\mathrm{t}\left(\overline{\mathrm{T}}-\overline{\mathrm{T}}_{\mathrm{a}}\right)}{\mathrm{C}_{3} \mathrm{r}^{*}} \frac{\Delta \mathrm{C}_{\mathrm{c}}}{\Delta \mathrm{Q}_{\mathrm{c}}}\right]^{1 / 2}-\frac{\mathrm{R}^{*}}{\mathrm{r}^{*}},
$$

where $R^{*}$ is the thermal resistance of the surface before the insulation is applied, adjusted for parallel heat loss $\left(\mathrm{m}^{2} \mathrm{~W} / \mathrm{K}\right)$. In insulating a storage tank, it is important to pay attention to the top and bottom (particularly the latter, because of conduction paths), and not just the sides.

\subsubsection{Storage Location}

\subsubsection{Interior Storage}

When space is available inside a building, it is valuable for storage because the system can then use shorter pipe runs and waterproofing is not needed. Any losses from storage can add to a building's cooling load, although mechanical equipment rooms are often not air conditioned. There must be some provision for containing or draining leaks as well as access to all parts of the tank. Mounting pads should be designed to isolate the tank thermally from the floor. 


\subsubsection{Exterior Storage}

If interior space is scarce, exterior storage problems must be addressed. The insulation must be waterproof, which usually necessitates a closed-cell foam insulation if temperatures permit. Because of the lower ambient temperatures and wind effects, more insulation is needed for an outside tank than an interior one. All penetrations for valves, pipes, supports, and instrumentation must be waterproofed. In freezing climates, a drainable sight gauge is recommended.

For aesthetic reasons, or to conserve ground area, storage tanks can be located underground. Of primary concern in such an application is the height of the local water table. If the bottom of the tank is below the water table, a holddown structure or added dead weight is needed to prevent flotation of the tank when it is empty. A commonly used support structure consists of a concrete footing with tank saddles to support the weight of the tank and steel straps to hold it down. High-density insulation must be used to withstand both upward and downward loads. Because of the serious problems a high water table can cause, most experienced solar system designers avoid using underground tanks under these circumstances. A current method of installing an underground tank involves prefoaming the tank with urethane, wrapping it with nylon fabric and mastic material, and setting it in a sand bed.

\subsection{REFERENCES}

Alexander, E. L.; Kutscher, C. F. 1978 (Aug.). Thermal Storage Subsystem Parameter Study. Solar Ten Megawatt Project Office Report No. 40X5131056-R. Canoga Park, CA: Rockwell International Inc. Energy Systems Group.

Allen, David, J. 1981. Personal communication.

Barley, C. D.; Wynn, C. B. 1978. "Optimal Sizing of Solar Collectors by the Method of Relative Areas." Solar Energy. Vol. 21 (No. 4); pp. 279-89.

Barnhart, J. S. 1981. "Energy Transport System Optimization for Distributed Networks of Solar Collectors." ASME Paper No. 81-SOL-1. Presented at the Energy Sources Technology Conference and Exhibition. 18-22 Jan. 1981, Houston, TX.

Baumann, H. D. 1979 (May). "A.Case for Butterfly Valves in Throttling Applications." Instruments and Control Systems.

Caputo, R. 1975. An Initial Study of Solar Power Plants Using a Distributed Network of Point Focusing Collectors. JPL 900-724. Pasadena, CA: Jet Propulsion Laboratory.

Cole, R. L•; Nield, K. J.; Rohde, R. R.; Wolosewicz, R. M. 1980. Design and Installation Manual for Thermal Energy Storage. 2nd Edition. ANL-79-15. Argonne, IL: Argonne National Laboratory.

deWinter, F. 1975. "Heat Exchanger Penalties in Double-Loop Solar Water Heating Systems." Solar Energy. Vol. 17; pp. 335-337. 
Dittus, F. W.; Boelter, M. K. 1930. University of Calif. (Berkeley) Pub. Eng. Vol. 2; p. 443.

Farrington, R. B.; Murphy, L. M.; Noreen, D. L. 1980 (April). A Comparison of Six Generic Solar Domestic Hot Water Systems. SERI/TR-351-413. Golder, CO: Solar Energy Research Institute.

Fried, J. R. 1973 (28 May). "Heat Transfer Agents for High Temperature Systems." Chemical Engineering.

HUD International Minimum Property Standards Supplement, Solar Heating and Domestic Hot Water Systems. 1977 Edition. Washington, DC: U.S. Department of Housing and Urban Development.

Iannucci, J. J. 1980 (June). "Thermal Energy Centralization Network: Design, Cost, and Performance for Disk, Trough, and Central Receiver Systems." Paper presented at International Solar Energy Society Meeting, Phoenix, Az.

Johnson, J. D. 1981 (10 Aug.). "Variable-Speed Drives Can Cut. Pumping Costs." Chemical Engineering.

Jones, G. F.; Lior, N. 1979. "Optimal Insulation of Solar Heating System Pipes and Tanks." Energy. Vol. 4 (No. 4); pp. 593-621.

Kreith, F. 1973. Principles of Heat Transfer. Third Edition. New York: Harper and Row Publishers, Inc.

Lauer, B. E. 1953. How to Evaluate Film Coefficients for Heat-Transfer Calculations. A technical manual reprinted from the 0 il and Gas Journal. Tulsa, OK: Petroleum Publishing Co.

Lobanoff, V. 1979 (June). "Specific Speed is a Useful Index for Pump Design and Selection." Power. Vol. 123 (No. 6); pp. 70-71.

Lunde, P. J. 1980. Solar Thermal Engineering: Space Heating and Hot Water Systems. New York: John Wiley and Sons.

McAdams, W. H. 1954. Heat Transmission. Third Edition. New York: McGrawHil1.

Morton, R. E. 1980 (Sept.). "Design of Collector Subsystem Piping Layouts." Line-Focus Solar Therma1 Energy Technology Development Seminar. Albuquerque, NM: Sandia National Laboratories.

Neerken, R. F. 1978 (3 Apr.). "Selecting the Right Pump." Chemical Engineering. pp. 87-98. (See also, "How to Select and Apply PositiveDisplacement Rotary Pumps.").

Parts, L.; Miller, D. R.; Leffingwe11, J. W.; Thompson, Q. E. 1980 (Sept.). Superior Heat Transfer Fluids for Solar Heating and Cooling Applications. ALO/45356-2. Monsanto Research Corp. 
Perry, R. H.; Chilton, C. H. 1973. Chemical Engineers Handbook 5th Edition. New York: McGraw-Hill Book Co.

Powe11, J. C.; et al. 1974. Dynamic Conversion of Solar-Generated Heat to Electricity. NASA CR-134724. Washington, DC: National Aeronautics and Space Administration.

Raju, K. S. N.; Chand, J. 1980 (11 Aug.). "Consider the Plate Heat Exchanger." Chemical Engineering. pp. 133-144.

Seider, E. N.; Tate, C. E. 1936. "Heat Transfer and Pressure Drop of Liquids in Tubes." Ind. Eng. Chem. Vol. 28; p. 1429.

Shames, I. H. 1962. Mechanics of Fluids. New York: McGraw-Hil1.

Thornton, J.; Herlevich, A.; Hooker, D.; Kriz, T. Forthcoming. Comparative Evaluation of Solar Thermal Systems for Thermal Applications. SERI/TR-253-1706. Golden, C0: Solar Energy Research Institute.

Williams, 0. M. 1978. "Thermal Chemical Energy Transport Costs for a Distributed Solar Power Plant." Solar Energy. Vol. 20, pp. 333-342. 


\section{SER'}




\section{SECTION 8.0}

\section{COMTROLS AND INSTRUIETTATION}

As in nonsolar process applications, controls and instrumentation play an important role in solar IPH systems. In this section, we describe the design aspects of controls and instrumentation in solar IPH systems. In Sec. 8.1, control fundamentals needed to design a solar control system are explained. Subsections address such items as controllers, control loops, measurement dynamics, noise, and control valve characteristics. In Sec. 8.2, the special control problems of solar energy systems are addressed, beginning with normal operating modes, and including start-up/shutdown, freezing/stagnation, emergency conditions, operator training, and checkout. Instrumentation is covered in Sec. 8.3, particularly including irradiation, temperature, flow, pressure, and level measurements.

\subsection{FUIDANGRTALS OF CONTROIS}

In this section, it is assumed that the designer already has some knowledge of process control, although several excellent textbooks are referred to. It is also assumed that the designer is familiar with the major elements of a closed control loop: the process, feedback (measuring) element, controller, control variable, feedback variable, manipulated variable, reference variable (set point), and uncontrolled variable (disturbance) (Grader 1970).

\subsubsection{Controllers}

The controller is the part of the control loop that implements corrective action as the process variable deviates from a desired set point. The control modes that characterize the corrective action include on-off, proportional, integral (reset), and derivative (rate). There are no adjustments to "on-off" control (unless a deadband is included), and the controller output changes full-scale as the process variable crosses the set point. The corrective action implemented with proportional control is normally a linear function of the error signal (process variable minus set point). The proportionality constant (i.e., the gain) is equal to the percent controller output change divided by the percent error change.

Integral control (reset) is usually combined with proportional control. It forces the controller output to change in accordance with the time integral function of the error signal and can reduce steady-state error. It also repeats initial proportional output response as long as the error signal persists. Derivative control is combined with proportional control to change the controller output in accordance with the rate of change of error signal. This action ceases when the error signal stops changing. 


\subsubsection{Common Control Loops}

The common types of control loops are flow, pressure, level, and temperature. Some rules of thumb are as follows.

F100 1oops: Proportional plus reset controllers are used almost exclusively. The process typically is very fast and noisy, and the flow measurement is usually nonlinear (square). The controller is characterized by low gain and fast reset.

Pressure loops: For a liquid, the process is fast and noisy with most of the lags in the control system, and the measurement is nonlinear (square). Linear valves and proportional plus reset controllers with low gain and fast reset are used. For a gas, the process is simple: linear with no dead time and no noise. Proportional controllers with high gain suffice, and valve characteristics are not critical. For vapor pressure control, equal percentage valves and proportional-reset-derivative controllers are employed. This process is slow compared with other pressure processes. Controller settings include moderate gain, a reset rate of 0.5 repeats per minute or less, and a derivative time of 0.5 minute or more.

Level loops: High-gain or proportional-plus-reset controllers are used for precise control, low gain proportional-plus-reset controllers for averaging control. Valve characteristics are important.

Temperature loops: Temperature control loops can vary greatly in complexity, because there really is no such thing as a typical temperature application. Almost all the temperature control problems in solar applications are heat transfer problems characterized by long time constants and slow reaction rates. Distance-velocity $\mathrm{lag}$ (also known as dead time) is common. The measurement lag can pose a serious problem, especially if the thermal system is protected with a well. The measurement time constant depends on the mass and surface area of the bulb (or the well), the measured fluid, and its velocity past the bulb. Special care should be taken in locating the bulb to maximize heat transfer; usually, the bulb should be placed at bends in the flow path.

Nonlinearities also cause complications in the temperature loops. Heat transfer processes have parameters that vary with flow, so that time constants and distance-velocity lag vary with load or operating point. Distance-velocity lags are not as evident as in other systems and are often overlooked in analysis. Imperfect mixing is a good example of hidden dead time.

Processes dominated by one large capacity, e.g., storage tanks in air heating systems, can be controlled with on-off controllers. Some cycling results, but only about $1 \%$ of span. Proportional plus reset control is used in smaller capacity systems where load changes are large and where distance-velocity and measurement lags are important. Most shell-and-tube heat exchangers fall into this category. Derivative action becomes helpful, provided the process is dominated by linear lags (e.g., a batch reactor). 
Controlling temperature by mixing hot and cold streams is more of a blending problem than a heat exchange problem. Good mixing and fast temperature measurement are the keys to simplifying the control job. Proportional-plus-reset controllers should be used.

In general, the following guidelines can be used in selecting controllers:

Use proportional control where

- the cycling action, due to on-off control, is undesirable;

- set-point changes are small or infrequent; and

- the steady-state deviation between the set point and the process variable (i.e., the offset) can be tolerated.

Add integral control where

- the offset must be reduced or eliminated, and

- the set point changes are frequent.

Do not add integral control when

- start-up overshoot must be eliminated, and

- the process can be controlled with high-gain proportional control.

Add derivative action to proportional control when

- the distance-velocity lag (e.g., dead time in the pipes) is negligible compared with either of at least two linear lags (e.g., storage tanks) in the process 1oop.

Do not add derivative action if

- the distance-velocity lag is a major time lag in the process; and

- noise is present--unless the noise/signal ratio is low. Do not use on flow control.

\subsubsection{Measurement Dynamics}

The time lag associated with a typical control loop can be linked to three distinct causes: the lag inherent in the process, the response lag of the detecting element, and the signal transmission lag. To minimize lag effects, detection response should be considered first and its lag effect reduced, if possible. These measurement lags can cause serious errors as the process is changing; $i . e .$, the slower the response, the more inaccurate the measurement. 
A classic example of detecting element lag is a temperature measurement using a filled system. The lag depends on the thermal capacity of the element and the surrounding fluid. of the common methods for detecting temperature changes, the filled system has the slowest response speed. To ensure quicker responses, the following precautions should be taken:

- The element should fit snugly inside the protecting well.

- The protecting well surface should always be clean.

- A high velocity of the fluids to be measured must be maintained: $0.3 \mathrm{~m} / \mathrm{s}$ ( $1 \mathrm{ft} / \mathrm{s}$ ) or more for liquids and $3 \mathrm{~m} / \mathrm{s}$ (10 ft/s) minimum for gases.

- Protecting wells of minimum thicknesses consistent with plant specifications should be selected (pressure requirements must also be met).

- Protecting wells should be immersed deeply into lines and vessels.

In genera1, if the dynamics of the temperature measuring system are fast, compared with the major secondary dynamic elements in the control loop, they can be ignored. Measurement dynamics cannot be ignored, however, if the temperature is controlled by mixing hot and cold streams. They can usually be ignored in slow-responding tank heating systems, but they are usually important in small heat exchangers. Finally, relative to temperature measurement, flow, pressure, and level elements respond instantaneously to process changes.

\subsubsection{Noise}

Noise comprises random, unwanted signals that can occur in many parts of the control loop, usually those associated with measurement. Examples of solar system noise are turbulence in differential-measured flow signals, random pulsations in pressure signals, and surface waves in level signals. Since derivative action amplifies high-frequency signals, it cannot be used if noise is present. Moreover, high controller gain can be a problem; hence, low-gain, reset controllers are generally used. Flow control is dominated by noise that is difficult to filter out because the process itself is fast.

In solid-state control systems, grounding practices have a significant effect on immunity to noise. Each ground should be connected to its respective reference point by no more than one wire (single-point grounding). Under no circumstances should two or more systems share a common single-ground wire, either equipment ground or control common. In general, noise entering the control system must be kept as low as possible by employing appropriate installation practices, especially when the anticipated noise signal is quite similar to the desired control input signal.

\subsubsection{Valves}

Most control valves are marked by one of three flow characteristics: quickopening, linear, or equal percentage. These different characteristics provide control-10op stability over the expected range of operating conditions. 
The quick opening characteristic provides a maximum change in flow rate at low stem travel while maintaining a linear relationship through most of the stem trave1. Usually, about $90 \%$ of valve capacity is achieved with $30 \%$ valve opening. This valve is used primarily for on-off service or in systems with constant pressure drops where linear characteristics are needed.

A valve with a linear characteristic produces flow directly proportional to the valve lift; e.g., $50 \%$ of valve lift corresponds to $50 \%$ of maximum flow. This characteristic is commonly specified for liquid level control and for control applications requiring constant gain.

An equal-percentage flow characteristic is one in which equal increments of stem travel produce equal percentage changes in existing flow. For example, when the flow is small, the change in flow is small; when the flow is large, the change in flow is large. The change is proportional to the quantity flowing before the change. Equal-percentage valves are often used when the pressure drop available over the control valve is not constant.

From a control point of view, the following conditions apply:

- For simple processes, valve characteristics are relatively unimportant. The less expensive quick-opening valve can be considered appropriate for on-off applications.

- If the required flow range is $3: 1$ or less, there is little difference between linear and equal-percentage valves. If the flow range is $8: 1$ or more, linear valves are preferable.

- If the pressure drop across the valve varies more than 2:1 or 3:1 with valve opening, equal percentage is probably the better choice, even if Iinear is the desired theoretical characteristic.

- If the valve is oversized, the equal-percentage characteristic allows somewhat better control because an oversized linear valve requires a lower controller gain at the operating point.

- For flow control, where the primary element is an orifice plate or another differential pressure device, use a linear valve if the pressure drop across the valve decreases as the valve opens. The installed characteristic will compensate for measurement nonlinearity.

Because these characteristics assume the pressure drop across the valve to be constant, the installed characteristic is usually quite different from the theoretical one. Equal-percentage valves tend to become linear, linear valves tend toward quick-opening, and quick-opening valves become useless except for on-off service. The larger the pressure drop across the valve, the better the flow control, and the control system will be able to handle large disturbances and upsets. From a heat exchanger and pump design standpoint, however, the valve pressure drop should be kept as small as possible. Thus, an engineering compromise must be made between controllability and power requirements. A good rule of thumb is to design the system so that the control valve in its half-open position takes about $25 \%$ of the total system pressure drop at design flow rate. The control valve range must also be considered in designing a control system. Most control valves work effectively. between $10 \%$ and $90 \%$ of the valve characteristic curve. At low flows, the control valve may be almost on its seat, and poor flow regulation can be the result. 
Other control elements include dampers, louvers, and variable-speed pumps. Dampers and louvers are used to throttle gas flows where control quality is not critical and pressures are low. Leakage rates can be high, but they may be reduced to very low levels (less than $0.1 \%$ ) by using soft edging on the damper blades. Pumps are often used for flow control by adjusting the stroke length or by varying the speed of a motor-driven shaft. Reciprocating pumps, which displace a known fixed value of fluid with each stroke, and diaphragm pumps, which have a flexible diaphragm, are commonly used. The latter cost less, but are limited to lower operating pressures because of their material strength limitations.

\subsubsection{Hiscellaneous Considerations}

- The control system will respond to disturbances according to their location in the control loop. Response is affected by the size of the time constants and gain elements in the loop.

- A good first guess of the time constant is the ratio of the volume to throughput.

- An index of controllability is the ratio of controller gain to the period of oscillation; the higher the gain and shorter the period, the easier the control job.

- The higher the controller gain, the less the offset (difference between the variable and set-point) following a load change. If controller gain is high, reset is unnecessary.

\subsubsection{Multivariable Control Loops}

\subsubsection{Cascade}

A cascade loop has two feedback controllers; the output signal of the master controller goes to the set point of the slave controller. The output of the slave controller goes to the final control element. The major time constant must not be in the slave loop in order to maintain control. Cascade control is most useful in temperature control systems and is not normally applied in fast control loops such as flow and pressure.

\subsubsection{Feed-Forward}

The basic notion of feed-forward control is to detect disturbances as they enter the process and make adjustments in manipulative variables so that output variables are held constant. The control does not wait until the disturbance has worked its way through the process to produce an error signal. If a disturbance can be detected as it enters the process, the feed-forward control takes immediate action to compensate for its effect on the process. 
The temperature-flow cascade loop just described can handle the collector outlet thermal lag problem. However, oscillation and overshoot of temperature responses have been found in a system where the controlling temperature sensor is not located properly. In such a case, the midfield temperature can be used together with the outlet temperature for temperature control. A simple way to implement this multiple-temperature approach is to feed-forward an average temperature obtainable from the summation of all applicable temperatures so as to damp out temperature variations during transient periods and still properly represent the collector temperature under steady operating conditions.

\subsubsection{Sp1it-Range Control}

Split-range control indicates two control valves operated by the same controller. For example, nitrogen make-up normally maintains the correct vessel pressure. However, under certain conditions, the vessel pressure may become too high, and the excess must be vented off. In these conditions, one valve is used for venting and one used for pressurizing. Usually, a small deadband is provided between valve operations; for example, the nitrogen make-up valve closes from $0 \%$ to $50 \%$ of signal range and the vent valve opens from $55 \%$ to $100 \%$ of signal range. In some cases, no deadband is required; in others, overlap is necessary.

\subsubsection{Overrides}

In IPH solar systems, it may be necessary to take more drastic control action on a primary control variable to maintain safe operation or protect process equipment. The primary variable maintains control as long as a second variable does not exceed a safe limit, at which point the second variable assumes control. For example, a mid-row temperature variable can be used to override an outlet-row temperature when overtemperature conditions are met (Schindwolf 1981).

\subsubsection{Computers}

A sequencing computer, such as a programmable logic controller (PLC), is very useful in a solar IPH system. The PLC assists in start-up and shutdown, and performs alarm, relay, and motor control functions. This system costs approximately $\$ 25,000$ (1981 dollars). Its advantages include

- Flexibility: logic can be changed in most cases without hardware modification.

- Reliability: it uses solid-state electronics.

- Reusable options: the controller can be reused no matter what logic changes are implemented.

- Maintenance reduction: indicator lights can assist in diagnostics and troubleshooting.

- Power savings: it uses less power than relay panels. 
It may also be wise to consider continuous control capability in addition to the sequencing logic. Although digital control may seem inappropriate initially, it allows the flexibility to implement other control logic for a low incremental cost as more process experience is gained. Information on equipment, materials, and services for process control can be found in the Chemical Engineering Deskbook (1979).

\subsection{COHTROL DESIGN}

The regulatory ability required of a process control system varies significantly for each of the three IPH system applications (steam, hot water, hot air); therefore, the designer must understand the dynamics of the process before making a decision about the degree of control required. A total systems approach is the key to the success of the control system. In general, the energy collection loop must be coordinated with the energy utilization loop, yet operate independently. In addition, the control system must protect the process in all emergency conditions.

There are many possible process configurations for solar industrial applications. Here three basic control systems are discussed: constant flow rate, constant flow rate with a three-way diverting valve, and variable flow rate generated by a throttling valve or a variable-speed pump. Also, control designs (Su and Castle 1979) are suggested that take into account the process dead time and insolation characteristics of solar IPH applications.

\subsubsection{Nornal Operating Modes}

In the normal production mode, the control system must maintain a balance between energy collection, storage, and usage. For example, the energy flow path could be one in which the energy collected is consumed only by the load, the energy is accumulated only in the storage device, or the energy is fed to the load and storage simultaneously. When the collector field is incapable of providing the energy delivery rate required by the load, alternative operations can be considered, such as activating the auxiliary heat source or thermal storage or even using the system to supply lower-temperature energy needs.

The control system is relatively simple for a constant flow-rate process (see Fig. 8-1). The designer does not have to be concerned with keeping the collector field outlet temperature constant, and the industrial process can handle any heat surges or slumps that occur. An auxiliary heat source can be used to make up any heat not produced in the collectors; however, this may complicate the controls because of heat source interactions. Two different pumps can be used: one for low flows and cold fluids at start-up and one for higher flows and temperatures at normal conditions. The instrumentation is standard for this concept and includes flow switches, level switches, pressure gauges, and thermocouples. The process information can be forwarded to a PLC to relate alarm and status conditions and can be forwarded to a data acquisition computer. The information is not, however, used in any continuous control capacity. 


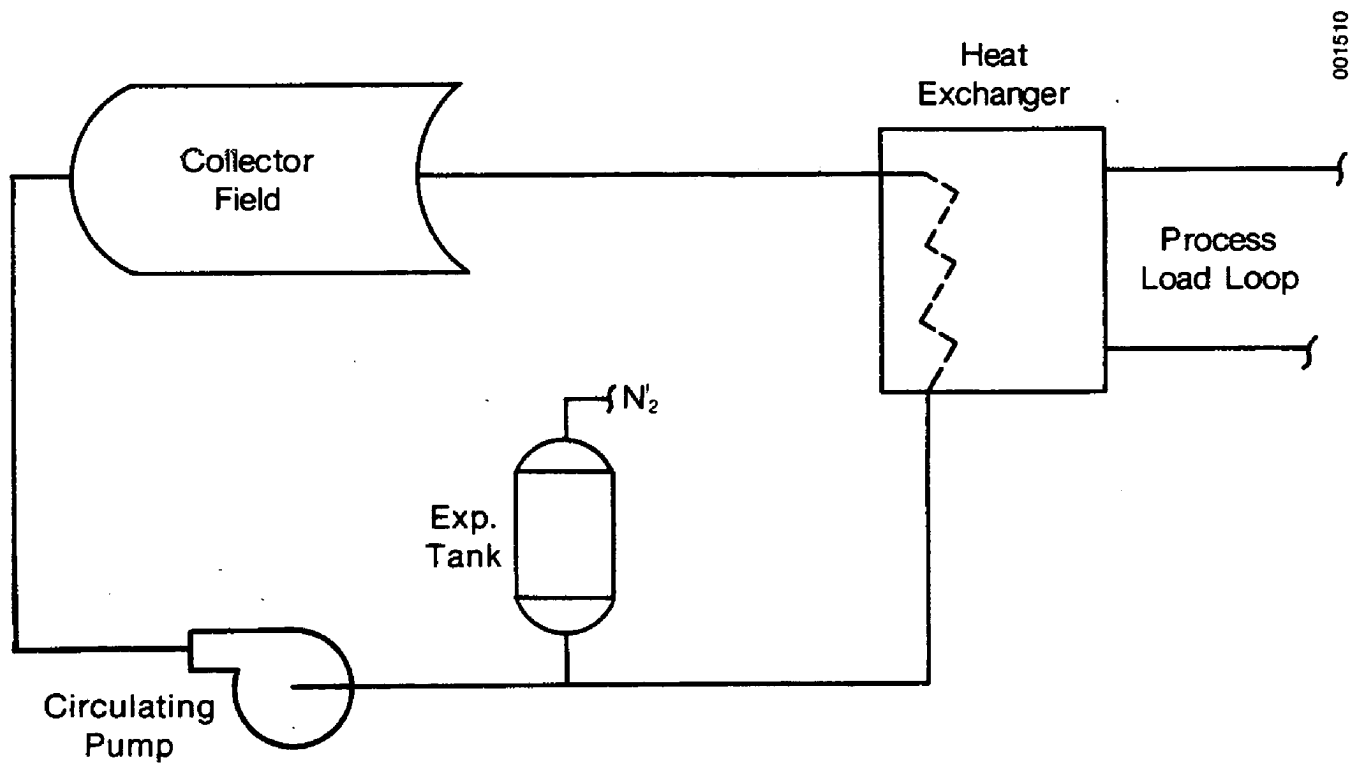

Figure 8-1. Constant Flow-Rate Control

The designer may enhance control capabilities by using a three-way diverting valve (or preferably 2 two-way valves) in a constant flow system (see Fig. 8-2). This valve can divert flow as the collector outlet temperature swings. The valve may be capable of throttling flow and providing more consistent energy flow to the industrial end user than the system shown in Fig. 8-1. The controls are more complicated because a sensor signal must be transmitted to the valve. Such a system controls the outlet temperature by adjusting the field inlet temperature. However, this type of control is characterized by large time delays and provides poor control over the outlet temperature.

The next step in Improving system performance involves implementing variable flow control. This control is not necessary unless the industrial user requires a constant temperature input. In that case, the flow must vary as insolation increases or decreases to maintain a constant field outlet temperature (Fig. 8-3).

Three options are avallable in constructing a variable flow control system:

- use a throttling valve with a constant speed pump,

- use a variable speed pump, or

- use a thrott1ing valve with a two-speed pump.

To determine which method is best for a given application, the value of the energy delivered by the solar energy system and required by the flow controller and the pump motor, along with the cost of each control system, should be considered. The first option listed above is the more traditional method. 


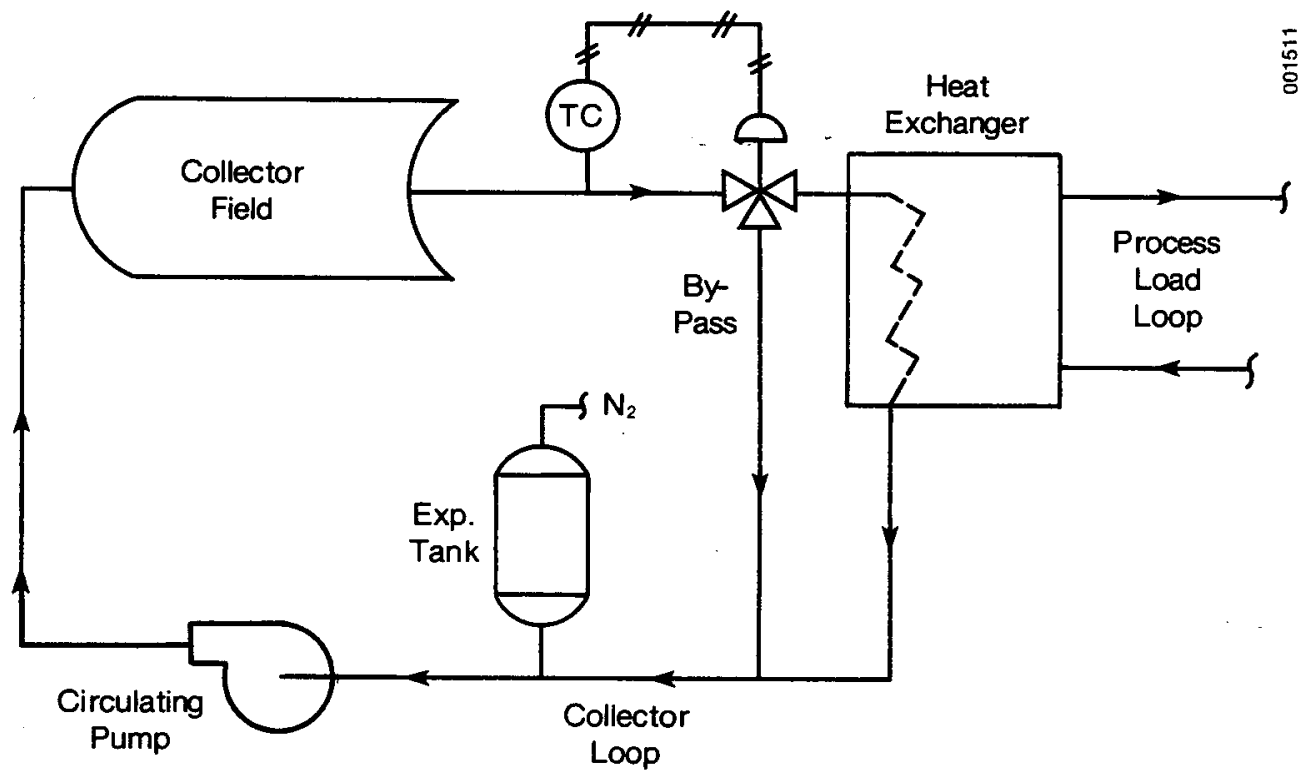

Figure 8-2. Constant Flow-Rate Control Using Three-Way Valve

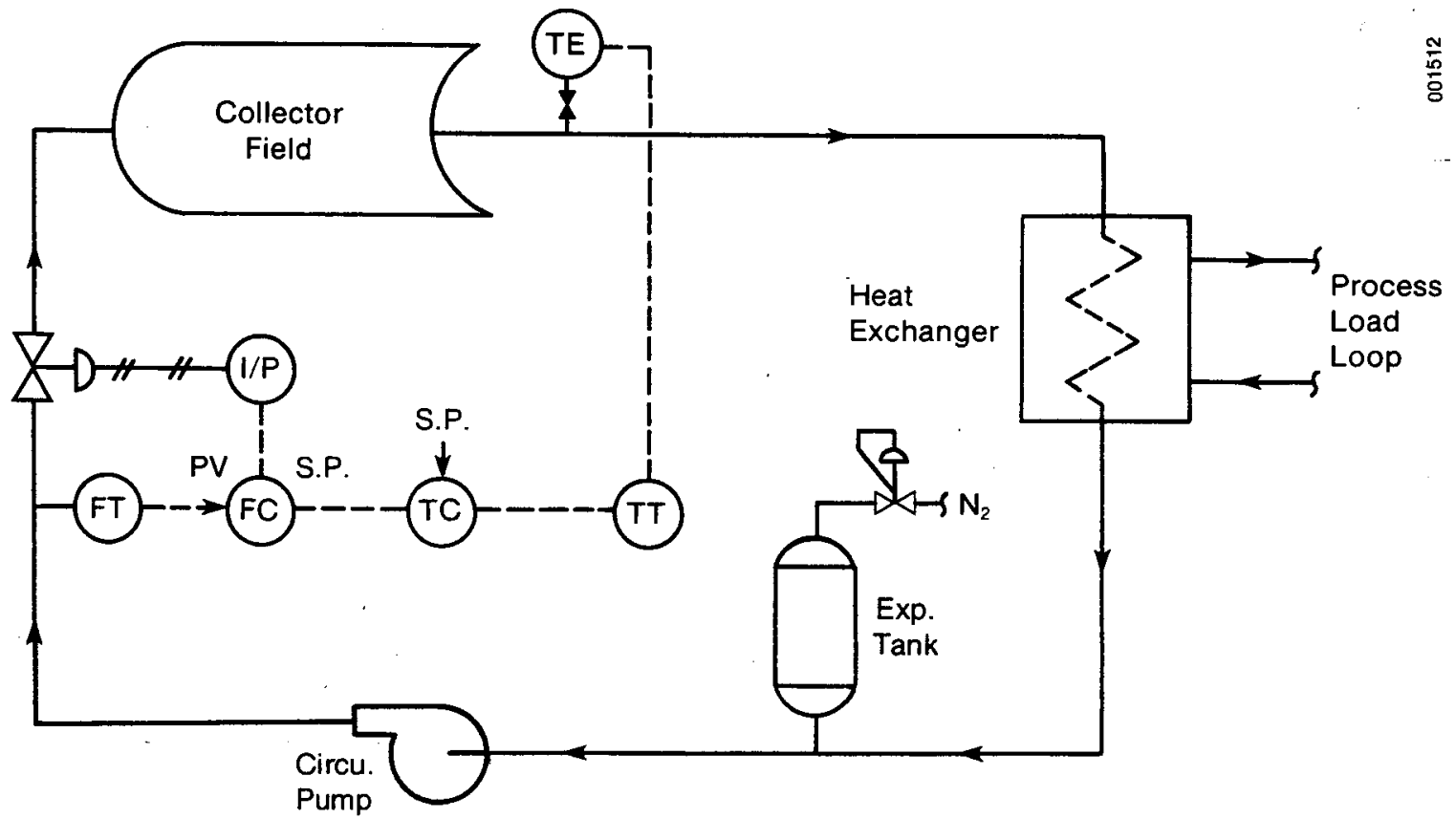

Figure 8-3. Outlet Temperature Control by Flow-Rate Manipulation 
According to Baumann (1979, 1981), this method has an economic advantage over a variable-speed pump for a process where operating conditions are maintained between $80 \%$ and $100 \%$ of design capacity. On the other hand, the second option is preferable when static head is not significant and when the average quantity of liquid being pumped is less than two-thirds of the maximum design flow rate. Unfortunately, typical solar IPH systems do not fit either of these models. Systems do not always operate near design conditions. Frequent start-ups and the wide-ranging viscosity of heat transfer fluids require the characteristics of both the first and second option. Therefore, the third option is a good compromise--using a throttling valve with a two-speed centrifugal pump. (See Sec. $\mathbf{8 . 1 . 5}$ for more on pumps and valves.)

The final control element, whether it is a valve or a pump, is manipulated by a signal from an analog controller or a microcomputer. The analog controller is more commonly used, but the microcomputer has advantages in flexibility and, in some cases, price. For example, if a designer first decides on proportional-only control, an analog controller might be used. If a vapor pressure should be needed later for a set point and this pressure were to be calculated from a temperature, a microcomputer would be needed. In retrospect, the computer would have been the better purchase, because it can handle both cases.

Tuning constants in an analog controller or a microcomputer algorithm are crucial to the control of flow in the solar system. Figures 8-4, 8-5, 8-6, and 8-7 have been prepared to help the designer specify controller tuning constants necessary for stable operation of the system. The constants selected are a function of sensor location, process dead time, instrument spans, valve characteristics, and type of collector. The tools were generated by a frequency response analysis by Wright (1980) and were tested by means of a rea1time dynamic computer simulation.

To use these tools, follow this procedure:

- Pick transmitter spans for temperature and flow.

Pick the temperature set point.

Calculate the $\Delta T$ across the solar field at steady-state conditions.

Calculate the $\Delta P$ across the field $\left(\Delta \mathrm{P}_{F}\right)$ at steady-state conditions.

Calculate the $\Delta \mathrm{P}$ across the valve $\left(\Delta \mathrm{P}_{\mathrm{v}}\right)$, at steady-state conditions.

Calculate the steady-state flow rate $\dot{\mathrm{M}}_{\mathrm{ss}}$.

- Specify $p$ (dimensionless), which is the ratio of the thermal mass of a unit length of fluid $\left(\rho c_{p} A\right)_{F}$ to the thermal mass of a unit length of the fluid and recelver tube $\left(\rho C_{p} A\right)_{R}$ :

$$
p=\frac{\left(\rho c_{p} A\right)_{F}}{\left(\rho c_{p}^{A}\right)_{F}+\left(\rho c_{p}^{A}\right)_{R}}
$$

where

$$
\begin{aligned}
\rho & =\text { density } \\
c_{p} & =\text { heat capacity } \\
A & =\text { cross-sectional area }
\end{aligned}
$$




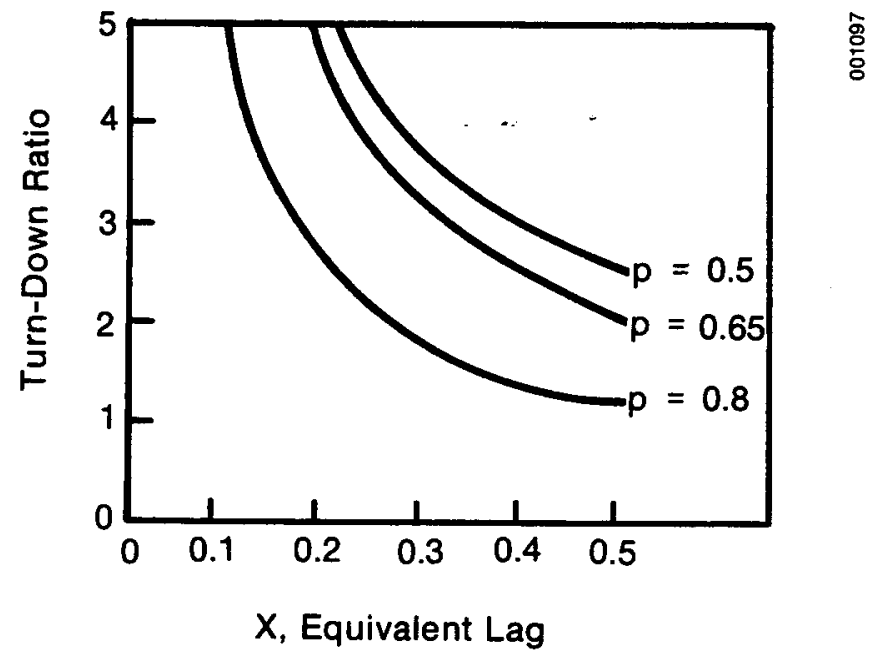

Figure 8-4(a). Turndown Ratio as a Function of Equivalent Lag and Capacitance Ratio (p) for Proportional Control

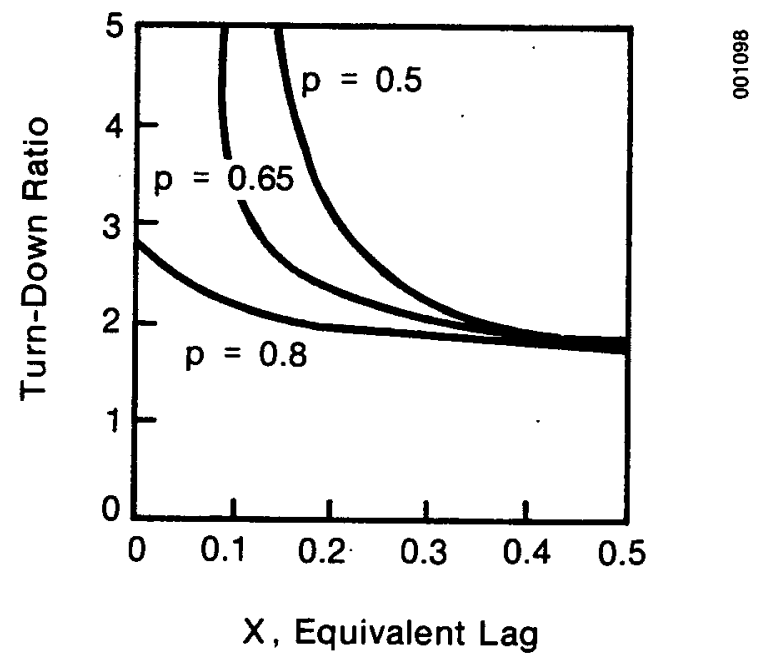

Figure 8-4(b). Turndown Ratio as a Function of Equivalent Lag and Capacitance Ratio (p) for Proportional-Integral Control 


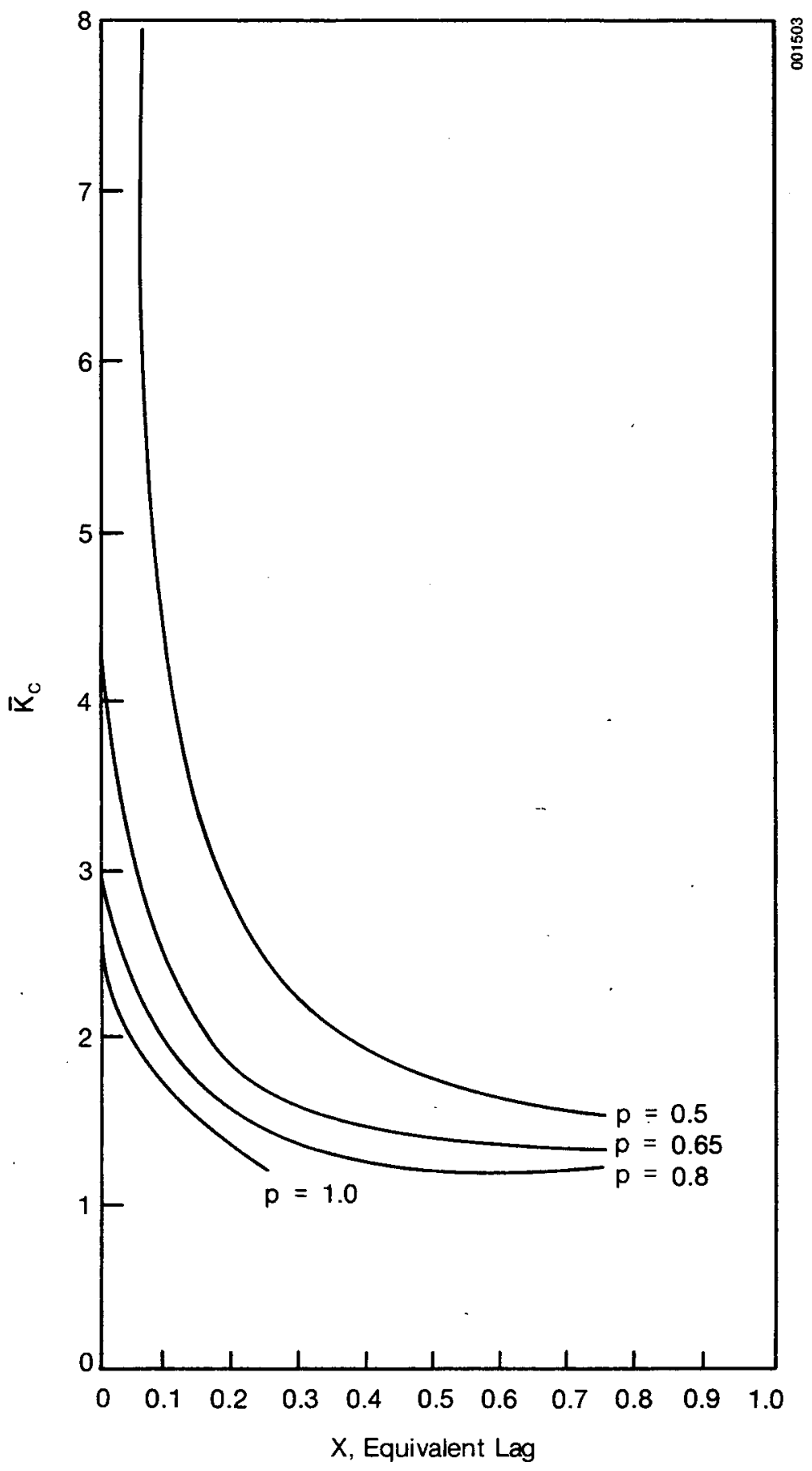

Figure 8-5. Dimensionless Controller Gain as a Function of Equivalent Lag and Capacitance Ratio (p) for Proportional-Only Control 


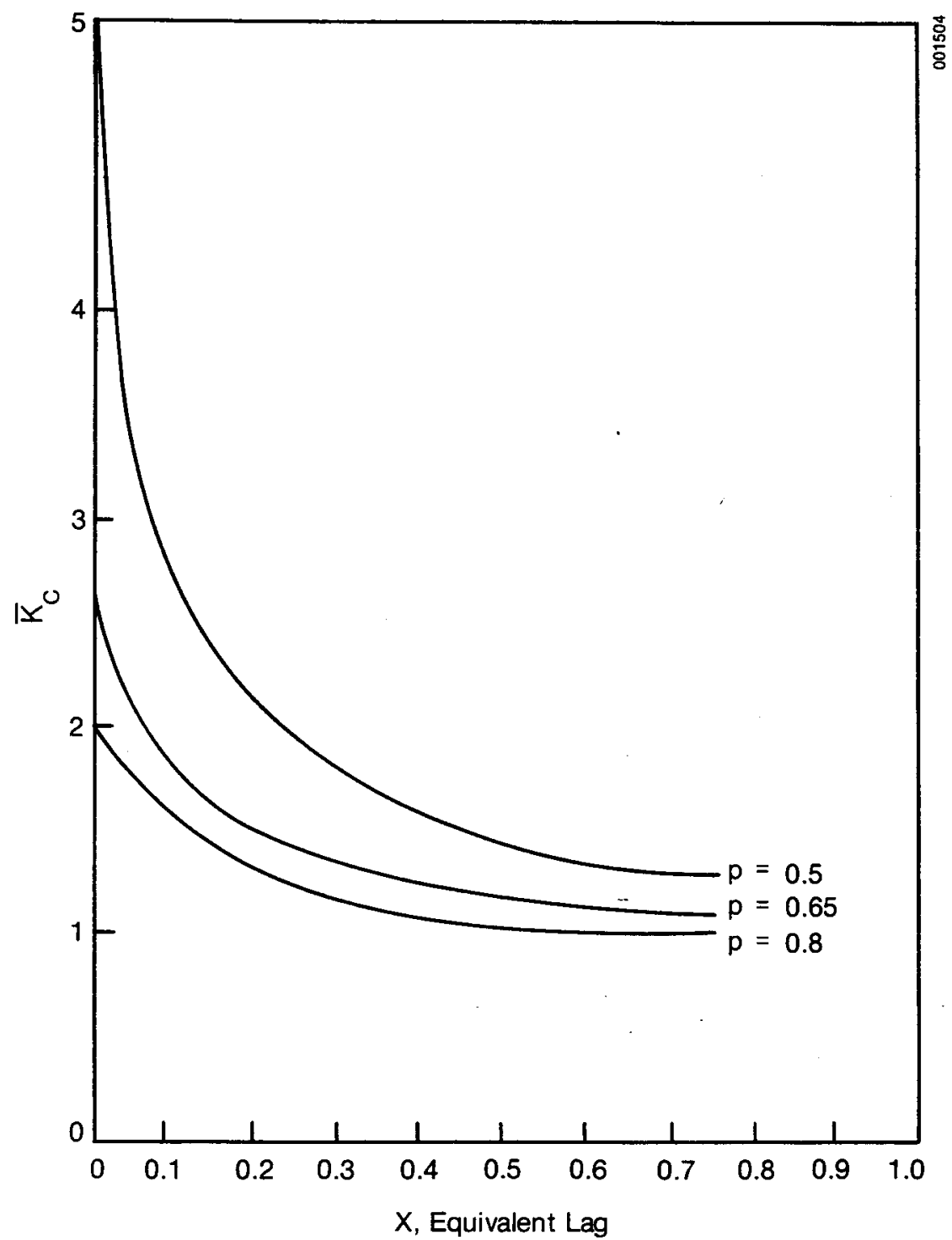

Figure 8-6. Dimensionless Controller Gain as a Function of Bquivalent Lag and Capacitance Ratio (p) for Proportional-Integral Control 


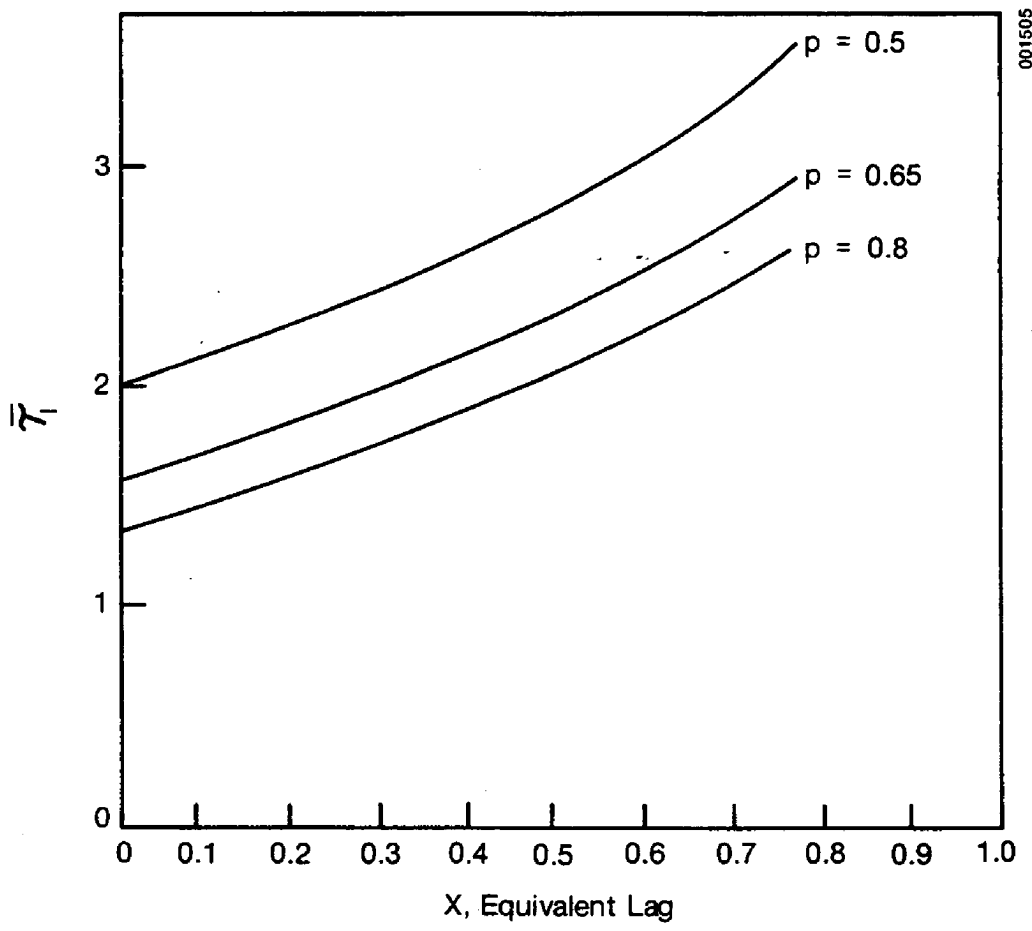

Figure 8-7. Dinensionless Integral Tine as a Function of Bquivalent Lag and Capacitance Ratio (p) for Proportional-Integral Contro1

- Specify X (dimensionless) for a single row of collectors. $X$ is the dead time associated with the piping from the end of the collector row to the sensor location divided by the collector row residence time.

An equivalent lag is an arithmetic average for the $X$ associated with each row in the collector field. For example, if we have three rows and only one sensor that is $12.2 \mathrm{~m}(40 \mathrm{ft})$ from the end of the first row, $6.1 \mathrm{~m}$ $(20 \mathrm{ft})$ from the second row, and $3.05 \mathrm{~m}(10 \mathrm{ft})$ from the third row, then

$$
s_{1}=\frac{40 A}{Q_{v, 1}}, s_{2}=\frac{20 A}{Q_{v, 2}} \text {, and } s_{3}=\frac{10 A}{Q_{v, 3}}
$$

where $Q_{v, 1}, Q_{v, 2}$, and $Q_{v, 3}$ are the steady-state volumetric flow rates in each row, and $A$ is the cross-sectional area of the pipe. Now, the lag for each row (assuming each row is $\mathrm{L}$ meters long) is

$$
\mathrm{x}_{1}=\frac{\mathrm{s}_{1}}{(\mathrm{~L}) \mathrm{A} / \mathrm{Q}_{\mathrm{v}, 1}}, \mathrm{x}_{2}=\frac{\mathrm{s}_{2}}{(\mathrm{~L}) \mathrm{A} / \mathrm{Q}_{\mathrm{v}, 2}}, \text { and } \mathrm{x}_{3}=\frac{\mathrm{s}_{3}}{(\mathrm{~L}) \mathrm{A} / \mathrm{Q}_{\mathrm{v}, 3}} \text {, }
$$

and the equivalent lag is

$$
x=\left(x_{1}+x_{2}+x_{3}\right) / 3
$$

- Determine whether the system has linear or equal-percentage valve characteristics by examining the ratio of $\Delta \mathrm{P}_{\mathrm{F}} / \Delta \mathrm{P}_{\mathrm{v}}$. If the ratio is small (less than 1), equal percentage is appropriate. If the ratio is greater than 1, the system has a linear characteristic. 
If the system has an equal-percentage characteristic, the suggested controller tuning constants will be stable for insolation turndown ratios of 5:1 or more; i.e., if the tuning constants are picked at a design point of $1000 \mathrm{~W} / \mathrm{m}^{2}$, they will be stable even if the insolation dips to $200 \mathrm{~W} / \mathrm{m}^{2}$ or lower.

If the system has a linear characteristic, Fig. 8-4 must be used. After defining $P$ and $X$, read the turndown ratio from the graph. The design insolation should be the minimum operating insolation multiplied by the turndown ratio. If a low turndown ratio is encountered, a smaller valve could be installed to increase $\Delta \mathrm{P}_{\mathrm{v}}$ and give the system more of an equalpercentage characteristic. This enhances the controllability of the field, but it also increases pumping requirements.

- Use Fig. 8-5 to pick a proportional-only constant $\overline{\mathrm{K}}_{c}$. If proportional integral control is desired, use Figs. 8-6 and 8-7 to pick a proportional $\left(\overline{\mathrm{K}}_{\mathrm{c}}\right)$ and integral $\left(\bar{\tau}_{\mathrm{I}}\right)$ constant. (Note that these constants are dimensionless numbers.)

- Calculate the fractional change for a $1^{\circ}$ change in $\Delta T$ across the field,

$$
\mathrm{TF}=1 / \Delta \mathrm{T} \text { across field. }
$$

- Calculate the corresponding change in the signal to the controller [use 103 to $21 \mathrm{kPa}$ ( 15 to $3 \mathrm{psi}$ ) span for pneumatic controllers; use 4 to $20 \mathrm{~mA}$ for electronic controllers]:

$$
\mathrm{PT}=\frac{(103 \mathrm{kPa}-21 \mathrm{kPa})\left(1^{0} \text { change }\right)}{\text { temperature transmitter span }} .
$$

- Calculate the corresponding change in flow rate per $1^{\circ}$ change in temperature:

$$
\mathrm{FF}=\left(\overline{\mathrm{K}}_{\mathrm{C}}\right)(\mathrm{TF})\left(\mathrm{F}_{\mathrm{SS}}\right)
$$

- Calculate the change in controller signal for the change in flow rate:

for linear characteristics,

$$
P Q=\frac{(20 \mathrm{~mA}-4 \mathrm{~mA})(\mathrm{FF})}{\text { flow transmitter span }} ;
$$

for equal percentage characteristics,

$$
P Q=\frac{(20 \mathrm{~mA}-4 \mathrm{~mA})(\mathrm{FF})}{\mathrm{F}_{\mathrm{SS}} \operatorname{lnR}} ;
$$

where $R$ is the valve characteristic (typically 20-50). 
- Calculate the gain

$$
\mathrm{K}=\frac{\mathrm{PQ}}{\mathrm{PT}}
$$

and proportional band (typically $0 \%-500 \%)=\frac{100}{\mathrm{~K}}$.

- Calculate the integral time

$$
\tau_{I}=\left(\bar{\tau}_{I}\right)\left(\tau_{d}\right),
$$

where $\tau_{d}$ is the process residence time. The reset rate (typically 0 to 5 repeats per minute) $=1 / \tau_{I}$.

Example:* Following the procedure we outlined:

- Temperature transmitter span is $-18^{\circ}$ to $538^{\circ} \mathrm{C}\left(0^{\circ}\right.$ to $\left.1000^{\circ} \mathrm{F}\right)$. Flow transmitter span is 0 to $10 \mathrm{gpm}\left(6.31 \times 10^{-4} \mathrm{~m} / \mathrm{s}\right)$. Temperature setpoint is $316.1^{\circ} \mathrm{C}\left(601^{\circ} \mathrm{F}\right)$. $\Delta \mathrm{T}$ across the field at steady-state conditions is $160^{\circ} \mathrm{C}$. The ratio $\Delta \mathrm{P}_{\mathrm{F}} / \Delta \mathrm{P}_{\mathrm{v}}>1$. The steady-state flow rate is $8.1 \mathrm{gpm}\left(5.1 \times 10^{-4}\right.$ $\left.\mathrm{m}^{3} / \mathrm{s}\right)$.

- $P=0.65$.

- Since each collector row is $97.5 \mathrm{~m}$ (320 ft) long, and the temperature sensor is $6.1 \mathrm{~m}(20 \mathrm{ft})$ from the end of each row, then

$$
\mathrm{X}=\frac{(20)(\mathrm{A}) / Q_{\mathrm{v}}}{(320)(\mathrm{A}) / Q_{\mathrm{v}}}=\frac{6.1}{97.5}=0.06
$$

- Because $\Delta \mathrm{P}_{\mathrm{F}} / \Delta \mathrm{P}_{\mathrm{v}}>1$, the system has a linear characteristic.

- For proportional-only control, use Fig. 8-5:

$$
\overline{\mathrm{K}}_{\mathrm{c}}=2.9 ;
$$

for proportional-integral control, use Figs. 8-6 and 8-7:

$$
\overline{\mathrm{K}}_{\mathrm{c}}=2.0 \text {, }
$$

and

$$
\bar{\tau}_{I}=1.7
$$

- $\mathrm{TF}=1 / 160^{\circ}=0.00625$.

- $\mathrm{PT}=(12) /(1000-0)=0.012$.

- For proportional-only control:

*Note: This realistic example is taken from Schindwolf (1981). 


$$
F F=(2.9)(0.00625)(8.1)=0.147 ;
$$

For proportional-integral control:

$$
F F=(2.0)(0.00625)(8.1)=0.10 \text {. }
$$

- For equa1-percentage characteristics,

Proportional: $\quad P Q=\frac{(12)(0.147)}{(8.1(\ln 50)}=0.0557$

Proportional-integral: $\quad P Q=\frac{(12)(0.1)}{(8.1)(\ln 50)}=0.038$.

- Proportional:

$$
\begin{aligned}
\mathrm{K} & =\frac{0.0557}{0.012}=4.64 ; \\
\mathrm{PB} & =\frac{100}{4.64}=21.5 \% ;
\end{aligned}
$$

Proportiona1-integral: $\quad K=\frac{0.038}{0.012}=3.2$;

$$
\begin{aligned}
\mathrm{PB} & =\frac{100}{3.2}=31 \% ; \\
\tau_{\mathrm{d}} & =(1-\mathrm{in} . \text { pipe, } 320-\mathrm{ft} \text { row, } 8.1 \mathrm{gpm}), \\
& =\frac{(320 \mathrm{ft})\left(0.006 \mathrm{ft}^{2}\right)}{0.02 \mathrm{ft}^{3} / \mathrm{s}} \frac{\mathrm{min}}{60 \mathrm{~s}}=1.6 \mathrm{~min} ; \\
\tau_{\mathrm{I}} & =(1.7)(1.6)=2.7 \mathrm{~min} . \\
& =\frac{1}{2.7}=0.37 \text { repeats } / \mathrm{min} .
\end{aligned}
$$

In this case, the large temperature transmitter span is producing high control loop gain. An improvement may be made by reducing the span from $-18^{\circ}$ to $538^{\circ} \mathrm{C}\left(0^{\circ}\right.$ to $\left.1000^{\circ} \mathrm{F}\right)$ to $204^{\circ}$ to $482^{\circ} \mathrm{C}\left(400^{\circ}\right.$ to $\left.900^{\circ} \mathrm{F}\right)$.

To test the tuning constants given above, a dynamic simulation of a solar IPH system was conducted. Again, for comparison and verification purposes, the model was made similar to the work of Schindwolf (1981). The numerical solution and process control analysis were done via the Advanced Computer Simulation Language (ACSL). ACSL is a control-oriented language useful in dynamic analysis.

Figures 8-8 and 8-9 show the solar system response to proportional and proportional-integral control for an inlet water temperature of $226.7^{\circ} \mathrm{C}\left(440^{\circ} \mathrm{F}\right)$, an outlet temperature setpoint of $316^{\circ} \mathrm{C}\left(601^{\circ} \mathrm{F}\right)$, and an insolation which is 

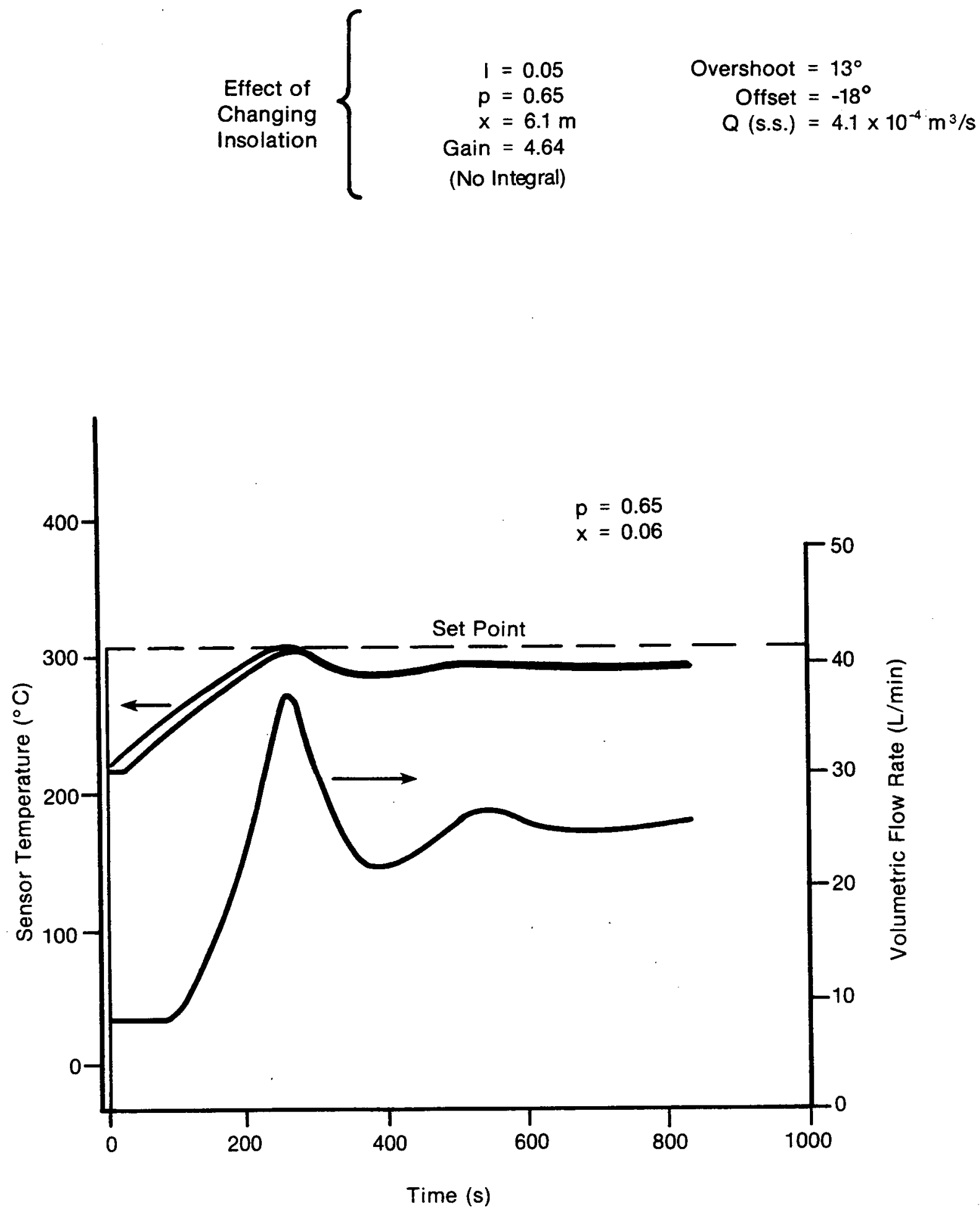

Figure 8-8. Solar System Response with Proportional-0nly Contro1 


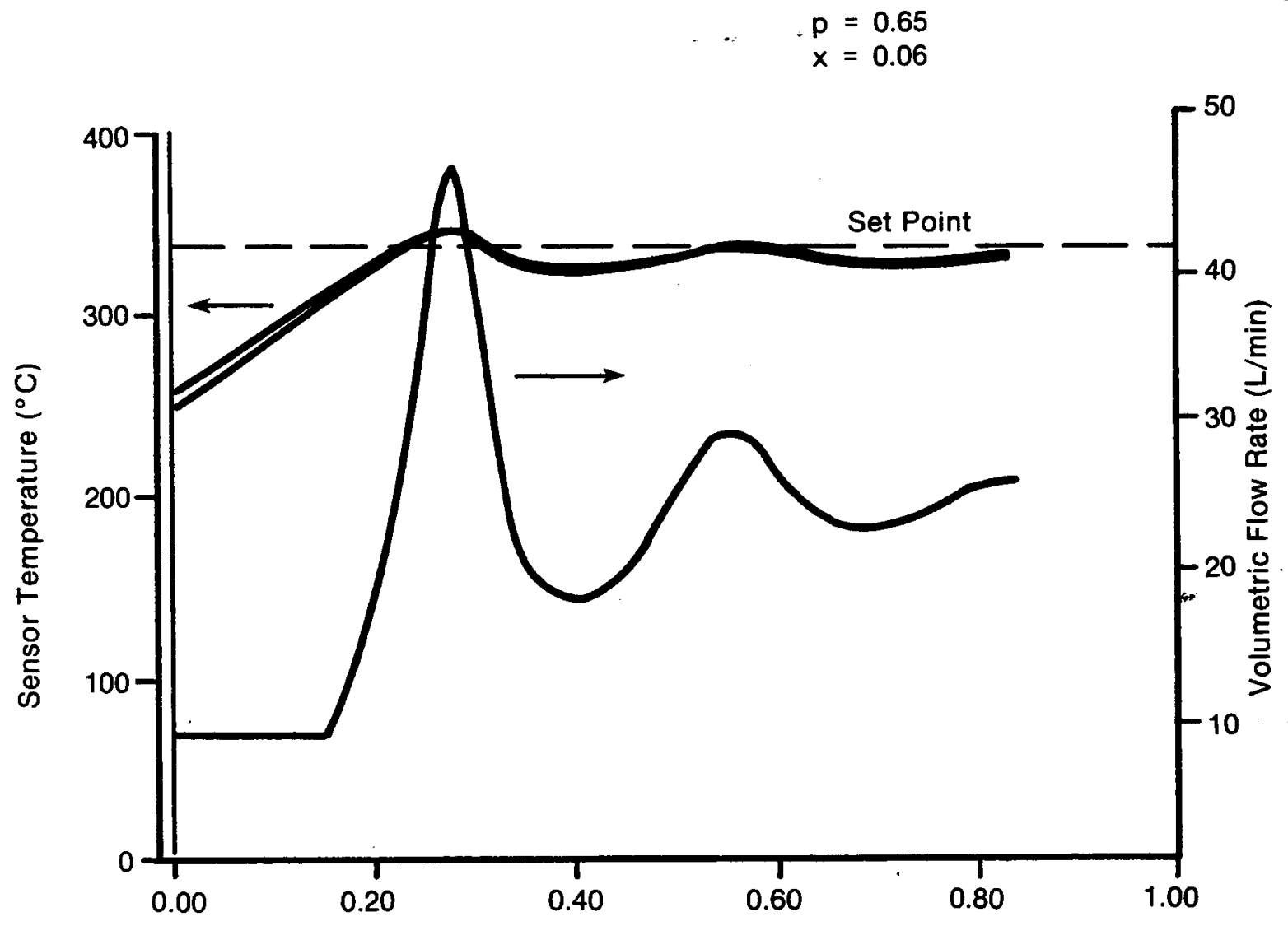

PIgure 8-9. Solar Systen Response with Proportional-Integral Control 
changed from 0 to $600 \mathrm{~W} / \mathrm{m}^{2}$. The design insolation was $800 \mathrm{~W} / \mathrm{m}^{2}$. Note that the addition of integral control eliminates the offset between the final temperature and the setpoint. Depending on the requirements of the system (i.e., offset and overshoot), designers may choose proportional-integral control rather than proportional-only control.

In general, these tools should be helpful during the design phase of the solar system. They will handle problems ranging from poor sensor location to incorrect transmitter span specifications. They are intended to give the designer a feel for control system performance before the system is built.

\subsubsection{Start-up/Shutdown}

The best way to manage the frequent start-ups and shutdowns of a solar IPH system is with a microcomputer or a PLC. These tools can implement relay logic and time delays that can stow tracking collectors and start or stop flow consistently and sequentially.

The start-up mode enables us to start process heat generation rapid1y at sunrise. When sufficient light intensity is sensed by the trackers (if any) or when a sufficient collector-storage $\Delta T$ is reached, the circulating pump is turned on. The control logic may include a start-up for low flows or viscous heat transfer oils.

If the solar system tracks, the start-up controls and safety logic include moving the collectors into a sun-tracking position and maintaining flow at a minimum. A well-designed tracking system is critical in optimizing energy production as well as in providing protection against overpressure, overtemperature, and other energency modes. The system should be able to (1) accept demand flow signals; (2) start the flow through the collectors; and (3) sense fluid temperature, $\mathrm{AC}$ power, solar intensity, and wind speed. Typical features of a shadow-band collector tracking system (the most popular tracker) are as follows:

- Each collector array is equipped with a shadow-band device, control circuit, and drive motor. With centralized control, a master controller is used to control all collector arrays.

- The system is capable of tracking in both rotational directions. Twospeed or multiple-speed tracking is desirable and allows the collectors to quickly reach a stow condition.

- A digital shaft encoder is used to measure the angular position of the collector shaft. Limit switches mounted on the collectors are used for fail-safe end travel to prevent mechanical damage.

- A standby emergency power source is needed to defocus and stow collectors to prevent equipment damage from overheating in the event of power failure.

Figure 8-10 is a flow chart of a typical collector control loop. As an example, the master controller uses the system-permissive signal and low-flow detection before sending a start-permissive signal to the individual collector 


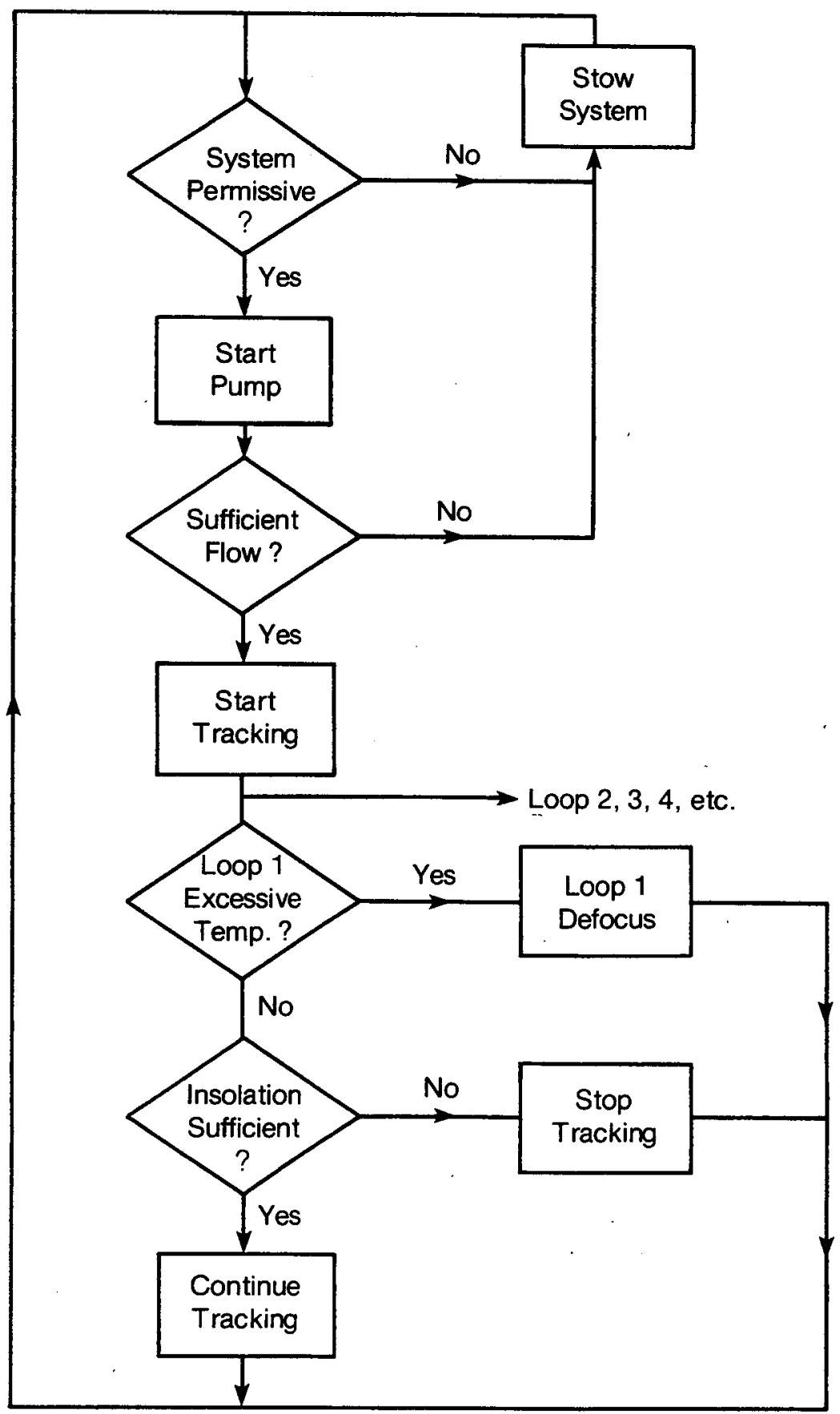


array controllers. The individual array controller is responsible for detecting excessive temperatures and for determining when there is sufficient insolation for an operation.

Computer-command position tracking is another approach to collector focusing . It can be the primary control method or a backup. With this system, a microcomputer implements a tracking algorithm that calculates the position of the sun and commands the motor to drive the collector trough to the correct angle.

Normal shutdown occurs near the end of the solar day and during periods when the time-averaged radiation falls below a specified level. The collector array is stowed in the safest position (minimum wind loading and maximum reflective surface protection). The circulating pump is stopped after a time delay, and the whole system is shut down according to a predetermined sequence. Overnight thermal losses may be lessened by extracting as much energy as practical from the collector field.

\subsubsection{Preezing/Stagnation}

Two strategies for freeze protection in a water-filled loop-are a drain-back system and a circulation loop. The drain-back system can reduce overnight losses, but can also cause corrosion in the collector piping and pressure surges at start-up. Water circulation from a storage or flash tank may be associated with significant heat losses over a year of operation, however. Generally, this type of freeze protection should be considered only in mild climates. In both cases, the freeze-protection point should be at least $2^{\circ} \mathrm{C}$ above the freezing temperature of the fluid. The fluid temperature must also account for night radiation losses, a significant factor in dry climates. To ensure that the coldest point in the system is known, several sensors in different locations should be monitored. In the circulation system, a time delay should be used which is sufficient to ensure that the entire loop is warmed to above freezing before the pump shuts off. Freeze protection should be automatically implemented in emergency conditions, such as during a power outage.

Stagnation caused by overpressure, overtemperature, or thermal shock can harm the collector system (thermal shock can be especially damaging to evacuatedtube collectors). The control logic should prevent stagnating collectors from being filled with cold fluid when they are above a critical temperature. For example, if evacuated-tube collectors stagnate during the day, the circulating pump should not be restarted until they have cooled to a safe temperature. Circuit-breakers should be located in a locked box to prevent tampering. Overtemperature and overpressure may be controlled by increasing the fluid flow rate, stowing the collectors, or both.

\subsubsection{Emergency Conditions}

Typical emergency shutdown conditions include abnormal temperature, pressure, flow rate, or fluid level; pump failure; excessive wind speed; and loss of power. The conditions are set by maximum temperatures and pressures that collectors can withstand and the vapor pressure, toxicity, and autoignition point of the heat transfer fluid. In the checkout phase, the necessary limit 
switches that indicate these emergency conditions must send the correct signals to the control area. For example, a low-flow or high-temperature condition requires stowing the collectors. Also, emergency conditions must be signalled to the operator by means of visual and audible alarms. The emergency shutdown logic should be fail-safe, and the control valves should go to the safest position if instrument air or electrical power is lost. If a PLC implements alarms and relays, the critical functions should be hard-wired to circumvent controller problems. A total system kill switch should also be provided for fire protection. The switch should stop fluid flow, stow collectors, and be accessible to firemen. Finally, checking out the automatic emergency conditions will be easier and safer if electrical simulation of control inputs are provided for.

\subsubsection{Operator Training/Display}

Operators should be trained in all normal and emergency modes of the system. They must be able to react quickly to alarms and know how to perform diagnostic procedures. They should be trained in emergency procedures and should keep a daily log of unusual occurrences, corrective actions, and routine maintenance activities. They should maintain up-to-date piping and instrumentation diagrams, post signs indicating if a control loop is on manual or if an alarm or override has been bypassed, and keep records of relief valve, interlock, and controller settings.

A process display should be visible to the operator, along with the solar field. The display should show flow directions and control loops. If a data acquisition system is used, the operator should be familiar enough with it to start it up, handle problems, and replace paper and tapes.

\subsubsection{Control System Checkout}

A complete, sequential checkout can save plant personnel time and prevent equipment damage during start-up. A checkout may include the following steps.

Before the electricity is turned on:

- Check the equipment and process configuration. Label equipment, flow direction, fuel lines, etc.

- Use an ohmmeter to perform point-to-point wiring checks. Check the continuity between instruments and terminal boxes, master terminal cabinets, and the motor control center. Note whether switch and alarm contacts are normally open or normally closed, and verify that the action is correct. Also check the continuity of the analog controller, the PLC, and the emergency shutdown relays.

- Ad just temperature, pressure, and flow limit switches. Also, ad just the valve travel limit switches.

- Dial in analog controller set points and tuning constants. 
With the electrical power on:

- Program the PLC to accept alarm conditions.

- Check the power distribution. Verify activation of the proper elements when individual circuits are activated on the operator panel.

- Verify functions of the Uninterruptible Power System transfer switch to alternate supply by operating the main power breaker.

- Perform a control loop function check. Input "dummy" signals at the sensor element, possibly using a resistance decade box. Verify that the controllers and the final control elements are working as signals are changed. Reconfirm that travel limit switches on valves are working properly by observing annunciator and control panel displays.

- Check the alarm functions. From the PLC keyboard, activate all alarms and status signals generated by the PLC. Simulate alarm conditions at the sensor element by manipulating instrument contacts (on or off). Verify that the corresponding alarms are activated and that the correct motor action is taken.

\subsection{INSTRUMENTATION AND DATA ACQUISITION}

An extensive treatment of this topic is beyond the scope of this section, but some observations are in order. First, instrumentation is needed both for system control and to provide information about the system's performance. And instrument control systems must be evaluated in terms of cost versus efficiency. In instrument applications, quality is often sacrified to minimize original costs, but such shortcuts can result in increased maintenance costs and loss of production time. Most instrument control systems are installed with a life expectancy of 10, rather than 25, years. A system must also be evaluated in terms of available operating personnel. Sophistication and complexity can work against plant efficiency without proper staff support (Andrew 1974).

To ensure continued accuracy, all sensors should be calibrated frequently according to the manufacturers' recommendations. The use of dependable visual gauges near control sensors is recommended to facilitate troubleshooting. When possible, the use of locally serviceable equipment will reduce the amount of downtime.

\subsubsection{Flow Heasurement}

Basic flow measurement instruments can be categorized as

- head meter (differential pressure across an engineered restriction)

- variable area or rotometer (weight)

- magnetic meter (velocity)

- turbine meter (velocity) 
- target meter (weight)

- vortex shedding meter (turbulence).

In choosing the correct instrument for the solar application, consider the operating.conditions. Note the range of flow rates required and the normal expected flow. The most common flow measurement, the head meter, is applicable only from a 3:1 to 5:1 ratio of flows. For indication only, a 5:1 ratio is acceptable; for closed-loop control, however, $3: 1$ is preferable. If a higher range is needed, it is necessary to use two head devices in parallel or use another type of device with a 10:1 or 20:1 range. Temperature and pressure variations must be known so that compensation can be included. Corrosion and viscosity effects must also be taken into account.

The orifice plate is the most common restrictive device used in head flow measurements. Orifice plates are inexpensive up to the larger pipe sizes and are very reliable. From a pressure-loss standpoint, venturi tubes have a decided advantage over orifice plates; from an accuracy standpoint, the two are similar. Because more test data are available on orifice plates, more certainty exists about their coefficients, especially at low Reynolds numbers. In the process industries of the United States, the American Gas Association (AGA) standards for installation of these devices are the most widely accepted.

Pitot tubes and (for air systems) hot wire anemometers can be used to measure flow rate. To determine total volumetric flow, however, a properly weighted array of point measurements must be employed.

The rotometer is a variable-area flowmeter consisting of a vertical tapered tube with a float that is free to move up and down within the tube as the flow varies. Rotometers are available in a variety of styles and can meet a wide range of service conditions. These flowmeters have an accuracy of $\pm 2 \%$ and a range of about 10:1. The pressure drop across the meter is constant once the float lifts off the float stop and ranges from a few centimeters of water (small-sized meters) to about $7 \mathrm{kPa}$ ( 1 psi) (larger meters).

Magnetic flowmeter measurement is independent of viscosity, density, temperature, and pressure. The meter's desirable features include

- no flow obstructions

- minimal pressure drop

- flexibility of pipe configurations, because the meter measures average velocity.

The following precautions need to be taken in installing the magnetic flowmeter:

- Conductivity must be above the recommended minimum.

- The meter must be full at all times. Air bubbles will cause errors.

Turbine meters consist of a straight-flow tube within which a turbine or fan is free to rotate about an axis fixed along the centerline of the tube. 
Accuracy is obtained by operating the meter in the linear portion of its range $(10 \%$ to $100 \%)$. At low fluid velocities, the number of pulses generated per $\mathrm{m}^{3}$ of flow is small and changes appreclably with flow rate. At about $10 \%$ of rated flow, however, a linear relation is maintained between pulses and flow. Within these limits, accuracy is normally $\pm 0.25 \%$ to $\pm 0.5 \%$; the repeatability of the turbine meter is excellent, ranging from $\pm 0.25 \%$ to $\pm 0.02 \%$; and the ranges are generally $10: 1$ or $20: 1$. The pressure drop across the meter varies with the square of the flow. But because the meter is inserted into the flow line, the entire mechanism is subject to dirt and erosive action. Turbine meters work best when they are used in a lubricating fluid.

Target meters function by measuring the force on a disc centered in the pipe with the plane of the disc at right angles to the direction of flow. The accuracy is $10.5 \%$ to $3 \%$ of flow range. Target meters are especially useful in measuring heavy, viscous, dirty, or corrosive fluids. They can handle pressures up to $10 \mathrm{MPa}(1500 \mathrm{psig})$ and temperatures up to $400^{\circ} \mathrm{C}\left(750^{\circ} \mathrm{F}\right)$.

Whatever flow measuring device is used, it is important to follow the manufacturer's recommendations regarding the lengths of straight pipe required upstream and downstream or to consult available standards.

\subsubsection{Level Measurement}

Level measurements fall into two general groups--direct and inferential. Direct level measurements, such as sight gauges, are not easily adapted to signal transmission, but they are simple and economical. Inferential methods utilize properties such as buoyancy, hydrostatic head, sonar, conductance, capacitance, radiation, and weight. Caution must be used in applying inferred level measurement; the measured property must have a well-defined relationship to the level. Otherwise, large errors can occur.

\subsubsection{Pressure Measurenent}

We11-known pressure elements include manometers, Bourdon tubes, bellows, diaphragms, and strain gauges. These instruments must also be compensated for process conditions, especially temperature. Pressure gauges account for a large percentage of pressure measuring elements used. Their accuracies vary from $\pm 0.1 \%$ to $\pm 5 \%$. Their ranges vary from a few centimeters of water to about $700 \mathrm{MPa}(100,000 \mathrm{psig})$ and from 0.1 to $760 \mathrm{mn}$ of mercury absolute.

\subsubsection{Tenperature Measurement}

The most common methods of measuring temperature are by means of thermocouples, filled systems, bimetallic elements, resistance elements, and thermistors. The choice of sensor depends primarily on four factors: system cost, accuracy, dependability, and adaptability to the process. The first consideration speaks for itself. The second factor requires a balance between different requirements; e.g., while one process must be controlled within a degree or two, others may vary several degrees with no loss of efficiency or quality. The third factor, dependability, is also a factor of process conditions. For example, high temperatures and oxidation may cause early failures 
in system elements. Adaptability to the process is simply selecting and locating a sensor so as not to upset the process functions; e.g., not placing a thermocouple in the path of an agitator or a thermowell in a stream that coats the well and thereby causes inaccurate measurements.

The thermocouple (TC) is the most versatile electronic temperature sensor. Various standard TCs are available in temperature ranges between $-185^{\circ} \mathrm{C}$ $\left(-300^{\circ} \mathrm{F}\right)$ and $1760^{\circ} \mathrm{C}\left(3200^{\circ} \mathrm{F}\right)$. Greater accuracies can be achieved by paying special attention to grounding and shielding:

- Ground all shields. An ungrounded shield does not provide noise protection.

- Ground a shield at only one point. Grounding at two points produces rather than prevents noise.

- For common mode noise rejection with a grounded couple, ground the shield on the extension wire at the couple. The shield should not be grounded in the control room.

Thermocouples are seldom placed directly in a process stream. Rather, they are placed inside protecting wells so that they may be removed or replaced without shutting down the process. The wells slow response time appreciably, but reduce the cost of replacement. In using thermocouples, one must ensure that sufficient immersion depth is provided to reduce conduction heat loss. High-quality extension wire should be uniformly calibrated and wires should not pass through sudden large temperature gradients.

Sealed metal bulbs or tubes, partially or completely filled with liquids or gas, are widely used as temperature sensors. Bulbs completely filled with liquid have high accuracies and fast response rates, but are limited to ranges of $-18^{\circ} \mathrm{C}\left(0^{\circ} \mathrm{F}\right)$ to $315^{\circ} \mathrm{C}\left(600^{\circ} \mathrm{F}\right)$. Partially filled vapor-pressure sensors are less expensive and can be specified for ranges between $230^{\circ} \mathrm{C}\left(450^{\circ} \mathrm{F}\right)$ and $540^{\circ} \mathrm{C}$ $\left(1000^{\circ} \mathrm{F}\right)$. Bimetallic sensors utilize dual strips, with different heat coefficients of expansion joined together. Most often employed in on-off control systems, they have ranges of $-75^{\circ} \mathrm{C}\left(-100^{\circ} \mathrm{F}\right)$ to $1100^{\circ} \mathrm{C}\left(2000^{\circ} \mathrm{F}\right)$, but slow response times and poor repeatabilities.

Resistance temperature detectors (RTD) are also common. These sensors are more expensive than TCs and require a current source and signal conditioning, but they are very stable. They provide good linearity from $-240^{\circ} \mathrm{C}\left(-400^{\circ} \mathrm{F}\right)$ to $900^{\circ} \mathrm{C}\left(1650^{\circ} \mathrm{F}\right)$, and their unamplified signals can often be transmitted over distances up to $100 \mathrm{~m}$ without degradation. Care should be taken to position the RTD at bends in the flow path to maximize heat transfer. Four-wire types are recommended to eliminate lead resistance effects, unless signal conditioning is located close to the measurement point.

Thermistors are the preferred sensor when great sensitivity is required. They are extremely nonlinear, which has limited their application; however, this is not a problem for a PLC or microcomputer. An excellent article by L. M. Tierstein (1978) reviews the companies that manufacture temperature sensors, regulators, and controllers. 


\subsubsection{Irradiation Heasurement}

A number of different types of instruments measure the intensity of solar radiation. Pyranometers that employ a photovoltaic cell are relatively inexpensive and have an accuracy of $3 \%$ to $5 \%$. For greater accuracy, the Eppley Precision Spectral Pyranometer (PSP) is commonly used. It utilizes a copperconstantan thermopile attached to a Parson's black receiver beneath two concentric glass domes with compensation for ambient temperature.

Measuring total radiation in the plane of the collectors is sufficient to determine array efficiency in nontracking collectors. Concentrating co1lectors essentially collect no diffuse radiation, but a measurement of direct radiation is required. A pyrhellometer that tracks the sun in two axes measures only direct radiation. To determine direct radiation normal to the aperture of tracking concentrators (needed for an array efficiency calculation), the measured radiation must be multiplied by the cosine of the angle between the collector aperture normal and earth-sun line. Since this value changes continuously during the day, the conversion would be performed by a data acquisition system.

One problem with the pyrheliometer is that it requires periodic adjustment, and its power cord must be unwound often. Solar field measurements are of ten not maintained well, so data are lost. A less accurate but more reliable means of determining direct radiation in the collector plane is to mount both total and shadow-band pyranometers (one each) on a collector. The shadow band blocks direct radiation, permitting only diffuse radiation to be measured. The direct radiation in the plane is the difference between total and diffuse radiation. If the shadow band is mounted parallel to the tracking axis, it will never require adjustment. Of course, if the collector is not tracking accurately, the measured radiation will be too low. Modern trackers, however, track accurately enough so that this should not be a problem.

\subsubsection{Converters}

Converters link electronic and pneumatic control systems together, change signal levels in the application of computers to control problems, and convert easily obtained sensing signals to other forms more easily transmitted. The units can be classified into five groups:

- current-to-pneumatic (I/P)

- pneumatic-to-current ( $P / I)$

- voltage-to-current ( $E / I)$

- voltage-to-pneumatic ( $\mathrm{E} / \mathrm{P})$

- current-to-current (I/I).

The first three converters--I/P, $P / I$, and $E / I--a r e$ the most common. Inputs to $I / P$ converters are normally $1-5,4-20$, or 10-50 mA. These shockproof and vibrationproof units may be mounted upright but not tilted more than $10 \%$ from the vertical centerline, and they may be mounted on or away from the actuating or control element. Finally, they can either signal a pneumatic positioner or 
can direct-load the control valve if a spring-loaded actuator and volume booster are used.

$P / I$ converters are used when pneumatic signals must be converted to electronic signals, for example, a pneumatic transmitter connected to an electronic controller. "They are also used when instrument air is not available at the controller and when long transmission distances are involved (more than $500 \mathrm{ft}$ ). The units may be installed in any orientation, have the ability to operate in vibrational environments, and have a built-in power supply.

E/I converters are widely used in the processing industries. For example, thermocouples, the most common millivolt-generating sensing element, require $\mathrm{E} / \mathrm{I}$ units to convert the signals to $1-5,4-10$, or $10-50 \mathrm{~mA}$ for inputs to controllers or other receivers. E/I temperature converters are designed to accept standard thermocouple inputs directly, converting them to high-level DC current outputs. These units normally have built-in temperature compensation and thermocouple burn-out protection.

\subsubsection{Data Acquisition}

Because the DOE-sponsored IPH field tests were experiments, they utilized fairly expensive, detailed data acquisition systems (DAS). Because of their complexity, these systems were kept separate from the control system so as not to compromise the reliability of the latter. Industrial owners funding their own IPH systems will probably want a much less sophisticated DAS. In that case, the small amount of data needed could simply be taken from the control system, thereby eliminating the extra costs that would be incurred by having two separate systems.

Data acquisition varies from a simple reading of energy collected to a detailed breakdown of all system energy balances. A study of different types of systems is given in Bush and Kutscher (1980). A discussion of the more sophisticated system can be found in Kutscher (1979) and Kutscher and Davenport (1980). Experience has shown that no matter what type of DAS is used, care must be taken to ensure reliability.

The data acquisition hardware (data logger or minicomputer, tape drives, printer, etc.) should be located in a sheltered environment with a temperature control. The area should be free from dust, steam, water leaks, and vibrations. It should also not be exposed to direct sunlight. Isolation transformers are recommended for systems that are susceptible to damage by voltage spikes. Ideally, the DAS should be capable of taking data whether or not the solar system is operating. Battery back-up should be employed so that the DAS can keep track of time and maintain memory during a power outage. It is also very important to select components that are compatible. Poor matches of data loggers and tape drives have caused problems in the past. 


\subsection{RETEREWCES}

Andrew, W. G. 1974. Applied Instrumentation in the Process Industries. Houston, TX: Gulf Publishing Co.; Vol. 1.

Baumann, "H. O. 1981 (29 June). "Control-Valve vs. Varlable-Speed Pump." Chemical Engineering. p. 81.

Baumann, H. 0. 1979 (May). "A Case for Butterfly Valves in Throttling Applications." Instruments and Control Systems. p. 35.

Buckley, P. S. 1964. Techniques of Process Control. New York: John Wiley \& Sons, Inc.

Bush, G.; Kutscher, C. F. 1980 (June). "Data Acquisition for Solar Industrial Process Heat Field Tests." Proceedings of the 1980 Annual Meeting. American Section of the International Solar Energy Society. Phoenix, Az.

Campbell, Donald P. 1958. Process Dynamics. New York: John Wiley \& Sons, Inc.

Chemical Engineering Deskbook. 1979 (15 Oct.). New York: McGraw-Hil1.

Considine, D. M.; and Ross, S. D. 1964. Handbook of Applied Instrumentation. New York: McGraw-Hill.

Eckman, D. P. 1958. Automatic Process Control. New York: John Wiley \& Sons, Inc.

Grader, Jerome. 1970. Basic Process Control. Taylor Instrument Company.

Harriott, Peter. 1964. Process Control. New York: McGraw-Hill.

Kutscher, C. F. 1979 (30 Mar.). SPIPS Data Acquisition System Guidelines. Golden, CO: Solar Energy Research Institute; memorandum to SPIPS contractors.

Kutscher, C. F.; Davenport, R. L. 1980. (Sept.). Monthly Reporting Requirements for Solar Industrial Process Heat Field Tests. SERI/MR-632-714. Golden, CO: Solar Energy Research Institute.

Luyben, W. L. 1973. Process Modeling, Simulation, and Control for Chemical Engineers. New York: McGraw-Hill.

Schindwolf, R. 1981 (July). Frequency Response Analysis of Fluid Control Systems for Parabolic-Trough Solar Collectors. SAND80-0385. Albuquerque, NM: Sandia National Laboratories.

Shinskey, F. G. 1967. Process Control Systems. New York: McGraw-Hill.

Su, W. S.; Castle, J. N. 1979 (July). State-of-the-Art of Solar Control Systems in Industrial Process Heat Applications. SERI/TP-39-240. Golden, CO: Solar Energy Research Institute. 
Tierstein, L. M. 1978 (Dec.). "Selecting Temperature Regulators and Controllers." Instrumentation Technology. pp. 52-59.

Torkelson, L. E. 1980 (Sept.). Pump Power Consumption Test Report. SAND80-1707. Albuquerque, MM: Sandia National Laboratories.

Wright, J. D. 1981 (July). "Analytical Modeling of Line-Focus Solar Collectors." Presented at the JACC, San Francisco, CA; Aug. 1980. 
SECTION 9.0

INSTALIATION AND START-UP

\subsection{INSTAhATION AID CHECROUT}

The reliability and performance of a solar system depend to a great extent on the quality of the original installation. Installation should conform to all applicable engineering standards and codes and should be consistent with good engineering practices. Although many facets of system installation will be familiar to contractors, some will be outside their range of experience, and these can cause unexpected difficulties. The following discussion focuses on items that are unique to a solar installation.

\subsubsection{Scheduling}

Constructing an industrial solar energy system requires a considerable amount of equipment and a variety of skilled personnel. Proper scheduling during both the equipment procurement and construction phases can do much to contain costs. For example, collectors should be delivered so that they are kept a minimum amount of time in storage. Collector components are fragile and easily damaged, so collectors should be inspected for damage upon receipt, and any damage claims should be filed as quickly as possible.

Final copies of all system drawings, specifications, codes, operation and maintenance manuals, and other appropriate documents should be available on site for reference. A detailed log should be kept to record progress and to note difficulties. Adequate tools, equipment, and spare parts should also be provided to complete all aspects of installation and start-up with a minimum of delay.

\subsubsection{Installing the Collectors}

The collector field should be located in an area that is not subject to shading from surrounding buildings and vegetation, and for this reason, the growth of vegetation in the collector field should be controlled.

\subsubsection{Installing Flat-P1ate Collectors}

Flat-plate collectors are, of course, nontracking, but they are usually tilted to maximize solar energy collection. However, neither the tilt nor the azimuth orientation of the collector is critical as long as they are within a few degrees of the desired angles. Consequently, some latitude is allowed in the accuracy of the support structure for tilt and azimuth angles. However, most flat-plate collectors have internal manifolds; thus, it is important to align connecting pipes correctly along the collector rows. Also, since the size of the internal manifold is fixed, only a limited number of collectors can be placed in parallel without the danger of flow maldistribution. 
Generally, connections are made with synthetic rubber connectors clamped over the tubes, leaving a sufficient gap to accommodate thermal expansion. Care should be taken not to overtighten these connectors, since this can lead to early system failure. Spring clamps are often used instead of screw clamps to prevent overtightening. Collectors and pipes should be sloped slightly in case it is necessary to drain the system. Slope requirements $[0.010$ to $0.021 \mathrm{~m} / \mathrm{m}(0.125 \mathrm{in}$. to $0.25 \mathrm{in}$. per $\mathrm{ft})]$ for drainable systems must be checked carefully. For collectors with external manifolds, it is important that thermal expansion of the header does not impose stresses on the connections to the absorber plate. Cyclic stresses can cause the connection to

fail.

The largest flat-plate collectors are usually $1.2 \mathrm{~m}(4 \mathrm{ft}$ ) wide by $2.4 \mathrm{~m}$ ( $8 \mathrm{ft}$ ) long and can be handled by two people. The collectors should be mounted rigidly to prevent the structure from flexing, which could break the glazing. Before choosing a collector initially, be sure to consider how easily glazing can be replaced in the field. It is also advisable to prevent liquid collectors from stagnating before they are turned on. Collectors are sometimes shipped with a black plastic cover; it should not be removed until the system is fully checked out under cold-flow conditions and is ready for heat collection. This is a sensible precaution, even though liquid flat-plate collectors should be designed to withstand stagnation conditions, which can produce temperatures in excess of $150^{\circ} \mathrm{C}\left(300^{\circ} \mathrm{F}\right)$. In general, collector installation is fairly rapid once the structure is in place, so it should be postponed to the latest possible date.

With roof-mounted structures, care should be taken to completely waterproof the points of attachment to the roof. Wind loads can cause the collector structure to move; the resulting damage to the roof can cause rainwater to leak into the building. This applies not only to flat plates but to other types of collectors as well.

\subsubsection{Installing Evacuated-Tube Collectors}

Current evacuated-tube designs incorporate integral manifolds. Consequently, installation procedures are very similar to those of flat-plate collectors. Connectors should be made of elastomers such as Viton that are designed to withstand high temperatures. As with flat-plate collectors, stagnation of the collectors during construction should be avoided. Evacuated-tube collectors containing copper heat conduction fins will suffer oxidation and subsequent spallation at stagnation temperatures, which can reach $371^{\circ} \mathrm{C}\left(700^{\circ} \mathrm{F}\right)$. Al1glass types, less susceptible to degradation under dry stagnation conditions, could pose a danger to construction personnel if they should handle the collector near the open end of the tube. All types of evacuated-tube collectors can suffer tube breakage if a cold fluid is inadvertently admitted while they are stagnating. Nondrainable evacuated-tube collectors made entirely of glass should be filled with liquid only during nighttime or cloudy conditions when the solar system is ready for heat removal. Heat removal from such collectors, once they are filled, should not be stopped, since stagnation under wet conditions can cause the tubes to break. Drainable collectors require strict adherence to pipe slope requirements. 


\subsubsection{Installing Iine-Focus Collectors}

The construction tolerances of the foundation work of tracking collectors are critical if the collector structure is to be aligned accurately. Twelve or more collector modules, with each module perhaps $3 \mathrm{~m}$ (10 ft) long, can be driven by a motor in a single string, so accurate alignment of the modules along the row is essential. This is generally achieved by placing studs precisely in the concrete foundation and adjusting the support structure on the studs. Although the concrete foundations along each row must be aligned accurately, it is not critical that all the rows be precisely parallel. Also, it is not necessary that the recelver tube of a parabolic trough collector be mounted absolutely horizontally. Some amount of slope can be tolerated, depending on the design of the bearing. In fact, construction on a southfacing slope in northern latitudes increases energy collection. Similarly, some differences in grade between modules of a two-axis tracking Fresnel lens collector can be tolerated, provided that the orientation of the receiver tubes can be maintained in parallel planes. As we have noted elsewhere, spacing of collector rows involves a compromise between shading losses and land use. Row-to-row spacings of two to three times the aperture width of the collector are usually appropriate for line-focus collectors. In latitudes below $45^{\circ}$, this spacing keeps the annual shading losses to reasonable levels (see also Sec. 6.2).

To ensure accurate tracking in windy weather, the support structure of a linefocus collector must be very rigid. This requirement increases the weight of the structure, so lifting equipment is generally required for installation. Substantial foundations are also required to support the weight of the collectors and, more important, to withstand wind loads both when the collectors are tracking and when they are stowed. At the same time, the foundation design must prevent water or ice from causing the supports to "heave," which would misalign and possibly damage the collectors. If soil conditions are favorable, an augered concrete foundation is typically the most economical support structure. A floating pier structure requires larger volumes of concrete and general1y must extend below the frost line. A foundation test program was undertaken at Sandia Laboratories in 1979 (Auld 1979) and suggested some economical foundation designs for parabolic troughs (Auld 1980).

Load-bearing requirements of struts and pylons vary according to their positions in the collector array. Exterior collectors are subject to higher wind loads than interior modules. Drive pylons must also be reinforced. Such considerations lead to considerable economies in construction. Wind tunnel tests have been carried out to characterize the wind loads experienced by parabolic troughs (Randall, McBride, and Tate 1980). The tests showed that interior collector modules installed in a collector field experience a $50 \%-65 \%$ reduction in peak wind loads. Also, a collector field surrounded by a fence or berm that is three-fourths of the maximun collector height exhibits a reduction in wind load nearly equivalent to that of the inside rows of collectors. An assessment of existing studies of wind loading on solar collectors (Murphy 1981) discusses these effects, particularly in regard to wind fences and berms.

On site, the collectors should be assembled according to the manufacturer's instructions. Once again, great care must be taken not to damage components. 
The selective surface of the receiver tube and the Pyrex glass envelope of a parabolic-trough collector should be cleaned carefully before installation, successively with detergent and organic solvent (Solar Kinetics, Inc. 1980). After cleaning, bodily contact with the selective surface should be avolded, because skin oils (and other substances) can cause the surface to degrade. The glass envelope should be installed concentric with the receiver to obtain the maximum benefit from the insulating air gap around the recelver. 0-ring seals are used at the end of the glass tubes to reduce dirt penetration into the annular air gap. Sufficient spacing between adjacent tubes is required for thermal expansion of the glass, which otherwise can result in breakage. Factory assembly in a sealed cavity should ensure the cleanliness of the receiver tube of a Fresnel lens collector.

An all-welded receiver tube is desirable but makes disassembly difficult (to replace a broken glass envelope, for example). Ferrule fittings joining collector tubes must be installed correctly to prevent possible leakage, especially in oil systems.

Flexhoses, installed at the ends of a parabolic trough receiver tube to accommodate the rotation of the collector, are points of weakness in the integrity of the collector piping system. Flexhoses should not be flexed past their minimum bending radius, and they function most effectively when they are installed to flex in one dimension only. Torsional stress can cause early failure; thus, imposing such stresses during installation and operation (e.g., after an incorrect installation) should be avolded (Boyd 1980). An example of correct flexhose installation with either rotatable or nonrotatable receivers is shown in Fig. 9-1. The flexhose is supported, and high radii of curvature are generally provided, by a stripwound metal insulation cover. Caution is required when welding near a flexible connection so as not to alter the properties of that connection. Flexible insulation is recommended if the flexhoses are to function effectively while in continuous motion. The insulation must be installed on the flexhose before it is connected to collector and field piping.

Other points to note when checking out a line-focus system are correct installation and alignment of the sun tracker (final adjustments can be made when fluid flow is initiated and the collectors are tracking); ensuring the presence of an overtemperature switch for each collector row (particularly for oil systems, which present the greatest fire hazard); and ensuring that adequate shielding from concentrated solar radiation is provided for instrument or electrical wiring and any other system components (e.g., bleed valves). The collector tracking mechanism should be tested after final assembly over its full range of trave1, but only on a cloudy day. Sun tracking can take place only with full fluid flow through the receiver. The flexhoses should rotate freely.

\subsubsection{Piping, Fittings, and Insulation}

Piping is a major consideration in solar installations. Piping design should conform to the guidelines presented in previous sections. In checking a solar installation, be sure that adequate allowance is made for thermal expansion. Solar system components frequently cycle through large temperature variations, and to prevent the buildup of thermal stresses, sufficient expansion loops, expansion bellows, or flexible connections are required. 


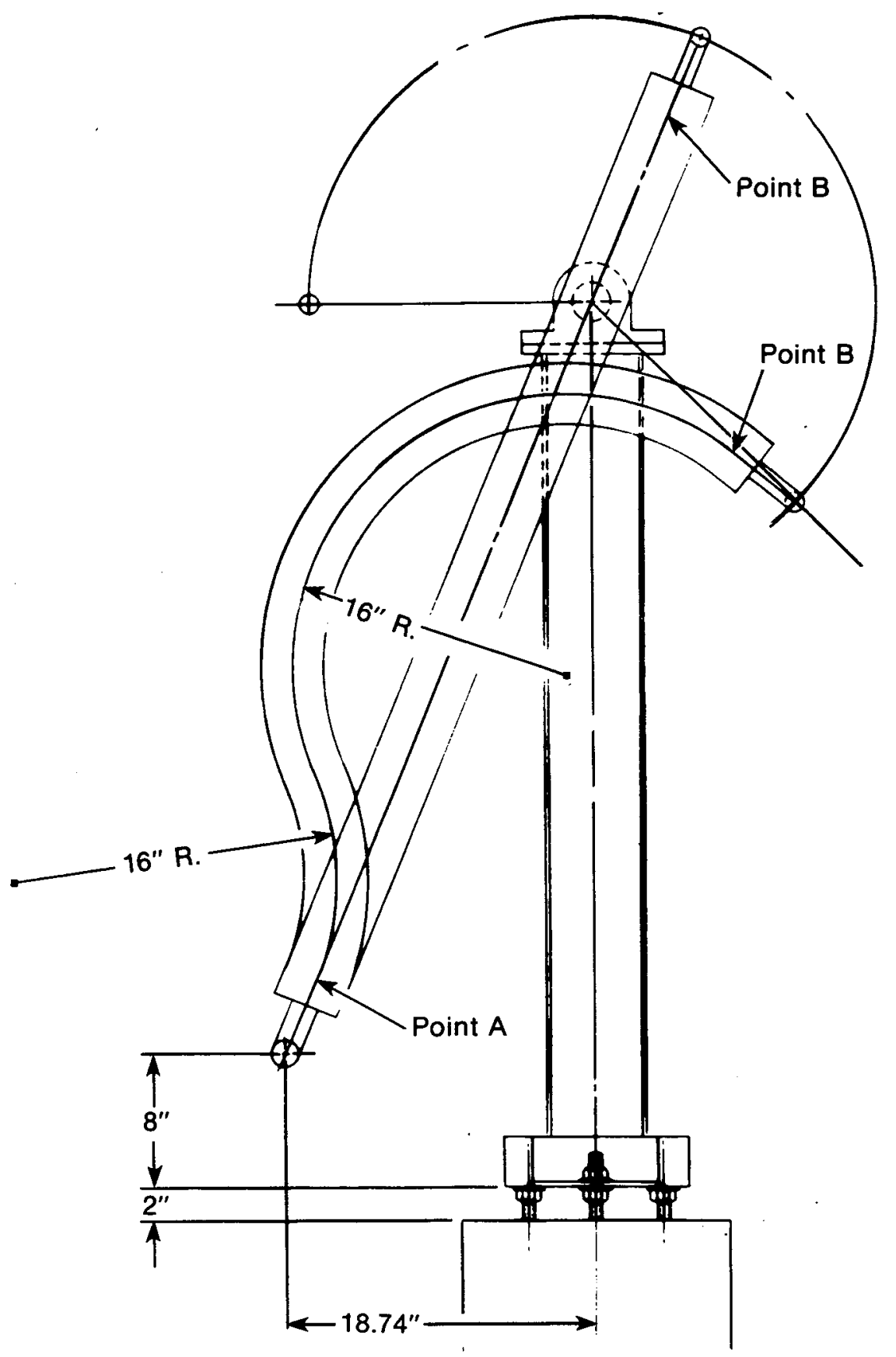

$\frac{8}{8}$

SOURCE: Boyd 1980.

Figure 9-1. Hose Deployment for Use With Either Rotatable or Nonrotatable Receivers 
Pipe schedules, gaskets, and fittings should conform to engineering drawings. Before being connected, pipe segments should be emptied of any dirt or gravel that may have accumulated in them, as that could damage the equipment. Fittings should be installed in the correct orientation to flow. Generally, valves in an oil system are installed with the stems positioned horizontally so that leaks will not drip into the insulation. Installing the valves upside down is inadvisable, because dirt can then accumulate in the valve body. When the valve is moved, the dirt will be forced into the fitting causing damage and eventual leakage. Where a fluid leak is possible, nonwicking insulation (e.g., foamed glass) can reduce the risk of fire to a great extent. And electrical or steam-tracing 1ines, if present, should be checked and turned on before they are insulated. In winter, the steam lines should be tested and completely drained until they are ready for reactivation, after the solar system is completed.

Valve packing, gaskets, and flange ratings should be checked carefully, particularly in oil systems. Graphite-impregnated asbestos ("grafoil") packing seems most effective in reducing oil leaks. Spira1-wound asbestos-filled gaskets should be used in raised-face flanges for oil systems if welded fittings cannot be employed. Oil suppliers often specify heavy-duty flanges and highstrength studs. Plain asbestos gaskets on raised-face flanges are generally satisfactory for high-pressure water systems. In low-temperature systems, rubber gaskets on smooth-face flanges or 0-ring joints can be used. In all cases, flanges should be joined with studs rather than machine bolts, and nuts should be tightened so as to avoid short bolting; equal lengths of exposed pipe.thread should be visible at each end of the stud.

The solar system should be pressure-tested before insulation is installed, and insulation must be thoroughly waterproofed. Insulation covers should be lapped to shed water and the seams should be caulked. Because the insulation cools at night, it is susceptible to moisture penetration. Insulating ability is seriously reduced when the insulation is wet and its structural integrity is compromised. Closed-cell insulation resists molsture better and can be worth the added cost. In systems that use flammable fluids, a nonwicking insulation should be used at any point that is susceptible to leaks to prevent fires that could result from oxidation-induced high temperatures.

Heat losses through supports, fittings, and instrument connections can and should be reduced. Pipe hangers and supports should be insulated from hot pipe. One way to do this is to use rigid insulation at support points and to loop the hangers around the insulation (see Fig. 9-2). Valves and fittings, including flanges, should be insulated as thoroughly as possible, consistent with safe operation of the system.

If possible, locate piping away from personnel walkways, because walking on nonrigid insulation can cause serious damage. However, the collector field should be accessible to personnel and vehicles as required. Underground piping is best installed inside a rigid conduit that is specially waterproofed with asphalt compounds. Conduits should be sealed to prevent the intrusion of 

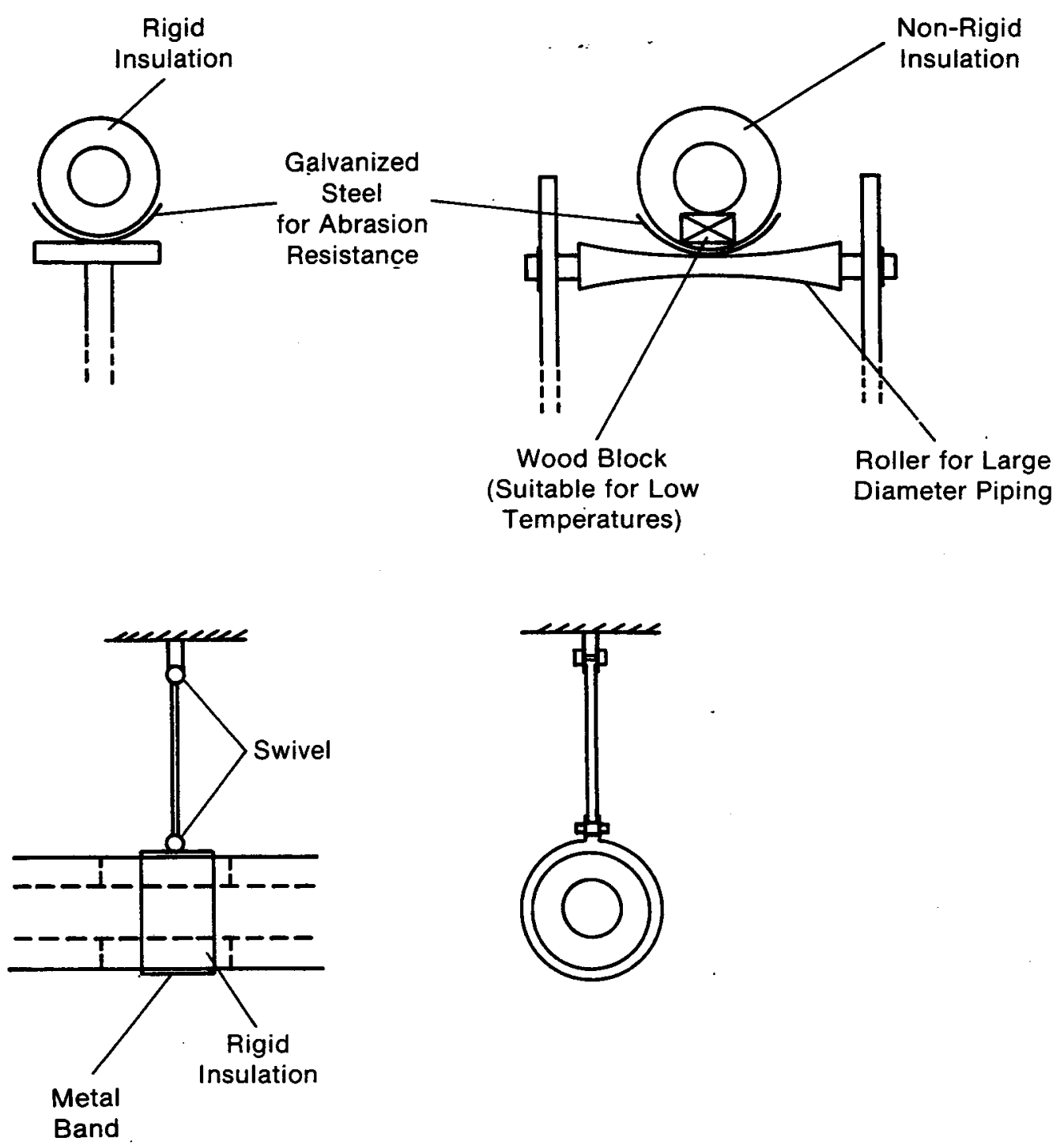

Figure 9-2. Examples of Insulation Techniques for Pipe Supports and Hangers 
rain or groundwater. If piping with conventional insulation is used in a culvert, the culvert should be free-draining, and water should not be able to enter it.

An adequate number of vents and drains should be located in the piping system, but these fittings should be confined to essential locations because they act as heat sinks. Dead ends, such as drain valves, are also possible freezing sites in water systems. The piping system should be designed to minimize pressure drop, which means that additional attention must be paid to pipefitting practices. For a drain-back system with sewer-flow, $Y$ connectors should be substituted for $T$ connectors, and pipe slope requirements are critical.

Locate relief valves wherever a section of piping or components can be isolated that is subject to possible pressure increases caused by thermal expansion. The number of relief valves required can be minimized by minimizing the number of isolation valves. Relief valves should be installed vertically (upward) and vented to a safe location. Valves vented to the atmosphere should have weep holes in outlet piping to prevent their filling with rainwater. Liquid relief valves should be free-draining downward. In a heat transfer fluid system, it is necessary to pipe the relief valves to a collection point to prevent fluid from spilling.

\subsubsection{Installing Heat Exchangers}

Heat exchangers must be mounted to provide sufficient clearance for disassembly or for removing the tube bundle. Piping should be supported so that forces are not directly applied to the heat exchanger. The shell should be fixed only at one end, and a shoe should be provided for free thermal expansion at the other end. Connections should be provided on the inlet and discharge lines for pressure and temperature gauges, as required. Locate vents and drains on both the shell and tube sides of the exchanger.

\subsubsection{Installing Punps}

The pump foundation and grouting should be carefully constructed according to the manufacturer's recommendations. Suction and discharge piping should be fully supported, so that forces are not transferred to the pump. There should also be adequate access to the pump so that it can be serviced. Pump life is largely determined by the correct alignment of the pump and the motor. Final adjustments are often made under operating conditions. If mechanical seals are installed, seal flushing lines should be correctly located and should usually include a centrifugal strainer. Seal cooling is generally not required unless fluid operating temperatures exceed $260^{\circ} \mathrm{C}\left(500^{\circ} \mathrm{F}\right)$. Heat rejection to cooling water can be a major source of thermal loss from a solar system.

Fittings for each pump should generally include a check, a suction strainer, and a discharge pressure gauge located within the pump isolation valves. Pump and motor nameplate data should be checked against design specifications. The design point should be located to the left of the maximum efficiency point on the pump curve so that flows greater than design do not overload the motor. The suction head on the pump should also be checked against the pump curve. Pumps and motors, and other equipment in the system, should be grounded. 
The cyclic nature of a solar system imposes severe stresses on mechanical components, especially those operating at high temperatures. This is particularly true for solar system pumps that are remotely controlled. Under such stress, correct installation and maintenance are even more important than for equipment operated continuousiy. A standby pump may be highly desirable.

Under normal operations, mechanical pump seals are highly reliable, cause minimal friction, and reduce leakage along the pump shaft to a negligible amount. However, these seals require. skilled installation, and they are expensive. If the seals should leak, they can spray liquid over a wide area. A packed stuffing box does not provide such a positive seal. Their leakage rates may be too high for an oil system but perfectly acceptable for water systems, and they should be considered as an alternative. Adjustments are easily made by unskilled personnel and repacking is equally simple. Failure is not likely to be catastrophic, evident only as increased leakage, and it is possible that packing glands could better tolerate the thermal cycling imposed on the components in a solar system. It appears that the greatest reliability can be attained by using redundant pumps.

\subsubsection{Installing Pressure Vessels and Storage Tanks}

Pressure vessels and storage tanks must be mounted on adequate foundations with thermal expansion taken into account. Fittings such as sight glasses (which should always be installed in conjunction with automatic level controls), level controllers, and valving must be insulated carefully to prevent localized freezing that could damage control systems. Relief-valve settings should be bench-tested for correctness. Ladders should be installed to provide easy access to all instruments and valves.

Care should be taken to avoid damaging the insulation covering when installing tanks underground. Sand or other suitable material should form a bed at least $15.6 \mathrm{~cm}$ (6 in.) thick below the tank and at least $5.4 \mathrm{~cm}$ ( 2 in.) thick around the tank as backfill. Drainage must be provided for all vessels. Underground tanks may require a sump pump. The placement and fabrication of baffles, vortex breakers, demisters, etc:, should also be checked against shop drawings.

Storage tanks and pressure vessels act as heat reservoirs as the solar system cools down overnight. Thermosiphon heat transfer can then cause significant heat loss. Connecting piping should, therefore, be constructed to prevent thermosiphoning in poorly insulated sections of the solar system. A downward sloping $U$ bend has been effective in preventing thermosiphoning from heat storage tanks. In drainback systems with return lines discharging into the top of the drain tank, considerable overnight heat losses can result from a "heat pipe effect," where water vapor condenses on the cooled pipe walls and returns to the tank in a continuous cycle. A solution devised by Sunmaster Corporation (Nestlé 1981) resolves this problem. The return lines are constructed with a dip tube that extends below the surface of the liquid. To allow the return piping to drain completely, a small vent line with check is constructed from the tank to the top of each return line (see Fig. 9-3). Correctly filling the tank is obviously critical to the success of this technique. 

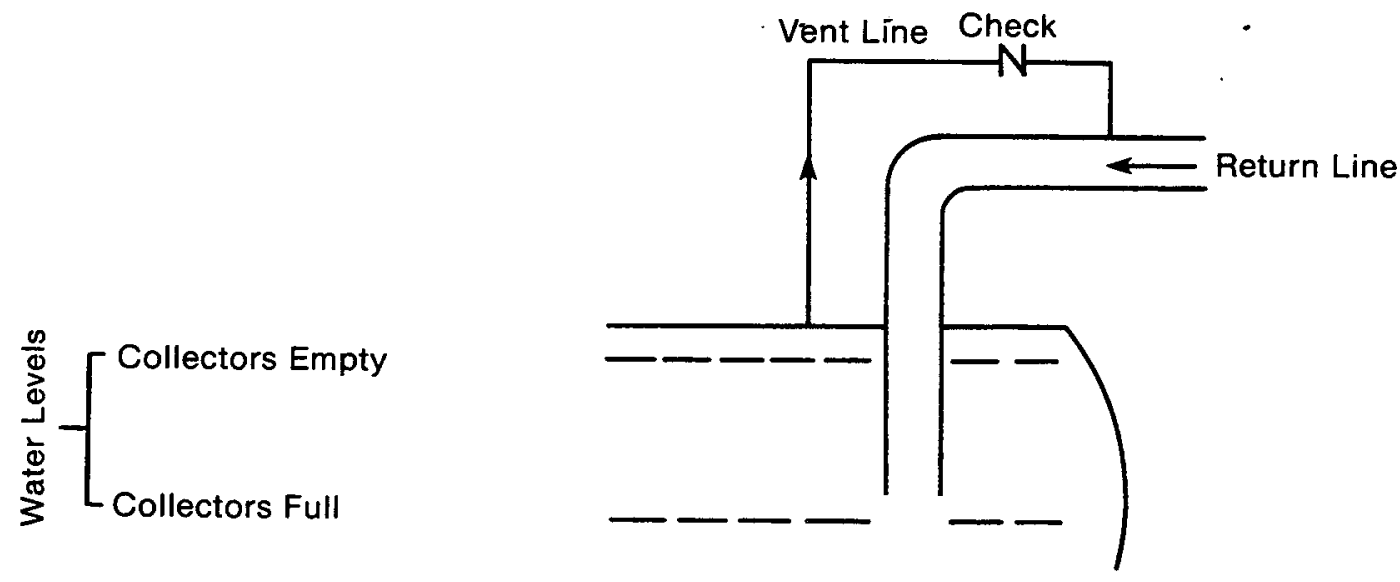

$\frac{6}{5}$

\section{Figure 9-3. Design for Reducing Overnight Heat Losses in Drainback Systems}

\subsubsection{Installing Controls, Electrical Lines, and Instrumentation}

It is particularly important to check controllers and instruments for correct labeling. Instrument wiring should be adequately shielded and grounded to eliminate signal interference. The fail-safe position of control valves should conform to specifications. The valves should be stroked manually to ensure that they open and close smoothly.

Flow measuring devices should be installed with adequate straight runs of upstream and downstream piping. Thermowells should be located so as to be sufficiently immersed in the fluid stream and should be insulated to prevent heat loss and incorrect readings. The operation of the auxiliary power supply, if any, should be checked. Similarly, the uninterruptible power supply to the data acquisition system should be fully charged and the battery charger should be operational.

Since there is little need to enter the collector field at night except for repairs, permanent outdoor lighting is not required; but it can be helpful where vandalism is a problem. However, sufficient electrical cable should be available so that power for lighting and equipment can be supplied to any part of the field.

\subsubsection{Personnel and Environmental Safety Precautions}

During the entire checkout of the solar system, the safe operation of the system should be ensured. Sharp edges or exposed piping that could cause injury or burns should be eliminated. Guard rails and ladder cages, as needed, 
should be required for roof-mounted structures. Depending on the types of fluids used in the solar system, safety showers and eye baths may be necessary at strategic locations. Pressure relief valves should be vented carefully. In high-pressure water systems, it may be necessary to restrict access to the operating collector field.

The fire protection system and alarms should be tested, and personnel should be instructed in the use of related equipment. Portable fire extinguishers should be strategically located. An emergency system shutdown switch should be easily accessible. Personnel should be equipped with eye-protection equipment when they enter fields of concentrated solar radiation.

Heat transfer fluids that could be harmful to the environment must be collected. Care should be exercised in the selection and use of herbicides to control the growth of vegetation in the collector field. More details on safety and environmental issues are given in Sec. 11.0 .

\subsection{START-UP}

The purpose of checkout and start-up procedures is to test the system thoroughly, so that future operations are as trouble-free as possible. With adequate supervision, as many start-up procedures as possible should be carried out by the same plant personnel who will later operate and maintain the solar system. Such work provides exceptional training and helps the staff to become familiar with the details of the system. Start-up procedures necessitate the close coordination of several people. Portable, two-way radios could be provided to personnel to ensure smooth operation.

\subsubsection{Line Flushing}

During system fabrication, lines and vessels invariably collect earth, scale, welding rods, and other debris. Vessels large enough for a person to enter should be wire-brushed and swept out. Lengths of piping should be isolated into sections and thoroughly flushed with water that is then discharged through an open line. Vessels, heat exchangers, and solar collectors should be valved off or isolated with blanks. Control valves and flow measurement devices should be removed or bypassed to prevent damage.

After their first flush, piping should be connected in a continuous circuit through a pump using temporary piping or fire hose. This is a good time to run in the pumps and motors, although the motors should be checked for correct rotation and run in before being connected to the pumps. (Note, however, that gear pumps, for example, which depend on a fluid for lubrication, may not be designed to pump water.) Each pump should be primed and the impeller and motor checked to ensure free rotation. The bearing case should be filled to the correct level with lubricating oil. Initially, the pump should be started against a closed discharge. This minimizes start-up current and avoids overloading the motor. After a few seconds, the discharge valve should be opened slowly. 
Table 9-1. Installation Checklist

Documentation

Piping and instrument diagram

System. drawings

Component specifications and drawings

Equipment 1ist

Construction codes

Operation and maintenance manuals

Progress log

Spare-parts list

Flat-plate and evacuated-tube collectors

Vegetation

Support structure

Collector alignment for tilt and azimuth

Row spacing

Manifold alignment

Manifold connectors installation and materials

Slope for drainage

Stagnation cover during construction

Support structure meets specifications

Rigidity of support and collector attachment

Access to collector field as necessary

Line-focus collectors

Collector alignment for azimuth

Alignment of receiver tubes

Row spacing

Access

Support structure

Assembly of recelver tube and cover

Cleanliness of receiver tube and cover

Alignment and support of flexhoses

Attachment of flexhoses

Alignment of sun trackers (check during fluid flow)

Travel of collector

Components shielded from concentrated radiation

Piping, fittings, and insulation

Provision for thermal expansion

Schedules and material of pipe and fittings

orientation of fittings to flow

Gaskets and packing

Short bolting of flanges

Adequate vents and drains

Valves for oil system installed horizontally

Relief valves installed vertically, vented to safe location, weep hole

Field pipefitting practices minimize pressure drop

Pipe placement allows access but isolated from foot traffic

Heat tracing check before installing insulation

Waterproofing insulation, particularly underground

Pipe supports isolated from pipe 
Table 9-1. Installation Checklist (Concluded)

Heat exchangers

Clearance for disassembly

Connecting piping fully supported

Thermal expansion

Instrument connections

Vents and drains

Pumps

Foundation

Connecting piping fully supported

Alignment of pump and motor

Seal flushing and cooling lines

Isolation valves, strainer, check, discharge pressure gauge

Free and correct rotation

Grounding

Suction head

Lubricating oil

Bearing temperatures, discharge pressure, motor current

Pressure vessels and storage tanks

Foundations

Thermal expansion

Conformity to construction drawings

Vessel internals

Placement, thickness, and type of backfill for underground tanks

Waterproofing

Thermosiphon breakers

Safety-valve settings

Controls, electrical and instrumentation

Labelling of instruments and controllers

Wiring shielded and grounded

Fail-safe position of valves

Free movement of valves

Orientation to flow of valves and instruments

Immersion of thermowells

Inlet and outlet pipe lengths around flow pressuring devices

Auxiliary power supply, uninterruptible power supply, battery charger

Safety and environmental

No sharp edges or exposed hot piping

Guard rails, ladder cages

Safety showers, eye baths

Fire extinguishers

Emergency shutdown

Collection of heat transfer fluids

Personnel training 


\section{SEPI}




\section{SECTION 10.0}

SOI.AR SYSTEM ECOHOMICS

When an industrial firm considers installing a solar IPH system, the primary deciding factor, in most cases, is whether or not such a system is economically feasible. In this section, we turn our attention to the economic analysis of solar IPH systems. Two simple methods of estimating total system cost are presented in Sec. 10.1. The Dickinson-Brown methodology for economic analysis of solar IPH systems is summarized in Sec. 10.2. Section 10.3 presents financing alternatives for solar IPH systems.

\subsection{METHODS OF SYSTEM COST ESTIMATION}

Two methods of obtaining a rough cost estimate of a solar IPH system are presented in this section. The first method uses the results of recent studies by Mueller Associates, Inc. (Mueller Associates, Inc. 1980 and 1981; Franta et a1. 1982), in which the investigators determined actual construction costs for 10 solar IPH systems and 24 solar heating and cooling systems by interviewing the various contractors involved in each project. The second cost-estimating method is that used in a computer program developed at SERI known as ECONMAT (see Stadjuhar 1982; and Brown et al. 1980). The approach is modular cost estimating (Guthrie 1969), and it enables one to estimate the total system installed cost from the cost of collector equipment (FOB) and a series of multiplicative factors that account for all other direct and indirect costs. This method is explained in more detail in Sec. 10.1.2.

\subsubsection{Historical IPH System and Subsystem Costs}

Mueller Associates (1980) summarized actual, normalized, and modified costs for 10 federally funded solar IPH systems. The systems they studied include those with both manufactured and site-built flat-plate collectors, evacuated tubes, and tracking concentrating collectors. These systems provide hot air, hot water, and steam to a variety of industrial processes. Later, Mueller Associates added 24 solar heating and cooling systems to their analysis, and the results were presented by Franta et al. (1982).

In these studies, system costs were divided into the following nine categories:

- Collector array (including tracking devices, if applicable)

- Collector support structure

- Piping/ductwork (including external collector manifold material cost, pumps, valves, expansion tanks)

- Insulation

- Heating/cooling equipment (a carryover term from an earlier Mueller Assoclates study of solar heating and cooling systems, including special nonauxiliary equipment) 
- Storage (Including storage insulation)

- Controls

- Electrical

- General construction (roofing, equipment rooms, excavation, painting).

Each category includes costs for materials, delivery, and installation labor. Actual costs reported by Mueller are the true year-of-construction costs and do not include the contractor's overhead and profit markup (OH\&P), design costs, or costs for data acquisition and recording equipment. Normalized costs account for inflation from the year of construction to 1981 and for differences in contractual configurations, and include a uniform OH\&P percentage for all projects. Modified costs are reported in 1981 dollars, including actual 1981 collector and control costs. They incorporate nominal oH\&P rates for the general contractor (25\% on bare materials and 1 abor and $10 \%$ on subcontracts), subcontractors ( $15 \%$ on bare costs), and use the national average skilled labor rate $(\$ 14.25 / \mathrm{h})$. Site-specific costs, such as those for extralong piping runs, excessive system check-out labor, collector repairs, and special construction, were not included in the modified costs. Modified costs are the most useful in terms of cost estimating, although the cost of any particular design may deviate significantly in various areas, and design costs themselves are not included.

\subsubsection{Historical System Costs}

Table 10-1 summarizes the modified costs as determined by Mueller Associates, Inc., for the 10 solar IPH systems that were examined in their first study. [Other characteristics of the systems are presented in Table 2-3: (see Sec. 2.3).] Subsystem costs are presented in Table 10-1 on a per unit collector area basis and also as a percentage of total system cost. Note that system costs vary considerably, and within each subcategory, large variations in cost are also evident. In this and the following subsections, largely excerpted from Franta et al. (1982), we examine the total and subsysten costs of the $10 \mathrm{IPH}$ and 24 heating and cooling systems in more detail. Although the statistical analyses presented here are not based solely on solar IPH systems, there are so many similarities between large heating and cooling systems and IPH systems that certain generalizations are appropriate.

Statistical tests show that the system's application is an important factor in total system cost. Of active systems, hot water systems cost the least, followed by direct air heating systems, liquid-to-air heating systems, and steamproducing systems, in that order. Unfortunately, the statistical tests did not indicate whether new systems were more or less expensive than retrofit systems, but most of the more expensive steam and cooling systems were retrofit projects.

Total cost data were also analyzed to determine whether economies-of-scale effects occur. To determine whether economies of scale affected these systems, the slope of a line plotted on a graph of $10 \mathrm{~g}$ system cost versus $10 \mathrm{~g}$ collector area was used. This approach produced a slope of 0.81 , significantly less than one, suggesting that economies of scale do exist. The 
Table 10-1. Modified Solar IPH Subsystem Costs

\begin{tabular}{|c|c|c|c|c|c|c|c|c|c|c|c|c|c|c|c|c|c|c|c|c|c|}
\hline \multirow{2}{*}{ Solar IPH System } & \multirow{2}{*}{$\begin{array}{l}\text { Array } \\
\text { S1ze } \\
m^{2} \\
\left(\mathrm{ft}^{2}\right)\end{array}$} & \multirow{2}{*}{$\begin{array}{c}\text { Total } \\
\text { Syotem } \\
\text { Cost } \\
\$\end{array}$} & \multirow{2}{*}{$\begin{array}{c}\text { Total } \\
\text { System } \\
\text { Cost } \\
\$ / \mathrm{m}^{2} \\
\left(\$ / \mathrm{ft}^{2}\right)\end{array}$} & \multicolumn{2}{|c|}{$\begin{array}{l}\text { Collector } \\
\text { Array }\end{array}$} & \multicolumn{2}{|c|}{$\begin{array}{l}\text { Support } \\
\text { Structure }\end{array}$} & \multicolumn{2}{|c|}{$\begin{array}{l}\text { Piping/ } \\
\text { Ductwork }\end{array}$} & \multicolumn{2}{|c|}{ Insulation } & \multicolumn{2}{|c|}{$\begin{array}{l}\text { Heating/ } \\
\text { Cooling } \\
\text { Equipment }\end{array}$} & \multicolumn{2}{|c|}{ Storage } & \multicolumn{2}{|c|}{ Control } & \multicolumn{2}{|c|}{ Electrical } & \multicolumn{2}{|c|}{$\begin{array}{c}\text { General } \\
\text { Construction }\end{array}$} \\
\hline & & & & $\begin{array}{c}\$ / \mathrm{m}^{2} \\
\left(\$ / \mathrm{ft}^{2}\right)\end{array}$ & $z$ & $\begin{array}{c}\$ / \mathrm{m}^{2} \\
\left(\$ / \mathrm{ft}^{2}\right)\end{array}$ & z & $\begin{array}{c}\$ / \mathrm{m}^{2} \\
\left(\$ / \mathrm{ft}^{2}\right)\end{array}$ & $\pi$ & $\begin{array}{c}\$ / m^{2} \\
\left(\$ / f t^{2}\right)\end{array}$ & * & $\begin{array}{c}\$ / \mathrm{m}^{2} \\
\left(\$ / \mathrm{ft}^{2}\right)\end{array}$ & $\%$ & $\begin{array}{c}\$ / \mathrm{m}^{2} \\
\left(\$ / \mathrm{ft}^{2}\right)\end{array}$ & $z$ & $\begin{array}{c}\$ / \mathrm{m}^{2} \\
\left(\$ / \mathrm{ft}^{2}\right)\end{array}$ & $z$ & $\begin{array}{c}\$ / \mathrm{m}^{2} \\
\left(\$ / \mathrm{ft}^{2}\right)\end{array}$ & $\%$ & $\begin{array}{c}\$ / \mathrm{m}^{2} \\
\left(\$ / \mathrm{ft}^{2}\right)\end{array}$ & $\%$ \\
\hline Campbell Soup & $\begin{array}{c}681.4 \\
(7,335)\end{array}$ & 330,850 & $\begin{array}{l}485.1 \\
(45.1)\end{array}$ & $\begin{array}{l}240.9 \\
(22.4)\end{array}$ & 49.7 & $\begin{array}{l}60.7 \\
(5.6)\end{array}$ & 12.5 & $\begin{array}{l}39.3 \\
(3.7)\end{array}$ & 8.1 & $\begin{array}{l}13.8 \\
(1.3)\end{array}$ & 2.8 & -- & - & $\begin{array}{l}62.7 \\
(5.8)\end{array}$ & 12.8 & $\begin{array}{l}11.0 \\
(1.0)\end{array}$ & 2.3 & $\begin{array}{l}32.5 \\
(3.0)\end{array}$ & 6.7 & $\begin{array}{l}24.7 \\
(2.3)\end{array}$ & 5.1 \\
\hline Gilroy Foods & $\begin{array}{c}552.8 \\
(5,950)\end{array}$ & 307,850 & $\begin{array}{l}556.9 \\
(51.7)\end{array}$ & $\begin{array}{l}297.1 \\
(27.6)\end{array}$ & 53.3 & $\begin{array}{l}58.4 \\
(5.4)\end{array}$ & 10.5 & $\begin{array}{l}82.7 \\
(7.7)\end{array}$ & 14.9 & $\begin{array}{l}31.0 \\
(2.9)\end{array}$ & 5.6 & $\begin{array}{c}8.0 \\
(0.7)\end{array}$ & 1.4 & -- & -- & $\begin{array}{l}36.3 \\
(3.4)\end{array}$ & 6.5 & $\begin{array}{l}22.7 \\
(2.1)\end{array}$ & 4.1 & $\begin{array}{l}20.7 \\
(1.9)\end{array}$ & 3.7 \\
\hline Home Laundry & $\begin{array}{c}603.5 \\
(6,496)\end{array}$ & 750,950 & $\begin{array}{c}1,244.3 \\
(115.6)\end{array}$ & $\begin{array}{l}411.1 \\
(38.2)\end{array}$ & 33.1 & $\begin{array}{l}187.7 \\
(17.4)\end{array}$ & 15.2 & $\begin{array}{l}329.5 \\
(30.6)\end{array}$ & 26.5 & $\begin{array}{l}30.1 \\
(2.8)\end{array}$ & 2.4 & $\begin{array}{l}15.0 \\
(1.4)\end{array}$ & 1.2 & $\begin{array}{l}13.3 \\
(1.2)\end{array}$ & 1.0 & $\begin{array}{l}91.0 \\
(8.5)\end{array}$ & 7.3 & $\begin{array}{l}67.7 \\
(6.3)\end{array}$ & 5.4 & $\begin{array}{l}98.0 \\
(9.2)\end{array}$ & 7.9 \\
\hline Johnson \& Johnson & $\begin{array}{c}1,070.2 \\
(11,520)\end{array}$ & 809,190 & $\begin{array}{l}756.1 \\
(70.2)\end{array}$ & $\begin{array}{l}307.0 \\
(28.5)\end{array}$ & 40.6 & $\begin{array}{c}104.9 \\
(9.7)\end{array}$ & 13.9 & $\begin{array}{l}112.8 \\
(10.5)\end{array}$ & 14.9 & $\begin{array}{l}20.9 \\
(1.9) .\end{array}$ & 2.8 & -- & -- & $\begin{array}{l}51.6 \\
(4.8)\end{array}$ & 6.8 & $\begin{array}{l}67.2 \\
(6.2)\end{array}$ & 8.9 & $\begin{array}{l}59.6 \\
(5.5)\end{array}$ & 7.9 & $\begin{array}{l}32.1 \\
(3.0)\end{array}$ & 4.2 \\
\hline LaCour & $\begin{array}{c}214.0 \\
(2,304)\end{array}$ & 130,160 & $\begin{array}{l}608.2 \\
(56.5)\end{array}$ & $\begin{array}{l}195.8 \\
(18.2)\end{array}$ & 32.2 & $\begin{array}{l}95.6 \\
(8.9)\end{array}$ & 15.7 & $\begin{array}{l}193.0 \\
(17.9)\end{array}$ & 31.7 & $\begin{array}{c}7.2 \\
(0.7)\end{array}$ & 1.2 & -- & -- & $\begin{array}{l}42.2 \\
(3.9)\end{array}$ & 6.9 & $\begin{array}{l}16.3 \\
(1.5)\end{array}$ & 2.7 & $\begin{array}{l}19.9 \\
(1.9)\end{array}$ & 3.3 & $\begin{array}{l}38.2 \\
(3.5)\end{array}$ & 6.3 \\
\hline LaPrance & $\begin{array}{c}544.5 \\
(5,861)\end{array}$ & 343,000 & $\begin{array}{l}629.9 \\
(58.5)\end{array}$ & $\begin{array}{l}289.5 \\
(26.9)\end{array}$ & 46.0 & $\begin{array}{l}81.1 \\
(7.5)\end{array}$ & 12.9 & $\begin{array}{l}142.1 \\
(13.2)\end{array}$ & 22.5 & $\begin{array}{l}43.7 \\
(4.1)\end{array}$ & 6.9 & -- & - & $\begin{array}{l}25.1 \\
(2.3)\end{array}$ & 4.0 & $\begin{array}{l}44.7 \\
(4.2)\end{array}$ & 7.1 & $\begin{array}{c}3.7 \\
(0.3)\end{array}$ & 0.6 & - & - \\
\hline Lamanuzzi \& Pantaleo & $\begin{array}{l}1,951.0 \\
(21,000)\end{array}$ & 475,050 & $\begin{array}{l}243.6 \\
(22.7)\end{array}$ & $\begin{array}{c}105.1 \\
(9.8)\end{array}$ & 43.2 & $\begin{array}{c}8.2 \\
(0.8)\end{array}$ & 3.4 & $\begin{array}{l}53.9 \\
(5.0)\end{array}$ & 22.1 & $\begin{array}{l}12.6 \\
(1.2)\end{array}$ & 5.2 & $\begin{array}{l}12.0 \\
(1.1)\end{array}$ & 4.9 & $\begin{array}{l}28.5 \\
(2.6)\end{array}$ & 11.7 & $\begin{array}{l}10.5 \\
(1.0)\end{array}$ & 4.3 & $\begin{array}{l}10.3 \\
(1.0)\end{array}$ & 4.2 & $\begin{array}{c}2.5 \\
(0.2)\end{array}$ & 1.0 \\
\hline Tropicana Products & $\begin{array}{c}929.0 \\
(10,000)\end{array}$ & 530,060 & $\begin{array}{l}570.6 \\
(53.0)\end{array}$ & $\begin{array}{l}338.1 \\
(31.4)\end{array}$ & 59.2 & $\begin{array}{c}105.4 \\
(9.8)\end{array}$ & 18.5 & $\begin{array}{l}60.3 \\
(5.6)\end{array}$ & 10.6 & $\begin{array}{l}21.6 \\
(2.0)\end{array}$ & 3.8 & $\begin{array}{l}10.1 \\
(1.7)\end{array}$ & 3.2 & - & - & $\begin{array}{c}5.2 \\
(0.5)\end{array}$ & 0.9 & $\begin{array}{l}18.9 \\
(1.7)\end{array}$ & 3.3 & $\begin{array}{c}3.0 \\
(0.3)\end{array}$ & 0.5 \\
\hline WestPoint Peppere11 & $\begin{array}{c}696.8 \\
(7,500) \\
\end{array}$ & 442,970 & $\begin{array}{l}635.7 \\
(59.1)\end{array}$ & $\begin{array}{l}255.3 \\
(23.7)\end{array}$ & 40.2 & $\begin{array}{l}68.2 \\
(6.3)\end{array}$ & 10.7 & $\begin{array}{l}84.4 \\
(7.9)\end{array}$ & 13.3 & $\begin{array}{l}32.4 \\
(3.0)\end{array}$ & 5.1 & $\begin{array}{l}22.5 \\
(2.1)\end{array}$ & 3.5 & -- & -- & $\begin{array}{l}114.4 \\
(10.6)\end{array}$ & 18.0 & $\begin{array}{l}58.3 \\
(5.4)\end{array}$ & 9.2 & $\begin{array}{l}0.2 \\
(0.02)\end{array}$ & 0.02 \\
\hline $\begin{array}{l}\text { York Buflding } \\
\text { Products }\end{array}$ & $\begin{array}{c}832.4 \\
(8,960)\end{array}$ & 490,110 & $\begin{array}{l}588.8 \\
(54.7)\end{array}$ & $\begin{array}{l}403.9 \\
(37.5)\end{array}$ & 68.6 & $\begin{array}{l}69.6 \\
(6.5)\end{array}$ & 11.8 & $\begin{array}{l}37.4 \\
(3.5)\end{array}$ & 6.4 & $\begin{array}{l}7.7 \\
(0.7)\end{array}$ & 1.3 & -- & -- & - & -- & $\begin{array}{l}62.5 \\
(5.8)\end{array}$ & 10.6 & $\begin{array}{c}7.7 \\
(0.7)\end{array}$ & 1.3 & - & - \\
\hline Average & $\begin{array}{c}807.6 \\
(8,693)\end{array}$ & 461,019 & $\begin{array}{l}632.0 \\
(58.7)\end{array}$ & $\begin{array}{l}284.4 \\
(26.4)\end{array}$ & 46.6 & $\begin{array}{l}84.0 \\
(7.8)\end{array}$ & 12.5 & $\begin{array}{l}113.5 \\
(10.5)\end{array}$ & 17.1 & $\begin{array}{l}22.1 \\
(2.1)\end{array}$ & 3.7 & $\begin{array}{l}15.1 \\
(1.4)\end{array}$ & 2.8 & $\begin{array}{l}17.2 \\
(3.5)\end{array}$ & 7.2 & $\begin{array}{l}45.9 \\
(4.3)\end{array}$ & 6.9 & $\begin{array}{l}30.1 \\
(2.8)\end{array}$ & 4.6 & $\begin{array}{l}27.1 \\
(2.4)\end{array}$ & 3.6 \\
\hline
\end{tabular}

Source: Mueller Assoclates, Inc. 1980. 
largest system by far, at Lamanuzzi and Pantaleo Foods, was also the least expensive, possibly because of design factors rather than an economies-ofscale effect. When that data point was removed from the analysis, the resulting slope was 0.77 , strengthening the argument for the existence of economies of scale.

An expectation of the solar community is that solar energy construction costs will decline as experience is gained in the design, installation, and mass production of solar components. Therefore, Mueller Associates tested total unit costs to determine whether the year in which a project was constructed was a significant cost factor. Since all costs were expressed in 1981 dollars, inflation was not a factor in the statistical test. Unfortunately, the results showed no significant evidence that costs are coming down. Similarly, the total unit cost data were tested to determine whether regional variations in labor and material costs were a cost-impacting factor. The regional cost factors used were taken from the city cost index for mechanical construction from Means Mechanical and Electrical Cost Data 1981. These cost varlations proved not to be a significant factor.

\subsubsection{Historical Subsystem Costs}

Collectors. Solar collectors represent one target area for cost reduction. Cost data for collectors, grouped according to the type of collector, show that site-built collectors are the least expensive, followed by liquid flat plates, air flat plates, evacuated tubes, and tracking collectors, in that order. The collector costs 1isted in Table 10-1 include the cost of mounting the collector on the support structure and the cost of connecting collectors to a manifold system, as well as the cost of the panels themselves. Thus, for example, while air flat-plate panels generally cost less than liquid ones, more labor is required for ductwork manifold connections than for piping manifold connections.

Support Structures. Collector support structure costs vary from $\$ 8.20 / \mathrm{m}^{2}$ of collector area to $\$ 188 / \mathrm{m}^{2}$. Statistical tests performed by Mueller Associates show that the single factor that most influences support structure costs is whether the structure is used for functions other than supporting the collector. These additional functions may include the following:

- House equipment

- Improve system appearance

- Provide reflectors

- Form building roof structure

- Form building waterproof membrane.

It is generally easier for the support structures of new systems to serve multiple functions. Fewer constraints are imposed by new building conditions, allowing designers to use more complex support systems. Retrofit conditions, however, are more constraining. Support structure data were also tested to determine whether ground/roof mounting, new/retrofit, and materials 
distinctions were cost factors, but they all proved not to be significant. In most cases, the support structure does not contribute to performance, so that "cheaper" could be "better" in many support structure designs. The wide variation in support structure costs certainly suggests that this subsystem can benefit from more cost-conscious design.

Energy Transport Equipment. Although these subsystem categories are reported separate1y in Table $10-1$, it is appropriate to combine them here because they all fall within the general mechanical construction category. These subsystem costs were statistically tested to see whether the particular IPH applications and the new-versus-retrofit distinction influence costs. Both proved to be significant cost factors. Air systems appear to be the least expensive, followed by hot water systems, liquid-to-air systems, and steam systems, in that order. The last is more expensive partly because of the additional heat exchange equipment required and because high-pressure piping must be used. New systems were about $\$ 50 / \mathrm{m}^{2}$ of collector area cheaper than retrofit systems in this subsystem category. The difficulty of fitting an energy transport system into an existing building raises costs. It is interesting to note that higher support structure costs tend to balance out the energy transport system cost savings in new construction.

Storage. Because of the wide variations in storage capacity per collector area encountered among the projects, storage costs are expressed in Table 10-1 in terms of storage capacity rather than collector area. Statistical tests showed that storage costs depend both on the type of storage vessel used and the location of the vessel. Unpressurized steel tanks were the least expensive, followed by fiberglass tanks, rock bins, and pressurized steel tanks. In terms of location, buried storage was least expensive, followed by exterior and interior storage. These costs do not include the added cost of extra piping on ductwork to and from buried and exterior storage. Nevertheless, the results are surprising, since most estimation techniques suggest that interior tanks, which do not require waterproofing, would be less expensive. Storage costs on the average represent only $7 \%$ of total system cost, and storage performance (particularly heat loss) has a great effect on system thermal performance. Therefore, it is important that storage subsystems be designed and built for optimum performance.

Electrical Systems and Controls. Electrical systems and controls costs were also tested to determine whether application and new/retrofit distinctions were cost factors. New systems were found to be significantly less expensive than retrofit systems. Retrofit electrical and controls costs were about $\$ 30 / \mathrm{m}^{2}$ higher than those for new installations. Projects with tracking collectors tended to have higher electrical and controls costs than those that did not, because of the tracking system controllers and the need to wire power lines out to the collector array. This was one reason steam system costs were significantly higher in this area. Otherwise, little difference in cost between the applications was evident.

\subsubsection{Estimating Construction Costs Using the Mueller Data}

This subsection, also excerpted from Franta et al. (1982), presents a method of estimating the construction cost of a solar system based on the historical 
data discussed above. However, because some of the projects no longer represent the state of the art, allowance has been made for cost data considered nonrepresentative.

The engineering fee varies and is difficult to estimate. Data on engineering fees were not collected for the demonstration projects, but some general guidelines for estimating such fees for solar energy systems can be estab1ished. Engineering fees include the cost of conceptual design, detailed design and specifications, bid supervision and evaluations, and construction supervision. Designing a commercial-scale solar energy system takes at least three person-months, if complete detalled specifications and drawings are to be provided. The designer's fee increases as the solar construction contract size increases and as the system becomes more complex. Design costs will also be higher if an architect or a structural engineer is required.

Cost-estimating manuals commonly allocate a percentage of the mechanical construction cost as an estimate of the mechanical engineer's fee, which ranges from $4 \%$ to $10 \%$. In solar design, this percentage is somewhat higher-typically, $6 \%$ to $20 \%$. Only smaller systems (less than $100 \mathrm{~m}^{2}$ ) or very complex ones would normally be associated with engineering fees higher than 15\%; only very large systems would entail fees less than $10 \%$.

Cost Estimating at the Conceptual Phase. During the conceptual phase, the designer needs an estimate of construction costs to perform feasibility and system sizing studies. At this point, the designer has, at best, a rough system design. The cost estimate can, therefore, only be approximate. Table 10-2 is a guideline for making "first-pass" estimates for the feasibility and sizing analysis. The table lists the various subsystems that make up a solar energy system, the design categories for that subsystem, the range of costs that might be expected, and what the authors consider to be a typical cost. Note that all costs are expressed in either 1981 dollars $/ \mathrm{m}^{2}$ of net aperture collector area or as 1981 dollars/liter or thousand kilograms of rocks, for the storage subsystem. No value is given for a fixed-cost component of the total system, because statistical tests of the demonstration projects' costs suggest that, for large systems $\left(>30 \mathrm{~m}^{2}\right)$, this cost component is too small. System costs can be described accurately solely as a variable cost per collector area.

To use the table to arrive at a total system cost estimate, add the typical subsystem costs associated with each appropriate design category. Use the ranges with your own judgment. For example, if you anticipate that an expensive support structure will be required because of roof structure design constraints, or if long piping runs will be required, then use values from the upper end of the ranges for the support structure and energy transport subsystems. However, try to avoid being too optimistic or pessimistic in choosing values. Table 10-3 describes in detail the sort of design factors to consider in selecting cost values from the ranges provided.

Because a significant economies-of-scale effect is seen among the demonstration projects, the preliminary cost estimates should be adjusted by an economies-of-scale factor. Figure 10-1 has been provided for that purpose. To use the figure, simply find the appropriate collector area, read up to the curve, and read over to the economies-of-scale factor. Then, multiply the total cost estimate by that factor. 
Table 10-2. Conceptual Phase Cost Rstimating Guide

(Includes materials, labor, contractor's overhead and profit in 1981 dollars)

\begin{tabular}{|c|c|c|c|c|}
\hline Subsystem & Category & $\begin{array}{l}\text { Cost } \\
\text { Range }\end{array}$ & $\begin{array}{l}\text { Typical } \\
\text { Cost }\end{array}$ & Units \\
\hline Collector array & $\begin{array}{l}\text { Site-built } \\
\text { Liquid flat plate } \\
\text { Air flat plate } \\
\text { Evacuated tubes } \\
\text { Tracking concentrator }\end{array}$ & $\begin{array}{r}65-130 \\
130-215 \\
150-250 \\
260-325 \\
215-430\end{array}$ & $\left.\begin{array}{l}110 \\
160 \\
195 \\
300 \\
325\end{array}\right\}$ & $\begin{array}{l}\$ / \mathrm{m}^{2} \\
\text { collector area }\end{array}$ \\
\hline $\begin{array}{l}\text { Support } \\
\text { structure }\end{array}$ & $\begin{array}{l}\text { Single function } \\
\text { Multiple functions }\end{array}$ & $\begin{array}{l}30-160 \\
75-270\end{array}$ & $\left.\begin{array}{r}95 \\
160\end{array}\right\}$ & $\begin{array}{l}\$ / \mathrm{m}^{2} \\
\text { collector area }\end{array}$ \\
\hline $\begin{array}{l}\text { Energy } \\
\text { transport }\end{array}$ & $\begin{array}{l}\text { Hot water } \\
\text { Liquid-to-air heat } \\
\text { Air heating } \\
\text { Steam } \\
\text { Heating and cooling }\end{array}$ & $\begin{array}{r}85-185 \\
170-325 \\
55-195 \\
110-325 \\
215-540\end{array}$ & $\left.\begin{array}{l}150 \\
235 \\
110 \\
195 \\
375\end{array}\right\}$ & $\begin{array}{l}\$ / \mathrm{m}^{2} \\
\text { collector area }\end{array}$ \\
\hline $\begin{array}{l}\text { Storage } \\
\quad \text { (1iquid) }\end{array}$ & $\begin{array}{l}\text { Unpressurized steel } \\
\text { tank } \\
\text { Pressurized stee1 } \\
\text { tank } \\
\text { Fiberglass tank }\end{array}$ & $\begin{array}{l}0.29-0.77 \\
0.53-1.80 \\
0.45-0.66\end{array}$ & $\left.\begin{array}{l}0.45 \\
0.77 \\
0.53\end{array}\right\}$ & \$/liter \\
\hline Storage (air) & Rock bin & $110-220$ & $150\}$ & $\$ / 1000 \mathrm{~kg}$ rocks \\
\hline $\begin{array}{l}\text { Electrical and } \\
\text { controls }\end{array}$ & $\begin{array}{l}\text { Hot water } \\
\text { Liquid-to-air heat } \\
\text { Air heating } \\
\text { Steam } \\
\text { Heating and Cooling }\end{array}$ & $\begin{array}{l}20-55 \\
30-95 \\
20-85 \\
20-195 \\
45-215\end{array}$ & $\left.\begin{array}{r}30 \\
55 \\
45 \\
130 \\
110\end{array}\right\}$ & $\begin{array}{l}\$ / \mathrm{m}^{2} \\
\text { collector area }\end{array}$ \\
\hline $\begin{array}{l}\text { Genera1 } \\
\text { construction }\end{array}$ & N/A & $0-160$ & $45\}$ & $\begin{array}{l}\$ / \mathrm{m}^{2} \\
\text { collector area }\end{array}$ \\
\hline
\end{tabular}

Source: Mueller 1981.

Cost Rotimating During the Design Phase. As the designer actually performs the detailed design work, he or she constantly makes decisions that will affect the project's construction cost. Many of these decisions involve cost/ performance trade-offs; for example, using higher efficiency collector panels will improve thermal performance but may also increase costs. An analysis of cost/performance trade-offs frequently need only consider "differential" costs of the more expensive options and incremental energy output additions that they provide. Other decisions may not affect thermal performance as much; for example, support structure design. By maintaining an attitude of cost consciousness and applying value engineering concepts, the designer helps to keep 
Table 10-3. Design Cost Factors

\begin{tabular}{|c|c|c|}
\hline Subsystem & Cost Factor & Comments \\
\hline \multirow[t]{2}{*}{$\begin{array}{l}\text { Collector } \\
\text { array }\end{array}$} & Manifold type & $\begin{array}{l}\text { Internally manifolded collectors cost about the same } \\
\text { as externally manifolded collectors, but require less } \\
\text { than half the labor to connect. }\end{array}$ \\
\hline & Panel size & $\begin{array}{l}\text { Larger panels may require less labor per collector } \\
\text { area for mounting and connection. }\end{array}$ \\
\hline \multirow[t]{5}{*}{$\begin{array}{l}\text { Support } \\
\quad \text { structure }\end{array}$} & $\begin{array}{l}\text { Roof-imposed } \\
\text { structural } \\
\text { constraints }\end{array}$ & $\begin{array}{l}\text { In some retrofit situations, the support structure } \\
\text { must span large distances, requiring larger, more } \\
\text { expensive structural members. }\end{array}$ \\
\hline & Flat/sloped roof & $\begin{array}{l}\text { In general, support structures for sloped roofs } \\
\text { require less material and labor. }\end{array}$ \\
\hline & $\begin{array}{l}\text { Number of penetrations } \\
\text { through roof membrane }\end{array}$ & $\begin{array}{l}\text { Roof penetrations are expensive and should be kept to } \\
\text { a mintmum. }\end{array}$ \\
\hline & Reflectors & Reflectors add materials costs. \\
\hline & Esthetic constraints & $\begin{array}{l}\text { "Cosmetic" details for support structures add signi- } \\
\text { ficantly to costs. }\end{array}$ \\
\hline \multirow[t]{3}{*}{$\begin{array}{l}\text { Energy } \\
\quad \text { transport }\end{array}$} & Long plpe/duct runs & $\begin{array}{l}\text { Long runs to and from an isolated collector array or } \\
\text { storage vesse } 1 \text { add to materials and labor costs. }\end{array}$ \\
\hline & Freeze protection & $\begin{array}{l}\text { Direct systems are probably less expensive. The type } \\
\text { and size of heat exchanger used in an indirect system } \\
\text { can affect energy transport costs significantly. }\end{array}$ \\
\hline & $\begin{array}{l}\text { Complexity/number of } \\
\text { modes }\end{array}$ & $\begin{array}{l}\text { Obviously, the simpler the system, the greater the } \\
\text { opportunity for cost savings. }\end{array}$ \\
\hline Storage & Size & $\begin{array}{l}\text { The most important cost factor is size--the storage } \\
\text { capacity per collector area. }\end{array}$ \\
\hline \multirow{2}{*}{$\begin{array}{l}\text { Electrical } \\
\text { and } \\
\text { controls }\end{array}$} & $\begin{array}{l}\text { Number of modes/number } \\
\text { of actuators }\end{array}$ & $\begin{array}{l}\text { The more complex the control system, the higher the } \\
\text { cost. }\end{array}$ \\
\hline & Monftoring equipment & $\begin{array}{l}\text { Instrumentation- and performance-monitoring equipment } \\
\text { can be very expensive. }\end{array}$ \\
\hline
\end{tabular}




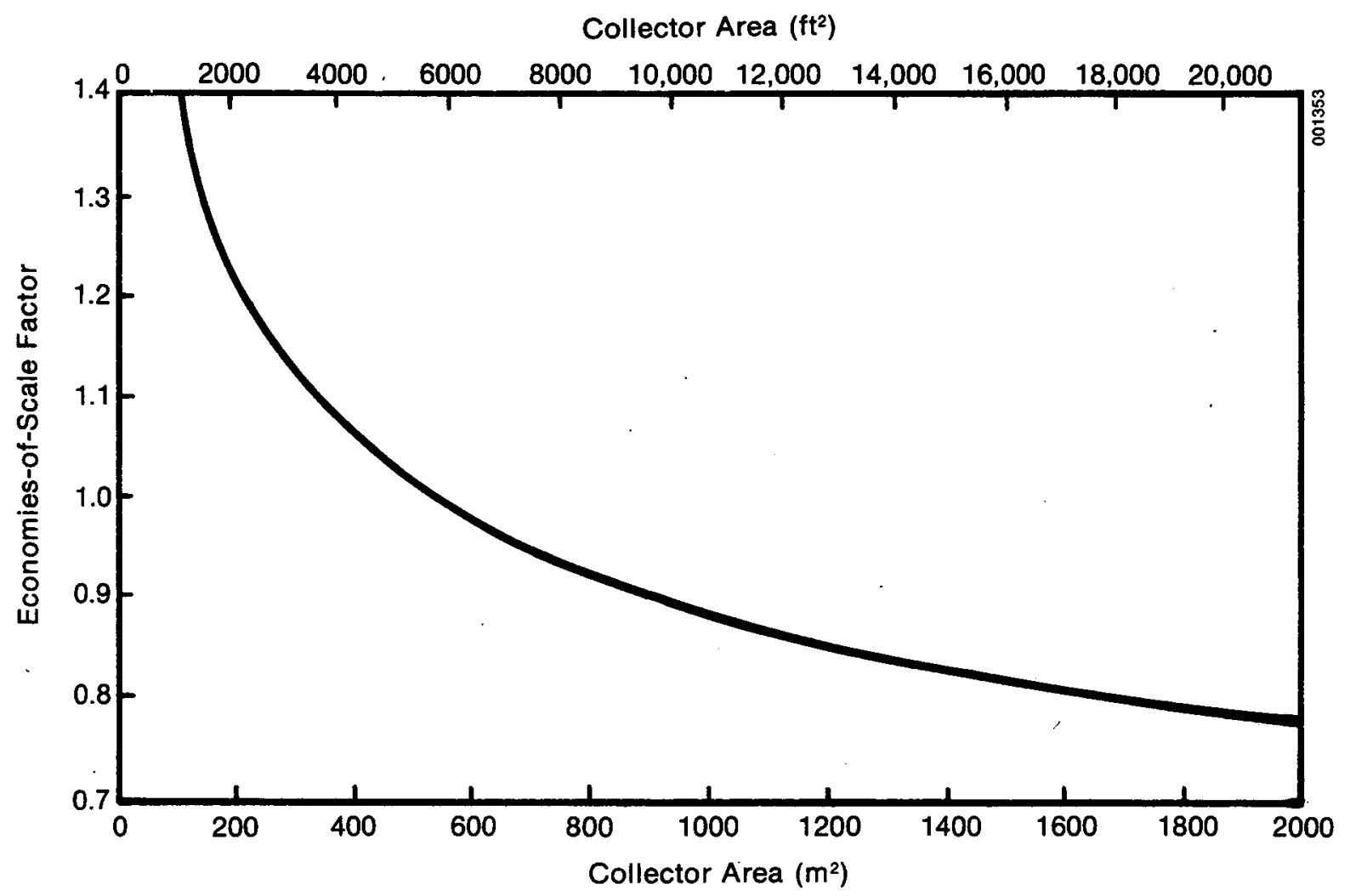

Figure 10-1. Economies-of-Scale Factor 
construction costs down. See also Table 10-3 for some of the design-related factors that impact construction costs. These factors can be useful to designers in two ways. First, they can help designers decide when to use the values in the range column in Table 10-2, to thereby refine the initial cost estimate at the same time that the initial conceptual design is refined. Second, the list may help designers maintain an attitude of cost-consciousness. While this list is by no means complete, these factors are among the more important cost-impacting decisions that designers face.

Cost Rstimating in the Post-Design Phase. After the system has been designed, complete with drawings and specifications, a detailed cost estimate (or takeoff) is normally prepared by the bidder or by the contractors who will bid on the project. The take-off allows the contractor to submit a bid that provides a reasonable profit over his costs without jeopardizing his chances of winning the bid. Often, the designer will also prepare a cost estimate, although this estimate is usually less detailed than the contractor's. This design estimate can be useful in assessing the bids. If all the bids are much higher than the estimate, perhaps additional contractors should be invited to bid. If the lowest bid is much lower than the estimate, perhaps the contractor's ability to perform should be questioned.

Contractors differ in the processes they use to prepare the take-off, but the following description represents what normally happens. First, the contractor looks at the design drawings, reads the specifications, and formulates a construction plan as a series of tasks. He then prices the major components by contacting suppliers and subcontractors. He then estimates the material and labor cost required to complete each task. He will obtain estimates or firm bids from any subcontractors he plans to use on the job. He will then add his overhead and profit rate and a contingency to arrive at a bid value. The labor and material cost estimates are often obtained from cost estimating manuals, although many contractors rely instead on cost data compiled from their own previous experience. However, these are generally insufficient in themselves for preparing a detailed take-off for a solar construction job. Table 10-4 provides additional cost information for the following solar construction tasks:

- Collector panel mounting--labor

- Collector array manifold-labor

- Support structure--labor and materials

- Rock bin storage--labor and materials.

The table format is similar to that found in cost-estimating manuals.

Non-Design-Related Cost Factors. Some of the factors that are not directly related to system design but that may affect system cost are listed below:

- Number of bidders for the construction contract. Substantial cost decreases can almost be ensured by inviting a large number of contractors to bid. 
Table 10-4. Cost Estimating Guide

\begin{tabular}{|c|c|c|c|c|c|}
\hline Item & $\begin{array}{l}\text { Material } \\
\quad(\$)\end{array}$ & $\begin{array}{l}\text { Labor } \\
(\$)\end{array}$ & $\begin{array}{l}\text { Labor } \\
\text { (hours) }\end{array}$ & $\begin{array}{c}\text { Total } \\
(\$)\end{array}$ & $\begin{array}{c}\text { Total } \\
\text { (inc1. sub. } \\
\text { OH\&P) }\end{array}$ \\
\hline $\begin{array}{l}\text { Mount and connect } \\
\text { collector panels (not } \\
\text { including cost of panels) }\end{array}$ & 9.70 & 10.80 & 1.1 & 20.50 & 25.30 \\
\hline $\begin{array}{l}\text { For afr collectors, } \\
\text { add: }\end{array}$ & 0.00 & 10.80 & 1.1 & 10.80 & 13.50 \\
\hline $\begin{array}{l}\text { For tracking collectors, } \\
\text { add: }\end{array}$ & 10.80 & 5.40 & 0.54 & 16.20 & 19.90 \\
\hline $\begin{array}{l}\text { For external manifold, } \\
\text { add: }\end{array}$ & 0.00 & 15.10 & 1.1 & 15.10 & 18.80 \\
\hline $\begin{array}{l}\text { Collector support } \\
\text { structure }\end{array}$ & 46.30 & 31.20 & 2.7 & 77.50 & 96.90 \\
\hline Maximum: & 77.50 & 51.70 & 4.3 & 129.20 & 161.00 \\
\hline Minimum: & 12.90 & 12.90 & 1.1 & 25.80 & 32.30 \\
\hline $\begin{array}{l}\text { For reflectors, } \\
\text { add: }\end{array}$ & 19.40 & 0.00 & 0.00 & 19.40 & 24.20 \\
\hline $\begin{array}{l}\text { For multiple functions, } \\
\text { add: }\end{array}$ & 32.30 & 19.40 & 1.6 & 51.70 & 64.60 \\
\hline $\begin{array}{l}\text { For sloped roof, } \\
\text { add: }\end{array}$ & 32.30 & 21.50 & 2.2 & 53.80 & 67.30 \\
\hline Rock bin ${ }^{b}$ & 65 & 55 & 5.5 & 120 & 155 \\
\hline Maximum: & 100 & 75 & 7.5 & 175 & 220 \\
\hline Min1mum: & 50 & 40 & 4.0 & 90 & 110 \\
\hline
\end{tabular}

${ }^{a}$ Costs are per $\mathrm{m}^{2}$ of collector area.

${ }^{b}$ Costs are per $1000 \mathrm{~kg}$ of rocks. 
- Number of contractors in area/general economic conditions. Contract bid values are sensitive to the laws of supply and demand. Contract bids will be lower if there are many contractors and little current construction in the area. The converse is also true.

- Transportation requirements. Transportation of materials to an isolated site may boost material costs.

- Time constraints. A tight completion deadline may require the use of overtime labor and boost labor cost.

- Material delivery delays. Construction schedules may be interrupted if delivery of important materials and equipment must be delayed which leads to increased costs.

- Weather/season. Inclement weather may interrupt construction schedules. Labor productivity may be reduced during cold winters and hot summers.

- Regional variations in labor and material costs. While this was not a significant factor in the demonstration projects, costs for a particular project may be affected by variations in local costs.

- Legal restrictions. Local building code restrictions and local union regulations may affect system cost.

- Contingency. The contingency allowance added to the contractor's bid depends heavily on the extent and nature of the contractor's experience with solar and government projects.

- In-house construction supervision versus construction management versus general contractor. Exploring the various contractual arrangements possible for the solar system construction can sometimes help reduce total construction cost.

Example of Cost Rstimating-Fairfield. The Fairfield solar energy system was designed in 1979 and 1980 and constructed in 1980. The system provides hot water for a nursing care facility. The solar energy system was retrofit onto the existing bullding, but the original roof was constructed with steel tubing stub-ups so that a solar collector support structure could be added more easily later on. Early in the design phase, the following design parameters were determined:

- Collectors. There was room for 144 liquid flat-plate collectors.

- Support structure. The stub-ups would enable a lightweight, steel support structure to be constructed relatively inexpensively.

- Energy transport. Freeze protection would use a glycol solution in the collector loop, separated from the rest of the system by a heat exchanger. A relatively long piping run would be required to connect the collector array to the mechanical room.

- Storage. A pressurized steel tank with a capacity of about $18,900 \mathrm{~L}$ (5000 gal) would be used. 
At this point, a preliminary cost estimate can be prepared using the values in Table 10-2, as follows:

Collector area: 144 panels $\times 1.86 \mathrm{~m}^{2} /$ panel
Collector array: $\$ 160 / \mathrm{m}^{2} \times 268 \cdot \mathrm{m}^{2}$

Support structure: $\$ 65 / \mathrm{m}^{2} \times 268 \mathrm{~m}^{2}$

(A figure from the lower end of the range

would be used because of the stub-ups.)

Energy transport: $\$ 170 / \mathrm{m}^{2} \times 268 \mathrm{~m}^{2}$

(A figure from the high end of the range would be used because of the long pipe runs.)

Storage: $\$ 0.77 / \mathrm{L} \times 18,900 \mathrm{~L}$

Electrical system and control: $\$ 30 / \mathrm{m}^{2} \times 268 \mathrm{~m}^{2}$

General construction: $\$ 45 / \mathrm{m}^{2} \times 268 \mathrm{~m}^{2}$

Total
$=268 \mathrm{~m}^{2}$

$=\$ 42,850$

$=17,420$

$=45,560$

This total, is then multiplied by the economies-of-scale factor from Fig. 10-1 for $268 \mathrm{~m}^{2}$, or 1.16 , to arrive at a total estimated construction cost of $\$ 163,000$. In the detailed design phase, the design was finalized with the following changes:

- The collectors selected had a net aperture area of $1.719 \mathrm{~m}^{2}\left(18.50 \mathrm{ft}^{2}\right)$ per panel for a total net aperture area of $1.719 \times 144=247.5 \mathrm{~m}^{2}$ $\left(2,664 \mathrm{ft}^{2}\right)$.

- The storage tank selected had a capacity of $15,140 \mathrm{~L}$ (4000 gal).

Using these final figures, a total construction cost estimate could be calculated as follows:

$\begin{array}{ll}\text { Collector array: } \$ 160 / \mathrm{m}^{2} \times 247.5 \mathrm{~m}^{2} & =\$ 39,600 \\ \text { Support structure: } \$ 65 / \mathrm{m}^{2} \times 247.5 \mathrm{~m}^{2} & =16,088 \\ \text { Energy transport: } \$ 170 / \mathrm{m}^{2} \times 247.5 \mathrm{~m}^{2} & =42,075 \\ \text { Storage: } \$ 0.77 / \mathrm{L} \times 15,140 \mathrm{~L} & =11,658 \\ \text { Electrical system and controls: } \$ 30 / \mathrm{m}^{2} \times 247.5 \mathrm{~m}^{2}= & 7,425 \\ \text { General construction: } \$ 45 / \mathrm{m}^{2} \times 247.5 \mathrm{~m}^{2} & =11,138 \\ \quad \text { Total } & \end{array}$

This value would then be multiplied by the economies-of-scale factor from Fig. 10-1 for $247.5 \mathrm{~m}^{2}$, or 1.18 , for a total estimated construction cost of $\$ 151,000$.

\subsubsection{Modular Cost Estimating}

Modular cost estimating (Guthrie 1969) calculates total system costs using a number of multiplicative factors applied to FOB cost. The procedure used in 
ECONMAT (Stadjuhar 1982) is diagrammed in Fig. 10-2, and the various factors that are applied are defined in Table 10-5.

To begin, the collector FOB cost is multiplied by CAMAT to arrive at the cost of auxiliary materials for the collector array. This cost is added to the collector cost to get the collector array materials cost. The collector array materials cost is then multiplied by PIMAT to obtain the cost of process interface materials. The sum of the materials costs are multiplied by EDO and FRTTAX to obtain estimates of engineering design, offices, freight, and tax costs, which are the indirect costs for the system. Separately, the collector array and process interface materials costs are multiplied by CALAB and PILAB, respectively, to estimate labor costs for installation of the array and interface equipment. These labor costs are multiplied by COVRHD to compute the construction overhead, which is added to the indirect costs previously calculated. Adding the materials and labor costs for the collector array and the process interface yields the total direct costs for the system. Finally, the sum of the direct and indirect costs is multiplied in turn by CNTG and FEE to obtain contingency cost estimates and the contractor's fee. Adding these cost components to the sum of the direct and indirect costs produces the estimated total system cost.

Certain values, based on data from previously built systems, are recommended for the parameters in Table 10-5; some depend on the collector type and others on the system type. These values are given in Table 10-6. Although the modular cost estimating method is usually accurate to within $\pm 20 \%$, because historical solar system cost data are limited, we cannot justify more than a $\pm 30 \%$ accuracy for solar IPH systems.

\subsection{LIFE-CYCLE COST ANALYSIS}

There are a number of methods to evaluate the economic feasibility of a solar IPH system. An important consideration, in addition to the performance of the system itself, is the cost of the conventional fuel that the solar system displaces. Thus, solar systems may be proposed for areas where sunlight is not plentiful but conventional fuels, like oil or natural gas, for example, are expensive or face curtailments in supplies.

The most popular methods of evaluating economic feasibility include net present value, payback, and internal rate of return. The simple payback method does not accurately reflect the profitability of an investment because it does not account for cash flows after the payback period. It is often used, though, to make initial estimates as to the value of an investment, particularly during uncertain economic times. The internal rate of return required of a solar investment is that rate of return giving a levelized (or annualized) cost of solar energy equal to the levelized cost of conventional fuel. The levelizing technique expresses annual required revenue as an equivalent constant revenue payable each year in current-year dollars. The method, proposed by Dickinson and Brown (1979), can be summarized as follows (Stadjuhar 1982): 


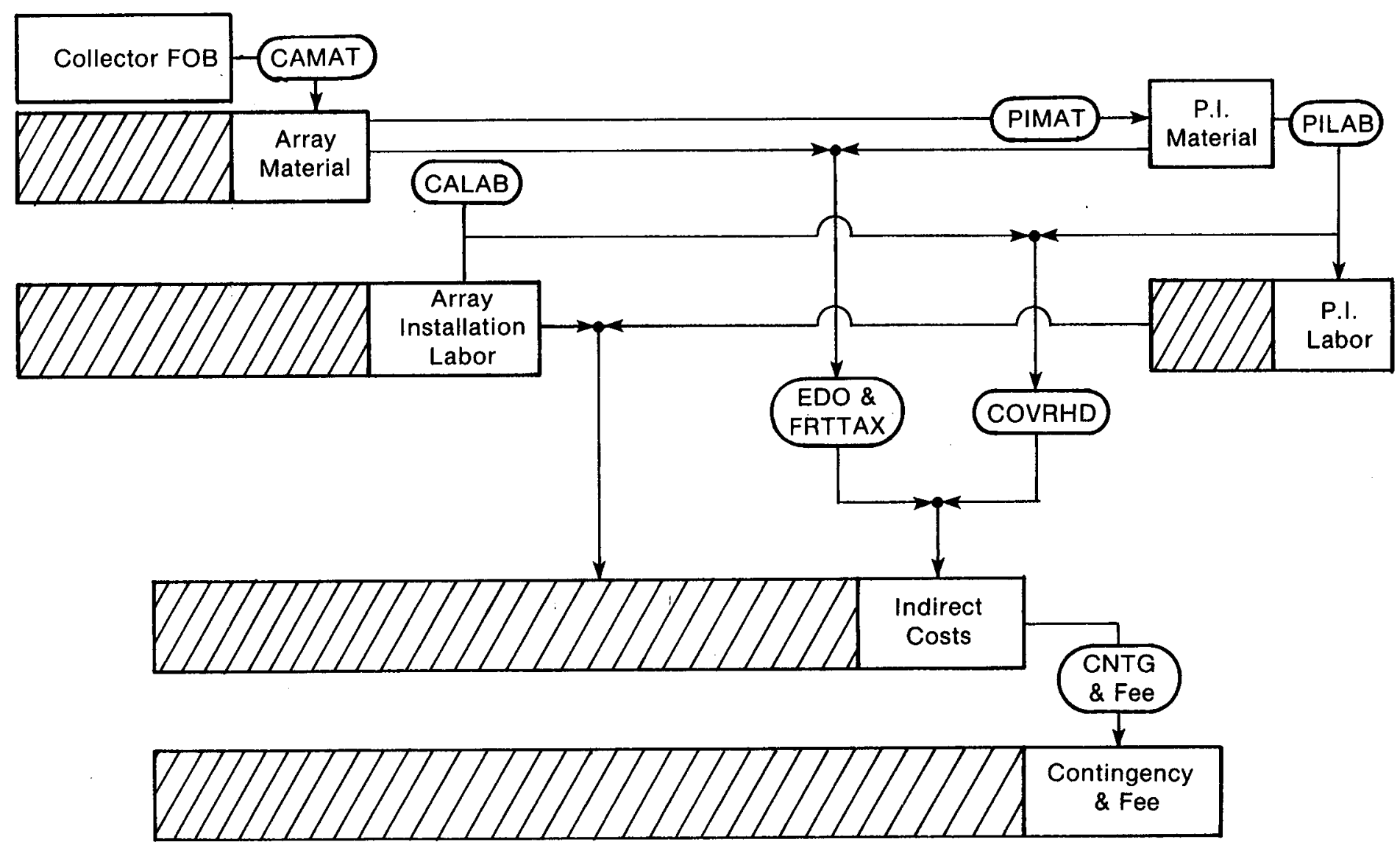

Note: Cost portions are not drawn to scale

Figure 10-2. Modular Cost-Estimating Procedure Used by ECONMAT 
Table 10-5. Factor Definitions for Modular Cost Estimating

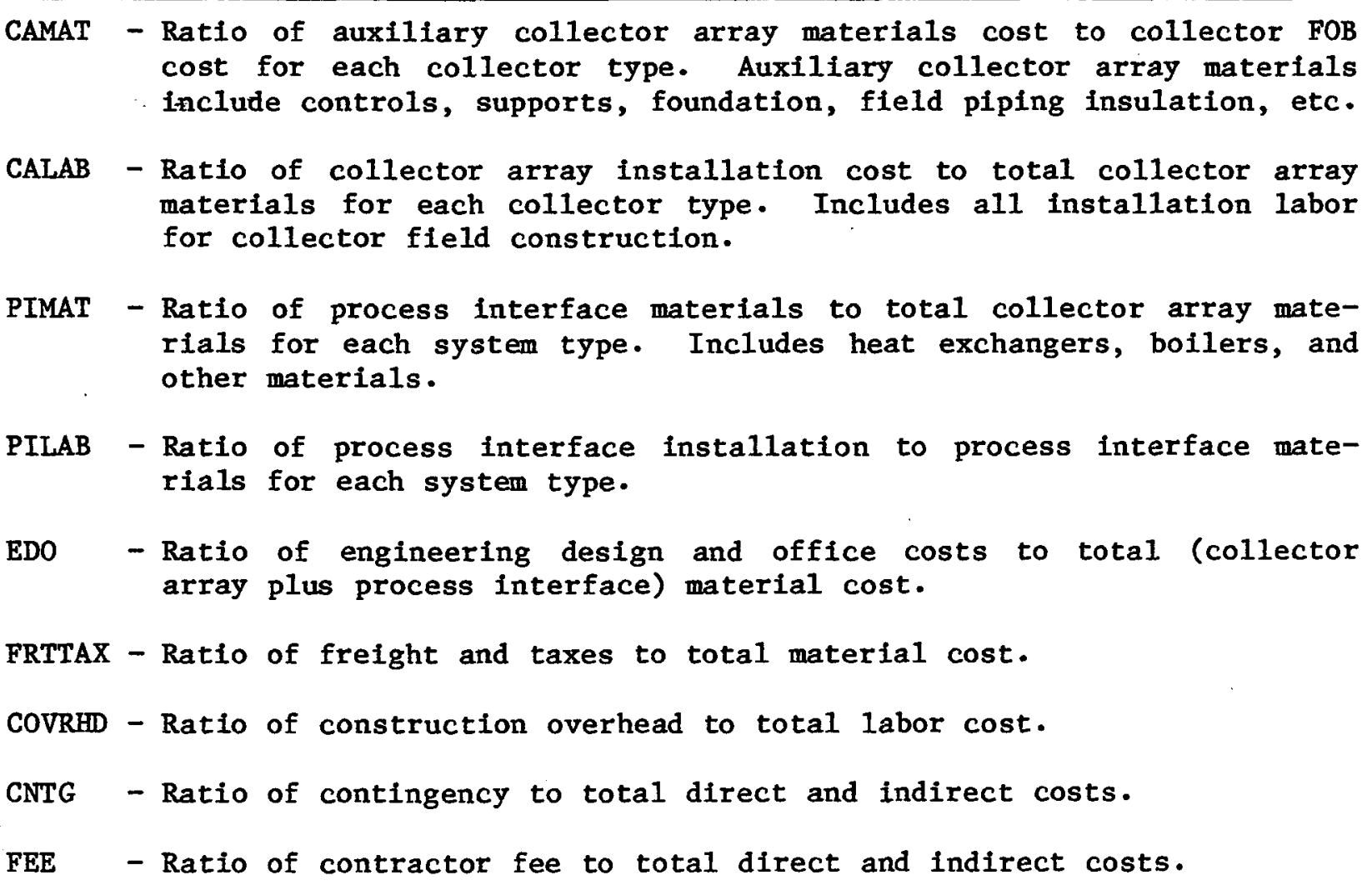

Source: Stadjuhar 1982.

Table 10-6a. Recommended Values for Modular Factors

(Collector-dependent values)

\begin{tabular}{cccccc}
\hline & $\begin{array}{c}\text { Flat } \\
\text { Plate }\end{array}$ & $\begin{array}{c}\text { Evacuated } \\
\text { Tube }\end{array}$ & CPC & $\begin{array}{c}\text { Parabolic } \\
\text { Trough }\end{array}$ & $\begin{array}{c}\text { Parabolic } \\
\text { Dish }\end{array}$ \\
\hline CAMAT & 0.19 & 0.21 & 0.22 & 0.14 & 0.13 \\
CALAB & 0.11 & 0.12 & 0.13 & 0.14 & 0.13
\end{tabular}

Source: Stadjuhar 1982 . 
Table 10-6b. Recomended Values for Modular Factors

(System-dependent values)

\begin{tabular}{|c|c|c|c|c|c|c|}
\hline & \multicolumn{2}{|c|}{ Hot Water } & \multicolumn{2}{|c|}{ Hot Air } & \multicolumn{2}{|c|}{ Steam } \\
\hline & Direct & Indirect & Direct & Indirect & $\begin{array}{l}\text { Flash } \\
\text { Boiler }\end{array}$ & $\begin{array}{l}\text { Unfired } \\
\text { Boiler }\end{array}$ \\
\hline $\begin{array}{l}\text { PIMAT } \\
\text { PILAB }\end{array}$ & $\begin{array}{l}0.02 \\
0.40\end{array}$ & $\begin{array}{l}0.04 \\
0.40\end{array}$ & $\begin{array}{l}0.04 \\
0.40\end{array}$ & $\begin{array}{l}0.05 \\
0.40\end{array}$ & $\begin{array}{l}0.07 \\
0.40\end{array}$ & $\begin{array}{l}0.11 \\
0.40\end{array}$ \\
\hline
\end{tabular}

Source: Stadjuhar 1982.

- Calculate the levelized price of the conventional fuel, including the effects of fuel escalation and fuel utilization efficiency.

- Calculate the levelized price of solar energy.

- Calculate the initial capital investment for the solar system using modular cost estimating or some other technique and adding land costs, if any.

- Calculate the annual energy delivered by the system.

- Calculate the annual energy capacity cost:

$$
\text { Capacity cost }=\frac{\text { Capital cost }}{\text { Annual energy delivered }} \frac{\$}{\mathrm{GJ} / \mathrm{yr}} \text {. }
$$

- Calculate the M-factor (Dickinson and Brown 1981), where $M$ is the single levelizing factor incorporating the effects of annual operation, maintenance, property, and insurance costs (OMPI), composite (federal and state) income tax rate, investment tax credit, depreciation, and required market discount rate (or rate of return) over the project lifetime.

- The levelized price of solar energy is the product of the M-factor and the annual energy capacity cost of the solar system:

Levelized price of solar energy $=\mathrm{M} \mathrm{x}$ capacity cost .

- The internal (or project) rate of return of the solar system is that rate of return (or discount factor) for which the levelized price of solar energy is equivalent to the levelized price of the conventional fuel. This is the annual after-tax rate of return on the unamortized equity investment and does not imply or require reinvestment (Stermole 1974, p. 57).

To calculate the required levelizing factors, use the capital recovery factor. It is defined as

$$
\operatorname{CRF}(R, N)=\frac{R}{1-(1+R)^{-N}},
$$


where

$$
\begin{aligned}
& \mathrm{R}=\text { internal rate of return or discount rate } \\
& \mathrm{N}=\text { the number of years covered by the analysis, usually taken as the } \\
& \text { system lifetime. }
\end{aligned}
$$

The capital recovery factor represents the constant revenue (or payment) required each year for $\mathbf{N}$ years for each dollar of capital invested (or debt owed) today. Values of CRF for various values of $R$ and $N$ are given in Table 10-7.

\begin{tabular}{|c|c|c|c|c|c|c|}
\hline \multirow{2}{*}{$\mathbf{N}$} & \multicolumn{6}{|c|}{$\begin{array}{c}R \\
(\%)\end{array}$} \\
\hline & 8 & 10 & 12 & 15 & 20 & 25 \\
\hline 1 & 1.08000 & 1.10000 & 1.12000 & 1.15000 & 1.20000 & 1.25000 \\
\hline 2 & 0.56077 & 0.57619 & 0.59170 & 0.61512 & 0.65455 & 0.69444 \\
\hline 3 & 0.38803 & 0.40211 & 0.41635 & 0.43798 & 0.47473 & 0.51230 \\
\hline 4 & 0.30192 & 0.31547 & 0.32923 & 0.35027 & 0.38629 & 0.42344 \\
\hline 5 & 0.25046 & 0.26380 & 0.27741 & 0.29832 & 0.33438 & 0.37185 \\
\hline 6 & 0.21632 & 0.22961 & 0.24323 & 0.26424 & 0.30071 & 0.33882 \\
\hline 7 & 0.19207 & 0.20541 & 0.21912 & 0.24036 & 0.27742 & 0.31634 \\
\hline 8 & 0.17401 & 0.18744 & 0.20130 & 0.22285 & 0.26061 & 0.30040 \\
\hline 9 & 0.16008 & 0.17364 & 0.18768 & 0.29057 & 0.24808 & 0.28876 \\
\hline 10 & 0.14903 & 0.16275 & 0.17698 & 0.19925 & 0.23852 & 0.28007 \\
\hline 11 & 0.14008 & 0.15396 & 0.16842 & 0.19107 & 0.23110 & 0.27349 \\
\hline 12 & 0.13270 & 0.14676 & 0.16144 & 0.18448 & 0.22526 & 0.26845 \\
\hline 13 & 0.12652 & 0.14078 & 0.15568 & 0.17911 & 0.22062 & 0.26454 \\
\hline 14 & 0.12130 & 0.13575 & 0.15087 & 0.17469 & 0.21689 & 0.26150 \\
\hline 15 & 0.11683 & 0.13147 & 0.14682 & 0.17102 & 0.21388 & 0.25912 \\
\hline 16 & 0.11298 & 0.12782 & 0.14339 & 0.16795 & 0.21144 & 0.25724 \\
\hline 17 & 0.10963 & 0.12466 & 0.14046 & 0.16537 & 0.20944 & 0.25576 \\
\hline 18 & 0.10670 & 0.12193 & 0.13794 & 0.16319 & 0.20781 & 0.25459 \\
\hline 19 & 0.10413 & 0.11955 & 0.13576 & 0.16134 & 0.20646 & 0.25366 \\
\hline 20 & 0.10185 & 0.11746 & 0.13388 & 0.15976 & 0.20536 & 0.25292 \\
\hline 21 & 0.09983 & 0.11562 & 0.13224 & 0.15842 & 0.20444 & 0.25233 \\
\hline 22 & 0.09803 & 0.11401 & 0.13081 & 0.15727 & 0.20369 & 0.25186 \\
\hline 23 & 0.09642 & 0.11257 & 0.12956 & 0.15628 & 0.20307 & 0.25148 \\
\hline 24 & 0.09498 & 0.11130 & 0.12846 & 0.15543 & 0.20255 & 0.25119 \\
\hline 25 & 0.09368 & 0.11017 & 0.12750 & 0.15470 & 0.20212 & 0.25095 \\
\hline 26 & 0.09251 & 0.10916 & 0.12665 & 0.15407 & 0.20176 & 0.25076 \\
\hline 27 & 0.09145 & 0.10826 & 0.12590 & 0.15353 & 0.20147 & 0.25061 \\
\hline 28 & 0.09049 & 0.10745 & 0.12524 & 0.15306 & 0.20122 & 0.25048 \\
\hline 29 & 0.08962 & 0.10673 & 0.12466 & 0.15265 & 0.20102 & 0.25039 \\
\hline 30 & 0.08883 & 0.10608 & 0.12414 & 0.15230 & 0.20085 & 0.25031 \\
\hline
\end{tabular}

Table 10-7. Values of Capital Recovery Factor

$$
\left(\operatorname{CRF}(R, N)=\frac{R}{1-(1+R)^{-N}}\right)
$$


The levelized price of conventional fuel can be calculated by

$$
P_{f}=P_{f o} \times L F,
$$

where

$$
\begin{aligned}
P_{\text {fo }}= & \text { the fuel price in the year zero } \\
L F= & \text { the levelizing factor, a function of the assumed total fuel cost } \\
& \text { inflation rate } g^{\prime} \text { (includes the general inflation rate), the sys- } \\
& \text { tem life } \mathrm{N} \text {, and the discount rate } \mathrm{R} \text {. }
\end{aligned}
$$

Defining

$$
R^{\prime \prime}=\frac{1+R}{1+g^{\prime}}-1 \text {, }
$$

the levelizing factor is given by*

$$
L F=\frac{C R F(R, N)}{\operatorname{CRF}\left(R^{1+N}, N\right)}
$$

Some sample values of LF for several values of $g^{\prime}, R$, and $N$ are given in Table 10-8.

Some elaboration is warranted here on the concept of "capacity cost." Up to this point, solar IPH system costs have been discussed in terms of total installed cost per unit of collector aperture area, a figure that is convenient for estimating the investment but does not reflect the energy benefit.

The capacity cost, however, defined as the investment I divided by the annual energy delivery from the solar systen $E_{S}$, represents the investment required to purchase one GJ (or MBtu) of annual energy output and is similar in meaning to other common capacity costs $(\mathrm{e} . \mathrm{g} \cdot, \mathrm{\$} / \mathrm{kW}$ for conventional electric power plants).

*This formulation of LF assumes that $g^{\prime}$ is constant. If a variable fuel inflation rate is desired, where $g_{t}$ is the rate in year $t$, then the levelizing factor is

$$
L F=\operatorname{CRF}(R, N) \cdot \sum_{t=1}^{N} \frac{\left(1+g_{t}\right) !}{(1+R)^{t}}
$$

where $\left(1+g_{t}\right) !=\left(1+g_{1}\right)\left(1+g_{1}\right) \ldots\left(1+g_{t}\right)$. 
Table 10-8. Values of the Levelizing Factor IF to Convert a ZeroYear Fuel Price to a Levelized Price Over $N$ Years $\left(L F=\frac{C R F(R, N)}{C R F\left(R^{\prime \prime}, N\right)}, R^{\prime \prime}=\frac{1+R}{1+g^{\prime}}-1\right)$

\begin{tabular}{lcrrrr}
\hline $\begin{array}{c}\text { Fuel Escalation } \\
\text { Rate } g^{\prime}(\%)^{a}\end{array}$ & $\begin{array}{c}\text { Market ROR } \\
R(\%)\end{array}$ & $R^{\prime \prime}(\%)$ & $\operatorname{CRF}(R, N)$ & $\operatorname{CRF}\left(R^{\prime \prime}, N\right)$ & LF \\
\hline $\mathrm{N}=10$ yr & & & & & \\
\hline & & & & & \\
6 & 10 & 3.77 & 0.16275 & 0.12188 & 1.34 \\
& 15 & 8.49 & 0.19925 & 0.15234 & 1.31 \\
& 20 & 13.21 & 0.23852 & 0.18585 & 1.28
\end{tabular}

$\mathrm{N}=15 \mathrm{yr}$

6

10

3.77

0.13147

0.08850

1.49

15

8.49

0.17102

0.12035

1.42

20

13.21

0.21388

0.15640

1.37

$\mathrm{N}=20 \mathrm{yr}$

$\begin{array}{rrrrrr}6 & 10 & 3.77 & 0.11746 & 0.07209 & 1.63 \\ & 15 & 8.49 & 0.15976 & 0.10559 & 1.51 \\ & 20 & 13.21 & 0.20536 & 0.14415 & 1.43 \\ 8 & & & & & \\ & 10 & 1.85 & 0.11746 & 0.06028 & 1.95 \\ & 15 & 6.48 & 0.15976 & 0.09061 & 1.76 \\ 10 & 20 & 11.11 & 0.20536 & 0.12648 & 1.62 \\ & & & & & \\ & 10 & 0 & 0.11746 & 0.05000 & 2.35 \\ & 15 & 4.55 & 0.15976 & 0.07721 & 2.07 \\ & 20 & 9.09 & 0.20536 & 0.11025 & 1.86\end{array}$

Source: Dickinson and Brown 1981.

$a_{\text {This }}$ is an overall escalation rate including general inflation. If the general inflation rate is $g$ and the differential fuel escalation rate is $e$, the overall fuel escalation rate $g^{\prime}$ is given by $1+g^{\prime}=(1+g)(1+e)$.

The levelizing factor $M$ for solar energy is defined by Dickinson and Brown (1981) as

$$
\begin{aligned}
M=\frac{C_{S}}{I}=0 M P I & +\frac{C R F(R, N)}{1-\tau}\left[(1-f)+f(1-\tau) \frac{C R F(r, L P)}{\operatorname{CRF}(R, L P)}+\frac{f \tau(C R F(r, L P)-r)}{(1+r) C R F\left(R^{\prime \prime}, L P\right)}\right. \\
& -\frac{T C}{1+R}-\tau \cdot \operatorname{DEP}+\left(\frac{1+g}{1+R}\right)^{t_{C}} \cdot m\left(t_{C}\right)(1-T C-\tau \cdot D E P) \\
& \left.-\left(\frac{1+g}{1+R}\right)^{N} S\right] .
\end{aligned}
$$


This equation is derived from an expression that can be solved for the levelized required revenue for the solar energy system $C_{s}$ that includes the following terms:

$$
\begin{aligned}
C_{s}= & \text { expenses }+ \text { loan repayment }+\tau\left(C_{s}-\text { expenses }-\right. \text { depreciation - loan } \\
& \text { interest })+ \text { equity repayment }- \text { investment tax credit }+ \text { major } \\
& \text { replacement costs }- \text { net salvage value, }
\end{aligned}
$$

where $\tau$ is the marginal composite (state plus federal) income tax rate.

The terms in the equation for $M$ are defined in the list of economic terms at the front of this handbook. Multiplying $M$ by the capacity cost of the system, the levelized price $P_{S}$ of solar energy is

$$
\mathrm{P}_{\mathrm{S}}=\mathrm{M} \cdot \frac{\mathrm{I}}{\mathrm{E}_{\mathrm{S}}}=\frac{\mathrm{C}_{\mathrm{S}}}{\mathrm{E}_{\mathrm{S}}}
$$

Some values of $M$ for various combinations of OMPI $_{O}$, tax credits, loan fraction, loan interest rate, system lifetime, depreciation period, and required rate of return on investment are listed in Table 10-9. A simplified form of the equation for $M$ is valid for cash investments (no loan) where no major replacement costs occur and salvage value is negligible (Brown et al. 1980):

$$
M=O M P I+\frac{C R F(R, N)}{1-\tau} 1-\left(\frac{T C}{1+R}-\tau \cdot D E P\right) \text {. }
$$

In comparing $P_{S}$ and $P_{f}$, we should remember that a unit of energy provided by the solar system may displace more than a unit of conventional energy when boiler or burner efficiencies, stack losses, and other factors are involved.

Defining a solar effectiveness factor $\varepsilon$ as

$$
\varepsilon=\frac{\text { fuel energy saved by solar system }}{\text { solar energy delivered }},
$$

we find that $P_{s}$ should be compared with $\varepsilon \cdot P_{f}$ for meaningful interpretations of this economic evaluation. Except in very unusual process arrangements, $\varepsilon$ is ordinarily the reciprocal of full-load boiler efficiency. Effects of variable boiler efficiency on $\varepsilon$ are, however, actually very small, as shown in Appendix A.

The rate of return $R$ that satisfies the expression

$$
P_{s}(R)=\varepsilon \cdot P_{f}(R),
$$

or

$$
M(R) \cdot \frac{I}{E_{S}}=\varepsilon \cdot P_{\text {fo }} \cdot L F(R)
$$

will be the required internal rate of return (IROR) for the solar system. This quantity generally indicates the profitability of a new endeavor. A graphical solution to $\mathrm{Eq} \cdot 10-10$ is very informative and is recommended. An 
Table 10-9a. Values of M-Factor ${ }^{a}$

$(R=0.10)$

\begin{tabular}{|c|c|c|c|c|c|c|c|c|c|c|c|c|c|c|c|c|c|c|c|}
\hline \multirow{4}{*}{$\begin{array}{l}\text { f (Loan } \\
\text { Fraction) }\end{array}$} & \multirow{4}{*}{$\begin{array}{l}\mathrm{TC} \\
\mathrm{OMPI}_{0} \\
\mathrm{DP}(\mathrm{yr}) \\
\mathrm{N}(y r)\end{array}$} & \multicolumn{6}{|c|}{0.2} & \multicolumn{6}{|c|}{0.3} & \multicolumn{6}{|c|}{0.5} \\
\hline & & \multicolumn{3}{|c|}{0.01} & \multicolumn{3}{|c|}{0.04} & \multicolumn{3}{|c|}{0.01} & \multicolumn{3}{|c|}{0.04} & \multicolumn{3}{|c|}{0.01} & \multicolumn{3}{|c|}{0.04} \\
\hline & & \multicolumn{2}{|r|}{7.} & \multirow{2}{*}{$\begin{array}{l}16 \\
20\end{array}$} & \multicolumn{2}{|r|}{7} & \multirow{2}{*}{$\frac{16}{20}$} & \multicolumn{2}{|r|}{7} & \multirow{2}{*}{$\frac{16}{20}$} & \multicolumn{2}{|r|}{7} & \multirow{2}{*}{$\frac{16}{20}$} & \multicolumn{2}{|r|}{7} & \multirow{2}{*}{$\frac{16}{20}$} & \multicolumn{2}{|r|}{7} & \multirow{2}{*}{$\frac{16}{20}$} \\
\hline & & 10 & 20 & & 10 & 20 & & 10 & 20 & & 10 & 20 & & 10 & 20 & & 10 & 20 & \\
\hline \multicolumn{20}{|c|}{$r=3 z$} \\
\hline 0.0 & & 0.156 & 0.119 & 0.138 & 0.196 & 0.168 & 0.187 & 0.126 & 0.098 & 0.117 & 0.167 & 0.147 & 0.165 & 0.067 & 0.055 & 0.074 & 0.107 & 0.104 & 0.123 \\
\hline 0.3 & & 0.123 & 0.082 & 0.101 & 0.163 & 0.131 & 0.150 & 0.093 & 0.061 & 0.080 & 0.133 & 0.110 & 0.129 & 0.034 & 0.018 & 0.037 & 0.074 & 0.067 & 0.086 \\
\hline $\begin{array}{l}0.5 \\
0.7\end{array}$ & & $\begin{array}{l}0.100 \\
0.078\end{array}$ & 0.058 & 0.077 & 0.141 & 0.107 & 0.126 & 0.071 & 0.037 & 0.056 & 0.111 & 0.086 & 0.104 & 0.012 & - & 0.013 & 0.052 & 0.043 & 0.062 \\
\hline $\begin{array}{l}0.7 \\
0.9\end{array}$ & & $\begin{array}{l}0.078 \\
0.056\end{array}$ & $\begin{array}{l}0.034 \\
0.009\end{array}$ & $\begin{array}{l}0.052 \\
0.028\end{array}$ & $\begin{array}{l}0.118 \\
0.096\end{array}$ & $\begin{array}{l}0.083 \\
0.058\end{array}$ & $\begin{array}{l}0.101 \\
0.077\end{array}$ & $\begin{array}{l}0.049 \\
0.027\end{array}$ & $\begin{array}{r}0.012 \\
--\end{array}$ & $\begin{array}{l}0.031 \\
0.007\end{array}$ & $\begin{array}{l}0.089 \\
0.067\end{array}$ & $\begin{array}{l}0.061 \\
0.037\end{array}$ & $\begin{array}{l}0.080 \\
0.056\end{array}$ & $=$ & $\overline{-}$ & $=$ & $\begin{array}{l}0.030 \\
0.008\end{array}$ & $\begin{array}{c}0.018 \\
--\end{array}$ & $\begin{array}{l}0.037 \\
0.013\end{array}$ \\
\hline \multicolumn{20}{|c|}{$r=9 x$} \\
\hline 0.0 & & 0.156 & 0.119 & 0.138 & 0.196 & 0.168 & 0.187 & 0.126 & 0.098 & 0.117 & 0.167 & 0.147 & 0.165 & 0.067 & 0.055 & 0.074 & 0.107 & 0.104 & 0.123 \\
\hline 0.3 & & 0.133 & 0.093 & 0.112 & 0.173 & 0.142 & 0.161 & 0.103 & 0.072 & 0.090 & 0.143 & 0.120 & 0.139 & 0.044 & 0.029 & 0.048 & 0.084 & 0.078 & 0.097 \\
\hline 0.5 & & 0.118 & 0.076 & 0.094 & 0.158 & 0.124 & 0.143 & 0.088 & 0.054 & 0.073 & 0.128 & 0.103 & 0.122 & 0.029 & 0.011 & 0.030 & 0.069 & 0.060 & 0.079 \\
\hline 0.7 & & 0.102 & 0.058 & 0.077 & 0.143 & 0.107 & 0.126 & 0.073 & 0.037 & 0.056 & 0.113 & 0.086 & 0.105 & 0.014 & $=$ & 0.013 & 0.054 & 0.043 & 0.062 \\
\hline 0.9 & & 0.087 & 0.041 & 0.060 & 0.127 & 0.090 & 0.108 & 0.058 & 0.019 & 0.038 & 0.098 & 0.068 & 0.087 & $\rightarrow$ & -- & - & 0.038 & 0.026 & 0.044 \\
\hline \multicolumn{20}{|c|}{$r=12 \pi$} \\
\hline 0.0 & & 0.156 & 0.119 & 0.138 & 0.196 & 0.168 & 0.187 & 0.126 & 0.098 & 0.117 & 0.167 & 0.147 & 0.165 & 0.067 & 0.055 & 0.074 & 0.107 & 0.104 & 0.123 \\
\hline 0.3 & & 0.139 & 0.099 & 0.118 & 0.179 & 0.148 & 0.167 & 0.109 & 0.078 & 0.097 & 0.150 & 0.127 & 0.146 & 0.050 & 0.035 & 0.054 & 0.090 & 0.084 & 0.103 \\
\hline 0.5 & & 0.127 & 0.086 & 0.105 . & 0.167 & 0.135 & 0.154 & 0.098 & 0.065 & 0.084 & 0.138 & 0.114 & 0.132 & 0.039 & 0.022 & 0.041 & 0.079 & 0.071 & 0.090 \\
\hline 0.7 & & 0.116 & 0.073 & 0.092 & 0.156 & 0.122 & 0.141 & 0.086 & 0.052 & 0.071 & 0.126 & 0.101 & 0.119 & 0.027 & 0.009 & 0.028 & 0.067 & 0.058 & 0.077 \\
\hline 0.9 & & 0.104 & 0.060 & 0.079 & 0.145 & 0.109 & 0.128 & 0.075 & 0.039 & 0.057 & 0.115 & 0.087 & 0.106 & 0.016 & -- & 0.015 & 0.056 & 0.045 & 0.064 \\
\hline $\begin{array}{l}\text { Add to } \\
\text { above for }\end{array}$ & & & & & & & & & & & & & & & & & & & \\
\hline $\mathrm{m}\left(t_{\mathrm{f}}\right)=$ & & 0.026 & 0.019 & 0.023 & 0.026 & 0.019 & 0.023 & 0.020 & 0.015 & 0.018 & 0.020 & 0.015 & 0.018 & 0.007 & 0.005 & 0.009 & 0.007 & 0.005 & 0.009 \\
\hline $\begin{array}{l}\mathrm{m}(\mathrm{t} \\
0.25(10)\end{array}$ & & - & 0.017 & 0.020 & -- & 0.017 & 0.020 & -- & 0.013 & 0.016 & -- & 0.013 & 0.016 & - & 0.005 & 0.008 & -- & 0.005 & 0.008 \\
\hline$s=0.20$ & & -0.045 & -0.022 & -0.022 & -0.045 & -0.022 & -0.022 & -0.045 & -0.022 & -0.022 & -0.045 & -0.022 & -0.022 & -0.045 & -0.022 & -0.022 & -0.045 & -0.022 & -0.022 \\
\hline
\end{tabular}

${ }^{\text {a }}$ Fixed parameters: $g=6 \pi, \tau=50 \%$, SOYD deprectation, LP $=10$ yr (for $N=10 \mathrm{yr}$ ), LP $=20$ yr (for $\left.N=20 y r\right), m(t)=0$, and $S=0$.

Source: Dickingon and Brown 1979. 
Table 10-9b. Values of M-Factor ${ }^{a}$

$(R=0.15)$

\begin{tabular}{|c|c|c|c|c|c|c|c|c|c|c|c|c|c|c|c|c|c|c|c|}
\hline \multirow{4}{*}{$\begin{array}{c}f \text { (Loan } \\
\text { Fraction) }\end{array}$} & \multirow{4}{*}{$\begin{array}{l}\mathrm{TC} \\
\mathrm{OMPI}_{0} \\
\mathrm{DP}(\mathrm{yr}) \\
\mathrm{N}(\mathrm{yr})\end{array}$} & \multicolumn{6}{|c|}{0.2} & \multicolumn{6}{|c|}{0.3} & \multicolumn{6}{|c|}{0.5} \\
\hline & & \multicolumn{3}{|c|}{0.01} & \multicolumn{3}{|c|}{0.04} & \multicolumn{3}{|c|}{0.01} & \multicolumn{3}{|c|}{0.04} & \multicolumn{3}{|c|}{0.01} & \multicolumn{3}{|c|}{0.04} \\
\hline & & \multicolumn{2}{|r|}{7} & \multirow{2}{*}{$\frac{16}{20}$} & \multicolumn{2}{|r|}{7} & \multirow{2}{*}{$\begin{array}{l}16 \\
20\end{array}$} & \multicolumn{2}{|c|}{7} & \multirow{2}{*}{$\frac{16}{20}$} & \multicolumn{2}{|c|}{7} & \multirow{2}{*}{$\frac{16}{20}$} & \multicolumn{2}{|c|}{7} & \multirow{2}{*}{$\frac{16}{20}$} & \multicolumn{2}{|r|}{7} & \multirow{2}{*}{$\frac{16}{20}$} \\
\hline & & 10 & 20 & & 10 & 20 & & 10 & 20 & & 10 & 20 & & 10 & 20 & & 10 & 20 & \\
\hline \multicolumn{20}{|c|}{$r=3 z$} \\
\hline 0.0 & & 0.208 & 0.171 & 0.200 & 0.247 & 0.216 & 0.246 & 0.173 & 0.143 & 0.173 & 0.212 & 0.189 & 0.218 & 0.104 & 0.088 & 0.117 & 0.143 & 0.133 & 0.162 \\
\hline 0.3 & & 0.152 & 0.109 & 0.138 & 0.191 & 0.154 & 0.183 & 0.118 & 0.081 & 0.110 & 0.157 & 0.126 & 0.156 & 0.048 & 0.025 & 0.055 & 0.087 & 0.071 & 0.100 \\
\hline 0.5 & & 0.115 & 0.067 & 0.096 & 0.154 & 0.112 & 0.142 & 0.081 & 0.039 & 0.069 & 0.120 & 0.085 & 0.114 & 0.011 & -- & 0.013 & 0.051 & 0.029 & 0.058 \\
\hline 0.7 & & 0.078 & 0.025 & 0.055 & 0.118 & 0.071 & 0.100 & 0.044 & -- & 0.027 & 0.083 & 0.043 & 0.072 & -- & -- & -- & 0.014 & - & 0.017 \\
\hline 0.9 & & 0.041 & - & 0.013 & 0.081 & 0.029 & 0.058 & 0.007 & -- & -- & 0.046 & - & 0.031 & -- & - & -- & -- & -- & $=$ \\
\hline \multicolumn{20}{|c|}{$r=9 x$} \\
\hline 0.0 & & 0.208 & 0.171 & 0.200 & 0.247 & 0.216 & 0.246 & 0.173 & 0.143 & 0.173 & 0.212 & 0.189 & 0.218 & 0.104 & 0.088 & 0.117 & 0.143 & 0.133 & 0.162 \\
\hline 0.3 & & 0.162 & 0.118 & 0.148 & 0.201 & 0.164 & 0.193 & 0.127 & 0.091 & 0.120 & 0.166 & 0.136 & 0.165 & 0.058 & 0.035 & 0.064 & 0.097 & 0.080 & 0.110 \\
\hline 0.5 & & 0.132 & 0.083 & 0.112 & 0.171 & 0.129 & 0.158 & 0.097 & 0.055 & 0.085 & 0.136 & 0.101 & 0.130 & 0.028 & - & 0.029 & 0.067 & 0.045 & 0.075 \\
\hline 0.7 & & 0.101 & 0.048 & 0.077 & 0.140 & 0.093 & 0.123 & 0.066 & 0.020 & 0.050 & 0.106 & 0.066 & 0.095 & - & -- & - & 0.036 & 0.010 & 0.039 \\
\hline 0.9 & & 0.071 & 0.013 & 0.042 & 0.110 & 0.058 & 0.088 & 0.036 & -- & 0.014 & 0.075 & 0.030 & 0.060 & $\rightarrow$ & - & -- & 0.006 & - & 0.004 \\
\hline \multicolumn{20}{|c|}{$r=12 x$} \\
\hline 0.0 & & 0.208 & 0.171 & 0.200 & 0.247 & 0.216 & 0.246 & 0.173 & 0.143 & 0.173 & 0.212 & 0.189 & 0.218 & 0.104 & 0.088 & 0.117 & 0.143 & 0.133 & 0.162 \\
\hline 0.3 & & 0.167 & 0.124 & 0.154 & 0.207 & 0.170 & 0100 & 0.133 & 0.097 & 0.126 & 0.172 & 0.142 & 0.1 & 0.064 & 0.041 & 0.070 & 0.103 & 0.087 & 0.116 \\
\hline 0.5 & & 0.141 & 0.093 & 0.123 & 0.180 & 0.139 & 0.168 & 0.106 & 0.066 & 0.095 & 0.145 & 0.111 & 0.140 & 0.037 & 0.010 & 0.039 & 0.076 & 0.055 & 0.085 \\
\hline 0.7 & & 0.114 & 0.062 & 0.092 & 0.153 & 0.108 & 0.137 & 0.079 & 0.035 & 0.064 & 0.119 & 0.080 & 0.109 & 0.010 & - & 0.008 & 0.049 & 0.024 & 0.054 \\
\hline 0.9 & & 0.087 & 0.031 & 0.061 & 0.127 & 0.077 & 0.106 & 0.053 & 0.004 & 0.033 & 0.092 & 0.049 & 0.078 & -- & - & -- & 0.023 & - & 0.023 \\
\hline $\begin{array}{l}\text { Add to } \\
\text { above for }\end{array}$ & & & & & & & & & & & & & & & & & & & \\
\hline $\begin{array}{l}\mathrm{m}\left(\mathrm{t}_{\mathrm{C}}\right)= \\
0.25(7)\end{array}$ & & 0.026 & 0.021 & 0.025 & 0.026 & 0.021 & 0.025 & 0.020 & 0.016 & 0.020 & 0.020 & 0.016 & 0.020 & 0.009 & 0.007 & 0.011 & 0.009 & 0.007 & 0.011 \\
\hline $\begin{array}{l}\mathrm{m}\left(\mathrm{t}_{\mathrm{q}}\right)= \\
0.25(10)\end{array}$ & & -- & 0.016 & 0.020 & -- & 0.016 & 0.020 & -- & 0.013 & 0.016 & -- & 0.013 & 0.016 & - & 0.006 & 0.009 & - & 0.006 & 0.009 \\
\hline$s=0.20$ & & -0.035 & -0.013 & -0.013 & -0.035 & -0.013 & -0.013 & -0.035 & -0.013 & -0.013 & -0.035 & -0.013 & -0.013 & $-0.035-$ & -0.013 & -0.013 & -0.035 & -0.013 & -0.013 \\
\hline
\end{tabular}

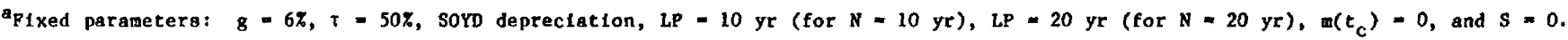

Source: Dickinson and Brown 1979. 
Table 10-9c. Values of M-Pactor ${ }^{a}$

$(\mathrm{R}=0.20)$

\begin{tabular}{|c|c|c|c|c|c|c|c|c|c|c|c|c|c|c|c|c|c|c|c|}
\hline \multirow{4}{*}{$\begin{array}{l}\text { f (Loan } \\
\text { Praction) }\end{array}$} & \multirow{4}{*}{$\begin{array}{l}\mathrm{TC} \\
\mathrm{OMPI} 0 \\
\mathrm{DP}(\mathrm{yr}) \\
\mathrm{N}(\mathrm{yr})\end{array}$} & \multicolumn{6}{|c|}{0.2} & \multicolumn{6}{|c|}{0.3} & \multicolumn{6}{|c|}{0.5} \\
\hline & & \multicolumn{3}{|c|}{0.01} & \multicolumn{3}{|c|}{0.04} & \multicolumn{3}{|c|}{0.01} & \multicolumn{3}{|c|}{0.04} & \multicolumn{3}{|c|}{0.01} & \multicolumn{3}{|c|}{0.04} \\
\hline & & \multicolumn{2}{|c|}{7} & \multirow{2}{*}{$\begin{array}{l}16 \\
20\end{array}$} & \multicolumn{2}{|r|}{7} & \multirow{2}{*}{$\frac{16}{20}$} & \multicolumn{2}{|r|}{7} & \multirow{2}{*}{$\frac{16}{20}$} & \multicolumn{2}{|c|}{7} & \multirow{2}{*}{$\frac{16}{20}$} & \multicolumn{2}{|r|}{7} & \multirow{2}{*}{$\frac{16}{20}$} & \multicolumn{2}{|r|}{7} & \multirow{2}{*}{$\begin{array}{l}16 \\
20\end{array}$} \\
\hline & & 10 & 20 & & 10 & 20 & & 10 & 20 & & 10 & 20 & & 10 & 20 & & 10 & 20 & \\
\hline \multicolumn{20}{|c|}{$r=3 \%$} \\
\hline 0.0 & & 0.266 & 0.232 & 0.271 & 0.304 & 0.275 & 0.314 & 0.226 & 0.198 & 0.237 & 0.264 & 0.240 & 0.280 & 0.147 & 0.129 & 0.169 & 0.185 & 0.172 & 0.212 \\
\hline 0.3 & & 0.187 & 0.142 & 0.181 & 0.225 & 0.185 & 0.224 & 0.147 & 0.108 & 0.147 & 0.185 & 0.150 & 0.190 & 0.067 & 0.039 & 0.079 & 0.106 & 0.082 & 0.121 \\
\hline 0.5 & & 0.134 & 0.082 & 0.121 & 0.172 & 0.124 & 0.164 & 0.094 & 0.047 & 0.087 & 0.132 & 0.090 & 0.130 & 0.015 & - & 0.018 & 0.053 & 0.022 & 0.061 \\
\hline 0.7 & & 0.081 & 0.022 & 0.061 & 0.119 & 0.064 & 0.104 & 0.041 & -- & 0.027 & 0.080 & 0.030 & 0.069 & -- & -- & -- & -- & -- & - \\
\hline 0.9 & & 0.028 & - & - & 0.067 & 0.004 & 0.044 & - & - & - & 0.027 & - & 0.009 & - & -- & -- & -- & -- & -- \\
\hline \multicolumn{20}{|c|}{$r=9 \%$} \\
\hline 0.0 & & 0.266 & 0.232 & 0.271 & 0.304 & 0.275 & 0.314 & 0.226 & 0.198 & 0.237 & 0.264 & 0.240 & 0.280 & 0.147 & 0.129 & 0.169 & 0.185 & 0.172 & 0.212 \\
\hline 0.3 & & 0.196 & 0.151 & 0.190 & 0.234 & 0.194 & 0.233 & 0.156 & 0.117 & 0.156 & 0.195 & 0.160 & 0.199 & 0.077 & 0.048 & 0.088 & 0.115 & 0.091 & 0.131 \\
\hline 0.5 & & 0.149 & 0.097 & 0.136 & 0.188 & 0.140 & 0.179 & 0.110 & 0.063 & 0.102 & 0.148 & 0.106 & 0.145 & 0.030 & -- & 0.034 & 0.068 & 0.037 & 0.076 \\
\hline 0.7 & & 0.103 & 0.043 & 0.082 & 0.141 & 0.086 & 0.125 & 0.063 & 0.009 & 0.048 & 0.101 & 0.052 & 0.091 & -- & $\rightarrow$ & -- & 0.022 & -- & 0.022 \\
\hline 0.9 & & 0.056 & - & 0.028 & 0.094 & 0.032 & 0.071 & 0.016 & - & -- & 0.055 & -- & 0.037 & -- & -- & -- & -- & -- & - \\
\hline & & & & & & & . & & $x=12$ & & & & & & & & & & \\
\hline 0.0 & & 0.266 & 0.232 & 0.271 & 0.304 & 0.275 & 0.314 & 0.226 & 0.198 & 0.237 & 0.264 & 0.240 & 0.280 & 0.147 & 0.129 & 0.169 & 0.185 & 0.172 & 0.212 \\
\hline 0.3 & & 0.201 & 0.157 & 0.196 & 0.240 & 0.200 & 0.239 & 0.161 & 0.123 & 0.162 & 0.200 & 0.166 & 0.205 & 0.082 & 0.054 & 0.094 & 0.120 & 0.097 & 0.136 \\
\hline 0.5 & & 0.158 & 0.107 & 0.146 & 0.197 & 0.150 & 0.189 & 0.118 & 0.073 & 0.112 & 0.157 & 0.115 & 0.155 & 0.039 & 0.004 & 0.044 & 0.077 & 0.047 & 0.086 \\
\hline 0.7 & & 0.115 & 0.057 & 0.096 & 0.153 & 0.100 & 0.139 & 0.075 & 0.023 & 0.062 & 0.114 & 0.065 & 0.105 & - & - & -- & 0.034 & - & 0.036 \\
\hline 0.9 & & 0.072 & 0.007 & 0.046 & 0.110 & 0.050 & 0.089 & 0.032 & - & 0.012 & 0.071 & 0.015 & 0.055 & $\rightarrow$ & -- & -- & - & -- & - \\
\hline $\begin{array}{l}\text { Add to } \\
\text { above fo }\end{array}$ & & & & & & & & & & & & & & & & & & & \\
\hline$m(t c)=$ & & 0.025 & 0.021 & 0.026 & 0.025 & 0.021 & 0.026 & 0.020 & 0.017 & 0.021 & 0.020 & 0.017 & 0.021 & 0.010 & 0.008 & 0.013 & 0.010 & 0.008 & 0.013 \\
\hline $\begin{array}{c}m\left(t_{c}\right)= \\
0.25(10)\end{array}$ & -- & 0.015 & 0.018 & - & 0.015 & 0.018 & -- & 0.012 & 0.015 & - & 0.012 & 0.015 & - & 0.006 & 0.009 & -- & 0.006 & 0.009 & \\
\hline$s=0.20$ & & -0.028 & -0.007 & -0.007 & -0.028 & -0.007 & -0.007 & -0.028 & -0.007 & -0.007 & -0.028 & -0.007 & -0.007 & -0.028 & -0.007 & -0.007 & -0.028 & -0.007 & -0.007 \\
\hline
\end{tabular}

aplxed parameters: $g=6 \%, \tau=50 \%$, SOYD depreciation, LP $=10 \mathrm{yr}\left(\right.$ for $N=10 \mathrm{yr}$ ), LP $=20 \mathrm{yr}($ for $N=20 \mathrm{yr}), \mathrm{m}\left(\mathrm{t}_{\mathrm{c}}\right)=0$, and $S=0$.

Source: D1ck1nson and Brown 1979. 
example of such a solution is presented in Fig. 10-3, and shows both the rapid increase in IROR as the loan fraction is increased and the sensitivity of IROR to the assumed fuel cost inflation rate.

\subsection{METHODS OP FTMATCING SOLAR SYSTEMS}

This section presents three financing methods for solar IPH systems, taken largely from the Proceedings of the 1980 Solar Industrial Process Heat Conference, particularly from the paper by Dickinson (1980). The first is the conventional method, in which the IPH user finances the system from in-house capital or loans. Second, conventional lease financing is discussed. Finally, we present the Solar Management Company (SMC) concept for financing solar IPH projects.

\subsubsection{Conventional Financing}

The usual assumption, in analyses of solar economics, is that the solar system will be conventionally financed. In this method of financing, the solar IPH user purchases the system using internal capital and funds obtained from external sources, such as from loans or the sale of bonds. This financing method is simple, but it has some drawbacks. For example, the IPH user is responsible for the construction and operation of the solar system, which might entail some risk to the company.

\subsubsection{Conventional Lease Arrangenents}

Leasing is an option that eliminates the need for owners to make the large initial capital investment required by conventional financing. It can also reduce the risk to IPH users, usually because the responsibility for constructing and operating the solar system rests with a third party and because payments are constant over the lease period. Lease payments, being expense items, are also tax deductible to users. Lessors, however, may be able to take advantage of an accelerated depreciation allowance that users, if they owned the system themselves, could not.

\subsubsection{Solar Management Company/Limited Partnership}

This concept, proposed by Charles Wilde of Winthrop Financial Co. (San Francisco, Calif.) is similar to methods of financing large construction projects like shopping centers and commercial buildings, oil and gas development programs, and other projects in the real estate and equipment industries. In this system, an agency, the Solar Management Company (SMC), enters into partnerships with groups of investors, each group being concerned with a particular solar IPH project. The investors, as limited partners, provide the equity part of the investment and participate in any income or losses from the project. They also obtain the tax credits and other advantages from the investment. The SMC acts as the general partner. The partnership owns the solar system and is responsible for its construction, operation, and maintenance. In turn, the IPH user agrees to purchase all energy delivered by the 


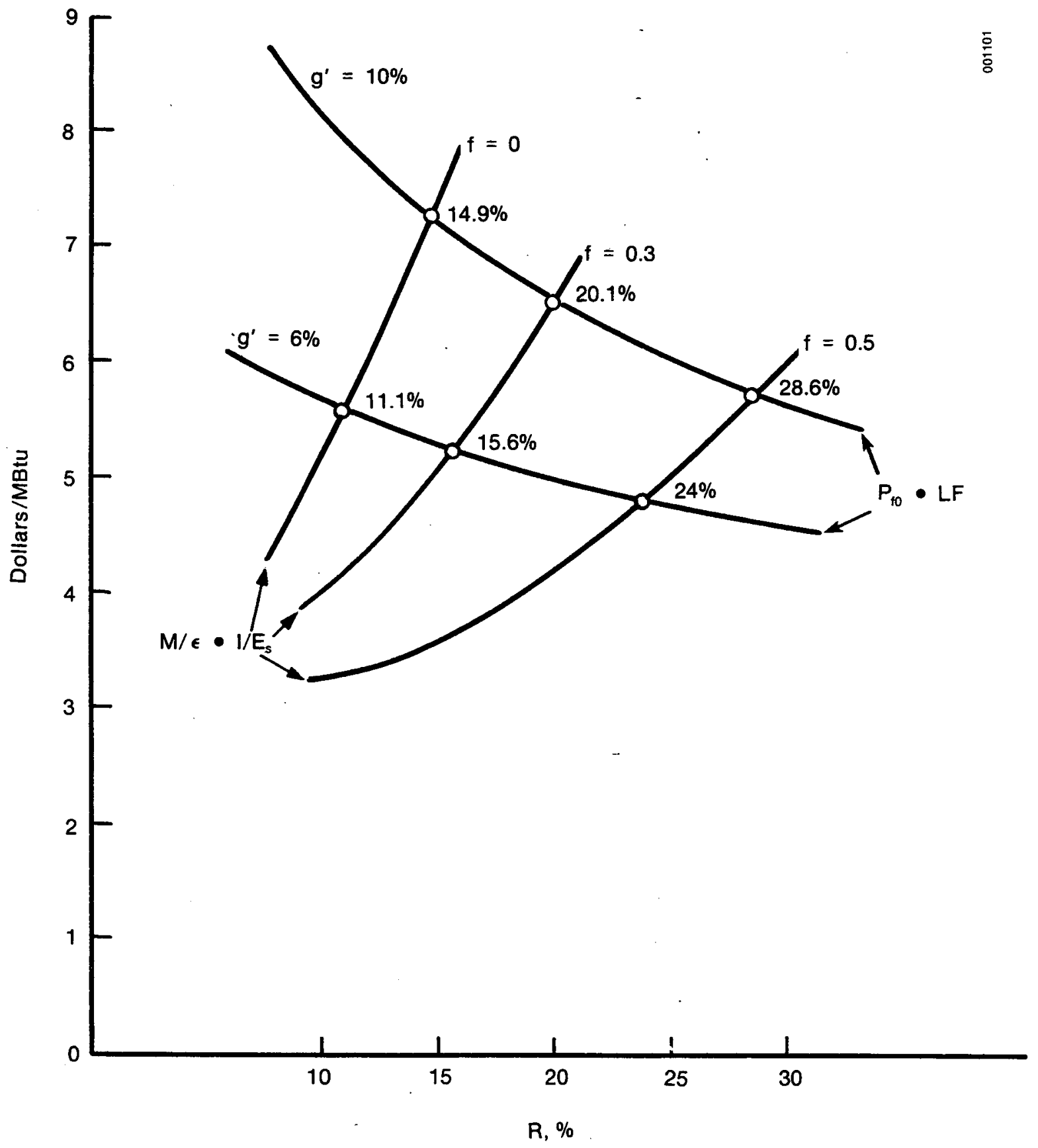

SOURCE: Dickinson and Brown 1979. 
solar system at stipulated rates less than those expected for the competing fossil fuel.

It is important to note that the concepts of project financing are complicated by an abundance of tax legislation. It is recoumended that a reputable tax accountant be consulted before embarking on any innovative financing arrangements. More information on financing alternatives can be found in Nevitt (1979).

\subsection{REFERENCES}

Brown, K. C. et al. 1980 (Jan.). End-Use Matching for Solar Industrlal Process Heat. SERI/TR-34-091. Golden, CO: Solar Energy Research Institute.

Dickinson, W. C. 1980 (Dec.). "The Role of Financing in the Marketability of Capital Intensive Solar Technologles for Industry." Proceedings of the Fifth Annual Solar Industrial Process Heat Conference. SERI/CP-632-952. Golden, C0: Solar Energy Research Institute; pp. 41-46.

Dickinson, W. C.; Brown, K. C. 1981 (11 Aug.). Economic Analysis of Solar Industrial Process Heat Systems. UCRL-52814, Rev. 1. Livermore, CA: Lawrence Livermore National Laboratory.

Franta, G. E. 1981 (June). Solar Design Workbook. SERI/SP-62-308. Golden, CO: Solar Energy Research Institute.

Guthrie, K. M. 1969 (24 Mar.). "Capital Cost Estimating." Chemical Engineering. pp. 114-133.

Means Mechanical and Electrical Cost Data 1981. Robert Snow Means Company, Inc., Kingston, MA.

Mueller Associates, Inc. 1981 (3 Aug.). Solar Energy System Construction Costs. Draft report $81-183$.

Mueller Associates, Inc. 1980 (12 Dec.). The Analysis of Construction Costs of Ten Industrial Process Heat Systems. MAI Report No. 210; MAI Project No. 80-168.

Nevitt, P. K. 1979. Project Financing. London: Euromoney Publications.

Stadjuhar, S. 1982 (Feb.). PROSYS/ECONMAT Users' Guide - Solar Industrial Process Heat Feasibility Evaluation. SERI/TR-733-724. Golden, C0: Solar Energy Research Institute. 


\section{SEPI喽}


SECTION 11.0

\section{SAFETY AND ENVIRONLENTAL ISSUES}

Solar IPH.systems call for many of the same safety measures as other industrial thermal systems. Some are unique to solar energy systems, however, and must be recognized and dealt with in the design phase. Solar energy systems are generally regarded as environmentally benign because they do not have smokestacks, they do not discharge toxic substances, and they do not have a direct impact on land or on plants and animals. While solar systems lack such obvious Indications of environmental degradation, they do have impacts, both positive and negative, on their environments. In designing these systems, it is necessary to assess these environmental effects so that their acceptability to plant management and to local, state, and federal agencies may be determined. This section addresses safety and environmental issues that pertain particularly to solar IPH. A summary of laws and agencies created to ensure that energy systems will be operated safely and in accordance with environmental quality constraints has also been included. We have tried to cover all the relevant laws and agencies in this section; however, detailed questions on specific requirements should be referred either to a lawyer or to an appropriate agency.

\subsection{SAFETY CONCERNS IN IPH SYSTEMS}

The philosophy behind solar energy system safety is that systems should be designed, built, and operated without creating additional hazards greater than those that already exist without the solar system. The major safety concerns in solar systems fall into six categories: fire safety, physical hazards, handling and disposal of hazardous fluids, overtemperature and overpressure protection, product contamination, and noise. Each of these is discussed in the following sections, and the regulations and governmental agencies involved in enforcing the safety requirements are described.

\subsubsection{Fire Safety}

There is a definite need for fire prevention and control measures in solar systems, for several reasons. Heat transfer fluids are often flammable or produce flammable products when they decompose. Sunlight, especially when it is concentrated, can heat exposed surfaces to very high temperatures, and this can result in degradation, outgassing, or ignition. Storage tanks are usually filled with hot, sometimes hazardous, fluids. To reduce risk to personnel and equipment and lessen the damage from a fire if one should occur, we must address two aspects of fire safety: (1) the materials used in solar systems and (2) the equipment and procedures necessary for fire protection.

\subsubsection{Materials}

The most important solar IPH materials to consider in regard to fire protection are the heat transfer fluids used in the systems. This is especially 
true in steam systems that employ an unfired boiler, where fluids may be under pressure at temperatures well above their flash points, so that leaks could pose severe fire hazards. The National Fire Protection Association (NFPA) (1973) defines flammable liquids as those with flash points below $37.8^{\circ} \mathrm{C}$ $\left(100^{\circ} \mathrm{F}\right)$ and combustible liquids as those with flash points of $37.8^{\circ} \mathrm{C}\left(100^{\circ} \mathrm{F}\right)$ or higher. The Minimum Property Standards published by the Department of Housing and Urban Development (HUD) for solar heating and hot water systems prohibits the use of flammable liquids in solar systems and restricts the use of combustible liquids to temperatures well below their flash points (1976). This type of restriction is, however, not always possible in IPH systems because of the high temperatures involved. In IPH systems, while it is best to use fluids below their flash points, other factors may be decisive in the selection of a fluid, such as its vapor pressure characteristics or whether it can be pumped at low temperatures. Heat transfer fluids of interest in solar IPH systems are discussed in Sec. 7.2 and their properties are summarized in Appendix B.

In addition to the direct hazard posed by combustible fluids, fire hazards may occur from exposure of heat transfer fluids or insulation materials to high temperatures, resulting in degradation or ignition. The flammability and flame-spread characteristics of insulating materials in a solar system should be considered, particularly when they are used in conjunction with a combustible working fluid. This is especially important in regard to fibrous insulation materials, where leaks may soak the insulation, making a large surface area subject to oxidation. The relevant properties of some popular insulating materials are given in Table 11-1.

Solar system components and structures must have adequate fire-retardant properties. The system design must avoid exposing flammable materials to elevated temperatures and to concentrated sunlight. In designing for the second of these, it is necessary to consider that solar energy can be focused off the ends of parabolic troughs onto support structures, flex hoses, etc. and can be focused at locations other than the absorber tube if the array is not tracking the sun properly. Adding collectors on roof structures may result in additional fire hazards because access becomes more difficult. Finally, lightning protection should be provided to all parts of the system to reduce the risk of fire from that source.

\subsubsection{Equipment and Procedures}

Fire safety equipment can prevent a considerable amount of damage in the event of a fire. One item highly recommended is a total system "kill switch" that will shut off collector flow and defocus or stow concentrators in the event of an emergency. This minimizes damage by cutting off the supply of fuel to a fire (the heat transfer fluid) and removing the concentrated sunlight that may be the heat source for the fire (in concentrators). Placing appropriate firefighting equipment at various locations around the system is recommended so that small fires can be extinguished immediately. Finally, the fire hazard from storage tanks containing combustible liquids may be reduced by placing a berm around the tank to contain leaks and keep a fire from spreading.

Procedures must also be set up for fire prevention and control. Plant personnel should be trained in using fire safety equipment, and drills should be 
Table 11-1. F1re-Resistance Properties of Varfous Insulating Materials

\begin{tabular}{|c|c|c|c|c|c|c|c|c|c|}
\hline $\begin{array}{c}\text { General } \\
\text { Types }\end{array}$ & $\begin{array}{l}\text { Spectf1c } \\
\text { Types }\end{array}$ & $\begin{array}{c}\text { Pire- } \\
\text { Resistance }\end{array}$ & $\begin{array}{l}\text { Flame } \\
\text { Spread }^{b}\end{array}$ & $\begin{array}{c}\text { Fue1 } \\
\text { Contr1buted }\end{array}$ & $\begin{array}{c}\text { Smoke } \\
\text { Developed }\end{array}$ & $\begin{array}{l}\text { Toxic Gases } \\
\text { Emitted }\end{array}$ & $\begin{array}{c}\text { Approximate } \\
\text { Temperature } \\
\text { Limits } \\
\left({ }^{\circ} \mathrm{C}\right)\end{array}$ & $\begin{array}{l}\text { Water Vapor } \\
\text { Permeab1l1ty } \\
{\left[\mathrm{kg} /\left(\mathrm{Pa}^{\circ} \mathrm{s}^{\circ} \mathrm{m}\right)\right]} \\
\times 10^{-12}\end{array}$ & $\begin{array}{c}\text { Molsture } \\
\text { Absorbtion } \\
\text { ( } \% \text { by volume) }\end{array}$ \\
\hline \multirow[t]{4}{*}{ Cellular plastic } & $\begin{array}{l}\text { Extruded } \\
\text { polystyrene }\end{array}$ & C & $5-25$ & $5-80$ & $10-400$ & Yes (CO) & 75 & $0.6-1.3$ & 1 \\
\hline & $\begin{array}{l}\text { Molded } \\
\text { polystyrene }\end{array}$ & c & $<25$ & $5-80$ & $10-400$ & Yes $(\mathrm{CO})$ & 75 & $0.9-4.4$ & 2 \\
\hline & Polyurethane & C & $30-50$ & $14-25$ & $116-233$ & $\operatorname{Yes}(C O)$ & 110 & $1.7-4.4$ & Negliglble \\
\hline & $\begin{array}{l}\text { Polylaocyanurate } \\
\text { Urea-formaldehyde }\end{array}$ & $\begin{array}{l}\mathbf{C} \\
\mathrm{C}\end{array}$ & $\begin{array}{c}25 \\
0-25\end{array}$ & $\begin{array}{c}0-5 \\
0-30\end{array}$ & $\begin{array}{c}55-200 \\
0-10\end{array}$ & $\begin{array}{c}Y e s(c 0) \\
-c\end{array}$ & $\begin{array}{l}120 \\
215\end{array}$ & $\begin{array}{l}2.9-4.4 \\
6.6-146\end{array}$ & Neg11gtble \\
\hline G1as8 & $\begin{array}{l}\text { Fiberglass bolts } \\
\text { Glass foam }\end{array}$ & $\begin{array}{l}\text { NC } \\
\text { NC }\end{array}$ & $\begin{array}{c}15-20 \\
5\end{array}$ & $\begin{array}{c}5-15 \\
0\end{array}$ & $\begin{array}{c}0-20 \\
0\end{array}$ & $\begin{array}{c}\text { Yes } \\
\operatorname{Yes}\left(\mathrm{CO}, \mathrm{B}_{2} \mathrm{~S}\right)\end{array}$ & $\begin{array}{l}540 \\
480\end{array}$ & $\begin{array}{c}146 \\
0\end{array}$ & $\begin{array}{c}0.1-0.2 \\
\text { Neg11g1ble }\end{array}$ \\
\hline Loose f111 & $\begin{array}{l}\text { Vermlcullte } \\
\text { Perlite } \\
\text { Ce1lulose }\end{array}$ & $\begin{array}{l}\mathrm{NC} \\
\mathrm{NC} \\
\mathrm{C}\end{array}$ & $\begin{array}{c}0 \\
0 \\
15-40\end{array}$ & $\begin{array}{c}0 \\
0 \\
0-40\end{array}$ & $\begin{array}{c}0 \\
0 \\
0-45\end{array}$ & $\begin{array}{c}\text { No } \\
\text { No } \\
\text { Yees }(\mathrm{CO})\end{array}$ & $\begin{array}{l}540 \\
650\end{array}$ & $\begin{array}{l}\text { H1gh } \\
\text { H1gh } \\
\text { H1gh }\end{array}$ & $\begin{array}{c}0 \\
\text { Low } \\
5-20\end{array}$ \\
\hline Miscellaneous & $\begin{array}{l}\text { Mineral wool } \\
\text { Calc1 um gillcate } \\
\text { Ingulating concrete }\end{array}$ & $\begin{array}{l}\mathrm{NC} \\
\mathrm{NC} \\
\mathrm{NC}\end{array}$ & $\begin{array}{c}15 \\
0 \\
0\end{array}$ & $\begin{array}{l}0 \\
0 \\
0\end{array}$ & $\begin{array}{l}0 \\
0 \\
0\end{array}$ & $\begin{array}{l}\text { No } \\
\text { No } \\
\text { No }\end{array}$ & $\begin{array}{r}1000 \\
816 \\
540\end{array}$ & $\begin{array}{c}>146 \\
0 \\
\text { Varies }\end{array}$ & $\underset{2}{2}$ \\
\hline
\end{tabular}

SOURCE: Adapted from Versar (1979) and Hess (1979).

${ }^{a}$ ASTM E-136, C = combust1ble, $\mathrm{NC}=$ noncombustible.

bASTM E-84.

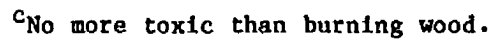

d 0.2 to 0.4 depending on relative humldity, up to $46 \%$ by Immersion. 
scheduled to ensure that correct procedures are known. The system should be designed so that the collector array is accessible and fire-fighting equipment is nearby, and egress paths should be available for plant personnel from all sites of possible trouble. It is recommended that the system design be reviewed for fire safety by the factory's insurance carrier. Finally, local fire departments should be made aware of the nature of fire hazards associated with the solar system. An inspection by fire prevention experts is also recommended to identify potential problems.

\subsubsection{Physical Hazards}

The most obvious physical hazards associated with solar systems involve high temperatures and concentrated sunlight. Because the hot absorbing surface on a solar collector must be exposed to sunlight, it cannot be covered with insulation. Although protecting personnel from accidental burns is difficult, warning labels and personnel training are the most effective approaches. Sunlight, either reflected off glazings or concentrated by reflectors or lenses, can cause a range of problems from annoyance to severe injury. Regular sunglasses may not provide adequate vision protection against this hazard. Sunlight is even more difficult to protect against than hot surfaces, because sunlight can be concentrated at a point in space that is not near any physical object; therefore, the danger is almost impossible to detect before an injury occurs.

Scalding from hot fluid leaks can also occur. This danger is aggravated by the large amount of piping present in most solar systems, so that there are more joints, flex hoses, and other materials that can leak. A perimeter fence installed around a ground-mounted collector array will not only enhance safety, but will also serve to deter vandalism. of course, the advantages must be weighed against the cost.

The glazing on solar collectors is another source of hazards. Glare from poorly placed arrays can annoy personnel and contribute to accidents if it should temporarily blind machine operators and drivers. In collectors glazed with glass, hazards arise from sharp fragments if the glazings are broken by impact or thermal shock or if they are in a position where personnel may fall through them. Falling on the glazings, and thereby coming into contact with the absorber plate, could cause burns.

Physical hazards may also emanate from the structural design of a solar energy system. Wind loads on support structures and collectors must be considered to avoid the possibility of parts blowing free in strong winds. Static loads, such as the buildup of snow between collectors in a sawtooth array, should be considered in design to reduce chances of breakage, leakage, and overstressing of components. Collectors are normally tilted at fairly high angles and have smooth surfaces. They also heat up rapidly so that snow and ice tend to fall off suddenly; this can be a problem with an overhead array under which people may walk.

Finally, the hazards associated with maintenance of solar systems also include glare, possible burns and cuts from glazings, and concentrated sunlight. Protective measures like handrails and lifelines can reduce injuries, and lock- 
out switches can be used to keep trackers or circulating pumps from operating while maintenance is being performed. An additional hazard from high temperatures and high pressures may result from stagnation of flat-plate or evacuated-tube collectors, or if an emergency causes a tracker to remain focused on the sun with no flow and maintenance work is attempted.

\subsubsection{Fluid Toxicity Considerations}

Safety problems related to hazardous fluids in solar energy systems nearly always involve the heat transfer fluids used in the system. Water is used extensively for low-temperature applications, but because of its vapor pressure characteristics, other fluids are often used for high-temperature applications. Even in low-temperature systems, however, water is of ten made toxic when antifreeze agents, rust inhibitors, or biocides are added. Thus, the problems associated with hazardous working fluids are not restricted to hightemperature systems.

The hazards involved in dealing with toxic materials are greatly reduced if the toxicity of the material is known, but this can be difficult. For example, it was noted that additives which make a fluid suitable for a solar system may also make that fluid toxic; this can be a problem if personnel are not aware that the additives are there or that they might be dangerous. For many solar fluids, the toxicity is not well-documented to begin with,* and in the environment of a solar system, many processes can work together to create toxicity in even the most innocuous fluids. For example, exposing fluids to high temperatures and pressures can cause them to break down chemically. This degradation can in turn create toxic substances or toxic or flammable fumes that could escape from the system and cause injury.

Bacterial and fungal growth may occur in low-temperature projects, posing dangers of disease, blocked flow, or product contamination. Many harmless materials may become toxic when brought into contact with products of corrosion from copper piping or surface coatings on aluminum collector panels. Toxic products of combustion may be released from fires. Even in the most carefully controlled system, mistakes may be made in which contaminants are inadvertently added to the system. Only by constant monitoring and maintenance of solar system fluids and proper labelling of all fill locations can most of these problems be eliminated.

\subsubsection{Protection from Overtemperature and Overpressure}

Solar energy systems are different from conventional systems in that if the energy they can deliver is not needed; that energy supply cannot be shut off. The systems heat up unless the collectors can be covered or defocused. Occasions when a system or collector could become stagnated include plant shutdowns, holidays, maintenance, system breakdown, low utilization of heat by the process, and blocked flow or imbalance in the collector piping. If this happens during a period of high irradiation, very high temperatures soon develop

*See Table B-8 in Appendix B. 
in the collectors that can degrade heat transfer fluids, damage mechanical components from thermal stress, cause outgassing of toxic or flammable gases from insulation, cause ruptures and leaks in pipes from high pressures, and increase the fire danger. Also, if flow is restored to collectors that have been stagnating, damage from thermal shock can occur when a cold fluid enters the hot collectors.

The solutions to problems of overtemperature and the overpressure that accompanies it are relatively straightforward. To avoid dangerous pressure buildup, it is necessary to install pressure relief valves in every section of the system that receives heat and that can be isolated from the rest of the system. An important safety consideration in using pressure- and temperaturerelief valves is to ensure that the discharge from the valves is piped to a safe location. Otherwise, injuries to personnel or serious damage to roofing materials or other equipment may result. To avoid stagnation of tracking collectors facing the sun, the emergency stow operation should be made as failsafe as possible so that collectors can be stowed under any circumstances. To reduce the incidence of thermal shock damage, the control system should be designed to lock out the pumps or make-up water lines when collector temperatures are above those considered safe enough for adding cool fluid.

\subsubsection{Product Contamination}

Product contamination from a solar energy system can be caused by spillage, leakage, or carryover of system fluids into the product, or by improper processing of the product (for example, if a poorly designed system permits unacceptable temperature variations to occur). Both physical and biological contamination are possible. Contamination can affect the palatability and wholesomeness of foodstuffs, soil or degrade nonfood items such as textiles, or cause products to spoil.

One of the most common concerns is the protection of potable process water from contamination by a solar system. The usual approach is to keep toxic system fluids physically separated from the potable water. Double separation, provided by a double-walled heat exchanger, a plate-type heat exchanger, or two regular heat exchangers in series, is normally employed; periodic tests for leakage are performed on the intermediate fluid to ensure that double separation is maintained. Usually, higher. pressure is maintained on the product side to further guard against leaks into the product. Another specific concern is the possibility of contamination of the water supply by back flow from solar system make-up water lines. Normally, back flow preventors or air gaps in the make-up lines will solve this problem.

In addition to these concerns, which involve direct contamination of the process from within the solar system, indirect contamination is also possible. Discharges from pressure-relief or overflow valves or leaks from the system may release contaminants to the plant environment that can come in contact with the product. These sources of contamination can be dealt with by properly disposing of system wastes and discharges and by proper system maintenance to reduce leakage. 


\subsubsection{Noise}

Noise rarely presents a safety problem in solar IPH projects. The noisiest parts of the system are usually the circulating pumps. However, if a system does include noisy equipment, operating and maintenance personnel must be adequately prötected from harm.

\subsubsection{Applicable Regulations and Agencies}

The most comprehensive set of laws dealing with safety in industrial operations is the Occupational Safety and Health Act (OSHA), which details safety standards for exposure to toxic fluids and gases, exposure to noise, and many other areas. The Consumer Product Safety Act deals with human safety questions derived from the use of consumer products, including devices and equipment. Laws dealing with hazardous fluids include the Toxic Substance Control Act and the Hazardous Substance Act of 1971. The Food and Drug Administration (FDA) sets limits for contamination of foodstuffs, and the United States Department of Agriculture (USDA) regulates the processes that are used in food industries. Legislation on noise safety is contained in the Walsh-Healey Pub1ic Contracts Act (for the Department of Labor), the Williams-Steiger Occupational Safety and Health Act of 1970, and in OSHA. Many guidelines for safe handling of discharges, toxic substances, and other materials are part of the environmental protection legislation discussed in Sec. 11.2. Finally, there are state and local safety regulations which must be followed at a particular site. A summary of regulations and the safety concerns they address is given in Table 11-2.

Table 11-2. Safety Regulations and Agencies

\begin{tabular}{ll}
\hline \multicolumn{1}{c}{ Safety Concern } & \multicolumn{1}{c}{ Appropriate Regulations or Agencies } \\
\hline Personnel safety & $\begin{array}{l}\text { Occupational Safety and Health Act (OSHA) } \\
\text { Consumer Product Safety Act }\end{array}$ \\
Hazardous substances & $\begin{array}{l}\text { Toxic Substance Control Act } \\
\text { Hazardous Substance Act of 1971 }\end{array}$ \\
Food processing & Food and Drug Administration \\
& U.S. Department of Agriculture \\
Noise & Walsh-Healey Public Contracts Act (Department \\
& of Labor) \\
Williams-Steiger Occupational Safety and Health Act \\
of 1970 \\
OSHA
\end{tabular}




\subsection{ENVIRONMENTAL ASPECTS OF SOLAR IPH SYSTEMS}

In recent years, there has been a gradually increasing awareness of environmental effects associated with nearly every aspect of social and industrial functions. One of the major reasons for the interest in solar energy is the belief that replacing conventional fuel sources with solar energy technologies will reduce damage to the environment without requiring changes or sacrifices in life style. This section examines the environmental impacts of solar IPH systems and describes applicable environmental protection laws.

\subsubsection{Environmental Impacts of Solar IPH Systems}

Both positive and negative environmental impacts accompany solar energy systems. On the positive side, solar systems in normal operation emit no carbon dioxide or other atmospheric pollutants. Since solar systems require little auxiliary energy to operate, they reduce the environmental damage and pollu-. tion resulting from the exploration, mining, processing, transportation, and storage of fossil fuels. Water requirements are normally low and are usually restricted to periodic washing and blow-down of the tanks. This enhances the suitability of solar energy systems in arid regions. And because a solar energy system uses solar energy--energy that would have heated the earth anyway--it is not a source of thermal pollution.

Negative environmental impacts of solar energy systems include land displacement and possible air and water pollution resulting from the construction, normal and emergency operations, and demolition of the solar system. Land use becomes a problem in IPH systems because of the large energy needs of many processes and the diffuse nature of solar energy. Roof mounting, which eliminates some of the problem by using the land area for two purposes, is frequently impractical because of cost, structural requirements, accessibility problems, or requirements for larger arrays (too large for roofs) to satisfy the energy needs of the process. The environmental ramifications of operating large, ground-mounted arrays are not yet well understood, but they could include changes in microclimate that occur because of a different energy balance on the ground below the collectors and changes in local ecology that result from the use of herbicides and other inhibitors under the collector array.

Direct environmental effects on local air and water quality during normal operation include pollution from herbicides and biocides used around the collectors to control weeds and pests, cleaning solutions and debris, disposal of wastes from the system, and release of products of outgassing and degradation. Fires and leaks can also cause damage as toxic fumes and liquids are released into the environment. The indirect environmental impacts of a solar energy system (which, however, are usually not all charged against the system) include those associated with the production and assembly of components, the construction of the system, the disposal of the system at the end of its useful life, and the generation and distribution of electricity needed to operate the system. 


\subsubsection{Tational Enviromental Protection Laws and Organizations}

The United States government has made a national commitment to preserve the environment, which is stated as follows:

... To declare a national policy which will encourage productive and enjoyable harmony between man and his environment; to promote efforts which will prevent or eliminate damage to the environment and biosphere and stimulate the health and welfare of man....

The Congress has backed this commitment with a series of laws designed to regulate and control environmental pollution and to work toward reducing it. The National Environmental Policy Act (NEPA) of 1969 (P.L. 91-190), from which the quote above was taken, is the most general of these environmental laws. Its purpose was threefold: to establish a national environmental policy, to require the generation of Environmental Impact Analysis (EIA) reports on federally supported projects, and to set up a Council on Environmental Quality (CEQ) to advise the President on environmental matters.

The greatest impact of the act has been the EIA report requirement. These environmental impact analyses have become very important in decisions about whether or not projects are environmentally acceptable. A major function of the CEQ has been to generate guidelines to assist planners in writing EIA reports and to detail many of the responsibilities and requirements not specified in the NEPA (CFR Title 40, Chap. V, Part 1500). Laws dealing with specific environmental concerns are discussed in the following sections, including air-pollution control, water-pollution control, waste disposal, noise, and land use. Table 11-3 summarizes the information contained in the following sections, listing applicable regulations, agencies, and requirements for different aspects of environmental protection.

\subsubsection{Air-Pollution Control}

The Clean Air Act of 1963 (P.L. 88-206), amended in 1970 (P.L. 91-604), provides the basis for air-pollution contro1. Under this act, all new "stationary sources" are required to install air-pollution control devices, and new and existing sources are required to monitor the generation and dispersal of air pollutants. The Environmental Protection Agency (EPA) was empowered to establish standards of air quality. and to enforce those standards. Fines of up to $\$ 25,000$ per day and prison sentences of up to one year were authorized, and the EPA was allowed to supersede state programs in its enforcement of standards if the state programs proved ineffective. Another law governing air pollution is the Toxic Substance Control Act, which considers the production, use, distribution, and disposal of toxic substances. It also covers the release of toxic gases during fires.

\subsubsection{Water-Pollution Control}

The major laws for water-pollution control are the Federal Water Pollution Control Act (FWPC) of 1956 (P.I. 84-660) as amended in 1972 (P.L. 92-500) and the Water Quality Act of 1965 (P.L. 89-234). Some of the provisions of these 


\section{Table 11-3. Summary of Environmental Agencies and Regulations}

\begin{tabular}{|c|c|c|}
\hline Environmental Area & Approprlate Regulations and Agenctes & Functions \\
\hline A11 & $\begin{array}{l}\text { Environmental Protection Agency (EPA) } \\
\text { Council on Environmental Quality (CEQ) } \\
\text { National Environmental Pollcy Act of } 1969 \text { (NEPA) }\end{array}$ & $\begin{array}{l}\text { Sets and enforces standards for pollutants, } \\
\text { discharges, emissions; monitors compliance with } \\
\text { regulations } \\
\text { Generates guidelines to assist In preparing Envi- } \\
\text { ronmenta1 Impact Assessments (EIAs); details } \\
\text { requirements not specified In NBPA } \\
\text { Requires EIA for projects with federal funding }\end{array}$ \\
\hline Alr pollution & Toxic Substance Control Act & $\begin{array}{l}\text { Requires all new stationary sources to install } \\
\text { air-pollution control devices } \\
\text { Requires new and existing sources to monitor alr } \\
\text { pollutants discharged } \\
\text { Empowers EPA to set standards and enforce them with } \\
\text { flnes and prison sentences } \\
\text { Covers toxic gases released in fires }\end{array}$ \\
\hline Water pollution & $\begin{array}{l}\text { Federal Water Pollution Control Act (FWPC) of } 1956 \text {, } \\
\text { amended In } 1972 \\
\text { Water Quality Act of } 1965 \\
\text { Safe Drinking Water Act } \\
\text { Resource Conservation and Recovery Act of 1976, } \\
\quad \text { Resource Recovery Act of } 1970\end{array}$ & $\begin{array}{l}\text { Requires permits and licenses from federal } \\
\text { government for dlscharging pollutants } \\
\text { Empowers EPA to control and enforce standards } \\
\text { Requires National Pollutant Discharge Elimination } \\
\text { permits; covers disposal of hazardous fluids } \\
\text { Covers 11quid and solid waste disposal }\end{array}$ \\
\hline Nolse & Environmental No1se Control Act of 1972 & $\begin{array}{l}\text { Empowers BPA to control and enforce standards on } \\
\text { nolse pollution }\end{array}$ \\
\hline Land use & $\begin{array}{l}\text { Local ordinances and zoning laws } \\
\text { Right-to-sun ordinances }\end{array}$ & . \\
\hline
\end{tabular}


laws aim to eliminate pollutant discharges into U.S. waters by 1985 , require that permits and licenses be obtained from the federal government to discharge pollutants, and empower the EPA to control and enforce standards. The Safe Drinking Water Act requires National Pollutant Discharge Elimination System permits and provides for the disposal of hazardous system fluids.

\subsubsection{Waste Disposal}

The Resource Conservation and Recovery Act of 1976, which replaced the Solid Waste Disposal Act of 1965 (P.L. 89-272) and its later amendments in the Resource Recovery Act of 1970 (P.L. 91-512), is the national law that deals with waste disposal. This includes both solid and liquid wastes (such as spent working fluids). Despite these national laws, however, waste control remains mostly a function of local government.

\subsubsection{Noise}

As mentioned in Sec. 11.1.6, noise is not normally a problem with solar IPH systems. The Environmental Noise Control Act of 1972 (P.L. 92-574), included among the amendments to the Clean Air Act, authorizes the EPA with control of noise pollution and allows that agency to override state authority.

\subsubsection{Land Use}

At present, there are no federal guidelines for land use, although such regulations are possible in the future. The important regulations concerning land use are normally found in local zoning laws and in state and local sun rights.

\subsubsection{State Enviromental Regulations}

Many states have enacted laws to protect their natural environments. Although a detailed discussion of each of these state laws is beyond the scope of this handbook, Table 11-4 summarizes the requirements of states that have adopted environmental restrictions beyond or in addition to the federal laws, as of April 1978. State officials should be contacted before construction begins to obtain the latest requirements.

\subsection{BIBLIOGRAPHY}

Arbuckle, J. Gordon; et al. 1978. Environmental Law Handbook. Washington, DC: Government Institutes, Inc.

Heer, John E., Jr.; Hagerty, D. Joseph. 1977. Environmental Assessments and Statements. New York: Van Nostrand Reinhold Co.

Kutscher, C. F., editor. 1981 (Mar.). Design Considerations for Solar Industrial Process Heat Systems. SERI/TR-632-783. Golden, CO: Solar Energy Research Institute. 
Searcy, Jimmy Q., editor. 1978 (Aug.). Hazardous Properties and Environmental Effects of Materials used in Solar Heating and Cooling (SHAC) Technologies: Interim Handbook. SAND78-0842. Albuquerque, NM: Sandia National Laboratories.

Strojan, Carl J. 1980 (Sept.). Environmental Aspects of Solar Energy Technologies. SERI/TP-743-826. Golden, CO: Solar Energy Research Institute.

U.S. Dept. of Energy. 1979 (Aug.). Environmental Readiness Document: Solar Agricultural and Industrial Process Heat. DOE/ERD-0025. Washington, DC.

Wakeman, David; Holton, John. 1978 (Sept.). Environmental and Safety Considerations for Solar Heating and Cooling Applications. NBSIR 78-1532. Washington, DC: National Bureau of Standards.

\subsection{REFERENCES}

Hess, L. Y., editor. 1979. Insulation Guide for Buildings and Industrial Processes. Energy Technology Review \#43. Park Ridge, NJ: Noyes Data Corp.

Department of Housing and Urban Development. 1976 (Apr.). Intermediate Minimum Property Standards for Solar Heating and Domestic Hot Water Systems. Interim Report. NSBIR 76-1059. Washington, DC: National Bureau of Standards.

National Fire Protection As sociation. 1973. NFPA 321: Basic Classification of Flammable and Combustible Liquids.

Versar, Inc. 1979 (May). Survey and Evaluation of Available Thermal Insulation Materials for Use on Solar Heating and Cooling Systems. Interim Technical Progress Report Under Contract No. EM-78-C-04-5363. 


\section{States with Comprehensive Statutory Bequirenents}

\section{Cal1fornia}

Source: Callfornla Environmental Quality Act, Ca1. Pub. Res. Code Section 21000 et seq. (Cum. Supp. 1978) (West).

Guidelines: Guidelines for Implementation of the Ca1Ifornia Environmental Quality Act of 1970, Ca1. Admin. Code tit. 14, Section 15000 et seq., as amended March 4, 1978. Guidelines are lssued by the Resources Agency of Callfornia.

Contact: Assistant to the Secretary for Resources, The Resources Agency, 1416 Ninth Street, Sacramento, Cal1fornia 95814

\section{Connecticut}

Source: Connecticut Environmental Policy Act of 1973, Conn. Gen. Stat. Ann. Section 22a-1a et seq. (Cum. Supp. 1978) (West).

Guldelines: No guldelines have been issued.

Contact: Planning and Coordination Unit, Department of Environmental Protection, 118 State Office Bullding, Hartford, ConnectIcut 06115

Hawa11

Source:
Guldelines:

Rules of Practice and Procedure and Environmental Impact Statement Reguirements, issued by the Environmental Quality Commission on June 2, 1975.

Contact:

Chalrman, Environmental Quality Commission, Office of the Governor, Room 301, 550 Halekauwila Street, Honolulu, Hawail 96813

Indlana

Source:

Indiana Environmental Pollcy Act, Ind. Code Ann. Section 13-1-10-1 et seq. (1973) (Burns).

Guidelines: EMB-2 and EMB-3, Ind. Admin. Rules and Regs. Ann. Section 13-1-10-3 et seq. and Section 13-7-5-1 et seq. (Supp. 1977). The Environmental Management Board prepared guidelines.

Contact: Coordinator of Environmental Programs, Indiana State Board of Health, 1330 West Michigan Street, Indlanapolls, Indlana 46202

Maryland

Source: Maryland Environmental Pollcy Act of 1973, Md. Nat. Res. Code Ann. Section 1-301 et seq. (Cum. Supp. 1977).

Guide1Ines: Revised Guidelines for Implementation of the Maryland Environmental Policy Act, Issued by the Secretary of the Department of Natural Resources, June 15, 1974.

Contact: Administrator, Clearing House Review, Department of Natural Resources, Tawes State office Bullding, Annapo11s, Mary- 
Tab1e 11-4. State Environmental Impact Statenent Requirenents (Continued)

(as of 1 Apri1 1978)

Massachusetts

Source :

Massachusetts Environmental Policy Act, Mass. Ann. Laws Ch. 30, Sections 61 and 62 (Cum. Supp. 1977) (Michle/Law. Co-op), as amended by 1978 Mass. Acts Ch. 947, January 10, 1978 .

Guidelines: Regulations Governing the Implementation of the Massachusetts Environmental Pollcy Act, issued by the Executive Office of Environmental Affairs on February 16, 1978.

Contact: Director, Massachusetts Environmental Impact Review office, Executive Office of Environmental Affalrs, Room 2001, 100 02202

Minnesota

Source:

Minnesota Environmental Pollcy Act of 1973, Minn. Stat. Ann. Section 116D.01 et seq. (1977) (West).

Guidelines: Rules and Regulations for Environmental Impact Statements, issued by the Minnesota Environmental Quality Council on Apri1 4, 1974, and amended on February 13, 1977

Contact: Director, Environmental Planning, Environmental Quality Board, Cap1tal Square Buiding, 550 Cedar Street, St. Paul, Minnesota 55101

\section{Montana}

Source: Montana Environmental Policy Act, Mont. Rev. Codes Ann. Section 69-6501 et seq. (Cum. Supp. 1977).

Guldelines: Untform Rules Implementing the Montana Environmental Policy Act. Final version adopted by the Montana Commission on Environmental Quality on January 15, 1976.

Contact: Montana Commission on Environmental Qua1Ity, Capitol Station, Helena, Montana 59601 .

New York

Source: New York State Environmental Qualfty Review Act, N.Y. Envir. Conserv. Law Section 8-0101 et seq. (Cum. Supp. 19771978) (McKinney) as amended by 1976 N.Y. Laws, Ch. 228, Section 5 and 1977 N.Y. Laws, Ch. 252, Section 9, et seq..

Guldelines: 6 N.Y.C.R.R. Park 617, revised January 24, 1978 by the Department of Environmental Conservation.

Contact: Environmental Quality Review Section, office of Environmental Analysis, New York State Department of Environmental Conservation, 50 Wolf Road, Albany, New York 12233.

North Carolina

Source: North Carolina Environmental Pollcy Act of 1971, N.C. Gen. Stat. Section 113A-1 (1975 Replacement). 
Table 11-4. State Environmental Impact Statement Requirements (Continued)

(as of 1 Apri1 1978)

Guldelines: North Carolina Department of Administration, Guidelines for the Implementation of the Environmental Pollcy Act of 1971, revised March 1, 1975.

Contact: Policy Advisor for Natural Resources, Division of Policy Development, Department of Adminfstration, 116 West Jones Street, Raleigh, North Carolina 27603.

Puerto Rico

Source: Public Environmental Polfcy Act, P.R. Laws Ann. t1t. 12, Section 1121 et seq. (Cum. Supp. 1976).

Guidelines: Guidelines for the Preparation, Evaluation and Use of Environmental Impact Statements, 1ssued by the Environmental Quality Board on December 19, 1972.

Contact: Executive Director, Environmental Quality Board, 4th Floor, 1550 Ponce de Leon Avenue, Santurce, Puerto Rico 19910

South Dakota

Source: South Dakota Environmental Policy Act, S.D. Codified Lawg Section 34A-9-1 et seq. (1977 Revision).

Gu1delines: Informal guldelines issued by the Department of Environmental Protection in 1974.

Contact: South Dakota Department of Environmental Protection, Foss Buliding, Plerre, South Dakota 57501

\section{Virginia}

Source:

Virginia Environmental Quality Act of 1973, Va. Code Section 10-17.107 et seq.

(Cum. Supp. 1977).

Guidelines: Procedures Manual for Environmental Impact Statements in the Commonwea1th of Virginia, revised June 1976, by the Governor's Council on the Environment.

Contact : Environmental Impact Statement Coordinator, Council on the Environment, 903 9th Street office Bullding, Richmond, Virginla 23219.

Washington

Source:

State Environment Policy Act, Wash. Rev. Code Ann. Section 43.21C.010 et seq. (Supp. 1976).

Guldelines: State Environmental Policy Act GuldeIfnes, Wash. Admin. Code Section 197-10, revised January 21, 1978, by the Department of Ecology.

Contact:

Environmental Review and Evaluation, office of Planning and Program Development, Department of Ecology, Olympla, Wash1ngton 98504

Wisconsin

Source: Wisconsin Environmental Policy Act of 1971, Wis. Stat. Ann. Section 1.11 (Cum. Supp. 1977-1978) (West). 
Table 11-4. State Environmental Impact Statement Requirements (Continued)

(as of 1 April 1978)

Guldelines: Revised Guidelines for the Implementation of the Wisconsin Environmental Po1icy Act, Issued by Governor's Executive Order No. 26 (February, 1976).

Contact: State WEPA Coordinator, office of State Planning and Energy, Room B-130, 1 West W11son Street, Madison, Wisconsin 53702

\section{States with Comprehensive Fxecutive or} Administrative Orders

\section{Michigan}

\section{Source:}

Michigan Executive Order 1974-4 (May, 1974).

Guidelines: Guidelines for the Preparations and $\mathrm{Re}-$ view of Environmental Impact Statements under Executive Order 1974-4, issued by the Environmental Review Board in November, 1975.

Contact: Environmental Review Board, Department of Management and Budget, Lansing, Michigan 48913

\section{New Jersey}

Source:

New Jersey Executive Order No. 53 (October 15,1973 ).

Guldelines: Guidelines for the Preparation of an Environmental Impact Statement, issued by the Office of the Commlssioner, Department of Environmental Protection, and revised In February 1974.

Contact: Chlef, offlce of Environmental Revew, Department of Environmental Protection,
P.0. Box 1390, Trenton, New Jersey 08625,
Utah

Source:

State of Utah Executive Order, August 27, 1974.

Guldelines: No guldelines have been issued.

Contact: Office of the Attorney General, State Capitol Building, Salt Lake City, Utah 84114

\section{States with Limited EIS Requirements}

Arizona

Source:

(a) Game and Fish Commisston Policy of July 2, 1971.

(b) Power Plant Transmission Line Siting Act, Ariz. Rev. Stat. Section 40-360 et seq. (Cum. Supp. 1977-1978).

Guidelines: (a) Memorandum by the Arizona Game and Fish Commission, "Requirements for Environmental Impact Statements," Issued June 9, 1971.

(b) No guidelines have been Issued.

Contact:

(a) Chief, Wild1ife Planning and Development Division, Artzona Game and Fish Department, 2222 West Greenway Road, Phoenix, Arizona 85023

(b) Chalrman, Power Plant Transmission Line Siting Committee, Attorney General's office, Room 200, 1700 West Washington, Phoenix, Arizona 85007

\section{Arkansas}

Source: 
Tab1e 11-4. State Environmental Impact Statement Requirements (Continued)

(as of 1 Apri1 1978)

Guldelines: Informal guidelines issued by the Arkansas Public Service Commission.

Contact: Public Service Commission, Justice BufldIng, Little Rock, Arkansas 72202

Delaware

Source :

(a) Delaware Coastal Zone Act, Del. Code Ann. tit. 7, Section 7001 et seq. (1974).

(b) The Wetlands Act, Del. Code Ann. t1t. 7, Section 6601 et seq. (1974).

Guldelines: (a) Permit Application Instructions and Forms and Information Material on Required Procedures for the Coasta1 Zone Act, adopted by the Delaware Office of Management, Budget, and Planning on July 1, 1977.

(b) Wetlands Regulations, adopted by the Department of Natura1 Resources and Environmental Control, December 23, 1976.

Contact: (a) Manager, Coastal Management Program, Delaware Office of Management, Budget, and Planning, Dover, Delaware 19901 .

(b) Wetlands Manager, Department of Natural Resources and Environmental Control, Division of Environmenta1 Control, Dover, Delaware 19901.

Florida

Source :

The Florida Environmental Land and Water
Guidelines: Developments Presumed to be of Reglonal Impact, Fla. Admin. Code Ch. 22F-2 (1978).

Contact: Bureau Chlef, Bureau of Land and Water Management, Division of State Planning, Department of Administration, 660 Apalachee Parkway, Tallahassee, Florida 32304.

Georgla

Source: State Tollway Authority Act, Ga. Code Ann. Section 95a-1241(e)(1) (1976).

Guldelines: Policy and Procedure Manual: State To11way Authority, revised by Georgia's Tollway Administrator's office in February 1973.

Contact: State Location Engineer, Division of Preconstruction, Department of Transportation, 2 Capitol Square, Atlanta,' Georgla 30334 .

Ma1ne

Source: Site Location Law, Me. Rev, Stat. tit. 38, Section 481 et seq. (Cum. Supp. 19771978).

Guidelines: Site Law Regulations and Guldelines, 1ssued by the Department of Environmental Protection.

Contact: Information and Education Division, Department of Environmental Protection, State House, Augusta, MaIne 04333. Management Act of 1972, F1a. Stat. Ann. Section 380.012 et seq. (Cum. Supp. 1977) (West). 
Table 11-4. State Enviromental Impact Statenent Requirements (Continued)

(as of 1 Apri1 1978)

Mississippi

Source :

Coasta1 Wetlands Protection Law, Miss. Code Ann. Section 49-27-1 et seq. (Cum. Supp. 1977), to be amended by Sen. Bi11 3498 (1978) (passed but not yet signed as of Apri1 1, 1978).

Guidelines: Rules and Regulations Pertaining to the Coasta1 Wetlands Protection Law, revised by Mississippi Marine Resources Counc11, Apri1 15, 1975.

Contact: Marine Projects Manager, Mississippl Marine Resources Counc11, P.0. Drawer 959, Long Beach, M1ss18sipp1 39560

Nebraska

Source and Guidelines :

Nebraska Department of Roads, Department of Roads Action Plan (1973), as revised by the State of Nebraska Environmental Action Plan, prepared by the Nebraska Department of Roads and approved by the Federal Highway Administration, June 24, 1975.

Contact:

Comprehensive Planning Coordinator, office of Planning and Programming, P.O. Box 94601, State Capitol, Lincoln, Nebraska 68509

Nevada

Source:

Utility Environmental Protection Act, Nev. Rev. Stat. Section 704.820 et seq. (1973).

Guidelines: No guidelines have been Issued.
Contact:

Chairman, Public Service Commission of Nevada, Kinkead Bullding, Carson City, Nevada 89701.

\section{New Hampshire}

Source: Electric Power Plant Transmission Line Siting and Construction Procedure, N.H. Rev. Stat. Ann. Section $162-\mathrm{F}: 1$ et seq. (Supp. 1975)

Guldelines: No guldelines have been lssued.

Contact: Secretary of Public Utilities Commission, 8 0ld Suncook Road, Concord, New Hampsh1re 03301 .

\section{New Jersey}

Source:

(a) Coastal Area Facility Review Act, N.J. Stat. Ann. Section 13:19-1 et seq. (Cum. Supp. 1977-1978).

(b) The New Jersey Wetlands Act of 1970 , N.J. Stat. Ann. Section 13:9A-1 et seq. (Cum. Supp. 1977-1978).

Guldelines: (a) CAFRA Rules and Regulations, N.J.A.C. $7: 7 \mathrm{D}-1.1$ et seq., effective November $18,1975$.

(b) Proceedura1 Rules and Regulations, N.J.A.C. $7: 7 \mathrm{~A}-1.1$ et seq., revised September 3, 1976.

Contact:

(a) Chief, Office of Coastal Zone Management, New Jersey Department of Environmental Protection, P.0. Box 1889, Trenton, New Jersey 08625 . 
Table 11-4. State Environnental Impact Statement Requirements (Concluded) (as of 1 Apri1 1978)

(b) Supervisor, Office of Wetlands Management, Division of Marine Services, Department of Environmental Protection, P.0. Box 1889, Trenton, New Jersey 08625

\section{South Carolina}

Source: South Carolina Coastal Management Act, S.C. Code Section 48-39-10 et seq. (Cum. Supp. 1977).

Guldelines : Final Rules and Regulations for Permits of Alterations of Critical Areas, 1ssued by the South Carolina Coastal Counc1l (1977) In the South Carolina State Register.

Contact: Executive Director, South Carolina Coastal Counc11, 116 Bankers Trust Tower, Columbla, South Carolina 29201.

\section{City BIS Requirements}

Bowle, Maryland

Source and The Bowle, Maryland Environmental Policy Guidelines: and Impact Statement Ordinance, passed by the City Council on May 3, 1971; Ordinance 0-2-73, Declaring an Environmental Pollcy and Providing for Environmental Impact Statements, passed by the City Counc1l on July 16, 1973; and Ordinance 0-14-76, Changing Notification and Referral Requirements under the Ordinance, passed by the City Council on September 8, 1976.

Contact: Planning Director, Office of Planning and Community Development, City Hall, Bowie, Maryland 20715.

New York C1ty

Source and Executtve Order No. 87, October 1973 and Guldelines: Executive Order No. 91, June 1, 1977.

Contact: Director, Office of Environmental Impact, New York C1ty Department of Environmental Protection, 2344 Mun1cipal Bullding, New York, New York 10007. 


\section{SझPI}


APPENDICES 
APPENDIX A

\section{EFFECTS OF SOLAR SYSTEMS ON THE EFFICIENCY OF HOT WATER BOILERS}

In this appendix, we analyze an apparent problem in interfacing solar hot water systems with industrial processes--backup hot water boilers, in particular. Figure A-1 shows a boiler efficiency curve* typical of many industrial boilers. The efficiency is nearly constant at $80 \%$ over most of the load range, but drops drastically below $20 \%-30 \%$ of full load. In solar IPH systems, full backup is usually required, so the backup boiler is sized for the entire load. However, if the solar energy system is capable of supplying a large fraction of the load, the backup boiler will be forced to run at much less than full load and, hence, at greatly reduced efficiency. If this happens, the solar effectiveness will decrease. In order to evaluate this problem, it is necessary to understand some details of boiler operation and how solar IPH systems interact with boilers. In the following sections, the operation of boilers is described, a simple analytical model is developed to consider long-term boiler efficiency, and the results of interfacing a boiler with a solar system are investigated.

\section{A.1 PRACTICAL OPERATION OF HOT HATER BOILERS}

Understanding practical boiler operation requires some knowledge of physical aspects of boiler efficiency and how boilers are controlled in normal applications. Basically, there are two sources of inefficiency in hot water boilers: heat losses from the boiler case, and losses in exhaust gases. Figure A-2 shows a breakdown of these losses for the boiler for which an efficiency curve was plotted in Fig. A-1. In Fig. A-2, the boiler losses, expressed as percentages of efficiency loss, are plotted as a function of the firing rate. The inefficiency at low firing rates results mainly from skin losses. Note that the skin losses depend primarily on the temperature of the boiler shell, so that whenever. the boiler is operated, the skin losses are constant regardless of the firing rate. For the boiler shown, the size of these losses is about $1.5 \%$ of the energy delivered at full load. The variation in the skinloss effect shown in Fig. A-2 is from this constant $1.5 \%$ of full 1oad, which becomes more important relative to the energy delivered as energy delivered decreases. Stack losses, on the other hand, are a relatively constant fraction of the energy delivered over the entire range of the load. These boiler characteristics will be used later to develop the analytical model of boiler operation.

Three control strategies are generally used for industrial boilers: on-off contro1, high-low firing, and full modulation. On-off control is used on small boilers, up to about $500 \mathrm{~kW}_{\mathrm{t}}(50 \mathrm{hp})$. High-low firing, which affords some additional load-following capability, is used on boilers up to about $1 \mathrm{MW}_{\mathrm{t}}(100 \mathrm{hp})$. Modulating burners are used with larger boilers, and are usually designed with a limit in turndown ratio of about four to one. Thus, the boiler can be modulated continuously over a range from one-fourth of full load

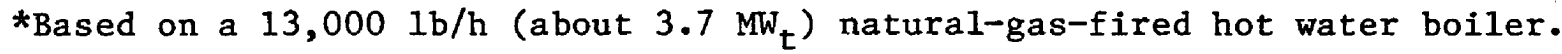




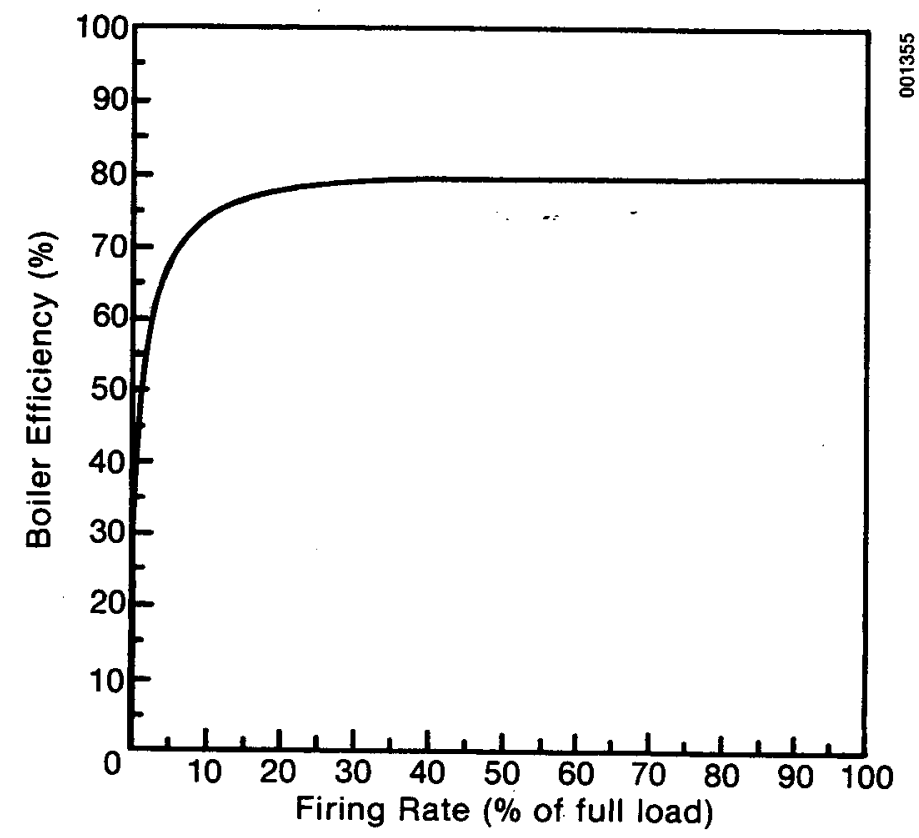

Figure A-1. Effect of Firing Rate on Boiler Efficiency

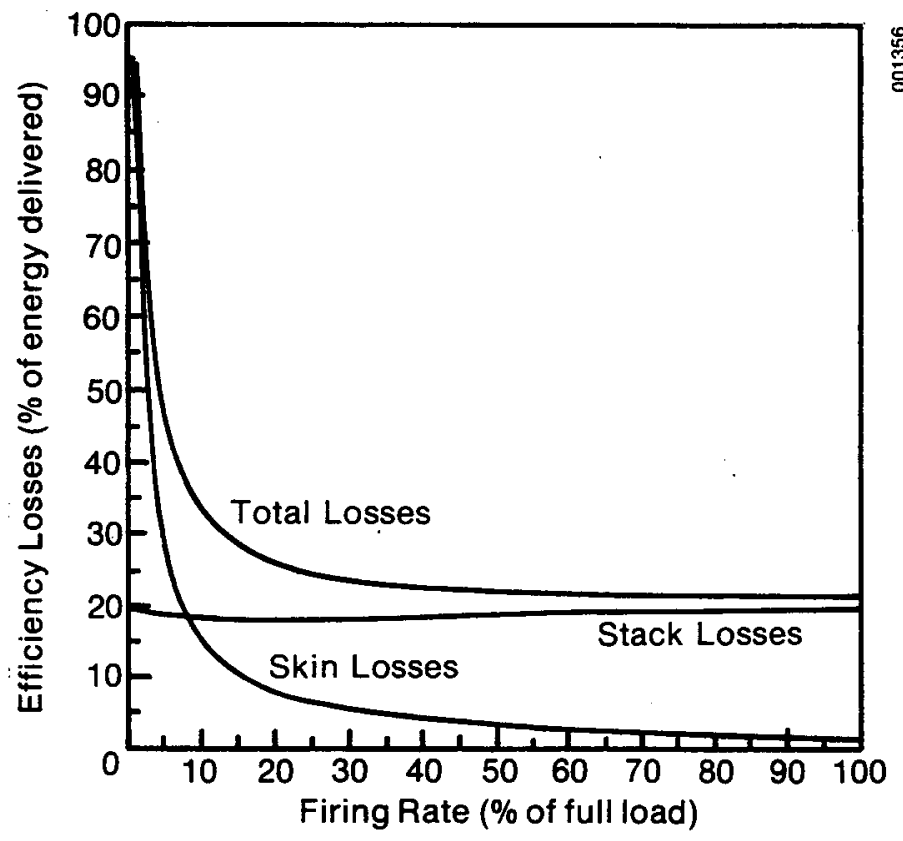

Figure A-2. Losses from a Typical Industrial Boiler 
up to full load. These control strategies and the boiler sizes to which they are applied are summarized in Table A-1. In the discussions that follow, full modulation of the firing rate is assumed, which is the most general case and from which the other types of control can be understood as Iimiting cases.

\section{A.2 ANALYTIGAL MODEL OF A TYPICAL HOT WATER BOILER}

Considering the characteristics of boiler efficiency and operation described above, it is possible to develop a simple model of boiler operation. The definition of instantaneous boiler efficiency is

$$
\eta_{B}=\frac{Q_{\text {del }}}{Q_{\text {fuel }}}
$$

where

$$
\begin{aligned}
Q_{\mathrm{del}} & =\text { the energy delivered to the process } \\
\mathrm{Q}_{\mathrm{fuel}} & =\text { the energy in the fuel consumed. }
\end{aligned}
$$

We can relate these energy values through an energy balance on the boiler:

$$
Q_{\text {de1 }}=Q_{\text {fuel }}-Q_{\text {skin }}-Q_{\text {stack }},
$$

where

$$
\begin{aligned}
Q_{\text {skin }} & =\text { the skin loss } \\
Q_{\text {stack }} & =\text { the heat loss in the exhaust flue gases. }
\end{aligned}
$$

Solving Eq $\cdot A-2$ for $Q_{\text {fuel }}$, and substituting in $E q \cdot A-1$,

$$
n_{B}=\frac{Q_{\text {deI }}}{Q_{\text {de1 }}+Q_{\text {skin }}+Q_{\text {stack }}} \text {. }
$$

Table A-1. Control Systems Used With Industrial Boilers

\begin{tabular}{ll}
\multicolumn{1}{c}{ Control System } & \multicolumn{1}{c}{ Size of Boiler } \\
\hline On-off & Up to $500 \mathrm{~kW}_{\mathrm{t}}(50 \mathrm{hp})$ \\
High-low-off & Up to $1 \mathrm{MW}_{\mathrm{t}}(100 \mathrm{hp})$ \\
$\begin{array}{l}\text { Modulating } \\
\quad \text { (typical turndown ratio of } 4: 1)\end{array}$ & Larger than $1 \mathrm{MW}_{\mathrm{t}}(100 \mathrm{hp})$ \\
\hline
\end{tabular}




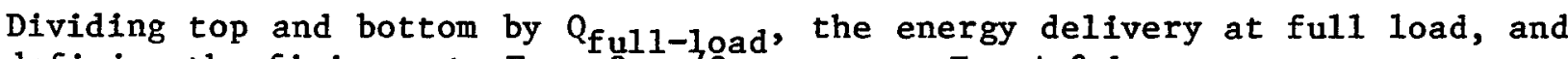
defining the firing rate $F$ as $Q_{\mathrm{de}}{ } Q_{\text {ful1-1oad, }} \mathrm{Eq} \cdot \mathrm{A}-3$ becomes

$$
n_{B}=\frac{F}{F+\frac{Q_{\text {skin }}}{Q_{\text {ful1-1oad }}}+\frac{Q_{\text {stack }}}{Q_{\text {ful1-1oad }}}} \text {. }
$$

As stated above, the skin losses are essentially constant, so that the quan-

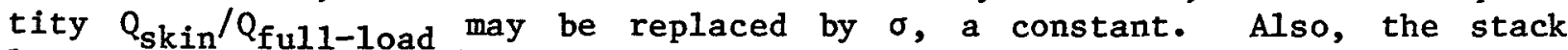
losses are approximately a constant fraction of the energy delivered, so that $Q_{\text {stack }} / Q_{\text {full-load }}$ can be written as $B F$, where $B$ is also a constant. This yields

$$
n_{B} \simeq \frac{F}{F+\sigma+\beta F} \text {, }
$$

or

$$
\eta_{B} \simeq \frac{1}{(1+B)+\sigma / F}
$$

According to Eq. A-6, skin losses cause the variation in $\eta_{B}$ seen with the firing rate. Without skin losses, the efficiency would be essentially constant over the full load range; but with skin losses included, the efficiency drops rapidly at low firing rates. The instantaneous efficiency given by Eq. A-5 may be used to obtain the average boiler efficiency over a time period. Integrating both the numerator and denominator of $\mathrm{Eq}$. A-5 over time, we have

$$
\bar{n}_{B}=\frac{\int_{0}^{t} F d t}{\int_{0}^{t} F(1+\beta) d t+\int_{0}^{t} \sigma d t} .
$$

Since $\beta$ and $\sigma$ are constants, then defining $\bar{F}=\frac{1}{t} \int^{t} F d t$ as the average firing rate over the time period, the average efficiency ${ }^{t}$

$$
\bar{\eta}_{B}=\frac{\bar{F}}{(1+B) \bar{F}+\sigma \tau} \text {, }
$$

where $\tau$ is the fraction of time that the boiler is turned on during the time period.

Dividing through by $\overline{\mathrm{F}}$, we obtain

$$
\bar{n}_{B}=\frac{1}{(1+\beta)+\frac{\sigma}{(\bar{F} / \tau)}} \text {. }
$$

Thus, the average efficiency is a function of $\bar{F} / \tau$. 
The function given by Eq. A-9 is plotted in Fig. A-3 for the nominal conditions $\sigma=0.015$ and $\beta=0.25$ to correspond to the typical boiler described earlier. With $\tau=1$, the curve in Fig. A-3 is the same as the instantaneous efficiency curve from Eq. A- 6 with $F$ replaced by $\bar{F}$. Therefore, it is possible to compare the efficiency curve predicted by the model with the actual boiler curve plotted in Fig. A-1. The shape of the analytical curve is very similar to the real boiler curve, with a maximum deviation from the real curve of less than $3 \%$. The deviation is less than $1 \%$ over $60 \%$ of the firing-rate range. This excellent agreement indicates that the analytical model describes the actual boiler well.

\section{A.3 EFFECT OF SOIAR SYSTEMS ON BOIIER EFFICIENCY}

\section{A.3.1 Solar System Influence on Boiler Fractional On-Time}

The configuration of a solar system has an influence on $\tau$, the fractional ontime for the auxiliary hot water boiler. The three types of systems considered here are series, series-bypass, and parallel (Fig. A-4). We assume that each system is connected to a sensible heat load that requires a certain flow rate of heated fluid at a particular temperature and returns the fluid at a lower temperature. In the series and series-bypass systems, solar energy preheats the process fluid. These system configurations are used for hot air and hot water process loads and for preheating make-up water in steam systems. The series-bypass system is set up so that the backup boiler can be bypassed and shut down when the solar system can supply the full load; in the simple

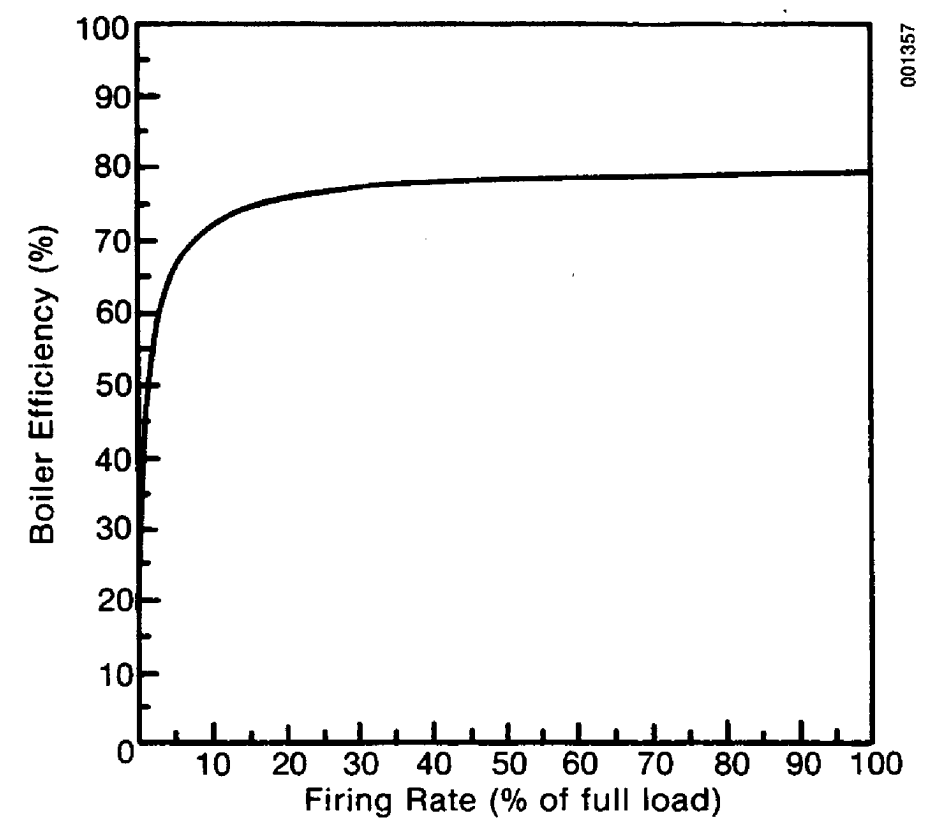

Figure A-3. Boiler Efficiency from Analytical Model 

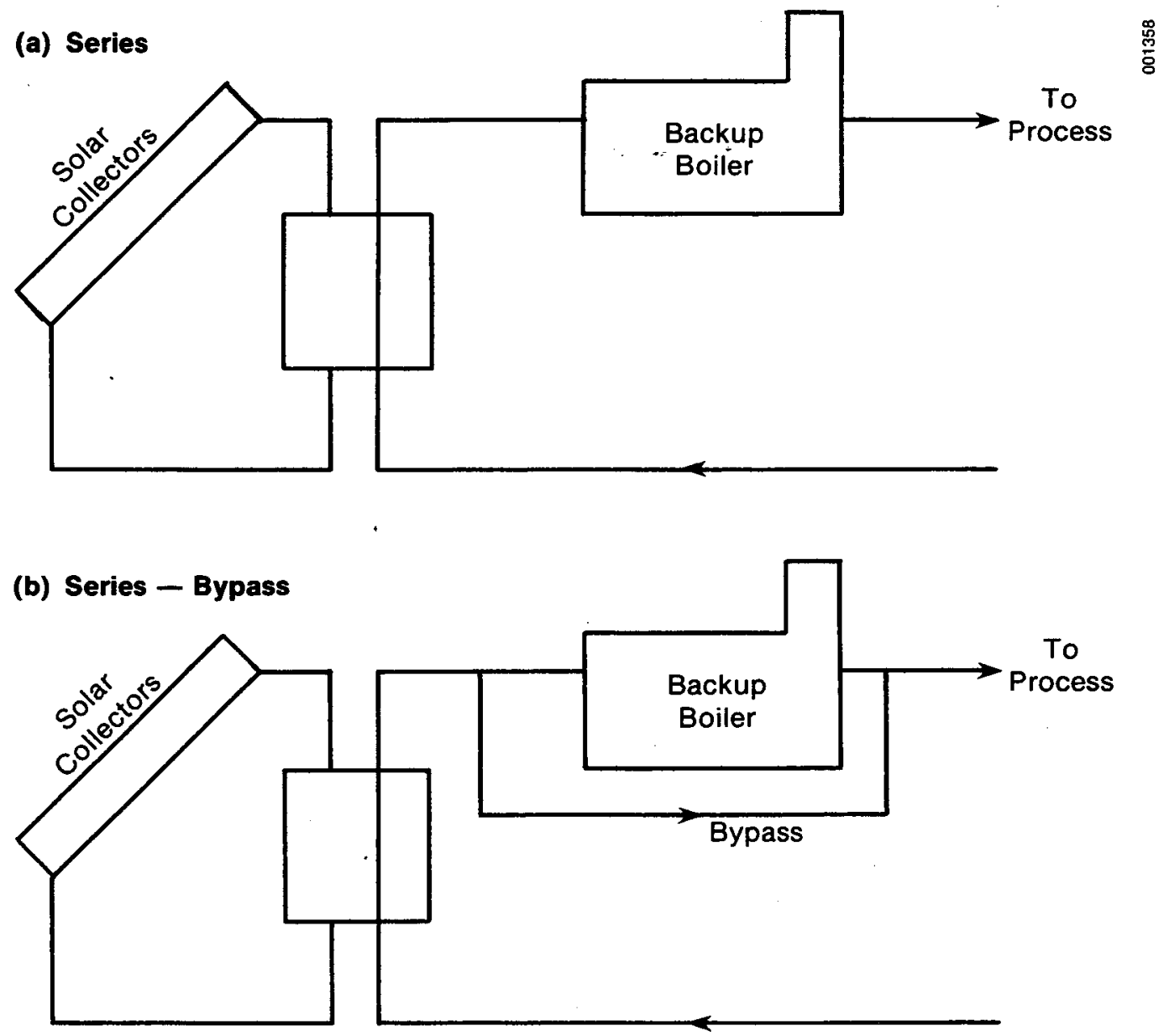

(c) Parallel

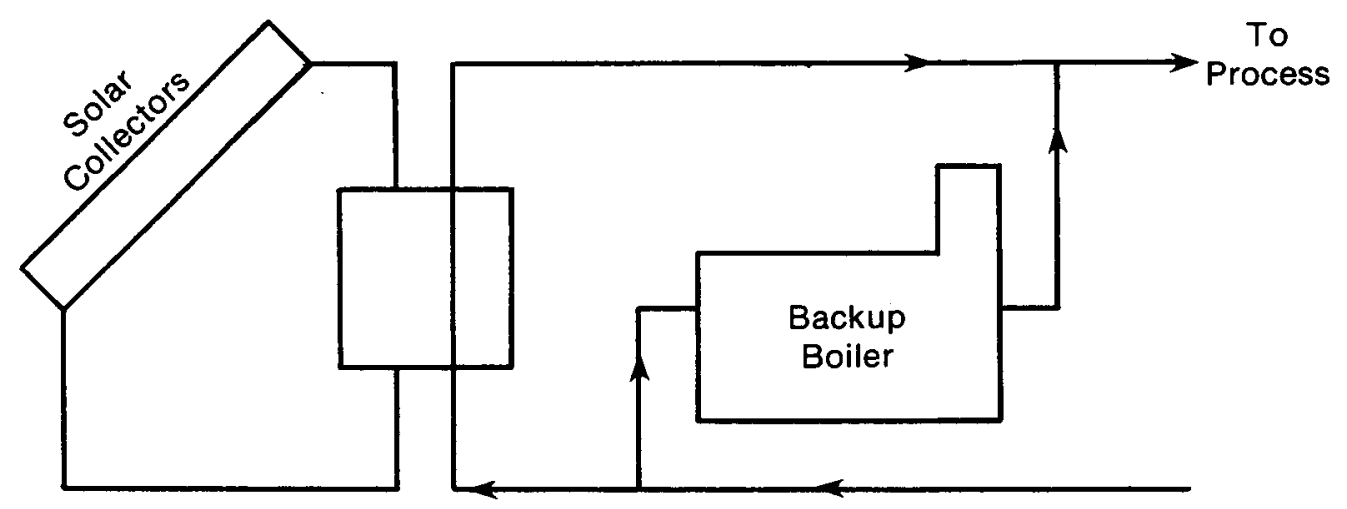

Figure A-4. Configuration of Solar IPH Systems and Backup Boilers 
series system, the boiler must maintain a low firing rate whenever the load is on to replace the energy lost from the skin of the boiler. In both the series and series-bypass systems, the boiler is modulated to make up the difference between the load and the solar contribution when the solar system cannot supply the full load. In the parallel system, the boller is operated in an on-off manner and the solar system supplies heat only when it can carry the entire load.

The influence of each system configuration on $\tau$ depends on how many hours the boiler may be shut down while the load is supplied totally by solar energy. As we noted, the simple series system does not allow for shutdown, because the boiler is always kept hot. Thus, $\tau$ for a series system is equal to one. In the series-bypass system, the boller may be shut down when solar energy supplies the entire load, so the value of $\tau$ may be less than one. Increased collector areas and small amounts of storage tend to decrease $\tau$ because the solar system heats up faster and can supply the full load more often. Moreover, $\tau$ has a minimum value for a given collector area and storage size in a parallel system, because any time the solar system delivers energy, the boiler can be shut down. Therefore, the boiler always either operates at full load efficiency or is shut down.

Reducing the value of $\tau$ decreases skin losses and increases overall boiler efficiency at a given average firing rate (Eq. A-9). This seems to favor parallel systems, or at least series systems with low turndown ratios* for the backup boiler (a parallel system can be thought of as a series system in which the turndown ratio of the boiler is one) to maximize the boiler's efficiency. However, because of the operational characteristics of solar systems, this is not the best approach to adopt for maximum overall fuel savings. In particular, the performance of the solar system decreases as the inlet temperature to the collectors increases. Therefore, a series system (or series-bypass) is much more efficient, because the inlet temperature to the collectors is lower than that of a parallel system. In a parallel system, the minimum temperature to the collectors is approximately the same as the load supply temperature, since the storage tank cannot be drawn down below that temperature. For a series system, however, the minimum collector inlet temperature is close to the make-up or load return temperature. More energy is provided by a series system, resulting in much higher fuel savings as boiler load is reduced--even if boiler efficiency is also slightly reduced.

\section{A.3.2 The Effect of Boiler Turndown Ratio on Solar Hot Water Systems}

The effect of the boiler turndown ratio on energy savings in a solar IPH system is also related to the way collector performance varies with inlet temperature. When the solar system is capable of supplying a large fraction of the load, most of the time the boiler will either be operated at its minimum firing rate or be turned off. Consider the effect of boiler turndown ratio on such a solar system. The solar system collects much more energy than the load requires at peak times, thereby carrying the entire load at those times while

*Turndown ratio is the ratio of full load firing rate (energy delivery) to the minimum firing rate possible with that boiler. 
also charging the storage. During those times, the boiler can be shut off. When the collection rate becomes less than the load, the system may continue to supply the whole load for a while if there is sufficient energy in storage, but eventually the storage tank temperature will decrease below the load temperature. To continue supplying the load, the backup boiler would then be turned on and operated at its minimum firing rate. Energy extraction from the solar storage would have to be reduced to the difference between the load and the minimum firing rate of the boiler so the load could be met. The lower energy extraction rate would cause the storage tank temperature to decrease more slowly than before the boiler was started. The reduced energy extraction rate from storage would continue until the storage tank cooled to where the boiler would have to modulate. The net result is that the storage tank would be warm the next day when collection starts.

The lower the minimum firing rate of the boiler, the greater the amount of energy that can be extracted from storage and the lower the collector inlet temperature the next day. Since a lowered inlet temperature leads to higher energy collection, a boiler with a large turndown ratio (i.e., one that can be operated at a low firing rate) improves the performance of the solar system. This, in turn, leads to greater energy savings, even if the boiler is somewhat less efficient at low firing rates.

To illustrate these effects, SOLIPH runs were made for solar IPH systems with a variety of collector areas and storage sizes. A constant water-heating load of $25 \mathrm{GJ} /$ day was specified, with water entering at $20^{\circ} \mathrm{C}$ at a flow rate of $1.15 \mathrm{~kg} / \mathrm{s}$ and a required load temperature of $80^{\circ} \mathrm{C}$. The turndown ratio of the auxiliary boiler in each case was varied from one (corresponding to an on-off boiler or parallel setup) to infinity (corresponding to a series system with a boiler capable of being modulated down to zero load). The results of these runs are plotted in Fig. A-5 as curves of annual energy savings versus the minimum firing rate of the backup boiler. The curves are labeled with the collector area and the number of hours of storage for the systems depicted by the curves. In all cases, reducing the minimum firing rate increased the performance of the solar system and increased fuel savings. For small collector areas, there is an obvious knee in the curve which occurs where the minimum firing rate becomes low enough that the storage is essentially exhausted overnight. Further decreases in minimum firing rate continue to decrease the storage temperature slightly but do not have as great an effect.

To put the effect of lowered boiler efficiency at low firing rates into perspective, the analytical model derived above can be used to calculate the extra fuel energy that must be used because the boiler efficiency changes_with firing rate from its full load value. For a given average firing rate $\bar{F}$ the fuel energy needed by the boiler is given by

$$
Q_{\text {fuel }}=\frac{Q_{\text {de1 }}}{\bar{n}_{B}} \text {, }
$$

which is derived from the definition of efficiency. Because $\bar{F}_{\mathrm{full-load}}=$ $\mathrm{Q}_{\mathrm{del}}$, we have 


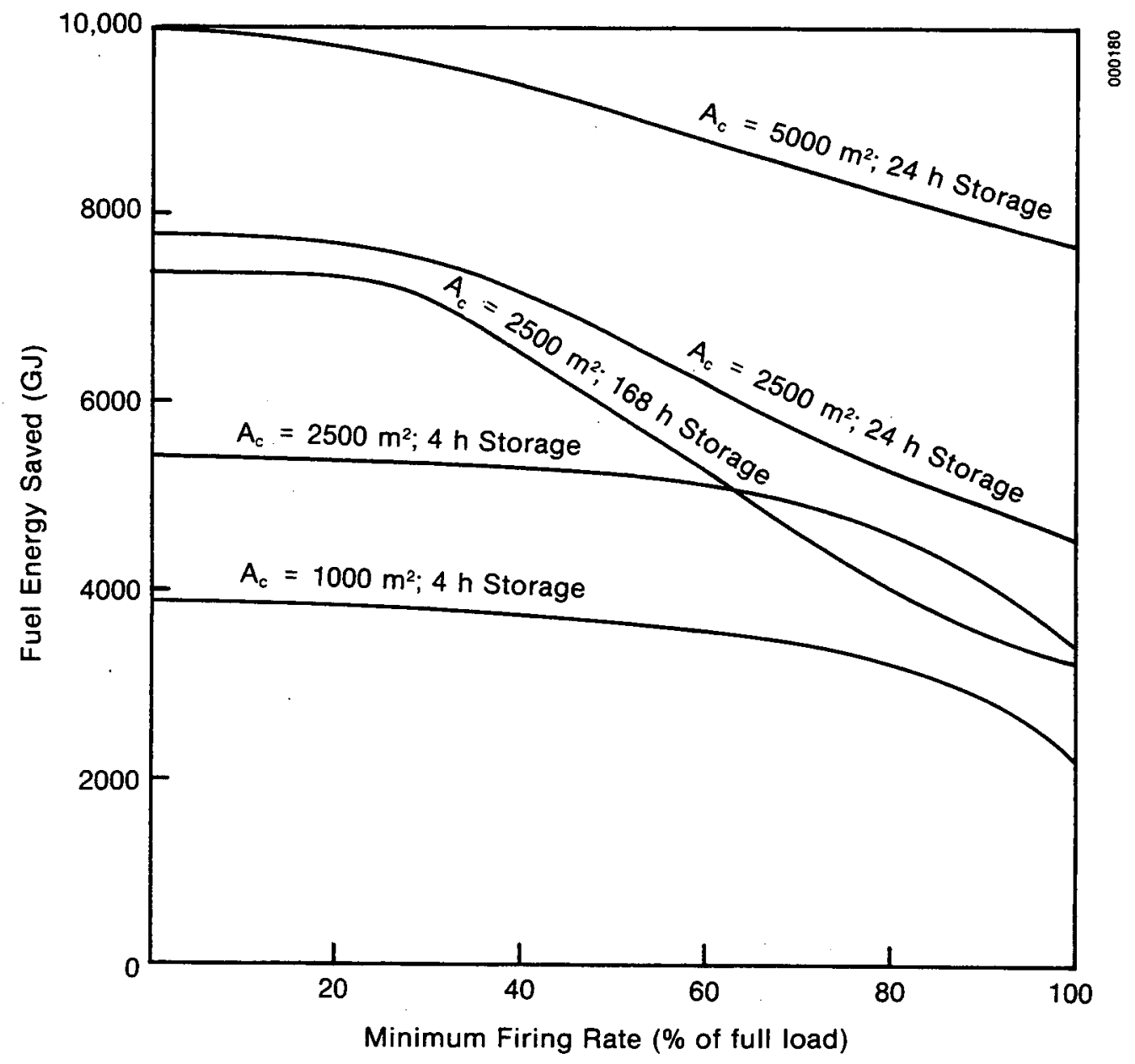

Figure A-5. Turndown Ratio of the Auxiliary Boiler 


$$
Q_{\text {fuel }}=\overline{\mathrm{F}} \mathrm{Q}_{\mathrm{ful1} \text {-1oad }} / \overline{\mathrm{n}}_{\mathrm{B}}(\overline{\mathrm{F}}) \text {, }
$$

where $\bar{n}_{B}(\bar{F})$ is the average boiler efficiency at the average firing rate $\bar{F}$.

Consider the worst case: a boiler that must be fired all the time, as in a simple series system. The extra energy that must be used because the boiler efficiency drops as the firing rate decreases is the difference between the fuel used at a firing rate $\bar{F}$ and a boiler efficiency of $\bar{n}_{B}(\bar{F})$ and that used at the same firing rate and an efficiency of $\bar{n}_{B}(1)$, or

$$
Q_{\text {extra }}=\frac{\bar{F} Q_{\text {ful1-load }}}{\bar{\eta}_{B}(\bar{F})}-\frac{\bar{F} Q_{\text {ful1-load }}}{\bar{\eta}_{B}(1)} \text {. }
$$

Substituting for $\bar{n}_{B}$ from Eq. A-9 and gathering terms, noting that $\tau=1$ for a system in which the boiler is never shut down, we obtain

$$
\text { Qextra }=\sigma(1-\overline{\mathrm{F}}) \mathrm{Q}_{\mathrm{fu} 11-10 a d} \text {. }
$$

With the nominal condition of $\sigma=0.015$, this function is plotted in Fig. A-6. The maximum effect of $1.5 \%$ of $Q_{\text {full-load }}$ is very small compared with the changes in total fuel use that result from small changes in such things as the turndown ratio, which in turn lead to changes in the solar system performance. To illustrate this point, Fig. A-7 shows the total fuel use plotted along with the extra fuel use caused by the boiler efficiency effect. Clearly, any penalty in fuel use caused by reducing the minimum boiler firing rate is very small compared with the savings in overall fuel use. In fact, such a penalty would be easily outweighed by the advantages of the reduced storage tank temperatures we discussed earlier.

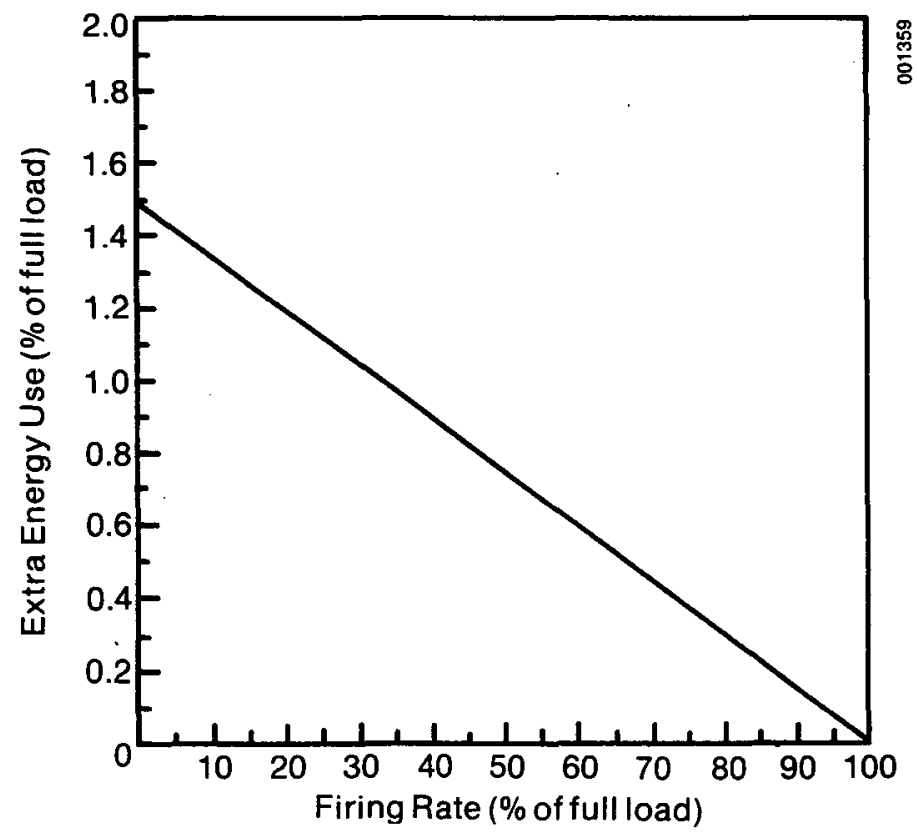

Figure A-6. Extra Energy Use 


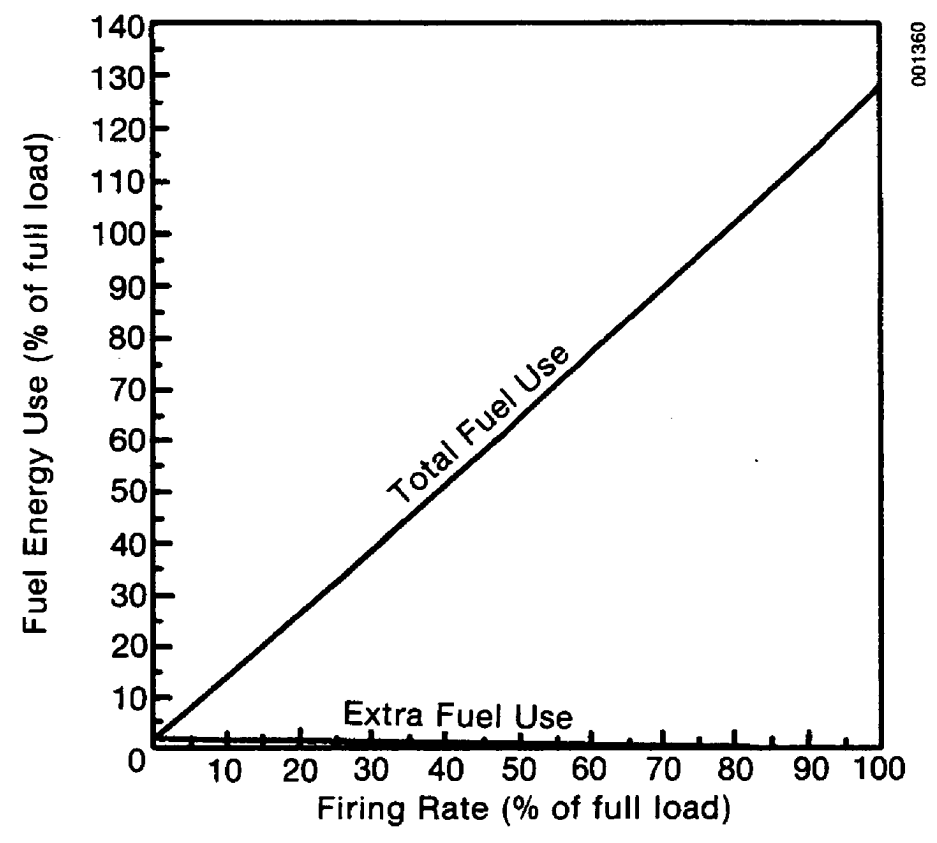

Figure A-7. Fxtra Fuel Energy Use Compared With Total Use

In conclusion, the decrease in boiler efficiency that results from decreasing the firing rate appears not to be a problem in solar hot water systems. The temperature dependence of the performance of solar systems has a profound effect on overall fuel savings, so that decreasing the minimum firing rate of the backup boiler to enhance the solar system's performance is more rewarding than raising it to enhance the efficiency of the boiler. 


\section{SEPI}




\section{APPENDIX B \\ PROPERTIES OF HEAT TRANSFER FLUIDS*}

Table

Page

B-1 Addresses of Manufacturers of Heat Transfer Fluids.............. 319

B-2 Melting, Pour, and Boiling Points of Heat Transfer Fluids.........323

B-3 Useful Temperature Ranges and Thermal Degradation

Temperatures of Heat Transfer Fluids...................... 325

B-4 Surface Tensions and Colors of Heat Transfer Fluids............. 327

B-5 Heats of Vaporization and Coefficients of Thermal

Expansion of Heat Transfer Fluids......................... 329

B-6 Flash Points, Fire Points, and Autoignition Temperatures

of Heat Transfer Fluids............................... 331

B-7 Recommended Fire-Extinguishing Agents for Heat Transfer

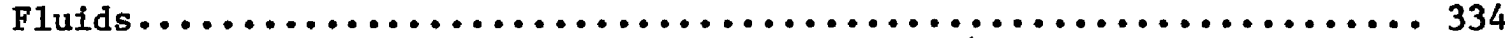

B-8 Physiological Properties of Heat Transfer Fluids.............. 335

B-9 Summary of Density Data............................. 341

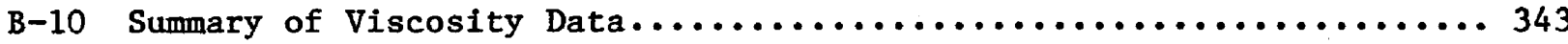

B-11 Summary of Specific Heat Data......................... 345

B-12 Summary of Thermal Conductivity Data..................... 347

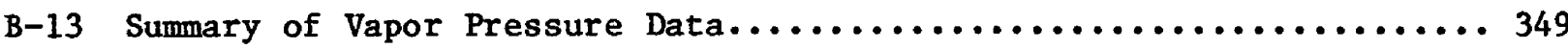

*Source: Adapted from Parts et al., 1980, Superior Heat Transfer Fluids for Solar Heating and Cooling Applications, Monsanto Research Corp. 


\section{SEPI䇏}


Table B-1. Addresses of Manufacturers of Heat Transfer Fluids

\begin{tabular}{|c|c|c|c|}
\hline Fluid & Manufacturer & Address & Phone \\
\hline \multicolumn{4}{|l|}{$\frac{\text { Bydrocarbons }}{\frac{\text { Petroleum-hased }}{\text { aliphatic hydrocarbons }}}$} \\
\hline Calorfa HT-43 & Exxon Company, U.S.A. & $\begin{array}{l}\text { P.o. Box } 2180 \\
\text { Houston, TX } 77001\end{array}$ & $713-656-5318$ \\
\hline Diala AX & Shell Oil Company & $\begin{array}{l}\text { One Shell Plaza } \\
\text { P.O. Box } 2463 \\
\text { Houston, IX } 77001\end{array}$ & $713-241-4334$ \\
\hline Mobiltherm 603 & Mobil oil Corporation & $\begin{array}{l}150 \text { East } 42 \text { ad Street } \\
\text { New York, NY } 10017\end{array}$ & $212-883-2630$ \\
\hline $\begin{array}{l}\text { Sllogram fieat Transfer } \\
\text { Fluid } 43\end{array}$ & A. Margolis \& Sons Corp. & $\begin{array}{l}1504 \text { Atlantic Avenue } \\
\text { Brooklyn, NY } 11216\end{array}$ & $212-773-6270$ \\
\hline Sunoco theat Iransfer oil 21 & Sun 011 Company & $\begin{array}{l}1608 \text { Walnut Street } \\
\text { Philadelphia, PA } 19103\end{array}$ & $215-972-4150$ \\
\hline Sunoco Heat Transfer ofl 25 & Sun oil Company & $\begin{array}{l}1608 \text { Walnut Street } \\
\text { Philarielphia, PA } 19103\end{array}$ & $215-972-4150$ \\
\hline Texatherm & Texaco, Inc. & $\begin{array}{l}4201 \text { River Road } \\
\text { Cincinnat1, OH } 45204\end{array}$ & $513-451-5151$ \\
\hline Thermia Dil C & Shell oil company & $\begin{array}{l}\text { One Shell Plaza } \\
\text { P.0. Box } 2463 \\
\text { Houston, TX } 77001\end{array}$ & $713-241-4334$ \\
\hline \multicolumn{4}{|l|}{$\begin{array}{l}\text { Synthetic aliphatic } \\
\text { hydrocarbons }\end{array}$} \\
\hline Brayco 898 & Bray oll Company & $\begin{array}{l}9550 \text { Flair Dr., } \# 301 \\
\text { EI Monte, CA } 31731\end{array}$ & $4: 15-575-1212$ \\
\hline Brayco 988 iF & Bray O11 Company & $\begin{array}{l}9550 \text { Flair Dr., } \# 301 \\
\text { E1 Monte, CA } 91731\end{array}$ & $415-575-1212$ \\
\hline $\mathrm{ESH}-4$ & Ethyl Corporation & $\begin{array}{l}1600 \text { West Eight Mile Rd. } \\
\text { Ferndale, MI } 48220\end{array}$ & $313-399-9600$ \\
\hline ESH-5 & Ethyl Corporation & $\begin{array}{l}\text { I6no Nest Zight Mile Rd. } \\
\text { Ferdale, MI } 48220\end{array}$ & $313-399-9600$ \\
\hline ESH-G & Ethyl Corporation & $\begin{array}{l}1500 \text { West Eight Mile Rd. } \\
\text { Ferndale, MI } 48229\end{array}$ & $313-399-9600$ \\
\hline $\mathrm{II}-30$ & Mark Enterprises, Inc. & $\begin{array}{l}50 \text { Hazel Terrace } \\
\text { Woodbridge, CT } 06525\end{array}$ & $2 n 3-3.99-5538$ \\
\hline $\mathrm{II}-30 \mathrm{C}$ & Mark Enterprises, Inc. & $\begin{array}{l}50 \text { Hazel Terrace } \\
\text { Voodbridge, CT } 06525\end{array}$ & $203-389-5598$ \\
\hline Uniroyal PAO-13C & Unirovat, Ine. & $\begin{array}{l}\text { Spencer Street } \\
\text { Naugatuck, CI } 06770\end{array}$ & $2 n 3-723-377 ?$ \\
\hline
\end{tabular}


Table B-1. Addresses of Manufacturers of Heat Transfer Fluids (Continued)

\begin{tabular}{|c|c|c|c|}
\hline Fluid & Manufacturer & Address & Phone \\
\hline \multicolumn{4}{|l|}{ Aromatic hydrocarbons } \\
\hline Dowtherm $\mathrm{J}$ & The Dow Chemical co. & $\begin{array}{l}2020 \text { Dow Center } \\
\text { Barstow Building } \\
\text { Midland, MI } 48640\end{array}$ & $517-636-3993$ \\
\hline Dowtherm LF & The Dow Chemical Co. & $\begin{array}{l}2020 \text { Dow Center } \\
\text { Barstow Building } \\
\text { Midland, MI } 48640\end{array}$ & $517-636-3993$ \\
\hline DXE & Gulf oil Chemicals Co. & $\begin{array}{l}\text { P.O. Box } 2900 \\
\text { Shawnee Misston, KS } \\
\quad 66201\end{array}$ & $913-722-3200$ \\
\hline Mobiltherm 600 & Mobil oil Corporation & $\begin{array}{l}150 \text { East 42nd Street } \\
\text { New York, NY } 10017\end{array}$ & $212-883-2630$ \\
\hline MCS -1958 & Monsanto Company & $\begin{array}{l}800 \text { N. Lindbergh BIvd. } \\
\text { St. Louis, MO } 63166\end{array}$ & $314-694-2153$ \\
\hline MCS -1980 & Monsanto Company & $\begin{array}{l}800 \text { N. Lindbergh Blvd. } \\
\text { St. Louis, MO } 63156\end{array}$ & $314-694-2153$ \\
\hline MCS-2046 & Monsanto Company & $\begin{array}{l}800 \mathrm{~N} \text {. Lindbergh Blvd. } \\
\text { St. Louis, MO } 63166\end{array}$ & $314-594-2153$ \\
\hline Therminol 55 & Monsanto Company & $\begin{array}{l}800 \text { N: Lindbergh Blvd. } \\
\text { St. Louis, MO } 63166\end{array}$ & $314-694-2153$ \\
\hline Therminol 50 & Monsanto Company & $\begin{array}{l}900 \text { N. Lindbergh Blvd. } \\
\text { St. Louis, MO } 63166\end{array}$ & $314-694-2153$ \\
\hline Therminol 66 & Monsanto Company & $\begin{array}{l}800 \text { N. Lindbergh Blvd. } \\
\text { St. Louis, Mo } 63166\end{array}$ & $314-594-2153$ \\
\hline Therminol 88 & Monsanto Company & $\begin{array}{l}800 \text { N. Lindbergh B1vd. } \\
\text { St. Louis, MO } 63166\end{array}$ & $314-694-2153$ \\
\hline \multicolumn{4}{|l|}{$\frac{\text { Glveols }}{\text { Ethylene glyco1-based }}$} \\
\hline Dowtherm $S R-1$ & The Dow Chenical Co. & $\begin{array}{l}2020 \text { Dow Center } \\
\text { Barstow Building } \\
\text { Midland, MI } 48640\end{array}$ & $517-636-3153$ \\
\hline Prestone II & Unton Carbide Corp. & $\begin{array}{l}\text { Tarrytown Center } \\
\text { Tarrytown, Ny } 10591\end{array}$ & $914-345-2241$ \\
\hline Sunsafe 100 & $\begin{array}{l}\text { Wuclear Technology Cord./ } \\
\text { IPD Energy Systems, Inc. }\end{array}$ & $\begin{array}{l}2050 \text { North Broad Street } \\
\text { Lansdale, PA } 19446\end{array}$ & $215-362-1178$ \\
\hline Sunsafe 130 & $\begin{array}{l}\text { Nuclear Technology Corp./ } \\
\text { NPD Energy Systems, Inc. }\end{array}$ & $\begin{array}{l}205 n \text { North Broad Street } \\
\text { Lansdale, PA } 19446\end{array}$ & $215-362-1178$ \\
\hline
\end{tabular}


Table B-1. Addresses of Manufacturers of Heat Transfer Fluids (Continued)

\begin{tabular}{|c|c|c|c|}
\hline Fluid & Manufacturer & Address & Phone \\
\hline UCAR TT-17 & Union Carbide Corp. & $\begin{array}{l}\text { Tarrytown Center } \\
\text { Tarrytown, } \sqrt{Y} 10591\end{array}$ & $914-789-3578$ \\
\hline Zerex & PPG Industries, Inc. & $\begin{array}{l}\text { P.0. Box } 4026 \\
\text { Corpus Christi, TX } \\
78408\end{array}$ & $512-883-4301$ \\
\hline
\end{tabular}

Propylene glycol-based Fluids

Dowfrost

Practical Solar Fluid

Solar winter Ban

Sunsafe 200

Sunsafe 230

Sunsol 60

UCAR FF-35

\section{Esters}

Stauffer $3664-A$

Therminol 44

Ethers

Dowthern $\mathrm{A}$

Dowtherm G

Therminol $\mathrm{VP}-1$
The Dow Chemical Co.

2020 Dow Center

$$
\text { Barstow Building }
$$

Midland, MI 48640

517-636-3158

Practical Solar Feat, Inc.

2216 Montgomery Stree

Bethlehem, PA 18017

Camco Manufacturing, Inc.

2804 Patterson Street

Greensboro, NC 27407

Nuclear Technology Corp./ NPD Energy Systems, Inc.

2050 North Broad Street

Lansdale, PA 19446

$205 n$ North Broad Street

Lansdale, PA 19446

P. 0. Box 1004

New Haven, CT 06508

Tarrytown Center

Tarrytown, NY 10591

215-865-5646

$919-292-4906$

$215-362-1178$

$215-362-1178$

$203-934-6301$

Union Carbide Corp.

Stauffer Chemicai Company

Nyala Farti Road

Westport, CT 06880

$800 \mathrm{~N}$. Lindbergh Blvd.

$203-222-3166$

Monsanto Company

St. Louis, MO 63166

$314-694-21.53$

The Dow Chemical Company

2020 Dow Center

Barstow Building

Midland, MT 48640

$517-536-3993$

The Dow Chemical Company

2020 Dow Center

Barstow Building

Midland, MI 48640

$517-636-3993$

ionsanto Company
800 N. Lindbergh Blvd.

St. Louis, MO 63166 
Table B-1. Addresses of Manufacturers of Heat Transfer Fluids (Concluded)

\begin{tabular}{clll}
\hline Fluid & Manufacturer & \multicolumn{1}{c}{ Address } & Phone \\
\hline UCON HTF-500 & Union Carbide Corp. & Tarrytown Cencer & 914-789-3578
\end{tabular}

\begin{tabular}{|c|c|c|c|}
\hline$S F-96(20)$ & General Electric Company & $\begin{array}{l}\text { Silicone Products Dept. } \\
\text { Waterford, NY } 12188\end{array}$ & $518-237-3330$ \\
\hline Syltherm 444 & Dow Corning Corporation & $\begin{array}{l}3901 \text { S. Saginaw Road } \\
\text { Midland, MI } 48640\end{array}$ & $517-496-4000$ \\
\hline$x 2-1162$ & Dow Corning Corporation & $\begin{array}{l}3901 \text { S. Saginaw Road } \\
\text { Midland, MI } 48640\end{array}$ & $517-496-4000$ \\
\hline \multicolumn{4}{|l|}{ Eluorocarhons } \\
\hline Freon 11 & $\begin{array}{l}\text { E. I. AuPont de Nemours } \\
\text { \& Co. }\end{array}$ & $\begin{array}{l}\text { Nemours Building } \\
\text { Wilmington, DE } 19898\end{array}$ & $302-774-2192$ \\
\hline Freon 114 & $\begin{array}{l}\text { E. I. duPont de Nemours } \\
\& \text { Co. }\end{array}$ & $\begin{array}{l}\text { Nemours Building } \\
\text { Wilmington, DE } 19898\end{array}$ & $3 n 2-774-219 ?$ \\
\hline Freon TA & $\begin{array}{l}\text { E. I. dePont de Nemours } \\
\& \text { Co. }\end{array}$ & $\begin{array}{l}\text { Nemours Building } \\
\text { Wilmington, DE } 19898\end{array}$ & $302-774-2192$ \\
\hline
\end{tabular}


Table B-2. Melting, Pour, and Boiling Points of Heat Transfer Fluids

\begin{tabular}{|c|c|c|c|c|c|c|}
\hline \multirow{2}{*}{ Fluid } & \multicolumn{2}{|c|}{ Melting Point } & \multicolumn{2}{|c|}{ Pour Point } & \multirow{2}{*}{$\frac{\text { Bolling }}{\left({ }^{\circ} \mathrm{C}\right)}$} & \multirow{2}{*}{$\frac{\text { Point }}{\left({ }^{\circ} \mathrm{F}\right)}$} \\
\hline & $\left({ }^{\circ} \mathrm{C}\right)$ & $\left({ }^{\circ} \mathrm{F}\right)$ & $\left({ }^{\circ} \mathrm{C}\right)$ & $\left({ }^{\circ} \mathrm{F}\right)$ & & \\
\hline
\end{tabular}

\section{Hydrocarbons}

Petroleum-based

aliphat1c hydrocarbons

Caloria MT-43
Diala AX
Mobiltherm 603
Silogram Heat Transfer Fluid 43
Sunoco Heat Transfer o11 21
Sunoco Heat Transfer O11 25
Texatherm
Thermia Oil C

Synthetic aliphatic hydrocarbons

Brayeo 888
Brayco 888 HF
ESH-4
ESH-5
ESH-6
H-30
II-3nC

$\begin{array}{cccccc}<-68 & <-90 & <-68 & <-90 & >260 & >500 \\ & & <-65 & <-85 & & \\ & <-57 & <-70 & & \\ & <-57 & <-70 & & \\ & & <-57 & <-70 & & \\ & & -32 & -25 & 295 & 560 \\ & & & & 327 & 620\end{array}$

Aromatic hydrocarbons

Dowtherm J
Dowtherm LF
DXE
Mobiltherm 600
MCS-1958
MCS-1980
MCS-2046
Therminol 55
Therminol 60
Therminol 66
Therninol 88

$\begin{array}{rrrrrr}<-73 & <-100 & & & 181 & 358 \\ -32 & -25 & & & 264 & 507 \\ & & -34 & -30 & & \\ & & -21 & -5 & 343 a & \sim 650 \text { a } \\ b & -40 & -40 & 327 & 620 \\ & & & & & \\ & & -15 & 5 & & \\ & & -40 & -40 & & \\ & & -68 & -90 & & \\ & & -28 & -18 & & \end{array}$

G1ycols

\section{Ethylene glycol-based} Fluids

Dowtherm SR-1 (50 wt-\%)

\begin{tabular}{|c|c|c|c|c|}
\hline-37 & $-35^{d}$, e & & & $100 \mathrm{e}$ \\
\hline-37 & $-34 \mathrm{e}$ & $(-22) \frac{1}{1}$ & $(-8)^{f} \frac{f}{-}$ & $108^{\mathrm{e}}$ \\
\hline
\end{tabular}


Table B-2. Melting, Pour, and Boiling Points of Heat Transfer Fluids (Concluded)

\begin{tabular}{|c|c|c|c|c|c|c|}
\hline \multirow{2}{*}{ Fluid } & \multicolumn{2}{|c|}{ Melting Point } & \multicolumn{2}{|c|}{ Pour Point } & \multicolumn{2}{|c|}{ Boiling Point } \\
\hline & $\left({ }^{\circ} \mathrm{C}\right)$ & $\left({ }^{\circ} \mathrm{F}\right)$ & $\left({ }^{\circ} \mathrm{C}\right)$ & $\left({ }^{\circ} F\right)$ & $\left({ }^{\circ} \mathrm{C}\right)$ & $\left({ }^{\circ} \mathrm{F}\right)$ \\
\hline $\begin{array}{l}\text { Sunsafe } 100(33 \text { vol-\%) } \\
\text { Sunsafe } 130(50 \text { vol-\%) } \\
\text { UCAR TF-17 (50 wt }-\%) \\
\text { Zerex }\end{array}$ & & & $(-25) \underline{f}$ & $(-13) f$ & $\begin{array}{l}106 \frac{\mathrm{e}}{110 \frac{\mathrm{e}}{\mathrm{f}}} \\
(180) \frac{\mathrm{f}}{\mathrm{f}} \\
(182)^{-}\end{array}$ & $\begin{array}{l}222 \frac{e}{e} \\
(356) \frac{e}{f} \\
(359) \frac{f}{f}\end{array}$ \\
\hline \multicolumn{7}{|l|}{$\begin{array}{l}\text { Propylene glycol-based } \\
\text { fluids }\end{array}$} \\
\hline $\begin{array}{l}\text { Dowfrost }(50 \text { wt-\%) } \\
\text { Solar Winter Ban } \\
\text { Sunsafe } 200(33 \mathrm{vol}-\%) \\
\text { Sunsafe } 230(50 \mathrm{vol}-\%) \\
\text { UCAR FF-35 (50 wt-\%) }\end{array}$ & -32 d, e & $-26 \underline{d, e}$ & & & $\begin{array}{l}110 \frac{e}{e} \\
109 \frac{e}{e} \\
103 \frac{e}{e} \\
107 \frac{e}{f}\end{array}$ & $\begin{array}{r}230 \frac{e}{e} \\
228 \frac{e}{e} \\
225 \frac{e}{e} \\
(324)^{\frac{f}{e}}\end{array}$ \\
\hline \multicolumn{7}{|l|}{ Esters } \\
\hline $\begin{array}{l}\text { Stauffer } 3664-\mathrm{A} \\
\text { Therminol } 44\end{array}$ & & & $\begin{array}{l}-59 \\
-62\end{array}$ & $\begin{array}{l}-75 \\
-80\end{array}$ & & \\
\hline \multicolumn{7}{|l|}{ Ethers } \\
\hline $\begin{array}{l}\text { Dowtherm A } \\
\text { Dowtherm G } \\
\text { Therninol VP-1 } \\
\text { UCON HTF-500 }\end{array}$ & $\begin{array}{l}12 \\
-7 \\
12\end{array}$ & $\begin{array}{l}54 \\
20 \\
54\end{array}$ & -37 & -35 & $\begin{array}{l}257 \\
302 \\
257\end{array}$ & $\begin{array}{l}495 \\
575 \\
495\end{array}$ \\
\hline \multicolumn{7}{|l|}{ Silicones } \\
\hline $\begin{array}{l}S F-96(2 n) \\
\text { Syltherm } 444 \\
X 2-1162\end{array}$ & & & $\begin{array}{r}-65 \\
-60 \\
-100\end{array}$ & $\begin{array}{r}-85 \\
-76 \\
-148\end{array}$ & & \\
\hline \multicolumn{7}{|l|}{ Fluorocarbons } \\
\hline $\begin{array}{ll}\text { Freon } 11 \\
\text { Ereon } 114 \\
\text { Ereon }\end{array}$ & $\begin{array}{r}-111 \\
-94 \\
-101\end{array}$ & $\begin{array}{l}-168 \\
-137 \\
-150\end{array}$ & & & $\begin{array}{r}24 \\
4 \\
44\end{array}$ & $\begin{array}{r}75 \\
39 \\
110\end{array}$ \\
\hline Water & 0 & 32 & & & 100 & 212 \\
\hline
\end{tabular}

anitial boiling point.

bolidifies slowly at $21^{\circ} \mathrm{C}\left(70^{\circ} \mathrm{F}\right)$.

Gyelting range.

dervstallization begins at this temperature unon cooling.

The data pertain to water solution of the glycol.

F The data pertain to the concentrate. 
Table B-3. Useful Temperature Ranges and Therma1 Degradation Temperatures of Heat Transfer Fluids

\begin{tabular}{|c|c|c|c|c|}
\hline \multirow[t]{2}{*}{ Fluid } & \multicolumn{2}{|c|}{ Temperature Range } & \multicolumn{2}{|c|}{$\begin{array}{l}\text { Thermal } \\
\text { Degradation } \\
\text { Temperature }\end{array}$} \\
\hline & $\left({ }^{\circ} \mathrm{C}\right)$ & $\left({ }^{\circ} \mathrm{F}\right)$ & $\left({ }^{\circ} \mathrm{C}\right)$ & $\left({ }^{\circ} \mathrm{F}\right)$ \\
\hline
\end{tabular}

Hydrocarbons

Petroleum-based

aliphattc hydrocarbons

Calorla HT-43

Diala AX

Mobiltherm 603

Silogram Heat Transfer Fluid 43

Sunoco Heat Transfer oil 21

Sunoco Heat Transfer OiI 25

Texatherm

Theraia oil C

Synthetic allphatic

\section{hydrocarbons}

Brayco 888

ESH-4

ESH-5

ESE-6

$\mathrm{H}-30$

Uniroyal PAO-13C

Aromatic hydrocarbons

Dowthera $J$

Dowtherm LF

Mobiltherm 600

MCS-1958

xCS-1980

MCS-2046

Therminol 55

Therminol 60

Therminol 66

Therminol 88

GIjcols

Ethylene glycol-based

\section{fluids}

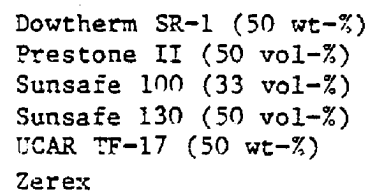

-7 to 316

-40 to 163

93 to 288

-9 to 316

-15 to 316

-15 to 316

-9 to 288

$$
\begin{aligned}
& 20 \text { to } 600 \\
&-40 \text { to } 325 \\
& 200 \text { to } 550 \\
& 15 \text { to } 600 \text { a } \\
& 5 \text { to } 600 \\
& 5 \text { to } 600 \\
& 15 \text { to } 550
\end{aligned}
$$

$>360>680$

$>316>600$

-54 to 149

-57 to 260

-57 to 260

-57 to 260

-32 to 295

27 to 302

-73 to 302

-32 to 316

-21 to 288

-23 to 288

Up to 399

-9 to 343

-18 to 316

-51 to 316

-18 to 343

149 to 399
-65 to 300 .

-70 to 500 o

-70 to $500 \frac{b}{b}$

-70 to 500 b

-25 to 563

80 to 575

$282 \quad 540$

$\sim 316 \sim 600$

$>316>600$

$282 \quad 540$

$293559 \mathrm{C}$

$286 \quad 546^{\circ}$

$>316>600$

405. 761 d

-10 to 550

Up to 750 e

15 to 650

0 to $600 \quad 304 \quad 579$

-60 to 600

0 to 650

300 to 750
$308 \quad 586 c$

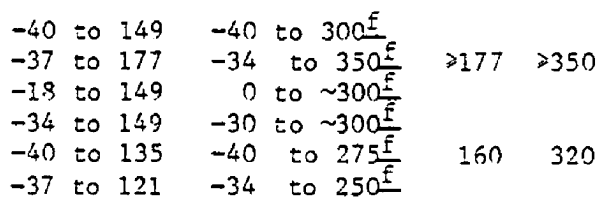


Table B-3. Useful Temperature Ranges and Thermal Degradation Temperatures of Heat Transfer Fluids (Concluded)

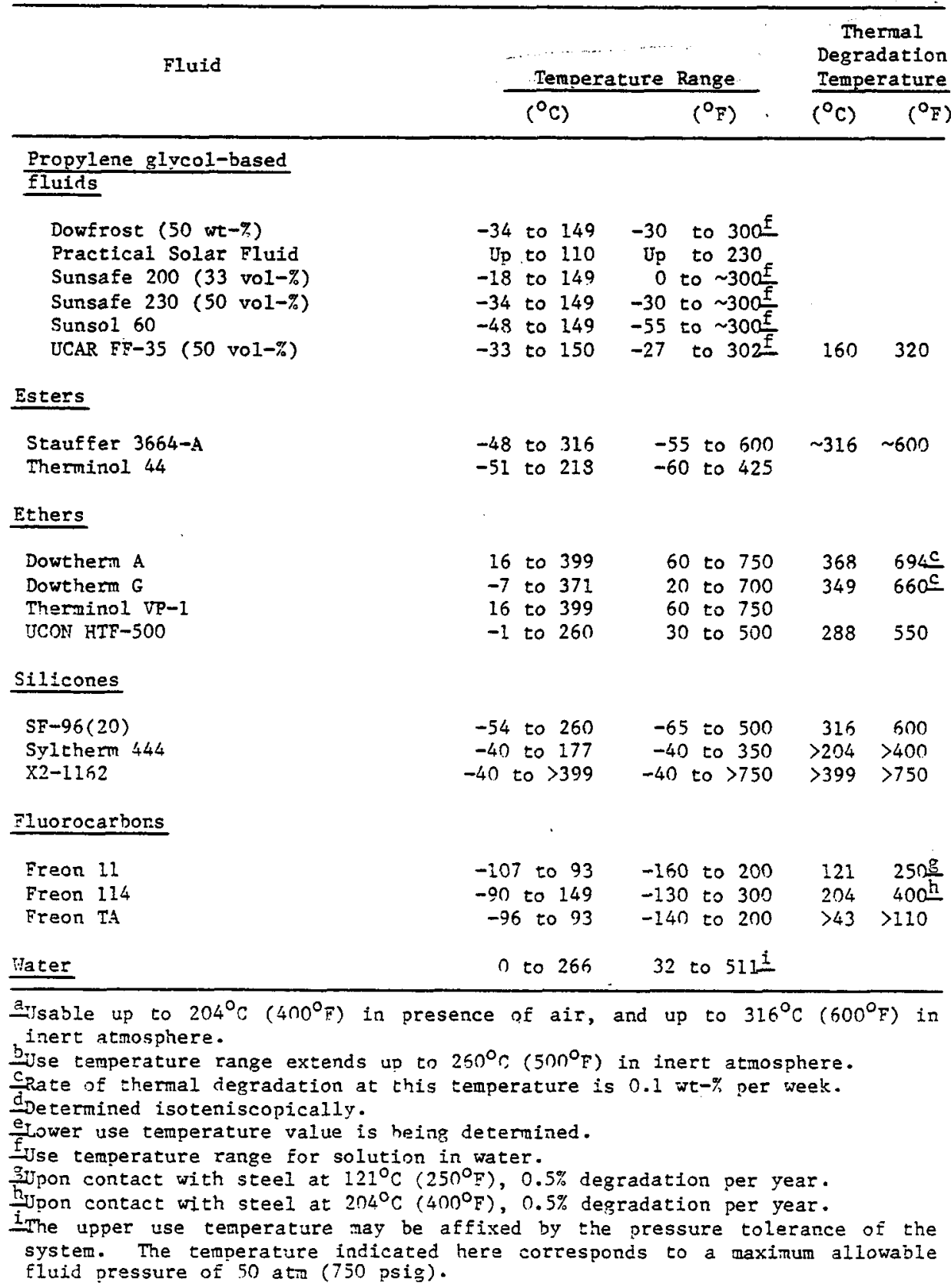


Table B-4. Surface Tensions and Colors of Heat Transfer Fluids

\begin{tabular}{|c|c|c|}
\hline Fluid & $\begin{array}{c}\text { Surface Tension } \\
(\mathrm{kN} / \mathrm{m})\end{array}$ & Physical Appearance, Color \\
\hline \multicolumn{3}{|l|}{ Hyd rocarbons } \\
\hline \multicolumn{3}{|l|}{$\begin{array}{l}\text { Petroleun-based } \\
\text { aliphatic hydrocarbons }\end{array}$} \\
\hline $\begin{array}{l}\text { Caloria HT-43 } \\
\text { Diala AX } \\
\text { Mobiltherw } 603 \\
\text { Silogram Heat Transfer Fluid } 43 \\
\text { Sunoco Heat Transfer o1 } 21 \\
\text { Sunoco Heat Transfer O1l } 25 \\
\text { Texatherm } \\
\text { Thermia Oil C }\end{array}$ & & $\begin{array}{l}\text { Pale yellow, L1.0 ASTM color } \\
\text { Pale yellow, L0.5 ASTM color } \\
\text { Pale yellow, } \\
\text { Pale yellow, L1.0 ASTM color } \\
\text { Pale yellow, L1.0 ASTM color } \\
\text { Pale yellow, 0.5 ASTM color } \\
\text { Pale yellow, L0.5 ASTM color } \\
\text { Pale yellow, 0.,5 ASTM color }\end{array}$ \\
\hline \multicolumn{3}{|l|}{$\begin{array}{l}\text { Synthetic aliphatic } \\
\text { hydrocarbons }\end{array}$} \\
\hline $\begin{array}{l}\text { Brayco } 888 \\
\text { Brayco } 888 \mathrm{HF} \\
\text { ESH-4 } \\
\text { ESH-5 } \\
\text { ESH-6 } \\
\text { U-30 } \\
\text { H-30C } \\
\text { Uniroyal PAO-13C }\end{array}$ & $\begin{array}{l}21 \\
49\end{array}$ & $\begin{array}{l}\text { Red } \\
\text { Red } \\
\text { Colorless } \\
\text { Colorless } \\
\text { Colorless } \\
\text { Green } \\
\text { Blue } \\
\text { Colorless }\end{array}$ \\
\hline \multicolumn{3}{|l|}{ Aromatic hydrocarbons } \\
\hline $\begin{array}{l}\text { Dowtherm J } \\
\text { Dowtherm LF } \\
\text { DXE } \\
\text { Mobilthem } 600 \\
\text { MCS-1958 } \\
\text { MCS-1980 } \\
\text { MCS-2046 } \\
\text { Therminol } 55 \\
\text { Therminol } 60 \\
\text { Therminol } 66 \\
\text { Therminol } 98\end{array}$ & $\begin{array}{l}\sim 38^{\mathrm{b}} \\
30.48 \text { at } 25^{\circ} \mathrm{C}\left(77^{\circ} \mathrm{F}\right) \\
35.24 \text { at } 25^{\circ} \mathrm{C}\left(77^{\circ} \mathrm{F}\right) \\
37.99 \text { at } 25^{\circ} \mathrm{C}\left(77^{\circ} \mathrm{F}\right)\end{array}$ & $\begin{array}{l}\text { Colorless } \\
\text { Colorless to light yeliow } \\
\text { Colorless to pale yellow } \\
\text { Clear liquid } \\
\text { Colorless to light yellow } \\
\text { Red liquid at } 75^{\circ} \mathrm{C}\left(167^{\circ} \mathrm{F}\right) \\
\text { Amber-reddish } \\
\text { Yellow } \\
\text { Light yellow } \\
\text { Clear, pale yellow } \\
\text { Crumbly, wax-like flakes at } \\
\text { ambient temperature. Light } \\
\text { amber liquid above melting } \\
\text { point. }\end{array}$ \\
\hline \multicolumn{3}{|l|}{ Glycols } \\
\hline $\begin{array}{l}\text { Ethylene glvcol-based } \\
\text { fluids }\end{array}$ & & \\
\hline $\begin{array}{l}\text { Dowtherm } \\
\text { Prestone II } \\
\text { Sunsafe } 100\end{array}$ & $\begin{array}{l}55^{\mathrm{C}} \\
56^{\mathrm{C}} \\
58^{\mathrm{d}} \\
56 \mathrm{C} \text { at }-4^{\circ} \mathrm{C}\left(25^{\circ} \mathrm{F}\right)\end{array}$ & $\begin{array}{l}\text { Red } \\
\text { Golden yellow } \\
\text { Colorless }\end{array}$ \\
\hline Sunsafe 130 & 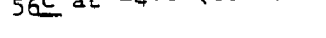 & \\
\hline
\end{tabular}


Table B-4. Surface Tensions and Colors of Heat Transfer Fluids (Concluded)

\begin{tabular}{|c|c|c|}
\hline Fluid & $\begin{array}{l}\text { Surface Tension } \\
(\mathrm{kN} / \mathrm{m})\end{array}$ & Physical Appear- \\
\hline $\begin{array}{l}\text { UCAR TF-17 } \\
\text { Zerex }\end{array}$ & $47.4^{\mathrm{C}}$ at $20^{\circ} \mathrm{C}\left(68^{\circ} \mathrm{F}\right)$ & $\begin{array}{l}\text { Pale yellow } \\
\text { Orange }\end{array}$ \\
\hline \multicolumn{3}{|l|}{$\begin{array}{l}\text { Propylene glycol-based } \\
\text { fluids }\end{array}$} \\
\hline $\begin{array}{l}\text { Dowfrost } \\
\text { Practical Solar Fluid } \\
\text { Solar Winter Ban } \\
\text { Sunsafe } 200 \\
\text { Sunsafe } 230 \\
\text { Sunsol } 60 \\
\text { UCAR FF-35 }\end{array}$ & $\begin{array}{l}45^{\mathrm{C}} \\
42 \mathrm{ge} \text { at } 25^{\circ} \mathrm{C}\left(77^{\circ} \mathrm{F}\right) \\
49^{\mathrm{C}} \text { at }-4^{\circ} \mathrm{C}\left(25^{\circ} \mathrm{F}\right) \\
45^{\mathrm{C}} \text { at }-4^{\circ} \mathrm{C}\left(25^{\circ} \mathrm{F}\right) \\
42.5^{\mathrm{C}} \\
35^{\mathrm{C}} \text { at } 25^{\circ} \mathrm{C}\left(77^{\circ} \mathrm{F}\right)\end{array}$ & $\begin{array}{l}\text { Colorless } \\
\text { Blue } \\
\text { Red } \\
\text { Colorless } \\
\text { Colorless }\end{array}$ \\
\hline \multicolumn{3}{|l|}{ Esters } \\
\hline $\begin{array}{l}\text { Stauffer } 3364-\mathrm{A} \\
\text { Therminol } 44\end{array}$ & 30.34 at $25^{\circ} \mathrm{C}\left(77^{\circ} \mathrm{F}\right)$ & $\begin{array}{l}\text { Arber } \\
\text { Yellow }\end{array}$ \\
\hline \multicolumn{3}{|l|}{ Ethers } \\
\hline $\begin{array}{l}\text { Dowtherm A } \\
\text { Dowtherm G } \\
\text { Therninol VP-1 } \\
\text { UCON HTF-500 }\end{array}$ & $\begin{array}{l}40.1 \text { at } 20^{\circ} \mathrm{C}\left(68^{\circ} \mathrm{F}\right) \\
47.6 \text { at } 20^{\circ} \mathrm{C}\left(68^{\circ} \mathrm{F}\right) \\
36.6 \text { at } 25^{\circ} \mathrm{C}\left(77^{\circ} \mathrm{F}\right) \\
37\end{array}$ & $\begin{array}{l}\text { Colorless to light straw- } \\
\text { colored } \\
\text { Light amber } \\
\text { Colorless to pale yellow } \\
\text { Reddish-amber }\end{array}$ \\
\hline \multicolumn{3}{|l|}{ Silicones } \\
\hline $\begin{array}{l}\mathrm{SF}-96(20) \\
\text { Syltherm } 444 \\
\times 2-1162\end{array}$ & $\begin{array}{l}20.6 \text { at } 23^{\circ} \mathrm{C}\left(73^{\circ} \mathrm{F}\right) \\
20.1 \text { at } 23^{\circ} \mathrm{C}\left(73^{\circ} \mathrm{F}\right)\end{array}$ & $\begin{array}{l}\text { Colorless } \\
\text { Colorless } \\
\text { Colorless }\end{array}$ \\
\hline \multicolumn{3}{|l|}{ Eluorocarbons } \\
\hline $\begin{array}{l}\text { Freon } 11 \\
\text { Freon } 114 \\
\text { Ereon } \text { IA }\end{array}$ & $\begin{array}{l}18.7 \text { at } 24^{\circ} \mathrm{C}\left(75^{\circ} \mathrm{F}\right) \\
12 \text { at } 25^{\circ} \mathrm{C}\left(77^{\circ} \mathrm{F}\right) \\
18 \text { at } 25^{\circ} \mathrm{C}\left(77^{\circ} \mathrm{F}\right)\end{array}$ & $\begin{array}{l}\text { Colorless } \\
\text { Colorless } \\
\text { Colorless }\end{array}$ \\
\hline Water & 72.0 at $25^{\circ} \mathrm{C}\left(77^{\circ} \mathrm{F}\right) \underline{f}$ & Colorless \\
\hline $\begin{array}{l}\text { aAST } 1976 . \\
\text { b-stimated value. } \\
\text { c-The data pertain to } 50 \% \\
\text { d-The data pertain to } 33 \% \\
\text { eThe data pertain to und } \\
\text { ETnternational critical }\end{array}$ & $\begin{array}{l}\text { ter. } \\
\text { ter. } \\
\text { ate. }\end{array}$ & \\
\hline
\end{tabular}


Table B-5. Heats of Vaporization and Coefficient of Theral Expansion of Heat Transfer Fluids

\begin{tabular}{ll} 
Fluid & $\frac{\text { Heat of Vaporization }}{(\mathrm{cal} / \mathrm{g})(\mathrm{Btu} / \mathrm{lb})} \frac{\text { Coefficient of Thermal Expansion }{ }^{\mathrm{a}}}{\left({ }^{\circ} \mathrm{C}^{-1}\right)}\left({ }^{\circ} \mathrm{F}^{-1}\right)$ \\
\hline
\end{tabular}

Hydrocarbons

Petroleun-based

aliphatic hydrocarbons

Caloria HT 43

Mobiltherm 603

Texatherm

$\begin{array}{rl}11 \times 10^{-4} & 6 \times 10^{-4} \\ 7 \times 10^{-4} & 4 \times 10^{-4} \\ 7 \times 10^{-4} & 4 \times 10^{-4}\end{array}$

Synthetic aliphatic

hydrocarbons
Brayco 888
a-30
$5.9 \times \frac{\mathrm{b}}{10^{-4}}$
$3.3 \times 10^{-4}$
Uniroyal PAO-13C

$7.6 \times 10^{-4} \quad 4.2 \times 10^{-4}$

Aromatic hydrocarbons

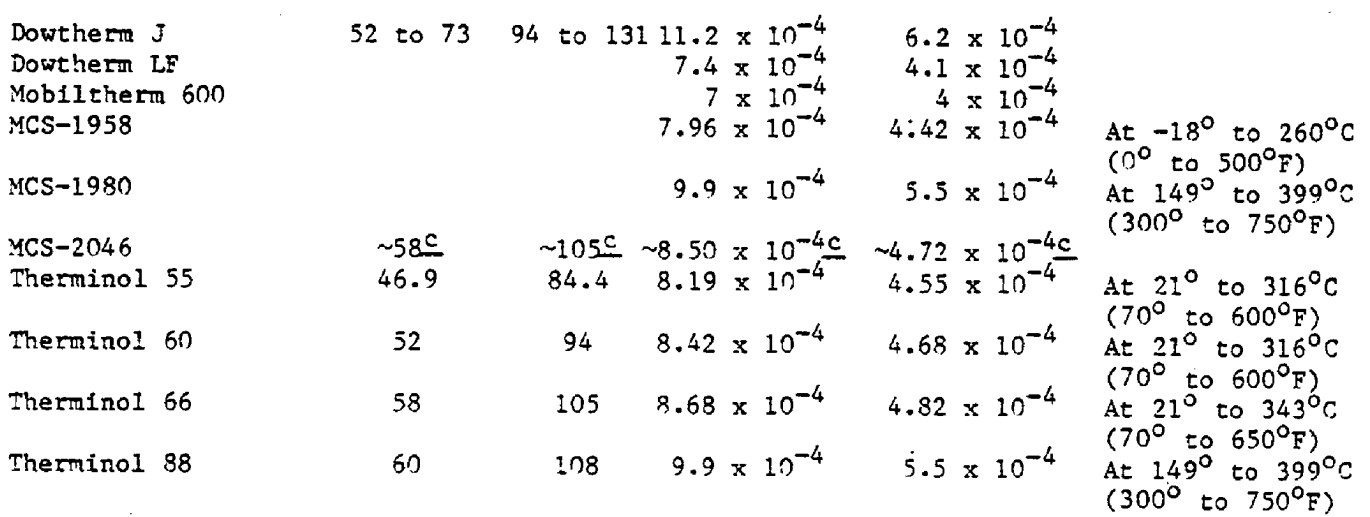

Glycols

Ethylene glycol-based fluids

Dowtherm SR-1
Prestone II
Sunsafe IOD
Sunsafe 130
ICAR TF-17
Zerex

$191 \frac{d}{2}$

$5 \times 10^{4} \underline{e}$

$5.2 \times 10^{-4 e}$

$5.0 \times 10^{-4 \frac{5}{2}}$

$5.4 \times 10^{-4 e}$

$\begin{array}{rrr}202 & 364 & 6.2 \times 10^{-4} \text { e } \\ 192 & 345 & 5 \times 10^{-4 e}\end{array}$

$3 \times 10^{-4 e}$

$3.4 \times 10^{-4 \frac{f}{s}}$

$2.8 \times 10^{-5 e}$

$3.0 \times 10^{-4 e}$

$3.4 \times 10^{-4 \mathrm{e}}$ At $20^{\circ} \mathrm{C}\left(68^{\circ} \mathrm{E}\right)$

Propylene g1ycol-based Fluids

Dowfrost

Sunsafe 200

\footnotetext{
$\begin{array}{rr}5 \times 10^{-4} \mathrm{e} & 3 \times 10^{-4 \mathrm{e}} \\ 5.4 \times 10^{-4 \mathrm{f}} & 3.0 \times 10^{-4 \mathrm{E}}\end{array}$
} 
Table B-5. Heats of Vaporization and Coefficient of Thermal Expansion of Heat Transfer Fluids (Concluded)

\begin{tabular}{|c|c|c|c|c|}
\hline \multirow{2}{*}{ Fluid } & \multicolumn{2}{|c|}{ Heat of Vaporization } & \multicolumn{2}{|c|}{ Coefficient of thermal expansion ${ }^{a}$} \\
\hline & $(\mathrm{cal} / \mathrm{g})$ & $(B t u / 1 b)$ & $\left({ }^{\circ} \mathrm{c}^{-1}\right)$ & $\left(o_{F}-1\right)$ \\
\hline $\begin{array}{l}\text { Sunsafe } 230 \\
\text { UCAR FF-35 }\end{array}$ & 164 & 296 & $\begin{array}{l}6.1 \times 10^{-4} \mathrm{e} \\
7.0 \times 10^{-4 \mathrm{e}}\end{array}$ & $\begin{array}{l}3.4 \times 10^{-4 \mathrm{e}} \\
3.9 \times 10^{-4} \underline{\mathrm{e}} \text { At } 20^{\circ} \mathrm{C}\left(68^{\circ} \mathrm{F}\right)\end{array}$ \\
\hline \multicolumn{5}{|l|}{ Esters } \\
\hline $\begin{array}{l}\text { Stauffer } 3664-A \\
\text { Therminol } 44\end{array}$ & 47 & 84 & $\begin{array}{l}13.3 \times 10^{-5} \\
10.0 \times 10^{-4}\end{array}$ & $\begin{array}{ll}7.4 \times 10^{-5} & \text { At } 38^{\circ} \mathrm{C}\left(100^{\circ} \mathrm{F}\right) \\
5.7 \times 10^{-4} & \text { At } 21^{\circ} \text { to } 218^{\circ} \mathrm{C} \\
& \left(70^{\circ} \text { to } 425^{\circ} \mathrm{F}\right)\end{array}$ \\
\hline
\end{tabular}

Ethers

\begin{tabular}{|c|c|c|c|c|c|}
\hline $\begin{array}{l}\text { Dowtherm A } \\
\text { Dowtherm G } \\
\text { Therminol VP-1 } \\
\text { UNCON HTF }-500\end{array}$ & $\begin{array}{l}50 \text { to } 71 \\
53.79\end{array}$ & $\begin{array}{r}90 \text { to } 127 \\
96.65\end{array}$ & $\begin{array}{r}9 \times 10^{-4} \\
7.0 \times 10^{-4} \\
7.6 \times 10^{-4}\end{array}$ & $\begin{array}{r}5 \times 10^{-4} \\
3.9 \times 10^{-4} \\
4.2 \times 10^{-4}\end{array}$ & $\begin{array}{l}\text { At } 20^{\circ} \text { to } 260^{\circ} \mathrm{C} \\
\left(68^{\circ} \text { to } 500^{\circ} \mathrm{F}\right)\end{array}$ \\
\hline
\end{tabular}

Silicones

$S F-96(20)$

Syltherm 444

$\mathrm{X} 2-1162$

$$
\begin{array}{ll}
10.7 \times 10^{-4} & 5.9 \times 10^{-4} \\
10.7 \times 10^{-4} & 5.9 \times 10^{-4} \\
10.8 \times 10^{-4} & 6.0 \times 10^{-4}
\end{array}
$$$$
\text { At } 25^{\circ} \text { to } 150^{\circ} \mathrm{C}
$$$$
\left(77^{\circ} \text { to } 302^{\circ} \mathrm{F}\right)
$$

Fluorocarbons

$\begin{array}{lrrrrr}\text { Freon 11 } & 47.4 & 85.4 \mathrm{~h} & 1.5 \times 10^{-1} & 8.5 \times 10^{-2} & \\ \text { Freon } 114 & 32.5 & 58.5 \frac{j}{i} & 2.2 \times 10^{-1} & 1.2 \times 10^{-1} & \\ \text { Freon IA } & 43.1 & 77.58 \frac{1}{2} & 1.4 \times 10^{-1} & 7.6 \times 10^{-2} & \\ \text { Water } & 539.7 & 971.5 \mathrm{~K} & 4.1 \times 10^{-4} & 2.3 \times 10^{-4} & \begin{array}{l}\text { At } 0^{\circ} \text { to } 100^{\circ} \mathrm{C} \\ \left(32^{\circ} \text { to } 212^{\circ} \mathrm{F}\right)\end{array}\end{array}$

a The coefficient of thermal expansion is defined by

$$
\alpha=\frac{v_{t}-v_{70}{ }^{\circ}}{v_{70} \mathrm{~F}} \times \frac{1}{\mathrm{t}_{\mathrm{o}_{\mathrm{F}}}-70},
$$

unless a different remperature interval is indicated in the table.

beported by the manufacturer to be similar to values for conventional petroleum oils.

Estimated value.

At atmospheric pressure.

eThe data pertain to $50 \%$ solution in water.

i The data pertain to $33 \%$ solution in water.

git $393^{\circ} \mathrm{C}\left(740^{\circ} \mathrm{F}\right)$.

$h_{\text {At }} 43.5^{\circ} \mathrm{C}\left(110.5^{\circ} \mathrm{F}\right)$

$i_{\text {At }} 3.8^{\circ} \mathrm{C}\left(38.8^{\circ} \mathrm{F}\right)$.

$j_{\text {At }} 23.8^{\circ} \mathrm{C}\left(74.9^{\circ} \mathrm{F}\right)$.

EAt $100^{\circ} \mathrm{C}\left(215^{\circ} \mathrm{F}\right)$. 
Table B-6. Flash Points, Fire Points, and Autolgnition Temperatures

of Heat Transfer Fluids

\begin{tabular}{|c|c|c|c|c|c|c|c|c|}
\hline \multirow{2}{*}{ Flutd } & \multicolumn{2}{|c|}{$\begin{array}{l}\text { F1ash Point, } \\
\text { Open Cup }\end{array}$} & \multicolumn{2}{|c|}{$\begin{array}{l}\text { Flash Point, } \\
\text { Closed Cup }\end{array}$} & \multicolumn{2}{|c|}{ Fire Point } & \multicolumn{2}{|c|}{$\begin{array}{l}\text { Autolgnition } \\
\text { Temperature }\end{array}$} \\
\hline & $\left({ }^{\circ} \mathrm{C}\right)$ & $\left({ }^{\circ} \mathrm{F}\right)$ & $\left({ }^{\circ} \mathrm{C}\right)$ & $\left({ }^{\circ} \mathrm{F}\right)$ & $\left({ }^{\circ} \mathrm{C}\right)$ & $\left({ }^{\circ} \mathrm{F}\right)$ & $\left({ }^{\circ} \mathrm{C}\right)$ & $\left({ }^{\circ} \mathrm{F}\right)$ \\
\hline \multicolumn{9}{|l|}{ Hydrocarbons } \\
\hline \multicolumn{9}{|l|}{$\frac{\text { Petroleum-based }}{\text { allphat1c hydrocarbons }}$} \\
\hline $\begin{array}{l}\text { Caloria HT-43 } \\
\text { Dlala AX } \\
\text { Mob1ltherm } 603 \\
\text { S1logram Heat Transfer Flu1d } 43 \\
\text { Sunoco Heat Transfer 011 } 21 \\
\text { Sunoco Heat Transfer 011 } 25 \\
\text { Texatherm } \\
\text { Thermia 011 C }\end{array}$ & $\begin{array}{l}204 \\
149 \\
216 \\
227 \\
229 \\
221 \\
235\end{array}$ & $\begin{array}{l}400 \\
300 \\
420 \\
440 \\
445 \\
430 \\
455\end{array}$ & $\begin{array}{l}168^{\mathrm{a}} \\
127 \mathrm{a} \\
>193 \\
191 \\
210^{\mathrm{a}} \\
189^{\mathrm{a}} \\
190^{\mathrm{a}}\end{array}$ & $\begin{array}{c}334^{\mathrm{a}} \\
261^{\mathrm{a}} \\
>380 \\
375 \\
410^{\mathrm{a}} \\
372^{\mathrm{a}} \\
374^{\mathrm{a}}\end{array}$ & $\begin{array}{r}221 \\
\sim 218\end{array}$ & $\begin{array}{r}430 \\
\sim 425\end{array}$ & $\begin{array}{c}354 \\
235^{\mathrm{a}} \\
>343 \\
385^{\mathrm{a}}\end{array}$ & $\begin{array}{r}670 \\
455^{a} \\
>650 \\
725^{a}\end{array}$ \\
\hline \multicolumn{9}{|l|}{$\frac{\text { Synthetic aliphatic }}{\text { hydrocarbons }}$} \\
\hline $\begin{array}{l}\text { Brayco } 888 \\
\text { Brayco } 888 \mathrm{HF} \\
\text { ESH-4 } \\
\text { ESH-5 } \\
\text { ESH-6 } \\
\text { H-30 } \\
\text { H-30C } \\
\text { Un1royal PAO-13C }\end{array}$ & $\begin{array}{r}160 \\
227 \\
224 \\
\\
238 \\
155 \\
182 \\
>279\end{array}$ & $\begin{array}{r}320 \\
440 \\
435 \\
\\
460 \\
310 \\
360 \\
>535\end{array}$ & $\begin{array}{l}155^{a} \\
200^{a} \\
190^{a} \\
200^{a} \\
202^{a} \\
130^{a} \\
185^{a} \\
225^{a}\end{array}$ & $\begin{array}{l}311 \frac{a}{a} \\
392 \frac{a}{a} \\
374 \frac{a}{392 \frac{a}{a}} \\
396 \frac{a}{266^{a}} \\
365^{a} \\
437 a\end{array}$ & $\begin{array}{r}177 \\
246 \\
246 \\
\\
266 \\
171 \\
>307\end{array}$ & $\begin{array}{r}350 \\
475 \\
475 \\
\\
510 \\
340 \\
>585\end{array}$ & $\begin{array}{l}215^{a} \\
386\end{array}$ & $\begin{array}{l}425 \\
770^{a}\end{array}$ \\
\hline \multicolumn{9}{|l|}{ Aromatic hydrocarbons } \\
\hline $\begin{array}{l}\text { Dowtherm } \frac{\mathrm{J}}{\mathrm{b}} \\
\text { Dowtherm LFc } \\
\text { DXE } \\
\text { Mob11therm } 600 \\
\text { MCS-1958 } \\
\text { MCS-1980 } \\
\text { MCS-2046 } \\
\text { Thermino1 } 55 \\
\text { Thermino1 } 60 \\
\text { Therminol } 66 \\
\text { Therminol } 88\end{array}$ & $\begin{array}{r}63 \\
127 \\
163 \\
\\
182 \\
204 \\
188 \\
179 \\
154 \\
179 \\
191\end{array}$ & $\begin{array}{l}145 \\
260 \\
325 \\
\\
360 \\
400 \\
370 \\
355 \\
310 \\
355 \\
375\end{array}$ & $\begin{array}{l}57 \frac{a}{a} \\
115 \frac{a}{a} \\
150 a \\
2177 \\
172^{a} \\
188^{a} \\
177 \frac{a}{a} \\
185^{a} \\
140^{a} \\
190^{a} \\
197 a\end{array}$ & $\begin{array}{r}135^{a} \\
239^{a} \\
302^{a} \\
7350 \\
342^{a} \\
370^{a} \\
351^{a} \\
365^{a} \\
284^{a} \\
374^{a} \\
387^{a}\end{array}$ & $\begin{array}{r}68 \\
138 \\
193 \\
\sim 199 \\
\sim 181 \\
232 \\
210 \\
210 \\
160 \\
194 \\
238\end{array}$ & $\begin{array}{r}155 \\
.280 \\
380 \\
\sim 390 \\
\\
450 \\
410 \\
410 \\
320 \\
382 \\
460\end{array}$ & $\begin{array}{r}430 \\
549 \\
545 \\
>343 \\
582 \\
538 \\
377 \\
357 \\
446 \\
374 \\
>538\end{array}$ & $\begin{array}{r}806 \\
1,020 \\
1,013 \\
>650 \\
1,080 \\
1,000 \\
710 \\
675 \\
835 \\
705 \\
>1,000\end{array}$ \\
\hline \multicolumn{9}{|l|}{$\frac{\text { Glycols }}{\frac{\text { Ethylene glycol-based }}{\text { flu1ds }}}$} \\
\hline $\begin{array}{l}\text { Dowtherm SR-1 } \\
\text { Prestone II } \\
\text { Sunsafe } 100 \\
\text { Sunsafe } 130 \\
\text { UCAR TF-17 } \\
\text { Zerex }\end{array}$ & $\begin{array}{l}(121) \frac{\mathrm{e}}{\mathrm{e}}, \mathrm{g} \\
(121) \frac{\mathrm{f}}{\frac{\mathrm{f}}{\mathrm{f}}} \\
(127))^{-127)}\end{array}$ & $\begin{array}{l}(250) \frac{a}{e}, g \\
(250)-\frac{g}{2} \\
(260) \frac{e}{a}, j \\
(260), \underline{y}\end{array}$ & $\begin{array}{l}(118) \frac{a}{e}, \frac{e}{g}, \underline{f} \\
(107), \underline{e}\end{array}$ & 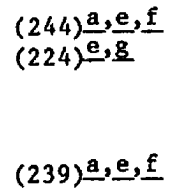 & $\begin{array}{c}(\sim 160) \frac{a}{e}, \frac{e}{g}, \frac{f}{\frac{f}{f}} \\
(124), \frac{f}{f} \\
(\sim 140) a, e, f\end{array}$ & $\begin{array}{l}(\sim 320) \frac{a}{e}, \frac{e}{g}, \underline{f} \\
(255)\end{array}$ & $\begin{array}{l}496 \frac{a}{h}(434) \frac{a}{h}, e \\
688 \text { (632) }\end{array}$ & $\begin{array}{r}925^{\mathrm{a}}(813) \underline{\mathrm{a}}, \frac{\mathrm{e}}{\mathrm{h}} \\
1,270=(1,170)^{\mathrm{h}}\end{array}$ \\
\hline
\end{tabular}

Hydrocarbons

troleum-based

nthetic aliphatic

Brayco 888

ESH-4

$\omega$

$\mathrm{H}-30 \mathrm{C}$

omatic hydrocarbons

Dowtherm Jb

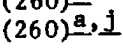

$(775) a$

$\underline{a} \underline{I}_{\text {See }}$ footnotes at end of table. 
Table B-6. Flash Points, Fire Points, and Autoignition Temperatures of Heat Transfer Fluids (Continued)

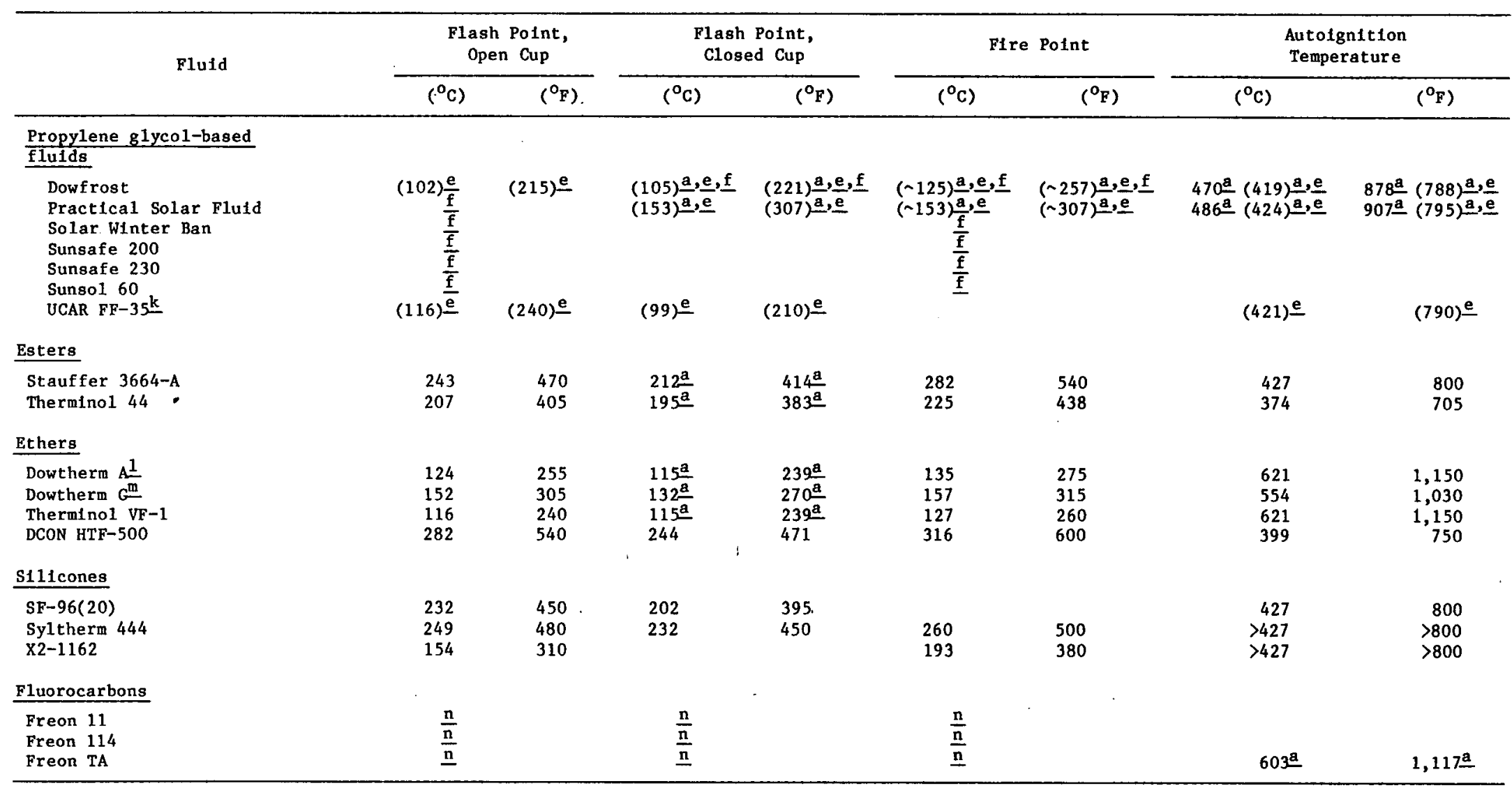


Table B-6. Flash Points, Fire Points, and Autoignition Temperatures of Heat Transfer Fluids (Concluded)

a Value determined in present work.

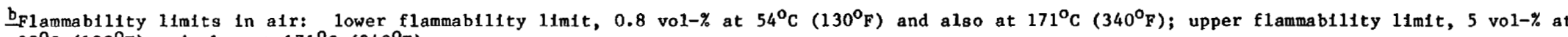
$88^{\circ} \mathrm{C}\left(190^{\circ} \mathrm{F}\right)$ and also at $171^{\circ} \mathrm{C}\left(340^{\circ} \mathrm{F}\right)$.

cFlammabllity limits in alr: lower flammability 1 imits, 0.8 vo1-\% at $149^{\circ} \mathrm{C}\left(300^{\circ} \mathrm{F}\right)$ and 0.5 vol-\% at $260^{\circ} \mathrm{C}\left(500^{\circ} \mathrm{F}\right)$; upper f1ammability $11 \mathrm{mits}$, 3.3 vol-\% at $149^{\circ} \mathrm{C}\left(300^{\circ} \mathrm{F}\right)$ and 6.2 vol $\%$ at $260^{\circ} \mathrm{C}\left(500^{\circ} \mathrm{F}\right)$.

${ }_{\text {d }}$ mat mifold 1gnition temperature $\sim 816^{\circ} \mathrm{C}\left(-1,500^{\circ} \mathrm{F}\right)$.

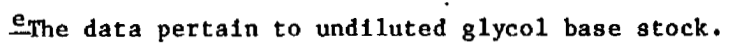

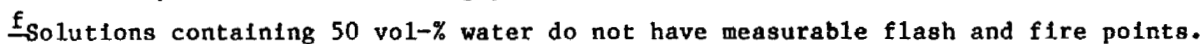

g Solutions containting up to 85 vo1-\% Prestone II in water do not have detectable flash and fire points.

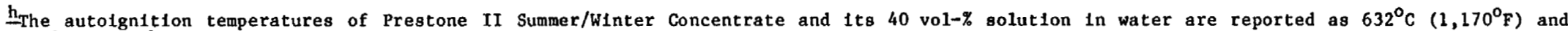
$688^{\circ} \mathrm{C}\left(1,270^{\circ} \mathrm{F}\right)$, respect 1 vely.

1.plammability limits in alr: lower flammability limlt, 3.2 vol-\%; upper flammability 1imit, 15.3 vo1-\%.

Izerex solutions in water, at concentrations lower than 80 vol-\%, do not have detectable flash and fire points.

kFlammablity limits in alr: lower flammab111ty limit, 2.6 vol-\%; upper flammability 11mit, 12.5 vo1-\%.

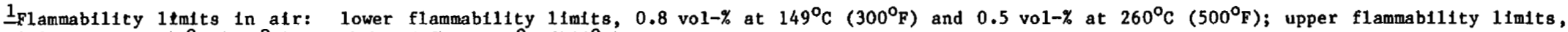
3.3 vol-\% at $149^{\circ} \mathrm{C}\left(300^{\circ} \mathrm{F}\right)$ and 6.2 vo1-\% at $260^{\circ} \mathrm{C}\left(500^{\circ} \mathrm{F}\right)$.

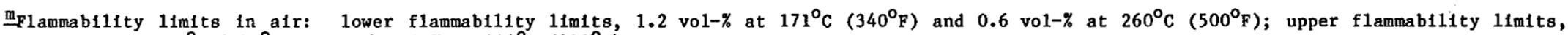
1.2 vo $1-\%$ at $171^{\circ} \mathrm{C}\left(340^{\circ} \mathrm{F}\right)$ and 3.3 vo1-\% at $204^{\circ} \mathrm{C}\left(400^{\circ} \mathrm{F}\right)$.

nFreon 11, Freon 114, and Freon TA are reported by the manufacturer not to exh1bit flash and fire points. 
Table B-7. Recommended Fire-Extinguishing Agents for Heat Transfer Fluids

\begin{tabular}{|c|c|}
\hline FIuid & Recommended Fire Extinguishing Agents \\
\hline \multicolumn{2}{|l|}{ Hydrocarbons } \\
\hline \multicolumn{2}{|l|}{$\frac{\text { Petroleum-based }}{\text { aliphatic hydrocarbons }}$} \\
\hline $\begin{array}{l}\text { Caloria HT }-43 \\
\text { Mobiltherm } 603 \\
\text { Silogram Heat Transfer Fluid } 43 \\
\text { Synthetic aliphatic } \\
\text { hydrocarbons }\end{array}$ & $\begin{array}{l}\mathrm{CO}_{2} \text {, dry chemical, foam, water spray or fog } \\
\mathrm{CO}_{2} \text {, dry chemical, foam } \\
\text { Same fire extinguishing agents that are applied to ofl fires }\end{array}$ \\
\hline $\begin{array}{l}\text { Brayco } 888 \\
\text { Brayco } 888 \mathrm{HF} \\
\text { i-30 } \\
\text { Uniroyal PAO-13C } \\
\text { Aromatic hydrocarbons } \\
\end{array}$ & $\begin{array}{l}\mathrm{CO}_{2} \text {, dry chemical } \\
\mathrm{CO}_{2} \text {, dry chemical } \\
\mathrm{CO}_{2} \text {, foam } \\
\mathrm{CO}_{2} \text {, dry chemical, foam, water }\end{array}$ \\
\hline $\begin{array}{l}\text { Dowtherm J } \\
\text { Dowtherm LF } \\
\text { DKE } \\
\text { Mobiltherm } 600 \\
\text { MCS-1958 } \\
\text { MCS-1980 } \\
\text { MCS-2046 } \\
\text { Thermino1 } 55 \\
\text { Therminol } 60 \\
\text { TherminoI } 66 \\
\text { Therminol } 88\end{array}$ & $\begin{array}{l}\text { Dry chemical, steam, water spray, or mist } \\
\text { Dry chemical, steam, water spray, or mist } \\
\mathrm{CO}_{2} \text {, dry chemical, foam, water spray; water spray may be } \\
\text { used to flush spills away from exposure } \\
\mathrm{CO}_{2} \text {, dry chemical, foam; firefighters must use self- } \\
\text { contalned breathing apparatus } \\
\mathrm{CO}_{2} \text {, dry chemical, foam, water spray, or mist } \\
\mathrm{CO}_{2} \text {, dry chemical } \\
\mathrm{CO}_{2} \text {, dry chemical, foam, water spray, or mist } \\
\mathrm{CO}_{2} \text {, dry chemical, foam, water spray, or mist } \\
\mathrm{CO}_{2} \text {, dry chemical, foam, water spray, or mist } \\
\mathrm{CO}_{2} \text {, dry chemical, foam, water spray, or mist } \\
\mathrm{CO}_{2} \text {, dry chemical }\end{array}$ \\
\hline \multicolumn{2}{|l|}{ Giycols } \\
\hline \multicolumn{2}{|l|}{$\begin{array}{l}\text { Ethylene glycol-based } \\
\text { fluids }\end{array}$} \\
\hline $\begin{array}{l}\text { Dowtherm SR-1 } \\
\text { Prestone II } \\
\text { UCAR TF-17 } \\
\text { Zerex }\end{array}$ & $\begin{array}{l}\mathrm{CO}_{2} \text {, dry chemical, foam, water mist for neat fluid; none } \\
\text { needed for diluted fluid } \\
\mathrm{CO}_{2} \text { or dry chemical for small fires; foam for large fires } \\
\mathrm{CO}_{2} \text { or dry chemical for small fires; foam and water for } \\
\text { large fires } \\
\mathrm{CO}_{2} \text {, dry chemical, water }\end{array}$ \\
\hline \multicolumn{2}{|l|}{$\begin{array}{l}\text { Propylene glycol-based } \\
\text { fluids }\end{array}$} \\
\hline $\begin{array}{l}\text { Dowfrost } \\
\text { UCAR FF-35 }\end{array}$ & $\begin{array}{l}\mathrm{CO}_{2} \text {, dry chemical, foam, water mist for neat fluid; none } \\
\text { needed for diluted aaterial } \\
\mathrm{CO}_{2} \text {, dry chemical for small fires; roam and water for large } \\
\text { tires }\end{array}$ \\
\hline \multicolumn{2}{|l|}{ Esters } \\
\hline Therminol 44 & $\mathrm{CO}_{2}$, dry chemical, foam \\
\hline \multicolumn{2}{|l|}{ Ethers } \\
\hline $\begin{array}{l}\text { Dowtherm } A \\
\text { Dowtherm } G\end{array}$ & $\begin{array}{l}\text { Dry chemical, steam, water spray, or mist } \\
\text { Dry chemical, steam, water spray, or mist }\end{array}$ \\
\hline \multicolumn{2}{|l|}{ Silicones } \\
\hline $\begin{array}{l}S F-96(20) \\
\text { Syltherm } 444 \\
X 2-1162\end{array}$ & $\begin{array}{l}\text { Any common firefighting agent } \\
\mathrm{CO}_{2} \text {, dry chemical } \\
\mathrm{CO}_{2} \text {, dry chemicai }\end{array}$ \\
\hline
\end{tabular}


Table B-8. Physiological Properties of Heat Transfer Fluids

\section{Fluld}

\section{Hydrocarbons}

Petroleum-based

aliphatic hydrocarbons

Caloria HT-43

Diala AX

Mobiltherm 603

Silogram Heat Transfer FIuId 43 Mut

Sunoco Heat Transfer HI 21

Sunoco Heat Transfer oil 25

Texatherm

Thermia oil $\mathrm{C}$

Synthetic aliphatic

\section{hydrocarbons}

Brayco 888

Brayco $888 \mathrm{HF}$

ESH-4

ESH-5

5SH-6

$\mathrm{H}-30$

ה-30C

Uniroyal PAO-13C

\section{Aromatic hydrocarbons}

Dowtherm $\mathrm{J}$
Acute oral $\mathrm{LD}_{50}>10 \mathrm{~g} / \mathrm{kg}$ body weight for rats. Skin contact: prolonged contact may cause mild irritation. Mutagenicity: Ares test negative

Not reported

Safe and nontoxic by Federal Hazardous Substances Act tests Mutagenicity: Ames test negative

Acute oral $L D_{50}>30 \mathrm{~g} / \mathrm{kg}$ body weight for rats. Inhalation: no effect expected at $25 \mathrm{mg} / \mathrm{m}^{3}$ of air. TLV $5 \mathrm{mg} / \mathrm{m}^{3}$ as oil mist. Skin contact: dermal $L_{50} \mathrm{~g} / \mathrm{kg}$ body weight. Mutagenicity: Ames test negative

Acute oral $L D_{50}>30 \mathrm{~g} / \mathrm{kg}$ body węight for rats. Inhalation: no effect expected at $25 \mathrm{mg} / \mathrm{m}^{3}$ of air. TLV $5 \mathrm{mg} / \mathrm{m}^{3}$ as oil mist. Skin contact: no irritation expected unless prolonged or repeated contact is allowed. Not expected to be toxic by dermal absorption

Low toxicity and nonirritating to operating personnel Not reported

Acute oral $\mathrm{LD}_{50}>40 \mathrm{~mL} / \mathrm{kg}$ body welght by ingestion or subcutaneously. Eye contact: no irritation by the Draize test. Mutagenicity: Ames test negative

$\mathrm{LD}_{50}>40 \mathrm{~mL} / \mathrm{kg}$. Eye contact: non-irrttating; Draize index 0 . Skin contact: nonirritating

Physiological effects similar to those of paraffin oils Physlological effects similar to those of paraffin oils Physiological effects similar to those of parafin oils Oral LD $50>30 \mathrm{~g} / \mathrm{kg}$ body weight. TLV $>17 \mathrm{ug} / 1$ iter. Mutagenicity: Ames test negative Not reported

$\mathrm{LD}_{50}>40 \mathrm{~mL} / \mathrm{kg}$ body weight. Skin contact: causes 10 irritation. Mutagenicity: Ames test negative

$\mathrm{LD}_{50}$ (rats) is in the range of $1-2 \mathrm{~g} / \mathrm{kg}$ body weight. Eye contact: up to nild irritation; no corneal injury likely. Skin contact: up to mild irritation upon single exposure; up to noderate irritation upon prolonged exposure, possibly mild edema and superficial burn. Not likely to be absorbed in acutely toxic amounts.

Mutagenicity: Ames test negative 
Table B-8. Physiological Properties of Heat Transfer Fluids (Continued)

\begin{tabular}{|c|c|c|}
\hline & Fluid & Physiological Effects \\
\hline Dowthern I & $L F$ & $\begin{array}{l}\mathrm{LD}_{50} \text { (rats) is in the range of } 2-4 \mathrm{~g} / \mathrm{kg} \text { body weight. } \\
\text { Inhalation: exposure should be liuited to } 1 \mathrm{ppm} \text { according } \\
\text { to OSHA guide (1975). Eye contact: may cause pain, slight } \\
\text { transient irritation; no corneal injury. Skin contact: } \\
\text { prolonged or repeated exposure may cause slight to moderate } \\
\text { irritation. Not likely to be absorbed in toxic amounts. } \\
\text { Mutagenicity: Ames test negative }\end{array}$ \\
\hline DXF & & $\begin{array}{l}\text { TLV not established; Suggested limiting exposure criterion } \\
\text { of mist is } 5 \mathrm{mg} / \mathrm{m}^{3} \text {. Skin contact: prolonged or repeated } \\
\text { contact may cause irritation. Prolonged exposure to mist } \\
\text { may cause Irritation of mucous membrane. Eye contact: may } \\
\text { cause irritation }\end{array}$ \\
\hline $\begin{array}{l}\text { Mobiitherm } \\
\text { MCS-1958 }\end{array}$ & 600 & $\begin{array}{l}\text { Not reported } \\
\text { Acute oral } \mathrm{LD}_{50} \text { (rats) is approximately } 8 \mathrm{~g} / \mathrm{kg} \text { body weight. } \\
\text { Mutagenicity: Ames test negative }\end{array}$ \\
\hline $\begin{array}{l}\text { MCS }-1980 \\
\text { Mrs- }-2046\end{array}$ & & Mutagenicity: Ames test negative \\
\hline Therminol & 55 & $\begin{array}{l}\mathrm{LD}_{50} \text { (rats) }>15.8 \mathrm{~g} / \mathrm{kg} \text { body weight. TLV is not } \\
\text { established. Inhalation: due to low volatility, no } \\
\text { observable effects on rats during and after } 6-\mathrm{hr} \\
\text { exposure. Eye contact: mild, reversible irritation to the } \\
\text { eyes of rabbits. Skin contact: nonlethal at the dose rate } \\
\text { of } 7.94 \mathrm{~g} / \mathrm{kg} \text { body weight. Mutagenicity: dmes test } \\
\text { negative }\end{array}$ \\
\hline Therminol & 50 & $\begin{array}{l}\text { Acute oral LD } 50 \text { (rats) is } 13.0 \mathrm{~g} / \mathrm{kg} \text { body weight. TLV is not } \\
\text { established. Inhalation: due to low volatility, no } \\
\text { observable effects on rats during and after } \mathrm{b}-\mathrm{hr} \\
\text { exposure. Eye contact: mild, reversible irritation to the } \\
\text { eyes of rabbits. Skin contacts nonlethal at the dose rate } \\
\text { of } 7.94 \mathrm{~g} / \mathrm{kg} \text { body weight. Mutagenicity: Ames test } \\
\text { negative }\end{array}$ \\
\hline Therminol & 66 & $\begin{array}{l}\text { Acute oral } \mathrm{LD}_{50} \text { (rats) is } 10.2 \mathrm{~g} / \mathrm{kg} \text { body weight. ILV is } \\
5 \mathrm{mg} / \mathrm{m}^{3}(0.5 \mathrm{ppm}) \text {. Inhalation: due to low volatility, no } \\
\text { observable effect on rats during and after 6-hr exposure. } \\
\text { Eye contact: mild, reversible irritation to the eyes of } \\
\text { rebbits. Skin contact: dermal LD } \text { LD }_{50} \text { (rats) is } 6.8 \mathrm{~g} / \mathrm{kg} \\
\text { body weight. Irritation upon exposure of abraded rabbit } \\
\text { skin to Theminol } 66 \text {. Mutagencity: Ames test negative }\end{array}$ \\
\hline Therminol & 88 & $\begin{array}{l}\text { Acute oral } L D_{50} \text { is } 50 \mathrm{~g} / \mathrm{kg} \text { bory weight. TLV is not } \\
\text { established. Eye contact: mild, reversible irritation to } \\
\text { the eyes of rabbits. Skin contact: no irritation upon } 24- \\
\text { hr contact with intact rabbit skin. Mutagenicity: Ames } \\
\text { test negative }\end{array}$ \\
\hline
\end{tabular}


Table B-8. Physiological Properties of Heat Transfer Fluids (Continued)

\begin{tabular}{l}
\hline Fluid \\
\hline Glycols \\
Ethylene glycol-based \\
$\frac{\text { fluids }}{}$
\end{tabular}

Dowtherm SR-1

Prestone II

Sunsafe 100

Sunsafe 130

UCAR TF-17

Zerex

Propylene gI ycol-based Eluids

Dowfrost

\author{
Ingestion: moderate to low single dose oral toxicity to \\ humans. Inhalation: $7-\mathrm{hr}$ exposure to saturated vapors \\ generated at $38^{\circ} \mathrm{C}\left(100^{\circ} \mathrm{F}\right)$ caused no adverse effects to \\ rats. Eye contact: may cause pain and mild irritation; is \\ not likely to cause corneal injury. Skin contact: \\ prolonged or repeated exposure may cause minor irritation, \\ even minor burn. Not absorbed in toxic amounts through \\ skin. Mutagenicity: Ames test negative \\ TLV $100 \mathrm{ppm}$. Confirmed cases of harmful effects relate onIy \\ to swallowing. It causes drunkenness, rapidly passing into \\ coma. Serfous or fatal kidney injury. Mutagenicity: Ames \\ test negative \\ Not reported \\ Not reported \\ Acute oral $L D_{50}$ (rats) is $8.54 \mathrm{~g} / \mathrm{kg}$ body welght. TLV is \\ $100 \mathrm{ppm}$ (vapor), $10 \mathrm{mg} / \mathrm{m}^{3}$ (particulate). Eye contact: \\ flooding the rabbit eye with UCAR TF-17 caused a reaction \\ no more severe than moderate inflammation. Skin contact: \\ undiluted UCAR TF-17 on rabbit belly caused faint redness \\ for a short duration \\ Single dose of $100 \mathrm{~mL}$ of ethylene glycol can be fatal to \\ human beings. Animal studies have indicated that smali \\ oral doses over a long perlod can produce severe kidney \\ injury, bladder stones, and liver damage. Inhalation: \\ TLV, recommended by the American Conference of Governmental \\ Industrial Hygienists is $100 \mathrm{ppm}$ of vapor or $10 \mathrm{mg} / \mathrm{m}^{3}$ \\ particulates. Inhalation may be a problem if ethylene \\ gIycol is hot, or if fog or mist is generated by heat or \\ violent agitation. Vapor inhalation overexposure may cause \\ irritation of the throat, mild headache, and low \\ backache. Mutagenicity: Ames test negative
}

Acute oral $L D_{50}$ (rats) $>30 \mathrm{~g} / \mathrm{kg}$ body weight. As much as $25 \%$ to $50 \%$ of propylene glycol ingested by humans appears unchanged in the urine in 24 hrs. Chronic oral toxicity is also very low. Rats receiving drinking water containing us to $10 \%$ propylene glycol over a period of 140 days developed no ill effects. Rats receiving $4.9 \%$ in their diet for 24 months were nornal in their growth. They sustained slight liver injury. Eye contact: propylene glycol is not expected to cause irritation. Skin contact: propylene 
Table B-8. Physiological Properties of Heat Transfer Fluids (Continued)

\begin{tabular}{|c|c|}
\hline Fluid & Physiological Effects \\
\hline $\begin{array}{l}\text { Practical Solar Fluid } \\
\text { Solar Winter Ban } \\
\text { Sunsafe } 200 \\
\text { Sunsafe } 230 \\
\text { Sunsol } 60 \\
\text { UCAR FF-35 }\end{array}$ & $\begin{array}{l}\text { glycol does not cause serious skin irritation. Very } \\
\text { severe, prolonged exposure may produce slight maceration of } \\
\text { the skin. Mutagenfcity: Ames test negative } \\
\text { Mutagenicity: Ames test negative } \\
\text { Not reported } \\
\text { Not reported } \\
\text { Not reported } \\
\text { Manufacturer's literature claims that Sunsol } 50 \text { is nontoxic } \\
\text { and does not contain hazardous ingredients } \\
\text { Acute oral LD } 50 \text { (rats) is } 26.3 \mathrm{~g} / \mathrm{kg} \text { body weight. ThV not yet } \\
\text { establisher. Inhalation: air saturated with propylene } \\
\text { glycol vapor at room temperature killed no animals exposed } \\
\text { for efght hours. Skin contact: LD } 5020 \text { mL/kg body } \\
\text { weight. Undiluted propylene glycol caused no irritation on } \\
\text { the tender skin of the rabbit belly }\end{array}$ \\
\hline
\end{tabular}

Esters

Stauffer $3664-A$

Accidental ingestion of large doses may produce symptons of nonspecific irritation of the gastointestinal tract, nausea, vomiting, cramps and diarrhea. Inhalation: high vapor concentrations may cause nonspecific irritation of mucous membranes in the upper respiratory tract. Skin contact: no irritation was observed when this material was applied onto the skin of rabbits. Mutagenicity: Ames test negative

Therminol 44

Acute oral $\mathrm{LD}_{50}$ (rats) is $13 \mathrm{~g} / \mathrm{kg}$ body weight. Inhalation: rats survived 6-hr exposure and 10-day observation period with no noticeable effects, when exposed to air aspirated through Thermino1 44. Eye contact: slight, reversible irritation to rabbit eye. Skin contact: mild irritation upon contact with rabbit skin. Mutagenicity: Ames test negative

Ethers

Dowtherm A

Acute oral $\mathrm{LD}_{50}$ (rats) $2-4 \mathrm{~g} / \mathrm{kg}$ body wefght. Inhalation: TLV 1 ppm. Eye contact: up to wild irritation but no corneal injury. Skin contact: short single exposure not likely to cause significant irritation. Prolonged or repeated exposure may cause up to mild irritation. iutagenicity: Ames test negative

Dowthern $G$

Acute oral $L_{50}$ (rats) $2-4 \mathrm{~g} / \mathrm{kg}$ body weight. Inhalation: suggested TLV I ppw. Eye contact: mild pain, wild

transient irritation and corneal haziness. Skin contact: mild skin irritation. Demal $L D_{50}>2 \mathrm{~g} / \mathrm{kg}$ body weight. Mutagenicity: Ames test negative 
Table B-8. Physiological Properties of Heat Transfer Fluids (Continued)

\section{Fluid}

Therminol VP-1

UCON $\mathrm{HTT}-500$

\section{Silicones}

$S F-96(20)$

Syltherm 444

$\times 2-1162$

Fluorocarbons

Freon 11
Physiological Effects

Acute oral $L_{50}$ (rats) $1.46 \mathrm{~g} / \mathrm{kg}$ body weight. Inhalation: TLV $1 \mathrm{ppm}$ or $7 \mathrm{mg} / \mathrm{m}^{3}$. Eye contact: slight, reversible 1rritation to rabbit eye. Skin contact: mild irritation upon contact with intact and abraded rabbit skin. Dermal $\mathrm{LD}_{50}>5.01 \mathrm{~g} / \mathrm{kg}$ body weight. Mutagenlcity: Ames test negative

Not yet established

Acute oral $L D_{50}>20 \mathrm{~g} / \mathrm{kg}$ body weight. Inhalation: LC 50 $>500 \mathrm{mg} / \mathrm{m}^{3}$ for 1 -hr inhalation. Eye contact: minor transient irritation by Draize test. Skin contact: no irritation. Mutagenicity: Ames test negative

Information about physlological effects of Syltheril 444 was not available from the manufacturer. However, Dow Corning Corporation supplied a report on the toxicology of silicones. On the basis of this report, poly(dimethylsiloxane), the base fluid of Syltherm 444, has very low toxicity in rats, when supplied orally. No deleterious effects were detected when fed at a concentration of $1 \%$ of the diet over a period of 90 days. Inhalation: vapor toxicity is low, partly because of the very low vapor pressure. Eye contact: transitory conjunctive irritation may be caused; no permanent effect. Skin contact: cause no acanthosis, are not absorbed through skin; used in protective skin creams and sprays. Mutagenicity: Anes test negative.

Information about physiological effects of X2-1162 was not available. However, Dow Corning Corporation supplied a report on the toxicology of silicones. On the basis of this report, poly(dimethylsiloxane), the base fluid of X21162 , has very low toxicity in rats, when supplied orally. No deleterious effects are detected when fed at a concentration of $1 \%$ of the diet over a oeriod of 90 days. Inhalation: vapor toxicity is low, partly because of the very low vapor pressure. Eye contact: transitory conjunctive irritation may be caused; no permanent effect. Skin contact: cause no acanthosis, are not absorbed through skin; used in protective skin creans and sprays

Inhalation: no effects at $1,000 \mathrm{ppm}$; L $_{50}$ (rats) $26,200 \mathrm{ppm}$. Cardiac sensitization in beagle dogs at 3,500 pptm. Mutagenicity: Ames test negative. Teratogenicity: no indications 
Table B-8. Physiological Properties of Heat Transfer Fluids (Concluded)

\begin{tabular}{|c|c|}
\hline Fluid & Physiological Effects \\
\hline Freon 114 & $\begin{array}{l}\text { Inhalation: no effects at } 1,000 \mathrm{ppm} \text {; LC } 50>600,000 \mathrm{ppm} \text {. } \\
\text { Cardiac sensitization in beagle dogs at } 25,000 \mathrm{ppm} . \\
\text { Mutagenicity: no indications. Teratogenicity: no } \\
\text { indications }\end{array}$ \\
\hline Ereon TA & $\begin{array}{l}\text { No data available for Freon TA. It is composed of } 89 \% \\
\text { trichlorofluoroethane and } 10 \% \text { acetone. The following data } \\
\text { pertain to trichlorofluoroethane. Inhalation: IC } 50 \text { (rats) } \\
90,000-100,000 \mathrm{ppm} \text {; TV 1,000 ppm. Cardiac sensitization } \\
\text { in beagle dogs at } 5,000 \mathrm{ppm} \text {. Mutagenicity: dmes test } \\
\text { negative. Ieratogenicity: no indications }\end{array}$ \\
\hline
\end{tabular}


Table B-9. Summary of Density Data $\left(\mathrm{kg} / \mathrm{m}^{3}\right)$

\begin{tabular}{|c|c|c|c|c|c|c|c|c|c|c|}
\hline \multirow{2}{*}{ Fluid } & \multicolumn{10}{|c|}{ Temperature $\left({ }^{\circ} \mathrm{C}\right)$} \\
\hline & -50 & -25 & 0 & 25 & 50 & 75 & 100 & 125 & 150 & 175 \\
\hline $\begin{array}{l}\text { Brayco } 888 \\
\text { Brayco } 888 \mathrm{HF}\end{array}$ & & & & $\begin{array}{l}818.5 \\
818.5\end{array}$ & & & & & & \\
\hline $\begin{array}{l}\text { Caloria HT-43 } \\
\text { Diala AX }\end{array}$ & & & & & $\begin{array}{l}834.1 \\
864.4\end{array}$ & $\begin{array}{l}816.3 \\
849.9\end{array}$ & $\begin{array}{l}797.9 \\
835.9\end{array}$ & $\begin{array}{l}780.6 \\
822.9\end{array}$ & $\begin{array}{l}763.3 \\
810.0\end{array}$ & 746.0 \\
\hline Dowfrost & & 1062.6 & 1049.6 & 1034.0 & 1016.7 & 999.4 & & & & \\
\hline $\begin{array}{l}\text { Dowtherm A } \\
\text { Dowtherm G }\end{array}$ & & & & & $\begin{array}{l}1036.1 \\
1084.4\end{array}$ & $\begin{array}{l}1016.0 \\
1061.9\end{array}$ & $\begin{array}{r}995.4 \\
1041.0\end{array}$ & $\begin{array}{r}973.8 \\
1022.5\end{array}$ & $\begin{array}{r}952.1 \\
1005.1\end{array}$ & $\begin{array}{l}930.5 \\
984.9\end{array}$ \\
\hline $\begin{array}{l}\text { Dowtherm J } \\
\text { Dowtherm LF }\end{array}$ & 919.8 & 899.7 & $\begin{array}{r}879.5 \\
1053.0\end{array}$ & $\begin{array}{r}860.2 \\
1031.4\end{array}$ & $\begin{array}{r}840.7 \\
1011.2\end{array}$ & $\begin{array}{l}821.1 \\
992.5\end{array}$ & $\begin{array}{l}801.6 \\
974.1\end{array}$ & $\begin{array}{l}779.9 \\
956.6\end{array}$ & $\begin{array}{l}758.2 \\
937.8\end{array}$ & $\begin{array}{l}735.2 \\
917.6\end{array}$ \\
\hline $\begin{array}{l}\text { Dowtherm SR-1 } \\
\text { DXE }\end{array}$ & & 1094.6 & 1081.6 & 1067.8 & $\begin{array}{r}1052.7 \\
955.0\end{array}$ & $\begin{array}{r}1036.3 \\
939.1\end{array}$ & $\begin{array}{r}1019.0 \\
923.2\end{array}$ & & & \\
\hline $\begin{array}{l}\text { ESH } 4 \\
\text { ESH } 5\end{array}$ & & & & $\begin{array}{l}818.5 \\
823.3\end{array}$ & & & & & & \\
\hline ESH 6 & & & & 828.2 & & & & & & \\
\hline $\begin{array}{ll}\text { Freon } & 11 \\
\text { Freon } & 114\end{array}$ & & $\begin{array}{l}1591.3 \\
1579.4\end{array}$ & 1533.6 & 1474.2 & & & & & & \\
\hline $\begin{array}{l}\text { Freon TA } \\
\text { H } 30\end{array}$ & & $\begin{array}{r}1503.5 \\
835.5\end{array}$ & $\begin{array}{r}1455.9 \\
833.7\end{array}$ & $\begin{array}{r}1404.9 \\
831.2\end{array}$ & 1348.7 & 1289.6 & & & & \\
\hline Mobil Therm 600 & & & & & & & 885.2 & 871.0 & 857.9 & 843.5 \\
\hline Mobil Therm 603 & & & & & & & 814.3 & 798.7 & 784.2 & 768.3 \\
\hline PAO $13 \mathrm{C}$ & & & & & 822.7 & 808.3 & 793.1 & 776.0 & 760.1 & 742.8 \\
\hline Practical Fluid & & & & & & & & & & \\
\hline Prestone II & & & & & 1055.0 & 1040.0 & 1024.2 & & & \\
\hline $\begin{array}{l}\text { SI-96 } \\
\text { Silogram } 43\end{array}$ & & 1078.6 & 1026.7 & 977.4 & 929.1 & 887.7 & 857.4 & 823.2 & 791.6 & 762.8 \\
\hline $\begin{array}{l}\text { Solar Winter Ban } \\
\text { Stauffer } 3664-A\end{array}$ & & & & 978.7 & & & & & & \\
\hline $\begin{array}{ll}\text { Sunoco } 21 \\
\text { Sunoco } 25\end{array}$ & & & & & & $\begin{array}{l}833.9 \\
833.9\end{array}$ & $\begin{array}{l}819.5 \\
819.5\end{array}$ & $\begin{array}{l}804.9 \\
804.9\end{array}$ & $\begin{array}{l}789.0 \\
789.0\end{array}$ & $\begin{array}{l}773.1 \\
773.1\end{array}$ \\
\hline Sunsafe 100 & & & & 1049.2 & & & & & & \\
\hline Sunsafe 130 & & & & 1070.0 & & & & & & \\
\hline Sunsafe 200 & & & & 1030.0 & & & & & & \\
\hline Sunsafe 230 & & & & 1039.6 & & & & & & \\
\hline Sunsol 60 & & & & & & & & & & \\
\hline Syltherm 444 & & & & & 925.6 & 904.9 & 883.6 & 863.2 & 841.6 & \\
\hline $\begin{array}{l}\text { Texatherm } \\
\text { Thermia C }\end{array}$ & & 900.0 & 884.2 & 868.3 & $\begin{array}{l}853.1 \\
857.2\end{array}$ & $\begin{array}{l}838.2 \\
841.4\end{array}$ & $\begin{array}{l}820.8 \\
824.8\end{array}$ & $\begin{array}{l}799.4 \\
806.2\end{array}$ & $\begin{array}{l}779.5 \\
789.1\end{array}$ & $\begin{array}{l}765.0 \\
776.2\end{array}$ \\
\hline Therminol 44 & 977.3 & 958.5 & 939.8 & 922.8 & 904.1 & 882.5 & 861.2 & 841.5 & 824.0 & 802.4 \\
\hline Therminol 55 & & 911.6 & 894.3 & 877.9 & 861.3 & 844.6 & 828.3 & 811.3 & 795.3 & 778.0 \\
\hline Therminol 60 & 1041.1 & 1023.8 & 1007.5 & 990.8 & 974.2 & 958.3 & 942.5 & 926.6 & 910.6 & 891.9 \\
\hline $\begin{array}{l}\text { Therminol } 66 \\
\text { Therminol } 88\end{array}$ & & 1038.2 & 1020.9 & 1003.6 & 987.0 & 970.6 & 953.3 & 936.0 & $\begin{array}{r}918.7 \\
1008.3\end{array}$ & $\begin{array}{l}901.4 \\
989.6\end{array}$ \\
\hline Therminol VP-1 & & & & & 1038.4 & 1019.2 & 999.0 & 978.6 & 956.9 & 935.3 \\
\hline UCAR FF-35 & & 1076.2 & 1060.4 & 1044.5 & 1027.9 & 1009.5 & 989.0 & 967.4 & 945.7 & \\
\hline UCAR TF-17 & & 1089.3 & 1083.6 & 1076.1 & 1061.1 & 1037.3 & 1010.6 & 986.6 & 965.0 & \\
\hline UCON HTF-500 & & & & & 1013.7 & 994.1 & 975.7 & 958.6 & 942.7 & 925.4 \\
\hline $\begin{array}{l}\text { Water } \\
\text { X2-1162 } \\
\text { Zerex }\end{array}$ & & & 1001.9 & 996.1 & $\begin{array}{l}987.5 \\
921.5\end{array}$ & $\begin{array}{l}974.3 \\
902.8\end{array}$ & $\begin{array}{l}957.7 \\
884.0\end{array}$ & $\begin{array}{l}938.5 \\
865.1\end{array}$ & $\begin{array}{l}916.8 \\
844.8\end{array}$ & $\begin{array}{l}892.3 \\
823.2\end{array}$ \\
\hline
\end{tabular}


Table B-9. Summary of Density Data $\left(\mathrm{kg} / \mathrm{m}^{3}\right)$ (Concluded)

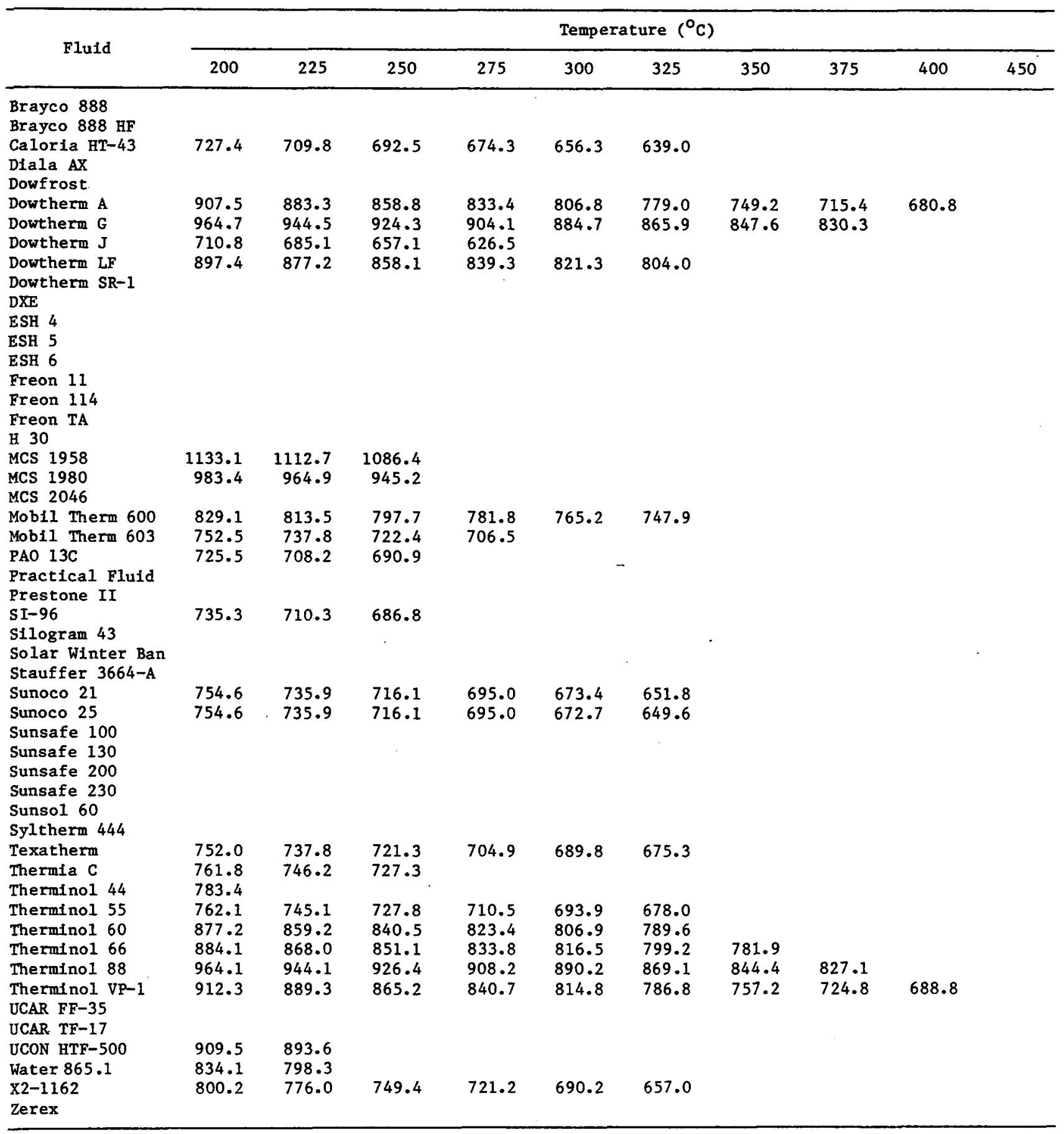


Table B-10. Summary of Viscosity Data (cp)

\begin{tabular}{|c|c|c|c|c|c|c|c|c|c|c|}
\hline \multirow{2}{*}{ Fluid } & \multicolumn{10}{|c|}{ Temperature $\left({ }^{\circ} \mathrm{C}\right)$} \\
\hline & $0-50$ & $0-25$ & 0 & 25 & 50 & 75 & 100 & 125 & 150 & 175 \\
\hline \multicolumn{11}{|l|}{ Brayco 888} \\
\hline $\begin{array}{l}\text { Brayco } 888 \mathrm{HF} \\
\text { Caloria HT- } 43\end{array}$ & 8817.19 & 2364.19 & 233.06 & 50.28 & $\begin{array}{l}16.65 \\
25.22\end{array}$ & $\begin{array}{r}7.76 \\
13.84\end{array}$ & $\begin{array}{l}4.55 \\
5.86\end{array}$ & $\begin{array}{l}3.07 \\
3.60\end{array}$ & 2.80 & 2.07 \\
\hline Diala AX & & & 53.31 & 26.04 & 8.98 & 4.26 & & & & 2.01 \\
\hline Dowfrost & & 80.66 & 29.90 & 5.98 & 2.28 & 1.29 & & & & \\
\hline Dowtherm A & & & & & 2.08 & 1.39 & 0.99 & 0.77 & 0.62 & 0.51 \\
\hline Dowtherm G & & & 112.39 & 46.42 & 9.17 & 3.99 & 2.46 & 1.67 & 1.18 & 0.88 \\
\hline Dowtherm $\mathrm{J}$ & 3.62 & 2.36 & 1.42 & 0.88 & 0.63 & 0.52 & 0.44 & 0.36 & 0.29 & 0.24 \\
\hline $\begin{array}{l}\text { Dowtherm LF } \\
\text { Dowtherm SR-1 }\end{array}$ & & $\begin{array}{l}30.02 \\
23.74\end{array}$ & $\begin{array}{l}12.64 \\
10.78\end{array}$ & $\begin{array}{l}4.18 \\
3.87\end{array}$ & $\begin{array}{l}2.38 \\
1.92\end{array}$ & $\begin{array}{l}1.52 \\
1.15\end{array}$ & 1.05 & 0.79 & 0.63 & 0.52 \\
\hline DXE & & & & & 12.01 & 8.59 & 6.13 & 4.37 & 3.10 & 2.22 \\
\hline ESH 4 & & 367.32 & 151.59 & 40.57 & 14.64 & 7.14 & & & & \\
\hline ESH 5 & & 616.89 & 246.90 & 60.18 & 20.12 & 9.25 & & & & \\
\hline ESH 6 & & 1009.40 & 388.40 & 83.30 & 25.58 & 11.30 & & & & \\
\hline Freon 11 & & & & 0.28 & & & & & & \\
\hline Freon 114 & . & & & 0.25 & & & & & & \\
\hline Freon TA & & & & 0.39 & & & & & & \\
\hline H 30 & & & 153.20 & 67.70 & & & & & & \\
\hline MCS 1958 & & 434.50 & 142.00 & 15.28 & 5.33 & 2.74 & 1.70 & 1.21 & 0.92 & 0.73 \\
\hline MCS 1980 & & & & & & & & 5.23 & 3.71 & 2.68 \\
\hline MCS 2046 & & & & & & - & & & & \\
\hline Mobil Therm 600 & & & & & & & & 3.78 & 2.64 & 1.92 \\
\hline Mobil Therm 603 & & & & & & & & 3.04 & 2.22 & 1.68 \\
\hline PAO I3C & & & & & 94.05 & 34.43 & 15.43 & 8.71 & 5.62 & 3.88 \\
\hline Practical Fluid & & & & & & & & & & \\
\hline Prestone II & & 23.73 & 10.47 & 3.52 & 1.76 & 1.11 & 0.69 & 0.50 & 0.40 & 0.31 \\
\hline $\begin{array}{l}\text { SI-96 } \\
\text { Silogram } 43\end{array}$ & 187.76 & 87.86 & 39.16 & 22.06 & 13.92 & 8.98 & 6.69 & 5.49 & 4.17 & 3.45 \\
\hline $\begin{array}{l}\text { Silogram } 43 \\
\text { Solar Winter Ban }\end{array}$ & & 40.00 & & & 23.28 & 11.15 & & & & \\
\hline Stauffer $3664-A$ & & & & & 19.28 & 10.83 & & & & \\
\hline Sunoco 21 & & 3150.08 & 1072.88 & 134.54 & 30.94 & 13.10 & & & & \\
\hline Sunoco 25 & & & & & 40.61 & 18.03 & & & & \\
\hline Sunsafe 100 & & & & & 1.24 & 0.79 & & & & \\
\hline Sunsafe 130 & & & & & 1.79 & 1.09 & & & & \\
\hline Sunsafe 200 & & & & & 1.54 & 0.93 & & & & \\
\hline Sunsafe 230 & & & & & 2.60 & 1.44 & & & & \\
\hline Sunsol 60 & & & 23.72 & 10.92 & & & & & & \\
\hline Syltherm 444 & . & 61.02 & 36.72 & 21.60 & 13.92 & 9.05 & 6.79 & 5.32 & 4.17 & 3.54 \\
\hline Texatherm & & & & & 31.00 & 13.77 & 6.72 & 4.03 & 2.77 & 2.03 \\
\hline Thermia C & & & 372.09 & 164.37 & 41.26 & 16.24 & 8.58 & 5.38 & & \\
\hline Therminol 44 & 2300.00 & 612.50 & 60.68 & 16.02 & 6.86 & 3.82 & 2.49 & 1.75 & 1.29 & 1.07 \\
\hline Therminol 55 & & 1732.28 & 582.08 & 70.65 & 19.40 & 8.16 & 4.37 & 2.72 & 1.87 & 1.39 \\
\hline Therminol 60 & 1265.60 & 334.10 & 31.85 & 8.72 & 3.93 & 2.38 & 1.63 & 1.21 & 0.96 & 0.76 \\
\hline Thermino1 66 & & 62932.35 & 18166.39 & 135.80 & 20.76 & 7.40 & 3.87 & 2.39 & 1.68 & 1.28 \\
\hline Therminol 88 & & & & & & & & & 1.55 & 1.18 \\
\hline Thermino1 VP-1 & & & & & 2.41 & 1.50 & 1.02 & 0.74 & 0.59 & 0.49 \\
\hline UCAR FF-35 & & 64.52 & 24.65 & 5.57 & 2.24 & 1.18 & 0.68 & 0.46 & & \\
\hline UCAR TF-17 & & 21.35 & 9.74 & 3.53 & 1.76 & 1.04 & 0.68 & 0.51 & & \\
\hline UCON HTF-500 & & & & & 46.13 & 22.47 & 11.98 & 7.44 & 5.30 & 4.18 \\
\hline Water & & & 1.53 & 0.96 & 0.56 & 0.39 & 0.29 & 0.23 & 0.20 & 0.17 \\
\hline $\mathrm{X} 2-1162$ & & & & & 8.99 & 6.17 & 4.35 & 3.14 & 2.32 & 1.76 \\
\hline Zerex & & & & & & & & & & \\
\hline
\end{tabular}


Table B-10. Summary of Viscosity Data ( $c p$ ) (Concluded)

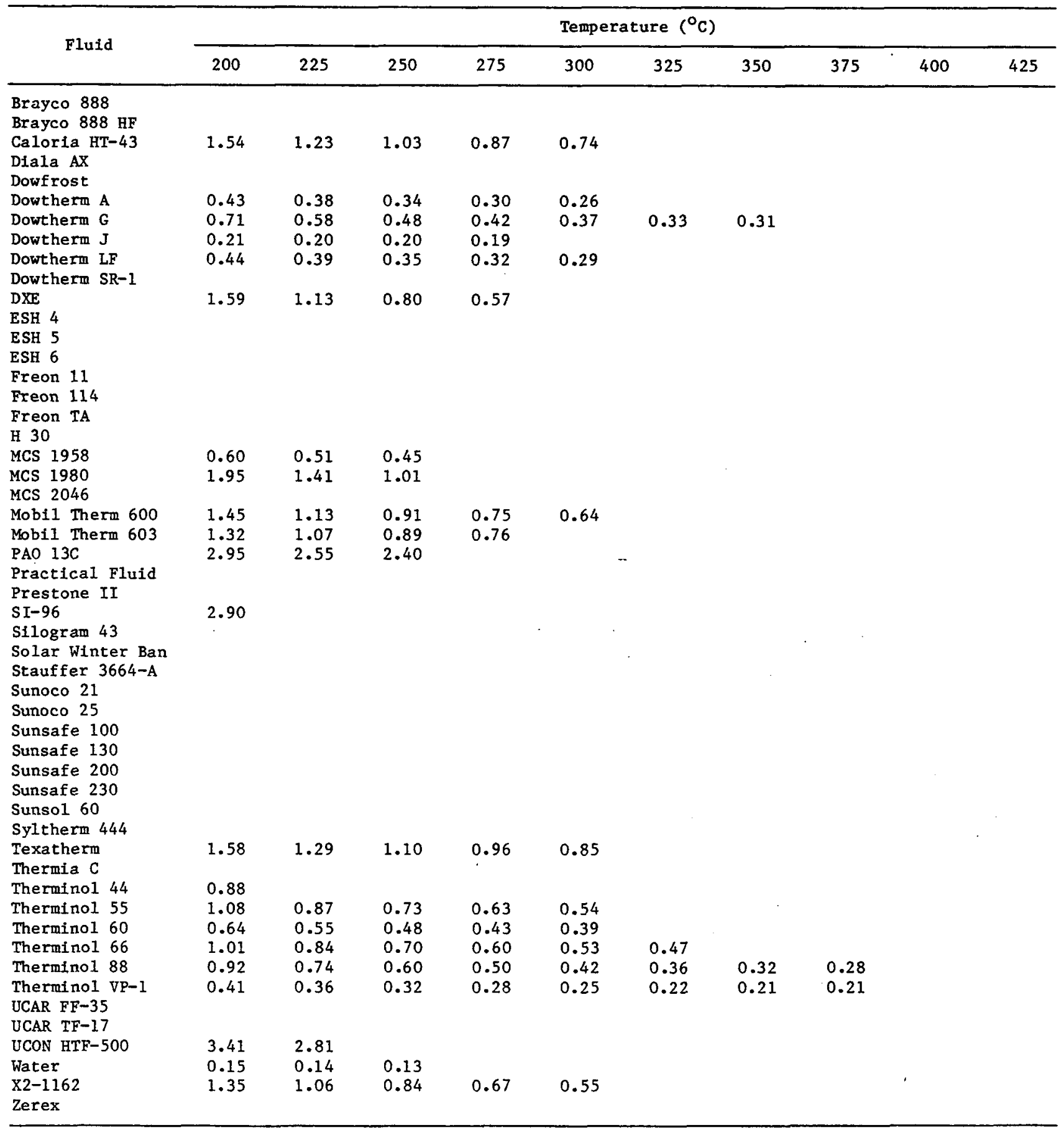


Table B-11. Summary of Specific Heat Data $[\mathrm{J} /(\mathrm{kg} \cdot \mathrm{K})]$

\begin{tabular}{|c|c|c|c|c|c|c|c|c|c|c|}
\hline \multirow{2}{*}{ Fluid } & \multicolumn{10}{|c|}{ Temperature $\left({ }^{\circ} \mathrm{C}\right)$} \\
\hline & -50 & -25 & 0 & 25 & 50 & 75 & 100 & 125 & 150 & 175 \\
\hline \multicolumn{11}{|l|}{ Brayco 888} \\
\hline Brayco $888 \mathrm{HF}$ & & 2071.6 & 2147.0 & 2244.9 & 2358.0 & 2456.8 & 2532.1 & 2613.4 & 2726.4 & \\
\hline Caloria НТ-43 & & & & & 1930.3 & 2009.1 & 2113.3 & 2204.9 & 2302.5 & 2393.0 \\
\hline Diala AX & & 1689.4 & 1783.6 & 1877.8 & 1972.0 & 2066.2 & 2160.4 & 2254.6 & 2348.8 & \\
\hline Dowfrost & & & 3457.6 & 3574.4 & 3685.7 & 3785.5 & 3875.9 & & & \\
\hline Dowtherm A & & & & & 1659.5 & 1731.1 & 1801.6 & 1870.1 & 1941.5 & 2009.3 \\
\hline Dowtherm $G$ & & & 1560.8 & 1636.2 & 1693.1 & 1745.0 & 1810.4 & 1848.0 & 1885.7 & 1923.4 \\
\hline Dowtherm $\mathrm{J}$ & 1647.2 & 1707.5 & 1773.2 & 1845.5 & 1922.7 & 2004.7 & 2092.4 & 2183.4 & 2277.8 & 2375.7 \\
\hline Dowtherm LF & & 1485.5 & 1560.8 & 1636.2 & 1711.5 & 1786.9 & 1862.3 & 1937.6 & 2013.0 & 2088.4 \\
\hline \\
\hline ESH 4 & & 2124.4 & 2162.0 & 2199.7 & 2237.4 & 2289.3 & 2374.7 & 2493.6 & 2642.7 & 2755.7 \\
\hline ESH 5 & & & & & & & & & & \\
\hline ESH 6 & & 2298.2 & 2313.8 & 2333.3 & 2351.4 & 2369.0 & 2392.1 & 2412.6 & 2430.0 & 2467.7 \\
\hline \multicolumn{11}{|l|}{$\begin{array}{l}\text { Freon } 11 \\
\text { Freon } 114\end{array}$} \\
\hline Freon TA & & & & 1277.0 & & & & & & \\
\hline H 30 & & 2250.0 & 2287.6 & 2347.9 & 2423.3 & 2498.7 & 2574.0 & 2649.4 & & \\
\hline MCS 1958 & & 1209.5 & 1254.7 & 1299.9 & 1345.1 & 1388.9 & 1430.4 & 1471.8 & 1513.3 & 1554.7 \\
\hline MCS 1980 & & & & & & & & 1836.0 & 1903.6 & 1967.7 \\
\hline MCS 2046 & & & & & 1637.0 & 1729.8 & 1821.2 & 1914.9 & 2005.5 & 2099.7 \\
\hline Mobil Therm 600 & & & & & & & 2071.6 & 2152.8 & 2264.2 & 2339.6 \\
\hline Mobil Therm 603 & & & & & & & 2123.5 & 2236.6 & 2347.9 & 2423.3 \\
\hline $\begin{array}{l}\text { PAO 13C } \\
\text { Pract1cal Fluid }\end{array}$ & & & & & 2201.7 & 2300.6 & 2392.8 & 2478.9 & 2561.6 & 2640.8 \\
\hline Prestone II & & & & & 3453.6 & 3555.3 & & & & \\
\hline SI-96 & & 1818.9 & 1841.5 & 1859.6 & 1878.3 & 1899.5 & 1919.4 & 1941.4 & 1960.4 & 1983.0 \\
\hline $\begin{array}{l}\text { Silogram } 43 \\
\text { Solar Winter Ban }\end{array}$ & & & & & $\begin{array}{l}2175.8 \\
3485.7\end{array}$ & $\begin{array}{l}2258.7 \\
3601.8\end{array}$ & 2342.6 & 2429.2 & 2516.1 & 2606.5 \\
\hline Stauffer $3664-A$ & & & & & 2153.7 & 2188.5 & 2228.7 & 2307.1 & 2443.2 & 2590.2 \\
\hline Sunoco 21 & & & & & & 2208.4 & 2292.3 & 2380.2 & 2475.0 & 2584.3 \\
\hline Sunoco 25 & & & & & & 2208.4 & 2292.3 & 2380.2 & 2475.0 & 2584.3 \\
\hline Sunsafe 100 & & & & & 3744.5 & 3816.1 & 3887.6 & & & \\
\hline Sunsafe 130 & & & & & 3479.2 & 3573.4 & 3667.6 & & & \\
\hline Sunsafe 200 & & & & & 3909.8 & 3951.2 & 3992.7 & & & \\
\hline Sunsafe 230 & & & & & 3702.6 & 3774.2 & 3845.8 & & & \\
\hline Sunsol 60 & & & & & 3490.2 & 3607.1 & 0.0 & & & \\
\hline Syl therm 444 & & 1469.2 & 1499.4 & 1529.5 & 1563.3 & 1599.6 & 1630.5 & 1653.1 & 1676.0 & 1706.2 \\
\hline Texatherm & & 1642.0 & 1755.1 & 1868.1 & 1962.8 & 2038.1 & 2123.5 & 2236.6 & 2349.6 & 2462.7 \\
\hline Thermia $C$ & & & & & 1973.8 & 2070.3 & 2164.6 & 2258.2 & 2348.4 & 2435.1 \\
\hline Therminol 44 & 1772.2 & 1836.2 & 1897.6 & 1960.2 & 2022.4 & 2082.7 & 2142.9 & 2204.4 & 2271.9 & 2332.2 \\
\hline Therminol 55 & & 1780.5 & 1863.4 & 1948.6 & 2033.4 & 2117.7 & 2203.4 & 2286.9 & 2373.4 & 2456.3 \\
\hline Thermino1 60 & 1327.2 & 1421.4 & 1515.6 & 1607.5 & 1699.8 & 1794.0 & 1888.2 & 1982.4 & 2076.3 & 2163.0 \\
\hline Therminol 66 & & 1427.8 & 1514.4 & 1603.4 & 1692.0 & 1780.0 & 1869.5 & 1956.7 & 2047.0 & 2133.7 \\
\hline Thermfnol 88 & & & & & & & & & 1957.7 & 2014.3 \\
\hline Therminol VP-1 & & & & & 1639.0 & 1704.5 & 1773.3 & 1844.9 & 1916.2 & 1980.2 \\
\hline UCAR FF-35 & & 3464.1 & 3501.8 & 3562.1 & 3637.5 & 3727.1 & 3840.1 & 3959.0 & 4109.7 & \\
\hline UCAR TF-17 & & 3054.7 & 3205.4 & 3356.1 & 3470.0 & 3559.6 & 3662.6 & 3737.9 & & \\
\hline UCON HTE-500 & & & & & 2046.5 & 2121.8 & 2187.2 & 2224.8 & 2262.5 & 2300.2 \\
\hline Water & & & 4197.0 & 4181.9 & 4179.7 & 4195.3 & 4217.9 & 4248.1 & 4320.6 & 4411.0 \\
\hline $\begin{array}{l}\text { X2-1162 } \\
\text { Zerex }\end{array}$ & & & & & 1685.8 & 1708.4 & 1731.0 & 1754.8 & 1784.7 & 1811.1 \\
\hline & & & & & & & & & & \\
\hline
\end{tabular}


Table B-11. Summary of Specific Heat Data $[\mathrm{J} /(\mathrm{kg} \cdot \mathrm{K})]$ (Concluded)

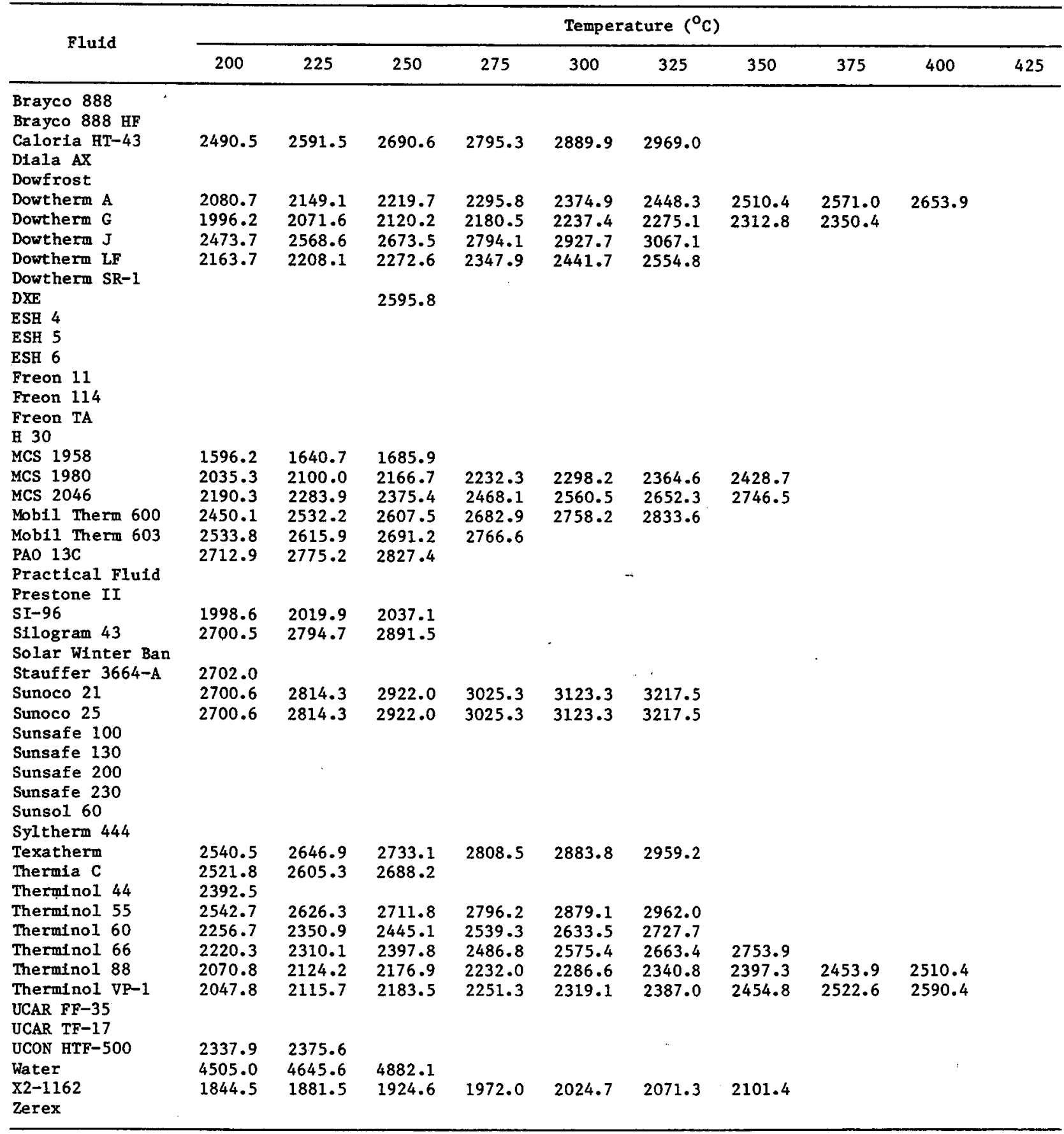


Table B-12. Summary of Thermal Conductivity Data [W/(m - K)]

\begin{tabular}{|c|c|c|c|c|c|c|c|c|c|c|}
\hline \multirow{2}{*}{ Fluid } & \multicolumn{10}{|c|}{ Temperature $\left({ }^{\circ} \mathrm{C}\right)$} \\
\hline & -50 & -25 & 0 & 25 & 50 & 75 & 100 & 125 & 150 & 175 \\
\hline \multicolumn{11}{|l|}{ Brayco 888} \\
\hline Calorfa BT- 43 & & & & & 0.118 & 0.114 & 0.111 & 0.107 & 0.103 & 0.100 \\
\hline Diala AX & & 0.134 & 0.132 & 0.131 & 0.129 & 0.127 & 0.125 & 0.123 & 0.121 & \\
\hline Dowfrost & & 0.400 & 0.394 & 0.388 & & & & & & \\
\hline $\begin{array}{l}\text { Dowtherm A } \\
\text { Dowtherm G }\end{array}$ & & & & & $\begin{array}{l}0.138 \\
0.131\end{array}$ & $\begin{array}{l}0.134 \\
0.130\end{array}$ & $\begin{array}{l}0.131 \\
0.129\end{array}$ & $\begin{array}{l}0.128 \\
0.128\end{array}$ & $\begin{array}{l}0.125 \\
0.126\end{array}$ & $\begin{array}{l}0.121 \\
0.126\end{array}$ \\
\hline Dowtherm J & 0.137 & 0.135 & 0.134 & 0.132 & 0.130 & 0.127 & 0.126 & 0.124 & 0.122 & 0.120 \\
\hline Dowtherm LF & & 0.148 & 0.144 & 0.140 & 0.137 & 0.134 & 0.131 & 0.128 & 0.124 & 0.121 \\
\hline \\
\hline ESH 4 & & & & & 0.179 & 0.165 & 0.151 & 0.138 & 0.128 & 0.119 \\
\hline \multicolumn{11}{|l|}{ ESH 5} \\
\hline ESH 6 & & & & & 0.175 & 0.162 & 0.150 & 0.139 & 0.129 & 0.122 \\
\hline Freon 11 & & & & 0.087 & & & & & & \\
\hline Freon 114 & & & & 0.059 & & & & & & \\
\hline Freon TA & & & & 0.066 & & & & & & \\
\hline H 30 & & & & & & & 0.130 & & & \\
\hline MCS 1958 & & 0.110 & 0.109 & 0.109 & 0.108 & 0.106 & 0.105 & 0.103 & 0.100 & 0.098 \\
\hline MCS 2046 & & & & & 0.120 & 0.118 & 0.116 & 0.114 & 0.112 & 0.110 \\
\hline Mobil Therm 600 & & & & & & & 0.119 & 0.117 & 0.115 & 0.113 \\
\hline Mob11 Therm 603 & & & & & & & 0.131 & 0.129 & 0.127 & 0.125 \\
\hline \multicolumn{11}{|l|}{ PAO $13 \mathrm{C}$} \\
\hline Practical Fluid & & & & & & & & & & \\
\hline \multicolumn{11}{|l|}{$\begin{array}{l}\text { Practical Fluid } \\
\text { Prestone II }\end{array}$} \\
\hline SI-96 & & 0.146 & 0.139 & 0.132 & 0.125 & 0.118 & 0.111 & 0.104 & 0.097 & 0.091 \\
\hline Silogram 43 & & & & & 0.132 & 0.130 & 0.128 & 0.126 & 0.125 & 0.123 \\
\hline \multicolumn{11}{|l|}{ Solar Winter Ban } \\
\hline Stauffer $3664-\mathrm{A}$ & & & & & 0.146 & 0.143 & 0.139 & 0.136 & 0.133 & 0.130 \\
\hline Sunoco 21 & & & & & & 0.129 & 0.127 & 0.125 & 0.123 & 0.121 \\
\hline Sunoco 25 & & & & & & 0.129 & 0.127 & 0.125 & 0.123 & 0.121 \\
\hline \multicolumn{11}{|l|}{ Sunsafe 100} \\
\hline \multicolumn{11}{|l|}{ Sunsafe 130} \\
\hline \multicolumn{11}{|l|}{ Sunsafe 200} \\
\hline \multirow{2}{*}{\multicolumn{11}{|c|}{$\begin{array}{l}\text { Sunsafe } 230 \\
\text { Sunsol } 60\end{array}$}} \\
\hline & & & & & & & & & & \\
\hline Syl therm 444 & & 0.150 & 0.147 & 0.145 & 0.143 & 0.140 & 0.138 & 0.135 & 0.133 & 0.131 \\
\hline Texatherm & & 0.137 & 0.136 & 0.134 & 0.132 & 0.130 & 0.128 & 0.126 & 0.125 & 0.122 \\
\hline Thermia $\mathrm{C}$ & & & & & 0.131 & 0.129 & 0.127 & 0.125 & 0.123 & 0.121 \\
\hline Thermino1 44 & 0.150 & 0.147 & 0.144 & 0.141 & 0.138 & 0.134 & 0.131 & 0.127 & 0.123 & 0.118 \\
\hline Therminol 55 & & 0.133 & 0.131 & 0.128 & 0.126 & 0.123 & 0.120 & 0.118 & 0.115 & 0.112 \\
\hline Therminol 60 & 0.138 & 0.136 & 0.134 & 0.132 & 0.130 & 0.128 & 0.126 & 0.124 & 0.122 & 0.120 \\
\hline Thermino1 66 & & 0.122 & 0.121 & 0.120 & 0.118 & 0.117 & 0.115 & 0.113 & 0.111 & 0.109 \\
\hline Therminol 88 & & & & & & & & & 0.128 & 0.126 \\
\hline Therminol VP-1 & & & & & 0.135 & 0.132 & 0.128 & 0.124 & 0.121 & 0.117 \\
\hline UCAR FF-35 & & & 0.385 & 0.382 & 0.380 & 0.377 & 0.373 & 0.368 & & \\
\hline UCAR TF-17 & & 0.419 & 0.419 & 0.419 & 0.418 & 0.415 & 0.408 & 0.400 & & \\
\hline UCON HTF-500 & & & & & 0.162 & 0.158 & 0.154 & 0.151 & 0.149 & 0.145 \\
\hline Water & & & 0.570 & 0.607 & 0.640 & 0.665 & 0.680 & 0.686 & 0.683 & 0.674 \\
\hline$\times 2-1162$ & & & & & 0.151 & 0.147 & 0.144 & 0.140 & 0.137 & 0.133 \\
\hline Zerex & & & & & & & & & & \\
\hline
\end{tabular}


Table B-12. Summary of Thermal Conductivity Data $[\mathrm{W} /(\mathrm{m} \cdot \mathrm{K})]$ (Concluded)

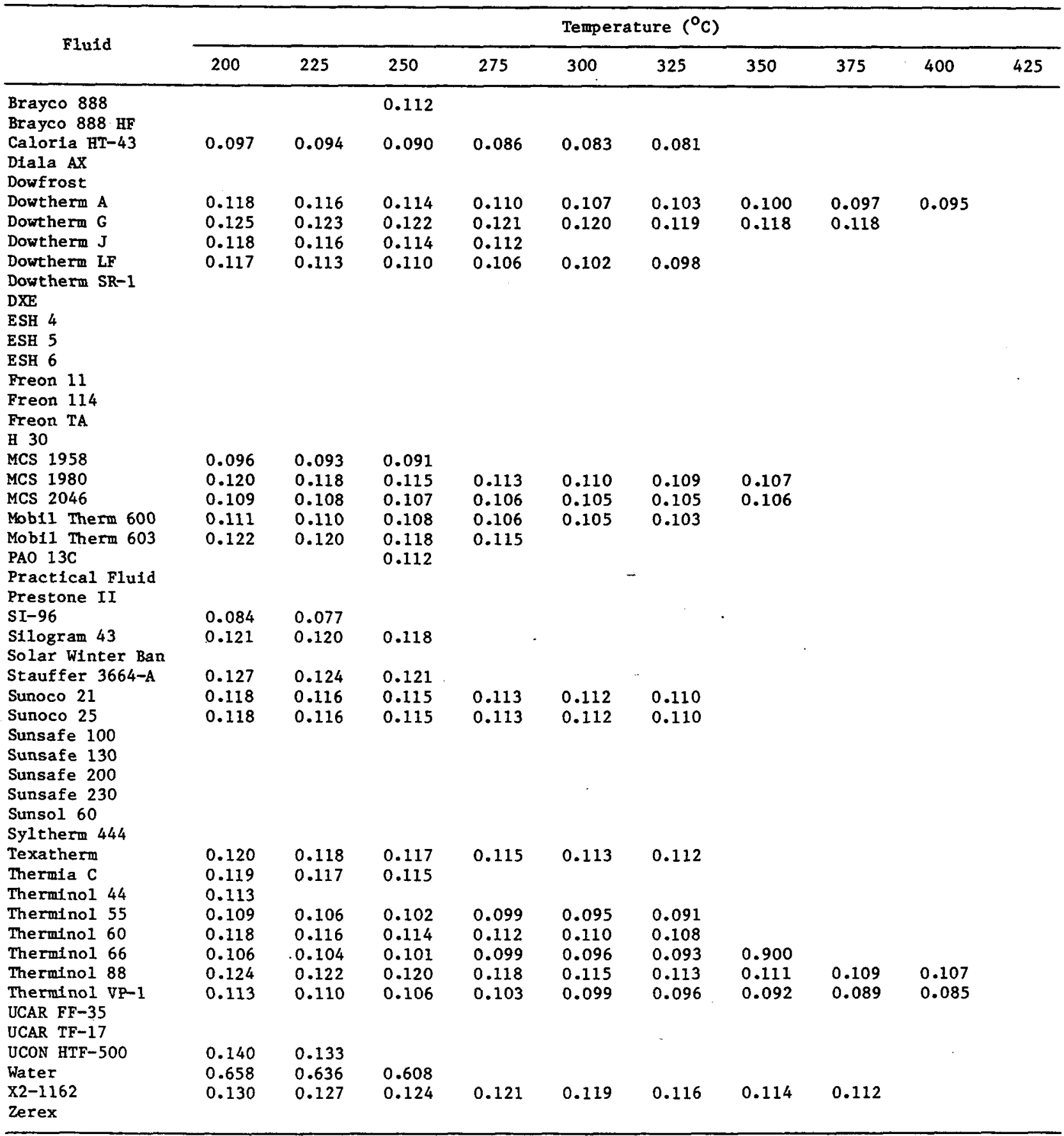


Table B-13. Summary of Vapor Pressure Data ( $\mathrm{Pa}$ )

\begin{tabular}{|c|c|c|c|c|c|c|c|c|c|c|}
\hline \multirow{2}{*}{ Fluid } & \multicolumn{10}{|c|}{ Temperature $\left({ }^{\circ} \mathrm{C}\right)$} \\
\hline & -50 & -25 & 0 & 25 & 50 & 75 & 100 & 125 & 150 & 175 \\
\hline \multicolumn{11}{|l|}{ Brayco 888} \\
\hline $\begin{array}{l}\text { Caloria HT-43 } \\
\text { Diala AX }\end{array}$ & & & & & & & 24 & 142 & $\begin{array}{l}436 \\
656\end{array}$ & $\begin{array}{l}1246 \\
1916\end{array}$ \\
\hline Dowfrost & & & & 3368 & 12956 & 37660 & & & & \\
\hline $\begin{array}{l}\text { Dowtherm A } \\
\text { Dowtherm G }\end{array}$ & & & & & 44 & 202 & 640 & 1806 & $\begin{array}{l}4596 \\
1512\end{array}$ & $\begin{array}{r}11256 \\
4032\end{array}$ \\
\hline Dowtherm $\mathrm{J}$ & & & & & 872 & 3062 & 8564 & 20472 & 43728 & 87107 \\
\hline $\begin{array}{l}\text { Dowtherm LF } \\
\text { Dowtherm SR-1 }\end{array}$ & & & & & 11404 & 33138 & & & 4200 & 13200 \\
\hline \\
\hline \multicolumn{11}{|l|}{ ESH 4} \\
\hline \multicolumn{11}{|l|}{ ESH 5} \\
\hline ESH 6 & & & & & & & & & $\cdot$ & \\
\hline \multicolumn{11}{|l|}{ Freon 11} \\
\hline $\begin{array}{l}\text { Freon } 114 \\
\text { Freon TA }\end{array}$ & & & 55560 & 239160 & 217680 & 350320 & & & & \\
\hline H 30 & & & & & & & & & 10464 & 11904 \\
\hline MCS 1958 & & & & & & & & & & 1192 \\
\hline \multirow{2}{*}{\multicolumn{11}{|c|}{$\begin{array}{l}\text { MCS } 1980 \\
\text { MCS } 2046\end{array}$}} \\
\hline & & & & & & & & & & \\
\hline $\begin{array}{l}\text { Mobil Therm } 600 \\
\text { Mobil Therm } 603\end{array}$ & & & & & & & & & 1796 & 3956 \\
\hline $\begin{array}{l}\text { Mobil Therm } 603 \\
\text { PAO 13C }\end{array}$ & & & & & & & & & 1536 & 2346 \\
\hline \multicolumn{11}{|l|}{ PAO $13 \mathrm{C}$} \\
\hline $\begin{array}{l}\text { Practical Fluid } \\
\text { Prestone II }\end{array}$ & & & & & 11036 & 41654 & & & & \\
\hline$S I-96$ & & & & & & & & & 208 & 388 \\
\hline \multicolumn{11}{|l|}{ Silogram 43} \\
\hline $\begin{array}{l}\text { Solar Winter Ban } \\
\text { Stauffer } 3664-A\end{array}$ & & & & & & & & & & \\
\hline $\begin{array}{l}\text { Stauffer 3664-A } \\
\text { Sunoco } 21\end{array}$ & & & & & & & & & & \\
\hline Sunoco 21 & & & & & & & & & 52 & 1222 \\
\hline Sunoco 25 & & & & & & & & & 52 & 1222 \\
\hline Sunsafe 100 & & & & & 18964 & 46504 & & & & \\
\hline Sunsafe 130 & & & & & 17850 & 43725 & & & & \\
\hline Sunsafe 200 & & & & & 20728 & 51058 & & & & \\
\hline Sunsafe 230 & & & & & 20836 & 47296 & & & & \\
\hline \multicolumn{11}{|l|}{ Sunso1 60} \\
\hline \multirow{2}{*}{\multicolumn{11}{|c|}{$\begin{array}{l}\text { Syltherm } 444 \\
\text { Texatherm }\end{array}$}} \\
\hline & & & & & & & & & & \\
\hline Thermfa C & & & & & & & & & 4 & 94 \\
\hline Therminol 44 & & & & & & & & 14 & 108 & 288 \\
\hline Therminol 55 & & & & & & & 24 & 128 & 324 & 864 \\
\hline Therminol 60 & & & & & & & 396 & 826 & 1696 & 3856 \\
\hline Therminol 66 & & & & & & & 24 & 128 & 324 & 864 \\
\hline Therminol 88 & & & & & & & & & 216 & 576 \\
\hline Therminol VP-1 & & & & & 44 & 202 & 640 & 1806 & 4592 & 11162 \\
\hline UCAR FF-35 & & & 67 & 3214 & 11744 & 34174 & 84988 & & & \\
\hline UCAR TF-17 & & & 484 & 3130 & & & & & & \\
\hline UCON HTF-500 & & & & & & . & & & & \\
\hline $\begin{array}{l}\text { Water } \\
\times 2-1162\end{array}$ & & & 611 & 4099 & 14945 & 43940 & 110268 & 238875 & 480842 & 905262 \\
\hline Zerex & & & & & & & & & & \\
\hline
\end{tabular}


Table B-13. Summary of Vapor Pressure Data ( $\mathrm{Pa}$ ) (Concluded)

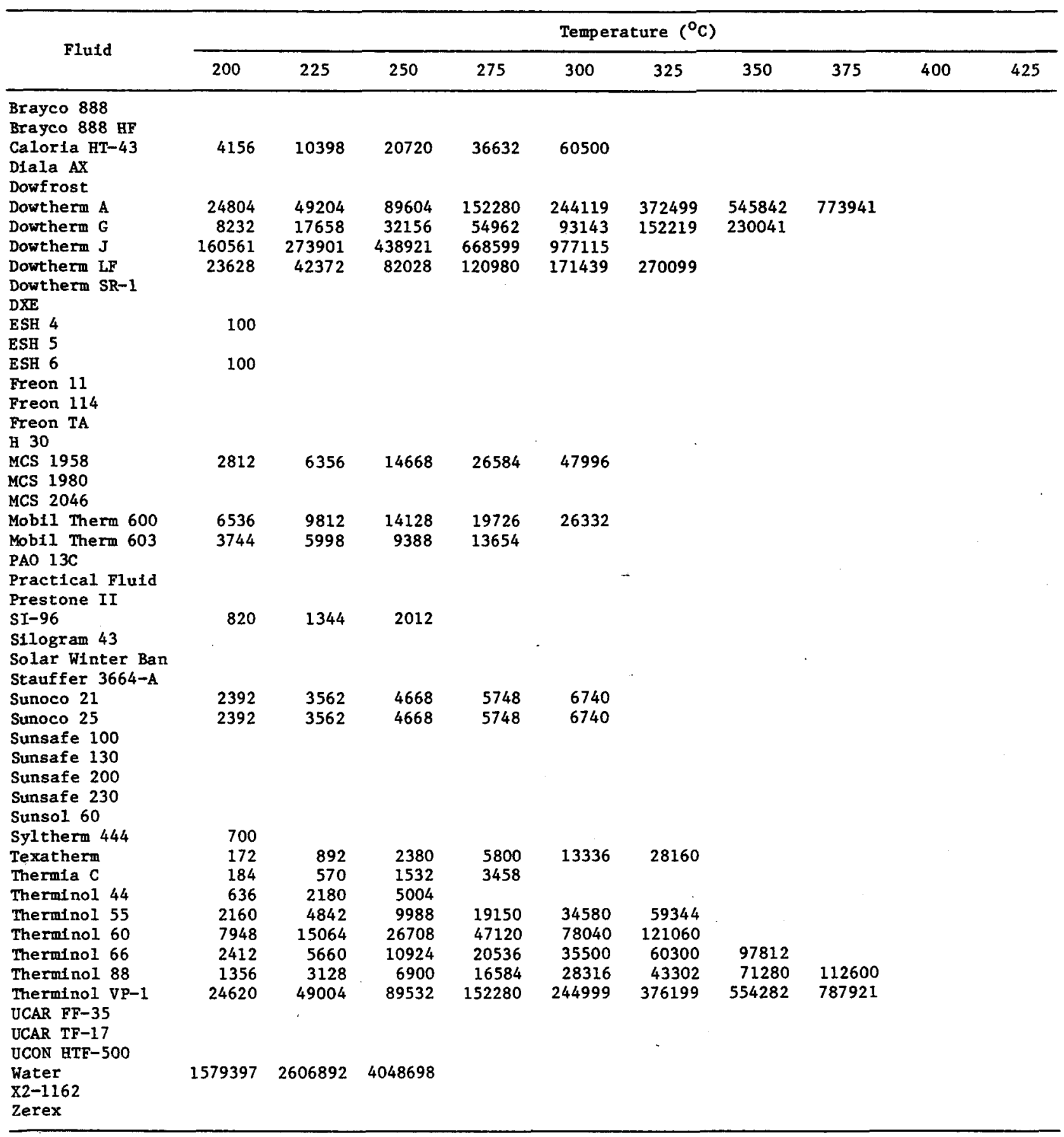




\section{APPENDIX C}

\section{THE SOLIPH COMPUTER PROGRAM}

The SOLIPH computer program was written specifically for the purpose of generating design tools for this handbook. Like other solar simulation codes (e.g., TRNSYS, SOLTES, etc.), SOLIPH is a quasi-steady-state, hour-by-hour mode1. For each hour of the year, climatological data (time, direct normal insolation, total horizontal insolation, and ambient temperature) are read from a TMY (Typical Meteorological Year) weather tape, available for 26 different weather stations. The executive routine reads all the system and climatological input data, and then calls various subroutines (collector, pipe, heat exchanger, storage, etc.) around closed piping loops. A starting point temperature is chosen for each pipe loop (the collector array inlet temperature in the collector loop), and energy balances are performed on each component. The program cycles through each loop as many times as necessary until the temperature distribution is essentially unchanged from the previous iteration (to within a specified temperature convergence criterion). Each hour, new climatological and loads inputs are used, and the program arrives at a new steady-state solution, until the entire year has been modeled.

A simple SOLIPH model is shown in Fig. C-1. The starting point for this configuration is the inlet collector temperature. The executive routine calls the collector subroutine, SOLCOL, which, based on input collector parameters

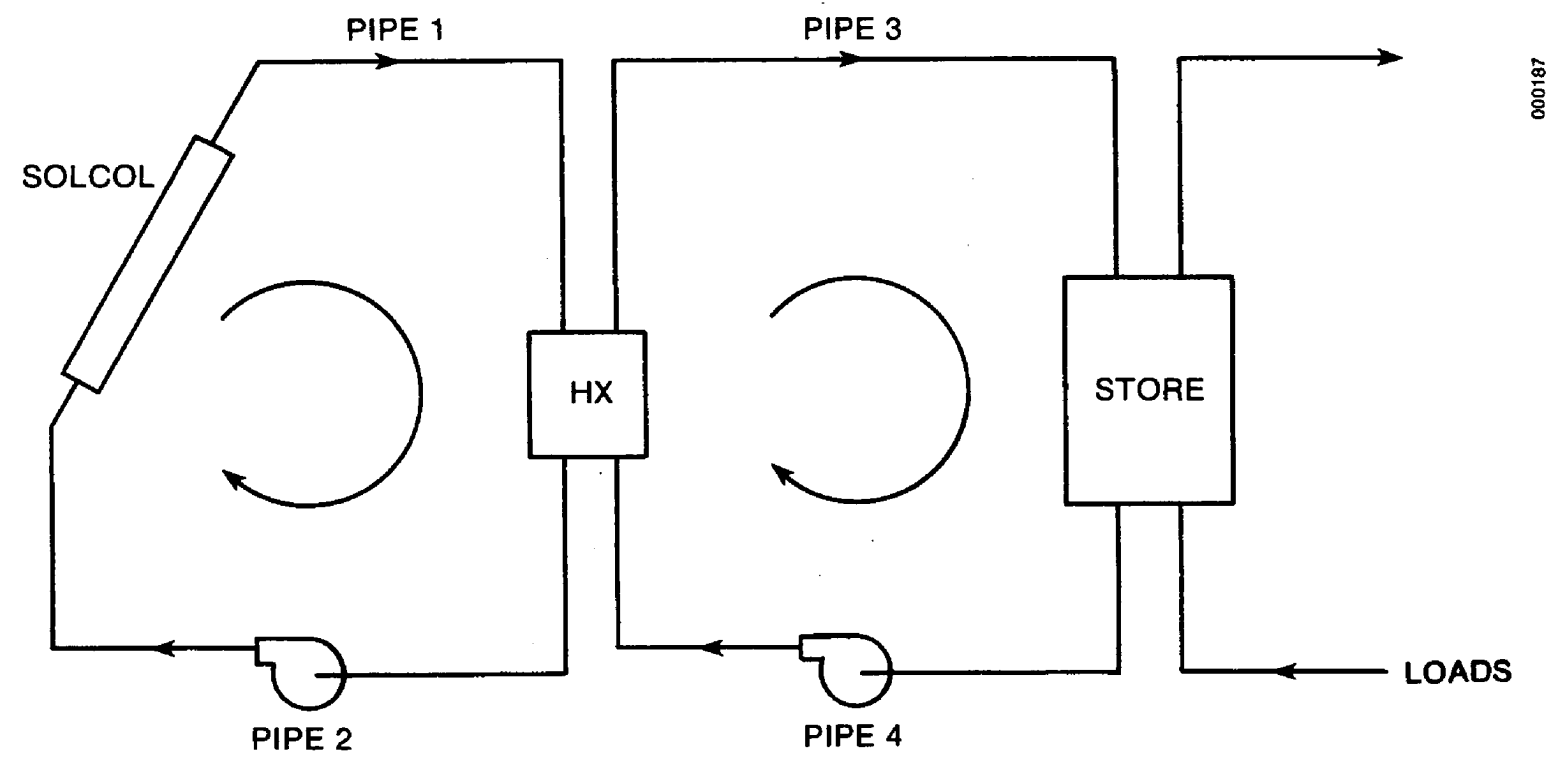

Figure C-1. A Simple SolIPH Configuration 
and climatological data, supplies a collector array outlet temperature. This is used as the inlet temperature for pipe 1. The pipe subroutine, PIPE, is called and, based on input pipe insulation and ambient temperature, supplies an outlet temperature. The outlet temperature is used as the hot-side inlet temperature to the heat exchanger. The heat exchanger routine, $\mathrm{HX}$, uses input effectiveness and the hot and cold inlet temperatures to compute the two outlet temperatures. The hot outlet temperature is then used as input for pipe 2. The PIPE subroutine is again called, and its outlet value replaces the inlet collector temperature we started with. If these two temperatures are not sufficiently close, the loop must be repeated.

First, however, the second loop is computed. The cold-side outlet temperature of the heat exchanger is used as input for pipe 3. The outlet from PIPE is used as the inlet storage temperature. The LOADS subroutine is called to determine the load at that hour and to allow a complete energy balance on the storage tank, and then STORE is called to determine a new storage tank temperature. This temperature is used as the input for pipe 4, and the output temperature from PIPE is compared with the inlet cold-side heat exchanger temperature originally assumed, thus completing the second loop. If either loop has not converged within the specified tolerance, both are reiterated.

To make the code as easy to understand as possible, energy calculations are done in the subroutines where they are most appropriate rather than at the end of the executive routine. So, for example, pipe energy loss is calculated in the PIPE subroutine, storage loss in STORE, etc. Since only temperature values are needed for loop iteration, calculating all energy values during each cycle would waste computer time. SOLIPH is set up to do these calculations only on the last iteration.

Output temperatures and energy values are supplied on hourly, daily, and monthly bases with an annual cumulative summary. Energy collected by the array, energy delivered to the load, and pumping energy are outputs. Energy losses are given separately for piping and storage and are also broken down according to whether they are operational (during collector pump operation) or nonoperational losses. Collector array efficiencies are given relative to useful energy in the plane of the collectors as well as to total horizontal energy. System efficiencies are supplied as the ratio of energy delivered to the load to insolation. Table $\mathrm{C}-1$ is a sample monthly summary.

Before we describe the various subroutines, we must point out that SOLIPH is not a highly user-oriented code like TRNSYS or SOLTES. To change the system configuration, the user does not change input data as he or she would for one of the other codes. Rather, the user changes the Fortran programming statements in the executive program. Thus, a CALL STORE might be replaced by a CALL HX. Although this is not an elegant approach, it saves the code from complexity and results in shorter run times. SOLIPH was designed to generate design tools, not for public use; therefore, it is not documented for such use. Rather, the design tools generated from SOLIPH should make detailed computer models unnecessary. The following section describes the basic algorithms used in each SOLIPH subroutine. 
Table C-1. Sample Monthly Summary Output

\begin{tabular}{|c|c|c|c|c|c|c|c|c|c|c|c|c|c|}
\hline Day & $\begin{array}{l}I \mathrm{TH}^{\mathrm{a}} \\
(\mathrm{GJ})\end{array}$ & $\begin{array}{r}\text { IBN } \\
\text { (GJ) }\end{array}$ & $\begin{array}{c}\text { IAVAIL } \\
\text { (GJ) }\end{array}$ & $\begin{array}{c}\text { IAPER } \\
(\mathrm{GJ})\end{array}$ & $\begin{array}{c}\text { QCOLL } \\
(G J)\end{array}$ & $\begin{array}{c}\operatorname{ETA}(1) \\
(\%)\end{array}$ & $\begin{array}{c}\operatorname{ETA}(3) \\
\left(z_{0}\right)\end{array}$ & $\begin{array}{l}\text { QDEL } \\
(G J)\end{array}$ & $\begin{array}{c}\text { OLOSS } \\
\text { (GJ) }\end{array}$ & $\begin{array}{c}\text { NOLOSS } \\
\text { (GJ) }\end{array}$ & $\begin{array}{c}\text { SLOSS } \\
(G J)\end{array}$ & $\begin{array}{c}\operatorname{ETA}(2) \\
(\overline{\%})\end{array}$ & $\begin{array}{l}\text { EPAR } \\
\text { (GJ) }\end{array}$ \\
\hline $\begin{array}{r}1 \\
2 \\
3 \\
4 \\
5 \\
6 \\
7 \\
8 \\
9 \\
10 \\
11 \\
12 \\
13 \\
14 \\
15 \\
16 \\
17 \\
18 \\
19 \\
20 \\
21 \\
22 \\
23 \\
24 \\
25 \\
26 \\
27 \\
28 \\
29 \\
30 \\
31\end{array}$ & $\begin{array}{l}16.05 \\
20.60 \\
23.52 \\
25.44 \\
32.45 \\
32.66 \\
29.67 \\
32.51 \\
29.38 \\
17.98 \\
10.74 \\
28.63 \\
26.82 \\
31.17 \\
23.90 \\
29.62 \\
30.25 \\
29.97 \\
30.86 \\
31.00 \\
30.94 \\
30.59 \\
30.72 \\
31.37 \\
24.82 \\
28.06 \\
12.45 \\
30.51 \\
29.46 \\
30.58 \\
23.18 \\
\end{array}$ & $\begin{array}{r}15.07 \\
24.84 \\
36.29 \\
46.97 \\
74.89 \\
69.16 \\
60.35 \\
69.76 \\
54.53 \\
20.80 \\
7.47 \\
52.03 \\
43.74 \\
65.71 \\
44.14 \\
66.41 \\
45.29 \\
66.34 \\
72.15 \\
72.73 \\
70.22 \\
65.98 \\
68.99 \\
72.75 \\
44.86 \\
50.96 \\
5.08 \\
72.40 \\
66.30 \\
73.21 \\
34.25\end{array}$ & $\begin{array}{l}20.18 \\
28.88 \\
35.40 \\
41.68 \\
58.58 \\
56.83 \\
50.57 \\
56.97 \\
48.85 \\
24.64 \\
12.54 \\
46.82 \\
42.21 \\
54.46 \\
39.56 \\
53.57 \\
45.83 \\
53.70 \\
56.65 \\
56.98 \\
56.02 \\
54.11 \\
55.35 \\
57.39 \\
40.74 \\
46.09 \\
13.08 \\
56.32 \\
52.93 \\
56.59 \\
34.25\end{array}$ & $\begin{array}{l}19.38 \\
28.69 \\
34.00 \\
40.52 \\
55.78 \\
54.57 \\
48.56 \\
54.55 \\
47.94 \\
24.25 \\
11.88 \\
45.28 \\
41.30 \\
52.18 \\
38.29 \\
51.65 \\
44.66 \\
51.33 \\
53.83 \\
54.12 \\
53.39 \\
51.76 \\
52.82 \\
54.72 \\
39.41 \\
44.73 \\
12.41 \\
53.52 \\
50.41 \\
53.72 \\
32.78\end{array}$ & $\begin{array}{r}0.00 \\
5.33 \\
6.97 \\
12.15 \\
17.52 \\
17.14 \\
14.87 \\
16.20 \\
12.44 \\
4.01 \\
0.00 \\
12.25 \\
8.98 \\
14.59 \\
8.82 \\
14.38 \\
9.39 \\
14.24 \\
15.61 \\
16.12 \\
15.78 \\
14.37 \\
15.29 \\
16.63 \\
10.31 \\
12.86 \\
0.00 \\
14.04 \\
11.57 \\
14.03 \\
3.38\end{array}$ & $\begin{array}{r}0.0 \\
25.9 \\
29.6 \\
47.8 \\
54.0 \\
52.5 \\
50.1 \\
49.8 \\
42.3 \\
22.3 \\
0.0 \\
42.8 \\
33.5 \\
46.8 \\
36.9 \\
48.6 \\
31.0 \\
47.5 \\
50.6 \\
52.0 \\
51.0 \\
47.0 \\
49.8 \\
53.0 \\
41.5 \\
45.8 \\
0.0 \\
46.0 \\
39.3 \\
45.9 \\
14.6\end{array}$ & $\begin{array}{r}0.0 \\
18.6 \\
20.5 \\
30.0 \\
31.4 \\
31.4 \\
30.6 \\
29.7 \\
25.9 \\
16.5 \\
0.0 \\
27.0 \\
21.7 \\
28.0 \\
23.0 \\
27.8 \\
21.0 \\
27.7 \\
29.0 \\
29.8 \\
29.6 \\
27.8 \\
29.0 \\
30.4 \\
26.2 \\
28.7 \\
0.0 \\
26.2 \\
23.0 \\
26.1 \\
10.3\end{array}$ & $\begin{array}{r}0.96 \\
0.00 \\
4.05 \\
6.52 \\
11.94 \\
12.95 \\
11.61 \\
12.04 \\
9.40 \\
0.00 \\
0.00 \\
5.06 \\
5.66 \\
8.52 \\
6.63 \\
8.15 \\
5.85 \\
8.26 \\
10.61 \\
11.50 \\
11.54 \\
10.43 \\
10.53 \\
11.82 \\
8.36 \\
8.15 \\
0.00 \\
6.33 \\
6.56 \\
-8.81 \\
0.00\end{array}$ & $\begin{array}{l}0.000 \\
0.093 \\
0.103 \\
0.137 \\
0.166 \\
0.165 \\
0.147 \\
0.171 \\
0.171 \\
0.060 \\
0.000 \\
0.162 \\
0.148 \\
0.172 \\
0.121 \\
0.177 \\
0.171 \\
0.173 \\
0.173 \\
0.170 \\
0.169 \\
0.171 \\
0.170 \\
0.170 \\
0.117 \\
0.138 \\
0.000 \\
0.183 \\
0.184 \\
0.184 \\
0.096\end{array}$ & $\begin{array}{l}0.283 \\
0.518 \\
0.541 \\
1.627 \\
0.864 \\
0.839 \\
0.803 \\
1.054 \\
1.033 \\
0.389 \\
0.505 \\
1.608 \\
0.738 \\
1.029 \\
0.746 \\
1.319 \\
1.218 \\
1.287 \\
1.009 \\
1.042 \\
1.048 \\
1.078 \\
0.985 \\
1.043 \\
1.005 \\
1.049 \\
0.582 \\
1.064 \\
1.157 \\
1.099 \\
0.751\end{array}$ & $\begin{array}{l}2.790 \\
2.586 \\
2.604 \\
2.569 \\
2.918 \\
2.958 \\
2.685 \\
3.034 \\
3.083 \\
2.725 \\
2.948 \\
2.979 \\
3.096 \\
3.066 \\
3.070 \\
3.058 \\
3.200 \\
3.133 \\
3.124 \\
3.075 \\
3.068 \\
3.113 \\
3.076 \\
3.079 \\
2.958 \\
2.849 \\
3.048 \\
3.296 \\
3.411 \\
3.368 \\
3.178\end{array}$ & $\begin{array}{r}4.8 \\
0.0 \\
11.4 \\
15.7 \\
20.4 \\
22.8 \\
23.0 \\
21.1 \\
19.2 \\
0.0 \\
0.0 \\
10.8 \\
13.4 \\
15.6 \\
16.8 \\
15.2 \\
12.8 \\
15.4 \\
18.7 \\
20.2 \\
20.6 \\
19.4 \\
19.0 \\
20.6 \\
20.5 \\
17.7 \\
0.0 \\
11.2 \\
12.4 \\
15.6 \\
0.0\end{array}$ & $\begin{array}{l}0.00 \\
0.27 \\
0.27 \\
0.37 \\
0.37 \\
0.37 \\
0.37 \\
0.37 \\
0.37 \\
0.16 \\
0.00 \\
0.37 \\
0.32 \\
0.37 \\
0.27 \\
0.37 \\
0.37 \\
0.37 \\
0.37 \\
0.37 \\
0.37 \\
0.37 \\
0.37 \\
0.37 \\
0.27 \\
0.32 \\
0.00 \\
0.37 \\
0.37 \\
0.37 \\
0.21\end{array}$ \\
\hline$b$ & 835.9 & 1633.7 & 1407.7 & 1352.4 & 349.3 & 41.8 & 25.8 & 222.3 & 4.26 & 29.31 & 93.14 & $\overline{16.0}$ & $\overline{9.57}$ \\
\hline
\end{tabular}

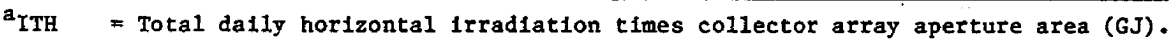

IBN = Dafly direct normal irradiation times collector aperture area (GJ).

IAVAIL = Daily usable irradiation in collector plane times collector aperture area (GJ).

IAPER = Dafly irradiation in collector plane times collector aperture area (GJ).

QCOLL = Dally energy collected by collector array (GJ).

$\operatorname{ETA}(1)=$ Collector array efficlency-QCOLL/ITH.

$\operatorname{ETA}(3)=$ collector array efficlency-QCOLL/IAPER.

QDEL = Dally collected energy delivered to the load (GJ).

QLOSS = Dally operational thermal system losses (during pump operation) (GJ).

NOLOSS $=$ Dafly nonoperational system thermal losses (during pump shutdown). (GJ).

SLOSS = Daily thermal losses from storage tank (GJ).

$\operatorname{ETA}(2)=$ System thermal effIciency- -QDEL/IAVAIL.

EPAR = Da1ly parasitic (pumping) energy (GJ).

bonthly total oz average. 


\section{C.1 THE SOLIPH SUBROUTINES}

\section{C.1.1 Subroutine SOLCOL}

This subroutine models a stationary solar collector array. Direct normal and total horizontal radiation and ambient temperature from the weather tape are used. Values of $F_{R} \tau \alpha, F_{R} U_{L}$, incident angle modifier coefficients, and the collector time constant are input, as well as collector tilt, azimuth, and ground-cover ratio.

First, insolation in the collector plane is calculated. SOLIPH does this in the following steps:

- Calculates hour-angle and declination. (A day-of-the-year function is used to determine declination.)

- Calculates incident angle and converts normal beam radiation to collector plane.

- Calculates diffuse radiation in horizontal plane.

- Converts diffuse to collector plane (including ground and sky terms).

- Adds direct, diffuse, and reflected beam in plane.

Now, it must be determined whether the collector pump is on. If the pump has been operated, this determination is based on the difference between previous collector outlet temperature and storage. If the pump is not on, as in early morning, a stagnation temperature is calculated as follows:

$$
T_{s}=T_{a m b}+\frac{K_{\alpha \tau} n_{0} I}{F_{R} U_{L}}
$$

where $\eta_{0}$ is the optical efficiency. The stagnation temperature is compared with the storage tank temperature, and if it is sufficiently higher, the pump is turned on. Several flags provide a deadband temperature range which allows for a typical $\Delta \mathrm{T}_{\text {on }} / \Delta \mathrm{T}_{\text {off }}$ control scheme. If the pump is on, collector efficiency is calculated from the Hottel-Whillier-Bliss equation (incident-angle corrected) and multiplied by insolation and collector area to yield energy collected. Collector outlet temperature is then

$$
\mathrm{T}_{\text {out }}=\mathrm{T}_{\text {in }}+\frac{\dot{\mathrm{Q}}_{\mathrm{col1}}}{\dot{\mathrm{M}} \mathrm{c}_{\mathrm{p}}} \text {. }
$$

If the pump is off, cooldown loss from the collectors is determined. For co1lector mass $M$, specific heat $C$, and loss coefficient $U$, we solve a timedependent, first-order ordinary differential equation:

O.D.E.: $\quad M_{p} \frac{d T}{d t}=-U_{L} A_{C}\left(T-T_{a m b}\right)+K_{\alpha \tau} n_{0} I A$

I.C.: $\left.\quad T\right|_{t=0}=T_{0}$ 
Soln.:

$$
T=T_{a m b}+\frac{K_{\alpha \tau_{0} n_{0}}}{U_{L}}+\left(T_{0}-T_{a m b}-\frac{K_{\alpha \tau_{0} n_{0} I}}{U_{L}}\right) e^{-\frac{U_{L} A_{C}}{M C} t} .
$$

The $\mathrm{K}_{\alpha \tau} \eta_{\mathrm{I}} \mathrm{I} / \mathrm{U}_{\mathrm{J}}$ term in the differential equation accounts for stagnation heating. $\alpha \tau^{\circ} \mathrm{MC}$ value for the collectors is found from the collector time constant $\tau_{c}$ as determined by ASHRAE 93-77 and input as

$$
\begin{gathered}
\tau \equiv \frac{M C}{2 \dot{M} c_{p}} \\
M C=2 \tau_{c} \dot{M} c_{p},
\end{gathered}
$$

where $\dot{M}$ is the collector mass flow rate value used in the ASHRAE test. Once the array temperature is calculated, energy loss is determined as MC times the difference between that temperature and the one for the previous time step. (At shutdown, the average of inlet and outlet temperatures is used for the first value.) These calculations apply only to the collectors and not the header pipes. The headers are lumped into the pipe runs to and from the collector array, and their losses are determined with the supply/return pipe losses.

\section{C.1.2 Subroutine TROUGH}

The parabolic trough subroutine first calculates incident angle for a northsouth or east-west trough array. Direct insolation on the aperture is then calculated, correcting for row-to-row shading losses. Pump status is determined by comparing available radiation to an input critical intensity. If the radiation is sufficient, an incident-angle modifier is calculated from input coefficients. The average fluid temperature $\bar{T}$ is determined as follows: the energy collected per unit area is the product of efficiency and irradiation and also the product of mass flow rate, specific heat, and fluid temperature rise. Setting these quantities equal, we have

$$
n_{o_{A}} I-U_{1}\left(\bar{T}-T_{a m b}\right)-U_{2}\left(\bar{T}-T_{a m b}\right)^{2}=\dot{M} c_{p}\left(\bar{T}-T_{i n}\right) .
$$

SOLIPH then uses the quadratic formula to solve this equation for $\bar{T}$. When the average fluid temperature is known, efficiency can be calculated from the input coefficients. (Second-order equations are used for the troughs.) The energy collected is then $\eta_{C} I A$, and outlet temperature is calculated just as it is for stationary collectors.

For situations in which the pump is off, the decaying receiver temperature and associated energy loss are calculated just as for stationary collectors. The exception is that an input receiver mass is used, so that it does not have to be calculated from an input time constant. The stagnation term is not included because parabolic trough collectors would be defocussed when the pump is of $f$. 


\section{C.1.3 Subroutine PIPE}

If the pump is operating, pipe outlet temperature is determined from inlet temperature, ambient temperature, and input insulation, using the solution of a first-order ordinary differential equation (see Fig. C-2):

O.D.E:

$$
-\dot{\mathrm{M}} \mathrm{c}_{\mathrm{p}} \frac{\mathrm{dT}}{\mathrm{dx}}=\mathrm{U \pi D}\left(\mathrm{T}-\mathrm{T}_{\mathrm{amb}}\right)
$$

B.C.:

$$
\left.T\right|_{x=0}=T_{i n}
$$

Soln.:

$$
T=T_{a m b}+\left(T_{\text {in }}-T_{a m b}\right) e^{-\frac{U \pi D}{\dot{M} c_{p}} x} .
$$

Energy lost is then

$$
\dot{\mathrm{Q}}_{\text {loss }}=\dot{\mathrm{M} \mathrm{c}_{\mathrm{p}}}\left(\mathrm{T}_{\text {out }}-\mathrm{T}_{\text {in }}\right) \text {. }
$$

To determine parasitic power, the Reynolds number is calculated first to determine which flow regime is present. The Colebrook equation determines the friction factor when flow is turbulent, and $f$ is calculated as $64 /$ Re when flow is laminar. For transitional flow, a simple linear interpolation between the two is used. Values for total equivalent pipe $L / D$, including fittings and elbows, are user inputs. Head is then determined as $H=f(L / D)\left(v^{2} / 2 g\right)$. For simplicity, a user input for average collector and heat exchanger pressure drops are added here, although they could also be in separate subroutines.

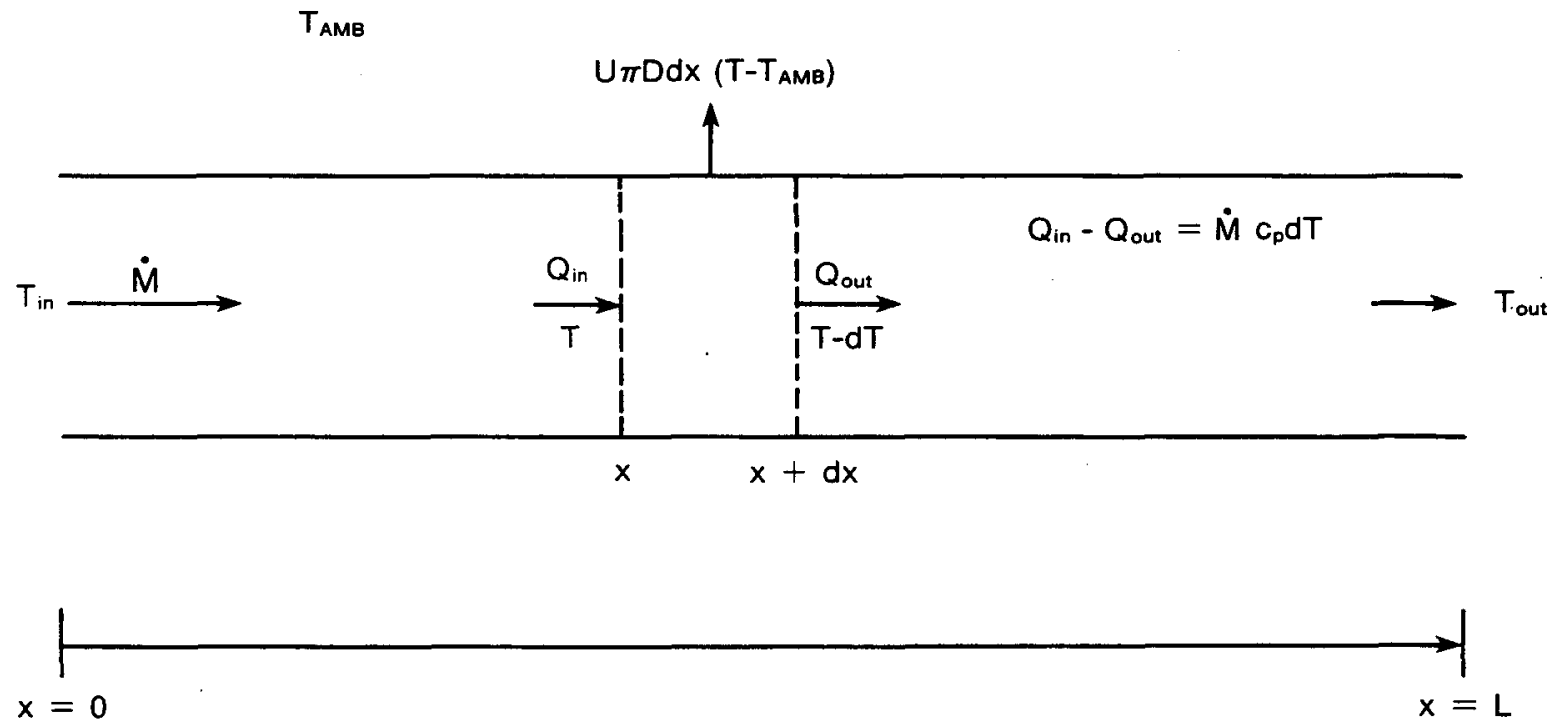

Figure C-2. Steady-State Pipe Loss Energy Balance 
If the pump is off, the solution for temperature decay is similar to that for the collectors:

$$
T=T_{a m b}+\left(T_{o}-T_{a m b}\right) e^{-\frac{U A}{M c_{p}} t} .
$$

The Mc product includes both the fluid and pipe metal. (Insulation heat capacity is usually neglected.) The cooldown energy loss is then the product of $\mathrm{Mc}_{\mathrm{p}}$ and the average temperature change over a time step. Note that this can be negative for the collectors and pipe. If they have cooled down to ambient and the ambient temperature rises, there will be a heat gain.

\section{C.1.4 Subroutine HX}

The heat exchanger subroutine uses the flow rates, hot and cold inlet temperatures, and the input effectiveness $\varepsilon$ to compute the hot and cold outlet temperatures using simple heat exchanger effectiveness equations (see Fig. C-3). Thus, we have

$$
T_{c-\text { out }}=T_{h-i n}-\varepsilon \frac{C_{\text {min }}}{C_{h}}\left(T_{h-i n}-T_{c-i n}\right)
$$

and

$$
T_{h-\text { out }}=T_{c-i n}+\varepsilon \frac{C_{\text {min }}}{C_{c}}\left(T_{h-i n}-T_{c-i n}\right),
$$

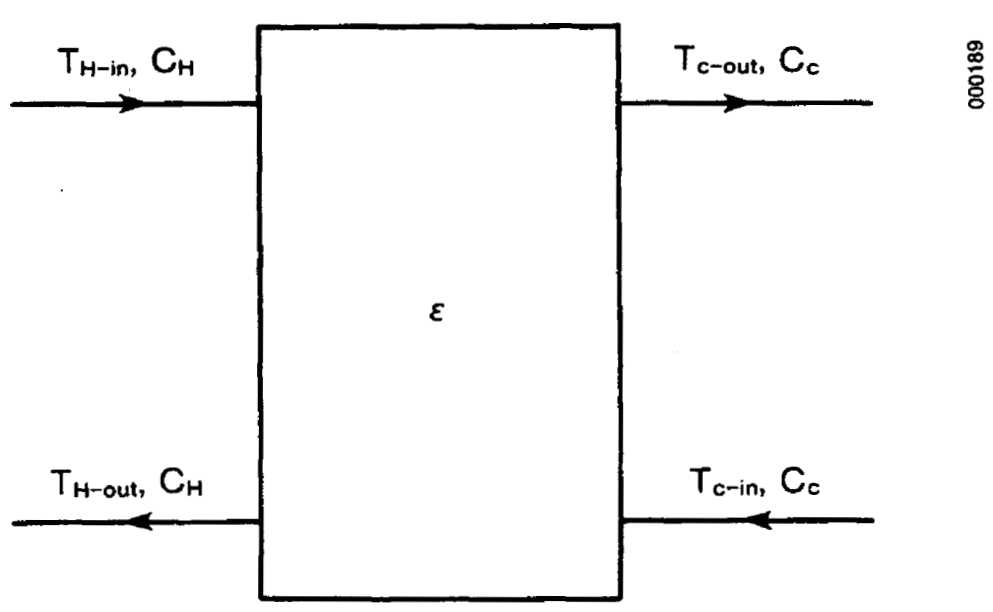

Figure C-3. SOLIPH Heat Exchanger Model 
where $C$ refers to heat capacitance flow rate, i.e., $\dot{M} c_{p}$ Heat exhanger thermal losses are considered to be negligible.

\section{C.1.5 Subroutine LOADS}

The LOADS subroutine supplies the load flow rate and return temperature at each hour needed to perform the loop energy balances. Load profiles and load delivery control schemes are changed by changing the code in LOADS. In a typical setup, LOADS first checks to see if a load exists for a given hour. If so, it calculates the difference between the storage tank and load return temperatures to determine whether flow should occur through storage. Several flags allow for a deadband, so that a $\Delta \mathrm{T}_{\text {on }} / \Delta \mathrm{T}_{\text {off }}$ control strategy can be used. The LOADS subroutine also has a mix valve capability that allows only a fraction of the load return fluid to pass through storage and then be mixed with bypassed load return fluid to limit the load supply temperature to a set value.

\section{C.1.6 Subroutine STORE}

The basic storage subroutine assumes mixed storage and takes skin losses into account. Flow into and out of storage occurs both on the collector side and the load side. If we call the inlet temperature on the collector (hot) side $\mathrm{T}_{\mathrm{h}}$ and the load return (cold) temperature to the tank $\mathrm{T}_{c}$, and the mixed storage temperature $\mathrm{T}$ (same as return to collectors and load supply) (see Fig. (-4), we have

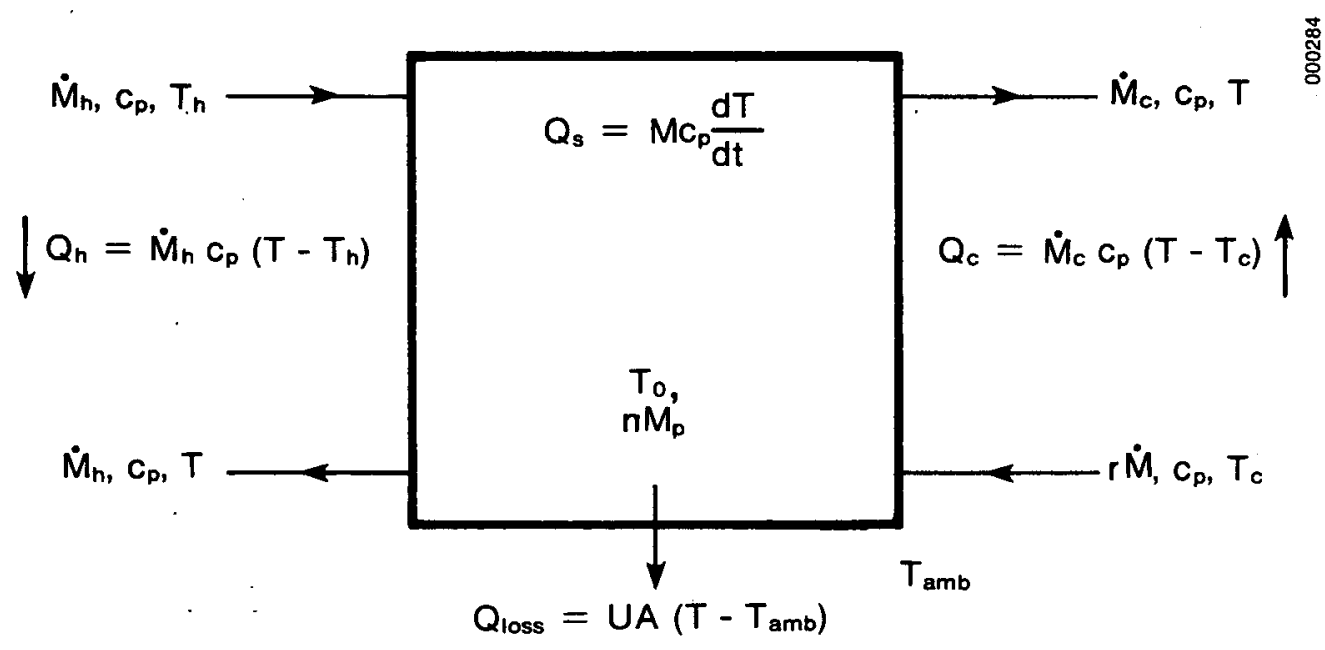

Figure C-4. SOLIPH Storage Tank Heat Balance 


$$
\begin{array}{ll}
\text { O.D.E.: } & M c_{p} \frac{d T}{d t}=\dot{M}_{h} c_{p}\left(T_{h}-T\right)-\dot{M}_{c} c_{p}\left(T-T_{c}\right)-U A\left(T-T_{a m b}\right) \\
\text { I.C.: } & \left.T\right|_{t=0}=T_{0} \\
\text { Soln.: } & T=T_{\infty}+\left(T_{0}-T_{\infty}\right) e^{-\frac{\dot{M}_{h} c_{p}+\dot{M}_{c} c_{p}+U A}{M c_{p}} t,}
\end{array}
$$

where

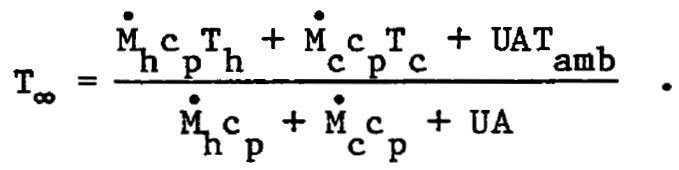

Note that, in the case of no flow on either side, the solution reduces to the same form as that for the pipe.

If $\mathrm{T}_{\mathrm{o}}$ is the storage tank temperature at the beginning of the time step, substituting in the time step (one hour) for $t$ in the above solution will give the tank temperature at the end of the time step. For the energy balance to work, however, we must use the average tank temperature during the time step $t^{\prime} ; i . e .$, we must integrate the above solution and divide by the time step. Thus,

$$
\bar{T}=\frac{1}{t^{t}} \int_{0}^{t^{\prime}} T d t
$$

The solution is

$$
T=T_{\infty}-\frac{T_{0}-T_{\infty}}{t^{\prime}} \cdot \frac{M c_{p}}{X}\left(e^{-\frac{X}{M c_{p}} t^{\prime}}-1\right),
$$

where $\mathrm{X}=\dot{\mathrm{M}}_{\mathrm{h}} c_{\mathrm{p}}+\dot{\mathrm{M}}_{c} c_{\mathrm{p}}+\mathrm{UA}$. The energy lost from storage is determined by integrating the product of $\mathrm{UA}$ and the difference between instantaneous storage-tank temperature and ambient temperature. Thus,

$$
\dot{Q}_{\text {loss }}=\int_{0}^{t^{\prime}} \mathrm{UA}\left(T-\mathrm{T}_{\mathrm{amb}}\right) \mathrm{dt} \text {, }
$$

the solution of which is

$$
Q_{\text {loss }}=U A\left(T_{\infty}-T_{a}\right) t^{\prime}+U A \frac{M c_{p}}{X}\left(T_{0}-T_{\infty}\right)\left(1-e^{\left.-\frac{X}{M c_{p}} t^{\prime}\right)}\right. \text {. }
$$

(We should emphasize here that, in all cases, SOLIPH merely uses the solution to a differential equation or integral rather than solves it.) The energy delivered to the load is calculated as the product of the load mass flow rate, specific heat, and difference between load return temperature and average storage temperature: 


$$
\dot{Q}_{d e 1}=\dot{M}_{c} c_{p}\left(\bar{T}-T_{c}\right)
$$

\section{C.1.7 Subroutine TCSTORE}

The thermocline storage subroutine (TCSTORE) is a simple 2-node model that works by stacking two mixed storage tanks, one on top of the other, and calling STORE twice. The storage volume and UA are divided equally between the two tanks. Energy delivered is the product of load flow rate, specific heat, and the difference between the top tank temperature and the load return temperature. Total energy loss is the sum of the losses from each tank.

\section{C.1.8 Subroutine BOILER}

This subroutine models an unfired boiler. The boiler is divided into a preheat section and a boiling section; total area is held constant. The temperature of the saturated steam to be delivered is specified, as are inlet hot (collector) and cold (load) temperatures and overall $\mathrm{U}$ value. Because thermal resistance on the oil (hot) side is dominant in both sections, using one $U$ value for both is a reasonable approximation. Oil flow can be varied to yield a constant steam flow (up to a specified limit), or a constant hot flow can yield a variable steam output. Outputs of the subroutine are hot-side outlet temperature and the unknown flow.

The algorithm solves four simultaneous equations. Two are heat exchanger equations (using $Q=U A \cdot$ LMTD), one for the preheater, the other for the boiler. The other two are energy balance equations, one across the preheater, the other for the boiler (see Fig. C-5).

Boiler:

$$
\begin{gathered}
\left(\dot{M} c_{p}\right)_{o i 1}\left(T_{h}-T_{i}\right)=\frac{U A_{1}\left(T_{h}-T_{i}\right)}{\ln \left(\frac{T_{h}-T_{s}}{T_{i}-T_{s}}\right)} \\
\left(\dot{M} c_{p}\right)_{o i 1}\left(T_{h}-T_{i}\right)=\dot{M}_{w} h_{f g} .
\end{gathered}
$$

Preheater:

$$
\begin{gathered}
\left(\dot{M} c_{p}\right)_{o i l}\left(T_{i}-T_{c}\right)=\frac{U A_{2}\left[\left(T_{i}-T_{s}\right)-\left(T_{s}-T_{w}\right)\right]}{\ln \left(\frac{T_{i}-T_{S}}{T_{c}-T_{w}}\right)} \\
\left(\dot{M}_{p}\right)_{o i 1}\left(T_{i}-T_{c}\right)=\dot{M}_{w} c_{p w}\left(T_{s}-T_{w}\right) .
\end{gathered}
$$




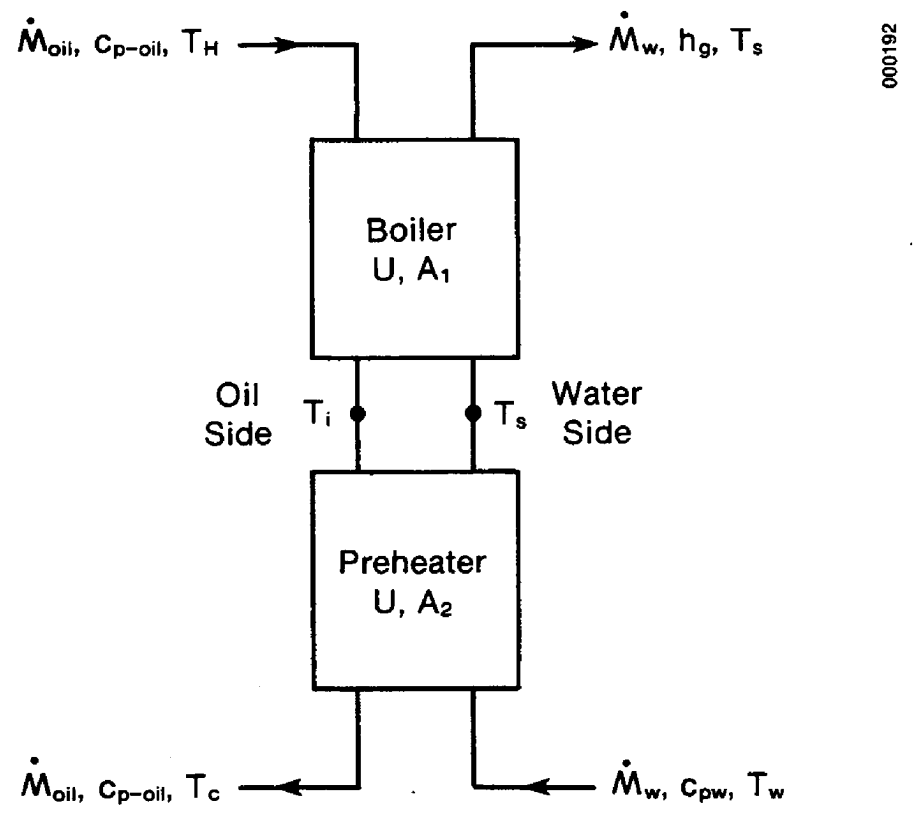

Figure C-5. SOLIPH Unfired Boiler Model

This gives us four equations in four unknowns: $T_{c}, T_{i}, A_{1}$, or $A_{2}$, and the unspecified flow. (We know the total area $A_{1}+A_{2}$, but do not know the breakdown.) Since the equations are nonlinear (two contain $10 g$ terms), we cannot solve them by Gaussian elimination. We must combine them into one equation in $\mathrm{R}$, defined as $\left(\dot{\mathrm{M}} \mathrm{c}_{\mathrm{p}}\right)_{\mathrm{oil}} /\left(\dot{\mathrm{M}} \mathrm{c}_{\mathrm{p}}\right)_{\mathrm{w}}$ to obtain

$$
\begin{aligned}
\mathrm{U}\left(\mathrm{A}_{1}+\mathrm{A}_{2}\right)= & \left(\dot{\mathrm{M}} \mathrm{p}_{\mathrm{p}}\right)_{o i 1} \mathrm{R}\left\{\ln \left[\frac{\mathrm{T}_{h}-\mathrm{T}_{s}}{\mathrm{~T}_{\mathrm{h}}-\mathrm{T}_{s}-\frac{1}{R}\left(\frac{\mathrm{h}_{f g}}{c_{p w}}\right)}\right]\right. \\
& +\frac{1}{1-R} \ln \left[\frac{\mathrm{T}_{h}-T_{s}-\frac{1}{R}\left(\frac{h_{f g}}{C_{p w}}\right)}{T_{h}-T_{w}-\frac{1}{R}\left(\frac{h_{f g}}{c_{p}}+T_{s}-T_{w}\right)}\right]
\end{aligned}
$$

Thus, we have one equation in one unknown, $R$. Subtracting $U\left(A_{1}+A_{2}\right)$ from both sides, we have an equation of the form $f(R)=0$. SOLIPH solves for the $R$ root by the Newton-Raphson method. Typically, fewer than five iterations are required. Once $R$, and hence the unknown flow rate, is determined, the energy delivered is calculated as 


$$
\dot{\mathrm{Q}}_{\mathrm{del}}=\dot{\mathrm{M}}_{\mathrm{w}}\left[\mathrm{h}_{\mathrm{fg}}+\mathrm{c}_{\mathrm{pw}}\left(\mathrm{T}_{\mathrm{s}}-\mathrm{T}_{\mathrm{w}}\right)\right] \text {, }
$$

and the oil return temperature as

$$
\mathrm{T}_{\mathrm{c}}=\mathrm{T}_{\mathrm{h}}-\frac{Q_{\mathrm{del}}}{\left(\dot{\mathrm{M}} \mathrm{c}_{\mathrm{p}}\right)_{\mathrm{oil}}}
$$

\section{C.1.9 Subroutine FLASH}

This subroutine models a flash valve, flash tank, and feedwater make-up valve (see Fig. (-6). All enthalpies are calculated as the product of specific heat and temperature, with the exception of saturated steam enthalpy $h_{g}$, which is determined from a separate steam properties subroutine (McClintock and Silvestri 1968).

\section{C.1.9.1 Flash Valve}

We assume that the pressure upstream of the flash valve is maintained at 5 psi greater than the saturation pressure (determined from the steam properties subroutine) in order to prevent boiling. Saturation pressure depends on the temperature at that point. The $\Delta P$ across the flash valve is, then, the difference between that upstream pressure and the saturation pressure of steam at

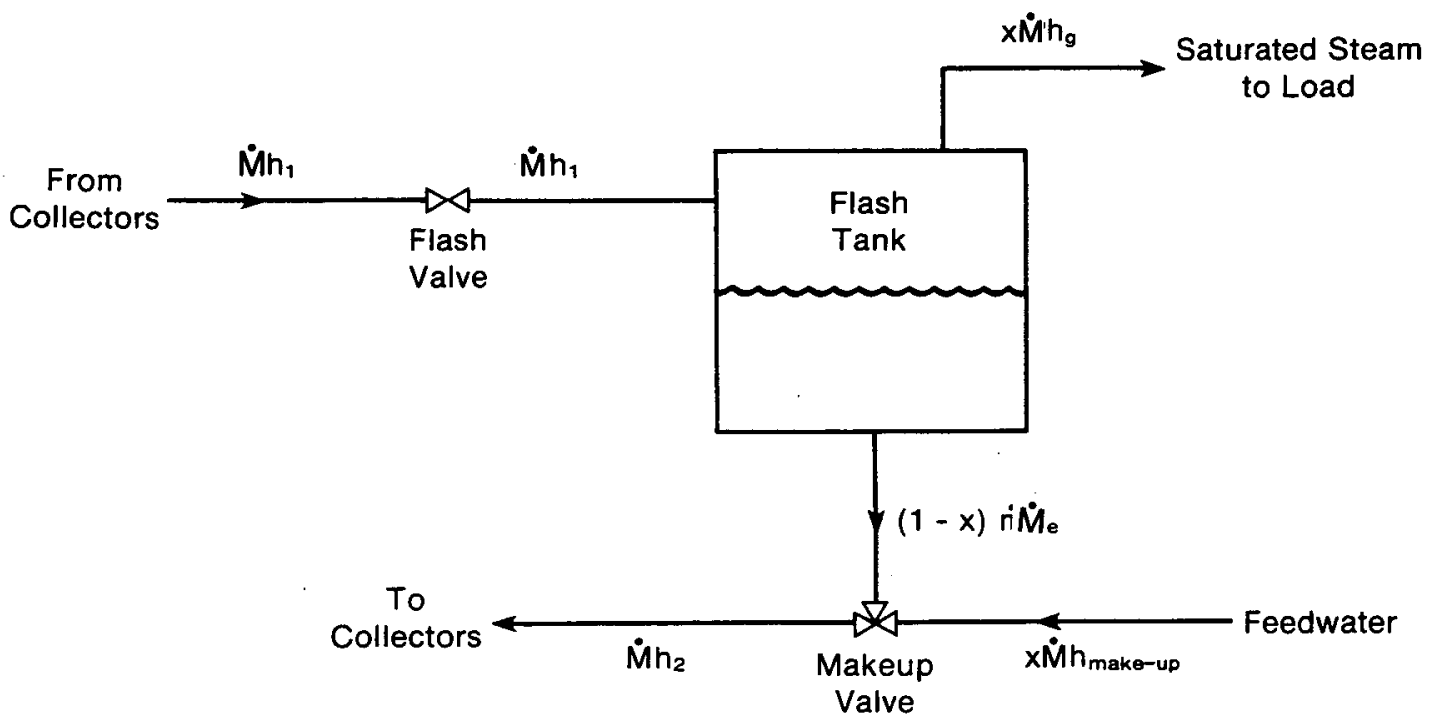

Figure C-6. SOLIPH Flash System Components and Energy Values 
the desired (input) delivery temperature. Parasitic power is calculated using this $\Delta \mathrm{P}$. If the upstream temperature is insufficient to supply steam at the desired temperature, the flash valve $\Delta P$ is arbitrarily set at 5 psi.

\section{C.1.9.2 Flash Tank}

First, the flash tank temperature is calculated as a function of time, with the same algorithm as that used in the storage tank subroutine. We assume for this calculation that no steam is delivered. Since the flash valve is a constant enthalpy device, this calculation is performed as if the upstream water were directly entering the flash tank. Thus,

$$
T=T_{\infty}+\left(T_{0}-T_{\infty}\right) e^{-\frac{\dot{\mathrm{M}}_{h} c_{p}+U A}{M c_{p}} t},
$$

where

$$
\mathrm{T}_{\infty}=\frac{\dot{\mathrm{M}}_{\mathrm{h}} \mathrm{c}_{\mathrm{p}} \mathrm{T}_{\mathrm{h}}+\mathrm{UAT}_{\mathrm{amb}}}{\dot{\mathrm{M}}_{\mathrm{h}} \mathrm{c}_{\mathrm{p}}+\mathrm{UA}},
$$

and $\dot{M}_{h} c_{h}$ is determined upstream of the flash valve. If the temperature $T$ at the end of the time step is less than the steam delivery temperature, no steam is delivered, and tank loss is calculated as it is in the storage subroutine:

$$
\dot{Q}_{10 s s}=U A\left(T_{\infty}-T_{a m b}\right) t^{\prime}+U A \frac{M c_{p}}{X}\left(T_{0}-T_{\infty}\right)\left[1-e^{-\frac{X}{M c_{p}} t^{\prime}}\right] \text {, }
$$

where $\mathrm{X}=\dot{\mathrm{M}}_{\mathrm{h}} \mathrm{c}_{\mathrm{p}}+\mathrm{UA}$. If the final calculated temperature exceeds the steam delivery temperature, and the initial temperature was less than the steam temperature, we must determine how long it took to reach the delivery temperature, since heating above this point is not physically possible. To do this, we replace $T$ with $T_{\text {steam }}$ in the temperature equation and solve for time, $\mathrm{t}_{\text {boil }}$. Energy loss during the heat-up period can be determined by substituting $t_{\text {boil }}$ for $t^{\prime}$ in the energy loss equation. For time step $t$ ', the time left after boiling is $t_{\text {left }}=t^{\prime}-t_{\text {boil }}$. During time $t_{\text {left }}$, the tank loss is simply

$$
Q_{s s, \text { loss }}=U A\left(T_{\text {steam }}-T_{\text {amb }}\right) t_{\text {left }} \text {. }
$$

To determine the amount of steam delivered, the steam quality must be calculated from an energy balance:

Enthalpy in $=$ steam enthalpy + recycled water enthalpy + heat losses + tank energy increase,

$$
\dot{\mathrm{Mh}}_{1}=\mathrm{x} \dot{\mathrm{Mh}}_{\mathrm{g}}+(1-\mathrm{x}) \dot{\mathrm{M}}_{\ell}+\dot{\mathrm{Q}}_{1 \text { oss }}+\dot{\mathrm{Q}}_{\text {inc }} \text {. }
$$

Solving for quality $x$,

$$
\mathrm{x}=\frac{\dot{\mathrm{Mh}}_{1}-\dot{\mathrm{Mh}}_{\ell}-\dot{\mathrm{Q}}_{\text {loss }}-\dot{\mathrm{Q}}_{\text {inc }}}{\dot{\mathrm{M}}\left(\mathrm{h}_{\mathrm{g}}-\mathrm{h}_{\ell}\right)} .
$$


The tank energy increase term is just

$$
\dot{Q}_{\text {inc }}=M c_{p}\left(T^{t}-T^{t-\Delta t}\right)
$$

Energy delivered to the load is the difference between enthalpy of delivered steam and enthalpy of the make-up water:

$$
\dot{Q}_{\mathrm{del}}=\mathrm{xM} g \dot{\mathrm{Mh}}_{\mathrm{g}}-\dot{\mathrm{xMh}}_{\text {make-up }} \text {. }
$$

\section{C.1.9.3 Make-up Va1ve}

One more energy balance is needed to determine the temperature of the water returned to the collectors. Referring to Fig. C-6, we find

Energy to collectors = energy from the tank + energy of make-up water,

$$
\begin{aligned}
\dot{M} h_{2} & =(1-x) \dot{M} h_{\ell}+x \dot{M}_{\text {make-up }} \text {, or } \\
\mathrm{h}_{2} & =(1-x) h_{\ell}+x h_{\text {make-up }} \text {. }
\end{aligned}
$$

The return temperature to the collectors $T_{2}$ is, then, $h_{2} / c_{p}$.

\section{C.2 VERIFICATION OF SOLIPH}

Because SOLIPH was written to make thousands of runs to generate design tools, it was important to check its accuracy. This was done using two methods: a "point" comparison of a specific detailed model with other recognized computer models and a parametric analysis compared with a recognized simplifed method. Fortunately, an IPH system had already been modeled simultaneously with several other codes. In mid-1979, a Systems Simulation and Economic Analysis Working Group sponsored by DOE modeled a sample problem IPH system with TRNSYS (two different programmers), DOE-2, and a code written at Los Alamos Scientific Laboratory which we will refer to as LASL. An attempt was also made to use the SOLTES program, but the user was unable to obtain satisfactory results in time. The example problem consisted of a CPC solar collector array, a heat exchanger, and a thermocline storage tank (Freeman 1980).

To check SOLIPH's performance, one of the task members modeled the sample problem with SOLIPH. Approximately 10 hours elapsed from the time work began until good results were output. Much of this time was spent incorporating a thermocline storage tank and mix valve which SOLIPH did not have at that time. Table C-2 shows monthly energy output results from SOLIPH compared with energy values supplied by the other programs. This comparison shows very good agreement for both the low- and high-temperature load cases.

Hourly plots of the storage tank temperature are given in Fig. C-7. Comparisons between the codes of energy collected and energy delivered on an hourly basis are shown in Figs. $\mathrm{C}-8$ and $\mathrm{C}-9$. In all cases, the codes are shown to agree very well. 
Table C-2. Comparison of SOLIPH Energy Outputs With Other Computer Models Used in SSEA Sample IPH Problem

\begin{tabular}{|c|c|c|c|c|c|c|c|}
\hline \multirow{2}{*}{$\begin{array}{l}\text { Computer } \\
\text { Mode1 }\end{array}$} & \multicolumn{5}{|c|}{$\begin{array}{c}\text { Open-Loop } \\
\text { Low-Temperature } \\
\text { Load }\end{array}$} & \multicolumn{2}{|c|}{$\begin{array}{l}\text { Closed-Loop } \\
\text { High-Tempera- } \\
\text { ture Load }\end{array}$} \\
\hline & $\begin{array}{c}\text { IHOR } \\
\left(\mathrm{MJ} / \mathrm{m}^{2}\right)\end{array}$ & $\begin{array}{l}\text { ICIN } \\
\text { (GJ) }\end{array}$ & $\begin{array}{l}\text { IACPT } \\
(G J)\end{array}$ & $\begin{array}{l}\text { QCOUT } \\
\text { (GJ) }\end{array}$ & $\begin{array}{l}\text { QSOUT } \\
\text { (GJ) }\end{array}$ & $\begin{array}{l}\text { QCOUT } \\
\text { (GJ) }\end{array}$ & $\begin{array}{l}\text { QSOUT } \\
\text { (GJ) }\end{array}$ \\
\hline \multicolumn{8}{|l|}{ January } \\
\hline $\begin{array}{l}\text { DOE-2 } \\
\text { TRNSYS (UW) } \\
\text { TRNSYS (ALTAS) } \\
\text { LASL } \\
\text { SOLIPH }\end{array}$ & $\begin{array}{l}345.0 \\
345.0 \\
345.0 \\
345.0 \\
344.6\end{array}$ & $\begin{array}{l}441.0 \\
444.0 \\
444.0 \\
444.0 \\
443.4\end{array}$ & $\begin{array}{l}419.0 \\
421.0 \\
423.0 \\
425.0 \\
424.4\end{array}$ & $\begin{array}{l}171.0 \\
172.0 \\
173.0 \\
172.0 \\
172.9\end{array}$ & $\begin{array}{l}164.0 \\
167.0 \\
166.0 \\
170.0 \\
166.8\end{array}$ & $\begin{array}{r}96.0 \\
98.0 \\
100.0 \\
90.0 \\
98.4\end{array}$ & $\begin{array}{l}73.0 \\
74.0 \\
76.0 \\
72.0 \\
77.4\end{array}$ \\
\hline \multicolumn{8}{|l|}{ July } \\
\hline $\begin{array}{l}\text { DOE-2 } \\
\text { TRNSYS (UW) } \\
\text { TRNSYS (ALTAS) } \\
\text { LASL } \\
\text { SOLIPH }\end{array}$ & $\begin{array}{l}876.0 \\
875.0 \\
875.0 \\
875.0 \\
874.7\end{array}$ & $\begin{array}{l}652.0 \\
645.0 \\
645.0 \\
647.0 \\
644.3\end{array}$ & $\begin{array}{l}590.0 \\
584.0 \\
588.0 \\
593.0 \\
592.8\end{array}$ & $\begin{array}{l}241.0 \\
241.0 \\
242.0 \\
243.0 \\
241.8\end{array}$ & $\begin{array}{l}235.0 \\
235.0 \\
234.0 \\
239.0 \\
235.1\end{array}$ & $\begin{array}{l}183.0 \\
179.0 \\
184.0 \\
174.0 \\
183.3\end{array}$ & $\begin{array}{l}166.0 \\
163.0 \\
167.0 \\
163.0 \\
167.9\end{array}$ \\
\hline \multicolumn{8}{|l|}{ Yearly Total } \\
\hline $\begin{array}{l}\text { DOE-2 } \\
\text { TRNSYS } \\
\text { TRNSYS (ALTAS) } \\
\text { LASL } \\
\text { SOLIPH }\end{array}$ & $\begin{array}{l}7625.0 \\
7625.0 \\
7625.0 \\
7628.0 \\
7624.7\end{array}$ & $\begin{array}{l}6980.0 \\
6987.0 \\
6987.0 \\
6980.0 \\
6970.0\end{array}$ & $\begin{array}{l}6408.0 \\
6396.0 \\
6431.0 \\
6468.0 \\
6492.0\end{array}$ & $\begin{array}{l}2622.0 \\
2626.0 \\
2646.0 \\
2639.0 \\
2653.0\end{array}$ & $\begin{array}{l}2472.0 \\
2485.0 \\
2482.0 \\
2531.0 \\
2501.0\end{array}$ & $\begin{array}{l}1838.0 \\
1828.0 \\
1880.0 \\
1762.0 \\
1863.0\end{array}$ & $\begin{array}{l}1559.0 \\
1552.0 \\
1588.0 \\
1545.0 \\
1595.0\end{array}$ \\
\hline
\end{tabular}

To test SOLIPH over a wide range of parameters, a variation study was conducted against FCHART 4.0. FCHART 4.0 is widely recognized and simple to run. A total of 20 annual runs of a simple flat-plate collector configuration were made with varlous combinations of the following 14 parameters:

- Collector peak optical efficiency

- Collector $\mathrm{U}_{\mathrm{L}}$ value

- Collector tilt

- Collector area

- Collector incident-angle modifier

- Ground reflectance

- Collector loop flow rate

- Steady-state pipe losses

- Storage size 


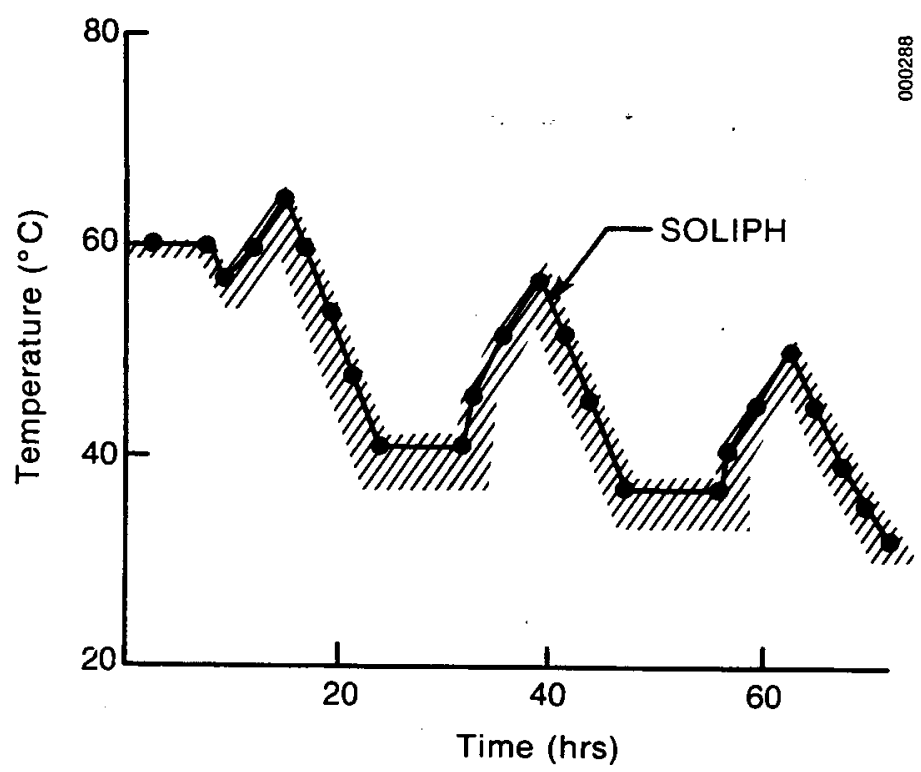

Figure C-7. Bottom Storage Tank Temperature vs. Time for SOLIPH and SSEA Results

(The shaded area represents the range of SSEA results.)

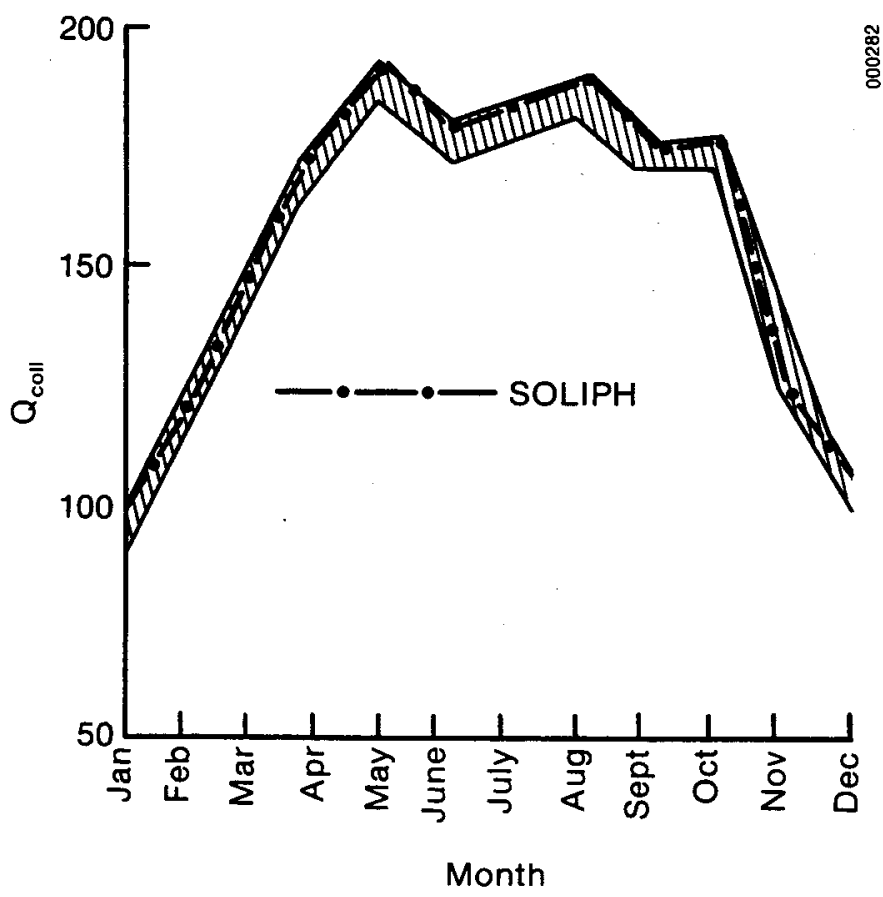

Figure C-8. Energy Collection Comparison Between SOLIPH and SSEA Results (The shaded area represents the range of SSEA results.) 


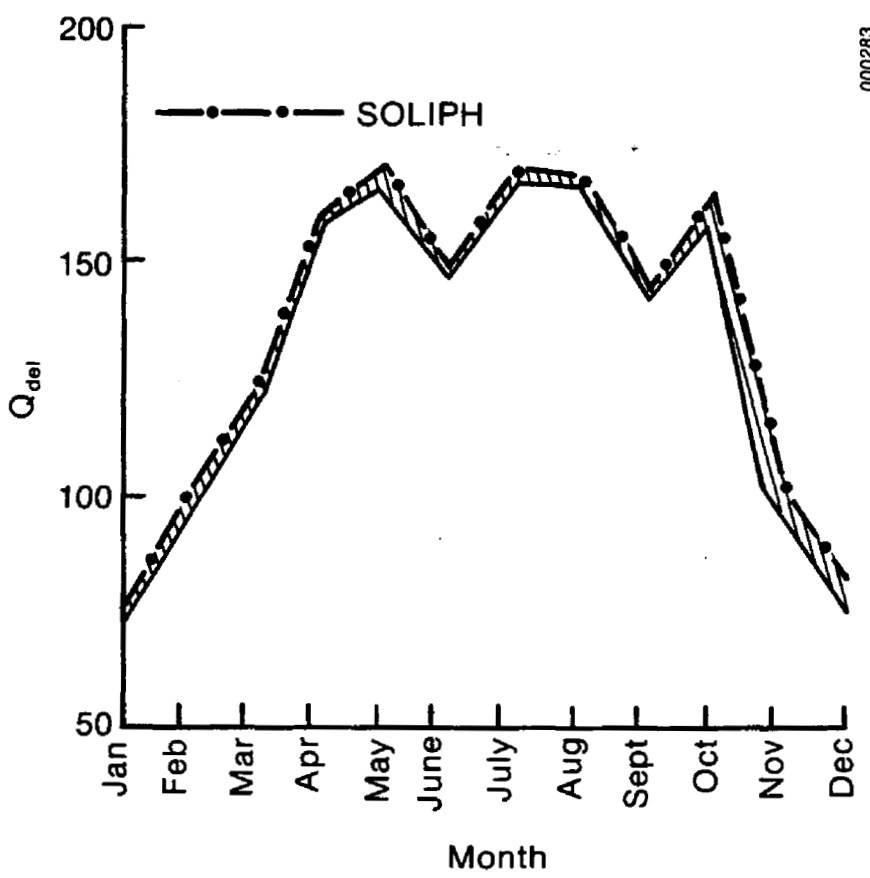

Figure C-9. Energy Delivery Comparison of SOLIPH and SSEA Results

(The shaded area represents the range of SSEA results.)

- Storage skin losses

- Load flow rate

- Storage tank minimum discharge temperature

- Load profile

- Load return temperature.

To permit a good comparison, all runs were made for one city, Albuquerque, and FCHART monthly insolation values were adjusted to agree with the TMY tape. Energy delivery values from SOLIPH and FCHART agreed to within $5 \%$ for 15 of the 20 runs. This agreement is considered good, since FCHART is a monthly code, and its accuracy is expected to be in the range of $5 \%$. Five of the runs, however, showed differences of from $5 \%$ to $11 \%$. In these runs, temperatures were higher than in the other cases. To determine the cause of these differences, we consulted with the University of Wisconsin Solar Laboratory, which developed FCHART and TRNSYS, the detailed hour-by-hour code from which FCHART was derived. The Solar Laboratory made several TRNSYS runs for direct comparison with SOLIPH runs. TRNSYS and SOLIPH agree in each case to within $1-1 / 2 \%$, but both exhibited differences from FCHART. The hypothesis was that the lower energy values from FCHART resulted because FCHART algorithms are more conservative at higher temperatures. In any case, the agreement between SOLIPH and TRNSYS further supported the accuracy of SOLIPH. 
To check the accuracy of the SOLIPH TROUGH subroutine, parabolic trough runs were compared with Sandia-Albuquerque trough predictions. Again, excellent agreement was found. Thus, the basic nonsteam components of SOLIPH have been verified. However, the unfired-boiler and flash-tank subroutines, the most recently developed SOLIPH capabilities, have not yet been verified. Indeed, TRNSYS and FCHART do not have these capabilities. Comparisons of SOLIPH outputs with hand calculations and checks on energy balances, however, lend credibility to their accuracy.

No attempt has yet been made to validate SOLIPH against field measurements, although TRNSYS has been validated for some solar heating cases. In genera1, differences between energy values measured in the field and those of a good computer model arise from inaccurate inputs to the computer model, rather than from inaccuracies in the model algorithms. For example, when SOLIPH models the heat loss from a 500-ft run of collector array return pipe, it uses an overall pipe loss coefficient as input. If the user inputs a $U$ value based only on the amount of pipe insulation, SOLIPH will probably underpredict the temperature drop in the pipe as compared with a field measurement, since piping in the field contains many heat loss mechanisms (such as, for example, uninsulated flanges and pipe supports).

In that case, code "validation" often involves simply trying higher $U$ values until the code results agree with the field measurements. The model has not been changed, but the input has been improved, although we do not know that the new U-value is entirely accurate. And we cannot be sure that the results are extremely accurate. In a well-insulated pipe, the temperature drop may be less than $1^{\circ} \mathrm{C}$. With a large mass flow rate, thermal losses can still be significant. But it is very difficult to measure them with great accuracy because of the problems associated with measuring a very small $\Delta T$. Thus, the experimental measurement used for the benchmark may itself only be accurate to within, say, $15 \%$. The point of all this is that experimental validation of a computer model does not ensure good results. The results can only be as accurate as the inputs.

\section{C.3 THE USE OF SOLIPH}

Because of its lack of user-oriented special features, SOLIPH is relatively fast running. A year-long, hour-by-hour simulation of a system that includes a collector array, heat exchanger, storage, and associated piping takes about $10 \mathrm{CPU}$ seconds of execution time. This amounts to a total cost of about $\$ 3.00$ on SERI's CDC 7600 computer. However, the thousands of runs needed to generate design tools resulted in a substantial expenditure for computer time.

Since the original version of SOLIPH was completed in early 1981, IPH handbook task members have contributed a large number of improvements to the model. The authors hope that future funding might permit SOLIPH's capabilities to be exploited further, to generate results that could not be obtained before publication of this handbook. More details on SOLIPH can be found in work by Kutscher (forthcoming). 


\section{C.4 REFERENCES}

Freeman, T. L. 1980 (Jan.). "A Comparison of the Predicted Performance of Several Solar System Simulation Codes for an Industrial Process Heating System." Proceedings of the Systems Simulation and Economic Analys is Conference. SERI/TP-351-431. Golden, CO: Solar Energy Research Institute.

Kutscher, C. F. Forthcoming. SOLIPH--A Detailed Computer Model of Solar Industrial Process Heat Systems. SERI/TR-253-1481. Golden, C0: Solar Energy Research Institute.

McClintock, R. B.; Silvestri, G. J. 1968. Formulations and Iterative Procedures for the Calculation of Properties of Steam. New York: The American Society of Mechanical Engineers. 


\section{S=PI}




\section{APPENDIX D}

\section{DERIVATION OF ANNUAL-PERPORMANCE EMPIRICAL CORREILATIONS}

An accurate closed-form solution for the annual energy collection of a solar system is not feasible because of the dynamic nature of the many variables that affect solar system performance. Instead, empirical correlations, as presented in Sec. 6.0, have been used. This appendix describes the approach used to provide those empirical correlations, presents the derivation of appropriate variable groupings for the key empirical correlations, and discusses the accuracy of the correlations.

\section{D.1 GENERAL METHODOLOGY}

The empirical correlations in Sec. 6.0 were based on the annual results of a detailed, hour-by-hour IPH system computer model, SOLIPH, described in Appendix $C$. Numerous SOLIPH runs were made to provide a sufficiently large data base to use in developing the empirical correlations. We made these computer runs so that the resulting empirical correlations would largely eliminate the need for others to make detailed computer simulations for each IPH system they design.

Simple first- or second-order polynomials were found to provide accurate, easy-to-use empirical correlations. They were generated with a multivariable regression analysis computer routine which provided polynomial fits to the annual results of detailed IPH system simulations. The regression analysis routine provided coefficients to the specific polynomial that minimized the sum of the squared differences between the SoLIPH-generated data points and the empirical fit.

First- or second-order polynomials were used to keep the empirical correlations as simple as possible. If high-order polynomial fits with many coefficients are provided, the fit may not correlate physically significant characteristics. Instead, extraneous polynomial terms may be fitting random fluctuations. This potential problem is especially significant with a small data base. The general rule in generating these empirical correlations is to keep the order of the polynomial as low as possible while maintaining a better than $4 \%$ accuracy (rms error).

The empirical annual energy correlations are somewhat subject to the weather and dependent on the solar irradiation data base used by the computer model. SOLIPH read hourly weather and solar irradiation data from Typical Meteorological Year (TMY) tapes. We selected these tapes because they were generated from long-term average weather and insolation information for each site. TMY tapes were available for the 26 stations of the SOLMET network. These stations are well distributed over the continental United States, as shown in Fig. D-1, and provide a suitably broad data base for empirical correlations. The total horizontal irradiation data on the tapes were measured values, while the direct normal insolation data were calculated from an algorithm, derived by the Aerospace Corporation, that measured direct normal irradiation data for five stations. 


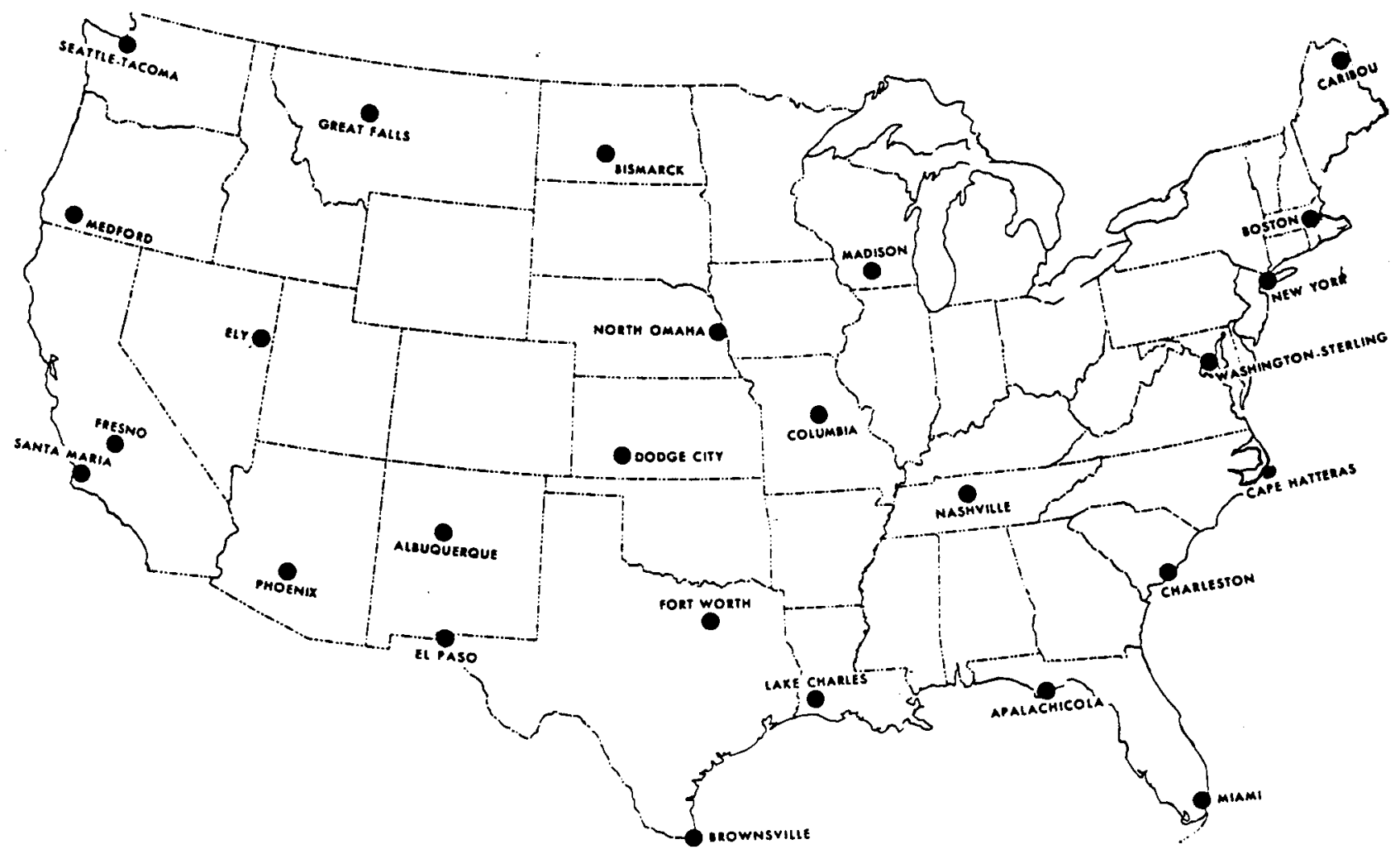

Figure D-1. The 26 Stations of the SOLMET Data Network 


\section{D.2 DERIVATION OF VARIABLE GROUPINGS}

The key factor in making accurate empirical correlations is to properly select the variable groupings used in the empirical correlation. Appropriate variable groupings are determined by investigating the algebraic form that the empirical solution (or in some cases, multiple solutions) would take. The form and the variables of these expressions indicate which variable groupings will produce accurate empirical correlations. Examples of the derivation of several correlations in Sec. 6.0 are given in the subsections that follow.

\section{D.2.1 The Base Annual Energy Collection Correlation}

The principal empirical correlation given in Sec. 6.0 is the correlation for average energy collection rate $q_{c}$, shown in $\mathrm{Fig} .6-1$. The variable groupings that produced these accurate, but simple, empirical correlations were identified in Eq. 6-3, the instantaneous rate energy collection equation.

Consider replacing all of these instantaneous values with long-term average values. (Long-term average values are denoted by a bar.) We can then write

$$
\overline{\dot{q}}_{c}=F_{s} F_{R}\left[\bar{I}_{a} \bar{\eta}_{o}-\bar{U}_{L}\left(T_{i n}-\bar{T}_{a}\right)\right] \text {. }
$$

$F_{R}$ and $F_{S}$ are constants for constant loop flow rates and a given heat exchanger.

Dividing through by $F_{S} F_{R} \bar{I}_{a} \bar{\eta}_{O}$, we obtain

$$
\frac{\overline{\dot{q}}_{c}}{F_{s} F_{R} \bar{I}_{a} \bar{n}_{0}}=1-\frac{\bar{U}_{L}\left(T_{\text {in }}-\bar{T}_{a}\right)}{\bar{I}_{a} \bar{n}_{0}} \text {. }
$$

This equation suggests that the average energy collection rate (normalized by the grouping $F_{S} F_{R} \bar{I}_{a} \bar{\eta}_{0}$ ) can be correlated as a function only of the variable grouping

$$
\frac{\bar{U}_{L}\left(T_{i n}-\bar{T}_{a}\right)}{\bar{I}_{a} \bar{n}_{0}} \text {. }
$$

However, the closed-form solution implied by Eq. D-1 cannot be used directly, because it solves for an instantaneous collection rate, given the average values of $\bar{U}_{\mathrm{L}}, \overline{\mathrm{T}}_{\mathrm{a}}, \overline{\mathrm{I}}_{\mathrm{a}}$, and $\bar{\eta}_{\mathrm{o}}$. This is not the same as the long-term average collection rate, given the average, but time-varying, values of $\bar{U}_{L}, \bar{T}_{a}, \bar{I}_{a}$, and $\bar{n}_{0}$. The value of Eq. D-1 lies in its suggestion that the long-term average energy collection rate, when normalized by the terms $F_{s}, F_{R}, I_{a}$, and $\bar{n}_{0}$, can be correlated as a function of only one variable grouping. With this form of an empirical correlation, an accurate, long-term average energy collection rate correlation has been determined. However, the empirical correlation given in Sec. 6.0 involves several further simplifications. 
First, we must replace the average collector heat-loss coefficient $\bar{U}_{\mathrm{L}}$ with a single value. Usually, $U_{\mathrm{I}}$ is considered to be a constant; this allows no compromise. Sometimes a collector's efficiency equation is fit to second order, and $\mathrm{U}_{\mathrm{L}}$ becomes a function of temperature. If so, we use the $\mathrm{U}_{\mathrm{L}}$ value as defined by the process load temperature. This assumption causes little loss in the accuracy of the empirical correlation because the second-order term is usually relatively small.

Next, we replace the long-term average optical efficiency $\bar{n}_{0}$ with the peak normal incidence optical efficiency $\eta_{0}$, which eliminates the need to account for incident-angle modifier effects at this point in the performance analysis. (Incident-angle effects are accounted for in Sec. 6.2.1.)

Finally, we deal with the quantity $\bar{I}_{a}$, the long-term average available irradiance on the aperture of the collector. This quantity is not easily defined, so we prefer a readily available irradiance measure that requires no further calculations. If such an irradiance measure is available and is directly proportional to $\bar{I}_{a}$, it can replace $\bar{I}_{a}$. The constant of proportionality is accounted for in the formulation of the empirical correlations. Adding another variable, site latitude, the long-term average values of total horizontal irradiance and direct normal irradiance yield this proportionality. For flat-plate and evacuated-tube collectors, the total horizontal irradiance is used. For parabolic trough collectors, the direct normal irradiance is used. Both of these irradiance measures are readily available from contour maps (see Figs. 3-1 and 3-2).

Now long-term average energy collection can be correlated as a function of the variable grouping

$$
\frac{U_{L}\left(T_{i n}-\bar{T}_{a}\right)}{\bar{I}_{h} n_{0}}
$$

for flat-plate and evacuated-tube collectors, and

$$
\frac{U_{L}\left(T_{i n}-\bar{T}_{a}\right)}{\bar{I}_{b} n_{o}}
$$

for parabolic troughs. This variable is the intensity ratio and serves as the basis of the empirical correlations given in Fig. 6-1. As noted in this discussion, the only additional variable needed is the site latitude.

\section{D.2.2 Mixed-Tank, Recirculation System Load/Storage Annual Modifier}

The modifier $F_{\ell-s}$ provided in Sec. 6.1.1.2 accounts for the impact that storage size and process load profile have on energy collection for a recirculation system. The analysis that provided the variable groupings that define $F_{\ell-S}$ follows.

As described in Sec. 6.1, instantaneous energy collection for a recirculation system can be written as 


$$
\dot{q}_{c}=F_{X} F_{R}\left[\bar{I}_{a} n_{0}-U_{L}\left(T_{s}-\bar{T}_{a}\right)\right],
$$

where $T_{s}$ is the storage temperature.

However, the average storage tank temperature for a recirculation (four-pipe storage) system is not a known quantity. Storage tank temperature varies during collector operation as the tank is charged and discharged. The effect of this variation on energy collection can be examined by considering the average elevation of the storage tank temperature. If $Q_{s t o r}$ is the average energy stored in the tank over a given time period, then

$$
Q_{s t o r}=Q_{c}-Q_{d} \text {, }
$$

where

$$
\begin{aligned}
Q_{c}= & \text { energy collected by the solar system } \\
Q_{d}= & \text { average process demand provided from storage while the collectors } \\
& \text { are operating. }
\end{aligned}
$$

The process load use rate is given by

$$
\dot{Q}_{p}=\dot{M}_{1 o a d} c_{p}\left(T_{\ell}-T_{\ell, r}\right) \text {, }
$$

where

$$
\begin{aligned}
\mathrm{T}_{\ell} & =\text { load supply temperature } \\
\mathrm{T}_{\ell, \mathrm{r}} & =\text { load return temperature. }
\end{aligned}
$$

Because all the process flow is preheated through the solar storage tank, the energy delivery rate to the process load is

$$
\dot{\mathrm{Q}}_{\mathrm{d}}=\dot{\mathrm{M}}_{10 \mathrm{ad}} \mathrm{c}_{\mathrm{p}}\left(\mathrm{T}_{\mathrm{s}}-\mathrm{T}_{\ell, \mathrm{r}}\right) \text {, }
$$

where $T_{S}$ is the temperature of the mixed storage tank.

Equations $D-4$ and $D-5$ can be combined to yield

$$
\dot{Q}_{\mathrm{d}}=\dot{\mathrm{Q}}_{\mathrm{p}}\left(\frac{\mathrm{T}_{\mathrm{s}}-\mathrm{T}_{\ell, \mathrm{r}}}{\mathrm{T}_{\ell}-\mathrm{T}_{\ell, \mathrm{r}}}\right)
$$

If $\mathrm{T}_{\ell}$ is greater than $\mathrm{T}_{s}$, the solar system supplies only a portion of the delivered energy. However, if $T_{s}$ exceeds $T_{\ell}, Q_{d}$ is limited to $Q_{r}$, which means that the energy delivery from the solar storage tank cannot exceed the process demand. This is generally accomplished by using a mixing valve which limits the load supply temperature to $T_{\ell}$. Thus, over an average daytime period, the energy delivery from storage is

$$
Q_{d}=Q_{p} C \min \left\{\frac{\bar{T}_{s}-T_{\ell, r}}{T_{\ell}-T_{\ell, r}}, 1\right\} \text {, }
$$


where

$$
\begin{aligned}
\overline{\mathrm{T}}_{\mathrm{S}}= & \text { average storage tank temperature during the time period } \\
\mathrm{C}= & \mathrm{a} \text { constant to account for the difference in operating hours of } \\
& \text { the process and the solar system. }
\end{aligned}
$$

Thus, the energy provided from the collectors to storage and then to the process load depends on the storage tank temperature. The elevation in storage tank temperature during a given time increment $\Delta t$ is

$$
\Delta \mathrm{T}_{\mathbf{s}}=\frac{\dot{\mathrm{Q}}_{\mathrm{s}} \Delta \mathrm{t}}{(\mathrm{Mc})_{\mathrm{stor}}}
$$

and since the tank is generally only discharged down to $T_{\ell, r}$, the average tank temperature is approximately

$$
\bar{T}_{s}=T_{\ell, r}+\frac{\dot{Q}_{s} \Delta t}{2\left(M c_{p}\right)_{s t o r}}
$$

From Eqs. $D-3$ and $D-7$, the average storage tank temperature can be written as

$$
\bar{T}_{s}=T_{\ell, r}+\frac{\dot{Q}_{c} \Delta t}{2\left(M c_{p}\right)_{s t o r}}-\frac{\dot{Q}_{p} \Delta t}{2\left(M c_{p}\right)_{s t o r}} C \min \left\{\frac{\bar{T}_{s}-T_{\ell, r}}{T_{l}-T_{\ell, r}}, 1\right\}
$$

The two solutions are now separated--one when the mixing valve is not being used and one when it is.

\section{D.2.2.1 Case 1: No Mixing Valve}

Solving Eq. D-10, when

$$
\frac{\bar{T}_{s}-T_{\ell, r}}{T_{\ell}-T_{\ell, r}}<1,
$$

we have

$$
\bar{T}_{s}=T_{\ell, r}+\frac{\dot{Q}_{c} \Delta t / 2\left(M_{p}\right)_{s t o r}}{1+\frac{\dot{Q}_{p} c \Delta t}{2\left(M c_{p}\right)_{s t o r}\left(T_{\ell}-T_{\ell, r}\right)}} \text {. }
$$

Now, substituting the solutions for $\bar{T}_{S}$ into Eq. D-2 and solving for $\dot{Q}_{C}$ on a per unit collector area basis (denoted as $q_{c}$ ), 


$$
\overline{\dot{q}}_{c}=\frac{\mathrm{F}_{\mathrm{X}} \mathrm{F}_{\mathrm{R}}\left[\overline{\mathrm{T}}_{\mathrm{a}} \eta_{\mathrm{O}}-\mathrm{U}_{\mathrm{L}}\left(\mathrm{T}_{\ell, \mathrm{r}}-\overline{\mathrm{T}}_{\mathrm{a}}\right)\right]}{1+\frac{\left.\Delta \mathrm{tF} \mathrm{F}_{\mathrm{R}} \mathrm{F}_{\mathrm{L}} /\left[2(\mathrm{mc})_{\mathrm{p}}\right)_{\text {stor }}\right]}{1+\dot{\mathrm{q}}_{\mathrm{p}} \Delta \mathrm{tC} /\left[2\left(\mathrm{mc} \mathrm{c}_{\mathrm{p}}\right)_{\text {stor }}\left(\mathrm{T}_{\ell}-\mathrm{T}_{\ell, \mathrm{r}}\right)\right]}}
$$

where (mcp) stor is the storage tank thermal capacitance per unit collector area. Note that the numerator is the energy collection rate for a solar system with infinite storage in which the collector inlet temperature never rises above the load return temperature. This quantity is defined as $q_{c}, \infty$ :

$$
\overline{\dot{q}}_{c, \infty}=F_{X} F_{R}\left[\bar{I}_{a} n_{0}-U_{L}\left(T_{\ell, r}-\bar{T}_{a}\right)\right]
$$

Dividing Eq. D-12 by Eq. D-13 to obtain the load/storage modifier,

$$
\mathrm{F}_{\ell-\mathrm{s}}=\frac{\dot{\mathrm{q}}_{\mathrm{c}}}{\dot{\mathrm{q}}_{\mathrm{c}, \infty}}=\left\{1+\frac{\mathrm{F}_{\mathrm{X}} \mathrm{F}_{\mathrm{R}} \mathrm{U}_{\mathrm{L}} \Delta t /\left[2\left(\mathrm{mc} \mathrm{c}_{\mathrm{p}}\right)_{\text {stor }}\right]}{1+\dot{\mathrm{q}}_{\mathrm{p}} \Delta \mathrm{tC} /\left[2\left(\mathrm{mc} \mathrm{c}_{\mathrm{p}}\right)_{\text {stor }}\left(\mathrm{T} \ell-\mathrm{T}_{\ell, \mathrm{r}}\right)\right]}\right\}^{-1},
$$

or

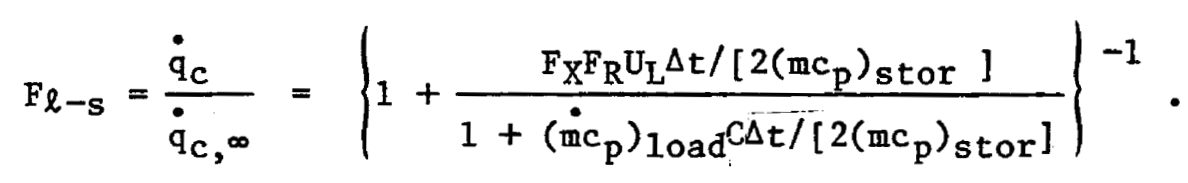

\section{D.2.2.2 Case 2: Mixing Valve}

Solving Eq. D-10, when

$$
\frac{\overline{\mathrm{T}}_{S}-\mathrm{T}_{\ell, \mathrm{r}}}{\mathrm{T}_{\ell}-\mathrm{T}_{\ell, \mathrm{r}}} \geqslant 1
$$

we have

$$
\overline{\mathrm{T}}_{s}=\mathrm{T}_{\ell, \mathrm{r}}+\frac{\dot{\mathrm{Q}}_{\mathrm{c}} \Delta t}{2\left(\mathrm{Mc}_{\mathrm{p}}\right)_{\text {stor }}}-\frac{\dot{\mathrm{Q}}_{\mathrm{p}} \Delta \mathrm{tC}}{2(\mathrm{Mc})_{\mathrm{p} t o r}} \text {. }
$$

Substituting $\overline{\mathrm{T}}_{\mathbf{S}}$ into Eq. $\mathrm{D}-2$ as before, yields

$$
\dot{q}_{c}=\frac{F_{X} F_{R}\left[\bar{I}_{a} \eta_{0}-U_{L}\left(T_{\ell, r}-\bar{T}_{a}\right)\right]}{1+\frac{F_{X} F_{R} U_{L} \Delta t}{2\left(m c_{p}\right)_{s t o r}}}+\frac{F_{X} F_{R} U_{L} \dot{q}_{p} \Delta t C}{2\left(m c_{p}\right)_{\text {stor }}}
$$

Again, dividing by $\dot{q}_{c}, \infty$ to obtain the load/storage modifier, 


$$
F_{1-s}=\frac{\dot{q}_{c}}{q_{c, \infty}}=\left[1+\frac{F_{X} F_{R} U_{L} \Delta t}{2\left(m c_{p}\right)_{s t o r}}\right]^{-1}+\frac{C F_{X} F_{R} U_{L} \dot{q}_{p} /\left[\dot{q}_{c, \infty} 2\left(m c_{p}\right)_{s t o r}\right]}{1+\frac{F_{X} F_{R} U_{L}}{2\left(m c_{p}\right)_{\text {stor }}}} \cdot(D-18)
$$

Note that in both cases the load/storage correction terms can be expressed in terms of only three variable groupings:

$$
\frac{\mathrm{F}_{\mathrm{X}} \mathrm{F}_{\mathrm{R}} \mathrm{U}_{\mathrm{L}}}{2\left(\mathrm{mc} \mathrm{c}_{\mathrm{p}}\right)_{\text {stor }}}, \frac{\dot{\mathrm{q}}_{\mathrm{c}, \infty}}{\dot{q}_{\mathrm{p}}} \text {, and } \frac{\left(\dot{\left.\mathrm{m} c_{p}\right)_{1 o a d}}\right.}{2(\mathrm{mc})_{\mathrm{ptor}}} \text {. }
$$

These three variable groupings are sufficient to define the storage/load correction term. If the constant $C$ in Eqs. $D-15$ and $D-18$ were known, and if it were possible to combine the solutions of Eqs. D-15 and D-18 based on the knowledge of how often the mixing valve is actually mixing fluid, one could conceivably solve directly for the storage/load correction factor. However, since this information is not available, the three variable groupings are correlated empirically with the results of the hour-by-hour computer simulations. The resulting polynomial expressions can be evaluated quickly for the impact of load profile and storage size. The value of deriving Eqs. D-15 and D-18 lies in finding the number and form of the variable groupings that will provide accurate empirical correlations.

Each of the three variable groupings is independent of the others in that none can be expressed as a combination of the others. Because they are independent, one variable grouping can be divided by another grouping and still remain independent. The third variable grouping was divided by the first grouping because the third grouping's range of values can be large, and it is inconvenient to express it graphically. The third grouping then becomes $\left(\mathrm{mc}_{\mathrm{p}}\right)_{\text {load }} /\left(\mathrm{F}_{\mathrm{X}} \mathrm{F}_{\mathrm{R}} \mathrm{U}_{\mathrm{L}}\right)$. Thus, the three independent variable groupings used for the graphic presentations of the storage/load modifiers are

$$
\dot{\mathrm{q}}_{\mathrm{c}, \infty} / \dot{\mathrm{q}}_{\mathrm{p}} ;(\mathrm{mc})_{\mathrm{p} t o r} / \mathrm{F}_{\mathrm{X}} \mathrm{F}_{\mathrm{R}} \mathrm{U}_{\mathrm{L}} ; \text { and }\left(\dot{\mathrm{m}}_{\mathrm{p}}\right)_{10 a d} / \dot{\mathrm{F}}_{\mathrm{X}} \mathrm{F}_{\mathrm{R}} \mathrm{U}_{\mathrm{L}} \text {. }
$$

\section{D.3 ACCURACY OF THE EMPIRICAL CORRELATIONS}

Several of the annual energy design tools given in Sec. 6.0 were based on regression analysis of the annual results of the computer code SOLIPH. In this section, we discuss the accuracy of these empirical correlations and the extent of the SOLIPH-generated data base upon which these fits were based.

First, consider the base energy collection correlations of Fig. 6-1. Data from all 26 stations were initially used in deriving energy collection correlations. These correlations are fundamental to the energy collection procedure; therefore, the entire weather data base was used. Hundreds of hour-byhour computer simulations of flat-plate, parabolic-trough, and evacuated-tube IPH systems were made to map the effects of various system-level variables. However, the empirical correlations that were generated from all of these data 
contained an anomaly. At high intensity ratios, the dependence of energy collection upon latitude was reversed for north-south parabolic troughs.

The source of this anomaly was the Seattle data--the TMY station with the lowest annual direct normal irradiation. The annual energy collection at this site, as determined by computer simulations, differs substantially from values calculated from the empirical fit. While the error is within $4 \%$ for intensity ratios below 0.3 , it increases to $5 \%$ at a critical intensity of 0.4 and then to $10 \%$ at a critical intensity of 0.6 . Above a critical intensity of 0.6 , the error remains at about $10 \%$. All of these errors are underestimation errors-that is, the empirical fit underestimates north-south parabolic trough energy collection for Seattle by up to $10 \%$. Because the data points for Seattle, which has a latitude of $47.5^{\circ}$, show such high deviations from the other data points, an empirical fit shifts to the Seattle data points. The shift is the natural result of a least squares fit. The resulting fit shows performance at high latitude locations to be as good as at low-latitude locations at the same direct normal irradiance, and at high intensity ratios. To avoid skewed correlations, the Seattle data points were not used in the regression analysis.

The Seattle data were also significantly different from the other 25 TMY sites for the flat-plate and evacuated-tube correlations. For these nontracking collectors, the Seattle data points were well below those predicted by the empirical fit. The empirical correlations provided in this handbook were found to be $11 \%$ to $17 \%$ too high for flat-plate and evacuated-tube collectors used in Seattle.

The uncharacteristic performance of Seattle solar systems as predicted by the TMY tape is puzzling. Although Seattle represents an extreme site because of its low annual irradiation, it is not clear why collector performance would be so atypical. The fact that the flat-plate correlation for seattle is an overestimate but the parabolic-trough correlation is an underestimate suggests that its diffuse-to-total-irradiation ratio is significantly higher than that of any of the other 25 sites. However, a thorough investigation of this anomaly was beyond the scope of this handbook. The fact that the empirical fits do not closely predict Seattle performance was not judged a great liability; this or a similar area is not likely to be a potential IPH site in the near future because of its poor annual irradiation. IPH systems in Seattle can be designed with the correlations in this handbook, but corrected according to the errors given above.

The accuracy of the unshaded annual energy collection correlations is shown in Table $\mathrm{D}-1$. The accuracy is tabulated in terms of relative rms error over the 25 stations. The relative rms error is defined as

$$
\varepsilon_{\mathrm{rms}}=\left[\frac{1}{\mathrm{n}} \sum_{i=1}^{n}\left(\frac{\dot{\mathrm{q}}_{\text {actual }}-\dot{\mathrm{q}}_{\mathrm{fit}}}{\dot{\mathrm{q}}_{\mathrm{fit}}}\right)^{2}\right]^{0.5},
$$

where $\dot{q}_{\text {actual }}$ is the actual energy collection as determined by the detailed hour-by-hour computer code, and $\mathrm{q}_{\mathrm{fit}}$ is the predicted energy collection as calculated from the empirical correlation. 
Table D-1. Accuracy of Annual Energy

Correlations in Fig. 6-1

\begin{tabular}{lc}
\hline \multicolumn{1}{c}{ Type of collector } & $\begin{array}{c}\text { rms Error } \\
(\%)\end{array}$ \\
\hline Flat plate/evacuated tube & 2.8 \\
East-west axis trough & 3.5 \\
North-south axis trough & 3.2 \\
\hline
\end{tabular}

The summation is taken over all the data points that were generated for that particular type of collector. About 300 computer runs for each type were sufficient to map out collector performance. The runs contained variations in collector operating temperature, collector $\mathrm{U}_{\mathrm{L}}$ value, and collector optical efficiency for the 25 TMY sites.

The load/storage modifiers provided in Sec. 6.1.1.2 for mixed-tank recirculation systems involved numerous variables. This variable quantity necessitated many annual SOLIPH runs, and over 400 SOLIPH runs were necessary for each SOLMET site considered. To keep the total number of runs needed for this design tool to a reasonable level, only 5 of the 26 solmET sites were considered. They were: Albuquerque, N. Mex.; Brownsville, Tex.; Caribou, Maine; Dodge City, Kans.; and Omaha, Neb. These sites were chosen because they represent wide ranges in annual irradiation and geographic latitude.

For each of the five cities and for all four types of collectors (parabolic troughs are counted twice because of the two tracking orientations), annual SOLIPH results were generated for parametric variations in load flow rate, load $\Delta \mathrm{T}$, storage size, and collector performance characteristics. The accuracy of the empirical correlations with respect to the SOLIPH runs is summarized in Table D-2:

Table D-2. Accuracy of Load/Storage

Modifiers in Figs. 6-4

Through 6-11

\begin{tabular}{lc}
\hline Type of Collector & $\begin{array}{c}\text { rms Error } \\
(\%)\end{array}$ \\
\hline Single-Shift Modifiers (8-hr day) \\
Flat plate & 3.2 \\
Evacuated tube & 3.4 \\
East-west axis trough & 2.9 \\
North-south axis trough & 3.8 \\
Three-Shift Modifiers (24-hr day) \\
Flat plate & 3.6 \\
Evacuated tube & 3.0 \\
East-west axis trough & 1.6 \\
North-south axis trough & 2.4 \\
\hline
\end{tabular}


The row-to-row shading-loss factors given in Sec. 6.3 were generated using all 26 SOLMET sites as the data base. As the $F_{\text {shade }}$ figures show, shading losses are defined by the latitude of the site and the ground-cover ratio. Other factors influence shading losses, but to a much smaller extent. For example, the operating temperature of the collector affects the time the collector begins operation. Collectors providing energy at high temperatures (high intensity ratios) require more irradiance before they can provide useful heat; therefore, they start slightly later in the morning than if they were providing lower-temperature energy. However, over the year, start-up time appeared to influence $F_{\text {shade }}$ only slightly. A relative rms error of less than $2 \%$ was found, and the largest errors occurred for large ground-cover ratios. In fact, for ground-cover ratios of 0.4 or below, the largest error in $F_{\text {shade }}$ for any of the 26 SOLMET sites was just above $1 \%$. 


\section{SEPI}




\section{APPENDIX $\mathbf{E}$ \\ DERIVATION OF ANNUAL PERFORMANCE MODIFIERS \\ $\mathbf{F}_{\mathrm{B}}, \mathbf{F}_{\mathbf{F}}, \mathbf{n}_{\mathbf{0}}$ ' and $\mathbf{U}_{\mathrm{L}}$ '}

This appendix presents the derivation of several annual performance modifiers. $F_{B}$ is the unfired-boiler steam system modifier used in Sec. 6.1.2.1. $\mathrm{F}_{\mathrm{F}}$ is the flash-steam system modifier. The modified optical efficiency $n_{0}$ ' and heat loss coefficient $\mathrm{U}_{\mathrm{L}}{ }^{\prime}$ are derived and shown to account for steadystate piping losses, as discussed in Sec. 6.4.1.

\section{E.1 $F_{B}$, THE UNFIRED-BOILER FACTOR}

Typically, energy collection of a solar collector (see Sec. 5.0) is written as

$$
\dot{\mathrm{q}}_{c}=\mathrm{F}_{\mathrm{R}} \mathrm{n}_{0} \mathrm{I}_{\mathrm{a}}-\mathrm{F}_{\mathrm{R}} \mathrm{U}_{\mathrm{L}}\left(\mathrm{T}_{\mathrm{c}, \mathrm{i}}-\mathrm{T}_{\mathrm{a}}\right) \text {, }
$$

where

$$
\begin{aligned}
& \dot{q}_{c}=\text { energy collection rate of solar collector per unit collector } \\
& \text { area } \\
& F_{R}=\text { collector heat removal efficiency factor } \\
& n_{0}=\text { collector optical efficiency } \\
& I_{a}=\text { available irradiance on collector plane } \\
& \mathrm{U}_{\mathrm{L}}=\text { collector overall heat-loss coefficient } \\
& T_{c, i}=\text { temperature of fluid at inlet to collector } \\
& \mathrm{T}_{\mathrm{a}}=\text { ambient temperature. }
\end{aligned}
$$

However, the collector inlet temperature is not a known quantity for an unfired-boiler system. Using the unfired-boiler factor $\mathrm{F}_{\mathrm{B}}$ permits energy collection to be written as

$$
\dot{q}_{c}=F_{B}\left[F_{R} n_{O} I_{a}-F_{R} U_{L} \cdot\left(T_{s}-T_{a}\right)\right],
$$

where $T_{S}$ is the steam saturation temperature.

To illustrate the derivation of $F_{B}$, consider the unfired-boiler system of Fig. E-1. Saturated water at temperature $T_{S}$ is supplied to the boiler and vaporized to produce saturated steam. The thermal energy required to vaporize the water is supplied by the fluid heated by the solar collectors. The temperature of this heated fluid is $T_{c, 0^{\circ}}$ As this fluid passes through the boiler, it cools to a temperature ${ }^{T} T_{c, i}$. The unfired boiler has a heat 


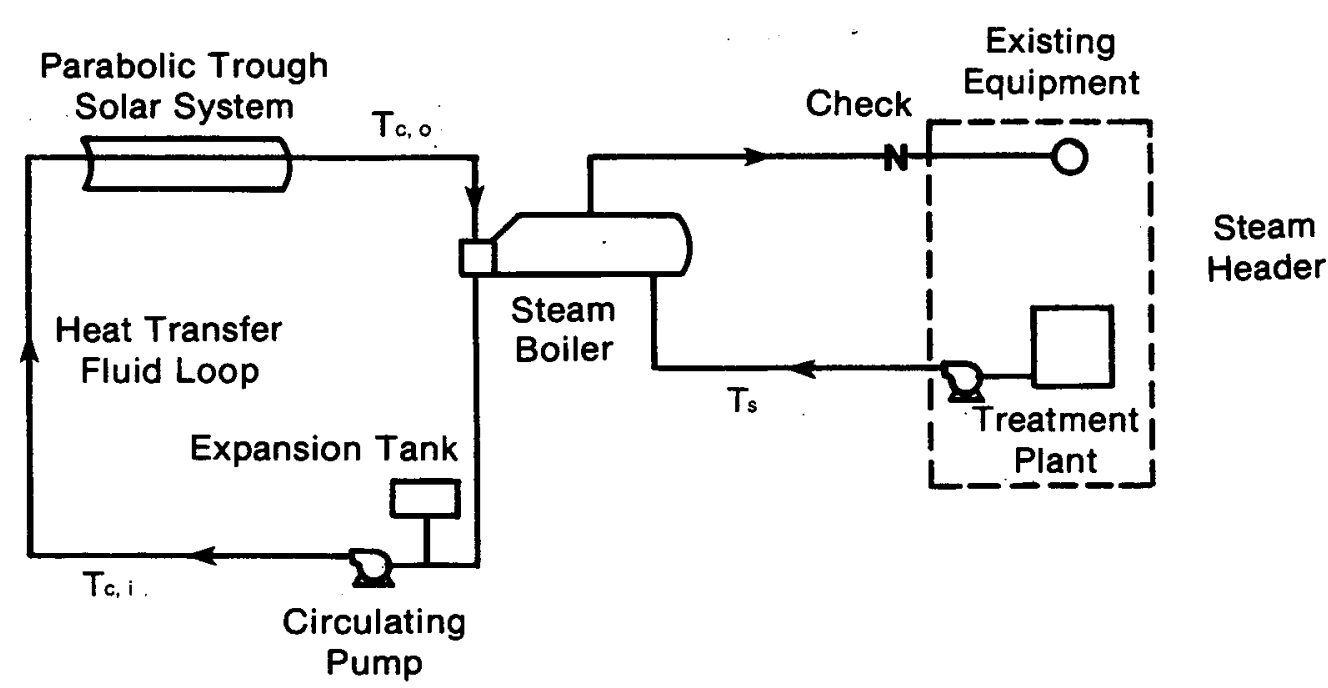

\section{Figure E-1. Unfired-Boiler System}

exchanger area $A_{b}$ and an overall heat transfer coefficient of $U_{b}$. This leads to the energy balance

$$
\dot{\mathrm{q}}_{\mathrm{c}} \mathrm{A}_{\mathrm{c}}=\dot{\mathrm{M}}_{\mathrm{c}} \mathrm{c}_{\mathrm{p}}\left(\mathrm{T}_{\mathrm{c}, \mathrm{o}}-\mathrm{T}_{\mathrm{c}, \dot{i}}\right)=\mathrm{U}_{\mathrm{b}} \mathrm{A}_{\mathrm{b}} \Delta \mathrm{T}_{\mathrm{m}},
$$

where

$$
\begin{aligned}
\dot{\mathrm{M}}_{\mathrm{c}} & =\text { collector loop flow rate } \\
\mathrm{c}_{\mathrm{p}} & =\text { collector loop fluid specific heat } \\
\Delta \mathrm{T}_{\mathrm{m}} & =\text { log-mean temperature difference across unfired boiler. }
\end{aligned}
$$

The log-mean temperature difference for the unfired boiler is

$$
\Delta T_{m}=\frac{T_{c, o}-T_{c, i}}{\ln \left(\frac{T_{c, o}-T_{s}}{T_{c, i}-T_{s}}\right)}
$$

Substituting Eq. E-4 into $\mathrm{E}-3$ and solving for $\mathrm{T}_{\mathrm{c}, \mathrm{i}}$ results in

$$
\mathrm{T}_{\mathrm{c}, i}=\mathrm{T}_{s}+\frac{\mathrm{T}_{\mathrm{c}, 0}-\mathrm{T}_{\mathrm{s}}}{\mathrm{e}^{\mathrm{U}_{\mathrm{b}} \mathrm{A}_{\mathrm{b}} / \dot{\mathrm{M}}_{\mathrm{c}} \mathrm{c}_{\mathrm{p}}}} .
$$


SEP

TR -1356

From Eq. E-3, we have

$$
\mathrm{T}_{\mathrm{c}, 0}=\mathrm{T}_{\mathrm{c}, \mathrm{i}}+\frac{\dot{q}_{\mathrm{c}}}{\dot{\mathrm{m}}_{\mathrm{c}} \mathrm{c}_{\mathrm{p}}}
$$

where $\dot{\mathrm{m}}_{\mathrm{c}}$ is the collector loop flow rate per unit collector area $\left(\dot{\mathrm{M}}_{\mathrm{c}} / \mathrm{A}_{\mathrm{c}}\right)$.

Substituting Eq. E-6 into Eq. E-5 provides

$$
T_{c, i}=T_{s}+\frac{T_{c, i}+\frac{\dot{q}_{c}}{\dot{m}_{c} c_{p}}-T_{s}}{e^{U_{b} A_{b} / \dot{M}_{c} c_{p}}} \text {. }
$$

Solving for $T_{c, i}$ yields

$$
T_{c, i}\left(1-e^{-U_{b} A_{b} / \dot{M}_{c} c} p\right)=T_{s}\left(1-e^{-U_{b} A_{b} / \dot{M}_{c} c} p\right)+\frac{\dot{q}_{c} / \dot{m}_{c} c_{p}}{e^{U_{b} A_{b} / \dot{M} c} c}
$$

This can be reduced to

$$
T_{c, i}=T_{s}+\frac{\dot{q}_{c}}{\dot{m}_{c} c_{p}}\left(e^{U_{b} A_{b} / \dot{M}_{c} c} p-1\right)^{-1} .
$$

If we substitute this expression for $T_{c, i}$ into Eq. E-1, we get

$$
\dot{q}_{c}=F_{R} \eta_{o} I_{a}-F_{R} U_{L}\left[T_{s}+\frac{\dot{q}_{c}}{\dot{m}_{c} c_{p}}\left(e^{U_{b} A_{b} / \dot{\mathrm{M}}_{c} c_{p}}-1\right)^{-1}-T_{a}\right] \text {. }
$$

Solving for $\dot{q}_{c}$, we get

$$
\dot{q}_{c}=\frac{F_{R} \eta_{o} I_{a}-F_{R} U_{L}\left(T_{s}-T_{a}\right)}{1+\frac{F_{R} U_{L}}{\dot{m}_{c} c_{p}}\left(e U_{b} A_{b} / \dot{M}_{c} c_{p}-1\right)-1} \text {. }
$$

385 
Equation E-11 can now be written as

$$
\dot{\mathrm{q}}_{c}=\mathrm{F}_{\mathrm{B}}\left[\mathrm{F}_{\mathrm{R}} \eta_{\mathrm{O}} \mathrm{I}_{\mathrm{a}}-\mathrm{F}_{\mathrm{R}} \mathrm{U}_{\mathrm{L}}\left(\mathrm{T}_{\mathrm{s}}-\mathrm{T}_{\mathrm{a}}\right)\right],
$$

where

$$
F_{B}=\left[1+\frac{F_{R} U_{L}}{\dot{m}_{c} c_{p}\left(e^{\left.U_{b} A_{b} / \dot{M}_{c} c_{p_{-}}\right)}\right.}\right]^{-1} \text {. }
$$

This expression is used in Sec. 6.1.2.1 to define the annual performance of an unfired boiler steam system.

\section{E.2 $\dot{F}_{F}$, THE FLASH STEAM SYSTEM FACTOR}

The flash-steam system factor is solved in the same manner as $F_{B}$. A flashsteam system is shown in Fig. E-2. Consider the collector/flash valve/flash tank as a "black box" in which feedwater enters and steam leaves. The feedwater mass flow rate must equal the steam mass flow rate. The feedwater typically enters the tank at a temperature well below the saturation temperature, so that the solar system requires two heating steps. First, the feedwater is heated to saturation, and then the saturated water is vaporized into saturated steam. The solar system energy collection rate is therefore related to the feedwater (or steam) mass flow rate as

$$
\dot{\mathrm{q}}_{c}=\dot{\mathrm{m}}_{\mathrm{f}}\left[\mathrm{c}_{\mathrm{p}}\left(\mathrm{T}_{\mathrm{s}}-\mathrm{T}_{\mathrm{f}}\right)+\Delta \mathrm{h}_{\mathrm{fg}}\right] ;
$$

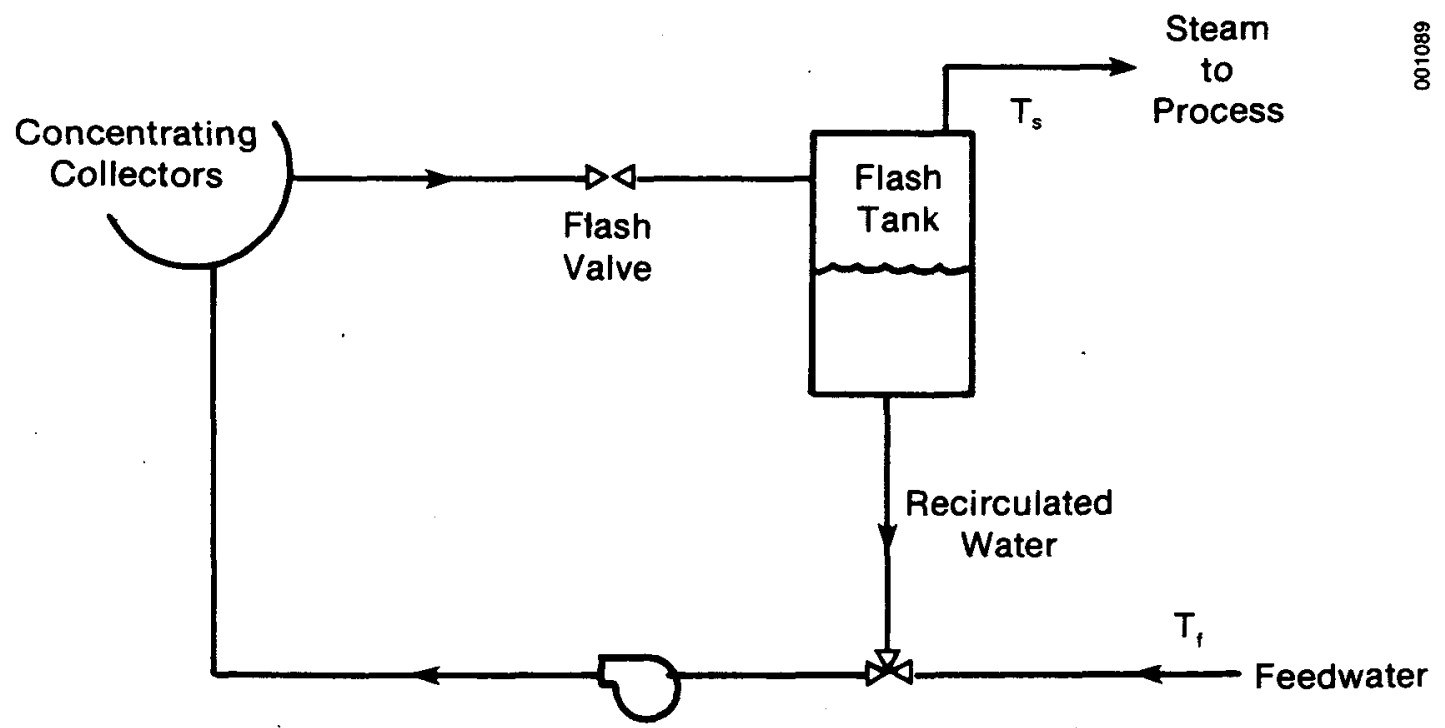

Figure E-2. Flash-Steam System 
where

$$
\begin{aligned}
\dot{\mathrm{m}}_{\mathrm{f}} & =\text { feedwater mass flow rate per unit collector area } \\
\mathrm{c}_{\mathrm{p}} & =\text { specific heat of feedwater } \\
\mathrm{T}_{\mathrm{s}} & =\text { steam saturation temperature } \\
\mathrm{T}_{\mathrm{f}} & =\text { feedwater temperature } \\
\Delta \mathrm{h}_{\mathrm{fg}} & =\text { heat of vaporization of feedwater to steam. }
\end{aligned}
$$

Equation E-13 can be written in terms of the feedwater mass flow rate as

$$
\dot{\mathrm{m}}_{\mathrm{f}}=\frac{\dot{\mathrm{q}}_{\mathrm{c}}}{\mathrm{c}_{\mathrm{p}}\left(\mathrm{T}_{\mathrm{s}}-\mathrm{T}_{\mathrm{f}}\right)+\Delta \mathrm{h}_{\mathrm{fg}}} .
$$

The flow stream feeding the collectors is made up of two mixed flow streams. One flow stream is the feedwater and the other is recirculated water from the flash tank:

$$
\begin{aligned}
& \dot{\mathrm{m}}_{\mathrm{c}}=\dot{\mathrm{m}}_{\mathrm{f}}+\dot{\mathrm{m}}_{\mathrm{r}}, \text { or } \\
& \dot{\mathrm{m}}_{\mathrm{r}}=\dot{\mathrm{m}}_{\mathrm{c}}-\dot{\mathrm{m}}_{\mathrm{f}},
\end{aligned}
$$

where

$$
\begin{aligned}
& \dot{\mathrm{m}}_{\mathrm{c}}=\text { mass flow rate through collector field per unit collector area } \\
& \dot{\mathrm{m}}_{\mathrm{f}}=\text { feedwater mass flow rate per unit collector area } \\
& \dot{\mathrm{m}}_{\mathrm{r}}=\begin{array}{l}
\text { mass flow rate of recirculated water from flash tank per unit } \\
\text { collector area. }
\end{array}
\end{aligned}
$$

The temperature of the fluid entering the collectors $T_{c, i}$ is the mixed stream temperature:

$$
\mathrm{T}_{\mathrm{c}, i}=\frac{\dot{\mathrm{m}}_{\mathrm{f}} \mathrm{T}_{\mathrm{f}}+\dot{\mathrm{m}}_{\mathrm{r}} \mathrm{T}_{\mathrm{r}}}{\dot{\mathrm{m}}_{\mathrm{c}}}
$$

Substituting Eq. E-16 and Eq. E-14 into Eq. E-17, the collector inlet temperature can be written as

$$
\mathrm{T}_{\mathrm{c}, \mathrm{i}}=\frac{\dot{\mathrm{q}}_{\mathrm{c}} / \dot{\mathrm{m}}_{\mathrm{c}}}{\mathrm{c}_{\mathrm{p}}\left(\mathrm{T}_{\mathrm{s}}-\mathrm{T}_{\mathrm{f}}\right)+\Delta \mathrm{h}_{\mathrm{fg}}} \mathrm{T}_{\mathrm{f}}+\left[1-\frac{\dot{\mathrm{q}}_{\mathrm{c}} / \dot{\mathrm{m}}_{\mathrm{c}}}{\mathrm{c}_{\mathrm{p}}\left(\mathrm{T}_{\mathrm{s}}-\mathrm{T}_{\mathrm{f}}\right)+\Delta \mathrm{h}_{\mathrm{fg}}}\right] \mathrm{T}_{\mathrm{s}} \cdot(\mathrm{E}-18)
$$


If we substitute this expression for $T_{c, i}$ into $E q \cdot E-1$, we obtain $\dot{\mathrm{q}}_{c}=\mathrm{F}_{\mathrm{R}} \mathrm{n}_{\mathrm{o}} \mathrm{I}_{\mathrm{a}}-\mathrm{F}_{\mathrm{R}} \mathrm{U}_{\mathrm{L}} \frac{\dot{\mathrm{q}}_{\mathrm{c}} / \dot{\mathrm{m}}_{\mathrm{c}}}{\mathrm{c}_{\mathrm{p}}\left(\mathrm{T}_{\mathrm{s}}-\mathrm{T}_{\mathrm{f}}\right)+\Delta \mathrm{h}_{\mathrm{fg}}} \mathrm{T}_{\mathrm{f}}+\mathrm{T}_{\mathrm{s}}-\mathrm{T}_{\mathrm{s}} \frac{\dot{q}_{\mathrm{c}} / \dot{\mathrm{m}}_{\mathrm{c}}}{\mathrm{c}_{\mathrm{p}}\left(\mathrm{T}_{\mathrm{s}}-\mathrm{T}_{\mathrm{f}}\right)+\Delta \mathrm{h}_{\mathrm{fg}}}-\mathrm{T}_{\mathrm{a}}$.

Solving for $\dot{q}_{c}$, we have

$$
\dot{q}_{c}=\frac{F_{R} n_{o} I_{a}-F_{R} U_{L}\left(T_{s}-T_{a}\right)}{1+\frac{F_{R} U_{L} / \dot{m}_{c}}{c_{p}\left(T_{s}-T_{f}\right)+\Delta h_{f g}}\left(T_{f}-T_{s}\right)} .
$$

Equation $\mathrm{E}-20$ can now be written as

$$
\dot{\mathrm{q}}_{\mathrm{c}}=\mathrm{F}_{\mathrm{F}}\left[\mathrm{F}_{\mathrm{R}} \mathrm{n}_{\mathrm{o}} \mathrm{I}_{\mathrm{a}}-\mathrm{F}_{\mathrm{R}} \mathrm{U}_{\mathrm{L}}\left(\mathrm{T}_{\mathrm{S}}-\mathrm{T}_{\mathrm{a}}\right)\right] \text {, }
$$

where

$$
\mathrm{F}_{\mathrm{F}}=\left[1-\frac{\mathrm{F}_{\mathrm{R}} \mathrm{U}_{\mathrm{L}} / \dot{\mathrm{m}}_{\mathrm{c}}}{\mathrm{c}_{\mathrm{p}}\left(\mathrm{T}_{\mathrm{S}}-\mathrm{T}_{\mathrm{f}}\right)+\Delta \mathrm{h}_{\mathrm{fg}}}\left(\mathrm{T}_{\mathrm{S}}-\mathrm{T}_{\mathrm{f}}\right)\right]^{-1}
$$

This expression is used in Sec. 6.1.2.2 to define the annual performance of flash-steam solar systems.

\section{E.3 no' AND $\mathrm{U}_{\mathrm{L}}^{\prime}$, THE STKADY-STATE PIPE LOSS MODIFIERS}

By a simple adjustment of the collector parameters $U_{L}$ and $\eta_{0}$, we can include the effects of steady-state thermal losses from the piping to and from the collector array.

Consider the solar system shown in Fig. E-3. The inlet piping and outlet piping have overall heat loss coefficients $U_{1} A_{f}$ and $U_{0} A_{0}$, respectively. The mass flow rate of the collector fluid is $m_{c}$, and the specific heat of the fluid is $c_{p}$. The temperature delivered at the end of the outlet is $T_{c, o}$ and that at the entrance of the inlet pipe is $T_{c, i}$. The temperature drops along the inlet and outlet pipes are $\Delta \mathrm{T}_{1}$ and $\Delta \mathrm{T}_{0}$, respectively.

The useful power delivered to the heat exchanger from the collectors is

$$
\dot{\mathrm{Q}}_{\mathrm{u}}=\dot{\mathrm{M}}_{\mathrm{c}} \mathrm{c}_{\mathrm{p}}\left(\mathrm{T}_{\mathrm{c}, 0}-\mathrm{T}_{\mathrm{c}, \dot{\mathrm{i}}}\right) \text {. }
$$

Using the collector efficiency equation, $\dot{Q}_{u}$ can also be expressed as

$$
\dot{Q}_{u}=A_{c} F_{R}\left[I_{a} \eta_{0}-U_{L}\left(T_{c, i}-\Delta T_{i}-T_{a}\right)\right]-\dot{Q}_{l, \text { tot }},
$$




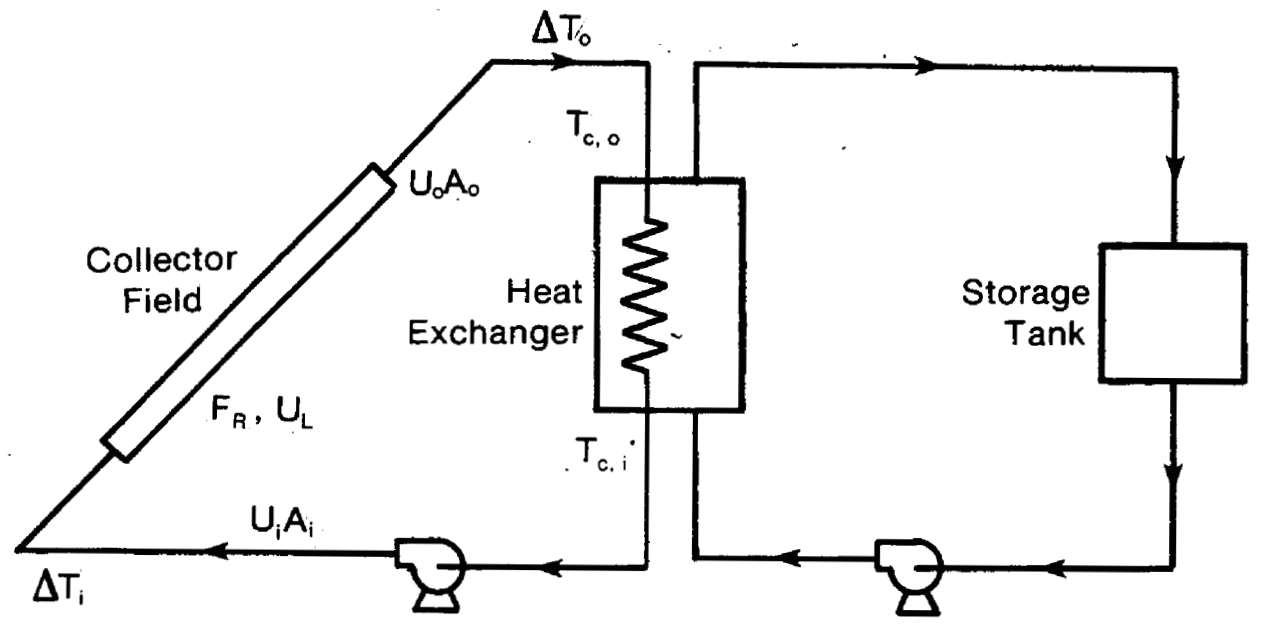

Figure E-3. Double-Loop Solar System

where

$$
\begin{aligned}
A_{c} & =\text { collector area } \\
I_{a} & =\text { irradiance in the plane of the collectors } \\
T_{a} & =\text { ambient temperature } \\
\dot{Q}_{\ell, t o t} & =\text { total heat losses from the inlet and outlet pipes. }
\end{aligned}
$$

To calculate $\dot{Q}_{l}$, tot, we consider first the losses from the inlet pipe. The governing differential equation is

$$
\dot{\mathrm{M}}_{\mathrm{c}} c_{\mathrm{p}} \mathrm{dT}=\mathrm{U}_{\mathbf{i}}\left(\mathrm{T}-\mathrm{T}_{\mathrm{a}}\right) \mathrm{dA} \mathrm{A}_{\mathbf{i}},
$$

where

$$
\begin{aligned}
& A_{i}=\text { outside surface area of the inlet pipe } \\
& U_{1}=\text { heat loss coefficient of the inlet pipe. }
\end{aligned}
$$

This has the following solution for the outlet temperature of the pipe:

$$
\mathrm{T}_{\mathrm{c}, i}-\Delta \mathrm{T}_{i}=\mathrm{T}_{\mathrm{a}}+\left(\mathrm{T}_{\mathrm{c}, i}-\mathrm{T}_{\mathrm{a}}\right) \mathrm{e}^{-\mathrm{U}_{i} \mathrm{~A}_{i} / \dot{\mathrm{M}}_{\mathrm{c}} \mathrm{c}_{\mathrm{p}}}
$$


Since the heat loss is $\dot{\mathrm{M}}_{c} c_{p} \Delta \mathrm{T}_{i}$, the heat loss $\dot{Q}_{\ell, i}$ from the inlet pipe is

$$
\dot{Q}_{l, i}=\dot{\mathrm{M}}_{c} c_{p}\left(\mathrm{~T}_{c, i}-\mathrm{T}_{\mathrm{a}}\right)\left(1-\mathrm{e}^{-\mathrm{U}_{\mathrm{i}} \mathrm{A}_{i} / \dot{\mathrm{M}}_{\mathrm{c}} \mathrm{c}_{\mathrm{p}}}\right) \text {. }
$$

The solution is similar for the outlet pipe, with $T_{c, 0}+\Delta T_{0}$ replacing $T_{c, i}$, and $\Delta T_{0}$ replacing $\Delta T_{i}$ :

$$
\mathrm{T}_{\mathrm{c}, 0}=\mathrm{T}_{\mathrm{a}}+\left(\mathrm{T}_{\mathrm{c}, 0}+\Delta \mathrm{T}_{0}-\mathrm{T}_{\mathrm{a}}\right) \mathrm{e}^{-\mathrm{U}_{\mathrm{o}} \mathrm{A}_{\mathrm{o}} / \dot{\mathrm{M}}_{\mathrm{c}} \mathrm{c}_{\mathrm{p}}}
$$

so that the heat loss from the outlet pipe is $\dot{M}_{c} c_{p} \Delta T_{0}$, or

$$
\dot{Q}_{l, 0}=\dot{M}_{p}\left(T_{c, 0}-T_{a}\right)\left(e^{+\mathrm{J}_{o} A_{o} / \dot{M}_{c} c_{p}}-1\right)
$$

Adding the contributions from the inlet and outlet pipes (Eqs. E-26 and E-28),

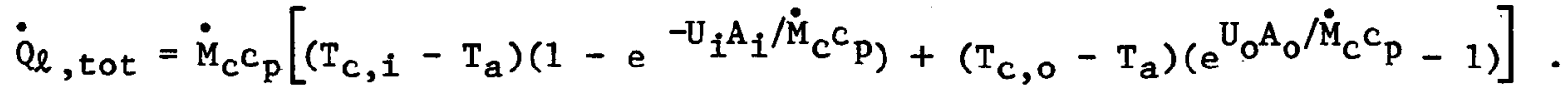

Rearranging this equation and substituting $\dot{\mathrm{Q}}_{\mathrm{u}}$ from Eq.E-22,

$$
\dot{\mathrm{Q}}_{\text {, tot }}=\dot{\mathrm{M}}_{\mathrm{c}} \mathrm{c}_{\mathrm{p}}\left(\mathrm{T}_{\mathrm{c}, \mathrm{i}}-\mathrm{T}_{\mathrm{a}}\right)\left(\mathrm{e}^{\left.\mathrm{U}_{\mathrm{o}} \mathrm{A}_{\mathrm{o}} / \dot{\mathrm{M}}_{\mathrm{c}} \mathrm{c}_{\mathrm{p}}-\mathrm{e}^{-\mathrm{U}_{\mathrm{i}} \mathrm{A}_{\mathrm{i}} / \dot{\mathrm{M}}_{\mathrm{c}} \mathrm{c}_{\mathrm{p}}}\right)+\dot{\mathrm{Q}}_{\mathrm{u}}\left(\mathrm{e}^{\mathrm{U}_{\mathrm{o}} \mathrm{A}_{\mathrm{o}} / \dot{\mathrm{M}}_{\mathrm{c}} \mathrm{c}_{\mathrm{p}}}-1\right)} \cdot\right.
$$

Now we can substitute Eqs. E-25 and E-30 into Eq. E-23, obtaining

$$
\begin{aligned}
\dot{Q}_{u}= & A_{c} F_{R} I_{a} n_{o}-A_{c} F_{R} U_{L}\left(T_{c, i}-T_{a}\right)\left(e^{-U_{i} A_{i} / \dot{M}_{c} c} p\right)-\dot{M}_{c_{p}}\left(T_{c, i}-T_{a}\right)\left(e^{U_{o} A_{o} / \dot{M}_{c} c_{p}}\right. \\
& \left.-e^{-U_{i} A_{i} / \dot{M}_{c} c} p\right)-\dot{Q}_{u}\left(e^{U_{o} A_{o} / \dot{M}_{c} c} p-1\right)
\end{aligned}
$$

Solving for $\dot{\mathrm{Q}}_{\mathrm{u}}$,

$$
\begin{aligned}
& \dot{Q}_{u}=A_{c} F_{R}\left[\frac{I_{T}^{n_{0}}}{e^{U_{0} A_{0} / \dot{M}_{c} c} p}-\frac{U_{L}\left(T_{c, i}-T_{a}\right)}{e^{U_{0} A_{o} / \dot{M}_{c} c} p} e^{-U_{i} A_{i} / \dot{M}_{c} c_{p}}\right. \\
& \left.+\frac{\dot{M}_{c} c_{p}}{A_{C}{ }_{F} R}\left(e^{U_{0} A_{0} / \dot{M}_{c} c_{p_{-}}} e^{-U_{i} A_{i} / \dot{M}_{c} c} p\right)\right] \text {. }
\end{aligned}
$$


This can be written in the same form as Eq. E-23:

$$
\dot{Q}_{u}=A_{c} F_{R}\left[I_{T} n_{o}^{\prime}-U_{L}^{\prime}\left(T_{c, i}-T_{a}\right)\right] \text {, }
$$

except that now the piping losses are included in the modified values $n_{0}^{\prime}$ and $\mathrm{U}_{\mathrm{L}}^{\prime}$ which are defined as follows:

$$
\begin{aligned}
& n_{0}^{\prime}=n_{0} e^{-U_{0} A_{0} / \dot{M}_{c} c_{p}} \\
& U_{L}^{\prime}=U_{L} e^{-U_{0} A_{0} / \dot{M}_{c} c} p\left[e^{-U_{i} A_{i} / \dot{M}_{c} c} p+\frac{\dot{M}_{c} c_{p}}{A_{c} F_{R} U_{L}}\left(e^{U_{0} A_{0} / \dot{M}_{c} c_{p}}-e^{-U_{0} A_{0} / \dot{M}_{c} c_{p}}\right)\right] \cdot(E-35)
\end{aligned}
$$

The modified $n_{0}$ and $U_{L}$ values defined by Eqs. E-34 and E-35 can be employed directly in the variable groupings used for calculations of energy collection in Sec. 6.0 . 


\section{SEP구룰}




\section{APPENDIX F}

AMBIEMT TEMPERATURE DATA FOR 72 U.S. CITIES*

\begin{tabular}{|c|c|c|c|c|c|}
\hline & $\mathrm{T}_{\mathrm{a}} * *$ & $\mathrm{~T}_{j} * *$ & & $T_{a}^{* *}$ & $\mathrm{~T}_{j}^{* * *}$ \\
\hline Al buquerque, NM & $\begin{array}{l}16 \\
22\end{array}$ & $\begin{array}{r}3 \\
14\end{array}$ & Las Vegas, NV & 22 & 9 \\
\hline $\begin{array}{l}\text { Apalachicola, FL } \\
\text { Astoria, OR }\end{array}$ & 22 & 14 & Lemont, IL & 11 & $\begin{array}{r}-2 \\
2\end{array}$ \\
\hline $\begin{array}{l}\text { Astoria, OR } \\
\text { Atlanta, GA }\end{array}$ & $\begin{array}{r}9 \\
18\end{array}$ & $\begin{array}{l}5 \\
8\end{array}$ & $\begin{array}{l}\text { Lexington, } \mathrm{KY} \\
\text { Lincoln, NE }\end{array}$ & $\begin{array}{l}15 \\
13\end{array}$ & $\begin{array}{r}3 \\
-2\end{array}$ \\
\hline $\begin{array}{l}\text { At lanta, GA } \\
\text { Bismarck, ND }\end{array}$ & $\begin{array}{r}10 \\
7\end{array}$ & -11 & Little Rock, AR & $\begin{array}{l}13 \\
18\end{array}$ & $\begin{array}{r}-2 \\
7\end{array}$ \\
\hline Blue Hill, MA & 10 & -2 & Los Angeles, CA & 19 & 13 \\
\hline Boise, ID & 16 & -2 & Madison, WI & 10 & -6 \\
\hline Boston, MA & 12 & 0 & Medford, OR & 14 & 4 \\
\hline Brownsville, TX & 25 & 17 & Miami, FL & 26 & 22 \\
\hline Cape Hatteras, NC & 19 & 9 & Midland, TX & 26 & 22 \\
\hline Caribou, ME & 4 & -11 & Nashville, TN & 17 & 6 \\
\hline Charleston, SC & 21 & 12 & Newport, RI & 9 & -1 \\
\hline Cleveland, $\mathrm{OH}$ & 12 & -1 & New York, NY & 13 & 2 \\
\hline Columbia, MO & 14 & 0 & Oak Ridge, TN & 16 & 6 \\
\hline Columbus, $\mathrm{OH}$ & 13 & 0 & Oklahoma City, OK & 18 & 4 \\
\hline Davis, CA & 18 & 9 & Omaha, NE & 14 & -5 \\
\hline Dodge City, KS & 15 & 1 & Phoenix, AZ & 23 & 12 \\
\hline East Lansing, MI & 7 & 3 & Portland, ME & 9 & -4 \\
\hline East Wareham, MA & 11 & 0 & Rapid City, SD & 10 & -4 \\
\hline E1 Paso, TX & 19 & 8 & Riverside, CA & 20 & 13 \\
\hline Ely, NV & 10 & -3 & St. Cloud, MN & 7 & -10 \\
\hline Fort Worth, TX & 21 & 9 & Salt Lake city, UT & 13 & -2 \\
\hline Fresno, CA & 19 & 8 & San Antonio, TX & 22 & 12 \\
\hline Gainesville, FL & 23 & 17 & Santa Maria, CA & 16 & 12 \\
\hline Glasgow, MT & 7 & -11 & Sault Ste. Marie, MI & 6 & -9 \\
\hline Grand Junction, Co & 17 & -3 & Sayville, NY & 13 & 2 \\
\hline Grand Lake, Co & 5 & -8 & Schenectady, NY & 10 & -4 \\
\hline Great Falls, MT & 9 & -4 & Seattle, WA & 12 & 4 \\
\hline Greensboro, NC & 16 & 6 & Seabrook, NJ & 14 & 4 \\
\hline Griffin, GA & 19 & 9 & Spokane, WA & 10 & -3 \\
\hline Hatteras, NC & 18 & 10 & State College, PA & 9 & -1 \\
\hline Indianapolis, IN & 13 & 1 & Stillwater, OK & 18 & 5 \\
\hline Inyo Kern, CA & 20 & 8 & Tampa, FL & 24 & 18 \\
\hline Ithaca, NY & 10 & -3 & Tucson, AZ & 22 & 12 \\
\hline Lake Charles, LA & 22 & 13 & Upton, NY & 13 & 2 \\
\hline Lander, WY & 8 & -7 & Washington, DC & 15 & 3 \\
\hline
\end{tabular}

*These data have been compiled from Table C-1 of Applications of Solar Energy for Heating and Cooling of Buildings, ASHRAE GRP 170, 1977.

${ }^{* * \mathrm{~T}_{\mathrm{a}}}=\begin{aligned} & \text { average annual daytime temperature, }{ }^{\circ} \mathrm{C} ; \mathrm{T}_{\mathrm{j}}=\text { average January daytime } \\ & \text { temperature, }{ }^{\circ} \mathrm{C} .\end{aligned}$ 


\section{SEPI缕}




\section{APPENDIX G}

\section{SOURCES OF INFORMATION}

Technical Reports Produced from U.S. Government-Sponsored Research

National Technical Information Service (NTIS)

U.S. Department of Commerce

5285 Port Royal Road

Springfield, VA 22161

(703) 557-4600 (Write for free NTIS Energy Catalog, NTIS/PR-78)

\section{SOLMET}

U.S. Department of Commerce

National Oceanic and Atmospheric Administration (NOAA)

Environmental Data Service

Nationa1 Climatic Center

Asheville, NC 28801

(704) 258-2850, Ext. 683

$\underline{T M Y}$

I. J. Ha11, R. R. Prairie, H. E. Anderson, and E. C. Boes

Generation of Typical Meteorological Years for 26 SOLMET Stations.

SAND 78-1601, Sandia Laboratories, A1buquerque, NM, August 1978.

TRNSYS, F-Chart

University of Wisconsin Solar Energy Laboratory

Engineering Research Building

1500 Johnson Drive

Madison, WI 53706

(608) 263-1586

U.S. Department of Energy (DOE) Publications

Technical Information Center (TIC)

U.S. Department of Energy

P.0. Box 62

Oak Ridge, TN 37830 
Solar Product Information

Solar Products Specification Guide

Solar Age (magazine)

Published in 1979 by: Solarvision, Inc.

Church Hi11

Harrisville, NH 03450

Solar Engineering Master Catalog and Solar Industry Index. SEM 1980. Solar Energy Industries Association, 1978.

General Information

Solar Energy Information Locator

SERI/SP-751-210

Solar Energy Research Institute

1617 Cole Boulevard

Golden, CO 80401

(303) 231-1415

Solar Energy Information Data Bank (SEIDB)

Solar Energy Research Institute

1617 Cole Boulevard

Golden, CO 80401

(303) 231-1415

Superintendent of Documents

U.S. Government Printing Office

Washington, DC 20402

(Write for free Solar Energy Bibliography \#9) 


\section{APPENDIX H}

\section{GLOSSARY}

Availability-the fraction of time that a solar energy system is available to be used by an industrial process. It does not include climatic conditions that might render the system unusable, but is meant to be a measure of the mechanical reliability of the solar system. Availability is defined as

$$
\begin{aligned}
& \text { Solar System } \\
& \text { Availability }
\end{aligned}=\frac{\text { Total Time Period - Periods of Solar System Downtime }}{\text { Total Time Period }} \times 100 \% \text {. }
$$

Beam Irradiance--solar radiation that has not been scattered by dust or water in the atmosphere and is, therefore, capable of being focused.

Central Receiver--a concentrating solar energy collector consisting of a field of ground-mounted heliostats that reflect sunlight onto a receiver mounted on a tower. The heliostats track the sun to maintain reflected sunlight on the receiver.

Clearness Index--the ratio of the clear-day beam irradiance at a location to the irradiance calculated for the standard atmosphere at the same location and date.

Collector Efficiency--the ratio of energy collected by an individual solar collector or an array of collectors to the energy incident on the collector or array. The energy incident is normally the energy within the acceptance angle of the collector, or, for flat-plate collectors, the total energy in the collector plane.

Diffuse Irradiance-solar radiation that is scattered by air molecules, dust, or water droplets before reaching the ground and so cannot be focused.

Direct Normal Irradiance--beam irradiance measured perpendicular to the direction of the sun.

Direct System Configuration--a system configuration in which the process working fluid is heated directly in the solar collectors before being delivered to the process.

Double-Walled Heat Exchanger--a heat exchanger with two physical walls to separate the fluid being heated and the fluid being cooled to prevent mixing. An intermediate fluid transfers the heat between the two walls (see Fig. H-1). Double-walled heat exchangers are used primarily to avoid contamination of one fluid (usually potable water) by another fluid (usually a toxic heat-transfer oil).

End Loss--energy that is focused off the end of a parabolic trough collector when it is not at normal incidence to the sun. This energy normally misses the receiver and is not, therefore, collectable. 


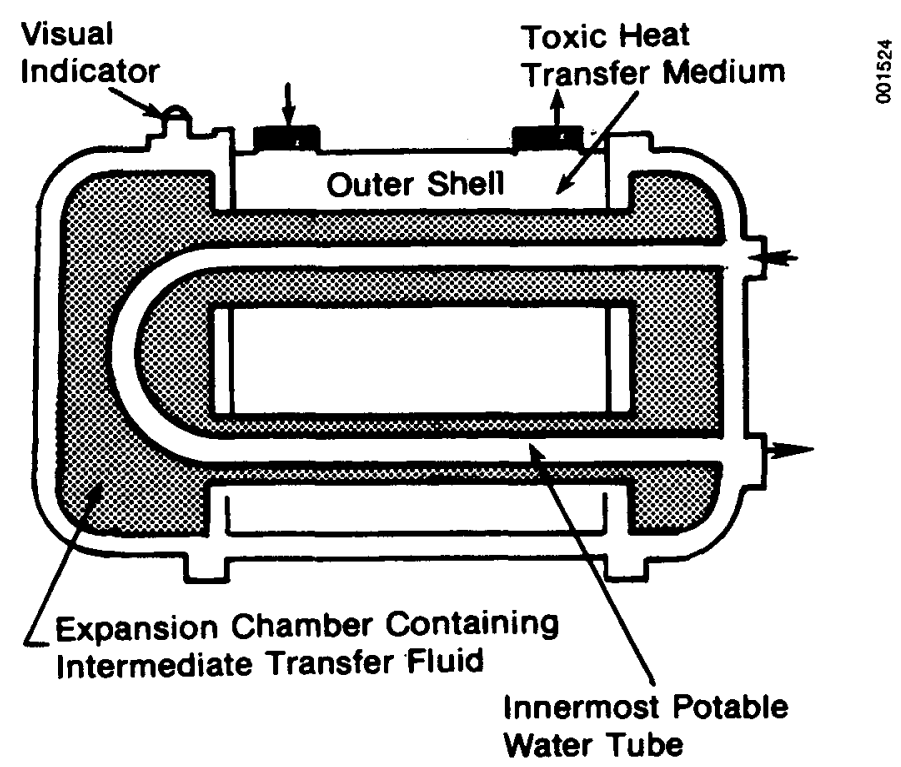

\section{Figure I-1. Double-Walled Heat Exchanger}

Evacuated-Tube collector-a solar collector in which the absorber is contained within a glass envelope (usually two concentric cylinders sealed together at one or both ends), and the envelope is evacuated to eliminate convection heat transfer. Several tubes are usually contained in a collector module (see Fig. H-2).

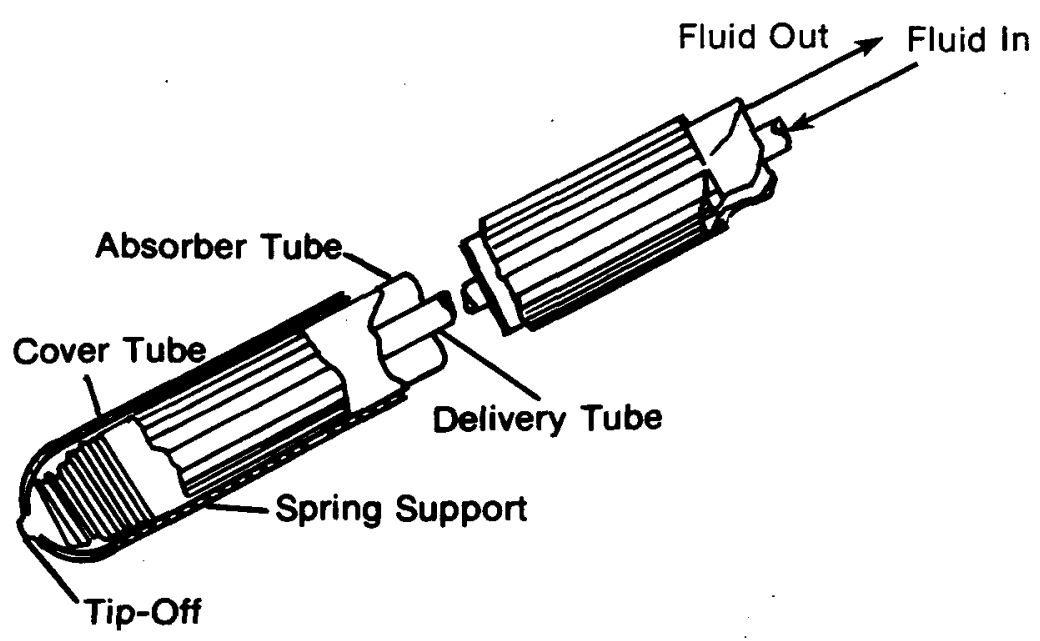

Figure \#-2. Concentric Glass Evacuated-Tube Collector 
F-CHART Procedure--a solar system performance and sizing procedure, developed by the University of Wisconsin, for solar heating and cooling applications. The procedure is expressed in terms of a universal f-chart family of curves.

Flash-Steam System--a system configuration in which water at a pressure sufficient to prevent boiling is circulated through the collector field and then flashed to steam across a throttling valve into a separator where the steam is removed for delivery to the process.

Flash Tank--the tank in a flash-steam system in which steam and water are separated.

Flat-P1ate Collector-a solar collector consisting of a flat, black absorber plate of metal or other suitable material insulated on the bottom and edges and covered by one or more transparent cover(s). Heat is removed from the collector by air or liquid that circulates through or around the absorber plate (see Fig. H-3).

Global Irradiance-the total solar irradiance (beam plus diffuse) incident on a flat surface.

Ground Cover Ratio--the ratio of collector aperture area to the land area occupied by the collector array.

H-Q Curve-the characteristic locus of operational points for a pump, expressed as a curve of flow rate versus head on the pump.

Heat Pipe--a heat transfer device with a very low thermal resistance that consists of a sealed chamber containing a liquid and its vapor. Heat is transferred by liquid evaporation at the hot end of the chamber, vapor flow to the cool end, and vapor condensation at the cool end of the chamber. The liquid is returned to the hot end by a wick, by gravity, or by means of a pump.

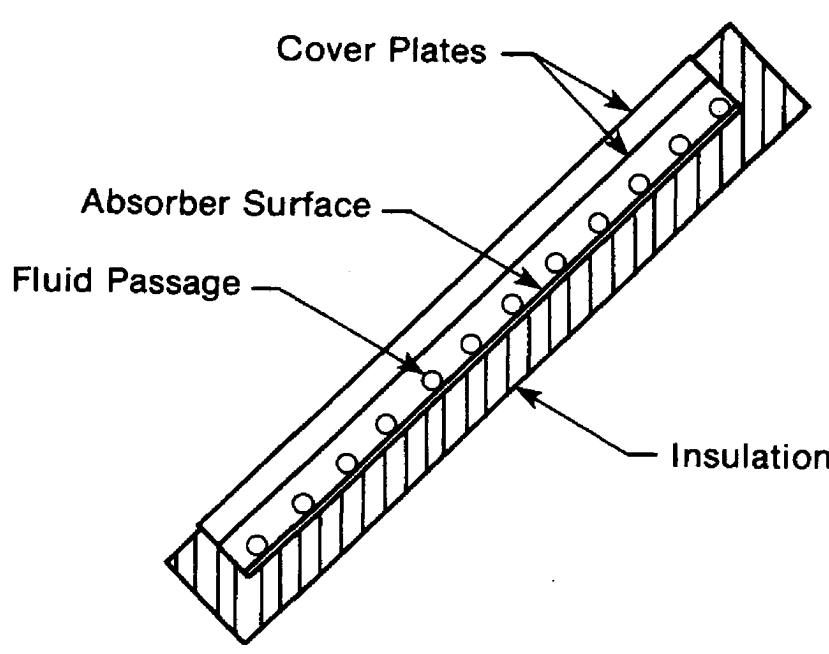


Heat Transfer Efficiency Factor (HTEF)--an index that relates the heat transfer coefficient and the pumping power requirement for a heat transfer fluid, independent of mass flow rate. A fluid with a high HTEF value will have relatively low pumping power requirements for a given heat transfer coefficient.

Heliostat--a ground-mounted reflector assembly that tracks the sun to reflect sunlight onto the absorber of a central receiver.

Industrial Process Heat (IPH)--thermal energy used in an industrial process (usually heated air or liquid, steam, or radiant heat).

Incident-Angle Modifier--the factor by which the optical efficiency of a solar collector is multiplied to account for the angle of incidence of the sunlight on the collector.

Indirect System Configuration--a system configuration in which the collector loop contains a fluid separate (and usually different) from the fluid used in the industrial process. The process fluid is heated by heat exchangers.

Irradiance--radiant power flux on a surface $\left(\mathrm{W} / \mathrm{m}^{2}\right)$.

Irradiation--the time integral of irradiance $\left(\mathrm{J} / \mathrm{m}^{2}\right)$.

Life-Cycle Costing--an economic analysis method that considers all of the re1evant costs over the life of a system, including acquisition, maintenance, operation, and disposal. The method compares design and ownership alternatives, and also analyzes the present worth of all future costs.

Linear Concentrating Collector--a solar collector in which the sunlight is focused in one dimension, either by reflectors or other optical devices, onto a linear absorber smaller in surface area than the collector aperture. Except at low concentration ratios, these collectors must track the sun to keep the focused sunlight on the receiver; they collect primarily the beam component of sunlight.

Optical Efficiency--the efficiency at which a solar collector would operate if no thermal losses occurred and, therefore, optical losses were the only constraints on performance. The intercept of the efficiency curve of a collector for the fluid parameter $(\Delta T / I)$, equal to zero.

Parabolic Dish Collector--a point-focus solar collector consisting of a reflector in the shape of a paraboloid of revolution, a receiver fixed at the focal point of the reflector, and a two-axis tracker to point the collector at the sun.

Parabolic Trough Collector--a linear concentrating solar collector in which the sunlight is collected by reflection off a parabolic reflector (Fig. H-4).

Parasitic Energy--the energy (usually electricity) required to run the solar system, including pumps, trackers, and the control system. 


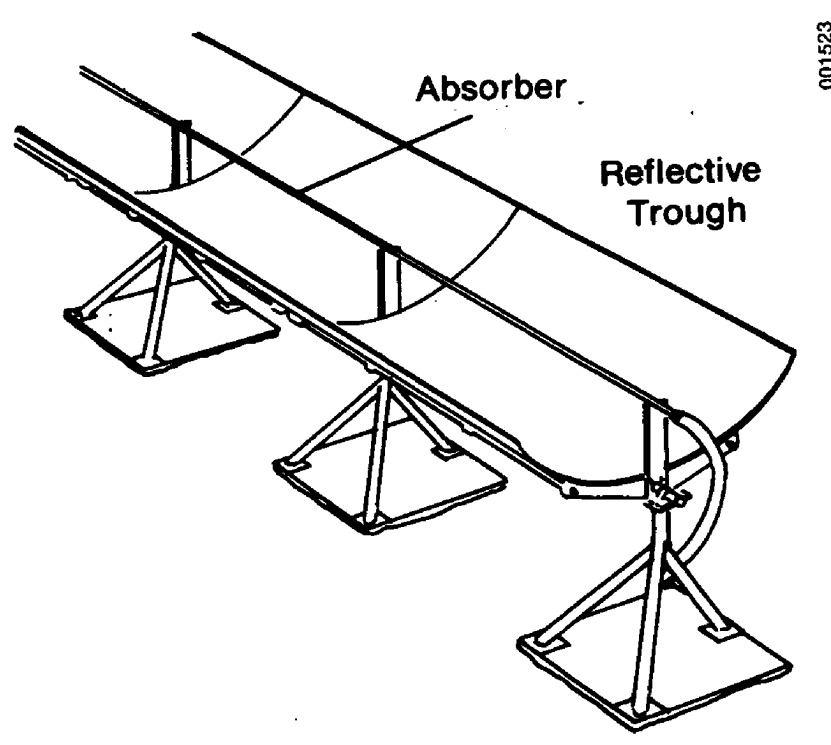

Figure E-4. Parabolic Trough Collector

Phase-Change Material (PCM)--a substance that undergoes a reversible phase change when energy is added to it at a nearly constant temperature. Such materials are used to store energy in latent heat, which is more efficient in terms of stored energy density than sensible heat systems.

Point-Focus Collector--a solar collector in which beam radiation entering the collector aperture is focused in two dimensions to a point at a receiver. Concentrating the sunlight in two dimensions requires that the collector track the sun in both elevation and azimuth; theoretical concentration ratios of about 11,000 are possible.

Pyranometer--an instrument for measuring global irradiance (see Fig. $\mathrm{H}-5$ ).

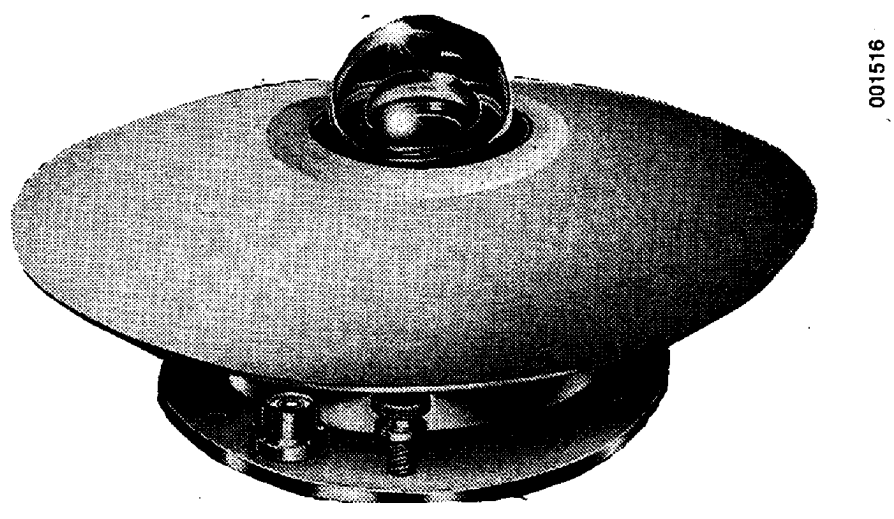

Figure A-5. Pyranometer 


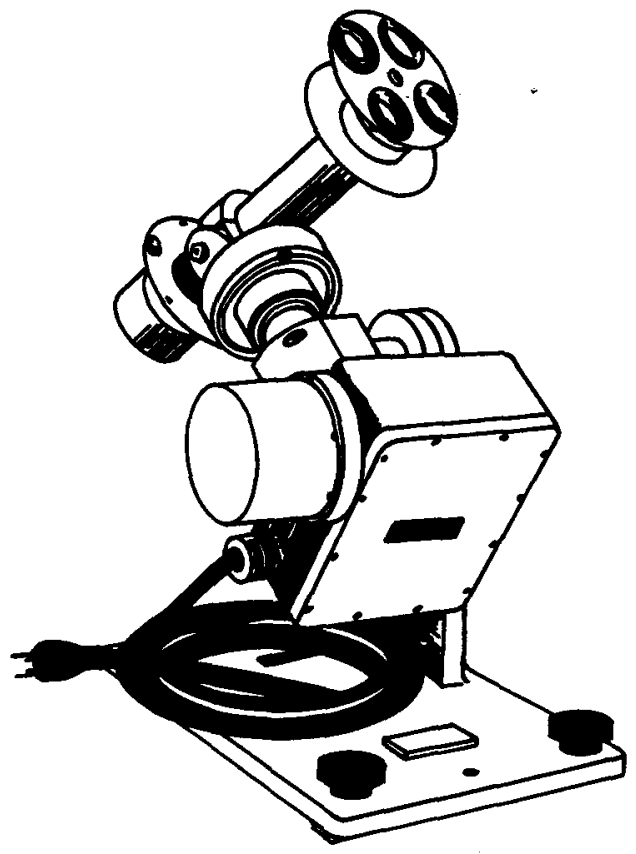

$\frac{5}{5}$

Figure I-6. Pyrheliometer

Pyrheliometer--an instrument for measuring direct normal irradiance (Fig. $\mathrm{H}-6$ ). The instrument must track the elevation and azimuth of the sun.

R-Value-a measure of the thermal resistance of a particular thickness of insulating material.

Rock Bin Storage--a thermal storage component for air systems consisting of a large container filled with rocks and fitted with plenums so that air can be blown through the device, transferring heat to or from the rocks by convection.

Solar Heating and Cooling (SHAC)--a program begun in the 1970 s by the U.S. Department of Energy to demonstrate solar energy applications for heating and cooling buildings and for hot water production for residential and commercial use.

Sawtooth Array Configuration-a collector array layout with flat-plate collectors arranged in parallel east-west rows (Fig. $\mathrm{H}-7$ ).

Selective Surface--a surface treated so that its absorptance for solar radiation is increased relative to its emittance for infrared radiation. 


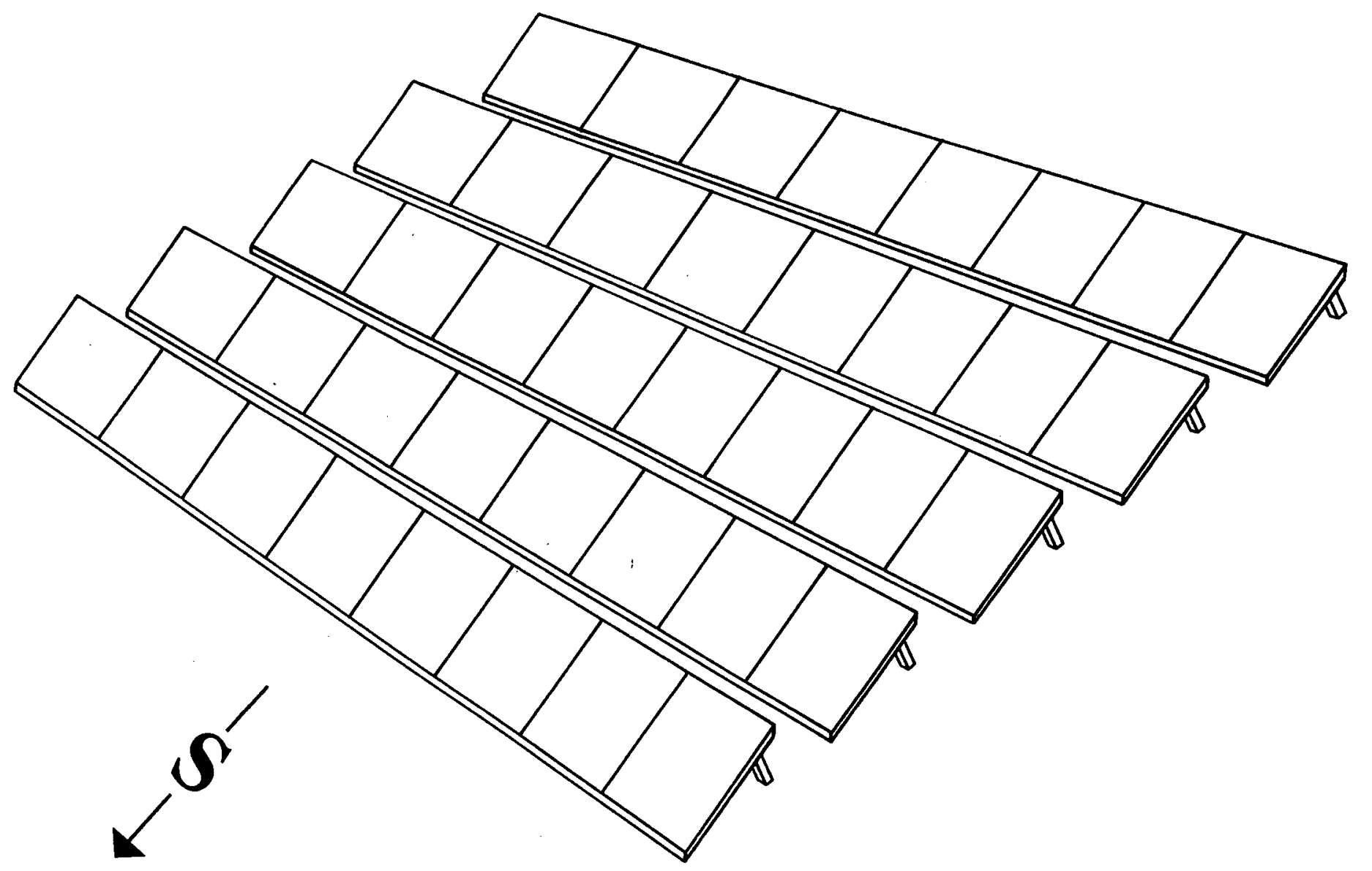

Figure H-7. Sawtooth Array Configuration 
Shading Loss--the loss of available sunlight due to shading of the collectors by other collectors in the array at low elevation angles of the sun.

Solar Effectiveness--the ratio of fuel energy saved because of energy delivered by the solar system to the energy delivered by the solar system. This factor is used in comparing the cost of energy delivered by a solar energy system to the cost of energy from conventional sources.

Solar Fraction--the fraction of the total process load that is supplied by the solar energy system.

Solar Pond--a low-cost solar collector concept. Two kinds of solar ponds are the most popular: shallow solar ponds and salt gradient solar ponds. Shallow solar ponds consist of bags of water heated by the sun during the day and drained at night. They supply energy at temperatures up to $50^{\circ} \mathrm{C}$. Salt gradient solar ponds work on the principle that solar-heated water with high concentrations of dissolved salt will remain at the bottom of the pond by virtue of its higher density. Salt gradient ponds produce heat at temperatures up to $90^{\circ} \mathrm{C}$ and provide for seasonal storage as well as solar collection.

SOLMET--an acronym for the National Oceanic and Atmospheric Administration (NOAA) network of 26 meteorological measurement stations and the data obtained from that network. Locations of the SOLMET sites are listed in Table $\mathrm{H}-1$ and are shown in Fig. D-1.

Stagnation--the condition in which a solar collector is allowed to be in a sun-facing position with no coolant flow. Temperatures reached in stagnation are much higher than normal operating temperatures, especially in evacuatedtube collectors and concentrating collectors.

System Thermal Efficiency--the ratio of the thermal energy delivered to the process by the solar energy system to the solar energy incident on the collector array. The energy incident is normally the energy within the acceptance angle of the collector, or the total in the collector plane for flat-plate collectors.

Typical Meteorological Year (TMY)--a set of typical-year, hour-by-hour meteorological values for SOLMET locations derived from statistical analysis of many years of data from each SOLMET station (see SOLMET).

Unfired Boiler--a vessel designed to produce steam using hot heat transfer oil as the heat source. Normally, such vessels come as a package with their own condensate level control, etc.

Utilization--a measure of how well a solar system is utilized by the industrial plant to which it is attached. It is further defined as the ratio of the period of time that the solar system is operated by the industrial plant to the period of time that the solar system is available for use (i.e., the time it is not down for maintenance), or

Periods of Operation of the Solar System $\underset{\text { Utilization }}{\text { Solar System }}=\frac{\text { to Collect Energy for the Process }}{\text { Total Period of Time - Periods of Solar }} \times 100 \%$. System Downtime 
Table \#-1. 26 SOLMET Sites

\begin{tabular}{|c|c|c|c|c|c|}
\hline & Location & $\begin{array}{l}\text { WBAN } \\
\text { Number }\end{array}$ & $\begin{array}{c}\text { North } \\
\text { Latitude } \\
\text { (degrees) }\end{array}$ & $\begin{array}{c}\text { West } \\
\text { Longitude } \\
\text { (degrees) }\end{array}$ & $\begin{array}{l}\text { Approximate } \\
\text { Elevation } \\
\text { (m) }\end{array}$ \\
\hline $\mathrm{AZ}$ & Phoenix & 23183 & 33.4 & 112.0 & 330 \\
\hline \multirow[t]{2}{*}{$\mathrm{CA}$} & Fresno & 93193 & 36.8 & 119.7 & 90 \\
\hline & Santa Maria & 23273 & 34.9 & 120.4 & 70 \\
\hline $\mathrm{DC}$ & Washington & 93734 & 39.0 & 77.1 & 20 \\
\hline \multirow[t]{2}{*}{ FL } & Apalachicola & 12832 & 29.7 & 85.0 & 0 \\
\hline & Miami & 12839 & 25.8 & 80.3 & 0 \\
\hline $\mathrm{KS}$ & Dodge City & 13985 & 37.8 & 100.0 & 700 \\
\hline LA & Lake Charles & 3937 & 30.2 & 93.2 & 0 \\
\hline $\mathrm{ME}$ & Caribou & 14607 & 46.9 & 68.0 & 140 \\
\hline MA & Boston & 94701 & 42.4 & 71.1 & 0 \\
\hline MO & Columbia & 3945 & 39.0 & 92.3 & 230 \\
\hline MT & Great Fa11s & 24143 & 47.5 & 111.3 & 1020 \\
\hline NE & Omaha & 94918 & 41.4 & 96.0 & 320 \\
\hline $\mathrm{NV}$ & Ely & 23154 & 39.3 & 114.9 & 1960 \\
\hline $\mathrm{NM}$ & Al buquerque & 23050 & 35.1 & 106.6 & 1510 \\
\hline $\mathrm{NY}$ & New York & 94728 & 40.8 & 73.9 & 0 \\
\hline NC & Cape Hatteras & 93729 & 35.3 & 75.6 & 0 \\
\hline ND & Bismarck & 24011 & 46.8 & 100.9 & 510 \\
\hline OR & Medford & 24225 & 42.4 & 122.9 & 420 \\
\hline SC & Charleston & 13880 & 32.9 & 80.0 & 0 \\
\hline TN & Nashville & 13897 & 36.1 & 86.8 & 180 \\
\hline \multirow[t]{3}{*}{$\mathrm{TX}$} & Brownsville & 12919 & 25.9 & 97.7 & 10 \\
\hline & El Paso & 23044 & 31.8 & 106.3 & 1210 \\
\hline & Fort Worth & 3927 & 32.8 & 97.4 & 200 \\
\hline WA & Seattle & 24233 & 47.5 & 122.4 & 40 \\
\hline WI & Madison & 14837 & 43.1 & 89.5 & 260 \\
\hline
\end{tabular}




\section{SEPI}




\section{CONVERSION TABLES}

Adapted with permission from the Annual Book of ASTM Standards, Part 41. Copyright, American Society for Testing and Materials, 1916 Race Street, Philadelphia, Pa. 19103. 


\section{SER1数}




\section{CLASSIFIED LIST OF UNITS}

To convert from

$\mathrm{ft} / \mathrm{s}^{2}$

free fall, standard (g)

gal

$\mathrm{in} / \mathrm{s}^{2}$

degree (angle)

minute (angle)

second (angle) to

Multiply by

\section{ACCELERATION}

metre per second squared $\left(\mathrm{m} / \mathrm{s}^{2}\right)$ metre per second squared $\left(\mathrm{m} / \mathrm{s}^{2}\right)$ metre per second squared (m/s $\mathrm{s}_{2}$ ) metre per second squared $\left(\mathrm{m} / \mathrm{s}^{2}\right)$

ANGLE

$$
\begin{aligned}
& \text { radian (rad) } \\
& \text { radian (rad) } \\
& \text { radian (rad) }
\end{aligned}
$$

$1.745329 \mathrm{E}-02$

$2.908 \quad 882 \quad \mathrm{E}-04$

$4.848 \quad 137$ E-06
$3.048000 * \mathrm{E}-01$

$9.806 \quad 650 * \mathrm{E}+00$

$1.000000 * \mathrm{E}-02$

$2.540000 * \mathrm{E}-02$

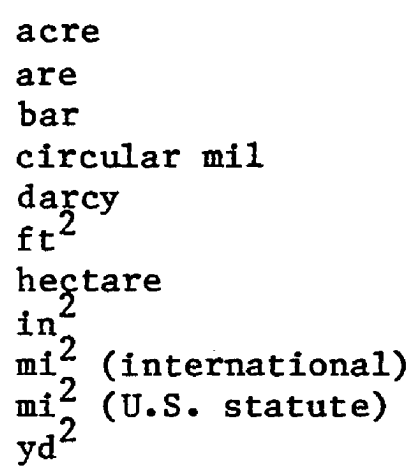

acre

are

bar

circular mil

darcy

hectare

in $^{2}$

$\mathrm{mi}^{2}$ (international)

$\mathrm{yd}^{2}$ (U.S. statute)

\section{AREA}

square metre $\left(\mathrm{m}_{2}^{2}\right)$

square metre $\left(\mathrm{m}^{2}\right)$

square metre $\left(\mathrm{m}^{2}\right)$

square metre $\left(\mathrm{m}^{2}\right)$

square metre $\left(\mathbb{m}^{2}\right)$

square metre $\left(\mathrm{m}^{2}\right)$

square metre $\left(\mathrm{m}_{2}^{2}\right)$

square metre $\left(\mathrm{m}_{2}^{2}\right)$

square metre $\left(\mathrm{m}^{2}\right)$

square metre $\left(\mathrm{m}_{2}^{2}\right)$

square metre $\left(\mathrm{m}^{2}\right)$

BENDING MOMENT OR TORQUE

$4.046873 \mathrm{E}+03$

$1.000 \quad 000 * \mathrm{E}+02$

$1.000 \quad 000 * \mathrm{E}-28$

$5.067075 \mathrm{E}-10$

$9.869233 \mathrm{E}-13$

$9.290304 * \mathrm{E}-02$

$1.000000 * \mathrm{E}+04$

$6.451600 * \mathrm{E}-04$

$2.589988 \mathrm{E}+06$

$2.589998 \mathrm{E}+06$

8.361274 E-01

$1.000000 * \mathrm{E}-07$

$9.806650 * \mathrm{E}+00$

$7.061552 \mathrm{E}-03$

$1.129848 \mathrm{E}-01$

$1.355818 \mathrm{E}+00$

BENDING MOMENT OR TORQUE PER UNIT LENGTH

$1 \mathrm{bf} \cdot \mathrm{ft} / \mathrm{in}$

Ibf•in/in

newton metre per metre $(\mathrm{N} \cdot \mathrm{m} / \mathrm{m})$

5.337866 E+01 newton metre per metre $(\mathrm{N} \bullet \mathrm{m} / \mathrm{m})$

Note: An asterisk $(*)$ after the sixth decimal place indicates that the conversion factor is exact and that all subsequent digits are zero. All other conversion factors have been rounded to the figures given in accordance with ASTM E-380 Sec. 4-4. Where less than six decimal places are shown, more precision is not warranted. 


\section{CAPACITY (SEE VOLUME) \\ DENSITY (SEE MASS PER UNIT VOLUME) \\ ELECTRICITY AND MAGNETISM ${ }^{1}$}

abampere
abcoulomb
abfarad
abhenry
abmho
abohm
abvolt
ampere hour
EMU of capacitance
EMU of current
EMU of electric potential
EMU of inductance
EMU of resistance
ESU of capacitance
ESU of current
ESU of electric potential
ESU of inductance
ESU of resistance
faraday (based on carbon-12)
faraday (chemical)
faraday (physical)
gamma
gauss
gilbert
maxwell
mho
oersted
ohm centimetre
ohm circular-mil per foot
statampere
statcoulomb
statfarad
stathenry
statmho
statohm
statvolt
unit pole

abampere

abcoulomb

abhenry

abmho

abohm

abvolt

ampere hour

EMU of capacitance

EMU of current

EMU of electric potential

ESU of electric potential

ESU of inductance

ESU of resistance

faraday (based on carbon-12)

faraday (chemical)

faraday (physical)

gamma

gauss

mho

ohm centimetre

ohm circular-mil per foot

statampere

statcoulomb

statfarad

stathenry

statmho

unit pole

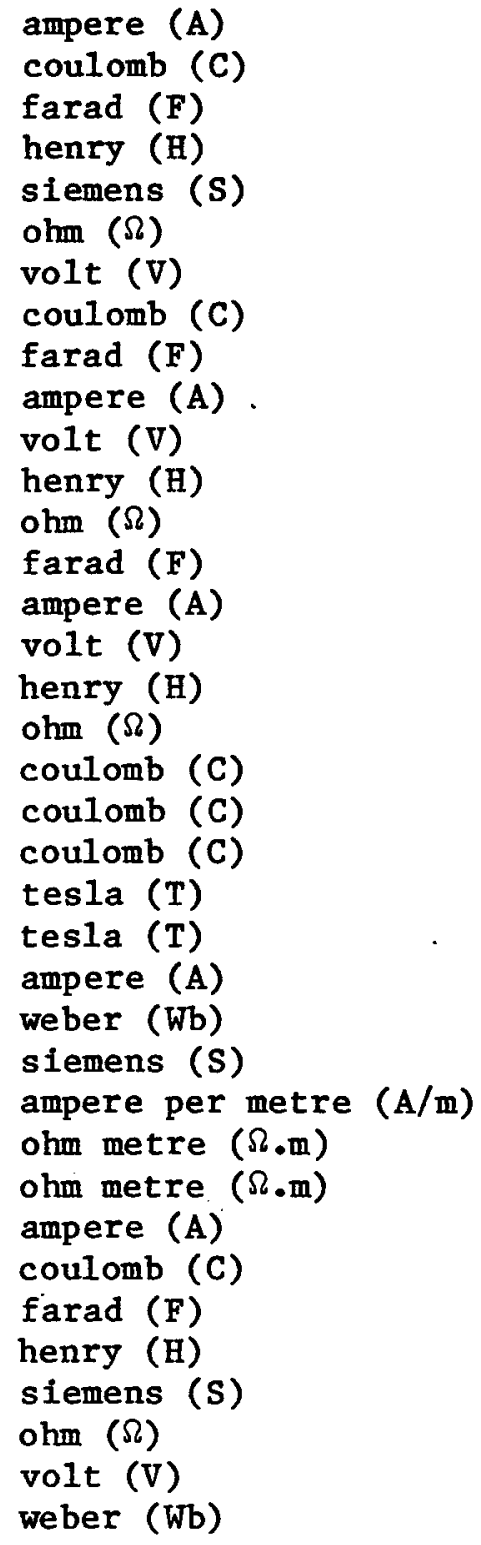

$1.000000 * \mathrm{E}+01$

$1.000 \quad 000 * \mathrm{E}+01$

$1.000000 * \mathrm{E}+09$

$1.000000 * \mathrm{E}-09$

$1.000000 * \mathrm{E}+09$

$1.000 \quad 000 * \mathrm{E}-09$

$1.000000 * \mathrm{E}-08$

$3.600000 * \mathrm{E}+03$

$1.000000 * \mathrm{E}+09$

$1.000 \quad 000 * \mathrm{E}+01$

$1.000000 * \mathrm{E}-08$

$1.000 \quad 000 * \mathrm{E}-09$

$1.000000 * \mathrm{E}-09$

$1.112650 \mathrm{E}-12$

$3.3356 \quad \mathrm{E}-10$

$2.9979 \quad E+02$

$8.987554 \quad E+11$

$8.987554 \quad E+11$

$9.64870 \quad \mathrm{E}+04$

$9.649 \quad 57 \quad \mathrm{E}+04$

$9.652 \quad 19 \quad \mathrm{E}+04$

$1.000000 * \mathrm{E}-09$

$1.000000 * \mathrm{E}-04$

$7.957747 \mathrm{E}-01$

$1.000000 * \mathrm{E}-08$

$1.000000 * \mathrm{E}+00$

$7.957747 \quad \mathrm{E}+01$

$1.000000 * \mathrm{E}-02$

$1.662426 \mathrm{E}-09$

$3.335640 \mathrm{E}-10$

$3.335640 \mathrm{E}-10$

$1.112650 \mathrm{E}-12$

$8.987554 \quad E+11$

$1.112650 \mathrm{E}-12$

$8.987554 \quad \mathrm{E}+11$

$2.997925 \mathrm{E}+02$

$1.256 \quad 637 \quad \mathrm{E}-07$

ENERGY (INCLUDES WORK)

British thermal unit

(International Table)

British thermal unit (mean)

British thermal unit

(thermochemical)

$$
\begin{aligned}
& \text { joule (J) } \\
& \text { joule (J) } \\
& \text { joule (J) }
\end{aligned}
$$

$\begin{array}{lll}1.055 & 056 & \mathrm{E}+03 \\ 1.055 & 87 & \mathrm{E}+03 \\ & & \\ 1.054 & 350 & \mathrm{E}+03\end{array}$

${ }^{1}$ ESU means electrostatic cgs unit. EMU means electromagnetic cgs unit. 
To convert from

British thermal unit $\left(39^{\circ} \mathrm{F}\right)$

British thermal unit $\left(59^{\circ} \mathrm{F}\right)$

British thermal unit $\left(60^{\circ} \mathrm{F}\right)$

calorie (International Table)

calorie (mean)

calorie (thermochemical)

calorie $\left(15^{\circ} \mathrm{C}\right)$

calorie $\left(20^{\circ} \mathrm{C}\right)$

calorie (kilogram, Interna-

tional Table)

calorie (kilogram, mean)

calorie (kilogram,

thermochemical)

electronvolt

erg

$\mathrm{ft} \cdot 1 \mathrm{bf}$

ft-poundal

kilocalorie (International

Table)

kilocalorie (mean)

kilocalorie (thermochemical)

$\mathrm{kW} \cdot \mathrm{h}$

therm

ton (nuclear equivalent of TNT)

W.h

W.s to

Multiply by

joule (J)

joule (J)

joule (J)

joule (J)

joule (J)

joule (J)

joule (J)

joule (J)

joule (J)

joule (J)

joule (J)

joule (J)

joule (J)

joule (J)

joule (J)

joule (J)

joule (J)

joule (J)

joule (J)

joule (J)

joule (J)

joule (J)

joule (J)
$1.05967 \quad \mathrm{E}+03$

$1.05480 \quad \mathrm{E}+03$

$1.05468 \quad \mathrm{E}+03$

$4.186800 * \mathrm{E}+00$

$4.190 \quad 02 \quad \mathrm{E}+00$

$4.184000 * \mathrm{E}+00$

$4.18580 \quad \mathrm{E}+00$

$4.18190 \quad \mathrm{E}+00$

$4.186800 * \mathrm{E}+03$

$4.190 \quad 02 \quad E+03$

$4.184000 * \mathrm{E}+03$

$1.602 \quad 19 \quad \mathrm{E}-19$

$1.000 \quad 000 * \mathrm{E}-07$

$1.355818 \mathrm{E}+00$

4.214 $011 \mathrm{E}-02$

$4.186800 * \mathrm{E}+03$

$4.190 \quad 02 \quad \mathrm{E}+03$

$4.184000 * \mathrm{E}+03$

$3.600000 * \mathrm{E}+06$

$1.055056 \mathrm{E}+08$

$4.184 \quad \mathrm{E}+09$

$3.600000 * \mathrm{E}+03$

$1.000 \quad 000 * \mathrm{E}+00$

ENERGY PER UNIT AREA TIME

Btu (thermochemical)/( $\left.\mathrm{ft}^{2} \cdot \mathrm{s}\right)$

Btu (thermochemical)/(ft $\left.\mathrm{t}^{2} \cdot \mathrm{min}\right)$

Btu (thermochemical)/(ft $\mathrm{f}^{2} \cdot \mathrm{h}$ )

Btu (thermochemical)/(in $\left.{ }^{2} \cdot s\right)$

cal (therrmochemical)/( $\mathrm{cm}^{2} \cdot \mathrm{min}$ )

$\mathrm{erg} /\left(\mathrm{cm}^{2} \cdot \mathrm{s}\right)$

$\mathrm{W} / \mathrm{cm}^{2}$

W/in watt per square metre $\left(\mathrm{W} / \mathrm{m}_{2}^{2}\right)$ watt per square metre $\left(\mathrm{W} / \mathrm{m}^{2}\right)$ watt per square metre $\left(\mathrm{W} / \mathrm{m}^{2}\right)$ watt per square metre $\left(\mathrm{W} / \mathrm{m}^{2}\right)$ watt per square metre $\left(\mathrm{W} / \mathrm{m}^{2}\right)$ watt per square metre $\left(\mathrm{W} / \mathrm{m}^{2}\right)$ watt per square metre $\left(\mathrm{W} / \mathrm{m}^{2}\right)$ watt per square metre $\left(\mathrm{W} / \mathrm{m}^{2}\right)$
$1.134893 \mathrm{E}+04$

$1.891489 \mathrm{E}+02$

$3.152481 \mathrm{E}+00$

$1.634246 \mathrm{E}+06$

$6.973333 \mathrm{E}+02$

$1.000000 * \mathrm{E}-03$

$1.000000 * \mathrm{E}+04$

$1.550003 \mathrm{E}+03$

FLOW (SEE MASS PER UNIT TIME OR VOLUME PER UNIT TIME)

FORCE

dyne

kilogram-force

kilopond

kip (1000 lbf)

ounce-force

pound-force ( $1 \mathrm{bf}$ )

Ibf/1b (thrust/weight

[mass] ratio)

poundal

ton-force (2000 1bf) newton (N)

newton (N)

newton (N)

newton (N)

newton (N)

newton (N)

newton per kilogram (N/kg)

newton (N)

newton (N)
$1.000000 * \mathrm{E}-05$

$9.806650 * \mathrm{E}+00$

$9.806650 * \mathrm{E}+00$

$4.448222 \mathrm{E}+03$

$2.780139 \quad \mathrm{E}-01$

$4.448222 \mathrm{E}+00$

$9.806 \quad 650 \mathrm{E}+00$

$1.382550 \mathrm{E}-01$

8.896444 E+03 
FORCE PER UNIT AREA (SEE PRESSURE)

\section{FORCE PER UNIT LENGTH}

$1 \mathrm{bf} / \mathrm{ft}$

$\mathrm{lbf} /$ in newton per metre $(\mathrm{N} / \mathrm{m})$ newton per metre $(\mathrm{N} / \mathrm{m})$
$1.459390 \mathrm{E}+01$

$1.751268 \mathrm{E}+02$

HEAT

Btu (Inţernational Table) -ft/ $\left(h \cdot f t^{2} \cdot o_{F}\right)(k$, thermal conductivity)

Btu (thermochemica1) $f t /$ $\left(h \cdot f t^{2} \cdot{ }^{\circ} F\right)(k$, thermal conductivity)

Btu (International Table) -in/ $\left(h \cdot \mathrm{ft}^{2} \cdot \mathrm{o}_{\mathrm{F}}\right)(\mathrm{k}$, thermal conductivity)

Btu (thermochemica1)・in/ $\left(h \cdot f t^{2} \cdot o_{F}\right)(k$, thermal conductivity)

Btu (Intternational Table) -in/ $\left(s \cdot \mathrm{ft}^{2} \cdot{ }^{\circ} \mathrm{F}\right)(\mathrm{k}$, thermal conductivity)

Btu (thermochemical) $\bullet$ in/ $\left(s \cdot f t^{2} \cdot o^{\circ}\right)(k$, thermal conductivity)

Btu (International Table) $/ \mathrm{ft}^{2}$

Btu (thermochemical)/ft ${ }^{2}$

Btu (International Table)/ $\left(h \cdot f t^{2} \cdot{ }^{\circ} F\right)(C$, thermal conductance)

Btu (thermochemical)/ $\left(\mathrm{h} \cdot \mathrm{ft}^{2} \cdot \mathrm{o}_{\mathrm{F}}\right)(\mathrm{C}$, thermal conductance)

Btu (International Table)/ $\left(s \cdot f t^{2} \cdot{ }^{\circ} F\right)$

Btu (thermochemica1)/ $\left(s \cdot f t^{2} \cdot o_{F}\right)$

Btu (International Table)/1b

Btu (thermochemical)/1b

Btu (International Table)/ $\left(1 b \cdot{ }^{\circ} F\right)(c$, heat capacity)

Btu (thermochemical)/ $\left(1 \mathrm{~b} \cdot \mathrm{O}_{\mathrm{F}}\right)$ (c, heat capacity)

Btu (International Table) $/ \mathrm{ft}^{3}$

Btu (thermochemical) $/ \mathrm{ft}^{3}$

cal (thermochemical) $/\left(\mathrm{cm}^{\bullet} \mathrm{s} \cdot{ }^{\circ} \mathrm{C}\right.$ )

cal (thermochemical) $/ \mathrm{cm}^{2}$

cal (thermochemical)/ $\left(\mathrm{cm}^{2} \cdot \min \right)$

cal (thermochemical)/(cm ${ }^{2} \cdot \mathrm{s}$ ) watt per metre kelvin $[\mathrm{W} /(\mathrm{m} \cdot \mathrm{K})] \quad 1.730735 \mathrm{E}+00$

watt per metre kelvin $[\mathrm{W} /(\mathrm{m} \cdot \mathrm{K})] \quad 1.729577 \mathrm{E}+00$

watt per metre kelvin $[\mathrm{W} /(\mathrm{m} \cdot \mathrm{K})] \quad 1.442 \quad 279 \mathrm{E}-01$

watt per metre kelvin $[\mathrm{W} /(\mathrm{m} \cdot \mathrm{K})] \quad 1.441314 \mathrm{E}-01$

watt per metre kelvin $[\mathrm{W} /(\mathrm{m} \cdot \mathrm{K})] \quad 5.192204 \mathrm{E}+02$

watt per metre kelvin [W/(m*k)] $5.188732 \mathrm{E}+02$

joule per square metre $\left(\mathrm{J} / \mathrm{m}^{2}\right) \quad 1.135653 \mathrm{E}+04$

joule per square metre $\left(\mathrm{J} / \mathrm{m}^{2}\right) \quad 1.134893 \mathrm{E}+04$

watt per square metre kelvin

$\left[\mathrm{W} /\left(\mathrm{m}^{2} \cdot \mathrm{K}\right)\right]$

5.678263 E+00

watt per square metre kelvin

$\left[\mathrm{W} /\left(\mathrm{m}^{2} \cdot \mathrm{K}\right)\right]$

watt per square metre kelvin

$\left[\mathrm{W} /\left(\mathrm{m}^{2} \cdot \mathrm{K}\right)\right]$

watt per square metre kelvin

$\left[\mathrm{W} /\left(\mathrm{m}^{2} \cdot \mathrm{K}\right)\right]$

joule per $\mathrm{kilogram}(\mathrm{J} / \mathrm{kg})$

joule per kilogram $(\mathrm{J} / \mathrm{kg})$

joule per kilogram kelvin

$[\mathrm{J} /(\mathrm{kg} \cdot \mathrm{K})]$

joule per kilogram kelvin

$[\mathrm{J} /(\mathrm{kg} \cdot \mathrm{K})]$

joule per cubic metre $\left(\mathrm{J} / \mathrm{m}^{3}\right)$

joule per cubic metre $\left(\mathrm{J} / \mathrm{m}^{3}\right)$

5.674466 E+00

$2.044 \quad 175 \quad E+04$

$2.042808 \quad \mathrm{E}+04$

$2.326000 * \mathrm{E}+03$

$2.324444 \mathrm{E}+03$

$4.186800 * E+03$

$4.184000 * \mathrm{E}+03$

$3.725895 \mathrm{E}+04$

$3.723 \quad 402 \quad E+04$

$4.184000 * \mathrm{E}+02$

$4.184000 * \mathrm{E}+04$

$6.973333 \mathrm{E}+02$

$4.184000 * \mathrm{E}+04$ 
To convert from

cal (International Table)/g

cal (thermochemica1)/g

cal (International Table)/ $\left(g \circ{ }^{\circ} \mathrm{C}\right)$

ca1 (thermochemical) $/\left(\mathrm{g} \cdot{ }^{\circ} \mathrm{C}\right.$ )

cal (thermochemical)/min

cal (thermochemical)/s

c10

$o_{F \cdot h \cdot f t^{2} / B t u \text { (International }}$ Table) ( $R$, thermal resisţance)

${ }^{\mathrm{o}_{\mathrm{F}}} \mathrm{F} \cdot \mathrm{h} \cdot \mathrm{ft} \mathrm{t}^{2} / \mathrm{Btu}$ (thermochemica1) ( $R$, thermal resistance)

${ }^{O_{F} \cdot h \cdot f t^{2} /(B t u \text { [International }}$ Table]-1n) (thermal resistivity)

${ }^{O} \mathrm{~F} \cdot h \cdot f t^{2} /($ Btu [thermochemica1] in) (thermal resistivity) $f t^{2} / \mathrm{h}$ (thermal diffusivity)

angstrom
astronomical unit
chain
fathom
fermi (femtometre)
foot
foot (U.S. survey)
inch
light year
microinch
micron
mil
mile (international nautical)
mile (U.S. nautical)
mile (international)
mile (U.S. statute)
parsec
pica (printer's)
point (printer's)
rod
yard

$\mathrm{cd} / \mathrm{in}^{2}$

footcandle

footlambert

lambert joule per kilogram ( $\mathrm{J} / \mathrm{kg}$ ) joule per kilogram (J/kg) joule per kilogram kelvin $[\mathrm{J} /(\mathrm{kg} \cdot \mathrm{K})]$

joule per kilogram kelvin

$$
[\mathrm{J} /(\mathrm{kg} \cdot \mathrm{K})]
$$

watt (W)

watt (W)

kelvin square metre per watt $\left(\mathrm{K} \cdot \mathrm{m}^{2} / \mathrm{W}\right)$

keIvin square metre per watt $\left(\mathrm{K} \cdot \mathrm{m}^{2} / \mathrm{W}\right)$

kelvin square metre per watt $\left(\mathrm{K} \cdot \mathrm{m}^{2} / \mathrm{W}\right)$

kelvin metre per watt $(\mathrm{K} \cdot \mathrm{m} / \mathrm{W})$

kelvin metre per watt

$(\mathrm{K} \cdot \mathrm{m} / \mathrm{W})$

square metre per second $\left(\mathrm{m}^{2} / \mathrm{s}\right)$

\section{LENGTH}

Multiply by

$4.186800 * \mathrm{E}+03$

$4.184000 * \mathrm{E}+03$

$4.186800 * \mathrm{E}+03$

$4.184000 * \mathrm{E}+03$

$6.973333 \mathrm{E}-02$

$4.184000 * \mathrm{E}+00$

2.003712 E-01

$1.761102 \mathrm{E}-01$

$1.762280 \mathrm{E}-01$

$6.933471 \mathrm{E}+00$

$6.938113 \mathrm{E}+00$

$2.580640 * \mathrm{E}-05$

$1.000000 * \mathrm{E}-10$

$1.495979 \mathrm{E}+11$

$2.011684 \quad \mathrm{E}+01$

$1.828804 \mathrm{E}+00$

$1.000000 * \mathrm{E}-15$

$3.048000 * \mathrm{E}-01$

$3.048006 \mathrm{E}-01$

$2.540000 * \mathrm{E}-02$

$9.460 \quad 55 \quad \mathrm{E}+15$

$2.540000 * \mathrm{E}-08$

$1.000000 * \mathrm{E}-06$

$2.540000 * \mathrm{E}-05$

$1.852000 * \mathrm{E}+03$

$1.852000 * \mathrm{E}+03$

$1.609344 * \mathrm{E}+03$

$1.609347 \mathrm{E}+03$

$3.085678 \mathrm{E}+16$

$4.217518 \mathrm{E}-03$

$3.514598 * \mathrm{E}-04$

$5.029210 \mathrm{E}+00$

$9.144000 * \mathrm{E}-01$

\section{LIGHT}

candela per square metre $\left(c d / m^{2}\right) 1.550003$ E+03 $\operatorname{lux}(1 \mathrm{x})$

$1.076391 \mathrm{E}+01$

candela per square metre $\left(\mathrm{cd} / \mathrm{m}_{2}^{2}\right) 3.426259 \mathrm{E}+00$

candela per square metre $\left(\mathrm{cd} / \mathrm{m}^{2}\right) 3.183099 \mathrm{E}+03$ 
MASS

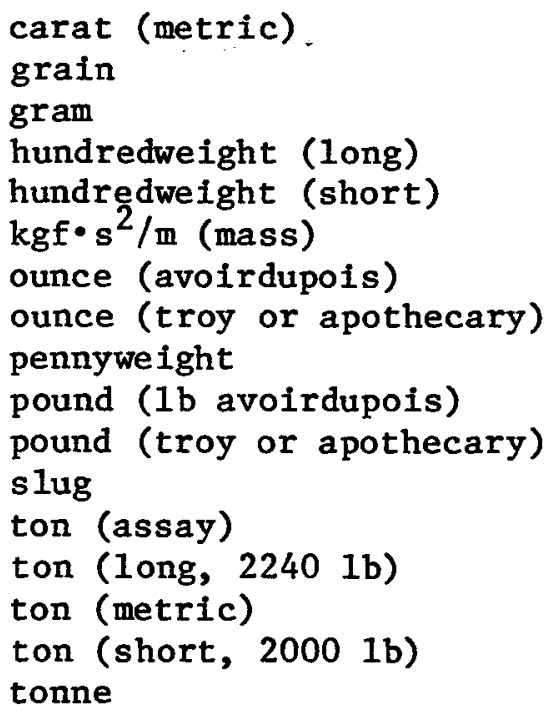

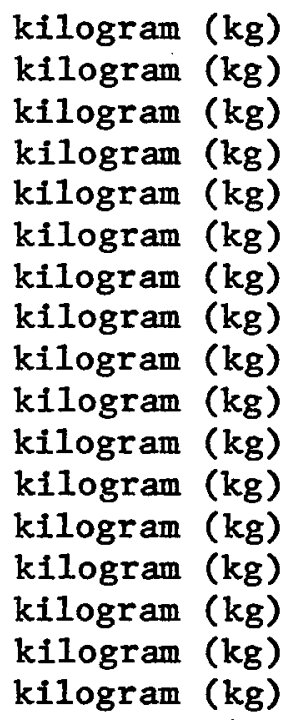

kilogram per square metre $\left(\mathrm{kg} / \mathrm{m}_{2}^{2}\right)$ kilogram per square metre $\left(\mathrm{kg} / \mathrm{m}^{2}\right)$ kilogram per square metre $\left(\mathrm{kg} / \mathrm{m}^{2}\right)$
$2.000000 * \mathrm{E}-04$

$6.479891 * \mathrm{E}-05$

$1.000000 * \mathrm{E}-03$

$5.080235 \mathrm{E}+01$

$4.535924 \quad \mathrm{E}+01$

$9.806650 * \mathrm{E}+00$

$2.834952 \mathrm{E}-02$

$3.110348 \mathrm{E}-02$

$1.555174 \mathrm{E}-03$

4.535924 E-01

$3.732417 \mathrm{E}-01$

$1.459390 \mathrm{E}+01$

$2.916 \quad 667 \quad \mathrm{E}-02$

$1.016047 \mathrm{E}+03$

$1.000000 * \mathrm{E}+03$

9.071.847 E+02

$1.000000 * \mathrm{E}+03$

MASS PER UNIT CAPACITY (SEE MASS PER UNIT VOLUME)

MASS PER UNIT LENGTH

denier
$1 \mathrm{~b} / \mathrm{ft}$
$\mathrm{lb} / \mathrm{in}$
tex

perm $\left(0^{\circ} \mathrm{C}\right)$

perm $\left(23^{\circ} \mathrm{C}\right)$

perm?in $\left(0^{\circ} \mathrm{C}\right)$

perm・in $\left(23^{\circ} \mathrm{C}\right)$

$1 \mathrm{~b} / \mathrm{h}$

$1 \mathrm{~b} / \mathrm{min}$

$\mathrm{Ib} / \mathrm{s}$

$1 \mathrm{~b} /(\mathrm{hp} \cdot \mathrm{h})$ (SFC, specific fuel consumption) ton $($ short $) / h$ kilogram per metre $(\mathrm{kg} / \mathrm{m})$

kilogram per metre $(\mathrm{kg} / \mathrm{m})$

kilogram per metre $(\mathrm{kg} / \mathrm{m})$

kilogram per metre $(\mathrm{kg} / \mathrm{m})$
$1.111 \quad 111 \mathrm{E}-07$

$1.488164 \quad \mathrm{E}+00$

$1.785797 \mathrm{E}+01$

$1.000000 * \mathrm{E}-06$

MASS PER UNIT TIME (INCLUDES FLOW)

$3.051517 \mathrm{E}-01$

$3.390 \quad 575 \quad \mathrm{E}-02$

$4.882 \quad 428 \quad E+00$ 
To convert from

Multiply by

MASS PER UNIT VOLUME (INCLUDES DENSITY AND MASS CAPACITY)

grain/gal (U.S. 1iquid)

$\mathrm{g} / \mathrm{cm}^{3}$

oz (avoirdupois)/gal

(U.K. liquid)

oz (avoirdupols)/ga1

(U.S. liquid)

oz (ayoirdupois) $/ \mathrm{in}^{3}$

$\mathrm{Ib} / \mathrm{ft}^{3}$

$1 b /$ in $^{3}$

lb/gal (U.K. liquid)

1b/ga $\frac{1}{3}$ (U.S. 11quid)

$1 \mathrm{~b} / \mathrm{yd}^{3}$

slug/ $\mathrm{ft}^{3}$

ton (long) $/ \mathrm{yd}^{3}$

ton (short) $/ \mathrm{yd}^{3}$ kilogram per cubic metre $\left(\mathrm{kg} / \mathrm{m}^{3}\right)$ kilogram per cubic metre $\left(\mathrm{kg} / \mathrm{m}^{3}\right)$

kilogram per cubic metre $\left(\mathrm{kg} / \mathrm{m}^{3}\right)$

kilogram per cubic metre $\left(\mathrm{kg} / \mathrm{m}^{3}\right)$ kilogram per cubic metre $\left(\mathrm{kg} / \mathrm{m}^{3}\right)$ kilogram per cubic metre $\left(\mathrm{kg} / \mathrm{m}^{3}\right)$ kilogram per cubic metre $\left(\mathrm{kg} / \mathrm{m}^{3}\right)$ kilogram per cubic metre $\left(\mathrm{kg} / \mathrm{m}^{3}\right)$ kilogram per cubic metre $\left(\mathrm{kg} / \mathrm{m}^{3}\right)$ kilogram per cubic metre $\left(\mathrm{kg} / \mathrm{m}^{3}\right)$ kilogram per cubic metre $\left(\mathrm{kg} / \mathrm{m}^{3}\right)$ kilogram per cubic metre $\left(\mathrm{kg} / \mathrm{m}^{3}\right)$ kilogram per cubic metre $\left(\mathrm{kg} / \mathrm{m}^{3}\right)$

POWER

Btu (International Table)/h watt (W)

Btu (International $\mathrm{Table}$ )/s watt (W)

Btu (the rmochemical)/h

Btu (thermochemical)/min

Btu (thermochemica I)/s

cal (thermochemical)/min

cal (thermochemica1)/s

erg/s

$\mathrm{ft} \cdot 1 \mathrm{bf} / \mathrm{h}$

$\mathrm{ft} \cdot 1 \mathrm{bf} / \mathrm{min}$

$\mathrm{ft} \cdot \mathrm{Ibf} / \mathrm{s}$

horsepower ( $550 \mathrm{ft.1bf} / \mathrm{s}$ )

horsepower (boiler)

horsepower (electric)

horsepower (metric)

horsepower (water)

horsepower (U.K.)

kilocalorie (thermochemica1)/min

kilocalorie (thermochem-

ical)/s

ton (refrigeration) watt (W)

watt (W)

watt (W)

watt (W)

watt (W)

watt (W)

watt (W)

watt $(W)$

watt (W)

watt (W)

watt $(W)$

watt (W)

watt (W)

watt (W)

watt (W)

watt (W)

watt (W)

watt (W)
$1.711806 \mathrm{E}-02$

$1.000000 * E+03$

$6.236021 \quad E+00$

$7.489152 \mathrm{E}+00$

$1.729994 \mathrm{E}+03$

$1.601846 \mathrm{E}+01$

$2.767990 \mathrm{E}+04$

$9.977633 \mathrm{E}+01$

$1.198264 \quad \mathrm{E}+02$

5.932764 E-O1

$5.153788 \mathrm{E}+02$

$1.328939 \mathrm{E}+03$

$1.186553 \mathrm{E}+03$

PRESSURE OR STRESS (FORCE PER UNIT AREA)

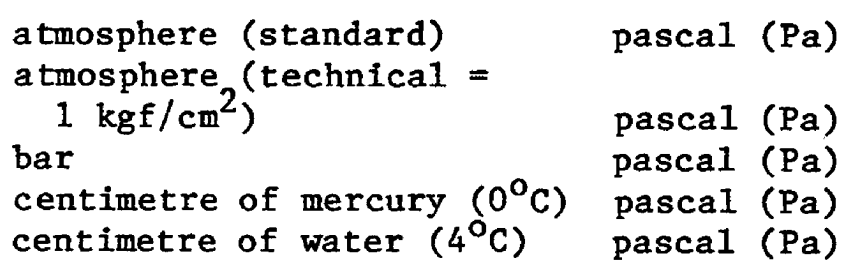

atmosphere (standard) pascal ( $\mathrm{Pa}$ )

\author{
pascal ( $\mathrm{Pa})$ \\ pascal $(\mathrm{Pa})$ \\ pascal $(\mathrm{Pa})$ \\ pascal $(\mathrm{Pa})$
}

2.930711 E-01

$1.055056 \mathrm{E}+03$

$2.928751 \mathrm{E}-01$

$1.757250 \mathrm{E}+01$

$1.054350 \mathrm{E}+03$

$6.973333 \mathrm{E}-02$

$4.184000 * \mathrm{E}+00$

$1.000000 * \mathrm{E}-07$

$3.766161 \quad \mathrm{E}-04$

2.259697 E-02

$1.355818 \mathrm{E}+00$

$7.456999 \mathrm{E}+02$

$9.809 \quad 50 \quad \mathrm{E}+03$

$7.460000 * E+02$

$7.35499 \quad \mathrm{E}+02$

$7.460 \quad 43 \quad \mathrm{E}+02$

$7.457 \quad 0 \quad$ E+O2

6.973333 E+01

$4.184000 * \mathrm{E}+03$

$3.516800 \mathrm{E}+03$
$1.013250 * \mathrm{E}+05$

$9.806650 * \mathrm{E}+04$

$1.000000 * \mathrm{E}+05$

$1.33322 \quad \mathrm{E}+03$

$9.80638 \quad \mathrm{E}+01$ 
To convert from

dyne $/ \mathrm{cm}^{2}$

foot $8^{\text {f }}$ water $\left(39.2^{\circ} \mathrm{F}\right)$ $\mathrm{gf} / \mathrm{cm}^{2}$

inch of mercury $\left(32^{\circ} \mathrm{F}\right)$

inch of mercury $\left(60^{\circ} \mathrm{F}\right)$

inch of water $\left(39.2^{\circ} \mathrm{F}\right)$

inch of water $\left(60^{\circ} \mathrm{F}\right)$

$\mathrm{kgf} / \mathrm{cm}^{2}$

$\mathrm{kgf} / \mathrm{m}^{2}$

$\mathrm{kgf} / \mathrm{mm}^{2}$

$\mathrm{kip} / \mathrm{in}^{2}$ (ksi)

millibar

millimetre of mercury $\left(0^{\circ} \mathrm{C}\right)$

poundal $1 / \mathrm{ft}^{2}$

$\mathrm{bff} / \mathrm{ft}^{2}$

$1 \mathrm{bf} / \mathrm{in}^{2}$ (psi)

psi

torr $\left(\mathrm{mmHg}, 0^{\circ} \mathrm{C}\right)$ to

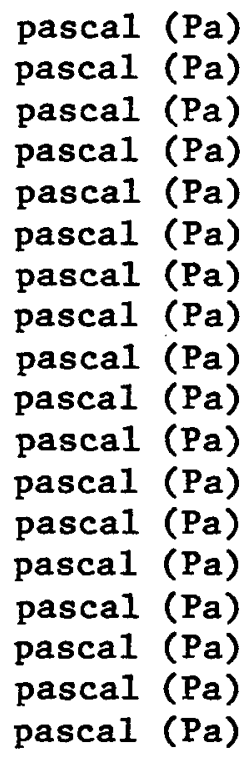

SPEED (SEE VELOCITY)

STRESS (SEE PRESSURE)

TEMPERATURE

degree Celsius

degree Fahrenheit

degree Fahrenheit

degree Rankine

kelvin

day

day (sidereal)

hour

hour (sidereal)

minute

minute (sidereal)

second (sidereal)

year (365 days)

year (sidereal)

year (tropical) kelvin ( $K$ )

degree Celsius

kelvin (K)

kelvin ( $\mathrm{K}$ )

degree Celsius

TIME

second (s)

second (s)

second (s)

second (s)

second ( $s$ )

second (s)

second (s)

second (s)

second (s)

second (s)
Multiply by

$1.000000 * \mathrm{E}-01$

$2.98898 \quad E+03$

$9.806 \quad 650 * \mathrm{E}+01$

$3.386 \quad 38 \quad \mathrm{E}+03$

$3.376 \quad 85 \quad E+03$

$2.49082 \quad E+02$

$2.4884 \quad \mathrm{E}+02$

$9.806 \quad 650 * \mathrm{E}+04$

$9.806 \quad 650 * \mathrm{E}+00$

$9.806 \quad 650 * \mathrm{E}+06$

6.894757 E+06

$1.000000 * \mathrm{E}+02$

$1.333 \quad 22 \quad \mathrm{E}+02$

$1.488 \quad 164 \mathrm{E}+00$

$4.788 \quad 026 \quad \mathrm{E}+01$

$6.894757 \mathrm{E}+03$

$6.894757 \mathrm{E}+03$

$1.33322 \mathrm{E}+02$
$8.640000 * \mathrm{E}+04$

$8.616409 \mathrm{E}+04$

$3.600000 * \mathrm{E}+03$

$3.590170 \mathrm{E}+03$

$6.000000 * \mathrm{E}+01$

$5.983617 \mathrm{E}+01$

9.972696 E-01

$3.153600 * \mathrm{E}+07$

$3.155 \quad 815 \mathrm{E}+07$

$3.155 \quad 693 \quad \mathrm{E}+07$

TORQUE (SEE BENDING MOMENT)

VELOCITY (INCLUDES SPEED)

$\mathrm{ft} / \mathrm{h}$

$\mathrm{ft} / \mathrm{min}$

$\mathrm{ft} / \mathrm{s}$

$\mathrm{in} / \mathrm{s}$

$\mathrm{km} / \mathrm{h}$ metre per second $(\mathrm{m} / \mathrm{s})$

metre per second $(\mathrm{m} / \mathrm{s})$

metre per second $(\mathrm{m} / \mathrm{s})$

metre per second $(\mathrm{m} / \mathrm{s})$

metre per second $(\mathrm{m} / \mathrm{s})$
$8.466 \quad 667 \quad \mathrm{E}-05$

$5.080000 * \mathrm{E}-03$

$3.048000 * \mathrm{E}-01$

$2.540000 * \mathrm{E}-02$

$2.777 \quad 778 \quad \mathrm{E}-01$ 
To convert from

knot (international)

$\mathrm{mi} / \mathrm{h}$ (internationa1)

$\mathrm{mi} / \mathrm{min}$ (International)

$\mathrm{mi} / \mathrm{s}$ (international)

$\mathrm{mi} / \mathrm{h}$ (international) to

metre per second $(\mathrm{m} / \mathrm{s})$

metre per second $(\mathrm{m} / \mathrm{s})$

metre per second $(\mathrm{m} / \mathrm{s})$

metre per second $(\mathrm{m} / \mathrm{s})$

kilometer per hour $(\mathrm{km} / \mathrm{h})^{2}$

\section{VISCOSITY}

pascal second ( $\mathrm{Pa} \cdot \mathrm{s})$

square metre per second $\left(\mathrm{m}^{2} / \mathrm{s}\right)$

square metre per second $\left(\mathrm{m}^{2} / \mathrm{s}\right)$

pascal second ( $\mathrm{Pa} \cdot \mathrm{s})$

pascal second $(\mathrm{Pa} \cdot \mathrm{s})$

pascal second ( $\mathrm{Pa} \cdot \mathrm{s})$

pascal second ( $\mathrm{Pa} \cdot \mathrm{s})$

pascal second ( $\mathrm{Pa} \cdot \mathrm{s}$ )

pascal second ( $\mathrm{Pa} \cdot \mathrm{s}$ )

1 per pascal second [1/(Pa.s)]

pascal second ( $\mathrm{Pa} \cdot \mathrm{s})$

square metre per second $\left(\mathrm{m}^{2} / \mathrm{s}\right)$
Multiply by

$5.144 \quad 444$ E-01

$4.470 \quad 400 * \mathrm{E}-01$

$2.682240 * \mathrm{E}+01$

$1.609344 * \mathrm{E}+03$

$1.609344 * \mathrm{E}+00$

$1.000000 * \mathrm{E}-03$

$1.000 \quad 000 * \mathrm{E}-06$

$9.290304 * \mathrm{E}-02$

$1.000000 * \mathrm{E}-01$

$1.488 \quad 164 \mathrm{E}+00$

4.133789 E-04

$1.488164 \quad \mathrm{E}+00$

$4.788 \quad 026 \mathrm{E}+01$

$6.894757 \mathrm{E}+03$

$1.000000 * \mathrm{E}+01$

$4.788026 \mathrm{E}+01$

$1.000000 * \mathrm{E}-04$

\section{VOLUME (INCLUDES CAPACITY)}

acre-foot

barrel (oil, $42 \mathrm{gal}$ )

board foot

bushel (U.S.)

cup

fluid ounce (U.S.)

$\mathrm{ft}^{3}$

gallon (Canadian liquid)

gallon (U.K. liquid)

gallon (U.S. dry)

gallon (U.S. 1iquid)

gill (U.K.)

gil1 (U.S.)

$\mathrm{in}^{3}$

Iitre

ounce (U.K. fluid)

ounce (U.S. fluid)

peck (U.S.)

pint (U.S. dry)

pint (U.S. liquid)

quart (U.S. dry)

quart (U.S. 1iquid)

stere

tablespoon

teaspoon

$\mathrm{yd}^{3}$ (register) cubic metre $\left(\mathrm{m}^{3}\right)$

cubic metre $\left(\mathrm{m}^{3}\right)$

cubic metre $\left(\mathrm{m}^{3}\right)$

cubic metre $\left(\mathrm{m}^{3}\right)$

cubic metre $\left(\mathrm{m}_{3}^{3}\right)$

cubic metre $\left(\mathrm{m}_{3}^{3}\right)$

cubic metre $\left(\mathrm{m}^{3}\right)$

cubic metre $\left(\mathrm{m}^{3}\right)$

cubic metre $\left(\mathrm{m}^{3}\right)$

cubic metre $\left(\mathrm{m}_{3}^{3}\right)$

cubic metre $\left(\mathrm{m}^{3}\right)$

cubic metre $\left(\mathrm{m}_{3}^{3}\right)$

cubic metre $\left(\mathrm{m}^{3}\right)$

cubic metre $\left(\mathrm{m}^{3}\right)$

cubic metre $\left(\mathrm{m}^{3}\right)$

cubic metre $\left(\mathrm{m}^{3}\right)$

cubic metre $\left(\mathrm{m}^{3}\right)$

cubic metre $\left(\mathrm{m}^{3}\right)$

cubic metre $\left(\mathrm{m}^{3}\right)$

cubic metre $\left(\mathrm{m}^{3}\right)$

cubic metre $\left(\mathrm{m}_{3}^{3}\right)$

cubic metre $\left(\mathrm{m}_{3}^{3}\right)$

cubic metre $\left(\mathrm{m}^{3}\right)$

cubic metre $\left(\mathrm{m}^{3}\right)$

cubic metre $\left(\mathrm{m}^{3}\right)$

cubic metre $\left(\mathrm{m}_{3}^{3}\right)$

cubic metre $\left(\mathrm{m}^{3}\right)$
$1.233 \quad 489 \quad \mathrm{E}+03$

1.589873 E-01

$2.359737 \quad \mathrm{E}-03$

3.523907 E-02

$2.365882 \quad$ E-04

$2.957353 \quad \mathrm{E}-05$

2.831685 E-02

$4.546090 \mathrm{E}-03$

$4.546 \quad 092 \quad \mathrm{E}-03$

4.404884 E-03

$3.785 \quad 412 \mathrm{E}-03$

$1.420654 \mathrm{E}-04$

$1.182941 \mathrm{E}-04$

$1.638706 \mathrm{E}-05$

$1.000 \quad 000 * \mathrm{E}-03$

2.841307 E-05

$2.957353 \quad \mathrm{E}-05$

$8.809768 \mathrm{E}-03$

5.506105 E-04

4.731765 E-04

1.101221 E-03

$9.463529 \mathrm{E}-04$

$1.000000 * \mathrm{E}+00$

$1.478676 \mathrm{E}-05$

$4.928922 \quad \mathrm{E}-06$

$2.831685 \mathrm{E}+00$

$7.645549 \mathrm{E}-01$

${ }^{2} \mathrm{Although}$ speedometers may read $\mathrm{km} / \mathrm{h}$, the $\mathrm{SI}$ unit is $\mathrm{m} / \mathrm{s}$. 
VOLUME PER UNIT TIME (INCLUDES FLOW)

$\mathrm{ft} \mathrm{t}^{3} / \mathrm{min}$

$\mathrm{ft}^{3} / \mathrm{s}$

gallon (U.S. liquid)/(hp.h)

(SFC, specific fuel

$\mathrm{in}^{3} / \mathrm{min}$

gallon (U.S. 1lquid) per day

gallon (U.S. liquid per min cubic metre per second $\left(\mathrm{m}^{3} / \mathrm{s}\right) \cdot 4.719474 \quad \mathrm{E}-04$

cubic metre per second $\left(\mathrm{m}^{3} / \mathrm{s}\right) \quad 2.831685 \mathrm{E}-02$

cubic metre per joule $\left(\mathrm{m}^{3} / \mathrm{J}\right) \quad 1.410089 \mathrm{E}-09$

cubic metre per second $\left(\mathrm{m}^{3} / \mathrm{s}\right) \quad 2.731 \quad 177 \quad \mathrm{E}-07$

cubic metre per second $\left(\mathrm{m}^{3} / \mathrm{s}\right) \quad 1.274 \quad 258 \mathrm{E}-02$

cubic metre per second $\left(\mathrm{m}^{3} / \mathrm{s}\right) \quad 4.381264 \mathrm{E}-08$

cubic metre per second $\left(\mathrm{m}^{3} / \mathrm{s}\right) \quad 6.309020 \mathrm{E}-05$

WORK (SEE ENERGY) 


\section{INDEX}

Bold-face page numbers in this index refer to pages containing an illustration, a table, or both. The page may also contain text supporting the entry. For definitions of technical terms, the reader is referred to the glossary, Appendix $\mathrm{H}$.

Absorber plates

coatings, 53,55

materials used in, 54

selective surfaces of, 55

Absorptance, of absorber plate coatings, 55

ACSL, computer language, 224

American Gas Association, standards for meter installation, 232

American Society of Heating, Refrigerating, and Air Conditioning Engineers (ASHRAE), and test standards, 69

American Soclety for Testing and Materlals (ASTM), and test standards, 72

Argonne National Laboratory

and CPC design, 63

and hot water system design, 38

Array, sawtooth, 53, 403

Auxiliary heater

in direct hot air systems, 35

In series and parallel configurations, 50

Availability, 132-35

Bimetallic sensors, 234

Botler turndown ratio, 311-312, 313

Botlers

backup, 305-309, 310, 311-15

controls for, 305,307

Capacity cost, 79, 273, 275

Checkout procedures, 230-31, 239-49

Collectors, 53 (see also flat-plate collectors, evacuated-tube collectors, line-focus collectors, and parabolic trough collectors)

central recelvers, 65

compound parabolic concentrators, 63,64

cost comparison of, 259, 260

energy balance of, 67

evacuated-tube, 56-58

flat-plate, 53-56

for hot water systems, 38

Instantaneous efficiency of, 67

instantaneous performance of, 65-73

line-focus, 63,65

Ilquid, 38

locating, 32

multiple-reflector, 65

operating temperatures of, 12

parabolic dish, 65

parallel and series, 141-42

performance of, $66-68$

point-focus, 63,65

stowing, $65,73-80,286$

testing materials for, 28

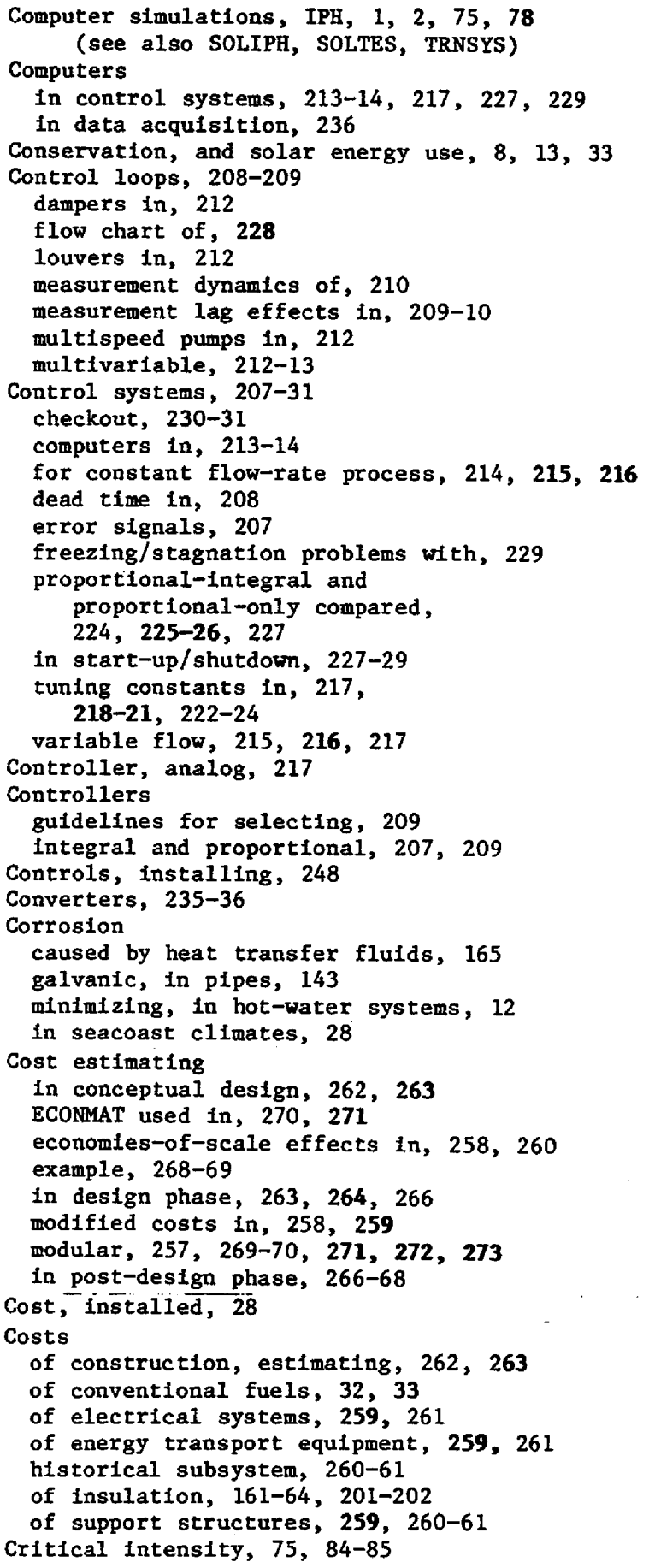




\section{INDEX (Continued)}

Data acquisition, in IPH field tests, 236 Degradation

caused by atmospheric pollutants, 28 of collector glazings, 55

of collectors in industrial environments, 8 observed in IPH field tests, 19, 20

underground piping minimizes, 32

Department of Energy, U.S.

funded collector efflclency tests, 73

funded IPH, SHAC field tests, 1 publications of, 395

Design

conceptual, elements of, 2-4

control system, 214-31

methodology, 2-4

preliminary, elements of, 2-4

Drain-back systew, freeze protection in, 229

Drying and dehydration, 13-15

ECONMAT, used in cost estimating, 257

Economics, solar IPH system, 257-83

affects future of solar energy in industry, 22 capital-intensive nature of, 32

federal and state tax credits affecting, 32 and industries with greatest solar potential, 33-34

Economies of scale, effects, in cost estimating, 258,260

Economies-of-scale factor, 265

Efficlency, boiler, 305-15

effect of firing rate on, 306, 312, 314-315

and fractional on-time, 309,311

losses in, 305, 306

Efficiency, collector

and high temperatures, in

flash-steam systems, 41

in hot water systems, 50

testing, 69-72

Efficiency, instantaneous

of collectors, 65

curves for IPH collectors, 67-68, 68

Effictency, optical

and collector performance, 68-69

and incident-angle weighting

factors for north-south troughs, 118

Efficiency, system, vs. temperature, 28

Energy collection, annual

determining correlation for, 84-114

key variables in, 83-84

Emergency controls, 229-30

Energy collection, annual

derivation of, 371-81

step-by-step method of calculating, 135-38

Energy collection rate, average annual, $75,78,79$

Energy use, in U.S. industry, 7, 8, 10, 11

End-loss factor, in parabolic troughs, $115,118,119$

Enthalpy, in flash-steam systems, 40

Environmental Issues, 292-303

air pollution effects, 292

EIA reports, 293

environmental agencies and regulations, $293,294,295$

environmental regulations, state, 295, 297-303
Impacts of IPH systems, 292

industrial contamination of collectors, 8

land use, 295

NEPA, 293

waste disposa1, 295

water pollution, 292-93, 295

Evacuated-tube collectors, 56, 57, 58

annual recirculation system storage-load modifiers for, 98,102

advantages of, 56

installing, 240

mounting, 56

operating temperatures of, 56,58

selective surfaces of, 56

vacuum in, 56

Field tests, IPH, 16-22

1ist of projects, 17-18

major types of collectors $1 \mathrm{n}, 53$

problems encountered in DOE-funded, 20-22

Financing alternatives, 281-83

F1ash-steam system factor, derivation of, $386-88$

Flash-steam systems, $16,40,41$

Flat-plate collectors, 53, 54, 55-56

advantages of, 53

annual incident-angle modifier correction for, 117

annual recirculation-systen storage-load modifler for, 97, 101

enclosures for, $55-56$

Installing, 239-40

mounting, 53

Flexhoses, installing, 243

Flow meters, 231-33

Flow rate

optimum collector, 141

in unfired-boller system, 42

in variable-volume storage system, 109

Fluid loading, 251

Fouling resistances, 185

Freeze protection

in flash-steam systems, 39

heat losses from, 129-30

In hot water systems, $36,38,39,40$

when water is the heat transfer fluid, 165

in unfired-boiler systems, 16

Fresnel lens collectors, 63, 64, 65

Fuels, conventional

antipollution laws could limit use of, 28

costs of, 32,33

used in industry, 8,10

Glazing

degradation of, 55

for flat-plate collectors, 55

hazards assoclated with, 288

problems with, in DOE-funded IPH field tests, 20-22

replacing, in the field, 240

transmittance properties of, 55, 56

Ground-cover rat1o, 120, 122

Heat exchanger factor, $88,187-88$ 


\section{INDEX (Continued)}

Heat exchangers, 182-92

example of, 183

floating heads in, 192

in hot water storage systems, 43

installing, 246

opt Imum, 189

plate, 192

selecting, 190-93

two-tube, single-shell pass, 190

sizing techniques for, 184-87

Heat loss

annua 1, 200-201

coefficient, for collectors, 66

reducing, in drainback systems, 248

underground piping minimizes, 32

Heat removal efficlency factor, 66

Heat transfer coefficient, 184, 185-87

Heat transfer efficiency factor, 139, 166-68, 169,170

Heat transfer flufds, $164-69,317-50$

aliphatic hydrocarbons, 165

aromatic hydrocarbons, 165-66

as corrosion Inhibitors in hot water systems, 38

flammability of, 170

in flash-steam systems, 41

relative efficiencies of, 168

silicones, 166

thermal properties of, $166-70$

toxicity of, 170

water, 164-65

water/glycol mixtures, 165

Hellostats, 65

Hot water solar IPH systems, $36-38$

direct, 36,37

example, 13

indirect, 36, 37, 38

industrial uses of, 12

multiple reflector collectors in, 13

shell-and-tube heat exchangers in, 13

Hot-water-to-air solar IPH systems, 14

Incident-angle modifiers, 68

for collectors In IPH applications, 69

effect of, on annual performance, 115-18

Incldent-angle modifier coefficient, 117

Insolation

direct normal, 27

global, 26

Installation, 239-49

checklist, 254-55

of collectors, 239-42

of controls, electrical lines, and instrumentation, 248

of heat exchangers, 246

of piping, fittings, and insulation, 242-44, 245,246

of pressure vessels and storage tanks, 247 of pumps, 246-47

Instantaneous energy balance, steady-state, 66 Instrumentation, 231-36 (see also instruments, measurement)

Installing, 248

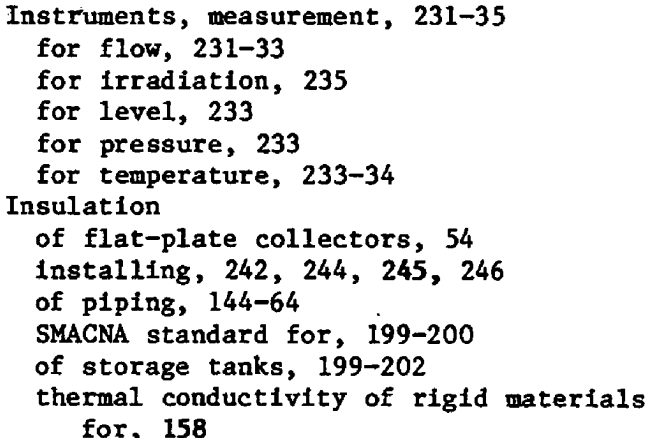

for, 158

typical thicknesses, at various temperatures, 146

Intensity ratio, 75, 78, 84-87, 93

Irradiance

direct normal, 75, 77, 86

losses, direct and diffuse, in row-to-row shading, 122

total horizontal, 76,86

Irradiation, maximum daily available, 109

"Kill switch," 286

Life-cycle cost analysis, 270-281

capacity cost $1 \mathrm{n}, 273,275$

capital recovery factor in, 273, 274

internal rate of return $1 \mathrm{n}, 270,273-74,277$, 281,282

levelized cost of conventional fuel, 275

levelized cost of solar energy, 270, 273

levellzing factor, 275, 276

M-factor, 273, 276-77, 278-280, 281

payback in, 270

Line-focus collectors

direct steam generation 1n, 43

installing, 242-43

in steam systems, 40

Load-storage modifiers, 95, 97-104

Materials

in storage tanks, 199

tests of, for environmental effects, 28

thermal conductivity of insulating, 158

Mueller Associates, Inc., 257-58, 261-69

National Bureau of Standards, and collector performance tests, 69

No-storage IPH solar system

appropriateness of, 89

predicting annual performance of, 90-93

sizing techniques for, 89-90

Nolse, 291, 295

Oxifice plates, 182, 232

OSHA, 291

Outgassing

in flat-plate collectors, 56

hazards of 285,290

Overpressure, hazards of, 290

Overtemperature, hazards of, 289-90 


\section{INDEX (Continued)}

Parabolic trough collectors, 59, 60-61 advantages of, 59

annual recirculation system storage-load modifiers for, 99, 100, 103, 104

end losses of, 118-19

maximum operating time of, 110

mounting of, 59

orientation of, $60-61$

in steam systems, 15

suitabllity of, in U.S. IPH aplications, 9

Payback period

expected by industry, 8

In Iffe-cycle cost analysis, 270

Performance, annual

climatic effects on, 130, 131, 132

of flash-steam systems, 113-14

of a mixed-tank, recfrculation system, 93-107

of a no-storage system, 90-93

overnight losses and, 127-29

steady-state losses and, 126-27

and thermal-1oss effects, 122, 126-30

of unfired boiler systems, 111-13

of variable-volume storage systems, 107-11

Performance, collector, 74, 75

Performance modifiers, annual, derivation of, 383-91

Performance tests, 252-53

Phase-change materfals

Glauber's salt, 195-97

in latent heat storage, 195-97

Pipe sizing techniques

fluid velocities in, 143

Perry and Chilton method, 143

Piping

advantages of underground, 32

collector field configurations, 139, 140, 141 flushing, 249-50

Installing, 242, 244, 245, 246

insulation of, 144

optimal insulation thickness for, 163-64

Piping configurations

center-feed, 140,141

direct-return, 139,140

pressure drop in, 142-43

reverse-return, 139, 140, 141

Pressure tests, 250-51

Pressure vessels, Installing, 247

Product contamination, 290

Pumping power

effect of fluid properties on, 167-68

required by various pumps, 175-176

Pumps, 170-79, 263

Pumps, centrifugal

capacity vs. NPSHR for, 177

head-flow curves for, 173,178

mult1speed, 175-76

NPSHR for, 173,175

selection curves for, 174

single-speed, 171-75

Pumps, positive displacement, 176, 179

Pyranometers, 235, 401

Pyrhellometers, 235, 402

Reflective coatings, 60
Resistance. temperature detectors, 234

Rock-bin storage, 13, 36

Row-to-row shading effects, 119, 122

geometries, 121

shading-loss modifiers for flat plates, evacuated tubes, 123

shading-loss modiflers for parabolic troughs, 124,125

Safety, 285-91

flammable fluids and, 285-86

fire prevention and control, 285-86, 287, 288

insulation hazards and, 286, 287

in Installation, 248-49

"kill switch" for, 286

matertals hazards and, 285-86

physical hazards and, 288-89

regulations and agencles, 291

Sandia National Laboratorles

and AR-coated receivers, 61

and SOLTES, 2

and trough efficlency, 72-73

and trough foundations, 241

She11-and-tube heat exchangers, 190, 191

SI conversion factors, 407-18

Solar Energy Research Instltute

and SOLIPH simulation, 2

and test standard for concentrating collectors, 72

Solar management company, concept of, 281, 283

Solar ponds, 61, 63

SOLIPH, 2, 83, 96, 351-69

SOLTES, 2

Start-up procedures, 249-53

Steady-state plpe loss modifiers, 388-91

Steam systems, 38, 40-43

in IPH, 15-16

line-focus collectors in, 40

unfired-bollers in, 15-16

Stefan-Boltzmann constant, 148

Storage, $88,193-203$

calculating annual performance for system with, 93-107

costs, 259,261

depends on process schedule, 32

latent heat, 195-97

location of, 202-203

media, 194-95, 196, 197

optimum insulation thickness of, 200-202

rock-bin, 194-95

sensible heat, 194-95

Storage systems

comparative study of, $47,49,50$

dual-med1um rock/011, 47

four-plpe, 45,46

hot water, $43,44,45,46$

mixed-tank, 47,48

two-pipe, 46

varlable-volume, 45, 47, 48, 107, 108, 109-11

Storage tanks, 197-202

installing, 247

insulation of, 199-202

materials for, 199

multiple, 199

slingle, 199 


\section{IMDEX (Concluded)}

Stratification (see thermocline tanks)

Sultability of solar systems

economic factors in, 32-33

environmental factors in, 25-27, 29-31

factors that determine, 8

of parabollc trough collectors in IPH, 9

plant malntenance factors $1 \mathrm{n}, 33$

process factors in, 28,32

Sun trackers

flux-Ilne, 60

shadow-band, 60

and control systems, 227

System configurations, 35-51

parallel, 50-51

principal, in IPH applications, 35

serles, 50-51

System/process Interface, 50-51

Thermistors, 234

Thermocouples, 233-34, 236

Tanks, pressurized vs. unpressurized, 38, 39, 40

Temperature

distributions among IFH users, 11

of process determines appropriate collector, 10,12

Temperatures, amblent

average dafly freezing, in U.S., 31

January datly averages, U.S., 29

July dally averages, U.S., 30

in selected U.S. citles, 393

\author{
Temperatures, operating \\ when glycols are heat transfer flulds, 165 \\ of parabollc troughs, 59 \\ when wer is heat transfer fluid, 165 \\ Thermal conductivity \\ of rigid insulating materlals, 158 \\ Thermocline tanks, 45, 46, 47, 48 \\ Thermosiphoning, prevention of, 38 \\ TMY, SOLIPH used data of, 377-87 \\ Toxicity, of IPH fluids, 289 \\ TRNSYS, 2 \\ Tubes \\ In flat-plate collectors, 54 \\ In evacuated-tube collectors, 56-57 \\ Unf1red-bo1ler factor, 112, 383-86 \\ Unfired-bo1ler systems, 42 \\ circulating fluids in, 42 \\ sizing collectors for, 112-13 \\ storage wethods for, 47-50 \\ Utflization, 132-35 \\ Valves, 179-82, 210-12 \\ Varlable-volume storage systems, $45,47,48$, \\ $107,108,109-11$ \\ Water-to-alr systems, 36 \\ dellinter heat exchanger factor, 188, 193 \\ Wisconsin, Untversity of, 2
}




\begin{tabular}{|c|c|c|}
\hline $\begin{array}{l}\text { Document Control } \\
\text { Page }\end{array}$ & \begin{tabular}{|c|c|}
$\begin{array}{c}\text { 1. SERI Report No. } \\
\text { TR-253-1356 }\end{array}$ & 2. NTIS Accession No. \\
\end{tabular} & 3. Recipient's Accession No. \\
\hline \multicolumn{2}{|l|}{ 4. Title and Subtitte } & 5. Publication Date \\
\hline \multirow{2}{*}{\multicolumn{2}{|c|}{$\begin{array}{l}\text { Design Approaches for Solar Industrial Process } \\
\text { Heat Systems. }\end{array}$}} & Auqust 1982 \\
\hline & & 6. \\
\hline $\begin{array}{l}\text { 7. Author(s) Charles } \\
\text { Douglas Doughert }\end{array}$ & $\begin{array}{l}\text { - Kutscher, Roger Davenport, Kenneth May, } \\
\text {, Randy Gee, Michael Masterson }\end{array}$ & 8. Performing Organization Rept. No. \\
\hline \multirow{2}{*}{\multicolumn{2}{|c|}{$\begin{array}{l}\text { 9. Performing Organization Name and Address } \\
\text { Solar Energy Research Inst itute } \\
1617 \text { Cole Boulevard } \\
\text { Golden, Colorado } 80401\end{array}$}} & $\begin{array}{l}\text { 10. Project/Task/Work Unit No. } \\
1007.99\end{array}$ \\
\hline & & $\begin{array}{l}\text { 11. Contract (C) or Grant (G) No. } \\
\text { (C) } \\
\text { (G) }\end{array}$ \\
\hline \multirow{2}{*}{\multicolumn{2}{|c|}{ 12. Sponsoring Organization Name and Address }} & $\begin{array}{c}\text { 13. Type of Report \& Period Covered } \\
\text { Technical Report } \\
\end{array}$ \\
\hline & & 14. \\
\hline \multicolumn{3}{|l|}{ 15. Supplementary Notes } \\
\hline \multicolumn{3}{|c|}{$\begin{array}{l}\text { 16. Abstract (Limit: } 200 \text { words) This document is meant to serve as a handbook for the design of } \\
\text { solar industrial process heat systems. It is divided into three parts: I. Objectives } \\
\text { and Fundamentals; II. Conceptual Design; and III. Prel iminary Design. Part I describes } \\
\text { the design methodology and gives an overview of the use of solar energy in industry. } \\
\text { Part I describes how to determine whether solar energy makes sense for a particular } \\
\text { application, discusses the basic system configurations used to supply hot water or } \\
\text { steam, and supplies computer-generated graphs that allow the user to select a collec- } \\
\text { tor type. Part III provides for detailed energy calculations including the effects of } \\
\text { thermal losses and storage, describes the selection of subsystem components (e.g., } \\
\text { fluids, piping, heat exchangers, pumps, valves), and explains control systems, instal- } \\
\text { lation and start-up details, economics, and safety and environmental issues. A number } \\
\text { of appendices supply important data and explain how results used in the text were } \\
\text { derived. }\end{array}$} \\
\hline \multirow{3}{*}{\multicolumn{3}{|c|}{$\begin{array}{l}\text { 17. Document Analysis Solar drying; Solar process heat ; Steam generation ; Manuals ; } \\
\text { a. Descriptors Design ; Economics ; Performance ; Evacuated tube collectors; Flat plate } \\
\text { collectors ; Parabolic trough collectors : Heat transfer ; Heat transfer fluids ; } \\
\text { Control equipment: Cost ; Safety : Hazards } \\
\text { b. Identifiers/Open-Ended Terms System design ; Design tools ; Conceptual design ; Preliminary } \\
\text { design ; Computer simulations ; System performance; Industrial process heat systems : } \\
\text { Cost estimating }\end{array}$}} \\
\hline & & \\
\hline & & \\
\hline \multirow{2}{*}{\multicolumn{2}{|c|}{$\begin{array}{l}\text { 18. Availability Statement } \\
\text { National Technical Information Service } \\
\text { U.S. Department of Commerce } \\
5285 \text { Port Royal Road } \\
\text { Snrinafield. Virainia } 27161\end{array}$}} & $\begin{array}{l}\text { 19. No. of Pages } \\
452\end{array}$ \\
\hline & & $\begin{array}{l}\text { 20. Price } \\
\$ 14.50\end{array}$ \\
\hline
\end{tabular}

